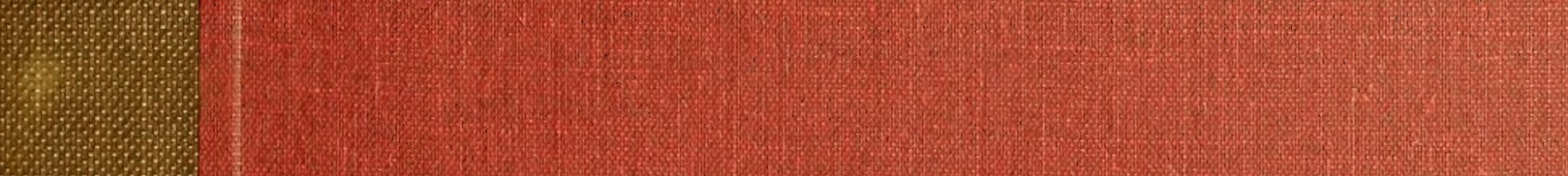

$x^{2}$

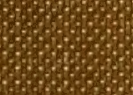

(15)

(1) (1)

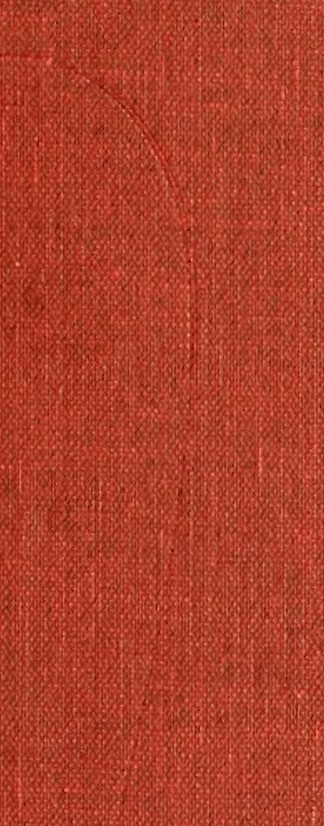

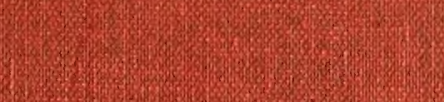

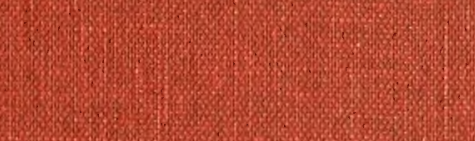
: \% a 








IX. On the Structure and Development of the Skull in the Pig (Sus scrofa). By W. K. PAREER, F.R.S.

Received Mray 17,二Read June 19, 1873.

Mr intention for some time past has been to follow up the Morphology of the Fish's skull by that of the Mammal; and as amongst the "Placentalia" the Guineapig (Cavia aperea) takes a very low place, it was chosen as the type to work out. I have been led to change my plan, however, and to take a medium type by an unexpected supply of materials kindly put into my hands, in November 1871, by my friend Mr. Charles STEWART; these were about seventy cmbryos of the Common Pig, a considerable number of which were barely two thirds of an inch in length, whilst others measured 6 inches in a straight line from the snout to the tuberosity of the ischium*.

As the tissues in the earlier stages were only in a nascent condition, the greatest care has been taken to harden them for slicing into sections and for dissection from without inwards; and no labour has been spared in this matter the sections being made after the hardened embryos had been imbedded in solid paraffin. 'These extremely thin objects were colonred with an ammoniacal solution of carmine, and then transferred to slides, on which they were mounted in acid glycerine. The coarser sections of the larger embryos, to be used as opaque objects, were made without imbedding, after the specimens had been immersed in a dilute solution of nitric or muriatic acid, to which had been added some chromic acid $\phi$; in the former way I have been able to obtain views of the tissues of the earliest stage under a magnifying-power of as much as 600 diameters, although about 50 diameters has been found to be the most useful, showing, as such a lesser enlargement does, the various parts in relation to each other, and enabling the eye to follow the granular thickenings which are becoming differentiated into special tissues.

The study of this particular type of Mammalian skull has been facilitated by preparatory work in many other types of this Class, extending over a period of thirty-three years; but I have determined not to bring any thing forward relating to special modifications until this more exhaustive piece of work has seen the light.

'The first impulse in this direction was given me by an invaluable work which appeared long ago; I refer to WV. Cineseldev's 'Anatomy of the Human Borly' (London, 1722, 8vo). But my newer stand-point is from the 'Elements of Comparative Anatomy' (1864), by Professor Huxley (Lecture 7 th to the end).

* 'The actual length of these embryos, measured along the curved line of the spine to the end of the tail, is about one half more than is given by my practical and easier method of admeasurement.

+ All the finer sections and preparations were made by my sou, Mr. T. J. IARKER.

MDCCCLXIIV.

2 Q 
Since the older writer, no native anatomist has arisen more fitted to hold and to handle this difficult subject than the author of those "Lectures."

I shall follow up this matter from point to point in the same manner as that pursued in the papers already offered to the Society; and my endeavour is to link on paper to paper so that they may form an organic whole, the idea and purpose being the same in each, and the special mode of treatment the same.

In the present communication more relative anatomy has been given than in the former papers; I have to steer between the confusion arising from the display of too many parts, and the baldness of a mere account of skeletal structures.

If the nasal and auditory sense-capsules were as easy of elimination as the eyeball, the skull and face would present a much less complex problem; but they soon become part and parcel of a most intricate cranio-facial unity, and everywhere intrude themselves upon the observer.

A certain convenient subdivision of this especial piece of morphological work can be made; thus we have-

1st. The notochordal region of the skull.

2nd. 'The pronotochordal region of the same.

3̂rd. The facial arches.

4th. 'The sense-capsules.

The metamorphosis of the original and, as it were, larval parts here obtains its highest degree; the distance which has to be travelled by the morphologist between the startingpoint and the goal may be conceived of if the primary form (Plate XXVIII. fig. 5) be compared with the finished condition of the skull (Plate XXXVI. fig. 4).

In observing the growth-changes that bring about this result, a large amount of histological labour is involved; in the present piece of work that part of the research has been taken pains with as much as if it had been intended to write upon the tissues, and not upon their massing and arrangement. The determination of homologous parts in this type, as compared with the elements that build up the skull of the Fish, the Frog, and the Bird, has not been by any means the most difficult part of my toil; they arrange themselves, and assume their own titles, in a very ready manner; for the difficulties of terminology will all melt away as soon as a sufficient number of types have been traced down to their embryonic "roots." Many parts will have to be re-named; but this will be easy work when the true reason for the change is made plain.

As the skeletal parts are all composed of the various kinds of "connective tissue," and as these kinds are intimately related to, and often pass insensibly into, one another, it is not easy to keep to a consistent terminology in describing them.

'This class of tissues becomes hardened by bone-salts at very different ages; and in any homologous territory, if ossification is late, the tissue becomes hyaline cartilage first; in other types the like tract may become bony, whilst, as yet, the tissue is extremely soft and young: in intermediate conditions bone is formed in a tissue which is indifferent; it 
looks like hyaline cartilage, but the cells are crowded, and it is formed into bone before the intercellular substance has time to appear*

In the Mammal, more than in any other type, the original parts are all the more completely transformed, in that the bony substance formed in the primordial cartilage becomes very large in relation to its first model ; and, moreover, the "investing bones" formed in the subcutaneous web become very large indeed, as compared with the small granular territory, the soft model' in which they first appeared.

Also in no other type do the primary facial rods become segmented, arrested, and metamorphosed to the sane degree as in this the highest vertebrate Class.

\section{First Stage.-Embryo Pig, $7 \frac{1}{2}$ to 8 lines long.}

The primordial skeleton of the most highly specialized Mammal is as simple as that of the lowest brain-bearing Fish ; the form of the fotal head (Plate XXVIII. fig. 1) may be aptly compared with that of the Fish and Frog (see my former papers on those types). In embryos $7 \frac{1}{2}$ lines in length the thee brain-vesicles $\left(\mathrm{C}^{n}, \mathrm{C} 2, \mathrm{C} 3\right)$ are hollow, the film of soft brain-substance merely lining the enclosing membranous cranium. 'The foremost of the vesicles has budded into the two rudimentary hemispheres above the primary sac, the "thalamencephalon" (Plate XXVHI. figs. 3 \& 6, C 1, C 1"); yet at this stage the cutis does not corer the whole of the third vesicle (C 3 ) nor the whole of the auditory sac (au.). The head is bent over upon the thin-walled thorax, and the cervical region of the spinal chord is very outbent and swollen (fig. 1).

The Visceral Clefts.-After noticing the brain-vesicles and the three pairs of sensecapsules $\left(o l ., e_{.}, \alpha u\right.$.), the foundations of which are already well laid, the eye detects that peculiar dehiscence of the facial wall, the continuous face being cloven by the formation of a series of slits or cuts, which pass quite through the substance of the cheek and neck. By the older embryologists these are counted from behind the mouth; but in my last paper, especially, I have shown that the mouth itself is a great, double, completed cleft, and that there is a secondary cleft in front of it, the "palato-trabecular" or preoral cleft $(c l .1)$. But the "first postoral " is in reality the second cleft; this is the largest in the embryo pig, with the exception of the mouth. Behind this there are three others; and the first of these, the "sccond postoral," is the counterpart of the most anterior of those through which the water-currents pass in the osseous fish. Below and behind the clefts the fre limb is seen in rudiment. ITere it will be seen that there is a deficiency in the number of clefts behind, as compared with the gill-bearing vertebrates (see papers on Frog and Salmon). Only the first "postoral" cleft is persistent and functional, the three behind soon closing in. I shall describe, anon, what becomes of the persistent clefts, that in front of and that behind the great mouth-cleft. Between the clefts are formed the arches; these facial bars have some resemblance to ribs, but are formed independently of axial parts, whereas the ribs are evident downgrowths from the vertebral portions of the "Somatomes."

* See on this subject, "On the Connectiro Tissues," by A. Rolcetr, in Stricrer's "Human and Comparatire Histology,' translated by H. Power for the New Sydenham Society. London, 1870, pp. 47-146. 
Where the facial arches most closely imitate ribs, as in the first and second postoral, the "capitulum" and the "tuberculum" are applied to a part to which they have no proper morphological relation-namely, to a sense-capsule. 'This is one of the many modifications the morphological elements are subjected to in the cephalic region.

The original pattern of the facial system of a vertebrate is simple in the extreme; the paired rods are accurately like each other, but their development is not quite synchronous; the secondary preoral pterygo-palatine $(p . p q$.$) is overshadowed and slow in growth$ (see Plate XXVIIl. fig. 2, where the arches are drawn as though the object were transparent)*. The facial thickenings between the clefts which contain the arches may be seen with considerable clearness, especially in front (fig. 3); here in front of (above) the mouth towards the mid line we see the clubbed ends of the trabecula ( $t r$.) roofed over by the nasal sacs. Below and somewhat behind these are the pterygo-palatine arches $(p \cdot p \cdot q$.$) ,$ in the thick outer wall of which the maxillaries and malars will be developed, and the pith of which will become, by early ossification, the palatine and pterygoid bones. Below the inferior, transverse, large mouth, the thickenings which contain the first and second postorals are seen-Meckelian and hyoid. 'The cleft which is formed between the trabecular and the pterygo-palatine bars is best scen in the side view (figs. $1 \& 2, c l .1$ ); it opens in the inner canthus of the eye. The two pairs of preoral rods will be best understood by reference to a palatal view of the skull with the postorals cut away (fig. 4), and to the diagrammatic view of the skull and face as seen from below (fig. 5). It is easy to see, by a reference to the palatal view (fig. 4), that we are now standing on the same level as the "Dipnoi" amongst the Fishes; the external nostril (e.n.) and the internal (i.n.) lie on the same plane; a free intervening growth of cartilage, binding the arches together, with no further metamorphosis of the parts, would produce a true parallel to the skull of those remarkable Fish. The sinuosities of the upturned palate (fig. 4), its plaits and its crevices, are easily understood by reference to the diagram (fig. 5).

First Preoral Arch. -The trabecular rods form together an elegantly lyriform structure; they already have begun their extensive "commissure," being parallel now in their fore half. Behind, they are like callipers, and the blades are at some distance fiom each other; their apices, sharpened off, seem to approach the fore end of the investing mass (i.vo); but a scctional view (fig. $0, t r . c m ., i v$. ) corrects this error, and shows that these diverse parts lie on a totally distinct plane and far from each other, a fact I pointed out long ago in my paper on the Hog (Phil. Trans. 1S71, Plate III. p. 149). 'These trabecular blades embrace the pituitary body ( $m \%$ ); but their curve does not conform to its shape, and is altogether independent of it, being the proper "habit" or morphological fastrion of the arch. After forming the elcgant, pyriform, primordial pituitary space, the trabecula become thicker, narrower, and lie closely side by side; this is soon followed by fusion of their edges-the formation of the trabecular commissure (see Plate XXIX. fig. 4, tr.em.). These two rods do not end as a straight bar, but in front

* In my paper on the Frog (Phil. Trans. 1871, p. 145) the pterggo-palatine areade is described as a sccondary structure; in that on the Salmon (ibid. $1573, \mathrm{p} .109$ ) it is spolsen of as iudependent. It is a secondary arch. 
are bent upon themselves, as the finger's in clutching; hence the transverse crevice seen in the palate between the inner nares (fig. $4, i . n . c ., t r$. ). This retral grow th of the trabecular "cornua" is not so pronounced in the Frog (Phil. Trans. 1871, Plate V.), but is equal to the Mammal in the Bird ("Fowl's Skull," Phil. 'Trans, 1869 , Plate Lxxxr. figs. 1 \& 2, tr.). The median part of the upper lip, which is transverse and quite rudimentary in the youngest embryo (fig. $3, u_{.}$. .), has developed in a somewhat older specimen (fig. 4, $p n$.) into a pointed retral flap. 'This flap hides an azygous projection of the trabecular commissure, the "prenasal cartilage;" this axis of the premaxillaries is a part largely developed in Birds (see "Fowl's Skull," Plates LxxxI.-IIr. m.), where it is first retral, then vertical, and then foreturned, so that it is the principal factor in the exaggerated prognathism of that Class. Outsicle this process the trabecular comua are at present clubbed and bulbous (Plate XXVIII. figs. 3, 4, \& 5, c.tr.); afterwards they each send backwards a recurrent rod * The general appearance of the trabeculx, as seen from above, is shorn in Plate XXIX. fig. 4; their varying thickness is displayed in sections (Plate XXIX. figs. 1, 2, 3, \& 5, tr.).

Second Preoral Arch.-Even in the Osseous Fish I found the pterygo-palatine arch both late and feeble in its derelopment; in the Frog it is a long time before it appears, and grows very slowly, and is never more than a long conjugational band between the trabecular and mandibular rod. In the Mammal, as in the Bird, this primarily feeble rod is ossified hurriedly, as it were, before the cells can acquire any intermediate substance (see "Fowl's Skull," l'late LxxxI. figs. 1, 6, \& 11); yet in the present instance the bony plates that arise in and around these small sigmoid granular rods are some of the most complicated and the most massive in the whole head and face. Even through the palatal skin the hooked tops of the preoral arches can be seen (fig. 4); but whilst those of the trabeculie grow inwards, those of the pterygo-palatine bars grow upwards and outwards, persistent in the "hamular process." 'The direction of the whole bar (Plate XXVIII. figs. $4 \& 5, p \cdot p g_{\circ}$ ) is downwards and forwards, and their extremities or "cormu" approach each other below the trabecula: they are at present far apart in this originally cleft palate (figs. $4 \& 5$ ); the fold of mcous membrane covering each on its inner side gradually grows towards its fellow, and they eventually meet and coalesce. 'The thick cushion outside each bar is the niclus in which the maxillary and malar are developed; and the whole maxillo-palatine mass is a mere process or outgrowth of the first (postoral) arch, and is not an independent morphological region. At present the arch is subocular; but it does not correspond to the subocular bar of the 'Tadpole ("Frog's Skull," Plate V.), which is formed by the extremely long pier of the mandibular arch, the arrested conjugational pterygo-palatine lying quite in front of the eyeball.

\footnotetext{
* The distinctness of these rods from the surrounding tissues is purposely exaggerated in the accompanying illustrations, for they are imbedded in a gelatinous tissue rich with enclosed grinules or young cells, whose protoplasmie substance takes up the carmine rers frecly; and the differentiation of these rods is at present a matter of degree, that part of the blastema which will become hyaline cartilage being the most compact and crowded with young cells; next to this the naseent perichondrium; and the most gelatinous part outside is the rudimentary condition of the loose stroma or areolar connective tissue.
} 
In this stage a section of the head (affected as it is by the "mesocephalic flexure") which passes through the first cerebral vesicle and its upgrowth takes the pterygopalatine rods almost from end to end, whilst the trabeculie are cut directly through (Plate XXIX. fig. 5, tr.p.p.y.). 'Thus, as compared with the trabecular apices, the pterygopalatines descend a little before they send upwards the apical hook.

Third Arch, or First Postoral.-This rod, like its immediate successor, is stout, sigmoid, and strongly inhooked above; it does not at present meet its fellow at the mid line. This is the primordial mandible, $m n$, but it remains as the lower jaw for a very short time, and is not segmented into an upper and lower piece. 'There is a stage in all the oviparous Vertebrata in which this rod is free from segmentation; but, above the Lamprey, a pier and free arch are formed by subdivision of the bar. The tissue over it is thick, and in this overlying part the persistent mandible is formed (see Plate XXVIII. figs. 1, 4, \& 6, and Plate XXIX. figs. 5 \& 6, mk.).

The morphological changes that take place in the hooked and inbent apex are of the greatest interest; for now we arrive at the point where not only the hyoid arch is arrested and modified in relation to the outworks of the organ of hearing, but the mandible of the embryo is also suddenly given up to these secondary correlations. Considered in relation to their new function, the parts of the mandible of the mammal might, like those of the upper part of the hyoid arch, be included in the stapedian terminology*.

The Meckelian rod itself is shown in the vertical section near its extremity (Plate XXVIII. fig. 6, mk.), and in the palatal view (fig. 4, mk.) near its apex; near its apex it is seen on the outside in the lateral view of the sliced head (Plate XXIX. fig. $6, m k$.). But horizontal sections of the head are necessary to show the relation of the apex of this bar to the first postoral cleft, the rudimentary ear-drum cavity (see Plate XXIX. figs. 7, 8, $9, m k$.). These sections show that this very expanded cleft is being divided into two spaces, one of which (the inner) becomes the tympanic cavity, and the other the "meatus auditorius externus." The septum or diaphragm is formed by the lining skin of the cleft growing outwards from the side of the ear-sac, and inwards from the outer face; this latter growth is the most intense, being pushed in by the ingrowth of the apex of the embryonic mandible, which, growing inwards and backwards, carries the lining skin of the cleft before it; thus the "membrana tympani" is formed. Looking at these figures, we see at once that the "manubrium mallei" is the hooked apex of the primordial mandibular arch, and that therefore it must correspond with the large bifaceted backwardly placed head of the Bird's quadrate bone" $t$.

'The shoulder or tuberculum of this rib-like bar becomes the thick head of the

* See "On the Representatives of the Malleus and the Incus of the Mammalia in the other Vertebrata," by Professor Huxlex, 1'roc. Zool. Suc., May 27, 1869, pp. 391-407.

† I was under the impression that the "internal angular process" of the Bird's mandible ("Fowl's Skull," l'late LxxI. fig. 13, i.a.p.) was the homologue of the manubrium mallei of the mammal; it is not; both it and the posterior process $\left(\mu \cdot p_{0} p\right)$ are outgrowths formed lower down, and correspond in nature to the "opereular knob" of the nest or hyoid areh. 
hammer; the solid rod itself develops for a while, but by the time of birth has shrunk into the feeble, pointed "processus gracilis."

Fourth Arch, or Second Postoral. - At present this arch is extremely like the one in front of it (Plate XXVIII. fig. 5 , and Plate XXIX. figs. 5 \& 6, hy.); but it is flatter, and the right and left bars meet more closely and at an obtuse angle; its shoulder, also, is more upturned. This arch has been cut through in the palatal vertical views (Plate XXVIII. figs. $4 \& 6, h y$.); but the form of its tuberculum and capitulum are best seen in the horizontal section (Plate XXIX. figs. 7-10, $h y$.), and its shoulder or tuberculum is exposed in the sliced head (Plate XXIX. fig. 6, lly.). In this latter figure it is seen that the shoulder stands out like that of a Bird's rib, the head or capitular portion thrusting itself as far inwards as it can on to the periotic wall. The landmarks exposed in this figure are the portio dura and the top of the jugular vein (Plate XXIX. fig. $6, h y ., 7^{a}, j, v$.). In figs. $7,8, \& 10$ of the same, Plate, the horizontal sections show that the head of the hyoid growing towards the auditory mass is exactly like the head of the mandibular rod. The portio dura nerve is seen both at its entrance into and its exit from the facial wall in this figure, and it is of the utmost consequence to the morphologist as being a most safe landmark. In the outer lateral view it is seen escaping behind that part of the hyoid rod which becomes the "stylohyal" (Plate XXIX. fig. 6, $\left.h y, 7^{a}\right)$.

In one horizontal view (Plate XXIX. fig. T, $h y ., 7^{a}$ ) its whole auditory course is seen, on one side its entrance into the wall in front of the first postoral cleft, and its exit behind the hyoid in the other; the same thing is shown in Plate XXVIII. fig. $8,7^{a}$ (see also Plate XXIX. figs. 8-10, $7^{n}$ ). In most of these figures the head and neck of the hyoid are shown from above (Plate XXIX. figs. 7, 8) and from below (fig. 10, $\mathrm{my}$.); but in another seen from above (Plate XXIX. fig. 9) the section is through the rods a little lower down; and here we get a most instructive view, the shoulder evidently becoming dislocated from the neck, a process which will go on to complete separation of the parts.

Fifth Arch, or Third Postoral.-In this arch the Mammal has dereloped merely the counterpart of the "hypobranchial" segment of the first branchial arch; it is shown in a subhorizontal section in situ attached to the larynx (Plate XXIX. fig. $5, t h . h ., l x$. ), and in the diagrammatic figure (Plate XXVIII. fig. 5, th.h.) is seen beneath the auditory sacs. In my paper on the Frog (Plate vir.p. 171) I showed how that the thyrohyals were the hypobranchial remnants of the first and second branchial arches developed backwards; those of the Mammal are therefore strictly homologous with those of the Frog, the latter being formed by retention of a part, which part is alone developed in the former.

Looking again at the five pairs of facial arches as a whole, we see that the only arch, at present, which has developed a conjugational keystone piece is the first or trabecular: this is the "prenasal rostrum" which figures so largely in my former paper on the Bird's Skull. No other keystone appears afterwards in the Pig, save in the last pair; 
this becomes the "basihyal" of anthropotomy, but answers to the first "basibranchial of the Fish. These and the other "conjugations" will be shown in the more advanced stages.

The Notochordal Region and Membranous Cranium.-With the arrest of the somatomic divisions in the cephalic region of the embryo, and the great modification of the nerves of common sensation and of motion, we have no certain guide as to how much or how little of the spine the notochordal region corresponds to. 'The notochord retreating, relatively, from the fore end of the investing mass and becoming in time the temporary axis of a single basal bone, the basioccipital, although it gives a vertebral character to its own territory, is yet placed by its altered conditions in a new category.

In my first stage I take the skull when it has been fully bent upon itself-the "mesocephalic flexure;" and at this time the large notochord (Plate XXVIII. fig. 6, nc.) bends suddenly upwards, and ends in a free blunted point, exactly opposite that infolding of the membranous cranium which partially severs the second from the third cerebral vesicle (C2, C 3). The investing mass stops short of the apex of the notochord and lies beneath its plane. The relation of the two, as seen from above, is given in the horizontal view (Plate XXVIII. fig. 8), and as seen from below, diagrammatically, in fig. 5. 'The vertical section (Plate XXVIII. fig. 6) shows the notochord covered above with the membranous cranium (dura mater and cells of the cutis), and bearing in its hollow the medulla oblongata (m.ob.) and the vesicular cerebellum (C3). 'The three structures here seen behind the pituitary body $(\mathrm{p} \%$.) form the primordial " posterior clinoid wall;" and the rounded mass of delicate gelatinous stroma which lies above these three parts, in the hilus of the kidney-shaped third cerebral vesicle, is the "third or median trabecula" of RATIKE--a structure quite temporary, as that exccllent author averred, and of no morphological import*

Only in the basal region is there at present any developed hyaline cartilage (Plate XXVIII. figs. 5, 6, 8, and Plate XXIX. figs. 4 \& $7, i . v$.$) , although it does appear in$ large tracts afterwards infero-laterally, and even above also in the occipital region. At present all but the notochordal region of the cranium is a very soft and delicate membrane, inclosing the large blebs into which the great neural axis has developed. Afterwards this membrane will in certain parts split up into three strata-the dura mater within, the granular territories in which the "investing bones" develop will lie on the outside, and in the middle the hyaline cartilage of the occipital and sphenoidal regions. At present the skin is represented, but not thickened into distinguishable dermis, over the third resicle (Plate XXVIII. figs. 1, 2, \& 6, C 3); afterwards this vesicle will be entirely enringed behind, in the manner of a vertebra, the middle layer of the membrane chondrifying directly upwards from the investing mass. But in the basisphenoidal region only as much cartilage as was primarily related to the free end of the notochord (namely, the "postclinoid wall") has any. remnant in it comparable to a

* Ratise erred in supposing the "paired rafters," or symmetrical trabeculi, to be outgrowths of the investing mass of the notochord. 
vertebral structure; and the whole basisphenoidal territory, small as it is in the Pig, is very compound, having its origin in the two apices of the investing mass, in the apices and posterior end of the commissure of the trabecular rods, in a chondrified part of the cranial wall (related to the investing mass merely by coalescence at its postero-inferior angle), and, lastly, in a secondary growth of cartilage beneath the pituitary body. This last growth of cartilage is found in Sharks and Batrachians, but not in Teleostean Fishes nor in Lizards and Birds.

The basisphenoidal territory may be understood by drawing one imaginary line across the end of the trabecular commissure (Plate XXIX. fig. 4, tr.cm.), and a second across the apices of the investing mass, leaving a short tract in front of the posterior line; the figure itself ends at this second line.

'The cranial wall in the anterior sphenoidal region is altogether soft and gelatinous at present (Plate XXIX. fig. 5, a section through the primary cerebral vesicle, thalamencephalon, and its two outgrowths, the hemispheres); beneath this part the trabecular bands are now fairly differentiated $(t r)$, and these form the lower half of the compound presphenoid, as we shall soon see. 'These are the three proper cranial regions, corresponding to the cerebral vesicles, but not in any proper morphological sense answering to the divisions of the body, the somatomes; no other segment can be found, for the immense outgrowths of the first cerebral resicle lie upon the nasal roofs.

Even the posterior sphenoid loses what little relation it had to the notochord, which is absorbed by the basioccipital, and is largely formed by borrowing substance from the first facial arch; but the anterior sphenoid is a mere chondrification of the middle layer of the membranous cranium, the two wings mutually sending downwards an azygous plate which coalesces with the common crest of the trabecular bars.

The Sense-capsules. - The extent of the olfactory region is at present very small; afterwards the whole labyrinth takes up three fourths of the cranio-facial length. The squarish septum (Plate XXVIII. fig. 6, s.n.) looks almost directly downwards beneath the first cerebral vesicle, and the double roof of the labyrinth has the relation of an cave to the cerebral roof. The most projecting lidney-shaped part of the nasal roof is the "ala nasi;" and both lateral and front views of the embryonic head show how this is, as it were, grafted on to the upper surface of the down-bent trabecular bars. A great difficulty is got rid of here, which has cost me much trouble; for the alæ nasi are not formed out of the substance of the trabeculie, nor can they be considered, in the adult, merely the front and portico of the roof of the nasal labyrinth; they completely coalesce with the trabecular knuckles; and the rooting, ossified snout of the adult Pig is of a compound nature, principally, however, formed of the genuflection of the first visceral arch.

The passage from the outer to the inner nostril (Plate XXVIII. fig. 4, e.n., i.n.) is already tortuous (Plate XXVIII. fig. 7, a vertical section beyond the septum nasi); for already the mucous membrane has been thrown into baggy folds, into which soft outgrowths of the roof are entering, afterwards to become a labyrinth of cartilaginous MDCCCLXXIV. 
coils. The bilobate mass directly above the trabecular horn (al.tb., i.tb., c.tr.) has its anterior lobe developed into the curious "alinasal turbinals" immediately within the snout, whilst its hinder lobe becomes the long "inferior turbinal." The swelling below the down-turned roof is the rudiment of the "nasal turbinal," scarcely developed in the adult of this type; and the mass which lies beneath the rudiment of the olfactory crus (1) becomes the upper and middle turbinal (one mass in the Pig) and the true olfactory region. Vertical sections * show, most instructively, what could in nowise have been guessed at-namely, that the nasal labyrinth has its skeletal parts formed by the approximation and coalescence of two imperfect cylinders open freely below, and by these receiving at their junction below the ascending crest formed by the conjugated trabecula (Plate XXIX. figs. 1-3, al.s., al.e., tr.). When these trabecular bands continue flat (as in the cmbryo, Plate XXIX. figs. 1 \& 2, tr.), then we have, as in the Frog and the Crow, a cartilaginous floor to the nasal passages (see memoir on "Frog's Skull," Plate vir. fig. 6, and Plate x. fig. 3, s.n.l.; and also Proc. Roy. Micr. Soc., Oct. 2, 1872, p. 224, pl. 3S. fig. 1, s.n.). In most Mammals, and in Birds not belonging. to the Passerine group, the trabeculae narrow in to form the rounded thickened base of the whole " ethmopresphenoidal bar;" this process is seen to be beginning in the section through the posterior part of the nasal region (Plate XXIX. fig. 3, tr.). 'The section through the inner nares (Plate XXIX. fig. $3, i . n$.$) also shows the back wall of each nasal passage$ ( $p . n . w$.$) . These large rounded spaces are seen to have the rudiments of the last of the$ middle turbinal coils already continuous with the end wall. 'l'hese posterior walls correspond to the end of each "sphenoidal sinus ;" this is therefore the presphenoidal region, and behind the mesoethmoid; and the pyriform openings above were made through the front of the cranium and through the fore end of the cerebral hemispheres, where they bud-off the olfactory crus (see also Plate XXVIII. fig. 6, C 1 ${ }^{\circ}$, ol.). 'This same section has cut through the first cleft (first preoral or lacrymal passage) on its way to the nasal passage. 'The anterior extremity of the, as yet, soft palato-pterygoid $\operatorname{rod}\left(p \cdot y^{\prime} y_{0}\right)$ is here cut through, where it passes below the inner nostril (i.n.). 'The space between the rudimentary olfactory crus and the budding upper turbinal (Plate XXVIII. fig. $6, o l, s . n$.) is composed, at present, of an almost structureless gelatinous stroma; it is slow to form those cartilaginous bands afterwards, which, creeping between the olfactory filaments, form the cribriforin plate-a secondary morphological structure almost entirely peculiar to the Mammalian skull.

The eyeball only affects the skull from without, by modifying the facial and cranial structures to form its safe recess or orbit; but the earball is constructed after the fashion of the old cottage oven, being built into the side walls of the skull, bulging out on the outside, and having its nerve-mouth projecting also within.

In my last paper, on the Salmon's skull, I was able to show the infolding of the

* These vertical sections of the nasal region were made by the same slicing as the horizontal sections of the head further back: this depevded upon the hooked shape of the head at this stage ; the razor passed at right angles to the aasal roof, but parallel to the notochord. 
dermal layer to form the ear-sac, the cavity of which was wide open on the outer surface. In this piece of work "it was my hap to light upon" embryos the youngest of which were filming over this primordial "aqueduct;" the skin (ontis) is incomplete over" the top (Plate XXVIII. figs. $1 \&$ 2, au.), but the passage itself, learling into the rudimentary labyrinth, is closed by a gelatinous plug. The periotic walls come as near to cartilage, in their commenced solidification, as the investing mass and facial arches, and the outline of the sacs can be fairly made out. Their general form can be seen by referring to the horizontal views (Plate XXVIII. figs. 5 \& 8, and Plate XXIX. fig. 7, au.); but they are well outlined on the extcrnal surface (Plate XXVIII. figs. $1 \& 2, \alpha u$. ), and they are seen to be tuberose bodies, having a straightish imer margin, a sublobular outer margin, and their broadest end behind. They are separated by the breadth of the investing mass with its enclosed notochord, and this tract is narrowest in front. When the upper face is slightly pared off (Plate XXIX. fig. 6, au.), the opening of the aqueductus restibuli is shown; but this is best seen in a horizontal section, viewed from below (Plate XXIX. fig. 10), where it is seen imbedded in the periotic wall inside the "tegmen tympani" (t.ty.); a little behind it is seen the portio dura, which forms by its boring the "aqueductus Fallopii." In the same figure the opposite side of the section was made lower down, so that the roof of the tympanum (tegmen) is cut away, and the tympanic cavity cut through, exposing the head of the second postoral arch and the "aqueductus" just above its entrance into the cavity of the car-sac*.

The reader will observe that this passage has the appearance of being double; I could not, however, find more than one perforation. 'This opening into the auditory sac, which is large in my first and second stages in the Frog, has closed in the third stage ("Frog's Skull," Plates IIr. \& rv. au.); in the Salmon ("Salmon's Skull," Plate v.) it has not closed in "fry" of the first summer".

As for the cavity of the ear-sac, it is at present very rudimentary; the canals are but beginning to bud out from the postero-superior region, and the cochlea is perfectly ornithic (compare Plate XXVIII. fig. 8, cl., and Plate XXIX. fig. 7, rl., with "Fowl's Skull," Plate тхххп. fig. 1, cl.).

'The sections show the larger nerves and ressels, which serve as excellent landmarks, especially the trigeminal, the portio dura, the glosso-pharyngeal, the vagus, and the hypoglossal nerves $\left(5,7^{a}, 8,8^{a}, 9\right)$. The three last nerves all pass through soft stroma in the angle between the auditoly sac and the inresting mass; the large vessels also ("basilar artery" and "internal carotid") all lie, as dense ensheathed masses of young blood-corpuscles, in the most diffuent stroma, the fluidness and instability of which makes it an admirable "soil " for these fast-growing countless "roots." Before passing to the next stage I must again refer the reader to the diagrammatic figure (Plate XXVIII. fig. 5), that he may compare it with what I have already described in the embryos of the Fowl, Frog, and Osseous Fish at a similar stage. With the vantage-ground of this

* I hare not becn able to determine what relation this primary opening bears to the "aqueductus cochlex," or whether it is related to it at all. 
simple platform it will be easy to follow the metamorphosis of the primordial parts,' even in the Mammal, where such changes are most of all displayed, and to compare and harmonize them with the lesser degrees of transformation to be seen in Fowl, Frog, and Fish.

$$
\text { Second Stage.-Embryo Pig, } 1 \text { inch long. }
$$

Most of my illustrations of the complete embryonic skull will be made from a somewhat more advanced stage than this; but this second stage is of great importance in illustrating the morphology of the facial arches and auditory sacs*.

In this embryo chondrification has fairly set in, although the cells of the hyaline cartilage are still close together, quite as close as in the nidus of the vomer in the next stage, or the tissue in which the rostrum of the parasphenoid is developed in the cmbryo bird ("Fowl's Skull," Second Stage, Plate LXXXI. fig. 7, r.st.). Ossification has commenced also, and can just be seen in the nidus of the vomer, maxillary, and dentary; this last is the forwardest of the bony plates (Plate XXX. fig. 2, d.). Beginning at the snout we see that the aln nasi have chondrified, and that the retral trabecular horns (Plate XXX. fig. 1, al.n., c.tr.) have coalesced with them: the little papular prenasal cartilage $(p . n$.$) is well seen in this front view; beneath this, a little further back, the$ stroma becomes dense on each side and forms the premaxillary territories, and is ready to ossify. In the deepest and widest part of the ethmoidal region, a vertical section of which (Plate XXX. fig. 2) shows the commenced ingrowing of the proper turbinal folds, we see now that the descending nasal roofs and the ascending trabecular crests have all coalesced together to form the large mesoethmoid (m.eth.). A long scoop-shaped territory lies immediately under the trabecular base of this septum, and this granular tract is undergoing endostosis; it is forming the vomer $\left(v_{0}\right)$. Far on each side, above a rudimentary tooth-pulp, is a faint trace of the maxillary (mx.). In this "schizognathous" stage the root of the tongue is seen at no great distance from the freely exposed romerine region, and the oral cavity $(m$ ) has here steep sides, in the walls of which the primary palatal bars ( $p . p g$. ) are seen as compressed granular plates. On each side, below an inferior tooth-rudiment (t.), a large mass of nascent cartilage is seen, having a kidney-shaped section; and inside this a round rod of cartilage is seen, converging towards its fellow of the other side as it passes forwards. If my observations had ended here, the thick slab of granular tissue, with its incurved edges, would have merely been noticed as the proper dentary territory or nidus of the mammalian mandible; it is more than this, as the next two stages will show: the "rod" is MEckeL's cartilage (mk), the shaft of the first postoral arch. The dentary bone itself appears in this section, and is of a rich rose-colour in the preparation, one stained with carmine; the tissue around the osseous deposit is becoming colourless, like MEckEL's rod, for the carmine scarcely tints the cartilage. The other postoral bars are shown in this section; the "cornu minor"

* From a large number of exquisite sections of this stage I have only made the six illustrations here given; for what the rest show is better seen in a somewhat more adranced stage, the morphological level being essentially the same. 
$(c . h y$.$) is cut through near its junction with the long stylohyal, and the "cornu major"$ $(b r .1)$ is shown in its whole extent on each side; whilst between we have the basal piece ( $6.6 r$. ), not, truly, a basihyal, but answering to the first basibranchial of the Fish. The larynx (lx.) is below and behind them, and behind it is the osophagus $\left(\infty_{0}\right)$.

Another section (Plate XXX. fig. 3), taken further back than the last, shows the sphenoidal, auditory, and occipital regions as seen from above. The differentiation of parts has gone on very rapidly, whilst the embryo has merely become longer by one half, and the difficulties in the way of interpretation are largely removed.

In front the "anterior clinoid wall" (a.cl.) is seen to be symmetrically divided at the mid line; this is the junction of the trabeculre at the end of their long commissure, in front of the outbent blades which pass around the pituitary region. 'The pituitary cup is deep, wide, narrow above, and has a crescentic form, the concavity of which looks forwards. Between this actual cavity and the free ascending ends of the notochord and investing mass there is a large amount of gelatinous tissue, through which the wavy intemal carotids (i.c.) pass, converging and again diverging. 'l'he gelatinous tract, the base of the so-called "middle trabecula" (see Plate XXVIII. fig. 6, m.tr.), is widest close to the ear-sacs, and narrows to the edge of the pituitary pit; on each side of it is seen a bulbous mass, the Gasserian ganglion (5). On each side of the extremity of the notochord and investing mass are seen the well-defined ear-sacs, which are here cut through in their cochlear region; the coils are now well developed. On the left side the section is behimd and below that shown on the right, where the "malleus" or head of the first postoral is cut through, the shaft of the second arch, and the "meatus externus" and outer ear. Part of a similar section, taken lower down (fig. 4), displays the orbito-sphenoids in section (with their upper part cut away); and where they have coalesced with the trabecular commissure, there the optic nerves (2) are crossing. 'The alisphenoids (al.s.) are sections seen in their whole extent, but not their connexion with the basisphenoid, the notochordal region of which is displayed, backwards to where the basioccipital territory begins.

At a lower level closely packed cells are developing into cartilage, which will form a secondary floor to the pituitary body, the seat of the "sella turcica;" then the posterior sphenoid will be morphologically complete. The connexion of the two great postoral bars with the auditory capsule will be better understood by two more sectional views similar to the large figure (Plate XXX. fig. 3), but of more limited extent and more highly magnified: all these figures are made from the antero-inferior aspect of the up-tilted basis cranii, the sections, which in the nasal region were vertical (figs. 1 \& 2 ), being horizontal behind. Such a section (Plate XXX. fig. 5) through the outer ear or concha $(c a$.$) and head of the first postoral bar shows how curiously incurved this capitular$ portion is, and how that its apex is developed into an orbicular part, like that on the apex of the next bar. 'The shoulder, which articulates with the upper part of the next bar, is very bulbous, and at the root of the neck a conical boss is sent outward; the shoulder is the head of the malleus, the boss is the process for attachment of the 
tensor tympani muscle, and the rest of the neck with the rounded head is the "manubrium mallei" ( $m b$.). 'The dark jagged space is the tympanic cavity, a development of the first postoral cleft, and which runs forwards into the mouth-cleft as the Eustachian tube. Now it is easy to see how the membrana tympani is formed; for the inhooked apex of the mandibular rod, creeping like a tendril toward the auditory sac, necessarily carries with it the lining membrane of the cleft wrapped over its head. The shaft is not shown here, because it has been severed with the fore part of the shoulder or "tubercular" portion.

On the left side of the larger figure (Plate XXX. fig. 3) the fellow of this is seen, but cut away further backward. Below the "manubrium" is seen the shaft of the next arch (now to be called stylohyal); its direction is downwards and forwards to the root of the tongue; a good distance must be supposed between this and the section through the ceratohyal already described (Plate XXX. fig. 2, c.hy.).

The outer ear or concha $(c a$.$) is fast passing into cartilage ; it is curiously folded upon$ itself, and runs round the external orifice of the cleft; it is much morlified already from its Batrachian and Plagiostomous prototypes, the "annulus tympanicus" of the former, the "principal opercular" of the latter. "I'he interest attached to the vegetative gemmation of the membrana tympani is more than rivalled in the metamorphic changes that take place in the succeeding arch and in the neighbouring territory of the ear-sac. In the first stage we saw that the simply oval primordial ear-pouch was dereloping into a lobular form, and that there were three bulgings on the outer side of the sac (Plate XXV III. figs. 5 \& 8, an.). 'The middle of these, by a process of gemmation, has freed itself to a great extent from the wall of the ear-capsule, thus forming a "fenestra" in that wall, which, howerer, is closed by the separated nodule of cartilage. 'This twin bud (Plate XXX. fig. 6, st.) (it has two papular elevations which look forward and outward from its free surface) is covered externally by delicate indifferent tissue, rendy to become cartilage. Being in the posterior wall of the first postoral cleft, the second arch (hyoid), whilst sending its orbicular head inwards, does not become infolded in the mucous membrane lining the cleft, but is free to creep, tendrilwise, to the surface of the car-sac; this it does, and conjugation takes place between its orbicular "capitulum" and the freed auditory bud. But in the first stage we saw that a curious kind of segmentation was taking place through the shoulder of the second postoral bar (Plate XYIX. fig. 9, hy.); now that process is much more complete, and the simple bar has undergone a process the exact counterpart of that by which the blade of the orangeleaf articulates witl its petiole: whilst this has been going on, a rounded "tuberculum," distinct as that in the rib of a bird, has been developed on the detached upper segment (Plate XXX. fig. 6, s.c.i); this is the "short crus of the incus ;" the neck growing towards the eal-sac is the "long crus" (l.c.i.); its expanded, conjugating end the nidus of the "os orbiculare;" the helf-shoulder above is the body of the incus, which articulates with the shoulder of the arch in front (Plate XXX. fig. $3, i ., m$.); and the bigeminal segment of the auditory sac is the roung stapes (st.). 'The other half of the shoulder, or tubercular 
part of the rod, is continuous with the long descending part of the arch (see Plate XXX. fig. $\left.9, s t . h_{.}\right)$; it is the head of the stylohyal. Here we see that the second postoral arch grafts its capitular portion on to the auditory segment, and splits its tubercular portion into two new condyles, one of which, covered by the squamosal on the outside, articulates with the tegmen tympani; whilst the other, retreating very sensibly, coalesces with the ear-sac further backwards and downwards, close in front of the exit of the portio dura nerve. In the figure these parts are continuous; but the continuity is kept up at present by now cells, and these younger cells are all soft indifferent tissue as yet; their morphological differentiation will be explained in the next stage*.

Behindthe stylohyal and some distance outside the promontory ( $p r$.), the portio dura nerve $\left(T^{\alpha}\right)$ is secn in section, an excellent land-mark for the stylohyal; further backward the compound Sth nerve $\left(S^{a}, \delta^{b}\right)$ is seen in the "foramen lacerum posterius" $(f . l . p)$ ) ; the hypoglossal (9) is enclosed in the upgrowing exoccipital cartilage (Plate XXX. figs. 3, 9, e.o.).

'The relation of the auditory sac to the exoccipital (e.o) is shown in fig. 7 ; the whole arch of the horizontal canal is seen shining through the cartilage, and its ampulla is obscured by the fibres of the portio mollis nerve $\left(7^{b}\right)$; the Gasseran ganglion, and the compound sth nerve are also severed $\left(5,8^{a}, 8^{b}\right)$.

\section{Third Stage.-Embryo Pig, $1 \frac{1}{3}$ inch in length.}

Those metamorphic processes which were rapidly proceeding in the last stage have become very complete in this, where the embryo is one third longer: this stage must be copiously illustrated and described at length, as it is the best stepping-stme between the early simple and the later transformed conditions. The sections now to be described are a series from the end of the snout to the occipital region. Parallel to cach other, yet they do not keep the same vertical relation to the embryonic head, but become almost horizontal sections of the occipital region. the whole head at this stage is about equal in size to a horse-bean.

The first of these slices is through the end of the snout (Plate XXXI. fig. 1), and shows the coalescence of the alinasal cartilages with the backwardly bent trabecular cornua (al.n., c.tr.). The next (fig. 2) is through the foremost part of the septum nasi $\left(s . n_{0}\right)$ and ralvular fold of the nostril-rudiment of alinasal turbinal $(a l . t b$.$) : a more$ enlarged view of the lower half of the septum (fig. $2^{a}$ ) shows the large and massive trabecular cornua, and the prenasal part of the trabecular commissure between them. In the next (figs. $3 \& 3^{n}$ ) the cormua are now seen to be retral, for here they are becoming separate from the "prenasal;" still the base of the septum nasi as well as their

* I have studied the development of this interlygl tract in the Batrachia Anura and Ophidia, where it nerer eren chondrifies; in the Eel (Anguillu), where it is very small and indistinct as cartilage, and fades into a mere ligament: in the Osscous Fish (Salmo salur) and the Ganoid (Accipenser sturio), where it becomes an ossified rod of cartilage; and in the embryo of Linota cannabina, where it chondrifies after a time and fuses together again the incus and stylo-hyal. 
own direction is backwards. Further back (fig. 4) the septum is increasing in height, and the retral processes of the trabecular horns are now much smaller; these slender lamine I propose to call the "recurrent cartilages"*.

In the fifth and sixth sections (figs. $5,6,6^{\prime \prime}$ ) there is no longer any distinction between the rudimentary prenasal cartilage and the completely fuscd portion of the trabecular bar, the lower part of the septum nasi; but as this bud-like wedge of cartilage (see Second Stage, Plate XXX. fig. 1, p.n.) never becomes vertical, having its apex downwards as in the Chelonians, still less protruded forwards as in its large counterpart in the Bird, the bony plates that appear as its splints are not superior as in the Bird, nor anterior as in the Chelonian, but inferior. 'These plates are the premaxillaries, which appear in the Mammal below the snout (see also Caldevder, Philosophical Transactions, 1869, p. 166, Plate XIV. fig. 6, c, for its inferior position in Man). Yet in the Mammal the premaxillaries are related, as splints, more to the retral trabecular cornua themselves than to the arrested azygous cartilage impacted between them. So much of the alinasal cartilages as are depicted in the enlarged figure (fig. $6^{a}, a l_{.}$. ) is a separate segmentthe "appendix alo nasi." The next section (fig. 7) is behind the first third of the septum nasi, where the rudiments of the "hard palate" begin in front, the lips of which appear now on each of the padded bases of the septum, but are here far apart. 'The long cushion-like valvular mass in which the aliseptal folds (al.s.) end and dilate is the early form of the inferior turbinal, which is not so sharply separate from the alinasal turbinal $(a l . t b$.$) as in the Bird. A sharp process of mucous membrane is seen above this on each$ side, where the aliseptal cartilages bend inward; this is the rudiment of the "nasal turbinal" (see Huxley, 'Elem. Comp. Anat.' p. 248), which is but feebly developed in the Pig. In the thick mass which envelops the base of the septum two flat straps of cartilage are seen in section; these are the "recurrent laminx" (r.c.c), and they are contimued in this stage back to that part of the septum which, ossifying earlier than that in front, gets the name of "pexpendicular ethmoid" (see fig. 11). On each side of the lower palatal lip there is a rudimentary tooth-pulp shown in section; and above this, up to the nasal roof, the tissue is marked off from the shin and subcutaneous tissue; this is the granular nidus for the posterior margin of the premaxillary and the anterior margin of the maxillary. The detached piece of this section (fig. $7^{a}$ ) is the fore end of the lower jaw with tooth-pulps appearing, and with a curious result of the great prognathism of the type, namely, complete fusion of the ends of the primordial mandibular rods"MEckel's cartilages (ml.c.)." A section made near the middle of the septum (fig. 8), although answering on the whole to the $7 \mathrm{th}$, shows the tip of the vomer $(v$. $)$ and a very near approach of the lips of the hard palate, and, below (fig. $S^{a}$ ), the convergence of the mandibular rods and the fore end of a bony tract outside them; this is the dentary $(d$.$) ; the tongue (t g$.$) is here cut across.$

The minth section (fig. 9) takes in part of the frontal wall, with the foremost part of

* The "recurrent cartilages" are of great morphological importance; in future communications I hope to show their form and meaning in the Ophidians and in Birds, "Passerines," "Hemipods," the Rhea, \&c. 
the membranous cranium; here we shall see the "recurrent laminz" (rc.c.) on each side of the vomer $\left(v_{0}\right)$, and a still nearer approach of the edges of the under palatal floor. The tenth section (fig. 10) is through the most projecting part of the hemispheres, but in front of the olfactory crus; here, above the inferior turbinal, folds of cartilage are appearing in the roof, the foremost part of the upper turbinal (u.tb.). Here the septum, now to be called the perpendicular ethmoid (p.e.), is at its highest, and we are now behind the recurrent processes of cartilage. At this part the palatal bands meet each other, and in them a new bony centre has appearcd, the maxillary (ma.p.); like the premaxillary, it begins below. 'The next section (fig. 11) is through the widening ethmoidal region and the partly separated olfactory crura (1), as well as through the hemispheres $\left(\mathrm{C}^{a}\right.$ ). The twelfth section (fig. 12) is through the cavity of the hemisphere, which is being cut off from that of the olfactory crus (1): it is immediately in front of the eye, the anterior (inncr) canthus being cut through. This section is of great interest; here we are behind the aliethmoidal cartilages above, and the olfactory bulbs rest upon the soft mat through which their fibres root down into the nasal cavity. The walls, both outer and middle, reach further backward than the roof of the nasal sac; and in the middle wall we see the ribbed condition caused by thickening at the junction of the trabecular crests with the double keel sent down by the nasal ali. Here the middle turbinal arises above the inturned nasal wall which ends the inferior turbinal $\left(m . t b, i_{.} t b.\right)$. This section is behind the new maxillary centre, but shows a iarge tooth-rudiment on each side of the conjugating palatal flaps; the antagonist teeth appear in rudiment below on each side of the severed tongue (tg.), above the growing dentary $\left(d_{0}\right)$, whilst inside the dentary is the Meckelian rod ( $m k^{\circ}$ ).

'The next section (fig. 13) is through the anterior third of the eyeballs $\left(e_{0}\right)$ and the middle of the hemispheres (C I"), and behind the perpendicular ethmoid; here the rest of the septum is almost, if not entirely, of trabecular origin; the section is in front of the junction of the orbito-sphenoidal cartilages (o.s.) with the basal median part. But if the mesoethmoid is dying out here, the nasal wall $\left(n . w_{0}\right)$ continues much further backward, bordering the greater part of the so-called presplenoid (p.s.). We are now behind the upper and lower turbinal regions, and here the "middle turbinal" (m.tb.) is near its extremity; one interspace is cut through. 'This narrow, subcranial, presphenoidal part of the nasal labyrinth, running so far backwards parallel with the trabecular plate, is the "sphenoidal sinus ;" and if any osseous centres were to form in the wall of this narrow region, they would be, as in Man, the "bones of Bertin," the hindermost of the ossifications of the olfactory sacs. Bound strongly beneath the basifacial wall is the granular nidus of the vomer $(v$. $)$, kidney-shaped in section; and beneath it the posterior nares are imperfectly floored in this the region of the palatal bone ( $m$ m.), which is a centre just commencing in granular indifferent tissue less solic and clear than that of the vomer. Below the mouth this section differs from the last in that the dentary ( $\ell_{0}$ ) is thicker and lies closer to the mandibular rod (mk:).

The fourtenth section (figs. $14 \& 14^{a}$ ) is through the middle of the eyeuall, and MDCCCLIXIY. 
gives us the first intimation of the frontal $\left(f^{\circ}\right)$ outside the orbito-sphenoid (o.s.). The end of the middle turbinal is seen from behind in the sphenoidal sinus (sp.s.); at this part the nidus of the vomer is most solid, and comes nearest to hyaline cartilage (fig. $14^{u}, v^{\text {r }}$ ), a state of things first pointed out to me by my friend Mr. Cinas. Stemart.

The proper territories of each investing bone in the Pig evidently only want time that they might all become true cartilage; ossification sets in too soon for the formation of the intercellular substance, but each tract, before ossification, is a true morphological clement or organ, as much so as the cartilaginous "operculars" and "branchiostegals" of a Shark or the "labial cartilages" of a Myxinoid. In illustration of these remarks I have now to mention a fact new both to Professor Huxuey and myself, namely, that the substance which ossifies to become the dentary (figs. $14 \& 14^{a}$, d.) becomes for the most part very typical solid colourless cartilage, as much so as MEcKEL's cartilage, which it invests: I shall show this more fully in the next stage.

The fifteenth section (Plate XXXII. fig. 1) is through the fore edge of the optic foramen; and here we see the nasal wall $(n . w$.$) closing in upon the presphenoid (p . s$.$) ,$ and joining the end of the sphenoidal sinuses. Part of each optic nerre (2) is seen in this section, and for that reason the orbito-sphenoid appears distant from the median cartilage below; its continuity is seen in the vertical section (Plate XXXIII. fig. 4). Here the frontal $(f$.$) is growing down towards the orbit, to which it will form a ceiling.$

The sixtecnth section (Plate XXXII. fig. 2) is through the largest part of the hemispheres and the underlying thalamencephalon; the eye is cut through near its posterior canthus, and the optic chiasma is severed (2). This section is through the lowest part of the presphenoid, which is still invested below by the romer $(v$.$) ; and opposite the$ section of the hindermost part of the ascending palatine plate we see the fore part of the cartilaginous "external pterygoid plates" (e.p.l). The orbito-sphenoids (o.s.) are here at their greatest size, creeping far up the cranial wall and protecting the swelling hemispheres; the section through the dentary $\left(d_{0}\right)$ is close in front of the "coronoid process."

The serentecnth section (Plate XXXII. fig. 3) is through the large orbito-sphenoidal leares, where they join the presphenoid behind the optic foramen (see also Plate XXXIII. fig. 4, o.s., ps., 2). This is the last section which shows the vomer (v.), and here the razor passed through the soft, faintly ossified "internal pterygoid plate"pterygoid proper. The fore-turned extemal pterygoid plates (e.pg.) are here thick massive cartilages; and here, also, both the primary $\left(m k\right.$.) and secondary $\left(a r^{\circ}\right)$ elements of the mandible are composed entirely of hyaline cartilage; this part of the permanent lower jaw is the coronoid and fore part of the articular regions. This section through the posterior part of the palato-pterygoid bar is of great interest, as it gives the direction taken by the apex of the second facial bar, namely upwards and outwards, although the upverd bend is less in the Pig than in many Mammals; it has its fullest development in that small Ruminant, Tragulus javanicus.

In the cighteenth section the basisphenoid and its alie (1'late XXXII. fig. 4, 6.s., 
al.s.) are cut through obliquely, so as to show only the floor part of the latter; and the cartilage beneath the pituitary body is made to appear thicker than it is in reality (see Plate XXXIII. figs. $2 \& 3, p y$ ). On each side of the pituitary body the internal carotids are seen passing to the "circle of WiLLIS," and outside these the Gasserian ganglia. Overlapping the whole are the orbito-sphenoids (o.s.); and on each side of the flaps of the soft palate (s.pa.) MeскeL's cartilages are severed; and lower down the ceratohyals $(c . h y)$, thyrohyals $(t . h y$.$) , and larynx \left(l x_{0}\right)$ are shown.

The nineteenth section (Plate XXXII. fig. 5) is drawn a little more than half across, and on a larger scale. The curve of the cranio-facial axis makes this and the succeeding section rery oblique; and in this figure the basilar artery (b.a.) is tilted to show the bulbous end of the notochord $(n c$.): this thickish section is viewed from behind. The notochord ends now in the region of the future "spheno-occipital synchondrosis;" this narrow part of the basilar plate or investing mass is subcarinate. 'The razor' has passed through the cochlea $(\mathrm{cl}$.) parallel to the plane of its coils; orer this part of the auditory sac, which is scooped above at the side, lies the great Giasserian ganglion (5); and inside and above this the fore edge of the large superoccipital lamina (s.o.) is seen, serered close to the edge, so that there is here a discontinuity between it and the ear-sac, the reason of which is shown in the inner lateral riew (Plate XXIIII. fig. 3, cuu., s.o.), where a large rounded notch is seen in front of the occipital cartilage, bulged out at this part by the lateral sinus. At some little distance from the cochlea the first postoral (now a veritable "malleus") is severed through its head, neck, and shoulders; the head is now flattened: this section shows the thin edge of this manubrium, the thicker part being cut through in the next section (fig. $6, m b$.). This view (fig. 5, m.t.) well shows the imbedding of the manubrium in the membrana tympani, and the inner and outer regions of the first postoral cleft, thus divided by the head of the bar.

The twentieth section (P'ate XXXII. fig. 6 ) is a little oblique from side to side; it is thus practically double; the left hand shows parts in front of those displayed on the right. IIere, on the left, the manubrium mallei $\left(m l^{2}\right.$.) is cut through at its thickest, posterior part, and its solid shoulder (ml.) is seen, the part which articulates with the incus. The incus (i.) is seen on the right side, hiding the manubrium partly, and haring its "short crus" cut away: the figure shows the back of the thickish section. On the right side the section is behind the notch on the base of the fore edge of the superoccipital (s.o.). Below and outside the tympanic cavity (t.c.) the stylohyal $(s t . h$. ) is seen in oblique section as it passes downwards and forwards, and mesiad of this there is the large jugular vein $(j . v$. with a coiled radicle. The notochord ( $n c$. ) is very clearly seen in the substance of the basioccipital cartilage. On the right side the stapedial bud is seen projecting from the auditory capsule just above the section of the promontory $\left(s t ., w^{\prime}\right.$ ), and to this the orbicular "capitulum" of the second postoral is applying itself limpet-like. The twentyfirst section (fig. $T$ ) is from behind the left side of the last (reversed), and shows on the whole what is displayed on the right; in both (figs. $6 \&$ \& 7 ) we see the opening of the "aqueduct of the restibule," and in this the "aqueduct of Fallopins" containing the 
portio dura $\left(7^{a}\right)$, and mesiad of the jugular rein the glossopharyngeal nerve $\left(\delta^{a}\right)$ is cut through; outside the nerve, and below the stylohyal (st.h.), a part of the exoccipital (e.o.) appears. A similar section to the other side is also shown as a front view (fig. S); and here the relation of the portio dura $\left(7^{a}\right)$ to the hyoid arch is well seen. This figure does not show the incus, which is removed to display a new segment (i.hy.) that has arisen, the counterpart of the Sauropsidian "infrastapedial "(II.) and of the so-called "stylohyal" of the Fish (Cuv.); here it will be called the "interhyal " (P.), as it really wants a proper name. In the second stage (Plate XXX. fig. 6) I have displayed the relation of the segmenting second arch to the very Batrachian stapes (see "Frog's Skull," Plate II. figs. 12-16, st.); and on the same Plate (fig. S) I have put for comparison the state of things in the third stage; both are fiont views, and the apex of the stapes is towards the eye. 'The bigeminal papulx on the younger stapes are now connected by a bridge of cartilage, and the lateral dimples are the foot-hole of the little stirrup.

The round head of the short crus of the incus is seen articulating with the tegmen tympani (Plate XXX. fig. S, t.ty., $i$.); and below and behind it is the clavate head of the stylohyal, which is rearly to coalesce with the periotic cartilage at the junction of the epiotic and opisthotic regions (see Plate XXXVI. fig. 2, $i_{.}$, st.h., op., cp.). 'The descent of the dislocated hinder half of the shoulder of this second arch is not so great as in the Osscous Fish ("Salmon's Skull," Plate vr. fig. 2), but it is considerable; and this is a true third stage, as may be secn by comparing fig. 9, hy. in Plate XVIX. with figs. 6 \& S, Plate XXX. The binding, intervening band of new indifferent tissue which has grown in the gap of these divided parts has acquired a hardening nucleus of new cartilage, exactly as we see it in Ganoid and Osseous Fishes, c. g. Accipenser, Anguilla, Salmo. The portio dura $\left(T^{a}\right)$ is secn passing down its aqueduct behind these segments, and the upturued, inbent, long crus or neck of the rib-like bar ends in an elegant suckershaped disk, its capitulum or apex*.

On the same Plate the postoral arches of the third stage are shown in a side view (Plate XXX. fig.9); and a comparison of the undivided mandibular bar with the displaced fragments of the lyyoid will make things plain to the mind. 'The apices of the two bars come very near together; but whilst the first hooks backwards, downwards, and inwards, it does not graft itself upon the auditory sac; nor does its shoulder send backwards a sccondary pedicle so distinct as the "short crus of the incus." Moreover the shaft of the bar on the first arch keeps on its way normally, as in the carly embryo; but in the second arch this part has been segmented off, and displaced backwards and downwards, catching in its descent at the neck and head of the arch, but travelling still further in more adranced stages, until it rests and combines with the postero-inferior angle of the auditory mass. In the new web which grows between the two segments comes the sccondary "interhyal" segment; this, however, loses all its first relations, and finally

* In both these figures, put together for comparison, the parts of the second arch are coloured, and those of the auditory capsule are plain, for the sake of distinction, that the eye may learn to separate the "stapes" from the segments of the hyoid arch. 
coalesces with the neck of the projecting stapes (Plate XXXVI. figs. $\left.2 \& 3, i_{.} / y_{.}, s t.\right)$, and is half lost, at last, in the tendon of the "stapedius" muscle. 'The "cornu minor" (c.hy.) of Man is here seen (PJate XXX. fig. 9, c.hy.) below, articulating with the keystone of the arrested third postoral. "This lesser horn answers to the "hypohyal" (P.) of the Osseous Fish. The twenty-second section, a front view (Plate XXXIII. fig. 1), is through the three semicircular canals; the anterior canal (its arch) is above, near the superoccipital cartilage (a.se., S.o.), whilst the horizontal canal (h.s.c.) is laid bare at its crown and where its non-ampullar end enters the vestibule $(26$.$) . 'The posterior canal has the$ base of its ampulla laid open, and half the arch is seen shining through the cartilage; the lateral cerebellar recess (l.c.r.) is seen above the aqueductus vestibuli (uq.v.). The space between the auditory mass and the basi- and exoccipitals is the posterior formen lacerum (f.l.p.; see also fig. 3); the basilar artery lies on the basioccipital, and the notochord is within it $\left(b .0, b_{0} \ell_{0}, n c.\right)$.

From a series of sections taken horizontally in the nasal region, but which were cut through the investing mass at a right angle, or nearly so, I have selected two as of most importance in this demonstration. The first of these (Plate XXXII. fig. 9) is a fiont view, and shows the left mandibular rod coming forwards and downwards, its manubrium being buried in the tissue behind. 'The portio mollis $\left(\tau^{b}\right)$ is seen lying at the entrance of' the meatus internus. The anterior (superior) canal (a.s.c.) is cut through near its ampulla, and the cochlea $(\mathrm{cl}$.) is divided at right angles to the plane of its coils.

On the other side (left of the figure, right side of the head) the portio mollis $\left(7^{b}\right)$ is seen streaming into the labyrinth, and the portio dura $\left(T^{a}\right)$ is cut through close to the tegmen tympani (t.ty.). The crown of the anterior canal is here cut through, and the horizontal canal near its ampulla; here the "tegmen" is seen at its high anterior part, and the "short crus" of the incus lies in front of its descending portion, where the overlying horizontal canal dips before it turns inwards to enter the vestibule. 'The "long crus" of the incus $(i$ ) is shown hooking upwards, and expanding into its orbicular portion on the stapes (st.), the apex of which has been cut away, exposing the hole. The head of the stylohyal (st.l.) is cut through, and in the angle between $\mathrm{i}$ t and the long crus there is a large pisiform "interhyal" (i.h.y.). 'The basioccipital has an irregularly pentagonal section, show's the notochord in its centre, and is very distinct from the auditory mass: this distinction is rery clear and persistent in the Mammalia.

'The plane from which the last section was taken being sliced again, yielded what I have depicted in fig. 10: this is a back view, and the left sicle of the figure corresponds to the left side of the head. On the right side the occipital arch (s.o.) appears almost to its crown; on the left its fore edge is just missed.

The left side of this figure corresponds very nearly to the left of the last, but the razor has passed close behind the anditory nerve and through the promontory, where its cartilage passes as a narrow band between the fenestre ( $f$. ocklis and $f^{*}$. rotund 1 ), a tract which receives osseous matter from the "opisthotic" centre. Here the base of the stapes is towards the eye, and half of it is seen through the cochlear wall (promontory): the rest is as in the last figure. 
But the section of the right side, just a degree further back, is most instructive. 'The large superoccipital cartilage is scen embracing and walling in the great sinus (s.o., l.s.), and the periotic mass is severed at the junction of the anterior and posterior canals, so that the tube opened here is the "common canal" (c.e.). The posterior non-ampullar half of the horizontal canal (h.s.c.) is opened over the hinder part of the tegmen tympani. The promontory is cut through at the fenestra rotunda $\left(\mu r^{\circ}, f^{\prime} \cdot r_{\circ}\right)$, and outside this is seen the head of the stylohyal; all this long sinuous rod (st.h.) is exposed, and also the short ceratohyal $(c . h \%)$ at its base, where it is seen articulating with the three rudiments of the next arch (base and larger comua of hyoid of Man).

Reconstruction of the skull at this third stage from the foregoing materials will be rendered easier by light obtained from longitudinally rertical sections (Plate XXXII. figs. $2 \& 3)$. In these the first is made, in the facial region, a little to the left of the mid line, so as to give the left face of the scptum of the nose; in the next (fig. 3) the scptum is cut away, and the left face of the right turbinals exposed. In the first (fig. 2), the brain is sketched in ontline in situ; in fig. 3 it has been removed to display the inner wall of the cranium. 'The notochord (ne.) las retired from the posterior clinoid wall, and has becu buried in cartilage; it still hies, however, nearest the upper surface of the inresting mass. 'This may be compared with the like view in the first stage (Plate XXVIII. fig. 6). There the basifacial axis scarcely made a right angle with the basicranial; here these parts mect at an angle larger by one half: there the notochord mounted abore the inresting mass; here it has retired; and lies below the clinoid wall. The gelatinous space called by Risuke the "middle trabecula" is gone, and the reduplicated lining membrine of the cranium has formed the "tentorum cerebelli" (fig. 2, t.cb.). The huge cxpansion of the hemispheres $\left(\mathrm{C} 1^{a}\right)$ has hidden the middle vesicle ( $\mathrm{C} 2$ ), as seen from the outsicle. Behind the large cerebellum (C 3) the occipital cartilage (s.o.) is seen in section; anci below the rounded margin of the basioccipital (b.0.) is shown, the tract becoming thimner forwards, and then much thicker close to the pituitary borly $(m \%)$; it cnds above in the overlapping "posterior clinoid wall" (p.cl.). 'The pituitary depression is not saddle-like, but is a deep cup, floored by a good plate of cartilage. 'The anterior clinoid wall $\left(\alpha_{0} . c l_{0}\right)$ is rounded, and belongs to the presphenoid; the depression in front of it is for the optic chiasma. The median plate rises gently in front of the optic depression, and this higher part for a short distance belongs to the anterior sphenoidal territory: it is formed principally by the trabecular commissure and crests. 'The rest of the plate belongs to the perpendicular' ethmoid and septum nasi; the latter is the longest region and the former the highest. The latcral cthmoid (al.e.) is scarcely seen in this view (fig. 2). Below the pituitary borly the Justachian opening (cu.) is secn, in the root of the tongue the ceratohyal $(t y ., c . h y$.$) , and in the substance of the lower jaw the commissure of MECiEL's carti-$ lages (mki.).

These things and some other's are seen in the next figure (fig. :3). Outside the foramen magnum (f.m.) is seen the occipital condyle (o.c.); in front of this the "anterior" 
condyloid foramen " (9), and then the "foramen lacerum posterius" ( 8 ). Crest-like, above the foramen magnum and auditory mass, is the superoccipital cartilage (s.o.), ending in front in a sinuous manner, being notched and bulged out by the lateral sinus (l.c.). The ear-sac (au.) is an ovoidal flattened body, lying obliquely outwards and backwards, with its bored and scooped face on the inner side. 'The blind recess under the arch of the anterior canal is for the cercbellar process; the antero-inferior spaces are for the compound seventh nerve; the meatus internus has a small cartilaginous bridge in front of it, which passes upwards inside the canal for the portio dura. Between the ear-sac and the small thick alisphenoid (al.s.), there is a large shallow fossa for the Gasserian ganglion (5), and the space for the main part of the fifth nerve is merely the great chink between these two parts-the alisplienoid and the ear-sac. Hence in the Pig we see no "foramen ovale," and the "f. rotundum" has no distinctness from the chink between the orbito- and alisphenoids. Most of the alisphenoid is spent in forming the large "external pterygoid process," and its cranial part is small; here it is not the "ala major," as in Man. On the other" hand, the "alie minores" of Man are represented in the Pig by huge wings of cartilage, that spread themselves from the nasal to the auditory regions. 'This reversal in size of the anterior and posterior wings is like what we see in the Lizard, \&c.,-unlike the Bird's sliull in this respect, where the orbitosphenoids are aborted, the alisphenoids huge. As in the Lizard, the Mammalian orbito-sphenoid has a postneural band, which encloses the optic nerve (2) in a complete foramen: this is well developer in the Pig (Plate XXK. fig. 3, o.s. 2). In front of the optic nerve the base of this orbital wing is continuous with the trabecular commissure for some extent; the greater part of the so-called presphenoid is, hovever, trabecular in nature. The olfactory roof and wall extends backwards behind the septum, which graduates into the presphenoid; thus a large rounded notch exists on cach sicle, and the roof of the true olfactory region and floor of the rhinencephalon is soft; through this delicate tissue the olfactory filaments root dommards to the rudimentary upper and middle turbinal septa $(u . t b ., m . t b$.$) . Between the nerve-fibrils cartilage is beginning$ to appear, and thus a cribriform plate will be formed of secondary cartilage (fig. $3, c r \cdot p \cdot$.). In front of the upper turbinal a rudimentary " nasal turbinal " ( n.tb.) is formed by bending inwards of the aliseptal cartilage. Lower down this cartilage tums inwards, and develops into the inferior or anterior turbinal (i.tb.), attached to which in front is the small alinasal turbinal $(a l . t b$.$) .$

\section{Fonth Stage. Emblryo of the Pig, from 2 inches 1 lines to 2 inches 6 lines in length.}

From dissections and sections of embryos not larger than the grub of the honey-bee in the first, we come in this stage to specimens as large as a mouse.

This is an excellent stage for morphological comparison, as the skull may well be placed side by side with that of the adult Osseous and Ganoid Fish, Amphibian and Reptile, and with that of the ripe chick of the Common Fowl. It also corresponds rery closely in development with an early stage of the skull of Baldena japonice, Lac., sxcel- 
lently illustrated by the late Dr. Escinicit ("Ni 'Tavler til Oplysning af Hraldyrenes Bygning, udferte til utrykte Foredrag af afdede Etatsraad Dr. D. F. Escinicht:" Copenhagen, 1869. Edited by Professor Reminard, plate ii. figs. 1-3).

'The well-marked granular territories that at first invested the primordial sliull and face are now largely ossified, and these ossifications are massive in relation to so small a stull. As in the strong-legged "Herbivora "generally, and in the "Aves precoces," the development before birth and before hatching is very rapid, so that they are strong and in good liking at their first appearance. Moreover, the primordial parts are undergoing endostosis at many points, and from this time the bony metamorphosis takes place very rapidly. If this sliull (Plate XXXIV. figs. 1-7) be compared with that of the Bird ("Fowl's Sliull," Plate Lxxriv.-Lxxsir.), it will be seen that the premaxillaries (px.) do not reach to the end of the snout, instead of projecting beyond it, and they do not send a nasal process between the nasal bones up to the frontal. Here, in the Mammal, the maxillary is by fir the largest bone, and, with the linking malar and zygomatic spur of the squamosal, forms a strong subocular arch, one pier of which is formed by the maxillary and reaches near to the nostril, whilst the other pier is formed by the supratemporal and stretches orer the auditory capsule to the occiput (Plate XXXIV. fig. 1, mn ., j., „.sq.). This sigmoid, trilobate temporal (squamosal) bone, besides creping orcr the infero-lateral wall of the cranium by its squamous part, clamping the outer wall of the car-capsule by a long falcate process, and perfecting the great facial yoke (zygoma), also takes in a new relation; it articulates with a well-differentiated secondury mandible $(d)$. 'This is distinctively Mammalian; for in the highest Sauropsida (the Bird) the primordial and secondary mandibles have an equal derelopment, and are permanently combined as the free arch of the mandible, the large "pier" of which is merely the hugely dereloped head, neck, and shoulder of the first mandibular rod. In this stage of the Mammalian skull we catch the equivalence of these primary and investing parts; but the new hinge is formed already, and the primary bar, now at its highest relative development, shows no sign of segmentation into a pier (quardrate) and a firee arch (articulo-Meckelian). By the time of birth, the whole of the large succulent rod of cartilage which runs along the insicle of the lower jaw (fig. $7, d_{\text {., }} m k_{\text {. }}, m$.) and coalesces largely with its fellow in front will have shrunk up into a delicate fibrous band, lcaring a small bony style (processus gracilis) to the arrested upper part of the rod*. A bony ring is growing round both the preoral and the first postoral clefts; these are the lacrymal (l.) and the tympanic ( $t y$.$) ; the first of these has an outer facial$ development, and is not hidden in the orbit as in Man. 'The nasal, fiontal, and parietal bones $\left(m, f, p^{\prime}\right.$ ) form a regular double series; they are only equivalent to the inner layer of the scutes seen in the same region in Ganoid Fishes; yet they are rery thick, the thickness depending upon the fiee derelopment of connective (indifferent) tissue between the cutis and the primordial shull. The fontanelles are still wide open; but

: In the figure (Plate AXXIV. fig. $\%$, d.m.) the primary rod is cut through, and the mandible detached from its new hinge these farts will be described more in detail from the figures of scctions. 
the lower edge of the frontal has sent inwards from its eave a plate which reaches the orbito-sphenoid-the orbital plate. The agreements and the differences seen by comparing the Ornithic and Mammalian skulls are made very evident if this palatal view (Plate XXXIV. fig. 2) be put side by side with the figure of this region in the Ostrich's embryo ("Ostrich's Skull," Phil. 'Trans. 1866, Plate vir. fig. 4); at this stage the conformity is more remarkable than the difference.

'The dental (d.px.) part of the pig's premaxillary is broad and filled with tooth-sacs, which deeply groore it; the palatal processes ( $m$ m. i'.) are slender. The approximating maxillaries (mx.) do not hide the vomer ( $\bullet$ ); they are grooved by vessels down the middle of their palatine plate, whilst their dentary portion is hollow and shell-like, containing as it does large growing tooth-germs. The palatines $\left(p a_{0}\right)$ are ornithic, scarcely showing so much of the "hard palate" as a Green Tiurtle (Chelone mydus). The pterygoids ( $p q$ ) are thin in their ascending part, and are clubbed hooks below; they and the palatines both articulate with the great conjugational "basipterygoid," which here, as in the Ophidia, mainly arises from the alisphenoid; it is, however, formed of true cartilage, as in all the Sauropsida in which it occurs. This part, the "external pterygoid plate" (e.p $\%$ ), is a pronotochordal secondary structure; it arises at its root from the side of the apex of the trabecula. 'These apices of this first pair of bars do not project outwards and bachwards in the Pig as in the Kitten, nor does the "basitemporal " appear here in rudiment as the "lingula sphenoidalis;" both thesc. the process and the bone, are exquisitely and most instructively displayed in the Guineapig (Cavia aperea). 'The ring on which the tympanic diaphragm is stretched $\left(t y_{0}\right.$ ) is at present U-shaped, with its crura pointing backwards, and the larger on the outer and reper side; this crus has a flat flange which looks upwards. The vomer has the same relative size as in the embryos of the Ostrich and the Whale ("Ostrich's Skull," Plate vin. fig. 4, v, and Escrinicht "On the Cetacea," plate ii. fig. 2, I.).

In the endoskeletal parts we have to deal with two tissues at once, hyaline cartilnge and bone, principally endosteal at present, although rapidly gaining the surface and beginning to affect the perichondrium; I shall describe it first in the dissections and then in the sections. In the side view (Plate XXXIV. fig. 1) the tracts that are hardening in the arch of the occiput are shown; and of these there are five, namely the superoccipital and two pairs of exoccipitals (see also fig. 3). Moreover the superoccipital is double, as may be seen in a younger specimen (fig. 4, s.o.), but the two patches rum into each other in a day or so. 'The ossification of the exoccipital is remarkable; for within the substance of the massive condyle an epiplyysial centre appears, quite distinct at firsi from the large rambling growth above (figs. 1 \& 3, e.o.); these two points soon conlesce. The basioccipital (b.o.) is best studied in a sectional view (fig. 5), but its form is scen from above and below (figs. $6 \& 2$ ); it is spearhead-shaped in outline and thick as to substance; it is fast obliterating the notochord. The newer cartilage which underitoors the pituitary body is rapidly ossifying as basisphenoid (fig. 5, b.s.); the form of this centre is seen from below in fig. 2 : this is the only bone at present in the posterior MDCCCLXXIY. 
sphenoid. The real harmony between the outstanding bars on each side this bone and the basipterygoid spurs of the Lizard and Ostrich is here clearly shown; whilst the "extermal pterygoid plate" was only studied in Man (where it is said to be merely a periosteal outgrowth of the "ala major"), its homology with the "Sauropsidan" bar could not be determined; here it is a direct cartilaginous outgrowth of both base and wing, and its basal origin is from the side of the trabecular apex. Here it articulates with both palatine and pterygoid, being so liuge and developed to so great an extent laterally; there (see "Ostrich's Skull," Plate vil. fig. 4, pq., a.p.) the pterygoid is wedged in bodily betwecn the basipterygoid spur and the palatine; it is in that memoir called the "anterior pterygoid process" ( $a_{. p}$.), and by Professor HUALEY "basipterygoid" ("On the Classification of Birds," Proc. Zool. Soc. April 11th, 1867, p. 418). There is no special ossification in the confluent trabecular base beneath the orbito-sphenoids (figs. $2 \& 5, p . s$.$) , and these large wings have no centre orer and behind the optic fora-$ men, as in Man (figs. 1, 5, 6, o.s., 2); from these only the whole mass will be leavened. 'These wings have now coalesced with the lateral ethmoid (al.e.) in front, and overlap the auditory capsule (au.) behind, exactly as in Escrnicir's figure of the embryo of Baluna japonice (op) cit. plate ii. figs. $\left.1 \& 2, k,{ }^{*} G\right)$. The orbito-sphenoids are now at their highest degree of development (see in third stage, Plate XXXIII. fig. 3, o.s., and in the sixth, Plate XXXV. figs. 1, 3, 4, o.s.). In fiont of these orbito-sphenoidal melei there is no endostcal deposit, nor is there any for some time to come in the earsacs (ru.). 'The bird'seye view (fig. 6) shows how far, as in the Bird, the great septum of the nasal sacs ("mesocthmoid," continuous perpendicular plate, and septum nasi) continues backward beyond the primary roof (here compare fig. 6 with primordial struthions stull, op. cit. I'late nr. fig. 1, al.e., cr.g., o.s.). The cribriform plate is now sufficicntly adranced on cach side of the retral septum of the sacs to be fairly understood; it is a delicate comb-shaped lamina of secondary cartilage, with four long " teeth "growing inwards and forwards from its margin or "back;" the long interspaces admit the olfactory filaments. 'The common outer band does not fill in all the space which forms the floor to these huge rhinencephalic fossie, but, as in the embryo of the Ostrich and lowl "Fowl's Sliull," Plate cxxxr. fig. 4, eth.), the septum is continued backwards to the verge of the anterior sphenoid, and here, in the Pig, ends in a club-shaped manner.

Between the anterior edge of the orbito-sphenoid (o.s.) and the back of the comb-like lamina (figs. $5 \& 6, c r . l_{\text {. }}$ ) there is a considerable membranous space. The bulgings in the olfactory roof (al.e., al.s.) are caused, behind, by the upper and middle turbinals. now increasing in complexity, and further forwards by the inferior turbinals. Behind the postnemal commissure of the orbito-sphenoid (figs. $5 \& 6,0 . s_{0}$ ) the alisphenoids are obscurely seen (al.s.), overshadowed and obscured by the so-called "ale minores." 'They have no foramina in their substance, but the cranial nerves root down in front of and behind them; on the upper view the whole of the alae and the floor of the "sella turcica" are far from the cye, the posterion clinoid wall $(\mu \%$ ), the cud of the investing" mass, cropping up high into the cranial carity. The cal-sates are scen from without. 
within, above, and below (figs. 1, 2, 5, 6, au.), but as a mass they are not much changed from the last stage.

In the sectional view (fig. 5) the Eustachian tube (eu.) is seen below the basisphenoid (b.s.); below the soft palate the ceratohyal $(c . h y$.$) is cut through, and along the inside$ of the lower jaw the primary mandible is seen. 'This is better shown when dissected out (fig. T); and now its malleal end is ossified (this part is cut through in fig. I), whilst, below, the Meckelian commissure is severed, the bars uniting along their anterior fourth. I can only find one osseous centre here in the mandible, the dentary (d.); this is found in the rapidly chondrifying nidus, which, like a huge "inferior labial," obliquely overlaps the primary mandible; in Man, according to CALLENDER, there is an osseous centre at the chin in MECKEL's cartilage, and a second splint (splenial) on the inner face of the dentary (see Phil. 'Trans. 1869, Plate xur. figs. 6 \& 7, p. 170).

A few of the many sections prepared of this stage will now be described, and they will thoroughly explain the structure of the parts which have above been described mainly from dissections.

'The first is through the snout (Plate XXXIV. fig. S), and shows the arched cartilages, mited together in front, which were formed by fusion of the alie nasi with the overbent trabecular horns.

'The second (Plate XXXIV. fig. 9) is through the alo nasi (al.m.), fore part of septum $(s . n$.$) , alinasal turbinal \left(\alpha l . t l_{\text {. }}\right)$; and the masses with trilobate outline below are the recurrent trabecular horns $(r c . c$.$) .$

The third section (Plate XXXIV. fig. 10) shows a curious triradiate cartilage separated from the "ale nasi," this is the "appendix" (a.al.n.); here the trabecular conma are becoming slenderer.

The fourth (Plate XXXIV. fig. 11) shows the same parts further back; liere the recurrent process has become a smallish band lying flat on each side of the base of the septum, which is now becoming high, but has not commenced the inferior turbinal fold. 'The four-winged scetion, on each side, below the septum and recurrent cartilages: is the serered premaxillary ( $\mu^{*}$, see also fig 2).

'The fifth (Plate XXXIV. fig. 12) is through the midlle of the inferior turbinal (i.tb.): the pedate section here shows the upper limb coiled on itself, but not the lower at present. 'The recurrent lamine of the trabecular horns are running even past this point backwards; they are here vertical, and in close relation with the nidus of the scoop-shaped romer $\left(v^{*}\right)^{*}$. In this section the outer stratum of granular tissue overlying the nasal canals is norv ossified as the nasal bones $\left(n_{0}\right)$, and the mass of tissue overlying the pterygo-palatine bar lias become the maxillary ( $m x$.), with its deep dental groove and pulps and its palatine plate.

'The sixth (Plate XXXIII. fig. 4) section is through the solid anterior third of the

* The relation of these recuryent developments of the trabecular horus to the splints that belong to the first facial arch is of intense interest; I am rorking ont this subject in rarious groups; it is most complicated in I'asserine Birds, "Agithognathe" (IF.). They are eridently formed by the fusion of a "labial" with each trabecular horn. If tre add to this the "appendix alie nasi" and the sceondary mandible, we get thre preis of suctorial cartilages in an ordivary Mammal. 
frontals $\left(f^{\circ}\right)$, the true olfactory region, and the zygomatic process of the maxillary $(z \cdot m x$.$) ;$ above this is the orerlapping malar or jugal $(j$.$) 'The thick frontal slabs send inwards$ and dornwards an "orbital plate," which clamps the ethmoidal wall; this wall is seen to be separated by a very large space from the fore top of the septum or perpendicular ethmoid (p.e.), on each side of which lie the olfactory crura (1), and above these the fore part of the hemispheres $\left(\mathrm{C} I^{a}\right)$. Here we see that the comb-like floor of the olfactory crura (Plate XXXIV. figs. 5, 6, cr.p.) is connected with, and is the top of, a system of cartilaginous ingrowths, the upper and middle turbinals $\left(u . t b ., m_{.} t b\right.$ ), which, by repeated splitting, as it were, or rather by a process of foliation, is becoming more complex day by day. 'This section is through the most solid part of the vomer (v.), where it is squared below to rest upon the "hard palate" over its median suture; here the palatines are cut through their fore part, where they are thin bony scoops, protecting the outside of the posterior nostril passage. Large tooth-pulps (t.p.) are seen above and below, and the lower are in relation to a large dentary groove, the outer wall of which is rery massive and the inner a smaller rod : both of these sections are parts of a continuous dentary (d.); below the inner bony bar is the Meckelian rod ( $\left.m k_{0}\right)$, on each side of the base of the tongue (ty.).

The secenth section (Plate XXXIII. fig. 5) is through the fore part of the eyeballs (c.) and the sphenoidal sinuses (*pos.), the hinder part of the backwardly projected nasal labyrinth. At this point the septum, "perpendicular ethmoid," ends; and the pyriform section seen liere, at the posterior end of the large "rhinencephalic fosse" (see I'late IXXIV. fig. $(0, o l ., c r . p$.$) , is no longer indebted to the inturned nasal roof's for its height,$ which is due to the upgrowth of the trabecular crests*. 'This section is through the most solid part of the palatines ( $/ \mu$.$) , and their interior edge is thickening and growing$ inwards ready to form their part of the hard palate. Only the malar $(j$.$) is seen on$ the side and below, and mesiad of it is the coronoid process of the lower jaw ( $\mathrm{cr}$.). Meckin's cartilage ( $m k_{\text {. }}$ ) is now high up the inside of the jaw, which is here mainly composed of solid hyaline cartilage, the inner cells of which are rapidly proliferating as "osteoblasts." In the root of the tongue $\left(f y_{0}\right)$ the ceratohyals are seen articulating with the basi- and thyrohyals $\left(c . h y ., b . h y ., t h . h_{0}\right)$, now one piece of cartilage.

'The eighth section (Plate XXXIII. fig. 6) is one of the most instructive; it severs the orbito-sphenoids (o.s.) where they pass into the presphenoidal trabecular wall close at the back of the sphenoidal sinuses (see also in thind stage, Plate XXXII. fig. 1). 'This is the high part immediately in front of the optic foramina (I'late XXXIV. figs. 1, 5, $6,2)$. 'The orbito-sphenoids are overlapped above by the frontals $\left(f_{\circ}\right)$, and the presphenoid has the end of the vomer $(v$ ) beneath it. Here the thin ascending plate of the pterygoid, and its thick "hamular" part, is cut through; the osseous matter is scarcely continuous in the ascending part, and every now and then a separate "mesopterygoid" is developed.

* If the reader wishes to see an exact counterpart of this strueture displayed in the second facial arch or "palato-jterggoid," it is really at hand in the skull of the l'elican, where both the preoral arches form a long and solid "commissure", from which a ligh crest ascends. 
'The fore part of the curious thick leaf of cartilage which grows out of the ali- and basisphenoid is here cut through; it is the conjugating process between the first and second preoral arches. Here the zygomatic process of the squamosal (z.sq.) orerlaps the jugal $(j$.$) , and here the cartilaginous part of the lower jaw is nearly at its thickest; in the root$ of the tongue the stylohyals are severed at their junction with the ceratohyals $\left(c . h y_{0}\right)$.

'The ninth section (Plate XXXIII. fig. 7) has been made through the orbito-sphenoid (o.s.) close in front of the osseous nucleus (see Plate XXXIV. fig. 6, o.s.); it has passed down through the low part of the presphenoid, where it is crossed by the optic nerve, and where its territory ends and that of the basisphenoid $\left(b_{.} s_{*}\right)$ begins.

Hence in this figure we have the alisphenoids (al.s.) cut through beneath the orbital wings. It this point the hooked coronoid process is severed at its apex (cr.); and outside this is the "squamosal" (sq.), with its articular cartilage and "meniscus." Below these the articular and angular part of the lower jaw is shown; it is one mass of hyaline cartilage. MECKEL's cartilage and the stylohyal are also cut through.

Part of this section is shown from the right side (Plate XXXIII. fig. 8), magnified twice as much. Here the three cartilages that form the mandibular linge are all secondary, and, like the outer ear, suggest a reversion to the labial and opercular cartilages of the Shark.

The tenth section (Plate XXXIII. fig. 9) is through the malleal portion of the first preoral arch $\left(m l_{.}\right)$, the firont of the tegmen tympani $\left(t_{.} t_{y}\right)$, the long, overlapping, pos. terior angle of the orbito-sphenoid (o.s.), the cochlea ( $l$.$) , the stylohyal (st.h), and the$ "occipito-sphenoidal synchondrosis" with its enclosed notochord (b.o., ue.).

The eleventh section (Plate XXXIII. fig. 10) displays the ampulla of the anterior canal (a.se.), the general cavity of the labyrinth $(v b ., c l$.$) , and the tegmen tympani$ $(t . t y$.$) , with a bony eave formed by the squamosal (sq.) and roofing over the body of$ the incus (i). 'The incus is seen tuming up its "long crus" and spreading its orticuler apex over the top of the stapes (st.), which has been cut through from top to bottom, exposing the foot-hole. Below the stapes is the cartilaginous wall of the promontory $\left(m m^{\circ}\right)$, and outside this is a continuation of the tympanic cavity, in the outer wall of which is the stylohyal $(t y ., s t . h$.$) .$

\section{Fifth staye. Embryo Pig, 3 inches lony.}

This is merely introducer to show the ossification of the "alisphenoids" (Plate XXXIII. fig. 11, al.s.), which had not begun in the last, whilst in the next they are one solid mass of bone with the basisphenoid (b.s.). Here it will be seen that the posterior sphenoid is much simpler in the P'ig than in Man; in the Sheep at this stage I find it simpler still, not being able to discover any median centre; but the two alisphenoids are to be seen becoming pointed below, and growing towards each other; here, then, there appears to be no median piece, and thus the postsphenoid is like the anterior region, in which the orbito-sphenoids themselves fill in the mid region with bone. 'The contrary takes place in the Rodents; and especially in the Guimenpig (ceviu aperea) 
are the sphenoidal structures complex. As in other liodents, there is a large presphenoid as well as a basisphenoid; the alisphenoids are ossified from two centres on each side; long "lingular" pedicles are formed by the apices of the trabeculæ, and to these are articulated a pair of long, outstretched falcate bones, the evident counterparts of the "basitemporals" of the Bird. In this animal also the "external pterygoid processes" are basipterygoits, and the small pterygoid bone is attached to their apex. Even in the Ruminants these spurs are basal in their origin. (For the development of the human sphenoid, see Iluxuti, 'Elem. Comp. Anat.' p. 144.)

\section{Sixth Stage.-Embiyo P'igs, 6 inches long, niensured firom snout to ischium.}

'The head in this stage equals in size that of a squirrel, but its bones are much more dense. The roof-bones (Plate XXXV. figs. 1-3) are now applied to each other edge to cdge by sutures, and in certain places overlapping as squamx. 'The "anterior fontanelle" (fo.) is still open, but is much lessened; the parietal and occipital bones now form a good "lambdoidal suture." 'The nasals, frontals, parietals, squamosals, lacrymals, pre-

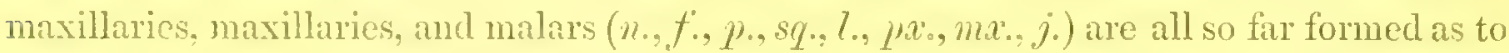
require but little change of size to fit them for their adult relationships. 'The palatal regrion (Plate $\mathrm{XXXV}$. fig. 2) shows a great development of the secondary floor or "hard palate," the palatines themselves being now tied together at the mid line below. 'The ossification of the cartilaginous skull has advanced greatly; the superoccipital is al large, strong shell of bone, and it is at present separated by a larger tract of cartilage from the exoccipitals than in the last stage (s.o., e.o.). The latter have now only one contre, for the epiphysis formed primarily in the substance of the condyle has coalesced with the outer deposit; this is now creeping far down into the substance of the long twisted paroccipital process $\left(\mu_{0} .0 c_{0}\right)$. The basioccipital (b.o.) now reaches from the foramen magnum to the spheno-occipital synchondrosis; and in front of it (fig. 2) the basisphenoid is now a thick mass of bone (see also fig. 3, 6.0., 6.s.). The presphenoidal region is hirlden below by the romer (fig. 2,v.), but in the section (fig. 3, p.s.) it is seen to be largely unossified. The alisphenoids (figs. $3 \& 4$, al.s.) are solidly anchylosect to the median piece; they are larger relatively to the orbito-sphenoids, but are still inferior in size and in place; they largely owe their size, laterally, to the cxtemal pterygoid processes (e.my), for their cranial region is small. The whole orbital wing is much more contracted, relatively (figs. 1, 3, 4, o.s.); it has become detached from the ethmoid, and is some distance from the auditory mass. The two centres are completely anchylosed at the mid line, and quite enring the optic passages (2); below (fig. 3), they are forming the presphenoid.

'The remainder of the facial axis and nasal septum is one sheet of solid cartilage; and so also is the complex nasal labyrintl, now much more complex in its turbinal growths and cribriform plate (u.th., cr.p.).

From the intimate impaction of the auditory mass into the sides of the cranium, its osscous centres have caused much confusion; this has, however, been greatest in the 
Oviparous Vertebrata, where the fusion of the periotic capsule with the skull proper is the greatest. Here, in the Pig, the bony deposits are formed much as in Man (see Huxuer, 'Elem. Comp. Anat.' pp. 147-156). A description such as that quoted above serves almost equally well for both types. Looking at the inner fiace of the capsule (figs. $3 \& 4$ ), we sec a creeping endosteal patch, which surrounds the "meatus internus," runs under the fore part or apex of the cochlea, and has found its way supero-posteriorly to the junction of the anterior and posterior canals (a.sc., p.sc.). seen from the outside (fig. $5, m o$.) the same bony tract is scen above and in front of the "fenestra ovalis" (f.ov.), below which it forms a sudden hook-like bend, which turns forwards, passing into the tract seen on the inside of the cochlea: this is the "prootic" ossification.

On the inside (fig. 3) a small hook of bone is seen in front of the "foramen lacerum posterius" (8); this is a spur sont round the back of the capsule from the outside, and the plate of which it is a process is seen from that aspect (fig. $5,0 \%$ ) covering the most bulbous part of the cochlea, the "promontory" ( $\mu \%$ ). 'This is the "opisthotic bone;" it sends forwards and downwards a long hook, which binds behind the hook of the prootic, beneath the apex of the cochlea. Another process of the opisthotic runs between the fenestra oralis and fenestra rotunda (f.ov, , f.r.) close in front of the head of the styloid cartilage (st.h.). Above the head of the styloid, and below the hinder end of the tegmen tympani, a smaller spatulate scute has appeared; this is the mastoid proper, or "epiotic." Behind this little bone the auditory mass is much contracted in the Pig, this part of the capsule being strongly clamped by the squamosal and impinged upon by the exoccipital (e.o.), where it gives off its "paroccipital process" (p.oc.). The "epiotic" centre will, moreover, ossify the true mastoid region; althongh it arises in a more forward position, it is less than that of Man (see HUXLEY, op. cit. p. 154, fig. $61, c p .0$. .). In the vertical section (fig. 11) the prootic and opisthotic centres are cut through, each at two places, the first (p\%o.) abore the stapes (st.) and inside the cochlea $(d$.$) , and the opisthotic appears below the stapes and in the substance of the promon-$ tory $(m \%)$. On the outside the semicircular canals are seen (u.sc., le.sc., p.sc.) imbedded in solid cartilage. The structures of the "middle ear" hare now acquired their almost full metamorphosis; these are enclosed in a large imperfect ring of bone, the tympanic (figs. $1 \& 2, t y$.$) . 'This bone is now becoming very thick, and its breadth has greatly$ increased; but as yet there is no bony meatus stretching outwards beyond the membrana tympani (m.t.). It will be seen in the lower view that there is an additional bone clinging to the inner edge of the tympanic; this wedge and two smaller ossicles which I shall describe in the next stage are the feeble counterparts of the auditory "bulla " of the "Felicke" and their congeners*.

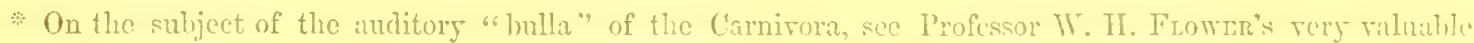
paper "On the Value of the Characters of the Thase of the C'ruium in the Classifiention of the Curnivora" dte.

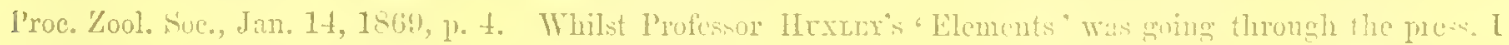

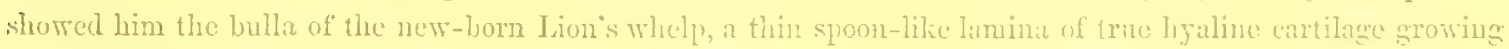

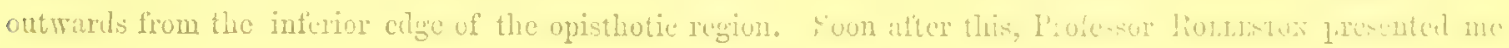


In the Pig the bullar ossifications are found in a very soft stroma of connective tissue, and not in thin cartilage; yet that stroma is connected with the outer and lower edge of the opisthotic and prootic regions; it is the membranous floor of this huge air-cell.

The "os bullie" already developer is seen in section, in its fore part (fig. 11, o.b.), it little in front of the auditory capsule, at the edge of the lower limb of the tympanic $(t y$.$) . The parts of the facial system of cartilages entering into the structure of the$ midale ear are shown in figs. I \& 12 ; the "manubrium mallei" (fig. $1, m b$. ) is now ossified, and so also is the incus (figs. 12,i.). 'The lingual part of the hyoid arch is continued upwards to the epiotic region (figs. $1 \& 5$, st.l.), and behind this flattened rod the portio dura nerve is seen escaping.

The little ccratolyal $(c . h y$.$) turns backward to articulate with the basal piece, to$ which also is attached the thyrohyals (fig. $1, b . h .$, t.hy.); the latter three parts belong: to the "third postoral arch."

'The ossification of the lower jaw (fig. I, l.) is almost complete, the unossified cartilage being principally condylar.

A series of sections selected from a large number now remain to be described; they will more fully illustrate this stage.

'The first of these (Plate XXXV. fig. 6) is through the anterior third of the "inferior turbinal ;" the pedate lower edge of the "aliseptal" cartilage here is secn to be coiled inwards above and below, the common back of the two coils lying towards the septum $(i . t b ., s . n$.$) . The sudden inbend of the aliseptal lamina higher up is the rudimentary$ "nasal turbinal" (n.tb.); below the septum is the vomer $\left(v_{*}\right)$, and below this the palatine processes of the premaxillaries are seen $\left(\mu \cdot x^{2}\right)$. 'The nasals (n.), the side of the premaxillarics, and maxillaries $\left(p^{2} \cdot, m x^{\circ}\right)$ show very thick in the section. On each side of the vomer the "recurrent apices of the trabecular horns" are still present (reco).

The second section (fig. 7 ) is through the complex upper and middle turbinal regions $\left(u . t b ., m . t l_{0}\right)$ and the high part of the perpendicular ethmoid (p.e.). 'The olfactory crura (1) are also cut through as they lie on the cribriform plate (cr.p.). This widest part of the true olfactory region is roofed in by very massive frontals $\left(f^{\circ}\right)$; the thin lower edge of these bones is the orbital plate. 'The xomer $(v$.) is here very decp; on each side of it the posterior nares are cut through, and these are protected by the long scoop-shaped processes of the palatines ( $p a_{0}$ ). A part of the maxillary is secn on each side of a large molar tooth with its pulp; and above, the outer piece of bone is the jugal $(j)$.

The third section (fig. S) is through the low part of the perpendicular ethmoid and the end of the cribriform plate, where it overlies the middle turbinal (m.tb.) only. 'The palatines ( $p \mu$ ) are here at their fullest development, their scooped portion underlying the end of the nasal wall $\left(\varkappa . w_{0}\right)$, and their subvertical plate sending inwards the palatal part of the hard palate.

with the head of a new-born Hyrux: and in this I fumd a large bulla, sesified separatcly from the true tympanic "smuulu," and eridently formed in il whell of true cartilage. 
The fourth section (fig. 9) instructs us how the olfactory labyrinth ends, as the sphenoidal sinus, on each side of the presphenoid; and it is seen that the fore edge of the orbito-sphenoids wall in this region, and underprop the thin descending orbital plate of the thick arching frontals $\left(o . s, f^{\circ}\right)$. On each side is the eye-socket, and below the presphenoid is the thin part of the vomer $(v$.$) ; the palatines (p(t)$ ) are here cut throngh behind the hard palate, and opposite them a section of the malar bone and lower jaw is shown $(j, d)$.

The fifth section (fig. 10) brings a number of bones into ricw ; the presphenoidal (trabecular) cartilage is rapidly ossifying from the coalesced orbito-sphenoidal centres $(o . s ., p . s)$; beneath this is the vomer $\left(c_{0}\right)$; and on each side, protecting the hinder nostrils, we see the thin part of the palatine and pterygoid $(p a, p \% \%)$; outside these is the fore-bent wing of bone known as the "external pterygoid plate" (e.p.g.).

The siath section (fig. 11) is through the postero-extemal part of the extemal pterygoid $(e . p \%$.) ; it binds strongly against the inner face of the articular ("glenoid") part of the many-spurred squamosal $(s q$.$) . Here the basisphenoid is cut through behind the$ "wings," and the internal carotids mount up here to reach the "circle of WiLLis ;" here the two limbs of the tympanic, the "os bullæ," and the stylohyal $\left(t y ., o . l_{.}, s h_{.} h_{\text {. }}\right)$ are cut through. The "glenoid hinge" is here with its meniscus, and the articular region of the lower jaw is still largely cartilaginous beyond the head of the articular surface.

The seventh section (fig. 12) is through the lower edge of the parietal ( $p$.), and also through the upper and lower edges of the squamosal (sq.) above, where it binds upon the mastoid region, and bclow, where it flanks the long paroccipital process ( $p . o c$.). The extremity of the sinuous, creeping tympanic carity is here seen $(t y$.$) , and outside it$ the stylohyal and tympanic $(s t . h ., t y$.$) are severed; below these is a section of the par-$ occipital spur. Orer the incus (i.) the horizontal canal is seen, and below the stylohyal the portio dura $\left(7^{a}\right)$. Inside the upper and outer portion of the rambling prootic centre the portio mollis $\left(T^{b}\right)$ is seen streaming in; the inner face of the cochlea has

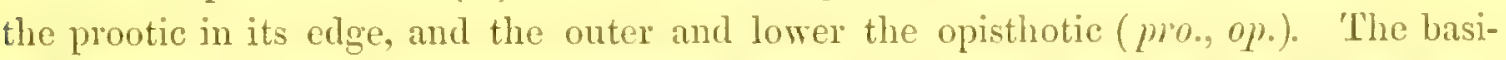
occipital (b.o.) is seen to have a subcrescentic form in section, and the cartilage at the edges of this elegant "basilar plate" will hare its outer edge ossified by the exoccipitals.

\section{Seventh Stage.-New-born Piys.}

Since the last stage the skull has almost doubled its length, and the process of ossification has gone on very rapidly; moreover the form of the entire skull has become much more specialized.

Wishing to limit the illustrations to this paper, I have given but few figures of the preparations made for my own research; but the head at this stage is most casily obtained by those interested in these studies. Moreorer the semi-adult condition of the skull, prior to any extensive anchylosis, will be fully illustrated. Besides the finish given to the general form of the skull by the now complete investing bones, the endoskeletal parts are well ossified. The whole of the occipital arch and its paroccipital processes, MDCCCLXIT. 
and the anterior and posterior sphenoids, are now thoroughly hardened. The "sphenooccipital synchondrosis" is of small extent, very thin, and a scarcely thicker tract of cartilage remains between the posterior and anterior sphenoids; yet these are each a single bone at this stage. 'The perpendicular ethmoid and septum nasi are still umossified ; but the inferior" turbinals are almost completely, and the "lateral masses" partially, converted into endosteal bone. The cribriform plate is soft, and so is the snout (Plate XXXVI. fig. 1); but this latter is everywhere burrowed with vessels prior to hardening.

Beneath the skull we see a most compact building together of the palatal, pterygoid, external pterygoid, and tympanic bony pieces; the thick, clubbed "hamular process" of the internal pterygoid is fixed as an undersetter to the solid nut-like tympanic, and dints it as an inturned loom dints the frontal in certain varieties of the Cow; this, however, is only a temporary state of things, and is quite recovered from in the lengthening head and face.

No "interparietals" have been found, adding two bones to the growing superoccipital, as seen in Man; this part, the superoccipital, is now a nearly vertical wall, the parietals finishing the roof above. 'The lower jaw is well ossified, and is now entirely free from the arrested primordial bar, MEckEL's cartilage. The three periotic centres have completely ossified the auditory mass, "petrosal " and "mastoid" (Plate XXXVI. fig. 2); and a small bilobate ossicle has appeared in the attached (confluent) head of the stylohyal (st.h.). Further down another centre has appeared in the middle of the long riblike bar, taking up nearly the middle third. The upper piece of bone (formed from two nuclei in the Lamb, and apparently also in the Pig) is called by Professor Flower* the "tympano-hyal," a term it may be well to retain. 'The rudimentary stylohyal of Man is ossified from the upper" centre; for "a centre of ossification appears in the styloid cartilage, and extending upwards and downwards, gives rise to the pyramid and styloid process" (Huxley, "Llem.' p. 160). Hence it will be seen that the tympanohyal and the upper. styloid bone are identical; both these bones are largely dereloped in the Osseous Fish, the so-called "epi- and "ceratohyals;" they occupy the great flat "cornu," at the base of which the short ceratohyal proper, with its two bony centres, is articulated. 'The unciform ceratohyal ("cornu minor") of the Pig is strongly attached by fibrous tissue to the transverse basal piece (Plate XXXVI. fig. 2, c.h.), now coalesced with its own rudimentary arch, the "cornua majora" of Man; these pieces are ossified proximally (fig. 2, th.h.), and these centres correspond with the first pair of hypobranchials of the Osseous Fish, the median part answering to the first basibranchial. The "stylo-mastoid foramen" (fig. 2, s.m.f., $\tau^{a}$ ) is seen transmitting the portio durn nerve; and this sends upwards and forwards the "chorda tympani" $\left(\sigma^{a^{\prime}}\right)$, to which is attached the smallest of the three "ossa bulli" $\left(0 . l^{\prime}.\right)$; the middle-sized piece is seen in front of the stylohyal $\left(0 . b^{\prime \prime}\right.$.). The rest of the drum-walls being removed and the squamosal, the outer face of the periotic mass shows the three semicircular canals

$$
\text { * In his raluable little work 'On the Ostcology of the Mammalia,' 1870, p. } 173 .
$$


above (a.sc., h.sc., p.sc.) and the cochlea below (cl.). The hollowed tegmen tympani (t.t.y.) has in its hinder recess the head of the incus $(i$.$) ; the recess ends in a round cup-like$ facet for the short crus of the incus, with its down-turned rounded hear; the "acetabulum " for this head is finished, externally, by the squamosal, part of which, having become adherent, is shown in the figure. Below this wall-chamber for the incus is the fenestra ovalis with the enclosed stapes (f.ov., st.); the long axis of the oval space and oval base of the stapes is upwards and forwards. The inturned liook of the long crus of the incus is now coupled to the neat head of the stapes by means of an intermediate bone, the "os orbiculare" (o.ob.), a special centre developed in the primary head of the second postoral bar, which, limpet-like, applied itself to that periotic "bud" which became the stapes, by a process similar to that which detaches the axillary buds in Litium tigrimum. In this figure the malleus is not given; it is shown in fig. 3 ( $m l$.). The processus gracilis $(p . q \%$ ) is reduced to a style, ending in fibrous tissue; the manubrium (mb.) is flat and slightly arcuate; the "head," articulated with the incus, is elegantly notched for this purpose, and fits on to the incus by a synovial joint, the miniature of that by which the tibia fits on to the astragalus in this same animal. Between the head and the manubrium the bone is thin, and is scooped externally; the head sends inward a rounded process (i.p.m. ), and the manubrium sends backwards an angular snag; this latter is for the attachment of the "tensor tympani" muscle. The little secondary nucleus of cartilage which we saw developed between the dislocated incus and stylohyal (Plate XXX. figs. \&\& 9, i.hy.) is now attached to the neck of the stapes by its broad outer end, whilst its bluntly pointed distal end is buried in the fibres of the tendon of the "stapedius" muscle (st.m.). This is the last effect of the high degree of metamorphosis exhibited by the second postoral bar of the Mammal. 'The fore edge of the exoccipital, with its paroccipital spur (fig. $2, e .0 ., p .0 c$.), is strongly clamped upon the auditory capsule; this is also made still stronger by the large posterior flange of the orergrowing squamosal, not shown in this figure.

'The under surface of the snout is also given at this stage, to show the complete coalescence of the alre nasi with the recurred trabecular horns, and their continuation backwards as the "recurrent laminie" (rc.c.), also the alinasal external segment or" "appendix." 'The solid fore end of the snout, already full of small blood-vessels, is ready to become the snout-bone for rooting; this bone is formed in the ossified linees of the trabeculx: the stunted, recurved prenasal cartilage is now undistinguishable from the base of the septum nasi, formed by the complete coalescence of a large tract of the trabcular bars, the long commissure of the foremost facial arch.

\section{Eighth Struge.-The Shull of a Pig 6 months old.}

This makes a more convenient lest stage than the adult, as here are still in existence the greater number of the sutural landmarks, so soon to be largely obliterated, whilst the change in general form is rather of interest to the zoologist than to the morphologist. The long angular skull (Plate XXXVI. fig. 4, and Plate XXXVII. figs, 1 \& 2) 
is an irregular pyramid, with two equal and two unequal sides and an oblique base. A complete contrast in outward form to the human skull, that of the Pig is straightest of all the types; it is very angular and strongly built, but its bone-tissue is inferior in density to that of the Sheep, being intermediate in this respect between the bone of a Ruminant and that of a Cetacean. The flat top of the skull, with its orbits flush with the top, indicate the semiaquatic habits of its owner; and the immense deptl and squareness of the base of the pyramid is correlative to the high neck and strong shoulders of this type: leverage is suggested by every ridge and every suag. Coming back to the morphology of the matter, I may remark that the long straight nasals (Plate XXXVII. fig. 1, n.) orexlap the snout in front, and only show their edge in the side view. They are articulated by suture along their outer edge with the upper edge of the long premaxillary wedge ( $\mu^{x}$.), and for a less extent with the maxillary (mx.); they terminate in a transverse line half an inch behind their maxillary suture. The frontals $\left(f^{\circ}\right)$ together form a somewhat pentagonal plate, divided along the mid line by the sagittal suture. 'The anterior third is deeply grooved, the grooves issuing from the "infraorbital foramen;" the posterior half of their outer margin is thick, and somewhat raised as the superorbital ridge. There is a large orbital plate (Plate XXXVII. fig. 1) which is bounded behind above by the short arrested postorbital process, and lower down and within by the orbito-sphenoid (o.s.). The upper surface of the parietals $(p \cdot)$ is of short extent, and divided by the continuation of the sagittal suture ; they are greatly pinched in to form the large temporal fossa $\left(t_{\text {. }} f^{*}\right)$; and behind they are somewhat impinged upon by the large superoccipital wall (s.o.).

The premaxillaries (Plate XXXVI. fig. 4, and Plate XXXVII. fig. 1, $p^{x}$.) have a large facial and a lesser palatine region, the palatine spurs ( $p \cdot p x$.) being slender and compressed. 'The huge maxillary $(m x$. ), besides forming most of the fore face and the anterior' root of the zygoma, by its last tooth-socket (a large pupiform cavity), binds behind upon the external pterygoid plate and descending extremity of the palatime (Plate XXXVII. fig. 1, mx.,pa.,e.py.). Below (see Plate XXXVI. fig. 4, mu.) it forms three fourth of the elegant grooved and ribbed hard palate; the double "posterior palatine foramen" (p.p.f.) is partly in this bone and partly in the palatine. The median suture of the hard palate (1'late XXXVI. fig. 4) is two thirds the length of the skull and face. 'The palatine bones $(p a$.$) by their primary ascending plate articulate with the vomer, and$ send forwards a long scoop-like process beneath the lateral ethmoids. After forming the elegant end of the hard palate they grow downwards as a thick boss, which articulates with the maxillary and extemal pterygoid process on the outside, and with the internal pterygoid plate on the inside. 'This latter bone, the "pterygoid "proper $(p \%)$, is very thin in its ascending part; and on the right side the uppermost squamous part is a separate piece, the mesopterygoid (P'late XXXVI. fig. 4, ms.pg.), a bone not commonly distinct in the Mammalia; yet in my collection it occurs in the Fox (Canis vulpes), and is subdistinct in the Hedgehog (Erinacens europeres); here, in the Pig, it is a small triangular scale. 'The inferior part of the pterygoid is thicker and is subfalcate, the 
hooked portion ("hamular process") being the apex of the pterygo-palatine arch. The top of the pterygoid, behind the mesopterygoid, has already conlesced with the posterior sphenoid at the root of the "ala," and externally also it is almost completely confluent with the "external plate" (e.pg.).

The thin dentate end of the romer (Plate XXXVI. fig. 4, v.) ends at the same transverse line with the mesopterygoids, whilst in front it reaches the fore margin of the premaxillaries within a barleycorn's length. The vomerine plate broadens a little to sit on and articulate with the upturned and doretailed edge of the palatine plate of the palatine bones, and also with the longer "harmony suture" of the maxillaries; its groove for the trabecular subseptal beam is rather deep. The complex nasal labyrinth is well ossified, but the septum between the inferior turbinals, supplied by the fifth nerve, is still soft. Beneath the large lacrymal, the "lamina papyracea" of the ectoethmoid is just seen beside the pupiform socket of the dercloping last molar tooth.

The lacrymal (Plate XXXVII. fig. 1, l.) is a notable bone on the outer cheek, with an upper and a lower canal; it is decply scooped where it articulates antorbitally with the orbital plate of the frontal (Plate XXXVII. fig. 1, l., f.); it forms part of the anterior root of the zygroma, and is nearly equally developed both within and without the orbit.

The malar or jugal $(j$.$) is a massire bar of bone, strongly set in at the front of the$ orbit between the lacrymal and maxillary (Plate XXXVII. fig. 1.j., l., m.). It is saddlebacked in its front thicker part, and its hinder half suddenly becomes only as thick as in front, so that the squamosal may yoke on to it; its lower surface is arcuate, its inner surface scooped, and its outer surface convex: almost an inch of space intervenes between the highest part of the malar and the descending postorbital spur of the frontal. The proper temporal bone, fitting scale-like to the temporal region of the skull, over the hinder edge of the frontal and the lower part of the parietal, is properly called the squamosal (sq.). This temporal part turns suddenly outwards to catch the pyriform condyle of the lower jaw, and then runs forwards and rides on the upper edge of the malar, stopping behind the concare portion of that bone. 'This zygomatic process of the squamosal rises sharp above the transwerse "glenoid" bridge, which is scooped above and below, has a convex transterse part in front, and an angular scooping behind: this part is clothed with articular cartilage, and the mandibular condyle rides freely unde; and up it, a meniscus intervening.

There is an acute ridge which runs obliquely up to the upper third of the superoccipital (Plate XXXVII. fig. 1, sq., s.o.); this rising wall closes in the dcep temporal fossa. This ridge of bone, running downwards also, binds strongly upon and conlesces with the rough rounded uplooking mouth of the "meatus auditorius externus" (m.e.). Below this part the squamosal splits into two narrow rough leares; the hinder of these is the "posttympanic process," and the front leaf is the "postglenoidal." The latter binds upon the side of the tympanic $(f y$.$) , the former runs down the fore edge of the par-$ occipital (paramastoid) process $(p . o c$ ) , and scoops its upper third. In front of the 
glenoid facet the squamosal is strongly sutured to the alisphenoid (al.s.) and to its great expanded wing $(e . p q$.$) . 'Together, the zygomatic elements make a strong, deep, and$ convex arch on each side, which starts rather sharply upwards.

The tympanic $(t y)$, now like a large fillert in form and size, although snaggy and ridged below, is principally a mass of square-chambered diploë. It has a small cavity, to the produced edge of which the membrana tympani is attached; and its former "crura" have met, run upwards, and formed the curious, ascending, coral-like meatus.

The flange of the anterior crus is now a squamous process beneath the squamosal, and close to the imner edge of the glenoidal cartilage. As there are no proper "foramina ovalia" in the posterior sphenoid, so there is a continuous "foramen lacerum " round the tympanic, and between it and the basis cranii (Plate XXXVI. fig. 4, f.l.p.). Looling through these large chinks we can see a small part of the periotic mass, which is very separate from the surrounding parts. The great occipital plane (Plate XXXVII. fig. 2, s.o., e.o., b.o.) is scooped abore (s.o.), and then the bone bends forwards, wedging itself in between the parietals: the upper element is alate above, and then narrows in and rests obliquely upon the exoccipitals $(e .0$.$) , forming the keystone of the archway for the$ medulla spinalis, the formen magnum $(f \cdot m$.$) . The arch again expands its sides, the$ exoccipitals spreading ont behind and over the mastoids, which further outwards are plastered over by the "posttympanic processes" of the squamosal. These lateral pieces run downwards as the long paramastoid, or, more correctly, paroccipital spurs; whilst their middle region juts out, and forms the diverging, semioval, subpedunculate articular condyles (oc.c.). Inside the paroccipital process there is a considerable foramen for the hypoglossal nerve (Plate XXXVI. fig. 4, ,). In front of the paroccipital process there is a canal, bounder on the outside by the posttympanic spur of the squamosal, and on the inside by the unciform tympanic. Looking up this canal we see that its imner half is occupied by a rod of bone, thickest below, where it is flat, the continuing cartilage being macerated off. This rod is the apex of the stylohyal"tympano-hyal" (FLOWER), and the open tube is the canal for the portio dura; its mouth is the "stylo-mastoid foramen."

The basioccipital (Plate XXXVI. fig. 4, b.o.) is a pentagonal lozenge of bone, joining the sides of its own arch by suture, and separated from the next basal piece (b.s.) by a narrow synchondrosis. This basioccipital plate is mammillate at the sides below, aud subcarinate mesially: it is the notochordal bone. Next in front is the basisphenoid ('late XXXVI. fig. 4, b.s.), now merely the basal part of an inverted arch of bone, the "posterior sphenoid." The narrow cartilaginous tract between this and the bar in front is liddden below by the end of the vomer, and by a sharp ridge which grows mesiad from each alisphenoid (Plate MXXVI. fig. 4, al.s., b.s., v.). The orbito-sphenoids have met below, ossifying the underlying trabccular bar, which part is ensheathed by the vomer. These large wings can be scen in the posterior part of the orbit around and above the optic foramen (Plate XXXVII. fig. 1, o.s., 2), and also from behind through the foramen magnum (Plate XXXVII. fig. 2, o.s., .). The change which has taken 
place in the little auditory ossicles is to small to require special notice. The mandibular rami (Plate XXXVII. fig. 3) are quite distinct from each other at present: they are large deep bones, with a small notch between the coronoid and articular regions; the latter is somewhat pyriform, with the narrow end inwards; the angular region is flat, with a round outline and a thick rugose edge.

\section{Ninth Stage.-The Skull in Adult Pigs.}

'The further changes that take place in the Pig's skull are mainly increase of size and extensive ankylosis. Besides referring the reader to the actual object, I may mention. that a short and useful account of this type of cranium will be found in Professor FLower's work, 'An Introduction to the Osteology of the Mammalia,' 1870, p. 172, and also in Professor Huxuey's 'Anatomy of the Vertebrated Animals,' 1871, p. 368.

\section{Sumiart.}

The most important results of the present investigation may be stated as follows:-

1. In a pig embryo, in which the length of the body did not exceed tro thirds of an inch, and four postoral clefts were present, the cranio-facial skeleton was found to consist of:-

(a) the notochord, terminating by a rounded end immediately behind the pituitary body.

(b) On each side of the notochord, but below it, a cartilaginous plate, which in front ends by a rounded extremity on a level with the notochord, whilst behind it widens out and ends at the free lower margin of the occipital foramen. These two plates, taken together, constitute the "investing mass" of RATike. In this stage they send up no prolongations around the occipital foramen; in other words, the rudiment of the basioccipital exists, but not that of the exoccipital nor superoccipital.

(c) The large oval auditory capsules lie on each side of the anterior half of the investing mass, with which they are but imperfectly united: there is no indication of the stapes at this stage.

(d) The trabecular or first pair of preoral visceral arches cnclose a lyre-shaped pituitary space; they are closely applied together in front of this space, and, coalescing, give rise to an azygous pracnasal rostrum: they are distinct from one another and the investing mass.

(e) The pterygo-palatine or sccond pair of visceral arches lie in the maxillo-palatine processes, and are therefore subocular in position. Each is a sigmoid bar of nascent cartilage, the incurved anterior end of which lics behind the interior nasal aperture, while the posterior extremity is curved outwards at about the level of the angle of the mouth. 'The pterygo-palatine cartilages are perfectly free and distinct from the first preoral and the first postoral arch, although developed in a process of the latter, and are therefore secondary arches.

(f) The mandibular or first pair of postoral visceral arches are stout cartilaginous rods of cartilage, which lie in the first visceral arch behind the mouth. The ventral or 
distal ends of these arches are not yet in contact; the dorsal or proximal end of each is somewhat pointed and sharply incurved, pushing inwards the membrane which closes the first visceral cleft and is the rudiment of the membrana tympani.

(g) 'The hyoid or second pair of postoral arches are in this stage extremely similar to the first pair, with which they are parallel. 'They are stout sigmoid rods of cartilage, which are separated at their distal ends, present an incurved process at their opposite extremities, and are not segmented.

(h) The thyrohyal or third postoral arches, which correspond with the first branchial of branchiate Vertebrata, are represented by two short cartilaginous rods which lie on each side of the larynx.

(i) The olfactory sacs are surrounded by a cartilaginous capsule, which has coalesced below with the trabecula of its side; while, within, the mucous membrane lining the capsule presents elevations which indicate the position of the future turbinal outgrowths of the capsule.

In this stage the posterior nares are situated at the anterior part of the oral cavity, as in the Amplibia; and the roof of the mouth is formed by the floor of the skull, the palatal plates of the maxille and palatine bones being foreshadowed by mere folds. The outer end of the cleft between the trabecula and the secondary preoral arch appears to be the rudiment of the lacrymal duct, while its inner end is the hinder nasal aperture. The gape of the mouth is the cleft between the second preoral and the first postoral arch. The auditory passage, representing the Eustachian tube, tympanum, and external auditory meatus, is the cleft between the first and second postoral arches. 'The proximal end of the mandibular arch, therefore, lies in the front wall of the auditory passage, and the hyoid in its hinder wall.

2. In an embryo pig, an inch in length, $(a)$ the notochord is still visible; $(b)$ the investing mass, the halves of which are completely confluent, has become thoroughly chondrified, and is continued upwards at each side of the occipital foramen to form an arch over it.

(c) The auditory capsules are still distinct from the investing mass, and a plug on the outer cartilaginous wall of each has become marked off as the stapes.

(d) The hinder ends of the trabecular arches have coalesced in front of the pituitary body, but they are not yet confluent with the investing mass.

(e) The pterygo-palatine rorls have increased in size; they have not become hyaline cartilage, but are begimning to ossify in their centre.

$(f)$ In the mandibular areh the proximal end has become somewhat bulbous, and is recognizable as the head of the malleus, whilst the incurved process, still more prominent than before, is the mambrim mallei. 'The rest of the arch is MEckeL's cartilage; outside this a mass of tissue appears, which is converted into cartilage, rapidly ossifies, and erentually becomes the ramus of the mandible.

(g) The proximal end of the hyoiden arch, similarly enlarging and articulating with the corresponding part of the mandibular arch, becomes the incus, the incurred process 
attaching itself to the outer surface of the stapes and becoming the long process of the incus. 'The incus, thus formed out of the proximal end of the hyoidean arch, becomes separated from the rest of the arch by conversion of part of the arch into fibrous tissue, and the moving downwards and backwards of the proper hyoid portion of the arch. A nodule of cartilage left in the fibrous comecting band becomes a styliform "interhyal" cartilage, while the proximal end of the detached arch becomes the stylohyal.

(h) The thyrohyals have merely increased in size and density; they closely embrace the larynx by theix upper ends.

(i) 'The olfactory capsules are well chondrified, and their descending inner edges have coalesced with each other and with the trabeculi below to form the great median septum : the turbinal outgrowths are apparent.

In this stage the alisphenoids and orbito-sphenoids appear as chondrifications of the walls of the skull, quite independent of the investing mass and the trabeculæ.

The floor of the pituitary space chondrifies independently of the trabeculx and the moieties of the investing mass, but serves to unite these four cartilaginous tracts.

3. In an embryo pig $1 \frac{1}{3}$ inch in length $(a, b, c)$ the primordial cranium is completely constituted as a cartilaginous whole, formed by the coalescence of the investing mass and its exoccipital and superoccipital prolongations, the modified trabeculæ, the subpituitary cartilage, the auditory capsules, the alisphenoidal and orbito-sphenoidal cartilages, and the olfactory capsules. The notochord is still to be seen cxtending in the middle line from the hinder wall of the pituitary fossa (now the clinoids of the sella turcica) to the posterior edge of the occipital region.

(d) The trabecular arches form the sides of the sella turcica, the presphenoid, and the base of the septum between the olfactory capsules; in front, where they form the azygous prenasal or "basitrabecular" element, they are developer backwards as "recurrent bands," elongations of the free recurved cornua.

(c) The pterygo-palatine arches, still increasing in size, but not chondrifying, now rapidly ossify; they are half-coiled lamine bounding the posterior nasal passages.

$(f)$ The mandibular arches and the rudimental ramus have become solid cartilage, and the latter is ossifying as the dentary; the distal part of cach mandibular rod unites with its fellow for some distance.

(y) The hyoid arches are now more fully segmented as incus, with its orbicular head, interhyal, stylohyal, and ceratohyal.

(h) The thyrohyals are merely larger and denser.

(i) The olfactory capsules have now the turbinal outgrowths all marked out as alinasal, nasal, upper, middle, and lower turbinals.

4. In pigs of larger size the form and proportions of all the parts of the cranium become greatly altered, and ossification takes place on an extensive scale, but no new structure is added.

5. It follows from these facts that the mammalian skull, in an early embryonic condition, is strictly conformable with that of an Osseous Fish, a Frog, or a Bird at a like period of development, consisting as it does of :- 
(a) A cartilaginous basicranial plate cmbracing the notochord, and stopping, like it, behind the pituitary body.

(b) Paired cartilaginous arches, of which two are preoral, while the rest are postoral.

(c) A pair of cartilaginous auditory capsules.

(d) A pair of cartilaginous nasal capsules.

Further, that in the Mammalia, as in the other Vertebrata the development of the skull of which has been examined, the basicranial plate grows up as an arch over the occipital region of the skull, and coalesces with the auditory capsules, laterally, to give rise to the primordial skeleton of the occipital, periotic, and basisphenoidal regions of the skull. 'The trabeculie become fused together, and, uniting with the olfactory capsules, give rise to the presphenoidal and ethmoidal parts of the cranium; and the moieties of the skull thus resulting from the metamorphosis of totally different morphological elements become united to give rise to the primordial cranium.

As in the Salmon and Fowl, the second pair of preoral arches give rise to the pterygopalatine apparatus; in the Frog this arch is late in appearance, and is never distinct from the trabecular and mandibular bars, serving as a conjugational band between them. 'The mandibular arch, which in the Salmon becomes converted into MEciel's cartilage, the os articulare, the os quadratum, and the os metapterygoideum, in the Frog into MEckeL's cartilage and the quadrate cartilage (which early becomes confluent with the periotic capsule), in the Bird into MEckeL's cartilage, the os articulare, and the os quadratum (which articulates movably with the periotic capsule), in the Pig is metamorphosed into the malleus, which is loosely connected with the tegmen tympani, an outgrowth of the periotic capsule.

Meckel's cartilage persists in the Fish and the Amphibia, but disappears early in the Bird, and still earlier in the Mammal. The permanent ossifications formed outside the primary mandible are all membrane-bones in Fish, Frog, and Fowl, but in the Mammal (exceptionally) the ramus has a cartilaginous foundation. In the Fish the hyoidean arch becomes closely united with the mandibular, and then segmented into the hyomandibular, the stylohyal, ceratohyal, and hypohyal-the hyomandibular or proximal segment articulating with the outer wall of the periotic, and many of the segments becoming dislocated.

In the Frog the hyoid also becomes segmented into three pieces. The middle serment becomes the suprastapedial (hyomandibular) with its extrastapedial process, and, extending inwards as mediostapedial, articulates with the stapes, developed by segmentation from the outer wall of the auditory capsule, the proximal part, or interstapedial, intervening. The stylohyal is dislocated and becomes connected with the auditory capsule below the stapes (opisthotic region).

In the Bird the hyoidean arch remains distinct from the mandibular; whilst in its primordial condition it coalesces by its incurved apex with the auditory capsule in front of the promontory, before the stapedial plug is segmented. It then chondrifies as three distinct cartilages-an incudal, a stylohyul, and, distally, a ceratolyal. The stapes becomes fice from the auditory capsule, but remains united with the cartilaginous part 
of the incus (mediostapedial); the ascending part islargely fibrous (suprastapedial), and the part loosely attached to the mandibular arch is the elongated extrastapedial. 'The short stylohyal afterwards coalesces with the body of the upper or incudal segment by an aftergrowth of cartilage (the "interhyal" tract); a long membranous space intervenes between it and the glossal piece (ceratohyal). "Thus the "columella" of the Bird is formed of three hyoidean and one periotic segment.

In the Pig the hyoidean arch is distinct, but articulates closely with the mandibular; its upper segment (hyomandibular) is converted into the incus, and becomes connected with the stapes, its disciform apex being ossified as the "os orbiculare." The stylohyal is dislocated and coalesces with the opisthotic region of the anditory capsule.

The views which have hitherto been entertained respecting the mode of development of the ossicula auditus of the Mammalia fall under four heads:-

1. According to ReicherT*, the malleus and incus both result from the metamorphosis of the cartilaginous skeleton of the mandibular arch, while the stapes proceeds from an after segment of the hyoidean arch, which becomes separated and imbedded in the outer wall of the auditory capsule.

'The latest writer on the subject, Semanet, supports ReIcIent's views in the main, but is not quite sure about the origin of the stapes.

2. Güntine \$ holds that not only the malleus and the incus, but the stapes as well, are the product of the metamorphosis of the skeleton of the mandibular arch.

3. Magitot and Robix $\oint$, on the other hand, maintain that the malleus only takes its origin from the skeleton of the mandibular arch. 'They consider the incus and stapes to arise independently, but do not expressly refer them to the skeleton of the second postoral visceral arch.

4. Professor HuxLeY\|, arguing from the anatomy of the mandibular and hyoidean arches in the lower Vertebrata, has put forward the view that the malleus of the Mammalia is the product of the metamorphosis of the proximal end of the cartilaginous skeleton of the mandibular arch, while the incus proceeds from the proximal end of the hyoidean arch, and is the homologue of the "suprastapedial" of the Sauropsida. IIe expresses no opinion respecting the origin of the stapes.

" "Ueber die Visceralbogen der Wirbelthicre," Múliege's Archiv, 1337.

†े Untersuchungen iiber die Lntwickelung der Heckel'schen Kuorpels und sciner Nachbargebilde. Dorpat, $187:$

+ Beobachtungen iiber die Entrickelung des Gehörorganes bei \fenschen und hüheren Säugethieren. Leipzig, 184 ?.

§ "Mémoire sur un organe transitoire de la oie fautale désigné dans le nom cartilage de Mecict," Annales des Sciences Naturelles, sér. 4, i., xriii. 186:.

" "On the Representatives of the Malleus and the Incus of the Mammalia in the other Tertebrata," Proceedings of the Zuological Society, 1869. 


\section{Explayation of Abbreviations.}

r.t.n. appendix ala nasi.

a.cl. anterior clinoid wall.

al.e. aliethmoid.

al.o. alinasal.

al.s. alisphenoid.

al.tb. alinasal turbinal.

aq. $v$, aqueduct of the restibule.

a...e. anterior semicircular canal.

$\alpha . t y$. annulus tympanicus.

$a$. auditory sac.

h.r. basilar artery.

b.tr. basibranchial.

1.7., l. . .,. basihyal.

h.o. basioccipital.

13.s. basisphenoid.

b.tr. basitrabecula.

c.t. conchn auris.

$\therefore$ common (auditory) canal.

c.h., c.hy. ceratohyal.

cl. cochlen.

c. 1, 2, \&c. 1st, 2nd, and following risceral clefts**

r. coronoil process of maudible.

ct. cutis.

c.tr. cormua trabeculx.

C 1. thalamencephalon.

(' 1 '. hemisphere.

('… 2nd corehral resicle.

('3. 3rd cerebral resicle.

7. dentary.

1.p. dentary part of premaxillary.

1. eycuall.

'l'. eniotic.

e.n. extermal nostril.

(.). exoccipital.

1.1.\%. estemal piterggoid plate.

(11. Eustaclizin tube.

f. frontal.

f. $\%$ foramen lacerum posterius.

fow. formen magnum.

fin. fenestrat oralis.

fir. fenestra rotumda.

h.br. hypolmanchial.

lew. horizontal scmicireular canal.

hiy. higoid. i.c. internal carotid artery.

i.l.y. interhyal.

i.n. inner nostril.

i. $1 . .$, . internal process of malleus.

i.tb. inferior turbinal.

$i v$. investing mass.

j. jugal.

i. ju jugular rein.

I. lacrymal.

l.c.i. long erus of ineus.

I.r.r. lateral cerebellar recess.

1.1. lower lip.

It. lip.

1s. lateral sinus.

1.x. larynx.

m. mouth.

mb. manubrium mallei.

me. meniscus.

m.f. meatus externus.

m.eth. mesethmoid.

mk. Hecrel's cartilage.

mk.c. Meckelian commissure.

m. malleus.

mn. mandible.

n.n. middle nostril.

m.ol. medulla oblongata.

m." $1: \%$ mesopterygoid.

m.th. midale turbinal.

w.t. $t$, middle trabecula.

m.ty. membrana tympani.

m.t. maxillary.

'"' $f^{\prime}$. maxillo-palatine.

ก. nasal.

u.u'. nasal wall.

o.b. os bullæ.

nce. occipital condyle.

a. œsophagus.

ol. olfactory sac.

o. 3 . os orbieulare.

(1). orbito-sphenoid.

"... opththalmic rein.

p. parietal.

wet. palatine.

j.t. perpendicular ethmoid.

* These may be counted from the lacryual or first preoral, or from the tympanic or first postoril. 
12y. pterygoid.

p.gr. processus gracilis.

p.n. prenasal cartilage.

p.n.u. posterior nasal wall.

p.oc. paroccipital.

$p \cdot p \cdot f$. posterior palatine foramen.

$p \cdot p g$. palato-pterygoid.

P.p. palatine floor of palatine.

p.p.x. palatal part of premaxillary.

$p r$. promontory.

pro. prootic.

ps. presphenoid.

p.sc. posterior semicircular canal.

2\%. pituitary body.

r.c. recurrent cartilages.

s.e.i. short crus of incus.

s.m.f. stylo-mastoid foramen.

s.n. septum nasi.

so. supero-occipital.

s.pe. soft palate.

sp.s. sphenoidal sinus.

s\%. squamosal.

s.t. sella turcica.

st. stapes.

st.h. stylohyal.

st.m. stapedius muscle. t.c. tympanic carity.

t.ch. tentorium cerebelli.

t.f. temporal fossa.

tr. tongue.

th.h. thyrohyal.

t.p. tooth-pulp.

ti. trubecula.

tr.cm. trabecular commissure.

t.ty. tegmen tympani.

ty. tympanic.

u.l. upper lip.

u.tb. upper turbinal.

i'. vomer.

$2 \%$ vestibule.

z.m.1. zygomatic process of maxillary.

z..i\%. \%รgomatic process of squamosal.

1. olfactory nerre.

2. optic nerre.

$\bar{s}^{\prime \prime}$. orghthalmic nerse.

5 . main part of 5 th nerve.

7 ". portio dura.

$7^{a \prime}$. chorda trmpani.

$7^{\circ}$. portio mollis.

'. glossopharyngeal.

sh. vagus.

9. hypoglossal.

Description of the Plates.

PLATE XXVIII.

First Stage.-Eimbryo Pig, $\frac{9}{3}$ inch in length.

Fig. 1. Side view of upper part of embryo. $\times 7$ diameters.

Fig. 2. A plan of the same, with facial arches. $\times 7$ diameters.

Fig. 3. A front view of the same. $\times 7$ diameters.

Fig. 4. A palatal view of the same, with the mandible and lower face removed. $\times 15$ diameters.

Fig. 5. A plan of the skull and face, seen from below. $\times 10$ diameters.

Fig. 6. A vertical section of the head. $\times 10$ diameters.

Fig. 7. Part of the same, with median part of nasal region removed. $\times 20$ diameters.

Fig. 8. Upper view of a horizontal section of the head. $\times 10$ diameters.

\section{PLA'TE XXIX.}

Fig. 1. 'Transversely vertical section of the nose, in front. $\times 12$ diameters.

Fig. 2. A similar section through the middle of the nasal region $\times 12$ diameters.

Fig. 3. Another section through the posterior nasal recion. $\times 12$ diameters. 
lig. 4. Horizontal section below the cranial cavity, exposing first arch, notochord, and investing mass. $\times 10$ diameters.

Fig. 5. A subhorizontal section through the eyes and root of tongue. $\times 10$ diameters.

Fig. 6. Part of the head, with outer part of cheek pared away. $\times 12$ diameters.

Fig. 7. A section made through the plane of the hinder part of cranium. $\times 12$ diameters.

Fig. S. Part of same section. $\times 20$ diameters.

Fig. 9. A similar section. $\times 26$ diameters.

Fir 10. Another subhorizontal section through the top of the first postoral cleft. $\times 20$ diameters.

\section{PLAIE XXX. \\ Second Stage.-Embryo Pig, 1 inch long.}

Fin. 1. Section across the end of the snout. $\times 10$ diameters.

Fig. 2. Section through ethmoid region, root of tongue, and larynx. $\times 12$ diameters.

Fig. 3. Section nearly in plane of the notochordal region, front view. $\times 10$ diameters.

Fin. 4. A similar section, lower down. $\times 10$ diameters.

Fig. 5. Part of a similar section through apex of mandibular arch, front riew. $\times 15$ diameters.

Fig. 6. A similar section through apex of next arch, front view. $\times 15$ diameters.

Fig. 7. Another similar section through periotic capsule in plane of horizontal canal. $\times 10$ diameters.

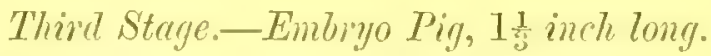

Fig. S. Part of a section through top of second postoral arch, corresponding with fig. 6 of second stage, front view. $\times 15$ diameters.

Fig. 9. Side view of the three postoral arches. $\times 15$ diameters.

\section{PIATE XXXT. \\ Thivel Stage (continued).}

Fin. 1. Ist section through nasal region. $\times 7 \frac{1}{2}$ diameters.

Wig. 2. 2nd section of same. $\times 7 \frac{1}{2}$ diameters.

Fig. 2a $2^{a}$ Part of fig. 2. $\times 22 \frac{1}{2}$ diameters.

1ig. 3. 3rd section of same. $\times 7 \frac{1}{2}$ diameters.

IYin. $3^{u}$. Part of same section. $\times 22 \frac{1}{2}$ diameters.

Fig. 4. 4th section of same. $\times 7 \frac{1}{2}$ diameters.

Fig. 5. 5th section of same. $\times 7 \frac{1}{2}$ diameters.

Fig. 6. 6th section of same. $\times 7 \frac{1}{2}$ cliameters.

Fin. 6 . Part of fig. 6. $\times 20$ diameters.

Fin. 7 . 7th section of nasal region. $\times 7 \frac{7}{2}$ diameters.

Iig. $7^{a}$. Mandibular portion of same section. $\times 7 \frac{1}{2}$ diameters. 
Fig. 8. Sth section of same. $\times 7 \frac{1}{2}$ diameters.

Fig. $S^{a}$. Mandibular portion of same section. $\times 7 \frac{1}{2}$ diameters.

Fig. 9. 9th section of nasal region. $\times 7 \frac{1}{2}$ diameters.

Fig. 10. 10th section of same. $\times T_{\frac{1}{2}}$ diameters.

Fig. 11. 11th section of same. $\times 7 \frac{1}{2}$ diameters.

Fig. 12. 12th section of same. $\times 7 \frac{1}{2}$ diameters.

Fig. 13. 13th section of same, head. $\times 7 \frac{1}{2}$ diameters.

Fig. 14. 14th section of same, head. $\times 7 \frac{1}{2}$ diameters.

Hig. 14". Part of fig. 14. $\times 14$ diameters.

\section{PLATE XXXII.}

Third Stage (continued).

Fig. 1. 15th section of same, head. $\times 7$ diameters.

Fig. 2. 16th section of same, hearl. $\times 7$ diameters.

Fig. 3. 17th section of same, head. $\times 7$ diameters.

Fig. 4. 18th section of same, head. $\times 7$ diameters.

Fig. 5. 19th section of same (part back view). $\times 14$ diameters.

Fig. 6. 20th sectiqn of same, head (back view). $\times 10$ diameters.

Fig. 7. 21st section of same (part back view). $\times 14$ diameters.

Fig. S. 21st part of section (front view). $\times 14$ diameters.

Fig. 9. Hinder part of a section taken horizontally through the nasal region (front view). $\times 10$ diameters.

Fig. 10. A similar section of same taken further backwards and lower down (back view). $\times 10$ diameters.

\section{PLATE XXXIII. \\ Third Stage (continued).}

Fig. 1. 22nd section of the same head (part seen from the front). $\times 14$ diameters.

Fig. 2. Vertical section of head. $\times 5$ diameters.

Fig. 3. The same, with brain and septum nasi removed. $\times 5$ diameters.

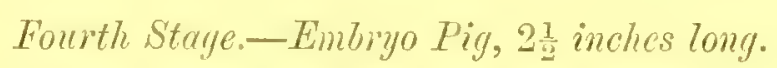

Fig. 4. Vertically transverse section through fore part of brain. $\times 5$ diameters.

Iig. 5. A similar section through fore part of orbit (part). $\times 5$ diameters.

Fig. 6. A like section through hind part of orbit (part). $\times 5$ diameters.

Fig. 7. A similar section through sphenoid (part). $\times 5$ diameters.

Fig. S. Part of same section (right side) $\times 14$ diameters.

Fig. 9. A similar section throngh the fore part of auditory sac. $\times 7$ diameters.

Fig. 10. Another section through hinder part of same. $\times 14$ diameters.

$$
\text { Fifth Stage.-Embing Pig, } 3 \text { inches long. }
$$

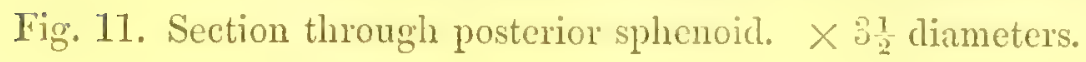




\section{PLA'E XXXIV. \\ Fourth Stage (continued).}

Fig. 1. Sicle view of skull. $\times 3 \frac{1}{2}$ diameters.

Fig. 2. Lower view of same. $\times 3 \frac{1}{2}$ diameters.

Fig. 3. End view of same. $\times \frac{1}{2}$ diameters.

Fig. 4. Upper occipital region of a somewhat younger embryo. $\times \frac{1}{2} \frac{1}{2}$ diameters.

Fig. 5. Section of skull (vertical). $\times 3 \frac{1}{2}$ diameters.

Fig. (i. Bird's-eye view of primordial skull. $\times \frac{3}{2}$ diameters.

Fig. 7. Inner view of compound mandible $\times 3 \frac{1}{4}$ diameters.

Fig. 8. 1st section through nasal region. $\times T$ diameters.

Fig. 9. 2nd section of same part. $\times 7$ diameters.

Fig. 10. 3rd section through nose. $\times 7$ diameters.

Fig. 11. 4th section of same. $\times 7$ diameters.

Fig. 12. 5th section through inferior turbinal. $\times 7$ diameters.

$$
\begin{gathered}
\text { PLATE XXXV. } \\
\text { Sixth Stage-Embryo Pig, } 6 \text { inches long. }
\end{gathered}
$$

Fig. 1. Side view of skull. $\times 1 \frac{1}{2}$ diameter.

Fig. 2. Lower view of same. $\times 1 \frac{1}{2}$ diameter.

Fig. 3. Vertical section of same. $\times 1 \frac{1}{2}$ diameter.

Fig. 4. Bird's-eye view of primordial skull. $\times 1 \frac{1}{2}$ diameter.

Fig. 5. Outer view of occipital and auditory regions. $\times 2$ diameters.

Fig. 6. 'Transversely vertical section through inferior turbinals. $\times 3$ diameters.

Fig. 7. Another through ethmoids. $\times 3$ diameters.

Fig. 8. Part of section through hinder part of nasal labyrinth. $\times 3$ diameters.

Fig. 9. Section through orbits. $\times 2$ diameters.

Fig. 10. Part of section through anterior sphenoid. $\times 3$ diameters.

Fig. 11. Section through hinge of lower jaw. $\times 2$ diameters.

Fig. 12. Section through periotic mass and basioccipital. $\times 3$ diameters.

$$
\begin{gathered}
\text { PLATE XXXVI. } \\
\text { Seventh Stage. - Pig at birth. }
\end{gathered}
$$

Fig. 1. Under view of snout-cartilages. $\times 5$ diameters.

Fig. 2. Auditory capsule, hyoid, and occiput. $\times \frac{1}{2}$ diameters.

Fig. 3. Auditory chain of bones. $\times 5$ diameters.

$$
\text { Eighth Stayg.-Pig, } 6 \text { months old. }
$$

Fig. 4. Jower view of sliull. Natural size.

\section{PLATE XXYVII.}

lig. 1. Side view of same. Natural size.

Fig. 2. End view of same. Natural size.

Fig. 3. Side view of lower jaw. Tatural size. 


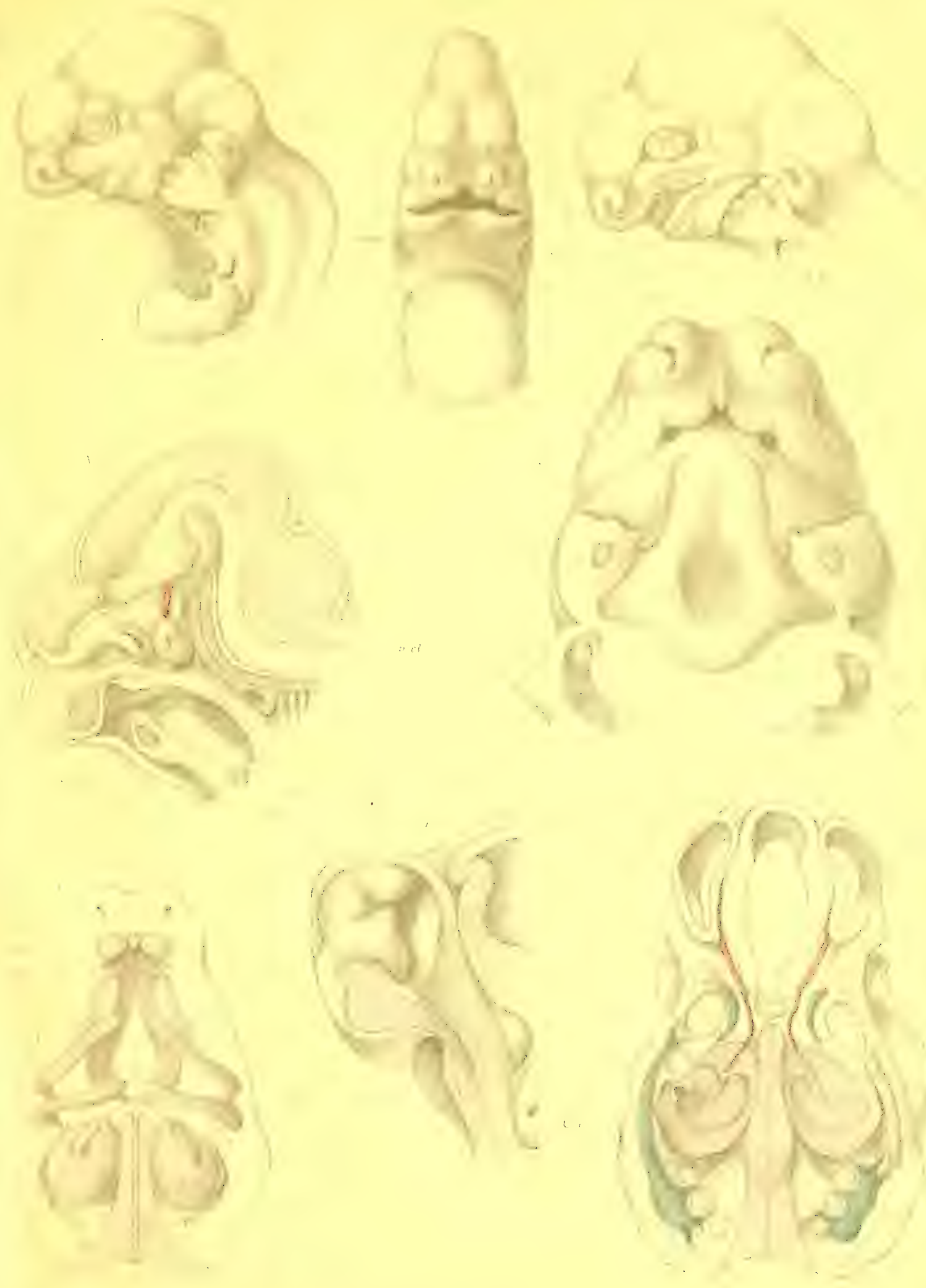





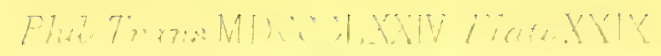
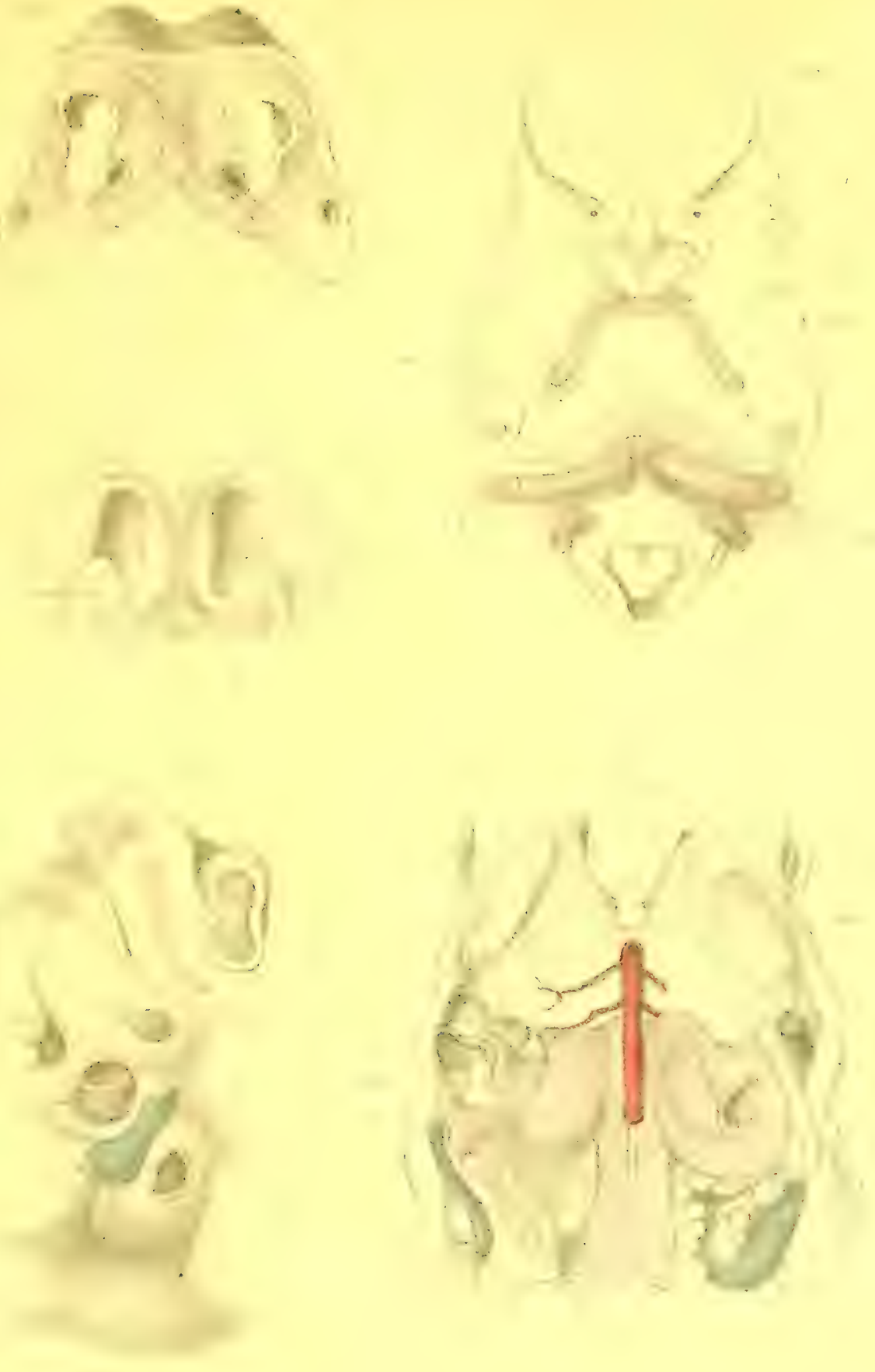

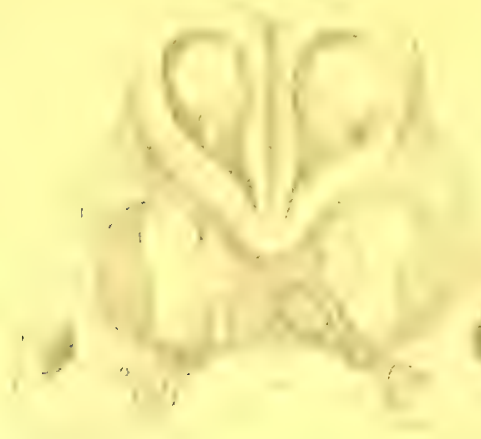

1
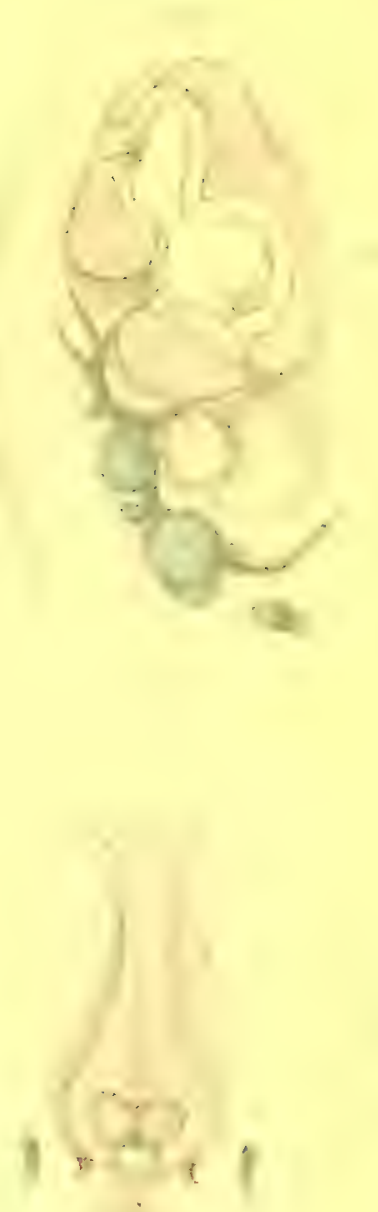

11

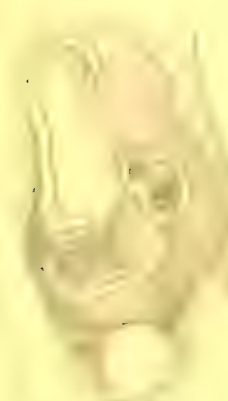

D.

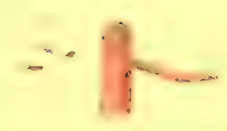

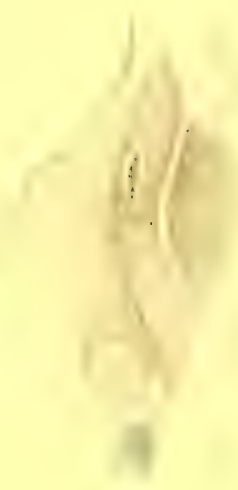

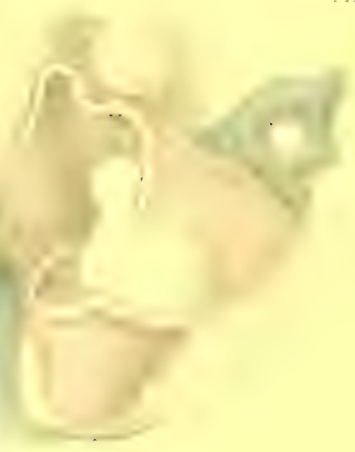




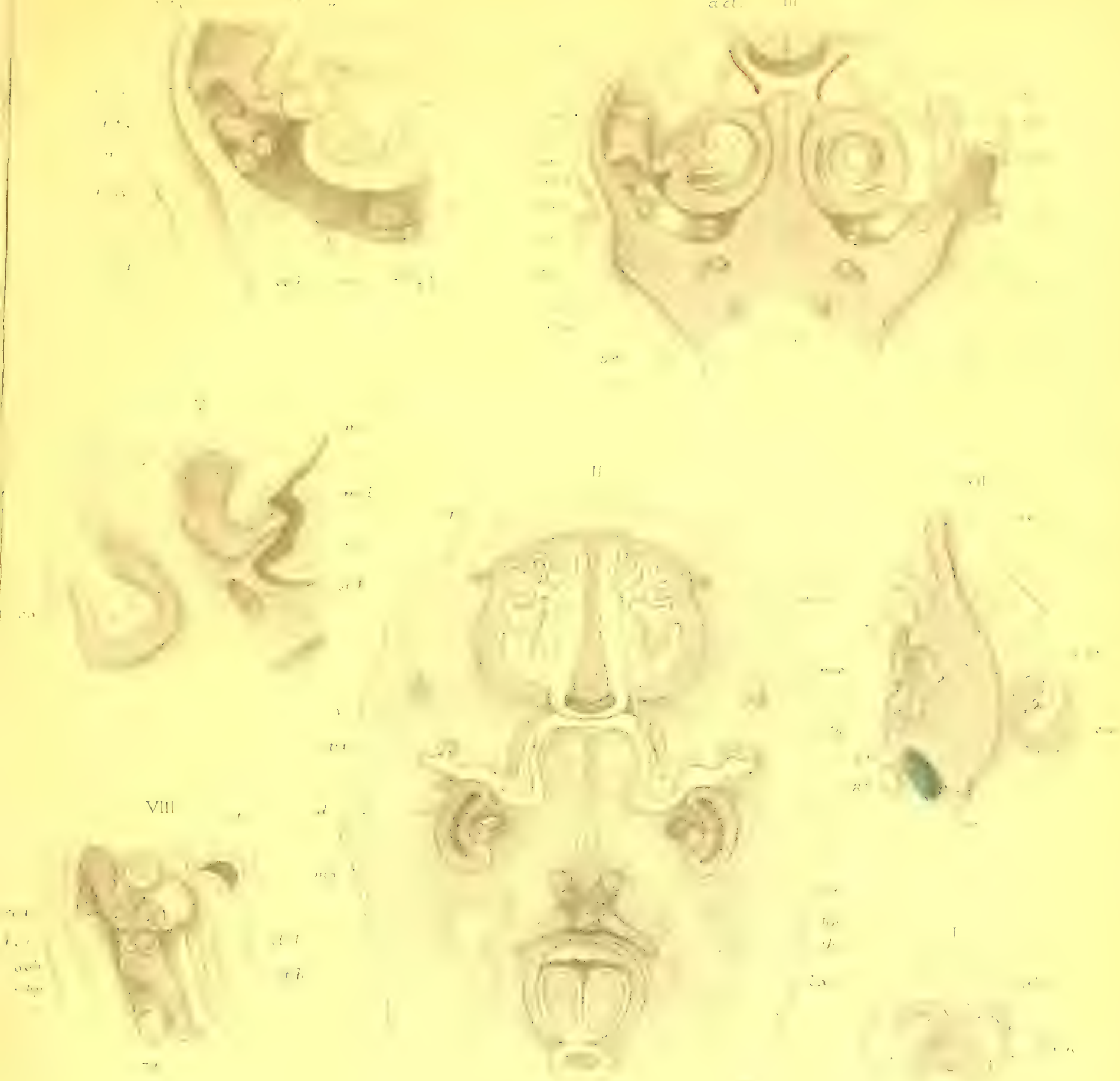

$\pi$
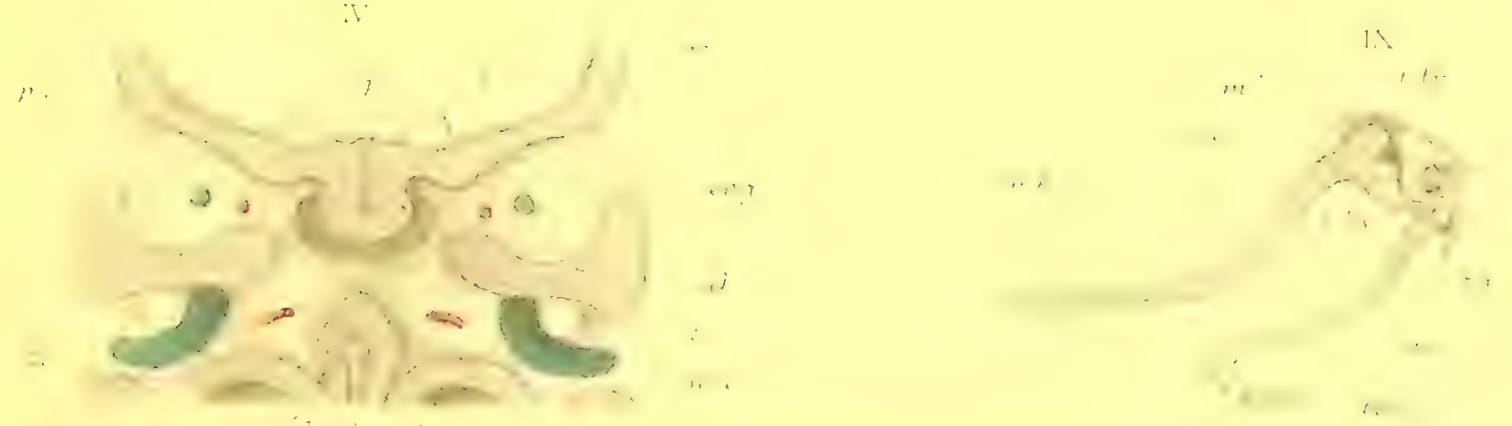

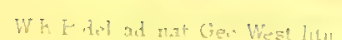

W Wor \& Q

$$
\begin{aligned}
& \text { Pi } \\
& \text { Figs 1 7. ind Stage. Figs 8, 9. Srat Stage }
\end{aligned}
$$



as $25-50$, 36

(4i)
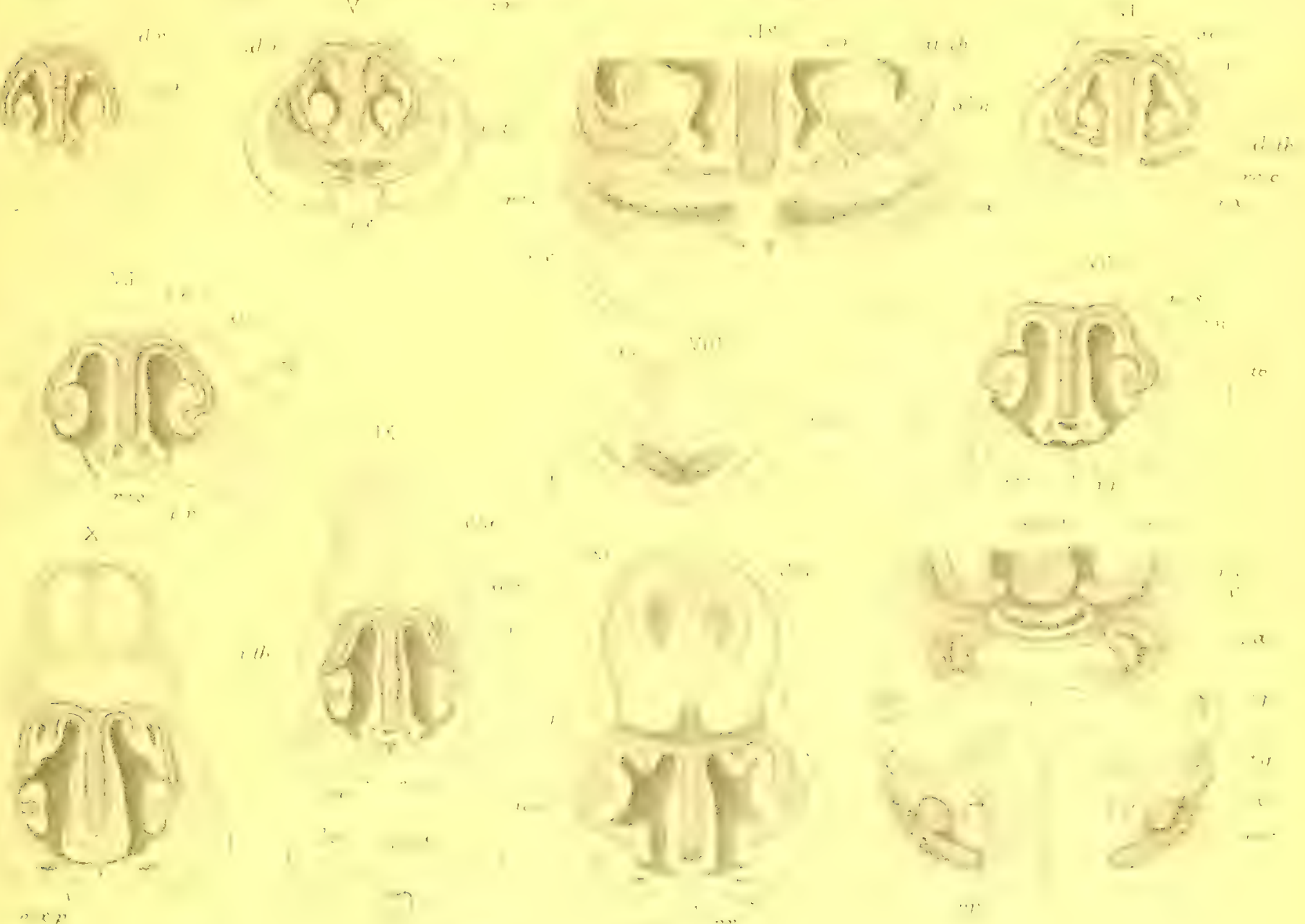

ii
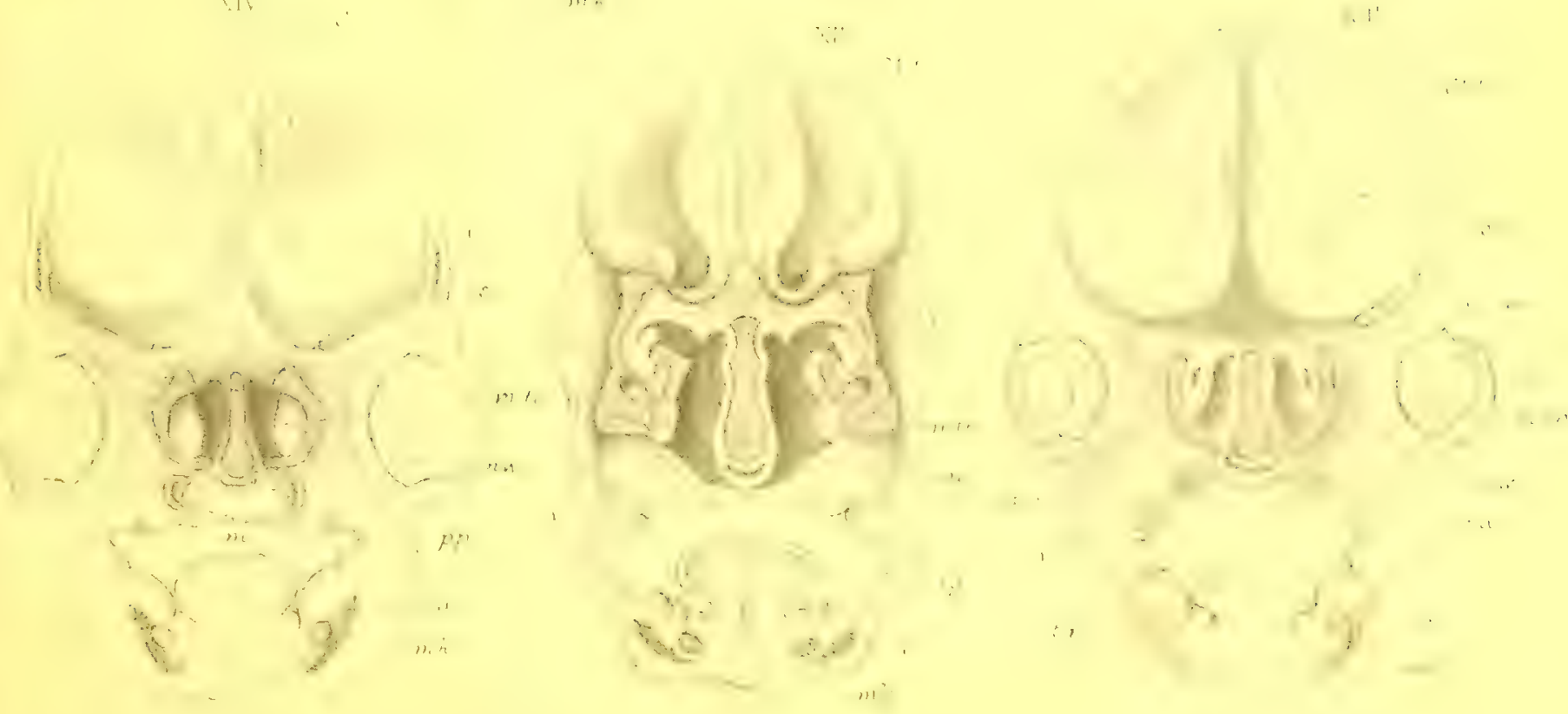


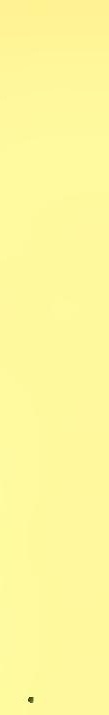




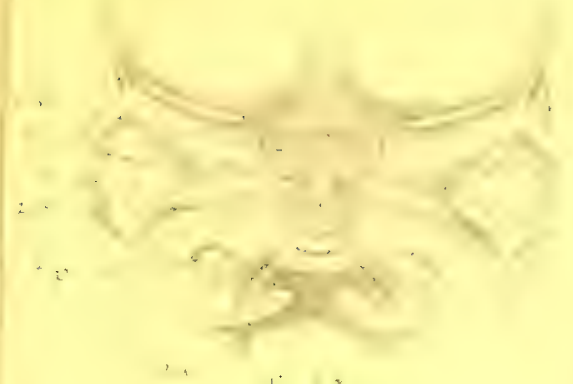

$\because i$
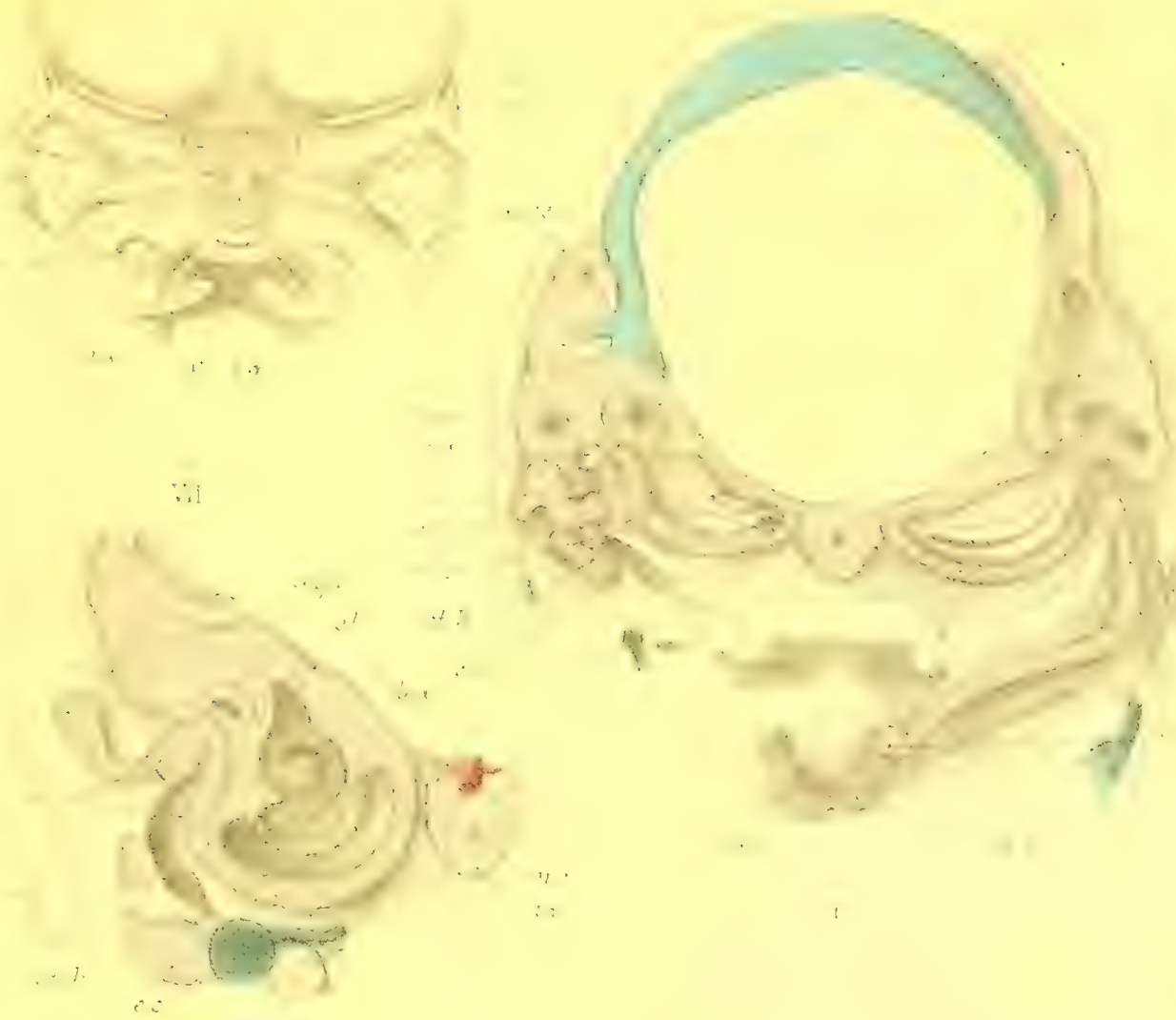

'.11
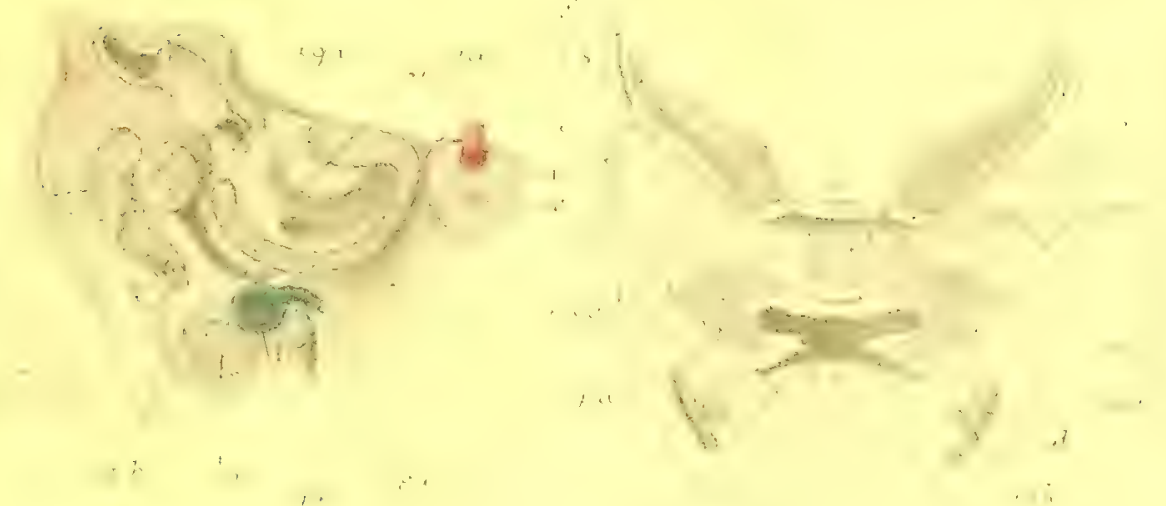

(1) Y
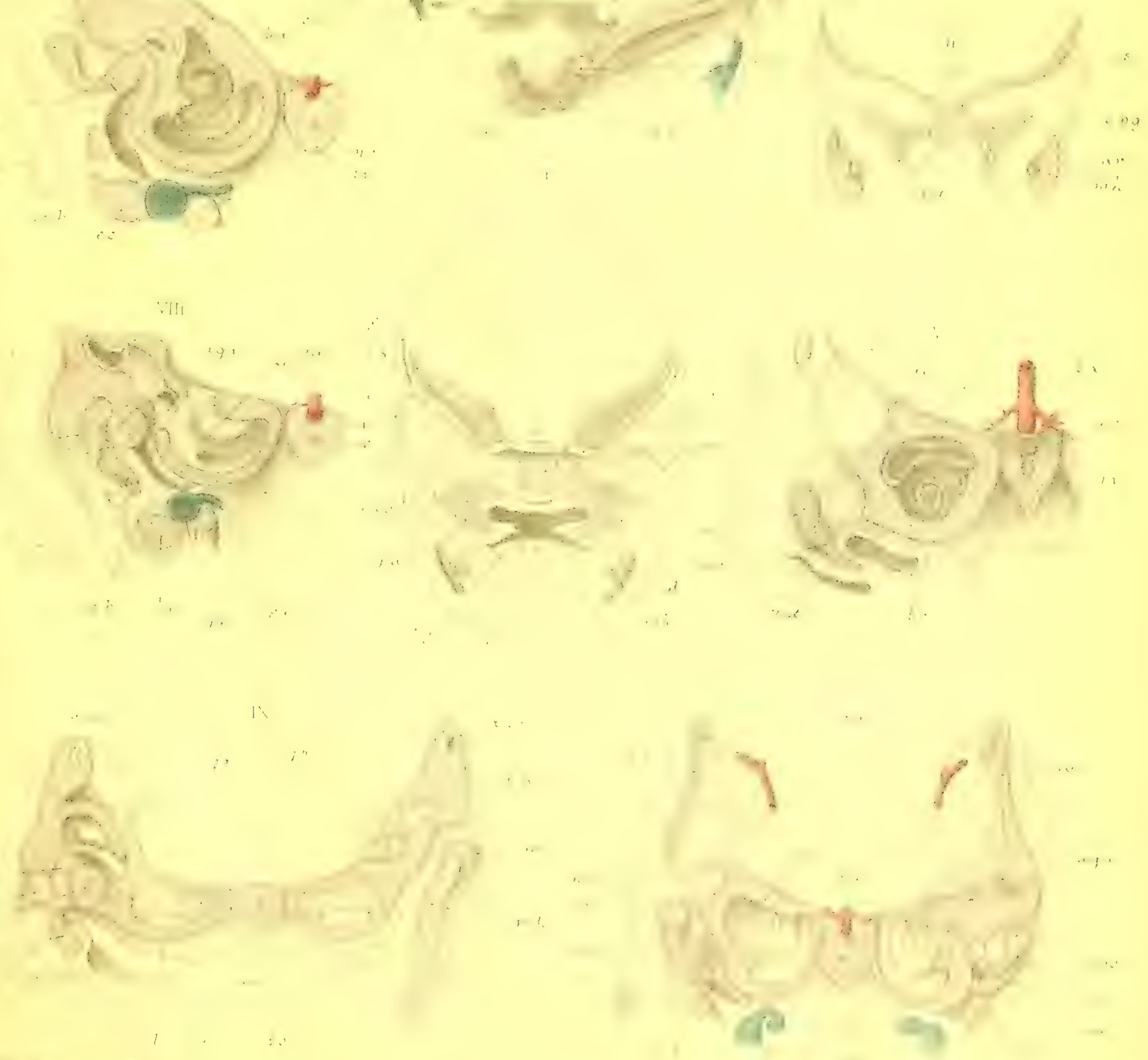


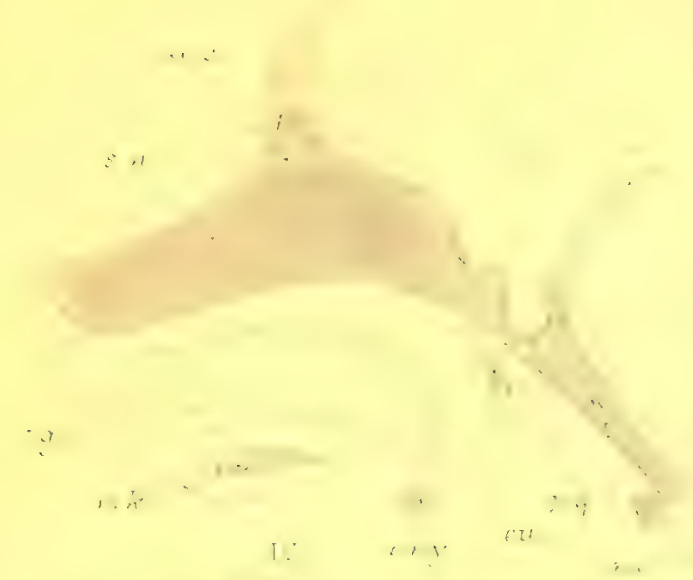

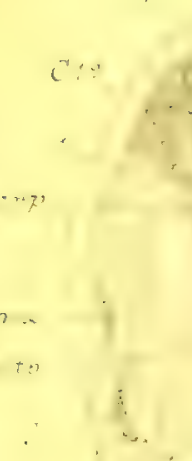

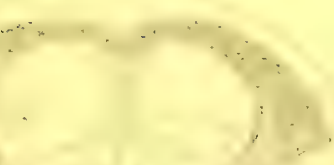

$\because+\cdots+\cdots$

$$
\text { . }
$$

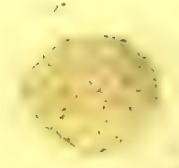

$\because$ 

WI:
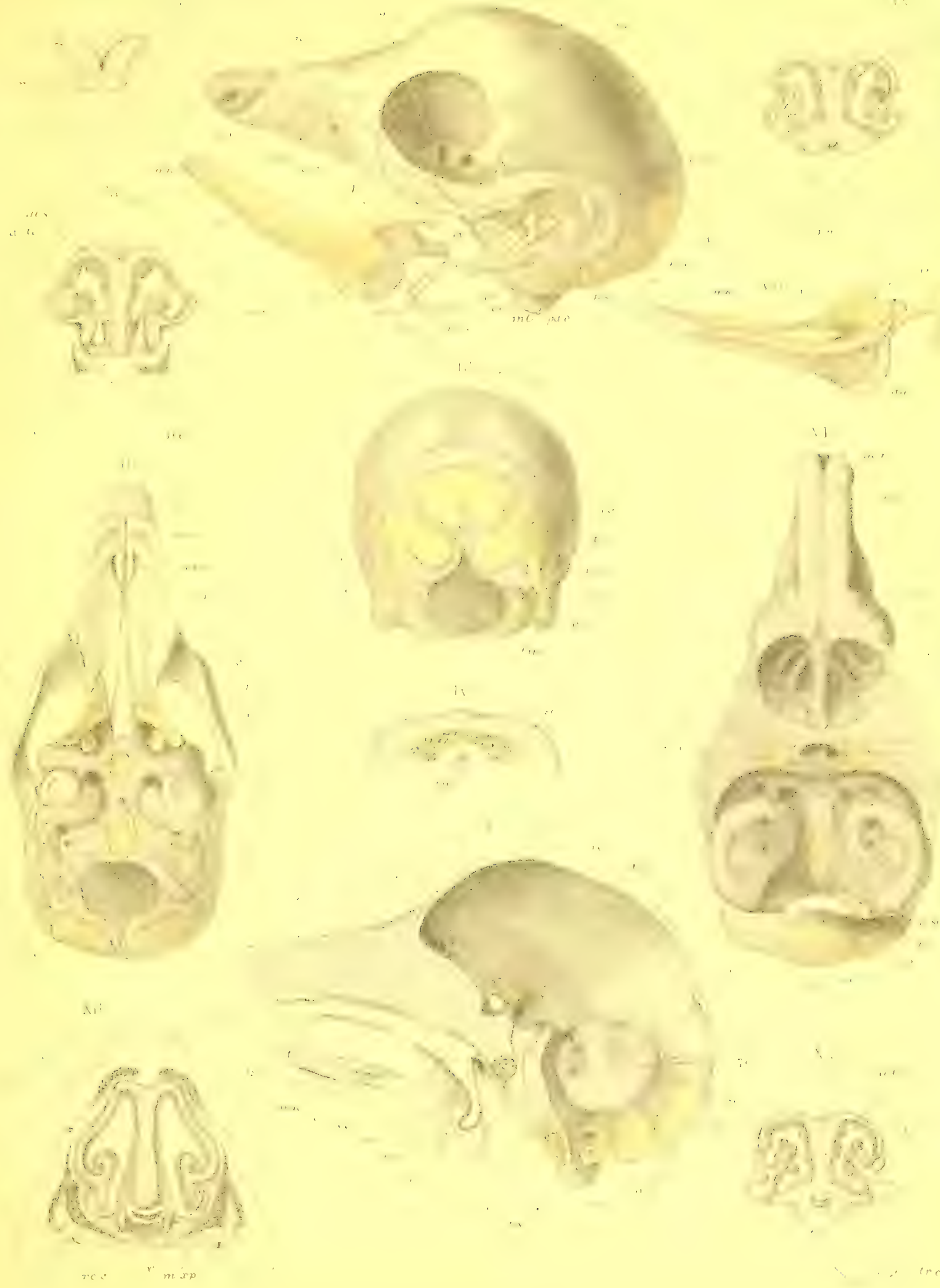

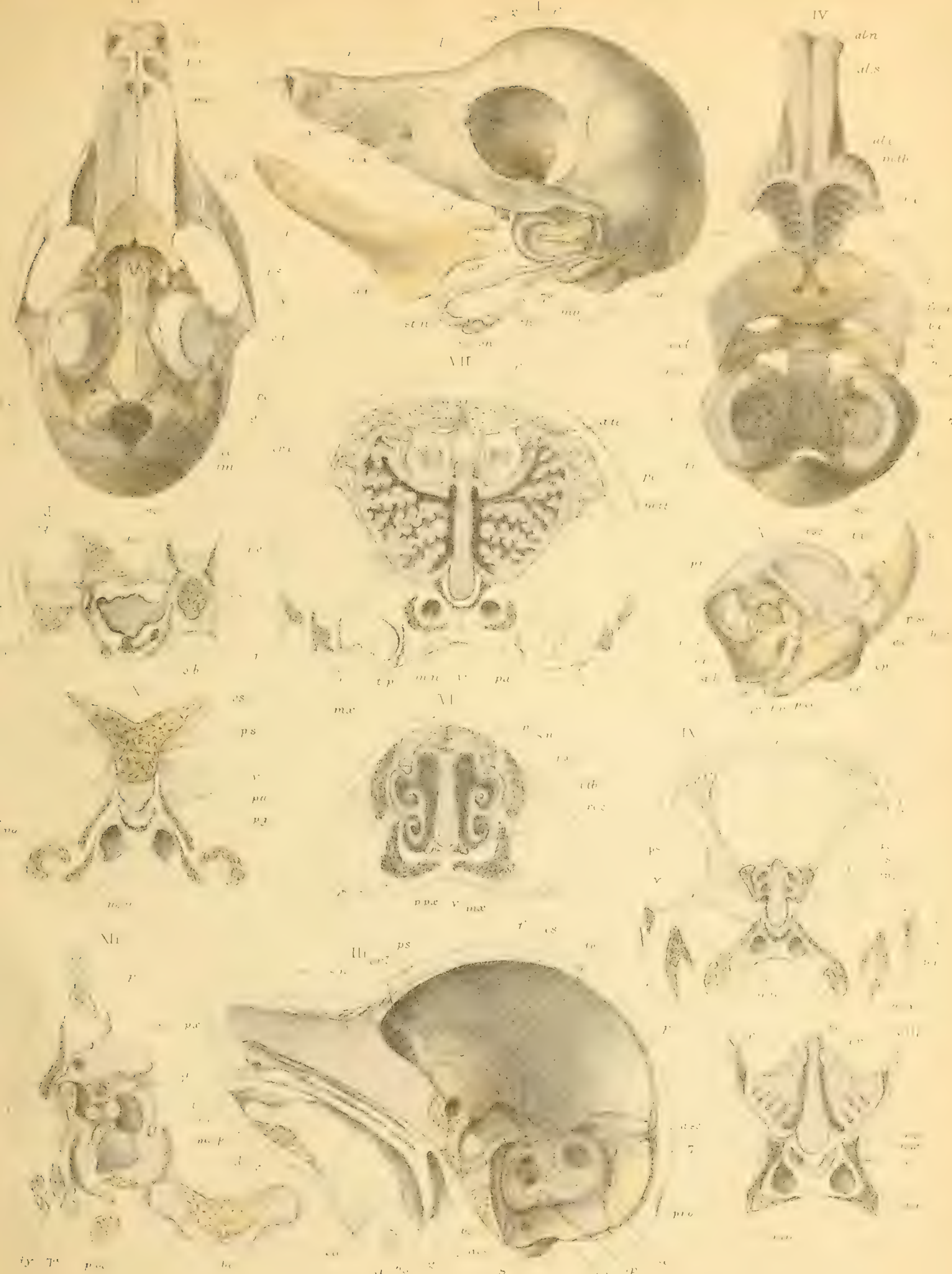

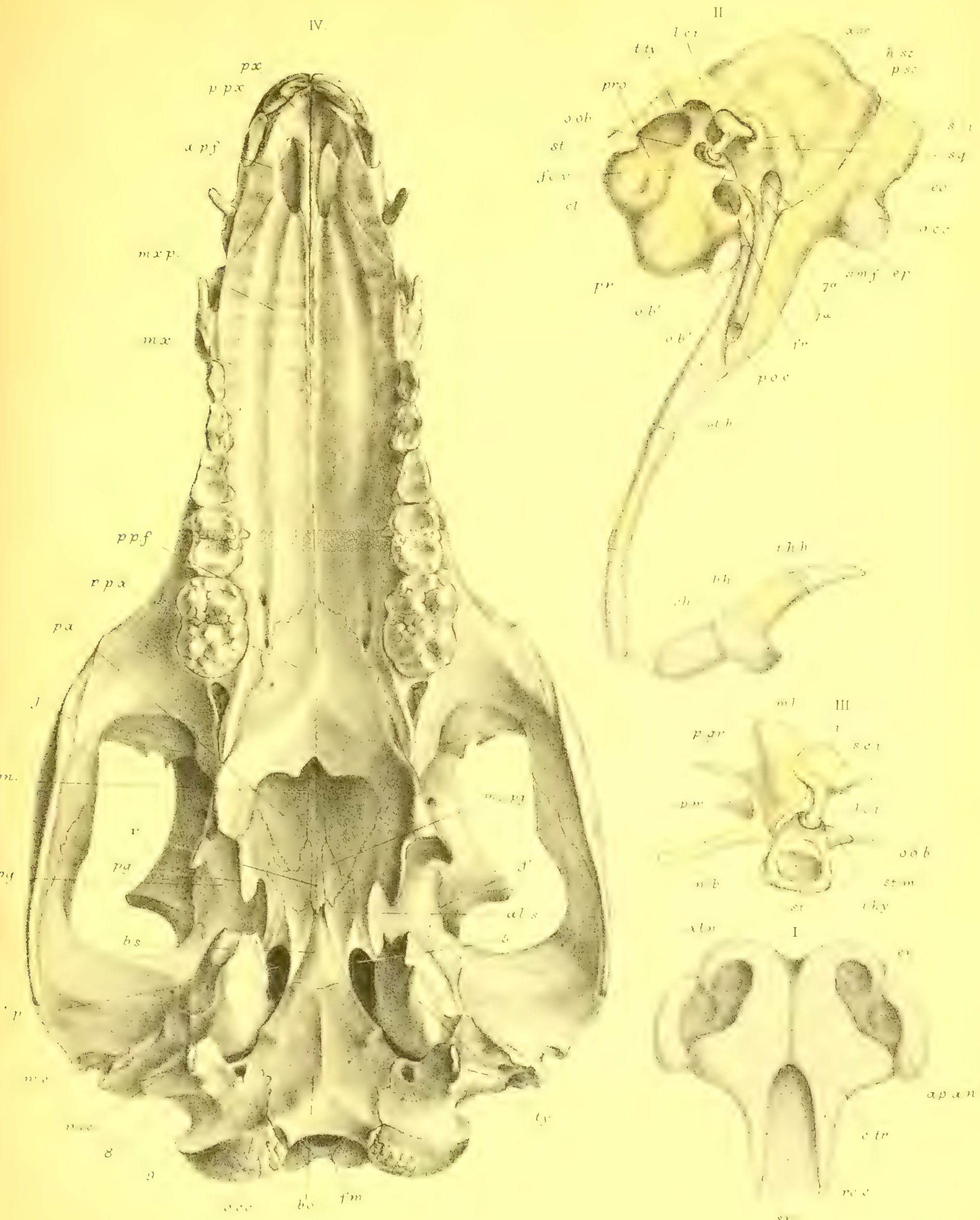


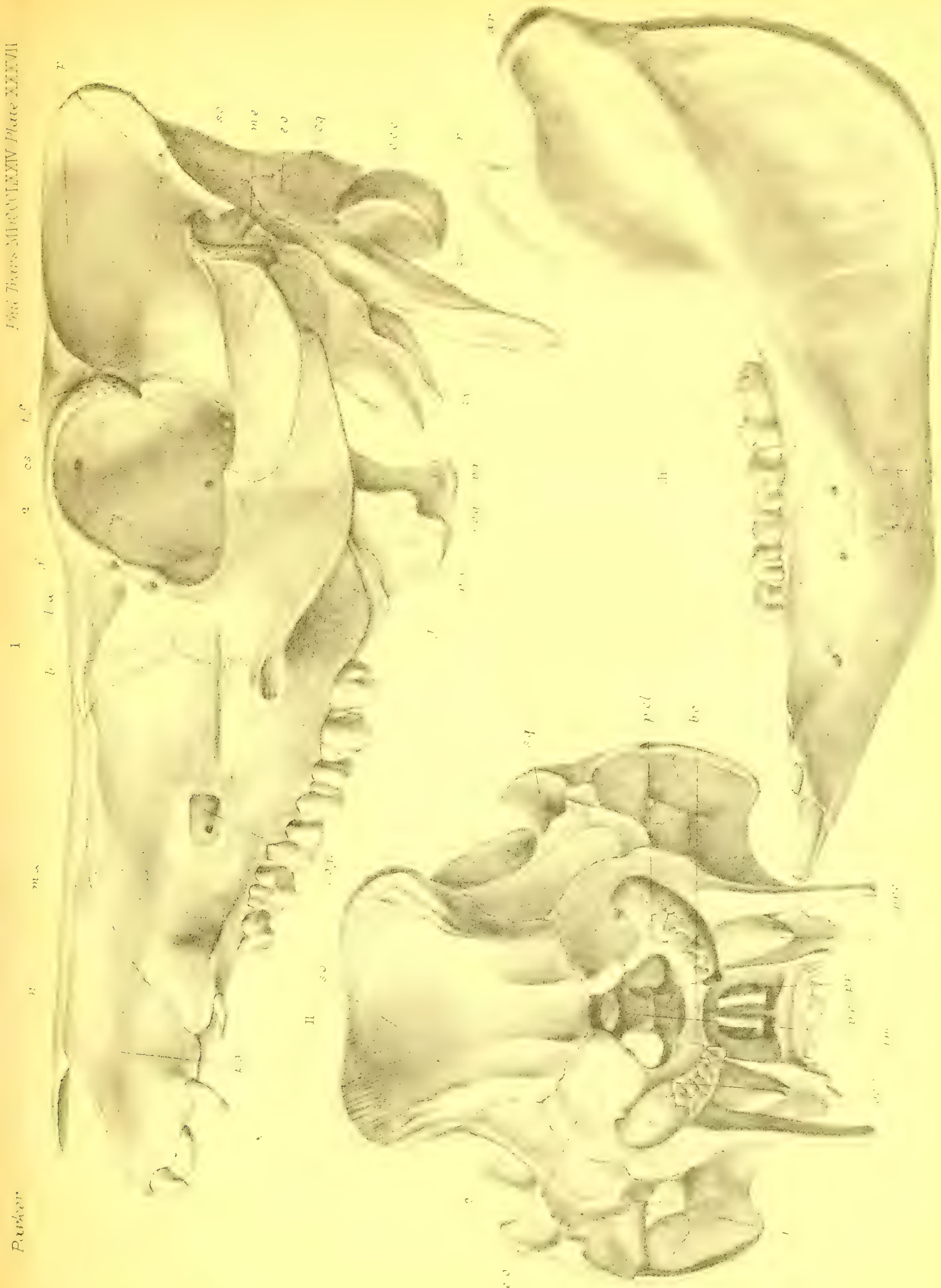


UN THE

\title{
STRUCTURE AND DEVELOPMENT
}

\author{
QP TII:
}

\section{· SKULL IN THE MAMMALIA.}

\section{PART II.-EDENTATA. \\ PART III.-INSECTIVORA.}

BY

WILLIAM KITCHEN PARKER, F.R.S. 



\title{
STRUCTURE IND DEVELOPIENT
}

(1) III

\section{SKULL IN THE MAMMALIA.}

\author{
PART TI.-EDENTATA. \\ PART III.-INSECTIVORA.
}

(3)

WILLIAI RITCHFA PARKER. F.R.S

Fom the PHILOSOPHICAL TRANSACTIONS OF THE ROYAL SOCIETY.-PART I. 1885. 
L O N I ON

HARRSON AND SUNA, PRINTERS IN OLDINARY TO HER MAJESTY,

ST, MAIRIY'S JANE. 


\section{PHILOSOPHICAL TRANSACTIONS.}

I. On the Structure and Development of the Skull in the Mammalia.Part II. Edentate.

By Wilutam Kitchen Parker, F.R.S.

Received May 26,--Read June 19, 1884.

[Plates 1-15.]

\section{INTRODUCTION.}

SiNCE my first attempt to work out the Mammalian type of skull, the greater part of my time has been spent upon Cold-blooded Vertebrata-Fishes, Amphibia, and Reptiles. But between the early part of 1873, when my paper on the skull of the Pig was presented to the Royal Society, to the beginning of 1882, when I was able to take up this Class once more, no time or chance was lost as far as materials for work go; during those nine years a very large collection of embryos and of early young of the various types of Mammalia was made.

This collection of materials is still going on, and will I trust go on for years to come. No work lies before me of greater importance; and if the skull, in the Orders of this, the highest Class, can thus be illustrated, it will give some roundness and shape to the efforts and labour of the whole life of a never-weary worker.

I am very grateful to the friends that have so kindly and zealously helped me by presents of specimens; in this present piece of work I have had the greater part of my materials from the following well-known Biologists; viz., Professor W. H. Flower, F.R.S., Dr. Güxtier, F.R.S., Professor St. George Mivart, F.R.S., Dr. P. L. 
Sclater, F.R.S., and H. M. WARd, Esq. (who lost no opportunity during his Botanical work in Ceylon of procuring valuable specimens for Professor Huxuex and me).

The order in which these materials are worked depends upon their fulness in any particular group; the Edentata are worked out, and the Insectivora are almost finished; then will come the Marsupials; this is not the "order of Nature," but of "necessity;" and those who are interested in these matters must classify the data, when they have been collected.

Nevertheless, I shall aim at bringing the Monotremata forward as soon as possible; thanks to Ur. Bennetr, of Sydney, and to Professor Moseley, I am able to begin at the Omithorhynchus and the Echidna. But my hopes, in that quarter, largely rest upon the results to be obtained by those whom the liberality of the Royal Society has put into a position for finding such treasures as the early stages of those archaic forms of Mammalia.

As to the "Order" now under consideration, the Edentata, I have worked out the skull in one or more embryos, as well as young, in all but the Anteaters; * happily, of that type I have the young in a very instructive stage.

My richest materials are in the family "Dasypodidx," or Armadillos. With this type I shall begin; it is perhaps, on the whole, the best, as it is not so intensely specialised as the rest, and thus is fittest for comparison with the Insectivora; the forms that are found on the highway of Mammalian life, and not in a bye-path, like the Edentata.

The Insectivora will be described in my next, or third, part.

\section{BIBLIOGRAPHY.}

a. On the Zooloryy, Embryology, and Morphology of the Edentata, and of the Mammatia, generally.

ALBRECIIT, $P$.

1. 'Mémoire sur le Basiotique.' Bruxelles, 1883.

2. 'Sur la Fossette Termienne du Crîne des Mammifères.' Avec une planche. Bruxelles, 1884. (Contains Marsupials, Edentates (Dasypus novencinctus), Slotlis, Orycteropus, Tatusia, Myrmecophaga.) Fig. 1, Halmaturus; fig. 2, Dasypus.

3. 'Sur les os intermaxillaires.' Bruxelles, 1883.

4. 'Sur la Valeur morphologique de l'Articulation mandibulaire du cartilage de MEckeL et des osselets de l'Ouie.' Bruxelles, 1883.

5. 'Sur la Valeur morphologique de la Trompe d'Eustache,' \&c. Bruxelles, 1884. (Important for Mammalian homologies.)

* I have since received from Professor Treves an embryo of Cyclotums that has not yet been worked out. An account of its skull will be given as an Appendix to the present papex. 
Allen, Harrison, M.D. "On a Revision of the Ethmoid Bone in the Mammalia." Bulletin of the Museum of Comparative Anatomy at Harvard College, Cambridge, Mass., U.S. Nov., 1882; plates $1-7$, pp. $135-164$.

BaLfour, F. MI. 'A Treatise on Comparative Embryology.' Vol. 2. London, 1881.

Bergmann, C. 'Einige Beobachtungen und Reflexionen iiber die Skelettsysteme der Wirbelthiere, deren Begrenzung und Plan.' Göttingen, 1816.

Betz, F. "Über den Primordialschädel des Menschen." 'Fronier's Notizen,' December, 1848.

BidDER, A. "De cranii conformatione ratione imprimis habitu Jacobsonii de cranio primordiali ejusque ossificatione sententic." Dorpat, 1817.

Brainville, DE. 'Osteographie,' 1835-54.

BOETTCHER, A.

1. "Bau und Entwicklung der Schnecke." Denkschriften d. Faiserl. Leop. Carol. Akad. d. Wissens., vol. xxxy.

2. Several papers on the structure of the ear in Vincirow's Archiv., Band xvii. and xix; 'Archiv für Anatomie und Physiologie,' 1869 ; 'Archiv für Ohrenheilkunde,' Band vi., 1871.

Borv, G. "Die Nasenhöhlen und der Thränennasengang der Amnioten Wirbelthiere." "Morphologisches Jahrbuch,' Bd. ii., 1876 ; Bd. v., 1879 ; and Bd. viii., 1882.

Brovs's "Klassen und Ordnungen des Thierreichs." Abtheilung Siugethiere, von C. G. GIEBEL, $1874-79$.

CorE, E. D. "On the Foramina Perforating the Posterior part of the Squamosal Bone of the Mammalia." Rend before the Amer. Phil. Soc., Feb. 6, 1880.

Decker, Frtedrtch. "Über den Primordialschidel einiger Süugethiere." 'Zeitschrift für wissenschaftliche Zoologie,' 1883 , pp. 190-233, plate 9.

DoLLo, J. " On the Malleus of the Lacertilia, and the Malar and Quartrate Bones of the Mammalia." Quart. Jour. Micr. Sci., xxiii., 1883. This paper contains a complete list of the literature on the ear, and a tabular arrangement of the views held by previous authors.

Doran, * A. G. H. "Morphology of the Mammalian Ossicula Auditûs." Trans. Linn. Soc., Ser. 2. Zool., vol. i., pp. 371-497, plates 58-64.

Dursx, E. "Zur Entwicklungsgeschichte des Kopfes des Menschen und der höheren Wirbelthiere." Tübingen, 1869.

Edwards, Henri Milne et Alpionse Milave. 'Techerches pour' servir à l'histoire naturelle des Mammifères' (2 vols.). Paris, 1868-1874.

FLOWER, W. H.

1. "On the Development and Succession of the Teeth in the Armadillos (Dasypodide)." Proc. Zool. Soc., 1868, pp. 378-380.

2. 'An Introduction to the Osteology of the Mammalia', 1885.

3. "On the Mutual Affinities of the Amimals composing the Order Edtentata." Proc. Zool. Soc,, 1882 , pp. 358-367.

4. Art. "Mammalia." Encyc. Brit, 9th edition, 1883.

5. "On the Orders and Families of the Mammalia." Proc. Zool. Soc, A pril 17, 1883, pp. 178-186.

Forbes, W. A. "On some points in the Anatomy of the grent Anteater (Arymecopturga jubatc)." Proc. Zool. Soc., 1882, pp. 287-302.

Fraser, A. "On the Development of the Ossicula Auditûs in the IIigher Mammalia." Plil.

Trans., 1882, Part III., pp. 901-925, I'lates 54-58.

* Mr. Doran gives a copions Bibliography of these special parts.

B ? 
Garrod, A. H. "Notes on the Anatomy of Tolypeutes tricinctus, with remarks on other Armadillos." Proc. Zool. Soc., 1878, pp. 222-230.

Gegenbaur, C.

1. "Ueber primäre und secundäre Knochenbildung, mit besonderer Beziehung auf die Lehre von dem P'rimordialcranium." 'Jenaische Zeitschrift,' vol. iii., 1867.

2. 'Comparative Anatomy.' Translated by I'rofessor E. IRay Lankester and Jefrery Bell. London, 1878.

GRAY, J. E.

1. "Ievision of the Genera and Species of the Entomophagous Edentata." Proc. Zool. Soc., $1865, \mathrm{pp} .359-386$.

2. "Notes on the Species of Bradypodide in the British Museum." Proc. Zool. Soc., 1871, pp. 428-449, plates 31-37.

Hannover, A.

1. "Primordial lrusken og dens Forbening i det Menneskelige Kranium fer Fodselen." Kopenhagen, 1880.

2. "On the Formation of Vertebre in the Human Skull." Transact. Internat. Med. Cong. London, 1881; 'Anatomy;' vol. i.

HASSE, C. "Die vergleichende Morphologie und Histologie der häutigen Gehörorgane der Wirbelthiere." Leipzig, 1873.

Heape, Walter. "The Development of the Mole (Talpa Europeca)." Quart. Journ, of Microscop. Sc. for July, 1883.

HENSEN, V.

1. "Zur Morphologie der Schnecke des Menschen und der Sïugethiere." Zeits. f. wiss. Zool., vol. xiii., 1863.

2. "Bemerkungen gegen die Cupula terminalis." "Archiv fuir Anatomie und Physiologie," 1878.

Hunt, Davin. "A comparative sketch of the Development of the Ear and Eye in the Pig." "Transactions of the International Otological Congress,' 1876.

Huscuke. "Ueber die erste Bildungsgeschichte des Auges und Ohres beim bebritteten Küchlein."

'Isis,' 1831, and MECKEL'S 'Archiv', vol. vi.

HuxLex, T. H.

1. "On the Theory of the Vertebrate Skull."-Croonian Lecture. Proc. Toy. Soc., Nov. 18, 1858.

2. 'Elements of Comparative Anatomy.' London, 1864.

3. 'A Mnual of the Anatomy of Vertebrated Animals.' London, 1871.

4. "On the liepresentatives of the Malleus and Incus of the Mammalia in the other Vertebrata." Iroc. Zool. Soc., 1869, pp. 391-407.

5. "On the Application of the Laws of Evolution to the Arrangement of the Vertebrata, and more particularly of the Mammalia." Proc. Zool. Soc., Dec. 14, 1880, pp. 649-662.

ITIRTL, J

1. "Verglcichend-ạnatomische Untersuchungen iiber das imnere Gehörorgan." Prag, 1845.

2. "Chlamydophorus truncutus." 'Denkschriften der Wiener Akademie,' ix., 1855.

KöLtiker. A.

1. "Mittheilungen der Naturforschenden Gesellschaft in Zurich," 1847.

2. "Berichte von der Königl. Zootomischen Anstalt zu Würzburg." 2. Berichte f. d. Schuljahr 1847-48; Leipzig, 1819.

$\therefore$ "Allgemeine Betrachtungen uber die Entstehtung des knijchernen Schädels der Wirbelthiere." Berichte v. d. Königl. Zoot. Anstalt zu Wrirzisurg, 184!. 
4. "Die Theorie des Primordialschïdels." Berichte v. d. Königl. Zoot. Anstalt zu Wüuzburg, 1850, II. Bd., p. 281.

5. "Entwicklungsgeschichte der Menschen und der höheren Thịere." Zweite Auflage. Leipzig, 1880.

Meckel, J. W. "Ueber die osteologischen Differenzen der Igelnten." Beitrag zur vergl. Anat, Heft I., pp. : it $56 ; 1808$.

Merer, H. "Der Knorpel und seine Verknöcherung:" Müllen's 'Archiv', 1849, p. 292.

Moldeninder, W. "Zur Entwicklung des mittleren und iusseren Ohres." "Morphologisches Jahrbuch,' vol, iii., 1877.

MIUrie, JAS. "On the Hahits, Structure, and Relations of the Three-banded Armadillo (T'olypoutes conurus)." Geoff. Is. Trans. Linn. Soc, vol. xxx., pp. 71-1:2, plates 20-26.

Owen, R. "On the Anatomy of the Great Antenter." Part I., Trans. Zool. Soc, iv., pp. 117-140, plates $37-40$; Part II., ihil., pp. 179-181, plates 51-53.

PARker, W. K. "On the Structure and Development of the Skull in the Pig (Sus scrof $a$ )." Phil. Trans., 1874, pp. 289-336, l: lates 28-37.

Parker, W. K., and Bettaxy, G. T. "The Morphology of the Skull." 1877.

Pouchet. "Mrémoire sur le Grand Fourmitier." P’aris, 1874.

liApr. "Anatomische Untersuchungen über die Elentaten." 2te Auflage; Tiibingen, 1852.

Ratnke, H. "Vierter Bericht iiber das Naturwissenschaftliche Seminar zu Königsberg, nebst einer Abhandlung über die Entwicklung des Schiidels der Wirbelthiere." Königsberg, 1839.

ReICHeRT, K. B.

1. "Vergleichende Entwicklungsgeschichte des Kopfes der nackten Anplibien, nebst den Bildungsgesetzen des Wirbelthierkapfes." Königsherg, 1833.

2. “Zur Kontroversa ïber đen Primordialschiidel.” MÜ̈LLER's 'Archiv,' 1849, p. 448.

ReIssner. "De auris interne formatione." Inaug. Diss., Dorjat, 1851.

SALEnskr, W. "Beiträge zur Entwicklungsgeschichte der knorpeligen Gehörhnöchelchen bei Säuge-

Sclater, P. L., and Holiwwood, F. "On Manis Temmineki." I'roc. Zool. Soc., 1878, pp. 632, 633.

thieren." 'Morphologisches Jahrbuch,' Bd, vi., M1. 41 ż 132 , plate 20.

Spondut, H. "Über den Primordialschädel der Siungethiere unrl des Menschen." Zürich, 1846.

STEIfendstrd. "Das Gehörorgan der Wirhelthiere." 'Arehiv füi Anatomie und I'hysiologie,' 1833 s.

Stannius, H. MülLer's 'Archiv,' 1849, p. 53̈.

Sutton, J. B.

1. "The Ossification of the Temporal Bone." Jour. of Anat. and I'liys., vol. 17, 1p. 498-508, plate 18.

2. "Development of the Inferior Maxilla." Reprinted from Trans. Odont. Soc., 188:"

Tuttle, Albert H. "The Relation of the External Meatus, Tympanum, and Eustachian Tube to the first Visceral Cleft." Proc. Amer. Acad. Sc., 1883-84, pp. 111-1:32, plates 1, 2.

Urbiatscuitsci, V. "Ueber die erste Anlage der Mittelohres und des Trommelfelles." Mitheil. a. d. Embryol. Institut, Wien, Heft i., 1877.

Weber, l. "De aure et auditu hominis et animalium." Lipsix, 1820.

White, E. W. "Notes on Chlamydophorus truncatus." Proc. Zool. Soc, 1880, 11). S-11.

Wiederishem, Rовт. "Lehrbuch der versleichenden Antomie der Wirhelthicre." Jena, 1883. 


\section{b. On JacoBson's Organ.}

Batogir. "Das Jaconson'sche Organ des Schafes." Sitzunggler. d. Kais. Akademie der Wiss. zu Wien, vol. xlii., p. 449.

Born, Gustav.

1. "On Jacobsox's Organ." Sitzung d. Naturw. Section, August, 1877, d. Sclnlesischen Ges. f. Vaterl. Cultur.

2. "Ueber die Nasenhöhlen und den Thrinennasengang der Amphibien." 'Morph. Jahrbuch,' Bd. ii., 1877, plates 39-41, pp. 577-616.

3. "Die Nasenhöhlen und der Thrïnenuaseugang der Amnioten Wirbelthiere." 'Morph. Jahrb., Bd. v., 1879, und Bd. viii., 1882.

Fleischei, R. "Beitrige zur Entwicklungsseschichte des JAConson'schen Organs und zur Anatomie der Nase." 'Sitzungsberichte der physikalisch-medizinischen Societiit für Erlangen,' 1877.

Gratiolet. 'Recherches sur l'organe de Jacobson.' I'aris, 1845.

JACobson, L. MÜ̈LLER's 'Archiv für Anatomie, I’hysiologie mnd wissenschaftliche Medicin,' 1844.

KLEIN, E.

1. "Contributions to the Minute Anatomy of the Nasal Mucous Membrane." "Quarterly Journal Microscopical Science,' vol. xxi., new ser., pp. 98-113, pl. 7.

2. "Histological Notes." Ibid., pp. 114-118.

3. "The Organ of JAcobson in the liablit." Q. J. M. S., xxi., 1881.

4. "A further Communication to the Minute Anatomy of the Guinea Pig." Q. J. M, S., 1881. Kölliker, A.

1. "Ueber die JacoBson'schen Organe des Menschen." "Gratulationschrift der Würzburger Medicin-Fakultiit für F. voN litnecher.' Leipzig, 1877.

2. 'Verhandlungen der physikalisch-1uedizinischen Gesellschaft zu TVürburg,' xvii. (1883), pp. 229-257 (four plates).*

Leboucq, H. "Le Canal naso-palatin chez l'Homme." 'Arehives de Biologie,' vol. ii., 1881.

LEGaL, E. "Die Nasenhöhlen und der Thrïnennasengang der amnioten Wirbelthiere." "Morpho-

logisches Jahrbuch,' Bd. viii., 188:.

Lerdig. 'Lehrbuch d. Histologie,' p. 218.

Loews. 'Beitrag zur Anatomie der Nase und Mundhöhle.' Berlin, 1878.

l'Aniser, T. J. 'Zootony' (py. $334-336$, fig. 64; Rabbit). London, 188t.

IVIEDERSifim, R.

1. "Das Kopfskelet der Urolelen," 'Morphologisches Jahrbuclı,' Bd. III., 1877.

2. 'Die Anatomie der Gymnophionen.' Jena, 1879.

3. "Die Stammesentwicklung des JACobson'sclien Organs." "Tageblatt der 54. Versammlung dentscher Naturforscher und Aexzte in Salzluurg,' 1881.

* For an abstract of this important paper, "On the Development of the Optic and Olfactory Organs of Human Embryos," see Jeur. Roy. Micros. Soc., 1884, pp. 201-203. 


\section{DASYPODIDE.}

First Stage. Embryos of Tatusia hybrida, $1 \frac{2}{3}$ inch long, measured, in these, and the rest, from snout to root of tail (see Plate 1, figs. 7, 8).

Second Stage. Embryos of Tatusia hybrida, 2 inches long.

'Third Stage. Embryos of I'atusia hybrida, 3 inches long.

Fourth Stage. Embryos of Tatusia peba, 3 inches long.

Fifth Stage. Embryo (ripe) of Tatusia hybrida, 4 inches long. Ripe young of Dusypus villosus, $3 \frac{2}{3}$ inches long.

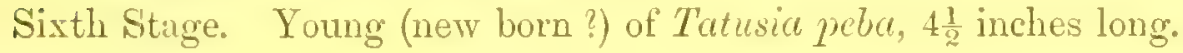

\section{First Stage.-Tatusia hybrida (1 $\frac{2}{3}$ inch long).}

In this, the youngest specimen obtained, I shall describe the chondrocranium with its commencing bony centres and visceral arches, as seen in dissection, and then give its structure in detail, as illustrated by a series of vertically transverse (transparent) sections.

Afterwards, in the second stage, the investing bones will be described in their form, as well as in their relations.

\section{General remarks upon the early skull of the Mammal.}

So great is the uniformity of the early chondrocranium in the Eutheria, or Placental Mammals, that this drawing (Plate 2, fig. 1), made from the skull of an outlying and low type, might serve as a diagram wherewith to illustrate the skull, at this stage, of the types of this Order, and of all the Orders above it.

The figure of a chondrocranium like this, but a little less advanced, before the osseous centres have commenced in it - that of the Mole-will be given in my next paper; and such a skull comes very near to that of a Shark or, still better, of a Skate.

The parts, or rather regions, of which it is composed, correspond very exactly with what is seen in those generalised, but not low, Fishes; and in this specimen, with bony centres appearing, the level is obtained which is permanent in the skull of the Dipnoi, and of such a low Ganoid as the Paddle-fish (Polyudon). *

As in Cartilaginous Fishes and Amphibians, the chondrocranium may be compared to a basin or a boat, the upper part being unfinished, leaving a membranous fontanelle of greater or less extent; this is only partially filled in, at present, by the investing bones, the frontals and parietals $(f, p)$.

The outline of this sectional view is very elegant, and quite similar to that of a vertical section of a Bird's skull at a like stage, except that the nasal roof-cartilages

* See Bridge, "On the Skull of Polyodon folium," Phil. Trans., 1878, Plates 55-57, pp. 683-733. 
run on along the whole extent of the median keeled bar-the intertrabecula; in the Bird they stop short, leaving a free cartilaginous rostrum, like that of a Shark or Skate, which, however, only lasts until it has served as a model on which the huge premaxillaries of the Bird are formed.

In the sides of this hollow cartilaginous structure, near the hind part, the large oval auditory capsules (a.s.c., chl.) are seen to have great distinctness; they are, however, confluent, with the chondrocranium proper, at various points-above, behind, and below, as the sections will show. These are the only sense-capsules displayed in a preparation of this kind, for the eye-balls are quite free from the solid cranial structure (and are, indeed, outside, in such a view as this), and the left nasal labyrinth has been removed.

Before describing this figure in detail, there is one remark to be made, namely, that here we have, clearly shown, the true diagnostic mank of a Mammalian skull. This mark is the rupture of the side walls, due to the pressure of the large lateral masses of the cerebrum. In front of the auditory capsules there is a large elegantly semicircular opening, the crown of the arch looking upwards and forwards.

Only the lower half of the wall has thus broken outwards; this "fault" forms the alisphenoid (al.s.), whilst the orbitosphenoid (o.s.), the so-called "lesser wing," is many times its size, and is continuous, over the archway, with the cartilage that rung on, backwards, into the supraoccipital region (s.o.)

There is nothing similar to this in that Sauropsidan skull which comes nearest to that of the Mammal; - the skull of the Crocodile (see Trans. Zool. Soc., vol. xi., plate 65 ), whilst in Birds the orbitosphenoids are very small even when they are most developed, as in Struthio (see Phil. Trans., 1866, Plate 7), and in that Class the alisphenoids almost finish the cranial cavity, being turned inwards towards each other, on each side of the back part of the orbital septum.

I lay especial stress upon this rupture, outwards, of the alisphenoid, and of the fact that the nasal roofs utilise the whole of the luge high-crested intertrabecula, because these are the most distinctive marks of the Mammalian skull, and they arise out of two things in which the Mammal shows its great superiority to even the highest Sauropsida, namely, the huge volume of the cerebrum, and the tenfold complexity of the nasal labyrinth.

A third clear diagnostic is seen in this very figure; this is the peculiar development of the antero-inferior part of the oblique auditory capsule, due to the development of the coils of the cochlea (figs. 1, 6, 8, chl.).

So that, at once, correlated with the sudden expansion, so to speak, of the cerebrum, we have these new and most important improvements in the organs of smell and of hearing.

At first sight, seeing how large the median bar (intertrabecula) is, with its internasal crest (perpendicular ethmoid and septum nasi, - p.e., s.n.), it might be supposed 
that the Mammalian skull was of the high kind, like that seen in many Teleostean Fishes, in Lizards, and in Birds.

It is not so, however, but belongs to the low kind, seen in Selachians and Amphibians ; and, like theirs, is hinged on to the spine by a pair of occipital condyles.

Hence the eye-balls are kept far apart, instead of coming very near each other as in most Birds, where, often, nothing but a membranous fenestri is found between the right and left capsules, and their special muscular apparatus.

But the face, as well as the skull, of the Mammal shows marks of excellence, such as are not seen in the Sauropsida, even in the higher kinds, as Crocodiles and Birds.

The great development of the nasal organs is correluted with a most remarkable growth of the bones of the upper jaw and the palate to form the " hard palate."

This is found in rudiment even in the Chelonia and in Birds; but especially in the Crocodilia, where, however, its excessive development-as in certain Edentata, e.g., Myrmecophaga-is not dependent upon, or correlated with, any great improvement in the organs of smell, but has to do with the peculiar manner in which these monsters take their prey.

But that great improvement just spoken of as appearing in the organ of hearing in the Mammal has wrought a change in the hinder face that has two most important bearings.

From the first promise of an ear-drum in the tailed Amplibia, to its highest fulfilment in the noblest of the Oviparous tribes-the Birds that nestle on high ("Aves Altrices "), - the only element from the visceral arches that is used for carrying the vibrations of the air inwards to the organ of hearing is the uppermost part of the hyoid arch-the "pharyngobranchial" element of the 2nd postoral arch, to speuk morphologically.

From the Salamandroids to the Singing Birds, all through the Amphibia and Sauropsida, the 1st postoral arch-which forms both the upper and lower jaw-is only segmented once, that is, into an epibranchial and a ceratobranchial element, or juint.

The upper piece is specially termed the "quadrate," and the lower the "urticuloMeckelian;" the one forms the swinging piece, hinge, or pier, to the compound lower jaw, and the other its axis or pith, the part which becomes covered with more or fewer "investing bones."

In these low "Eutheria," and also in both the "Metatheria," and the "Prototheria" (Marsupials and Monotremes), the modified visceral rod that runs through the drum cavity has two new elements added to the one (single or variously segmented) element derived from the hyoid arch.

This is an apparently sudden change, for we have it in the lowest or teatless Mammals; their ancestry, that should show us the earlier steps of the change, are, unfortunately, all extinct.

MDCCCLXXXV. 
In this dilemma not only Zoology, but Palæontology also, fails us utterly, but Embryology comes in with every stage and every link.

I have worked out the early condition of these parts in several kinds of Marsupials, and in the young of Ornithorhynchus; but even in the lower Eutheria, the Edentata, now to be described, and in the large and varied group of the Insectivora, I have been able to trace every step in the transformation of these parts.

I am now satisfied that the incus is the upper element of the first or mandibular arch; both Professor SALENSKy's and Professor Frasen's researches put this, I think, beyond doubt; and my own attempts, for a long time, to make the hyoid theory of this part agree with facts, only kept the subject in hopeless confusion.

The new elements of the ear-chain are, then, the arrested quadrate or incus, and the arrested and amputated articular region of the articulo-Meckelian rod, or primary lower jaw. The bony part of the "ramus" is the well-known dentary, with the coronoid and splenial bones in a sub-distinct state; the curtilage for the new articulation of the lower jaw is derived from a large superficial slab-a "lower labial "- the like of which is not found again until we gret as low down as the Chimæroids.

From this is derived the hinder half of the ramus, by transformation of its substance into bone; and from this we get the cartilage, both of the condyle and the glenoid cavity, and also of the intervening "meniscus."

Of course the drum cavity is the "first cleft;" and the concha auris, with its segmented meatus-tube, - the tympanic bone, the tympanic bulla, and the cartilaginous lining of the Eustachian tube, - all these are parts of a curiously specialised opercular growth belonging to the hinder edge of the first visceral fold and arch.

This last assertion has not been made as a stride across the types, from the Mammal to the Elasmobranch, but is the result of a very slow, step by step process, made during many years, "along all the lines" of Vertebrate morphology.

Vertical section of the skull of Tatusia hybrida. - First Stage (embryo, $1 \frac{2}{3}$ inch long).

The chondrocranium is now at its highest development; after this it will begin to decline, for osseous centres are already developing in it; these are the basioccipital, exoccipital, supraoccipital, basisphenoid, and alisphenoid (Plate 2, fig. 1, b.o., e.o., $\therefore(1, b . s$.$) .$

The notochord (nc.) is still to be seen in the basioccipital region, it is hooked downwards in front. The hasioccipital bone (b.o.) occupies the middle half of the vartilage between the foramen magnum and the posterior clinoid elevation; this latter is a moderately high ridge running crosswise.

The cartilage of the base of the skull becomes thicker in front of that ridge, and rises gently until it reaches the beginning of the great olfactory fossæ; the basisphenoid (b.s.) already occupies the hinder half of this more elevated tract of cartilage. 
The rest of the base of the skull forms a low triangle whose base is somewhat longer than the lower part which reaches backwards to the foramen magnum.

'The postero-superior side of this triangle is developed into two rounded lobes, the upper or fore lobe is the larger of the two. The hinder lobe is the top of the perpendicular ethmoid ( 2 .e.), behind the olfactory fossa with its cribriform plate (see Plate 5, fig. 1); whilst the front or upper enlargement is the crista galli, in solid cartilage.*

The longer upper side dips down gently to the snout, and is a little concave; the triangle does not end in a point, but in at rounded lobe. The lower part of all this nasal fore half of the basis cranii is a thick beum of cartilage, carrying a much thinner crest on its upper edge, which is continuous with it.

Embryologically, the "investing mass" may be said to reach to the posterior clinoid wall; but the notochord has retreated relatively from that point; the rest of the cartilage is "trabecular."

But the paired trabeculx, themselves, only reach as far as to the mirlle of the proper olfactory region, the septurn of which bears the name of "perpendicular" ethmoid" (p.e.); the filling in between these, behind, and all the rest of the middle part is formed by an azygous growth, the "intertrabecula."

The sides of the cartilaginous basin, whose narrow elongated floor has just been described, are formed by a very large sheet of cartilage, right and left. This just reaches the roof, or cover of the basin, in the hinder half, and the sides are imperfect in two places.

The occipital region, only, forms a complete belt or ring of cartilage.

The postpituitary region of the skull, for two-thirds of its horizontal, and for twothirds of its vertical, extent, is occupied by the intruded auditory capsules (u.s.c., chl.), which, above, below, and behind, have coalesced with the cartilage of the proper chondrocranium.

A more than semicircular space in front of these large capsules is occupied by a large fenestra whose very accurate arched outline looks forwards and upwards. The sinuous cartilaginous wall round this space is the orbitosphenoidal region, passing by a band, equal in width to the fenestra above, into the large supratemporal (or subparietal) tract (s.t.c.), which in turn runs into the orown of the occipital arch.

Half the preauditory fenestra is imperfectly occluded by the alisphenoid (above b.s.),

* In my paper on the Ostrich's skull (Phil. Trans., 1866, Plate 7) the counterpart of this crest is lettered cr.g., or clista galli, and is described as such in the text (p.118). But in the paper on the Fowl's skull (Phil. Trans., 1869, Plate 83) this part is not lettered, for I had been reminded by a friendly critic that the crista galli of Man is formed by ossification of fibrous tissue in the fore part of the falx cerebri. It is, however, preformed in cartilage in many Mammals, notably in these Edentata, and my lettering in the figures of the Ostrich's skull is correct. In the same paper (p. 120) the quadrate cartilage is identified with the incus; that view of it is, I feel satisfied, now, quite correct. 
or free, outstanding wing, not of cartilage now, but of bone. 'This fan-shaped tract has its broad part ossified separately, from the lower part or stem (see fig. 6, al.s.).*

At a distance from the basioccipital equal to the width of both the basal and lateral bony centres, the exoccipitals (e.o.) have appeared, they form part of the selvedge round the foramen magnum. Above another equally large space of cartilage we see the supraoccipital $\left(s .0_{0}\right)$ : it has a right and left half (see also fig. $6, s o_{0}$ ); each half is ear-shaped, the broad end being near the mid-line.

A considerable fossa runs between the occipital arch and the auditory capsule; this is occupied by the "lateral sinus" (s.c.), which communicates with the outer veins through a large hole, both above and below.

The foramina for the postanditory nerves are seen in this view; that for the hypoglossal (XII.) in the middle of the space between the exoccipital and basioccipital, and the double space for the vagus and glossopharyngeal (X., IX.) in the interspace or fissure between the auditory capsule and the front side of the occipital arch.

The multiperforate "meatus internus" for the 7 th and 8th nerves (VII., VIII.) has, beneath and in front of it, the projecting cochlea (chl.); and above it the arches of the anterior and posterior semicircular canals (a.s.c., p.s.c.), meeting in one common sinus; these can be seen shining thromgh the cartilage.

The lower alisphenoidal centre is deeply notched (above b.s.) to form an imperfect foramen ovale $\left(\mathrm{V}^{3}\right.$.) for the third branch of the trigeminal; the second and first branches $\left(\mathrm{V}^{1,2}\right.$. $)$ escape through the sphenoidal fissure-between the bulging alisphenoid and the concave posterior margin of the stem of the huge orbitosphenoid (o.m.). The lesser cranial nerves (3rd, 4th, 6th) escape also through this space, but the optic foramen (II.) is an oval hole pierced through the orbitosphenoidal stem. No part of the anterior sphenoid is ossified at present, nor any part of the nasal region.

The turbinal outgrowths of the proper olfactory region shown by the slicing away of the cartilage (fig. $5, u_{.} t b$ ) are very numerous; above and behind them, in the huge recesses for the olfactory lobes, the numerous branches of the 1st nerve are seen to be escaping through a membranous floor, which is having bands of cartilage formed in it (cr.p.), that pass round the various fissures through which the nervous bands escape.

The cartilage of the roof of the nasal labyrinth is shown in the main figure (fig. 1) as cut away from the large partition wall. In front, the alinasal region, behind the opening and near the mid-line, gives off a curious "recurrent cartilage" (rc.c.) of a lanceolate shipe, and scooped along the outside, except in front, where it forms a tube.

These cartilages (right and left) protect "JACOBson's organs," which are partly encapsuled by them; these parts are related to two small bones and to the vomer, as I shall show soon. In the figure of this vertical section the frontals and parietals $(f . p$.$) are shown, helping to fill in the great fontanelle; the nasals (n$.$) are seen over$

* In Birds, generally, and in many Rodents, the alisphenoid is formed from two osseous centres, but in a manuer very different to what is shown here. 
the septum nasi $(s . n$.$) ; the vomer \left(v_{0}\right)$ under it, and the palatine plates of the maxillaries and palatines $(m x$, pa.) are shown as forming the lard floor to the shallow naso-palatine canal. The "fuult" in the skull wall, where the small alisphenoid is thrust out, is partly filled in externally by the squamosal (sq.).

\section{First Slage (continued).- Tisceral arehes of Tiatusia hybrida.}

This stage, although more advanced than some I have been able to work out in certain Insectivora, is yet very valuable anl instructive; the two mandibles-the outer and the inner-are naw well developed, but the peculiar Mammalian transformation of the inner mandible has not yet taken place.

The superficial rumus.(Plate 2, fig. 3, d.) is full fon times the bulk of the primary articulo-Meckelian rod $(m k)$, and reaches backwards nearly to the thick articular region.

A row of small alveoli is seen in front of the coronoid process (cr.pr), which is peculiarly long and slender, and forms an acute angle with the condyloid part (cd.p.), a semi-oval mass of cartilage. The tip of the coronoid process is also cartilaginous, and so is the edge of the feebly developed angular process (ag.p.).

MECKEL's cartilage - the inner or primary mandible-is a very uniform terete rod, lying all along the inner fuce of the ramus, near its lower edge; it follows the sinuosities of the ramus up to the "mentum," where it is confluent with its fellow (fig. 2, mk.).

At this confluence there is developed a tongue-shaped non-segmented rudiment of a basimandibular element (b.mn.); this is more distinct in the Insectivora than in the Armadillos. There is no appearance, at this stage, of a distinct splenial, or of a distinct coronoid, bone inside the ramus, in this type. There is, however, here, as everywhere in the Mammalia, a very large tract of cartilage on which the hinder half of the dentary is formed, and out of which the new articular focet, that on the lower edge of the squamosal, the "glenoid" facet, is also developed.

'This subcutaneous slab of cartilage is manifestly the homologue of the lower labial of cartilaginous Fishes, as much as the bone itself corresponds with the anteroexternal splint of MEckeL's cartilage in Ganoids and Teleostei, the Amphibia and the Sauropsida - the well-knawn "dentary."

A preparation of the whole auditory and articular region of the skull shows many things in their proper relations (fig. 4). Part of the squamosal (sq.), with its glenoid facet $\left(g l . f_{0}\right)$, is figured, and the condylar $\left(c d . p_{0}\right)$ and angular part of the rumus or lower jaw, with its solidly cartilaginous hinder margin.

MECKEL'S cartilage, large and solid, is seen ruming along a groove on the inner face of the ramus, and in the other direction shows itself as a large pars articulare, with its sinuous condyloid face for articulation with a remarkable form of quadrate-now, evidently, the "incus," before ossification.

As in the Fowl and many other Birds, there is a long "internal angular process" to 
the articular region, and a pudiment of the well-known avian "posterior angular process;" in Mammals the former is called the "uanubrium of the mallens." Under the proximal part of MECKEL's cartilage, where it becomes the massive articular region, there is an ectosteal deposit--the well-known bony tract which develops into the articulare in oviparous types, often having an endosteal centre added to it, it is the "articulare externum" (Plate 2, fig. 4). Here it forms the outer rudiment of the bony malleus; it is partly hidden by the "amulus" (a.ty.).

In comparing the next or proximal segment of the first visceral arch with that of the Bird-the quadratum - there are two things to be noticed: first, that the "orbital process" is suppressed; and secondly, the head of the segment is articulated with the cranium further forwards than in most Birds. *

There is a neat head to the upper crus of this cartilage, called in human anatomy the "short crus of the incus" (s.c.i.), and this fits into a neat cup in the cartilarge of the ear capsule, above, just between the ampullæe of the anterior and horizontal canals (a.s.c.,h.s.c.). Below and behind the saddle-shinped condyle, the body of this segment narrows into the "long crus" (l.c.i.), and this part acquires an inturned "neck," very slender, which carries a discoid head-the pars orbiculare.

'This is another and new', or Mamnalian, character; here the top of the first visceral arch keeps outside the top of the second, as in Fishes, generally, and amongst the Sauropsida in the Chameleon (see Trans. Zool. Soc., vol. xi, plate 16, figs. 4 and 7); whereas in many Amphibia and Sauropsida the topmost hyoid element-the columella-rides over the quadrate.

The great specialisation which these parts have undergone, which they show so early in the embryo, is seen in the tilted position of the semicircular canals (a.s.c., h.s.c., p.s.c.) ; for in relation to the axis of the skull, the horizontal canal is almost vertical, and the two vertical canals are quite oblique in position. Thus the hinder part of the "tegmen tympani" $(t, t y$.$) fornis a recess for the stapes (s t$.$) and its muscle$ $(s t . m$.$) ; this is quite like the recess formed by the paroccipital wing in the Bird's$ skull.

The form of the stapes (which will be shown in the next stage) is quite normal; it is a short, flat, perforated column, the oval base of which fits accurately into the fenestra ovalis. In this figure it lies in the shade, within the incus, and the stapedius muscle (st.m.) is seen arising, tendinous, from its neck, and enlarging, backwards, to be inserted, fleshy, in the bottom of the recess at the back of the tympanic cavity.

As the parts in this early stage were newly, but completely, chondrified, I had a good chance for seeing the exact relations of the parts of the hyoid arch.

The stapes, as the counterpart of the Skate's hyomandibular, chondrifies separately ; it is the only pharyngobranchial element developed in the walls of the Mammalian

* I lay stress npon further forwards; no one has ever drenned of putting the Bird's quadrate into the hyoid category, notwithstanding that its articulation with the occipital arch is partly belind the aulitory rapsule. 
throat. In the Skate (Pristiumus, see Trans. Zool. Soc, vol. x., plate 35, fig. 4) all the pharyngobranchials are developed (chondrified) independently of the rest of the arches to which they belong, which for the most part undergo secondary segmentation into more or fewer joints.

Here the segmentation of that part of the arch which in Fishes carries the gills is more than normal; the feebly developed epihyal (c.hy.) is in two imperfectly divided joints, and the strong ceratohyal (c.hy.), which is imperfectly segmented from the lower epihyal, is completely cut across at its lower third.

Below this part there is the normal (ichthyic) hypohyal (h.hy.), the shortest of the segments. *

The basal part is a trifoliate basi-hyobrunchial $\left(b . h . b r_{0}\right)$, to the fore angles of which the hypohyals are articulated, and which gives off a pair of hypobranchial rudiments, and a free retral rudiment of the long, segmented basibranchial bar of Fishes.

I found only one inner segment of the opercular growth round the first cleft; the "concha auris" becomes tubular in the meatus externus, and partly segmented; the innermost segment in this case forms an imperfect ring, and its softish cartilage is rapidly becoming ossified to form the normal annulus tympanicus ( $a, t y)$, in a groove of which MeckeL's cartilage lies at its proximal end. 'The upper end is most ossified, the membrana tympani ( $m . t . \%$ ) is inserted into its immer face, and the radiating fibres of this membrane start from the internal angular process of the primary mandible (the manubrium mallei). The tensor tympani muscle $\left(t . t_{.} m_{0}\right)$ is manifestly the counterpart of one of the "adductor muscles" of the hinder part of the mandible of a Reptile or Bird.

This muscle, and the "stapedius," want tracing downwards; they are the accurate muscular correlates of the curiously specialised skeletal elements of this part of the skull.

\section{Vertically-transverse sections of the head of Tatusia hybrida.-First Stage.}

The figures given in Plates 3, 4, and the following descriptions must be compared with the figures and descriptions of the bisected and dissected chondrocranium; the latter is of a later stage (Plate 5, fig. 1).

Before going into details, I may remark that the huge nasal capsules that take up half the sections selected to be figured lie under the fore part of the skull, so that the floor on which the olfuctory lobes lie is the roof of the hinder and more important part of the nasal labyrinth. The septum between the two halves of this labyrinth is mainly formed of the intertrabecula, but the thicker part of the septum, where it is becoming lower behind, has the cornua trabeculie confluent with the azygous bar.

* In this, as in my former papers, the "hyomandibular," in all its modifications, is treated of as part of the hyoid arch. In ancestral forms it may have been a distinet areh (see AnTon Donkn's 'Studien,' 1885). 
There is no complete nasal floor, except close behind the external nostrils, in front, and in the blind end of each capsule, behind, where the presphenoid lies between each space: the cavities, there, right and left, being the embryonic form of the "sphenoidal sinuses."

To make these numerous and complex figures more intelligible, the related parts are merely indicated; the skeletal structures are the parts to be brought into prominence.*

1 st Section (Plate 3, fig. 1).-This section is through the end of the snout at the opening of the nostrils and in front of the lower jaws. 'The broad upper part passes sinuously into a narrower lower part, which has a concave outline below. The septum nasi $(s . n$.) is complete, and has two narrow wings below, that belong to the floor $\left(n . f_{0}\right)$, and wide arched wings above $(a l . n$.), bifid at their lower edge. The section of the prenarial cavity $\left(n . p_{*}\right)$ is lunate, for there is here the beginning of the thick valvular cushion of the nostril.

2nd Section (Plate 3, fig. 2).-This section is from behind the nostrils, but close to them; here the palatal hollow begins.

The septum $(s . n$.$) is thin in the middle at this part, and the alinasal roof-tracts$ are sharp at their lower edge. The two dilatations of cartilige below the septum are confluent here, and right and left of the solid foot there is a large pouch-shaped recess to the nostril (n.r.); this narial recess runs through several sections, showing that it, is of considerable width. At the top, the septum is beginning to dilate, and a valvular wing of the lining membrane is seen in this dilatation.

The narial valve $\left(n_{0} v_{0}\right)$ is very large here, and contains a section of a finger-shaped process of the alanasi. In the following sections this passes into the general cartilage, so that it is not a separate segment.

The nasal bones (n.) come into view as far forwards as this section (see also Plate 2, fig. 1), for they run well over the snout.

3rd Section (Plate 3, fig. 3). - This is through the whole fore face, for it takes in the top of the tongue $\left(t y_{0}\right)$ and the beginning of the lower jaws, where MEckEL's cartilages $(b . m n$.) are confluent. The septum uasi (s.n.) is very thin in the middle, but is expanded above; below, it stretches into a limited Hoor, flat below, and not far from the wide proximinal part of the valvular process, which supports the many-Jobed valve (n.v.). The nasal bones (n.) only are seen in this section.

4th Section (Plate 3, fig. 4). - In this section the Meckelian rods (mk.) are separate, the dentaries $\left(d_{0}\right)$ are cut across, and a tooth-socket $\left(t_{0}\right)$ is seen above each bone; above, the nasals $(n$.$) are seen. The septum nasi still thin below, is winged$ above, and these wings are the skeleton of a large upper narial lobe. The lower valve is smaller, but the whole passage is narrowed by folded thickenings of the lining

* These sections, and the rest of the thin transparent stained preparations of this kind, were made for me by one of my Sons, and the camera drawings of them by another; about one-sixth of the 163 sections made of this one head were drawn; only three-fifths of each drawing has been engraved. 
skin. The valvular process of cartilage is seen here to be merely a part of the wall, and there is but a small space between this aud the oblique flonr-tract attached to the bottom of the septum. Two of the foremost of a series of glandular crypts (gl.c.) are cut across, the larger of these is lodged between the side and floor.

5th Section (Plate 3, fig. 5).- About six of the sections made at this part show a complete double nasal tube, for here the wall, valvular process, floor, and septum, are all confluent. Here the septum $(s . n$.$) is much thicker throughout; it still retains the$ winged growth above, and the valvular folds of the lining skin are very numerous. Here the thickened septum is of less vertical extent, and the thick ends of the floor drop from their point of union with the septum. There is a crypt (gl.c.) here under the valvular process, and another at the upper third of the wall, between it and the lining membrane. The nasals $(n$.$) are wider here.$

6th Section (Plate 3, fig. 6).-At this part the floor of the alinasal fold has again become free from the base of the septum $(\sin$.$) , which is of small vertical extent, but$ thick-thickest in the middle The upper alate enlargement is gone, but the fold of skin is still large, and runs out transversely. This is the lust section showing the fold in the narial valve (n.v.), and there is a wide and hollowed space between it and the part forming the imner floor. 'That part is now tubular, the top of the tube (ic.c.) being sharp and fitting against the base of the septum. Besides the two pairs of glandular crypts (yl.c.), there is, in each tube of cartilage, an apparently glandular body; this is "JACoBson's organ" $(j .0$.$) , a structure which will appear in several of$ these selected sections.

Snall points of bone are now apparent beneath the nasal canal, right and left, these are the premaxillaries $\left(p x_{0}\right)$; the nasals $\left(n_{0}\right)$ are still seen above.

7th Section (Plate 3, fig. 7).-This section is Lehind the alinasal, in the fore part of the aliseptal region. 'The thickening which showed itself in the middle of the septum in the last section is now at the base; it is due to the fict that the intertrabecula is essentially a roundish and somewhat compressed bar of cartilage, which has shot up into a thick crest to join the roofs of the nasal capsule $(a l, s p)$. The middle valvular fold has now sunk down so as to be opposite the base of the septum; between it and the

\footnotetext{
* For accounts of the structure and meaning of this part the reader is referred to the "Bibliographical I ist." In my earlier papers on the skull my attention had not beeu directed to this part, and I was not then aware of the curious modification of the fore part of the shull cansed by it. In the paper on the Pig's skull (Phil. Trans., 1874, Plates 28-37) the supporting cartilage is figured and described as the "recurrent cartilage"-a name I shall retain. In the nore recent papers on the skull of the Snake (Phil. Trans., 1878, Plates 27-33), and in that on the skull of the Lizard (Phil. Trans., 1879, Plates 37-45), I have called the pair of JAConsox's organs by RathkE's term, namely, "nasal glauds;" this, however, is a misleading term, as they have nothing to do with the nasal glands of Birds. In the Snake and Lizard these parts are protected by cartilage derived from the alinasal region, but they are actually encapsuled in a pair of curious bones; these are the paired vomers, which form the "dish" and the septomaxillaries that form its "cover." The anterior puired romers are rery constant in Mammals; but I have not jet found the septomaxillaries in any member of this Class.
}

MUCCCLAXIY. 
outer fold the nasal canal is deep. The outer fold is not the same as in the last section; it is not a valvular fold of the external nostril, but the beginning of the "inferior turbinal" (i.tb.), and is formed as a pedate enlargement of the upturned wall. The cartilages protecting "JACobsov's organs" (j.o.) are no longer tubular, but form lialf" a tube, open externally, the organ lying in the outer hollow. But the cartilages themselves have an osseous counterpart protecting them on the inner side, and having their shape and direction; these are the "anterior paired vomers" $\left(v^{\prime}.\right)$, bones well known for their large development in the Ophidia and Lacertilia; they do not represent a divided "vomer," proper, which in nearly all Mammalia is well developed also, and begins above these bones, as the next section well shows. Two pairs of "crypts" are seen still, in section, and besides the large section of the nasal bones $\left(n\right.$.), we have the hinder edge of the premaxillaries (see Plate 2, figs. 6 and $8, p x_{0}$ ).

The palatal vault is very high here, it is partly occluded by the tongue $(t g$.$) ,$ below which the lower jaws are seen each with its Meckelian rod (mk), its dentary bone $\left(d_{\text {. }}\right)$, and its tooth socket (t.).

8th Section (Plate 3, fig. 8). - This is through the angle of the mouth and the middle of the inferior turbinal. The sertum nasi is here one-third deeper than in the last, and is more definitely bulbous below. The roof passes into at deep wall which ends in the inferior turbinal; this is two-lobed, now, and each lobe is convex in its inner and upper face; the wall of the nose is sharp below the turbinals.

The recurrent cartilage (r.c.) is largest at this part, and so are the small anterior paired vomers, but JACOBson's organ has the same diameter, nearly, as in the last section. Here the bifid fore end of the true vomer is cut across, close beneath the intertrabecular cartilage. The crypts (gl.c.) still appear, so that there are two rows of them on each side. Here the section of the nasal $(n$.$) is large, and the fore part of$ the maxillary $\left(m x_{0}\right)$ is cut across on each side; this bone appears in two parts ; this is because of the beginning of the alveolar groove, which runs between the lateral and palatine portions of the bone (see Plate 2, fig. 6).

The section of the tongue (tg.) is large here, and the dentary bone $(d$.$) outside$ MECKEL's cartilages ( $m k$.) is in several laminæ.

9th Section (Plate 3, fig. 9). - This section, of which more than halt is figured, and druwn on a smaller scale than the first eight, brings us into an increased complexity of the nasal libyrinth. The septum $(s . n)$ is like that of the last section, but the roof of the labyrinth is much flatter, and besides the more developed inferior turbinal, there is now the nasal turbinal $(n . t b$.), which runs obliquely from the roof to the side wall, enclosing a long oval space. In the main channel, inside this space, there is a free section of cartilige, it is triangular, and has its apex looking upwards, this is a "precurrent rrocess" of the middle turbinal (see also fig. $9 \Delta$, pc.c.); it is equally developed in these types, and in the Insectivorous Hedgehog-its largest growth is seen in the Aard-Vark (Orycteropus, Plate 15).

This section is near the cnd of JAconsor's organ and its related cartilages; but the 
proper romer $(v$.$) is now a large trough of bone composed of several lamince. 'The$ nasals and the maxillaries $(m x$.) are still seen in section, and below we have the dentary with its increasing laminæ, and MECKEL's cartilage ( $\left.m k_{\circ}\right)$.

10 th Section (Plate 3, for fig. 9A. read 10)-This is from a very slight distance belind the last, it: is given to show how soon the nasal turbinal ( $n . t b$.) becomes free below. In both this and fig. 9 the glandular crypts (gl.c.) are seen to be increasing in number, and to be crowding between the Schneiderian membrane and the cartilage.

11 th Section (Plate 3, fig. 11).-Here we see that the most complex part of the rasal labyrinth lies beneath the cribrifurm plate; the olfactory fibres (I.) are here seen entering from the olfactory lubes or "rhinencephala" $\left(\mathrm{C}^{16}\right)$. The septum here is the perpendicular ethmoid (p.e.) ; it is thinnish above, and very bulbous below; the crest above is the "crista galli."

The floor of the fore part of the cranium is here only perfect near the septum; but the cartilage increases, laterally, so that the olfactory nerves then pass through holes, and not through chinks as at present (see Plate 2, fig. 5). Here the upper part of the labyrinth answers to the upper turbinal in Man, and the lower part to his middle turbinal. The cartilage at this part encloses a large oblique oval cavity, round which a perfect ring of glandular crypts are packed. The inner process of cartilage, which runs free from that ring, is the hinder or proximal part of the free precurrent cartilage seen in the last two figures (see fig. $9 \Lambda, p c . c$. ).

Here we see that, behind, the recurrent cartilage ( ${ }^{\circ}$ c.c.) protecting J AcoBson's organ overlaps this curious fore-growth of the middle turbinal, for its section is still seen above the edge of the vomer $(v$.$) .$

The bones seen above the labyrinth are no longer the nasals, but the frontals (see Plate 2, fig. 7, f.), which are very large plates in this type, whilst the nasals are rather short. The maxillaries ( $m x_{0}$ ) are very large, and have many laminæe at this part, and the palatine plates (above $m$.) nearly meet at the mid-line. But between the frontals and maxillaries there is the huge lacrymal (l.; see also Plate 2, fig. 8), which has a facial as well as an orbital plate.

MEckEL's cartiliges ( $m k_{\text {. }}$ ) are seen below, with their protecting dentaries ( $\left.d_{\text {. }}\right)$ which are developing a considerable amount of diploë, here, at the middle of the ramus (see Plate 2 , figs. 3 and $8, d$. .).

12th Section (Plate 3, fig. 12). - This is through the fore part of the hemispheres $\left(\mathrm{C}^{\mathrm{ln}}\right.$.) and of the eye-balls (e). The nasal roof is cut through behind the cribriform plate (see Plate 5, fig. 1), and this part of the nasal labyrinth is sub-cranial, and the proper cranial walls are above, and external, to this part of the turbinals which are reduced to two folds. The outer of these folds of the middle turbinal $\left(m_{0} t b_{0}\right)$ is fired, both above and below, the inner is free, above; they are both turned inwards and upwards. This part of the capsule has, in some degree, coalesced with the septum (p.e.) both above and below; its very bulbous form at the base is well shown; this is the last figured section that shows only the intertrabecula. Indeed, even here, it is 
possible that the foremost part of the paired trabecula may have helped to thicken the bulbous part.

At a short clistince from the nasal wall the fore part of the orbitosphenoid is shown in section; but furcher forwards (see Plate 5, fig. 1, o.s.) that wing is continuous with the nasal wall. Over these parts the frontal shows itself twice, above, where it lies over the flattish hemispheres $\left(\mathrm{C}^{1 \pi}\right.$.), and laterally, where the orbital plate protects the orbitosphenoid over the eye-ball (e.).

The nasal channels are almost reduced to two sub-oval naso-palatine canals, for here the skin covering the vomer ( $\iota^{\prime}$ ) lies very near the skin covering the halves of the hard palate.

Four bony sections are seen here; the two small upper pieces are the hinder forks of the vomer $\left(v_{.}\right)$, the outer and larger plates are the palatine bones ( $\left.p a_{0}\right)$, which extend round the passage, above and below. Below, these bones soon meet at the mid-line, like the maxillaries, carrying on the hard palate (see Plate 2, fig. 6, mx., pa.); above, they nearly touch the forks of the vomer. Under each eye-ball there is a bony section, flattish and upturned externally; this is the jugal $(j$.$) . Nearer the mid-line the$ large high dentary $(d$.$) is seen, and inside its lower part MECKel's cartilage (m k$. $)$.

13 th Section (Plate 4, fig. 1).--This partial figure shows a very long part of the frontal bone $\left(f^{\circ}\right)$ and a lirger amount of orbitosphenoidal cartilage (o.s.), confluent, here, with the outside of the narrowing nasal labyrinth, but at a distance from its own root, the presphenoid. The median cartilage is still the perpendicular ethmoid (p.e.), and its shape here is very instructive; the extension of the cartilage below the nasal labyrinth is due to the addition, right and left, of a wedge-shaped tract-the comu trabeculæ to each side of the bulbous, crested intertrabecula.**

The cavity of the nasal labyrinth is now reduced to three small recesses, the outer nearly obsolete; and the folds of the middle turbinal $(m . t b$.) are confluent with both wall and Hoor, and look inwards and upwards. Here the top of the intertrabecula has lost the crest (crista galli); the cartilage here, behind the cribriform plate, is lowering towards the presphenoidal region.

In the last section the upper part of the mucous membrane lining the naso-palatine canals almost rested upon the lower so as to divide them imperfectly. Here these folds are more separated in the middle, and the canal (n.p.c.) is single, shallow in the middle and deeper at each end. Outside this common canal the pterygoid bone ( $p y$.) is seen merely hooking round the passage in a crescentic form.

The high coronoid region of the mandible $(d$.$) is here cut across, and MEcker's$ cartilage $\left(m k_{*}\right)$ is seen lying on the inturned lower edge; the jugal $(j$.$) still comes$ into section under the eye-socket.

$14 t h$ Section (Plate 4, fig. 2). - This is through the widest part of the orbito-

* This part is explained by what is seen in the early choudrocranium of the Turtle and the Crocodile (see 'Challenger Reports,' Zoology, vol. 1, plate 5; and 'Trans. Zool. Soc., rol. 11, plate 64, fig. 5; and plate 65 , figs. $2,3,7$ ). 
sphenoid (o.s.), which appears in the figure to be cut oft from its base; this is due, however, to the fact that this section is through the sphenoidal fissure. Here the basal part $(p . s$.$) is spindle-shaped in section; this is due to the fact that the trabeculpo$ are here adding their thickness to the solid intertrabecula, and that they are giving off the orbitosphenoids, which, here, are not continuous with their root. The frontal $(f$.$) is broad, and curls round the orbitosphenoid, into the orbit. Here the$ pterygoids $(2 g$ ) are very solid, and protect a transversely elliptical space, the nasopalatine canal (n.p.co). Above and outside each pterygoid, a small $V$-shaped section of bone is seen; this is the foremost part of the lower alisphenoidal centre (see Plate 2,

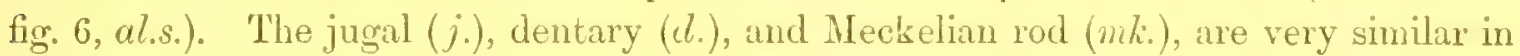
this to the last section.

15 th Section (Plate 4, fig. 3).-Here the presphenoid (p.s.) is far separated from the large upper band of the orbitosphenoid (see Plate 2, fig. 1, o.s.) ; its triple form answers to its compound nature, formed as it is from a bulbous middle, and two wedge-shaped, lateral, pieces-the intertrabecula and the trabeculx. The Mammalian type of skull is seen here, for the alisphenoid (al.s.) uverlaps the lower part of the orbitosphenoidal region, and lies a good distance outside it. There is a thick core of cartilage at this part, with an ectosteal deposit on its upper edge, the foremost part of which was seen in the last section. 'The naso-palatine canal (n.p.c) is kidneyshaped in section here, the "hilus" being above. On each side of this passage the pterygoids $(p g)$ are seen to be very thick in this their hinder part. Laterally, the point of the zygomatic process of the squamosal $(s q$.$) is seen riding over the hind$ part of the jugal $(j)$, and, inside this, the ramus of the mandible is seen to be composed of a mass of hyaline cartilage, besides the bony dentary (d.) which protects Meckel's $\operatorname{rod}(m k$.$) .$

16th Section (Plate 5, fig. 4). - We are here in the widest part of the hemispheres, and the tore part of the pituitary body (py.) is cut through. Beneath, the basal cartilage is composed of the beginning of the trabeculx $\left(t r_{0}\right)$, and it is seen to be double not triple.*

This prepituitary part of the busisphenoid $\left(b_{.} s_{n}\right)$ is cut across close in front of the narrow pedicle of the alisphenoid (see Plate 5, fig. 1, al.s., b.s.), in the innermost part of the sphenoidal fissure, so that the cartilage appears in two pieces on each side of the basal mass. 'The alisphenoid is not merely calcifying; it is being rapidly converted into bone, within, and, externally, has two thick ectosteal plates on it, an npper and a lower alisphenoidal bone (see Plate 2, fig. 6, and Plate 5, fig. 1, al.s.', al.s.). The parts of the mandible and face are like what are seen in the last section; but the naso-palatine canal (n.p.c.) has now opened into the fauces. 'The upper band of

\footnotetext{
* In these decalcified sections the lime-salts were removed, but the cartilage cells were bccoming calcified (see Plate 2, fig. 1, b.s.) as the basisphenoidal bone. In the 19 th and 20th Sections (Plate 4 , figs. 8,9$)$ the same is true of the middle of the basioccipital region.
} 
cartilage (o.s.) running from the orbitosphenoid to the auditory capsules still retains its breadth, and is protected by the frontal bone $\left(f^{\circ}\right)$.

17 th Section (Plate 4, fig. 5). - This section is through some very notable parts of the skull and its contents. The hemispheres are here at their widest part, and, below, the pituitary body $(p y)$ is cut through. Here is the wide spheno-auditory fissure (see Plate 2, fig. 6, and Plate 5), over which the large Gasserian ganglion (V.) lies.

The frontal $(f$.$) still protects the posterior band of the orbitosphenoid \left(o_{*} s_{0}\right)$, and below this an infero-lateral bone comes into section, namely, the squamosal (sq.), just where it is forming a broad part for the hinge of the lower jaw (cd.p.). Here this bne helps to form the cranial wall, in the re-entering angle between the frontal and parietal (see Plate 2, fig. $8 ; f, p_{\text {. }}$ ). The dentary bone (d.) and Meckel's cartilage $(m k$.$) are seen below that mass of superficial curtilage. The dentary \left(d_{\text {. }}\right)$ at its angular part here comes clnse to the pyriform cavity exposed at this part-the tympanic cavity (c.ty.); the broad end of this open section is below, and the narrow upper end turns a little outwards.

Below this space the epihyal cartilage (e.hy.) is cut across. Here the faucial passage is very narrow below; above it, the basis cranii is near the basioccipital region close behind the postclinoid elevation. The notochord $\left(n c_{0}\right)$ lies helow, in the primary chink between the two parachordal tracts; and its end is hooked downwards (see also Plate 3, fig. 13, nc.), a state of things first shown by BALFour in the Shark ('Elasmobranchs,' p. 209, Plate 14, figs. $9 \mathrm{~A}$ and 16A); and then by me in the Green 'T'urtle ('Challenger' Reports, Zoology, vol. i., plate 8, figs. 6 and $6 \mathrm{~A}$ ).*

The interauditory part of the basis cranii is, lore, twice as wide as it is thick; it is hollow above, and convex below ; the latter part being split, and having the notochord in the fissure. 'The bulbous end of the cochlear part of the auditory capsule (see fig. 6, chl.) is here cut across, just exposing the spiral cavity, and showing the apiculated fore end.

18 th Section (Plate 4, fig. 6).-The hemispheres $\left(\mathrm{C}^{1 a}\right.$ ), the mid-brain $\left(\mathrm{C}^{2}\right)$; the infundibulum, and the pituitary body $(p \%)$ are still seen (for the sections are a little oblique, and they incline downwards and backwards), but the basis cranii is cut through close bebind the postpituitary wall or elevation. The hinder part of the Gasserian gunglion (V.) is cut through, and under this the cochlea (chl.) has its cavity exposed; the notochord ( $n c_{0}$ ) is seen in the chink below, in the solid basinccipital cartilage (b.o.).

The backward extension of the orbitosphenoid (s.a.c.) is still seen, overlapped here by the parietal $\left(p_{0}\right)$. The squtmosal $(s q)$ is cut across behind the glenoid cavity, and below and within this part, at a moderate distance, Meckes's cartilage ( $m k$.) is still seen in section. Under and inside it there is a small crescentic tract of bone; this

* Whatever theory may tum out to be true as to the nature of the prepituitary part of the skull-the trabeculo and intertrabecula - we have here a most valuable landmark, for the down-turned end of the notochord is certainly the cephalic termination of the axis of the rertebrated creature. 


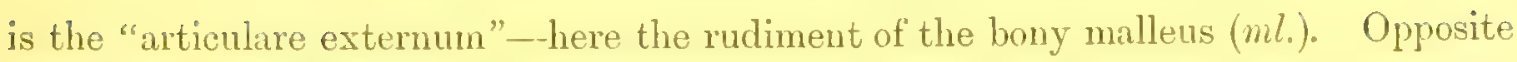
these parts the outer skin is somewhat enfolded; this is the beginuing, or fore margin, of the external auditory meatus (m.a.e.). The tympanic cavity (c.ty.) broadens towards MEckeL's cartilage, and has a concave upper border; it is very large at this part, and has the epibyal (e.hy.) below its lower, inturned recess.

19 th Section (Plate 4, fig. 7). - This is from a short distance behind the last, and is through the posterior clinoid wall, which is low and indistinct. The cochlea (chl.) is laid open at its anterior third, and the cartilaginous capsule is perforated above, and notched laterally, for the facial nerve (VII). Through the obliquity of the section the pituitary body $(p y$.) is still seen from behind; the internal carotid arteries (i.c.) are entering, right and lett.

The basis cranii is here at its narrowest part; this is the region of occipito-sphenoidal synchondrosis. The wall-cartilage is here of great depth; this may be called the supra-auditory tract of the chondrocranium (s.c.c.) between the hinder orbitosphenoidal band and the completed occipital roof (Plate 5, fig. 1). The squamosal (sq.) and the parietal (p.) are here seen cut through; the latter also reappears opposite the involution of the skin forming the outer ear. MEckel's cartilage is here seen where it is giving off the "manubrium mallei," and the bulbous form it has at this part gives the section the appearance of discontinuity between the head and the handle; this is corrected by the figure of the dissection (Plate 2, fig. 4).

This internal angular process of the lower element of the first arch is seen to push the lining of the drum cavity before it, in its growth downwards and inwards. Under and outside the cavity patches of cartilage are seen; these are parts of the annulated meatus, and the inner ring, on which the "os tympanicum" or cumulus is forming.

Below the cavity, the epihyal is seen cut across; below it the chorde tympani branch of the facial nerve was seen in section, and from the manubrium mallei the tensor tympanic rascle $(t . t m$.) is seen passing inwards and upwards.

20th Section (Plate 4, fig. 8). - The supratauditory cartilinge is not continuous, here, with the capsule; this tract is protected by the parietal $(p \cdot)$, and below the parietal a part of the squamosal (see fig. $7, s q$ ) is cut across. The large lateral lobes of the hemispheres are seen to cover the mid-brain; below this the basilar artery $\left(b . a_{0}\right)$ is seen, and right and left of the basis cranii the internal carotids (i.c.) are entering. Here the basioccipital cartilage (b.o.) is like a thick warped plank whose convexity is below. The space between the capsule and the basal part, which was slight in the last section, is widened here, and will become considerably wider where the 9 th and 10th nerves emerge.

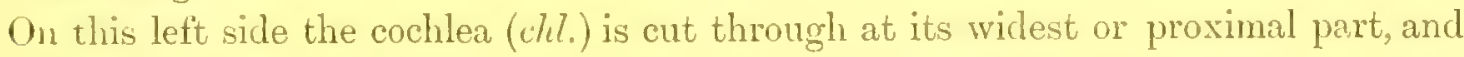
the tegmen tympani growing out from it covers the emerging facial nerve (VII.). Here the malleus $(\mathrm{ml}$.) is sectioned so as to show a continuous growth of curtilage from the head down to the end of the manubrium, the inturned end of which lies on that part of the infolded sin which becomes the membrana tympani. Under the crescentic 
cavum tympani the meatus (m.a.e.), at its proximal part, is cut through and is cartilaginous and partly bony; this is the "annulus;" below this is the epihyal (e.hy.), and below this the chorda tympani.

21st Section (Plate 4, fig. 9).-- In this section the inner wall of the capsule is broken up into three tructs, for here the related nerves (VII., VIII.) enter.

On its inner face the capsule appears very solid, this is partly due to the obliquity of the section, here, as we are at the proximal part of the cochlea, where it opens into the general vestibule $(\%)$. The outer face of the capsule is very broken up here, and there are several small tracts of curtilage to be accounted for. Below the narrowed end of the inner wall of the capsule the tympanic cavity (c.ty.) is seen as a large oval space, enlarged a little upwards; below this the ammulus is still seen, and outside that one of the imperfect rings of the meatus $\left(m . \alpha_{*} e_{0}\right)$; further outwards at the edge of the section the folds of the outer skin, at the passage of the ear, are shown.

Two fenestre are cut through in the infero-external wall of the capsule, these are the fonestra rotunda $(f, \%)$ below, and the fenestra ovalis $(f s .0$.$) above; the latter is$ partly occluded by a cartilaginous plate, the stapes (st.), which, being perforated by the stapedial artery $\left(s \alpha_{0} \alpha_{1}\right)$, appears in two pieces, these are the base and neck of the stapes; to the latter a short nueleus of cartilage is seen to be articulated, and a joint cavity exists between the two. Here we have the inturned, orbicular part of the long crus of the incus (l.c.i.)

Under the lessened tegmen tympani $\left(t . t y_{0}\right)$ we see a round tract of cartilage; this is the short crus of the incus (s.e.i.).

22nd Section (Plate 4, fig, 10).--This is from a part close behind the last section, and the description just given may serve, on the whole, for this. The head of the malleus is hidden by the short crus of the incus, and the cartilage is deficient in some degree. The facial nerve (VII.) is seen passing into its canal beneath the tegmen. The cartilaginous matrix of the "tnnulus" is shown for half its extent, and part of what seems to be another annulus belonging to the meatus is seen, both are lettered as meatus-cartilages (m.a.e.).

The three main openings of the capsule are still seen, namely, the meatus internus for the 7 th and 8 th nerves (VII., VIII.), the fenestra ovalis (fs.o.) with part of the base and one of the crura of the stapes (st.) in it; and, below, the fenestra rotunda $(f . r$.$) . Only the top of the incus (s.c.i.) is seen on the outside of the capsule, and over$ the stapes the facial nerve (VII.) is passing out. The flattening basioccipital cartilage (b.o.) is coalescing with the capsule on this side,

23rd Section (Plate 4, fig. 11). - This is a rery instructive section, showing the relation of the visceral artilages to the auditory capsule. 'That capsule is laid open in the fore part of the internal meatus, and the facial nerve (VII.) is seen from behind as it enters the cupsule, burrowing through it, and then reappearing over the incus (i.) under the tegmen tympani. Its chordia tympani, or mandibular branch (VII.'), is seen below the epilyyal before it crosses over (ontside) it to join the 
third branch of the trigeminal. On the inside the capsule and basioccipital cartilage are largely confluent at this part, but this is only for a short distance, between the ingoing of the internal carotid and the outgoing of the 9 th and 10 th nerves. The huge, swelling cochlea (see Plate 2, fig. 6, chl.) causes part of the floor of the capsule to appear, in this section, to be seen below the junction of the capsule with the base. Outside this part the fenestra rotunda $(f . r$.$) is cut across, and then, above it, the$ fenestra ovalis $\left(f_{s .0 .}\right)$, plugged with the base of the stapes which is cut through, so as to show the stapedial artery $\left(s_{.} a_{0}\right)$ in its hole. Here the incus $(i$.$) is severed through$ its body and long crus, so as to show it entire. The annulus and a large part of the meatus (m.a.e.) are seen here as cartilaginous bands. The tympanic cavity (c.ty.) is lessening. (This section is in front of the last two (figs. 9 and 10) for the supra-auditory cartilage (s.a.c.) is separate from the capsule; it should have been described before them).

$24 t h$ Section (Plate 4, fig. 12).-Here we are behind the cavum tympani, in the hinder part of the junction of the capsule with the basioccipital, for the 9 th and 10 th nerves are here cut through (but not lettered). Under the ascending cartilaginous wall, where the cartilage has thickened into the wall of the capsule, the anterior semicircular canal (a.s.c.) is cut across.

A large, irregular, open space is seen, the vestibule $\left(v b_{0}\right)$, and in the wall behind it, on the outside and below, the facial nerve (VII.) is seen emerging behind the epihyal, which is seen here in its union with the capsule. The front face of this section has been drawn; the small recess, here, is the back of the tympanic cavity, and the insertion of the stapedius muscle is seen below the hole for the escaping facial nerve (VII.).

Part of the meatus externus (m.a.c.) is laid open, and in the wall of that tube one of the imperfect rings of cartilage is shown. The parietal ( $\left.p_{0}\right)$ and the squamosal $(s q$.$) are cut through laterally, and, below, the fore edge of the atlas (vt.) comes into$ view, where it is overlapping the basis-cranii.

25th Section (Plate 4, fig. 13).-This section is somewhat oblique, both laterally and vertically. The mid and hind brain are cut through; the razor has passed close behind the basioccipital below, and in front of the supraoccipital above; hence the chondrocranium appears as two distinct tracts, right and left.

The supra-auditory cartilage (s.a.c.) is very deep here, and below its thick base we see the arch of the anterior canal $($ a.s.c.). This canal is also seen on the inner side of the capsule where it joins the posterior canal to form the common sinus; on the left side the horizontal canal (h.s.c.) is also cut across, and below it the ampulla of the posterior canal (p.s.e.; see also Plate 2, fig. 1). The formen for the two larger postauditory nerves shows part of the glosso pharyngeal (IX.), and of the vagus (X.) in situ, and that for the hypoglossal (XII.) does the same; the meatus-cartilage is cut across.

In my first Paper on the Mammalian skull - that of the Pig (Phil. Trans., 1874, Plates 28-37), the lateral internal view of the chondrocranium of the 3rd Stage MDCCCLXXXV. 
(Plate 33, fig. 3) shows the hugh orbitosphenoid as separate from the auditory capsule. It is so, afterwards, and in the 4 th Stage (Plate 34, figs. 5, 6) I have given perfectly correct figures. In the srd Stage the sections show the continuity of these tracts (Plate 32, fig. 6), but this upper tract was considered by me as part of the supraccipital roof. On the left side of the figure referred to, the cartilage $(s . o$.$) should$ have been lettered s.a.c.-"supra-auditory cartilage;" on the right that tract also lettered s.o. shows where the cartilaginous wall is passing into the occipital roof. My views as to the morphological meaning of some of the parts will be seen in this Paper to have undergone some change; I give here my last deductions.

I have not cumbered my description with mere details, although the actual sections tempted me to give a much more detailed account of the structures displayed in them. A comparison of the figured sections with the figured dissections will make everything plain, as every part may be identified and compared in the two sets of figures.

Dissection of the skull of Tatusia hybrida. - Second Stage (embryos, $2 \mathrm{in}$, and $2 \frac{1}{2} \mathrm{in}$. long).

This skull was dissected so as to leave all the investing bones in situ (Plate 2, figs. 6-8); part of it is shown as dislocated to display the hinder end of the mandible and the tympanic region (Plate 6, fig. 8). The endrocranium may be considered as altered very little since the last stage; the embryos, dissected, measured, not including their tail, the one 2 inches, and the other $2 \frac{1}{2}$ inches in length.

This somewhat more advanced stage is very valuable, however, with regard to the endocranium, for the bony centres formed in the cartilage are more perfect-not mere calcified tracts.

The lower view (Plate 2, fig. 6) shows the peculiar position of the outer nostrils (e.n.), namely, quite on the ventral aspect of the face; the Armadillos are terricolous in their habits. Behind and betreen the coiled valvular processes $\left(a l_{\text {. }} n_{0}, n_{0} v_{0}\right)$ the basal part is bilobate; from the back part of the double tract the protecting cartilages of JACoBson's organ (fig. 1, rc.c.) arise. In this figure they are hidden to some extent by two small bones lying one on each side of the mid line ( $v^{\prime}$.; see also Plate 3 , figs. 7,8$)$. These are the anterior paired vomers; they are thin, long shells of bone, concave within and above. Ontside these the small premaxillaries $\left(p x_{0}\right)$ are seen; they are notched below, and have no palatine process.

These parts lie in an angular space formed by the fore part of the huge maxillaries (fig. $6, m x$.); these latter bones have several well-marked regions; they extend from the premaxillaries to the zygomatic arch $(j$.$) , and then fork, behind, so as to enclose the$ fore margin of the open orbital floor. A long suture unites the two bones at the mid line, and outside this there are two parts of bone divided by a furrow which runs almost parallel with the median suture. Thus the palatine part is sub-distinct from the flange that grows from the alveolar region, with its double wall, its intervening imperfect tooth-sockets, and developing teeth. The maxillaries are scarcely seen from 
above (fig. 7), and, lying prone on the under part of the face, the infero-anterior orbital foramen, through which a large branch of the maxillary nerve $\left(\mathrm{V}^{2}\right.$.) passes, is well seen in the lower view.

The palatine bones $\left(p \alpha_{4}\right)$ are well developed, and they form two-fifths of the hard palate; their suture continues that of the maxillaries up to the front edge of the basisphenoidal region.

In general form they, together, suggest the shape of the human thorax as seen from the front, and are overlapped by the maxillaries that form their shoulder. In front, they interdigitate with those bones, and then have each a foramen in their front fourth; their "waist" is succeeded by a pair of small "haunches;" these are the pterygoids $(p g$.$) , smallish, thick shells of bone, which partly floor the naso-palatine$ canal, but do not meet in the middle. The ascending processes of the palatines and pterygoids are not seen in this view, but they have been described in the sections (1st Stage).

The orbital plates of the frontals $(f$.$) are seen in this view, and also the bones that$ form the zygomatic arch; these are the moderately large, but simple, jugal $(j \cdot)$, and the squamosal $(s q$.$) .$

Besides showing the orescentic, hollow glenoid facet $\left(g l_{f} f_{\text {. }}\right)$, this view gives us a good idea of the secondary, splint-like character of the latter bone, stretching from the jugal nearly to the occipital arch; it is beginring to be scooped out where it overlies the tegmen tympani $(t . t y$.$) . The hinder half of the endocranium is well shown in this$ view, obscured by no investing bones. In the openings of the orbits, below, we see the lateral ethmoidal masses containing the turbinals, and behind these the orbitosphenoidal cartilage (o.s.), perforated by the large optic nerve (II.). Overlapping that wing, and itself overlapped above and outside, we see the alisphenoid (al.s.), a half-opened fan of thick cellular bone, the handle of which is separately ossified. Between the handle and the orbitosphenoid we see the sphenoidal fissure through which pass the orbital and maxillary branches of the 5 th nerve $\left(V^{1,2}\right.$ ), and the $3 x^{2}$, 4 th, and 5 th orbital nerves.

In the hinder margin, behind the suture of the two centres of ossification, there is a large notch, becoming a formen; this is for the $3 \mathrm{rd}$ branch of the 5 th nerve $\left(\mathrm{V}^{3}.\right)$, and will be the foramen ovale.

The basis cranii is winged here, for the lower bone, forming the handle of the tan-shaped alisphenoid, does not ossify close up to the median beam; in that part, a little further backwards, a median bony centre, small and transverse, is seen; this is the basisphenoid (b.s.); it is below and in front of the postclinoid wall (see fig. 1).

The organs of hearing are highly developed in the Armadillos; here, right and left of the basis cranii, we see the huge cartilaginous capsules, with the special cochlear enlargement (chl.), larger, relatively, than I remember to have seen it in any Mammal of a moderate size; of course it is, relatively, very large in the smaller kinds of Bats.

In this view the cochlear bulbs $\left(c h l_{0}\right)$, the tegmen tympani $\left(t . t y_{0}\right)$ outside each, and L 2 
the lesser bulb forming the mastoid (opisthotic) region (op.) are all displayed; in the latter, the ampulla of the posterior, and the end of the horizontal canals (p.s.c., the latter is not lettered; it is in fig. 4) shine through the cartilige.

In the interspaces between these large ear-balls and the hind skull, the vagus and glossopharyngeal nerves (X., IX.) emerge, partly through the fissures, and partly in enclosing cartilage. The internal carotids enter the cranium between the cochlex and the basisphenoidal beam (b.s.). Under the tegrmen the facial nerve (VII.) makes its first exit, and then burrows the cartilage again, over and behind the junction of the epihyal ( $e . h y$.) with the capsule. Postero-extemally, the auditory capsule shows two large perforations, the foremost of these lies inside the hind part of the tegmen, and opens into the vestibule; this is the fenestra ovalis (fs.o.); the other, the fenestra rotunda $(f . r$.$) , opens into the cochlea \left(c h l_{\text {. }}\right)$ in the postero-lateral face of the first turu of the three-coiled "helix."

The basis cranii for the rest of the skull is half cartilage, spheno-occipital, and half bone, basioccipital (b.o.); this "centre" is oval, but truncated in front. Outside it, at a distance equal to its width, right and left, the hypoglossal nerve (XII.) burrows the solid cartilage of the base of the exoccipital wall. Behind this, at a like distance, the semi-oval condyles are seen (oc.c.), margining the huge sub-circular foramen magnum $(f . m$.$) , at its antero-inferior edge. The paroccipital thickenings outside the condyles$ are not large; the exoccipitals (e.o.) are beginning to harden the walls; and over the forumen magnum two tracts of bone are seen, the two supraoccipitals (s.o.).

In the upper view (Plate 2 , fig. 7 ) the parts seen are mainly superficial; the huge occipital roof, with its two ear-shaped bony centres (b.o.) are seen behind the great fontanelle $\left(f_{0 .}\right)$. In front, the roof of the alinasal region $(a l . n$. $)$ is but little shown, on account of the very forward position of the nasal bones $(n$.$) . These bones are nearly$ oblong, they project at the mid-line, in front, and are cut arvay, equally, behind; then they widen slightly. This region of the skull is like the narrow end of a gourd, and the rest may be likened to its bulbous part.

The frontals $(f$.$) , together, give a broad-waisted outline, being gently pinched in$ over the orbits; the parts there marked off are each as large as the parietals $\left(p_{0}\right)$, behind. Outside, the maxillaries, jugals, and squamosals $\left(m x_{0}, j ., s q.\right)$ are just seen ; the lacrymal (l.) also slightly. The fontanelle $(f v$.$) is still large and cruciform; it is$ pointed in front, and dilated behind.

But the side view (Plate 2, fig. 8) brings out the form and relations of the investing bones best; it also displays more of the inner skull; and with it the arches of the face are given. In front the alinasal cartilage and external nostril $\left(a l . n ., e_{n} n\right.$.) are seen; between the frontal and maxillary, the wall of the upper turbinal (u.tb.), and inside the orbit, at the bottom, in front, the wall of the middle turbinal (m.tb.).

Below the squamosal we see part of the capsule of the ear (chl.) where the tympanic should be; behind the squamosal, the opisthotic region with the enclused posterior 
canal (p.s.c.) shining through; below and behind it the occipital condyle (oc.c.) ; and above that the occipital arch and one of the supraoccipital bones (s.o.).

In this view the peculiar forward position of the nasals ( $n$.) ; the small infero-lateral premaxillary $\left(p x_{0}\right)$; the large maxillary $\left(m x_{0}\right)$, with its long nasal suture, its deficient upper facial plate, and its notclied jugal process, are seen. The infrarbital foramen $\left(\mathrm{V}^{2}.\right)$ is very low down; at a moderate distance above it is the large, shell-like lacrymal (l.), with an antorbital and a facial region, and the canal (l.c.) between. Here, as well as in the upper view, we see what a large amount of space is covered by the frontals $\left(f_{0}\right)$. The preorbital part of each bone is swelling, to fit over the huge, complex nasal capsule, and then, behind the supranibital "waist," the bone swells again to cover the hemispheres. The orbital plate is also very large, and hides most of the large orbitosphenoidal plate; the optic nerve (II.) can just be seen emerging from its stem. The parietals ( $p$.) are roundish shells, like the halves of a "bivalve;" they mearly reach the frontals in front, and rest upon the squamosals (sq.) below. These latter bones are nearly as large as the parietals, but of a very different shape. They reach nearly as far back, and much further forwards, but are not so deep. A large triradiate space separates the three main bones, here, below which the temporal fossa passes directly into the wide, gaping orbit. The zygomatic process of the squamosal is strong, and is clamped by the straight, thickish jugal $(j \cdot)$, behind which we see the edge of the glenoid cavity. The pustglenoid process is hollow, and of a triangular form ; the posttemporal process is rounded.

The lower jaw is very elegant, with its arcuate general ramus (d.) and its slender coronoid process separated by a narrow notch from the articular condyle, and the latter by a smaller notch from the angular process $\left(a g \cdot p_{0}\right)$; much solid cartilage still remains in these parts.

The endoskelctal part of this arch (Plate 2, fig, 8 ; and Plate 5, fig. 4) is of great interest. MEcket's cartilage ( $m k_{\text {. }}$ ) is full-sized, a long and solid rod, passing inwards and forwards to melt into its fellow in front. Behind the massive condyloid cartilage (Plate 5, fig. 4, cd.p.) the bony plate of the malleus is seen, under the dilating part of this primary jaw. The head of the malieus ( $m l_{0}$ ) has a very deeply scooped saddleshaped condyloid surface for articulation with the incus $\left(i_{*}\right)$; below this, the cartilage grows in a right angle to the main bar, and then forms the manubrium (m.mb.) by growing forwards again, as a slender terete rod. 'This is the "interual angular' process" of the Ovipara; but the posterior process $(p . a g$.$) is also to be seen as a$ tubercle above and behind the elbow of this long provess. On the inside, one-third the way up, we see the tensor tympani muscle (t.tmo). The incus $\left(i_{0}\right)$ has no ectostosis at present; its articular surface is a deep, oblique saddle; its short crus (s.c.i.) is a solid cone, and its long crus (l.c.i.) is large, long, somewhat constricted proximally, and supplied with a large inturned discoid ficet for articulation with the head of the stapes (st.).

That top piece of the hyoid arch (Plate 5, fig. 4, st.) is a solid little "stirrup," with 
a small round hole, a large face above for the incudal facet, and a thick dilated base ; the neck, with the stapedius muscle (st.m.), and interhyal (i.hy.) attached to it, is short.

Two changes have appeared in the arch of the hyoid; one is the complete fusion of the epihyal with the auditory capsule (see, also, Plate 2, figs, 4 and 8, c.hy.); and the other is the degeneration of the lower sub-segmented part of the epihyal into a ligamentous tract. The fused upper part has thickened; over it the chorda tympani (VII ${ }^{1}$.) passes from the facial nerve (VII.), behind.

The ceratohyal (chy.) has a larger upper, and a shorter lower, segment; then comes the thick ovoidal hypohyal $(h . h y$.$) , articulated to the trifoliate basihyo-$ branchial $\left(b . h . b r^{\circ}\right)$; the median lobe, here, is a rudiment of the long basibranchial series of the Ichthyopsida; the lateral processes are the "thyrohyals" (t.try.).

The annulus tympanicus (Plate 5, fig. 4, a.ty.) is forming out of a ligulate, $U$-shaped tract of softish cartilage,

\section{Endocranium of Tatusia hybrida.-Third Stage (embryo, 3 inches long).}

Although this embryo is one-third longer than the last, it has altered but little except in the size of the parts; yet some new osseous centres have appeared, and the others are more perfect. 'The endocranium, as seen from above (Plate 5, fig. 1), is a remarkable and a very complex structure. The basal line is occupied for the front two-thirds, by the huge nasal labyrinth; a large space, right and left of the remaining third, is taken up by the organs of hearing; the eye-balls occupy a considemble space, but they have dominated the cranial growths but little; the sockets are very imperfectly marked out.

The nasal labyrinth, with its right and left galleries confluent with the great median middle wall, is naturally divisible into three regions-the alinasal, aliseptal, and aliethmoidal (fig. 1, al.n., al.sp., al.e.). The first two of these regions are supplied with the ophthamic (orbitonasal) branch of the 5th nerve; the hinder region with the olfactory or 1 st nerve. So that, although these parts run into each other, there is an important difference between them; of course the alinasal region is merely vestibular.

The alinasal region (at.n.) is but little seen from above (compare figs. 1 and 5); there it runs across in front of the symmetrical, imperfect cylinders of the aliseptal region (at.sp.) as a narrow arched band. The last fourth of the long convex roofs of the labyrinth belong to the aliethmoidal region (al.e.), and have the inner part of the upper turbinals $(u . t b$.) growing within, and from them. Where this region begins, there the whole capsule spreads out, suddenly, into two widely divaricating, ovoidal masses, marked with the backs of the bifurcating turbinal outgrowths.

A lirge valley, in shape like a Butterfly, with its head backwards, lies between the large upper turlsinal masses; the "body" between the "wings" is the top of the perpendicular ethmoid ( $\left.1, e_{0}\right)$, whose highest, crested part is the cartilaginous crista 
galli (cr.g.). The diverging rows of spots, right and left, are the holes of the unossified cribriform plate $(c r . p$.$) , which extends some distance under the lateral masses. A$ much lesser region, shaped like a Butterfly, but with the head forwards, is seen behind the cribriform plate; its body or septum is low and thick, and the markings on each side, caused by the folds of the middle turbinal (m.tb.), diverge backwards and outwards, like the rows of the nerve passages. The septum, there, is the end of the perpendicular ethmoid $(p . e$.$) ; thence the presphenoid (p . s$.$) begins; it is hollow$ along the mid-line, for the roots of the huge, leafy wings are bulbous. Yet these swollen parts belong to the basal region, which, however, has no median bone in these types; they are formed by the trabecula cranii. All these winged parts may be aptly compared to Insects; here, the orbitosphenoids, growing outwards and forwards behind the nasal labyrinth, and the alisphenoids, growing out behind them, have a similar general form.

Where the swollen trabecular bars have grown up into wings, there the width lessens a little; it then increases, gently, and then suddenly becomes a large, dilated band, confluent with the aliethmoid in front, and continuous with the supra-auditory and supraoccipital cartilage (o.s., s.a.c., s.o.) behind. This tract has lessened very little since the first stage (Plate 2, fig. 1). The narruwish stem of the great lateral crunial band is ossified in its upper half, and this bone-the orbitosphenoid (o.s.)-runs along the front part of the root; the optic foramen (II.) lies on the lower edge of this new bony centre, midway between the two margins

The next dipterous growth has a bony median body-the body of the posterior sphenoid (b.s.). This ossification fits in between the swellings of the presphenoid, and is convex in front; it is short at present, and has a concave hinder margin reaching to the slightly elevated postclinoid wall. The proximal part of each wing is ossified by the basisphenoid; and the alisphenoid ( $a$ l.s.) is double on each side, for the rounded, outer free part is separately ossified from the narrow inner portion. This narrow part is concave at its lower inargin, to enlirge the sphenoidal fissure, through which the 1 st and 2 nd branches of the 5 th nerve pass ( $V^{1} ., V^{2}$.), besides the 3rd, 4th and 6th nerves. The inner bone is also notched at its outer part behind, and the bony matter is beginning to convert the notch for the 3rd branch of the 5 th nerve $\left(V^{3}\right.$.) into the foramen ovale.

The cartilage formed by the moieties of the investing mass (parachordals) becomes very narrow behind the postclinoid wall, between the large cochlex (chl.), and then it expands again as the threshold of the great occipital passage $(f . m$.$) . The sub-$ pentagonal basioccipital $($ b.o.) reaches halfivay to the basisphenoid $(b . s$.$) leaving a$ long synchondrosis. The basioccipital is notched in front, and has a concave hind margin, of less extent than its oblique sides. 'The sinuous margins of the proximal part of the exoccipital region have their larger concavity in the front, to let out the glossopharyngeal and vagus nerves (IX., X.) ; and behind and outside these passages the thick square tract of cartilage is perforated for the hypoglossul (XII.). 
'I'hen comes a short exoccipital bone $(e .0$. $)$ right and left, and then a considerable tract of cartilage between these and the supraoccipital bones (s.o.) above. 'The cartilage in which these latter centres lie is continuous with the broad, sinuous supra-auditory and orbitosphenoidal belt $\left(s_{.} \ell_{0} c_{0}, o_{.} s_{*}\right)$. Seen from above, the huge auditory capsules, with their apiculated helical cochlea $(c h l$.) are seen to be confluent with the proper chondrocranium both in front of and behind the passage for the 9th and 10 th nerves. A notch separates each cochlea from the upper mass of the capsule, and a well-formed archway is formed by the proximal coil of the cochlea over and in front of the compound meatus internus (VII., VIII.).

The end view of the chondrocranium (fig. 2) shows what a large occiput these types possess. The supraoccipital centres (s.o.) are still distinct, and meet over the forarnen magnum (f.m.), which is ovoidal in form, with the narrow end above; they occupy less than half their own region, at present. The exoccipitals (e.o.) are largely hidden in this view by the ear-shaped condyles (oc.c.); in front of these, the cochlea (chl.) can be seen, below, and in the distance. The paroccipital elevations outside the rondyles are but little developed; the cartilage is nearly convex. A lozenge-shaped truct of the ear-capsule is seen above their convexities, right and left, and all the three canals (a.s.c., h.s.c., p.s.c.) can be seen shining through it, so great is the obliquity of the capsule in its cranial setting; the large inner (IX., X.) and the lesser outer (XII.) nerves are also seen (the dotted line is wrong).

The tympanic region, from the outside, has been separately worked out and figured (fig. 3) on a larger scale. 'The annulus ( $\left.a_{0} t y_{0}\right)$ is fast becoming bony, especially in the end of the upper crus, where it is partly bifid, above, to form a rest for the processus gracilis of the malleus $(m l$.$) . That element is still a perfect mandible in itself; the$ stem $\left(m k_{0}\right)$ is drawn as cut across, in the figure.

The depth of the sinuous selliform condyle for the incus (i.) explains why the malleus shows a hole at this part in the section (Plate 4, fig. 7). The styliform ectostosis is now expanding and embracing the under face of the head of this bar; below and inside this bony tract the tensor tympani muscle $(t . t m$.$) can be$ seen arising by a narrow and short tendon, and then passing upwards and inwards, solid and fleshy. 'The posterior angular process behind the internal, or manubrium, is very indistinct; the latter is nearly parallel with the main bar. 'The sinuosities of the condyle of the well-formed but unossified incus $\left(i_{0}\right)$ correspond with those of the malleus; the short crus (s.c.i.) is thick, and fits into a neat cup in the auditory capsule, close over the ampulla of the horizontal canal (h.s.c.). The thick, long crus is almost parallel with the elbowed part of the malleus; it has a well-formed orbicular facet on its inturned end. The unossified stapes (st.) is also large and well formed; here it is figured looking outwards, inside the incus ; its ovoidal base has the narrow end looking upwards and forwards, according to the shape of the fenestra ovalis $\left(f_{s_{0}} o_{0}\right)$. The tendon of the stapedius muscle $\left(s t_{0} m_{0}\right)$ shows in its substance a considerable nucleus of cartilage, the interhyal $\left(i, h y_{0}\right)$ or infrastap dial. The slice of 
cartilage here drawn as taken off the auditory capsule sliows the horizontal and most of the posterior canal (h.s.c., p.s.c.) exposed in the tube of cartilage. Winding round the inside of the incus, where it has been cut off from its proximal part in the cranial wall, we see the facial nerve (VII.) forming an elegant arch nearly parallel with that of the horizontal canal. In front of its imbedded part in the figure there is an oblong tract of cartilage, this is the part where the epihyal (e.hy.) has coalesced with the capsule, and from this it has been cut away in this slice. Below this the facial nerve is seen to send upwards a fork, suddenly; this is considerably smaller than the stem of the nerve, and in the uninjured skull rides over the epibyal to get inside the manubrium mallei; this is the "chorda tympani" nerve (VII'.), forking over the visceral cleft to join the hindmost division of the 5 th nerve.

\section{Dissection of the Skull of Tatusia peba.-Fourth Stage (embryo, 3 inches long).}

The dissected skull of Tutusia peba shows some differences from that of T. hybrida that are specific, yet most of the changes now to be described are due simply to advanced growth.

Here the alæ nasi, nostrils, and narial valves (Plate 5, fig. 5, al.n., c.n., n.v.) are like what I have just described, but the bones just behind these cartilages are larger than we should find them in a species of $T$. hybrida of the same age; these are the premaxillaries $\left(p x_{0}\right)$ and the foremost paired vomers $\left(v^{\prime}\right)$. Still they are all distinct and characteristic, the premaxillaries being small, oblique, notched, lateral shells of bone, with no palatine portion, only with their lower edge curled in. The front paired vomers $\left(v^{\prime}.\right)$ are twice as large as in the last, and are long shells of bone, with their oblique hollow face turned outwards, towards "JAcobson's organ."

Interdigitating with these four bones we see the two maxillaries $\left(m x_{0}\right)$, large, inferiorly placed tracts of bone, showing the infraorbital foramina $\left(V^{2}\right.$.) on their under surface, halfway from their swollen shoulder to their suborbital notch.

I find several alveoli, with their teeth, on the hinder two-thirds of their lower margin, and then a flange from the inner alveolar wall growing intu the palatal region, as wide as the rest of the hard palate, but separated from it by a very distinct multiperforate groove. The jugal process is wide, and is clamped by the angular fore part of the jugal $(j$.$) which widens, inwards, at its middle part, and then becomes narrow$ where the zygomatic process of the squamosal rides upon it.

A very long sutural line runs along the palate from the alie nasi $(a l . n$.$) to the$ presphenoid (p.s.); in front this is formed by the front paired vomers; in the widdle by the maxillaries; and behind by the palatines $\left(p \alpha_{0}\right)$. Their mutual suture is two-fifths the length of that formed by the palatine plates of the maxillaries; the palato-maxillary suture is arched forwards. The palatines do not narrow in so much behind, as in the last (Plate 2, fig. 6), and they also are grooved to, and beyond, their foramen. The thick half-coiled pterygoids $(\nu \%$. ) also do not run so far under the skull, and they 
form a more gaping space for the "posterior nares;" they are notched behind, and have the "hamular process" suppressed.

The squamosal $(s q)$ with its crescentic glenoid facet $\left(g l_{.} f_{0}\right)$ is seen to run from its overlapping jugal part on the jugal to the hinder fice of the opisthotic region (op.). The postjugil elevation is followed by a pneumatic foramen $\left(p m . f_{0}\right)$ which opens into a definite air cavity. The semiosseous annulus tympanicus ( $a . t y$; ; see also fig. 7 ) is left on one side; on the other the capsule is exposed.

Along the middle, behind the posterior nares, the presphenoidal region (p.s.) is a thick roundish beam, quite free from bony deposit. But, laterally, in the funclus of the orbit, the roots of the orbitosphenoids (o.s.) are ossified, and the optic nerves (II.) are seen emerging. Behind the pterygoid, and opposite the last coil of the cochlere (chl.) the basisphenoid (b.s.) is seen to be a short broad tract; the cartilage between it and the basioccipital (b.o.) is half the extent of the basisphenoidal bone. Outside the pterygoids, the alisphenoid (al.s.) can be seen; in front of these is the sphenoidal fissure $\left(V^{1,2}\right.$ ), and at their junction, near the hind margin of the wing, is the foramen ovale for the 3 rd branch of the trigeminal nerve $\left(\mathrm{V}^{3}\right.$.).

On one side the mulleus $\left(m l_{0}\right)$ is seen stretching the membrana tympani (m.ty.), radiating to the annulus, and on the other the cochlea (chl.) and tegmen tympani $\left(t . t y_{.}\right)$are seen; also the two fenestra ( $f_{s . o}$ and the large hole behind it). On both sides the epihyal and the facial nerve (e.hy., III. read VII.) are shown, and also the passage for the 9 th and 10 th nerves (IX., X.).

The occipital arch has a good bony threshold, now, the six-sided basioccipital (b.o.), which has one side in the foramen magnum $(f . m$.$) . The large tribbate condyles (oc.c.)$ have the exoccipital bony centres (e.o.) creeping round them; they are still a long way from the basal bone, and the cartilage near them is perforated by the 12 th nerve (XII.), and over this passage there is now one large supraoccipital centre (s.o.).

The end view (fig. 7) shows how large this bone is, now that the two centres are fused together (see in the younger specimen-T. hylnida, fig. 2). The occipital cincture, in its upper part, is a large shield of bone and cartilage overlanping the opisthotic part of the auditory capsules $\left(o p_{0}\right)$, with their included posterior canals (p.s.c.) seer endwise; the skull is roofed-in by the parietals (p.), and flanked by the squamosals (s\%.).

The sectional view of this older specimen (Plate 5, fix. 6) shows what changes have taken place since the first stage (Plate 2, fig. 1); during this time the young have not doubled their size.

The arched line formed by the lower elge of the basis cranii is but little elevated; the main part of the internasal septum has almost a straight base. The prepituitary part is three and a half times as long as the postpituitary; the thickening of the great middle wall (p.e., i.tro), just in front of the presphenoid, has been caused by the flattened and pressed cornua trabeculæ; the rest of the thickening, below, is due to the intertrabecula, which is there seen to be a long prochordal tract. 
The snout is turned downwards, so that its lower angle projects but lictle beyond its upper; from that angle the scooped recurrent cartilages (l.s.c., read ro.c.) are seen to arise. The highest part of the partition-the crista galli (cr.g.) -is nearly mid-way between the bottom of the sella turcica $\left(b_{.} s_{0}\right)$ and the projecting end of the snout. From the septum, in front of that crest, the nasal roof has been cut away; behind, for some distance, the cribriform plate (cr.p.) grew from the sloping crest near its top. The lowering median cartilage becomes presphenoidal ; it is quite unossified at present; the basisphenoid (b.s.) and the basioccipital (b.o.) are seen, in section, with the lowish, thick postclinoid wall between them; the former is twice as thick and half as long as the latter. The large side-wall of cartilage reaching from the nasal capsule to the supraoccipital roof (n.s., s.a.c.) has lessened since the first stage (Plate 2, fig. 1) to one-half its relative size. Yet the band, even over the protruding alisphenoid, is still of considerable thickness. 'The fore corner of the orbitosphenoid is becoming free, outside the cribriform plate; its main part is only ossified in the narrow stem below; the upper outline is sinuous. The fontanelle between the frontals and parietals $\left(f, p_{0}\right)$ is nearly filled in by these bones, and the retreating cartilage exposes the squamosal (sq.) somewhat, at the base of the coronal suture. The alisphenoid (above b.s.) is now a single bone, and the foramen ovale $\left(V^{3}\right.$.) is finished by bony growths behind.

The supratemporal cartilage $\left(s_{.} \alpha_{0} c_{0}\right)$ is still two-thirds the width of the tilted auditory capsule, which is continuous with the band for some distance, hiding the fore part of the great sinus canal (s.c.). Below, and in front of that canal, the elevation for the anterior and posterior semicircular canals (a.s.c., p.s.c.) is not great, and the bollow for the "flocculus" is shallow. 'There is a difference of size in the whole capsule, and especially in the cochlea, as compared with what we have just seen in an embryo of T. hybrida of the same size (ing. 1), that is verv remarkable. This species also either has a smaller embryo, or its bones develop much earlier than in the other.

The whole capsnle has a well defined, definite outline, often widened into a chink, marking it out from the rest of the endocranium. 'There is a large porch over the actual openings of the meatus internus (VII., VIII.); and in front of these the cochlea swells up into the cavity of the skull. The occipital cincture is narrower than the oblique capsule, and has a very large keystone piece, the supranccipital (s.o.). The exoccipital (e.o.) is nearly twice the depth of each interspace of cartilage; it is notched for the hypoglossal (XII.), and has a concave face against the emerging vagus and glossopharyngeal (X., IX.).

Besides the large frontal and parietal $(f ., p$.$) , and the augle of the squamosal$ $(s q$.$) , the nasal \left(n_{0}\right)$, the palatine plate of the maxillary and palatine, and the small pterygoid (mx., pa., pq.) are all seen edgewise. In this section, detached from the skull, the lower jaw and its related parts are shown from the inside; it has the same elegant shape as the other species; its processes are still cartilaginous at their extremities. MEckel's cartilage $(m k$ ) $)$, fused with its fellow, is still complete along 
the inner fice of the ramus $\left(d_{0}\right)$; but the malleus $\left(m l_{0}\right)$ and incus $(i$.$) are now three-$ fourths of them bony; their shape is very similar to that of the other kind (fig. 3), but the head of the nulleus (fig. $8, \mathrm{ml}$.) is heavier, and its handle smaller. A similar difference may be seen in the incus (i.). The stapes also (st.) differ's in having a larger hole, a longer neck, and a larger nucleus of curtilage-the interhyal (or infrastapedial ; i.hy.) in the tendon of the stapedius muscle. These differences are partly due to age and are partly specific.*

Dissection of the skull of Tatusia hybrida.-Fifth Stage (ripe embryo, 4 inches long).

My most mature skulls of this type were those of ripe young; they are all that is needful, now, for the interpretation of the highly anchylosed skull of the adult.

The outer parts of the skull, as seen in a dissection of this specimen (Plate 6, figs. 1-4), give a good idea of the peculiarities of the Dasypodian type. The lower view (fig. 1) still shows the nostrils and alæ nasi $\left(\boldsymbol{e}_{.} n_{\text {. }}, a l_{.} n_{\text {. }}\right)$ on the under surface, but the bones have encroached on the cartilage, here. The premaxillaries $\left(p x_{0}\right)$ are larger and they have, now, a definite palatine tract; they fit, now, well into the notches of the maxillaries $(m x$.$) .$

The palatine part is not alike on the two sides, being more notched, and hooked on the left than on the right.

These parts do not meet in the middle, but space enough is left to expose the overlying front paired vomers $\left(v^{\prime}\right)$ The palatine portion of the maxillaries $\left(m x_{0}\right)$ only forms a narrow tract, gently widening backwards.

The alveolar region has teeth on all but the front fourth. In front of this tract the bone is notched for the premaxillary, and, behind, it bends round the palatine ( $p a$.$) .$ The flange from the alveolar region is on a higher plane than the submesial part of the hard palate; these two tracts are separated by a perforated sulcus, and the inner and higher bony tract is marked by the transverse ridges of the palatal skin. Outside these parts the maxillaries spread into large shells of bone, the under and inner part of which forms a tunnel for the infraorbital nerve $\left(\mathrm{V}^{2}\right.$ ). Behind the short floor of this tunnel the whole bone has it notched outline, the rounded concavity of which makes the fore and inner border of the imperfect orbit. 'The jugal process is broad and notched for the jugal or malar bone $(j$.$) . Inside these parts the penthouse formed by$ the orbital plates of the frontals $\left(f_{0}\right)$ can be seen. 'The rest of the hard palate is about half as long as that formed by the maxillaries; it is mainly made by the palatines ( $p a$.$) .$

* The remarkable differences just shown between these two closely allied specimens of the sub-genus Tatusia (or 9-luanded Armadillos) suggest the great importance of careful zoological (Taxonomic) work. Forms that to the eye of an observer not well trained in zoological work might easily be mistaken for unimportant varetics, may, to the eye of an expert, show very importint modifications. Moreover, any really important external specific claracter is almost sure to be correlated with some curious and instructive modification of deep-lying structures. 
They, together, look like the opened shells of a Bivalve, their fore margin is rounded and the hind part somewhat cut away; their sides are pinched in.

Behind them come the pterygoids $(m \%)$; these bones have grown considerably on to the paliute since the early stage (see Plate 2, fig. 6).*

This addition to the hard palate is rare in Mammals, even; and in this small degree is instructive, linking on these types to the Anteaters, where it takes place to the greatest degree. Their thickness also is worthy of note, for in another Neotropical Family of Edentata-the Sloths-the pterygoids are often curiously enlarged.

Behind the short, thick, jugal ( $j$.$) the squamosals (sq.) are seen to be of great$ length, reaching as far to the back as the occipital condyles.

They strongly clamp the auditory capsules over the tegmen, and opposite the manubrium mallei ( $m . m l_{\text {. }}$ ) they show the preumatic foramen, leading into their aircell. A pair of superficial bones are seen at their inner border ; these are the "annuli," finished crescents of bone, now ; they are more than semicircular, hollow within, and convex on their outside. Yet at present they do not ossify any part of the tube of the meatus externus, but when that segmented cartilaginous tube is removed, the membrana tympani (m.ty.) is well exposed in this surface view. The endocranium is largely exposed behind the hard palate, and the bony centres of the posterior sphenoid and occipital arch are seen, as well as some parts of the auditory capsule. A very small part of the orbitosphenoid (o.s.) is seen, where the optic nerve (II.) emerges. Belind these parts the alisphenoid is seen as one centre, right and left, confluent with the basal piece (al.s., b.o., read b.s.). 'The sphenoidal fissure and foramen ovale $\left(\mathrm{V}^{1},{ }^{2}, \mathrm{~V}^{3}\right.$.) are not well seen. There is a considerable synchondrosis between the basisphenoid and the six-sided basioccipital (b.o.), and also between that bone and the exoccipitals (e.o.) below, and between them and the large shield-shaped supraoccipital (s.o.), above. The emerging post-auditory nerves (IX, X, XII.) have their passages exposed, and the facial (VII.) is seen escaping from the stylo-mastoid foramen, behind the epihyal $(e . h y$.$) . The tympanic annulus fails to cover the imner side of the$ cochlea $(c h l$.$) , which is partly ossified.$

The peculiar form of the Armadillo's skull is shown in the upper view (fig. 2). Three pairs of investing bones, the nasals, frontals, and parietals $\left(n, f_{*}, p_{0}\right)$ cover nearly the whole of the top of the skull; the maxillaries, lacrymals, jugals, and squamosals $\left(m x_{0}, l ., j ., s q.\right)$ are just seen at the sides; at the end, the convex top of the supraoccipital is seen, and in front, a small tract of the alæ nasi ( $a l_{0} n$.). The nasals form,

\footnotetext{
* I am now satisfied that my oldest (ripe) young of this kind of Armadillo belonged, like the smaller specimens, to the species hybrila. For my second stage (Plate 2, fig. 6) shows the pterggoids with. a larger palatine tract than is seen in $T$, peba, one third longer (Plate 5, fig. 5). That skull is also longer and slenderer, whilst that of the older is like the skull of my second stage (Plate 2, fig. 6); both these are very broad in relation to their length. I feel sure that this ripe joung is really $T$. hybrida, although given to me as T. peba.
} 
in the outline of the top of the skull, a small neck to a large flask; they are half the length and ont-fourth the greatest width of the frontals. 'These latter bones swell over the huge turbinals, and are elesmintly concave at the middle of the orbit. The parietals are about the size, now, of the hinder, dilated two-thirds of the frontals.

The side view (Plate 6, fig. 3) displays many parts, and corrects the visual appearance of the other aspects.

There is considerable deflexion of the snout, the nasals reach nearly to the end, above, and the nostrils look downwards.

The premaxillaries now form a squarish tract, followed by the maxillaries which overlap them; these latter bones are half as long as the skull, they rise high, midway between the orbit and the end of the snout, have their infraorbital foramen $\left(\mathrm{V}^{2}\right.$.) very low, and their jugal process notched to let in the jugal. The large lacrymal $(l$.) has a roughly triangular outline, externally, the orbital margin, where it has its hole (l.c.), and its antorbital tinge, is concave. It covers in the upper turbinal region, which was exposed in the second stage (Plate 2, fig. 8); its upper suture, with the frontal, and its lower, with the maxillary, are nearly equal; both of those margins of the lacrymal are gently convex. The frontal $(f)$ swells over the lacrymal; it is then somewhat notched where it runs inwards as the orbital plate, which hides nearly all the orbitosphenoid; the whole bone is rounded where the roof passes into the orbital wall.

The large rounded parietal ( $(p)$ helps but little towards forming the temporal fossa; it has a slight concavity, besides, near its hind border, where it just overlaps the supraoccipital (s.o.). From that part, behind, but not quite so far back, the squamosal (sq.) reaches to the orbitosphenoid in front. Its three regions, the post-temporal, postorbital, and jugal are all nearly of equal length; the last of these is stout, and the pre-and postglenoid processes are well marked, the latter being the larger of the two.

In the postorbital region it forms a large triradiate suture with the frontal and parietal; these bones so united do nothing towards enclosing the orbital space, which is only marked out well in its antero-inferior half. Part of the palatine, pterygoid, and alisphenoid can be seen in this view, and also the annulus $\left(a_{0} y_{0}\right)$, the manubrium mallei ( $m . m l .$, line directed wrong), the epihyal (e.hy.), the facial nerve (VII.), the opisthotic region and the parts of the occipital arch (s.o., e.o., oc.co).

The lower jaw (figs. 3 and $3 \mathrm{~A}$ ) has retained its elegant shape; it has still some cartilage on its projections, especially for the condyle (cd.p.). The splenial and coronoid regions hang well over MeckeL's cartilage (mk。), which is still perfect. The malleus (figs. $3 \mathrm{~A}$ and $6, \mathrm{ml}$.) and incus (i.) are almost ossified, and the stapes (st.) now a slenderer and more elegant "stirrup," has the lower part of its crura, and the centre of its base, bony. The little module of cartilage in the stapedius (st.m.) is now a mere projection on the neck of the stapes. The upper ceratohyal (fig. 5, c.hy.) has a small ring of bone near its base; the rest of the hyoid arch is still cartilaginous, and is little altered since the last stage. 
The end view of the skull (fig. 4) shows a very large orbicular supraccipital (s.o.), divided vertically by two shallow sulci into three convexities. The lateral elevations have a large selvedge of cartilage, half their breadth, which has to be ossified by this large post-cranial shield of bone.

The paroccipital ridges are very obscurely marked off from the mastoid region (op.); but the exoccipitals $\left(e_{0} . o_{0}\right)$ are getting near to the upper centre (s.o.), over the large convex condy] es (oc.c.); these latter are wide apart, and show the basioccipital (b.o.) between them. The parietals, squamosals, and tympanics $\left(p_{0}, s q ., \alpha_{0} y_{0}\right)$ can be seen, end-wise, in this view, as also the epihyal and facial nerve (c.hy., VII.).

The auditory capsules were removed and figured separately on a larger scale (Plate 6, figs. 7,8 ).

The inner view (fig. 7 ) shows a very large squarish part above the bulbous coclilea (chl.), and having in it the canals, only the anterior and posterior marking this aspect, where they meet in one common sinus.

The antero-superior part runs forwards as a curved process, which is, indeed, the anterior part of the tegmen tympani (see also fig. 11). The meatus internus, with its yarious foramina (VII., VIII.), is very larne; another small hole is seen under the arch of the anterior canal (a.s.c.), which has no recess for the "flocculus," but only a gentle scuoping at this part. Another larger passage is seen, posteroinferiorly, inside the stylomastoid foramen (see fig. 8).

In the outer view (fig. 8) the large square top af the capsule has a sinuous outline postero-superiorly and antero-superiorly; but the mastoid margin, which contains most of the posterior canal (p.s.c.), is straight. It is deeply notched below for the facial nerve (VII.), the notch is the stylomastoid foramen, whose lower border is the epihyal spur (e.hy.), now separated from the ceratohyal.

Within and in front of these parts we see the fenestra rotunda $\left(f . r_{0}\right)$, and at a distance equal to its width, the fenestra ovalis $\left(f s_{0} o_{0}\right)$. Over these openings the tegmen tympani forms an arch, continued forwards in the free spur; over the tegmen the horizontal canal (h.s.c.) is seen shining through the cartilage. 'The ossification of the capsule is very low and generalised as in certain anurous Amphibia, e.g., Pseudis (see Phil. Trans., 1881, Plates 2, 10, 11, 12). The bony matter, which is formed endosteally, is showing itself everywhere on the convexity of the cochlea, on the spur of the tegmen, along the sinus of the anterior and posterior canals (fig. 7 ), and on part of their arches and their interspace.

Endocranium of Tatusia peba.-Sixth Stage (young specimen, apparently new-born, $4 \frac{1}{2}$ inches long).

These drawings (Plate 6, figs. 9-11) were made from dissections of a large ripe embryo or new-born young of Tatusia peba; this, and that figured in Plate 5, figs. 5-8, were the only long-headed specimens in my collection; I am satisfied that all 
the rest belonged to T' hybrida, for their skulls were all much wider and more bulbous in furm, they had much larger cochlex, and were far less ossitied in proportion to their size.

In a figure of the lower view of the endocranium, with the auditory capsules removed, and the vomers kept in situ, we get things that are very instructive (fig. 9).

The alre nasi $\left(a l \cdot n_{0}\right)$ are seen folding over the external nostrils $(e, n$.), which are inferior in aspect. The base of the septum, in this fore part, is alate and lobed where it gives off the recurrent cartilages (rc.c.); over them the aliseptal walls ( $\alpha$. sp. ) are seen. Below, and overlapping the recurrent cartilages, we see the inferior turbinals (i.tb.), now, endosteally ossified. The rest of the nasal labyrinth (al.e., ll.tb., n.tb., read $u . t b ., m . t b$.$) shows no bony deposit, externally, although the turbinals are beginning to$ harden within; these enfoldings are seen on the outer wall. 'The vomerine series of bones is half as long as the entire skull, the principal vomer (v.) being very large-a trough in which the solid intertrabecular beim rests. In front, that bone half overlies the anterior paired vomers $\left(v^{\prime}.\right)$, which are only one-fourth of its length and of its width, and are like miniature Razor shells (Solen), wide open ; their concavity is above. Widening backwards, the main vomer send off a short snag, right and left, at its hinder thixd; its hinder fourth is in two sharp forks, that expose the perpendicular ethmoid, and the presphenoid (p.e.,p.s.) in their angle. From the side spur to nearly the end of the fork, there is, on each side, a lanceolate scale of bone, one-fourth larger than the anterior vomers $\left(v^{\prime}\right)$, these are the posterior paired vomers $\left(v^{\prime \prime}\right.$, the line, by mistake, is carried to the left inferior turbinal), bones that help, afterwards, to bind the middle vomer to the ossifying ethmoidal masses.

Just overlying the forks of the vomer we see the forepart of the base of each orbitosphenoid (o.s.) ; the base of each of these bones is nearly equal to the extent of the basisphenoid $($ b.s.) behind; but there is no presphenoid between them, only the hind part of the great median cartilaginous beam.

'These wings are now lesser than those behind them, the alisphenoids ( $a$.s.) ; they are only two-thirds their breadth, and reach out, laterally, not quite so far. They are free, and emarginate above, the whole of that large cartilaginous band seen in young embryos having disappeared. 'The orbitosphenoids run forwards, as well as outwards, binding, obliquely, upon the great turbinal masses $(m . t b$.). Besides the upper notch, their whole hind margin is sinuous; and their base is thick, and perforated. The anterior margin, below, is carinute up to the outer fourth; behind this ridge, midway outwards, we see the optic foramen (II.).

The thick alisphenoids ( $a l . s$.$) have their wide roof perforated, and the fore part of it$ binds upon the thick base of the corresponding orbitosphenoid. The basal part of each wing is confluent with, but does not reach back so far as, the basisphenoid (b.s.). The anterior margin is concave, and the outer convex; the posterior margin projects backwards as an upper and a lower tooth-the latter being a process from the thick ribbed part behiud the larger foramen ovale $\left(V^{3}\right.$.), which is, now, in 
the middle of this plate. The thick basisphenoid $\left(b_{.} s_{*}\right)$ is almost as long as wide; it is emarginate, a little, botlı before and behind.

The synchondrosis has only half the extent shown in the last stage (fig. 1), and the basioccipital (b.o.) is now a large six-sided bone, having lessened cartilaginous interspaces between it and the exoccipitals (e.o.). These large centres of ossification are concave on the inner, and lobate on their outer, side; they are notched, below, by the hypoglossal nerve (XII.), and above are separated by a definite cartilaginous tract from the large shield-shaped supraoccipital (v.s., read s.o.). The broadly reniform condyles (oc.c.) are now mere caps of cartilage on the exoccipitals.

In the detached hyoid arch (fig. 10) the upper and lower ceratoluyals and the thyrohyals $(c . h y .$, t.hy.) are rapidly becoming ossified.

The auditory region (fig. 11), removed from the rest of the skull, and seen from the outside, shows a great increase of the bony deposit, which now runs round the large, squarish mass, and is especially developed over the tegmen tympani. The ossicula are now ossified; the processus gracilis of the malleus $\left(p r . g^{\circ}\right)$ is a large spatula, with no MECKEL's cartilage left, and lies in a groove in the upper crus of the welldeveloped shell-like annulus tympanicus ( $\ell_{0}(y)$. The stout incus $\left(i_{0}\right)$ is shown in situ, with the head of the stapes seen inside; that bone is also shown, detached, and it is now high, and narrow, and has a tubercle on its neck in the tendon of the stapedius. The epilhyal $(e . h y$.$) still shows a point of cartilage in front of the facial nerve (VII.);$ it is fibrous below.

\section{Dissection of the Slull of a ripe embryo of Dasypus villosus ( $4 \frac{2}{3}$ inches long).- Fifth Stage (continued).}

This was the largest, but not the oldest, of my specimens of young and embryo Armadillos; its centres of ossification were not, horrever, so much developed as in the specimen of Tutusia peba, which forms my fourth stagre (Plate 5, figs. 5-8). *

This is a much more massive kind of skull than that of a Tatusia, and the upper parts do not so completely overlie the lower; it is more generally outspread; evidently the genus Tatusia comes nearer to Myrmecophaga than does the genus Dasypus.

The lower view (Plate 7, fig. 1) shows a very wide and very short snout, with the nostrils $(e . n$. ) almost obliquely below. The base of the septum at this part is alate, and the valves of the openings (n.v.) very large, and coiled upon themselves. The whole space occupied by thess cartilaginous growths is transversely oval, and is neatly rimmed with bone. The nasals are only just hidden in this view by the cartilage (see fig. 2, n., al.n.); two-thirds of the rim is formed by the premaxillaries ( $p x_{0}$ ), which are twice as large as in Tutusiu. Much of the facial plate of these bones can

* These three kinds are all I hare been able to obtain in their early stages; yet they show a most extraordinary amount of variation, and suggest to me, that it would be well worth while to work out the various stages of every species in the Family.

MDCCCLXXXV. 
be seen in this view, for they converge in a very curious manner to form the fore end of the hard palate.

This fore part of the hard palate is semi-oval, and forms the beginning of the very elegant palatal roof which, altogether, would be a long ellipse if the pterygoids had closed in instead of keeping at the sides. The toothless dentary margin is curiously drawn inwards; and the higher palatal tract of each bone is concave, and has a large semicircular notch where it should meet its fellow; thus the even suture is cut into two short tracts. The suture between these bones and the maxillaries is sinuous, the latter pushing forwards externally and in the middle.

In the subcirculir space between the premaxillaries the front paired vomers $\left(v^{\prime}\right.$ ) are seen: they are convexo-concave styles as in Tatusia.

The broad hard palate $(m x$. ) with its convex sides and teeth running up to the premaxillaries, and back beyond the palatine suture, is much more normal than what we see in Tatusia, and the alveolar region is thicker. The teeth, six on each side, are still in one groove, and they give it a moniliform appearance. Inside this arcuate cavity the bone is thick and cross-grooved by the palatal skin; a row of holes, instead of a chink or fissure, separates the sides from the inner higher part of the hard palate. The great pinching-in of the fore part of the bone seen in the nine-banded kinds is not seen here, yet the infraorbital formen $\left(\mathrm{V}^{*}\right)$ is inferior, not lateral; its fioor is much larger.

The jugal process instead of going beyond the alveolar region does not reach so far, and is smaller. The palatal region of the palatine bone ( $\left.p a_{0}\right)$, instead of being very unlike that of the maxillaries, is very much like that tract. 'The two bones have a $W$-shaped hind margin, in front of which the bones are thick and rough as at the sides, just contrary to what the other kinds show; the palatines are widest where the pterygoid bones fit on to them; these latter bones $(p g$ ) fit obliquely to the outer half of the palatine edge, leaving its median notch free; they then run outwards and forwards.

They have a thick, ascending, or cranial part, and a retral inferior hamular process, which has a concave outer and a convex inner margin, and a slight inclination to the midline. Each bone is tipped with true cartilage as in the Hedgehog and Mole (as I shall show in my next part). Yet, notwithstanding the merely lateral position of the pterygoids, the hard palate hides the presphenoidal cartilage, which it does not in a Tatusia of the same age (Plate 6, fig. 1), and this great bony floor occupies the foremost two-thirds of the basal part of the skull. The jugals $(j)$ are altogrether larger than in the other genus, and they are much further apart, through the width of the skull. The squamosal $(s q$.$) carries a much larger glenoidal cartilage \left(g l_{f} f_{0}\right)$, and it lies at the beginning of the hindmost fourth, instead of the hindinost third of the skull's length. Also the annulus tympanicus $(\alpha . t y$.$) does not cover, in this aspect, the inner part of the squamosal, as in$ Tatusia; in this type that part is very large. Behind the condyloid lunule the bone forms a thick obtuse process with a pueumatic foramen in its postglenoid process. 
Inside the glenoid condyle the squamosal runs across and forwards, binding strongly on the solid alisphenoids ( $a l_{\text {.s. }}$ ); with their help, an oblique thick ridge of bone is formed, which runs, with a concave outline, outwards and backwards, from the pterygoid to the opisthotic corner of the ear-capsule (op.). There the broad thick basis cranii also has a concave margin which runs outwards and backwards, and thus a large, oblique, oval space is left in the floor of the cranium; this is filled in by the auditory capsule, mainly by its cochlear region (chl.). On the inside the fissure is filled with fibrous tissue until we come to the opening for the vagus and glossopharyngeal nerves (X., IX.). In the front of this fissure the interual carotid artery enters. Outside we see the higher part of the outer lamina of the squamosal helping to enlarge the tegmen tympani, and, in front, the facial nerve (VII.) escapes from the skull, and gains the hollow of the tegmen. It then runs along that arched way, and before escaping through the stylomastoid foramen burrows through the cartilage formed by the fusion of the auditory capsule with the epihyal (c.hy.).

Near this tunuel, on the side of the cupsule, we see the fenestra ovalis $(f s . o$. ), and at the fenestra rotunda $(f . r)$ the outside of the proximal coil of the cochlea $\left(c h l_{\text {. }}\right)$. The optic nerve (II.) can be seen emerging from the orbitosphenoid, and behind it an oblique tract of the alisphenoid is seen; it is very thick, has the formen ovale $\left(\mathrm{V}^{3}\right.$.) in its middle, and a suture appears right and left of this hole, due, I have no doubt, to a primary division of the bony deposit as in Tatusia, but with the suture more oblique.

Like the other structures, the parachordal region is much more outspread; the basisphenoid $\left(b . s_{0}\right)$ has a rounded outline, and does not yet reach the edges of the great cartilaginous beam. The basioccipital (b.o.), also, lies in a large tract of cartilage, reaching the sides nowhere; it is oval, with the long diameter median. A widish tract of cartilage exists between the basal and lateral bones-the exoccipitals (e.o.), on the edge of which, in front, the hole for the hypoglossal (XII.) is seen. The unossified capsules, in their opisthotic region (op.), run almost directly inwards, with scarcely any paraccipital elevation between them and the condyles (oc.c.). Instead of being in front of the general lower face of the skull, the large ovato-reniform condyles are behind it, and instead of the supraoccipital tract $\left(s_{*} o_{*}\right)$ being largely seen in this view, it is only apparent at the hinder outline of the formen magnum $(f . m$.$) .$

Hence the setting on of the head in these tro types is very different; here, it is much more terminal than in Tatusia, where it is almost as much under the head as in the Primates. On one side of my dissection the ear-drum was left in situ. The annulus (a.ty.) is only half as broad as in the other kind, although quite ossified; a considerable space, filled with fibrous tissue, exists between the annulus and the basis cranii. The malleus, Meckel's cartilage, and the membrana tympani ( $\left.m l_{\circ}, m k_{\circ}, m_{\circ} . t y.\right)$ are shown in this view, these will be better understood by reference to other figures (figs. $3 \mathrm{~A}$ and 6 ).

The upper view (Plate 7, fig. 2) shows the great breadth and shield-like form of G 2 
the skull, with its more outspread zygomatic arches, and its more definite orbital waist. 'The premaxillaries, maxillaries, lacrymals, jugals, and squamosals ( $\left.p x, m x_{0}, l_{*}, j ., s q_{*}\right)$ are all fairly in view in this aspect. Right and left of the median suture the three main roof bones, nasal, frontal, and parietal $\left(n_{.}, f_{.}, p_{.}\right)$, finish the roof; here, as in Tatusia, there is no interparietal, so large in the Insectivora. Both the nasals and the parietals are relatively about one-third larger in this kind, so that the frontals do not cover so liurge a proportion of the roof, nor are they specially swollen over the lateral ethmoids. Postero-laterally, the temporal fossæ, which open freely into the orbit, are well seen from above, and the squamosals form a rounded angle, behind, over the opisthotic cartilige (see fig. 1, op.). Mesiad of those elbows, the hind margin of the skull forms a neatish quadrant, the inner half of which is the ossified supraoccipital $\left(s_{\circ}.\right)$, which turns over the roof to an extent equal to half the sagittal suture; the lambdoidal suture is gently sinuous, the convexity of the line looking forwards in the middle and backwards at the sides.

If the side view be compared with that of the other kind (Plate 7, fig. 3 ; and Plate 6, fig. 3) the general likeness and the special differences of the two kinds will be seen.

Here, the premaxillaries $\left(p x_{0}\right)$ are twice as large, and the lacrymals $\left(l_{\text {. }}\right)$ only half the size of those of Tutusia; then the frontals $(f)$ being flatter, the maxillaries (mx.) are larger behind; their infraorbital foramen $\left(V^{2}.\right)$ is higher up and more exposed. 'The smaller lozenge-shaped lacrymal (l.) has its canal (l.c.) nearly in the middle of the facial part, and this bone, with the jugal $(j$.$) and frontal \left(f_{\text {. }}\right)$ form a more rounded and neater orbital rim, two-thirds round the space. But the orbit and the temporal fossa do but form one general valley, reaching from the lacrymal to a point over the head of the malleus ( $m l$.).

'The coronal suture is formed by the sinuous line of union of the thick edged frontals and parietals; it ends, below, on the squamosal, at its front third, opposite the end of the jugal, which bone $(j \cdot)$ is flat, thick, and especially enlarged both before and behind, where it rests on the maxillary, and where the jugal process of the squamosal rests on it. If the squamosal $(s q$.$) shows more in the upper, it shows less$ in the side view; its pre- and postglenoid processes are small, but the post-temporal part grows well down over the hinder tympanic recess.

Looking under the jugal, we see a small part of the orbitosphenoid, with its optic foramen (see fig. 1, 2), the chink for the 1 st and 2 nd branches of the 5 th nerve $\left(V^{1}, 2 .{ }^{\circ}\right)$, and the alisphenoid, with its foramen ovale and the suture across it $\left(\mathrm{V}^{3}{ }^{\circ}\right)$. Beneath these parts the palatal elements-maxillary, palatine, pterygoid ( $m x_{\circ}, p a_{0}, p g$ ) - are seen. The hamular process of the pterygoid is seen to look downwards, and to be capped with cartilage. 'The tympanic region is well seen in this side view of the skull ; the annulus, MEckeL's cartilage, malleus, incus, and membrana tympani ( $\alpha_{\circ}$. $\left.m k_{*}, m l ., m_{.} m l_{.} i_{*}\right)$ are all seen, and above them a considerable tract of the squamosal. The epihyal $(c . h y)$ is still continuous with the opisthotic cartilage (op.), and behind it the facial nerve (VII.) is emerging; these parts are very near the end of the skull, 
and between them and the condyle (oc.c.) there is a very inconspicuous paroccipital tract. The exoccipital and supraccipital (e.o., s.o.) are seen in the midst of large tructs of solid cartilage.

It is impossible to look at the end view (fig. 4) withont being reminded of low Ichthyopsidan types of skull; the cartilage is as solid as in them, and the osseous centres are mere patches in it. The general form of the occipital end-wall is transversely oval; it overhangs a little above (see fig. 3), and then curls over, above, where the bony centre (s.o.) - single now, but undoubtedly double once-is somewhat trilobate. This supraoccipital centre is thus like a sessile leaf with a trilobate uppel' outline, and a concave petiolar attachment; this is the lower margin over the formen magnum $(f . m$.$) . What looks in the side view (fig. 3$ ) like a large epiotic swelling is, in reality, seen here to be the thick convex edge, right and left, of the great supraoccipital shield. Here we see the whole line of demarcation between the nuditory cupsule and the back wall of the skull proper, converted into an arcuate chink, which becomes a triangular recess, below Outside this, the epiotic and opisthotic regions (op.) - to the latter of which the epihyal (e.h\%) is fused, and through which the fucial nerve (VII.) passes - is but a narrowish convex, lateral tract, thinning out below, where it flanks a very indefinite paroccipital tract $(p, 0 c$.). Inside that tract, and over and within the condyle (oc.c.), we see the orbicular, exoccipital (e.a.), only one-tenth the size of the once double upper bony tract $(s, 0$.$) .$

Like the rest of the skull the occipital basal margin and condyles are a very wide structure, the bony basioccipital does not reach the foramen magnum; this passage is lower than in Tatusia (Plate 6, fig. 4), it inclines upwards and backwards (see figs. I and 3). The parietals (p.) and squamosals $(s q$.$) are hardly seen in this view.$

The mandible (figs. 3, 3A) has the same general shape as in Toturi, but it is heavily built, and not at all like the elegantly slight structure seen in the other kind; the teeth also run further forwards, and are larger. Altogether this type is further from the Anteaters than the others, and on the whole less modified from the average Mammalian type.

A little cartilage is still seen in the coronoid and angular processes as well as in the articular"; MeckeL's cartilage $\left(m k_{0}\right)$ is still quite perfect. 'The malleus (figs. $3 A$ and $6, m l_{0}$ ) is unlike that of 'T'atusia, the heard is more solid, and the posterior angular process is more distinct, but high up, almost close to the articular condyle. 'The manubrium forms an acute angle with the main bar instead of being parallel with it, and having its "elbow" low down; it is also longer, and is dilated at its end.

The small, hooked ectosteal plate has only just begun to graft itself on the under face of the malleus. 'The incus (i.), which is quite unossified, is like that of 'Tatusia, and so is the stapes (st.); it also shows a small "interhyal" (i.hy.) in the tendon of the stapedius muscle (st.m.). The hyoid arch is quite normally Mammalian, and not like that of Tutusice; the epihyal (figs. 4 and 5 , e.hy.) lingers on as part of the general arch, which is thus tied to the skull ; the partly ossified upper ceratohyal $(c . h y$.$) , not$ 
yet segmented from it, thickens downwards, then comes the shorter ceratohyal (c.hy.) not ossified, and the hypohyal (h.hy.) the same. The body $(b . h .6 r)$ has no retral process, and is unossified at present; the thyrohyals $(t . h y$.$) are partly ossified, and$ are in this type segmented off from the body.

In these things Dasypus shows itself more as a normal Mammal, whilst Tatusia is very low and abnornal.

\section{BRADYPODID E.}

This second and only other group of Neotropical Edentata with imperfect teeth is in as great a contrast with the first as can be well imagined, and yet I quite agree with Professor Floww in looking upon all the Edentata from that region, toothed or toothless, as being suckers from one common root-stock (see Proc. Zool. Soc., 1882, pp. 358-367; and Art." Mammalia," Encyc. Brit., 9th edit., vol. 15, p. 384). I shall describe the South American forms first, and then take up the Palæotropical kinds; in both the extreme diversity of the existing forms, and in some cases their almost extinct condition-just one or two species of an extremely isolated type-suggest, powerfully, the great losses this group has suffered since its evolution.

If any one doubts that the short-faced Sloths are intrinsically of the same stock as the long-faced Anteaters of the same region, I would refer him to my figures and descriptions of the scapula in these curiously dissimilar forms ("Shoulder-girdle and Sternum,' Plates 21-23, pp. 199-207).

My materials for working out the skull in this group were as follows :-

First Stage. Embryo of Unau (Cholopus didactylus), $3 \frac{1}{4}$ inches long (Plate 1, figs. 1, 2.)

Second Stage. Embryo of Ai (Bradypus) (Aretopithecus), (—? sp.) 5 inches long.

Third Stage. Young of Unau (Cholopus IIoftmanni), 8 inches long.

Fourth Stage. Young, half-grown, of Ai (Bradypus tridactylus, Limn.).

I have just given reasons for supposing that the Tatous ( $I$ utusia) are less typical than the species of the genus Dasypus, so I shall now give reasons for considering the Bradypodidie, generally, as inferior to the Dasypodide, as a whole. Cuvifr's insight was never better shown than when he classed the heterogeneous Edentata togetherboth the Old and New World forms; and the same instinct, which led him to put the Monotremes with them, was not so far out as seems at first sight. I am satisfied that the Edentata in becoming "Eutheria" never utilized the Metatherian stage, but passed rapidly - at a bound, so to speak-from the Prototherian stage, into the basal region of the highest group. 'There, however, they have stayed; they are just equivalent, in their fullest development, to the lowest and must generalized of the Insectivora, some of which, very probably, are modified and improved "Metatheria," or Marsupials.

* This Embryo has seven cervical vertebra; C. Hofmmanni has only six. 


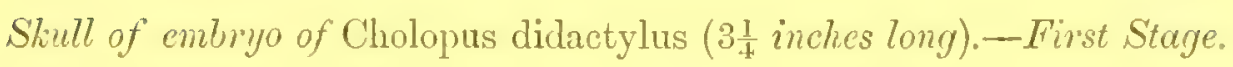

In this type the nostrils, as seen in the lower view (Plate 8, fig. 1, e.n.), are not inferior, but lateral ; and the alinasal floor $(a l . n$.) shows but a small distance in front of the premaxillaries $(p x$.$) ; the basil alæ reach to these openings, as the roofs do,$ above (fig. 2, al.n.). The premaxilluries are as small as in Tatusia, but they have each a well-formed palatine process, nemly as large as the narrow, anterior, or dentary tract. The pointed ends of these submesial spurs do not reach the inner part of the maxillary palatine plates $\left(m x_{i}\right)$, for these retreat considerably, leaving a considerable angle of membrane exposed; this, and the two round notches between the inner and marginal parts of the premaxillaries, form a cordiform tract, in the anterior lobes of which we see the openings of JACoBson's organs (j.o.). In this early embryo, about one-third ripe, the palatine plates of the maxillaries ( $m x_{0}$ ) are only just approximating even in the middle; in the hiud part, as in front, there is a considerable angular space, enclosed by these ingrowths of bone. The whole of this double tract is nearly square; the breadth across the foremost alveoli is greater than the length in the middle; at the sides, the last pair of alveoli overlap the palatines ( $p a$. $)$, and there make the side measurement the longer of the two. Already the foremost alveoli, with their teeth, project most, whilst the last pair project least; there is room for two sockets, with their teeth; between the first and second, a shallow groove is seen along this edentulous space. The inter-alveolar flange is separated from the inner part of the bone by a less distinct groove than that seen in Tutusia; behind, it forms, at its palatine end, a definite and widish space. In this view, the ficial part of the maxiliaries is seen, as a right and left wing; in this space the infraorbital foramen ( $\mathrm{V}^{2}$.), is well shown; its bridge, or floor, is narrow. The rest of the palate is very peculiar, it is quite a rough, generalized structure, the palatines ( $p u_{0}$ ) themselves being not so much developed in this region as the pterygoids are in Tatusia hybrida, at a somewhat later stage. There is an angular space between the palatine plates of these bones, in front, and behind; they do not meet at the mid line. They then, like the pterygoids of Tatusia hylrida, diverge, so as to leave a semi-oval space, in which the broad basis cranii is seen, or all its presphenoidal region (p.s.). The ascending or cranial part of the palatines is very limited; the wall formed by the bone is extremely thick and rough, and behind the last tooth socket each bone forms a rounded boss, from which the rest of the bone diverges gently.

But all this roughness is seen in a double degree in the pterygoids ( $\left.p g_{0}\right)$, which have a very reptiliau simplicity of form, and independence of the basis cranii, to which their attachment is very limited. Each bone is like a rough nut, in miniature; it is somerhat scooped postero-laterally, and at its end has a cupped carity, filled with hyuline cartilage; the remnant of the Ichthyopsidan cartilaginous "upper jaw."

The whole palate is very generalized, and therefore very instructive; it improves afterwards (see Plate 9, fig. 1), and yet in the large young of this genus the palatine 
plate of the palatines is as arrested as in the very open palate of a Rabbit, or the most closed ("desmognathous") palate seen in Birds, namely, in Podargus (sce Trans. Linn. Soc., ser. 2, Zool., vol. i., 'Tab. 23, figs 6-8).*

In the distance, the large orbital plates of the frontal are seen, and laterally, on the level of the palate, the jugals and squamosals $(j, s q$.$) ; these lateral parts have a pecu-$ liar independence of ench other. Such is not seen again until we are down among the Lizards and Serpents. Here the large jugal $\left(j_{\circ}\right)$ is articulated to the maxillary in front, but has its bifurcated hind part free. Answering to this structure, the zygomatic process of the squamosal (sq.) is aborted, and the large crescentic glenoid saddle ( $g l . f$. lies between two thick ridges of bone, its concavity looking forwards. These ridges meet behind the facet as a low, arched postglenoid tract, and then the rest of the bone, as seen in this aspect, runs outside the tegmen tympani (t.ty.), largely helping by its concavity to increase the size of the chamber in which the ossicula auditus $\left(m . m l ., m . k_{0}\right)$ lie, and along which the facial nerve (VII.) runs. A very small tract of skull-wall is seen between the pterygoids and the glenoid region, right and left, but the basis cranii is seen up the fore end of the presphenoidal region (p.s.).

That is all curtilaginous, and in this marvellously stout little skull the whole beam has twice the thickness it has in Tatusia. The basisphenoidal region is more than equal to the presplhenoidal in extent, but its middle two-thirds only is ossified; this basisphenoidal bone (b.s.) has all its four subequal sides concave; its outer sides are pressed upon by the pterygoids. Then comes a tract of cartilage which is longer than the bone, but narrows, backwards, for its hind margin is between the most bulging part of the large cochlex. The basioccipital (b.o.) is lozenge-shaped, with the front and hind angle truncated; it is larger than the basisphenoid, and, like it, reaches the edges of the basal cartilage. The occipital arch is less by far than the auditory region, and the paroccipital region is but little marked-as in the Dasypodidie. The large condyles (oc.c.) are partly under the skull, yet they are well seen behind (fig. 4); they are obliquely reniform and enclose a large, subcircular foramen magnum (f.m.). The exoccipitals (c.o.) are separated by a tract equal, nearly, to their own width from the other occipital centres (b.o., s.o.); the hypoglossal (XII.) notches the bone in its lower or anterior edge on the right side, nearer to the auditory capsule than to the condyle. Still further forwards the 9 th and 10 th nerves (IX., X.) pass out, the basal curtilage being notched for them behind the capsules.

These latter parts are very large, and wholly cartilaginous, at present; the cochlea has the appearance of being composed of only two coils, for the proximal part is one lirge curved convexity, the distal or hemispherical mass lying in its concavity. Both the fenestro $\left(f_{s}, ., f r_{0}\right)$ are seen in this view, and also the facial nerve (VII.), both along the tegmen, and at its exit behind the thick epihyal (e.hy.), which it notches.

\footnotetext{
* The Unau comes very near the extinct Colodon in the structure of its palate; compare these figures (Plate 8, fig. 1, Plate 9, fig. 1) with ReinHandT's admirable illustrations of that type ("Kompedovendyr. slagten Coksodon," Copenhagen, 1878).
} 
This somewhat lemurine skull, seen from above (Plate 8, fig. 2), shows in this early stage some promise of the stony solidity of the skull of the adult. The roof-bones are forming rapidly, and only a lozenge-shaped fontanelle ( $f \circ$. ) remains in the vertex. The premaxillaries $(p x$.$) are scarcely seen in this aspect; but the facial plate of the$ maxillaries $\left(m x_{0}\right)$, and the great front alveoli, come into view; between them the nasals $(n$.$) , behind the short snout (u l . n$.$) , are seen as short, wide bones, only one-third$ longer than broad, and having their fore edge cut away on the inside. The maxillaries and nasals form a convex margin to urite with the concave fore margin of the frontals $\left(f_{0}\right)$. Outside their narrow fore end the smallish lacrymals rest on the jugal process of the maxillaries, and behind these the jugals $(j$.$) come into view. Even$ now, in their narrow fore part, the frontals show that pitting which is a sure sign of a dense and solid bone in its early stage. The remainder of these bones is radially fibrous, like the parietals $(\%)$, and these plates are about equal, the fore part of the frontals being left out of consideration.

The supraorbital rim is better formed than in the Armadillos; its terminal or postorbital process is well defined. From it, forwards, the edge of the bone has a gently concave outline, so that, although the frontals narrow in, forwards, they form everywhere a large roof over the fore brain. The postorbital part of the frontals is one-third the extent of the whole, and it nearly reaches as far outwards as the large convex parietals $(p$.$) . In their re-entering angle, behind, we get a view of the upper$ half of the occipital arch (s.o.), which is ossified very early and very rapidly; much more so than in the Dasypodidx, although in neither of these types is there any "interparietal" or additional membrane bone, or bones. *

This cartilage bone shows the pitting, which is seen in the fore part of the frontals. 'The occipital condyles (see, also, fig. 1, oc.c.) can just be seen from above.

In the side view (fig. 3) we get a display of parts, the figure of which might serve as an elementary diagram of a Mammalian skull. The short, depressed snout shows

* There is something which has to be accounted for, here; the interparietal, which is formed nearly :1ways from two primary centres, and which figures so largely in Marsupials and Insectirores, and in the Eutheria above them, is totally absent in the Neotropical Edentates, and in the Pangolins of the Old World. In Orycteropus it is as large as in the Insectivorous Khyncocyon from the neighbouring region(Zanzibar, East Coast) - a type, the skull of which I suall compare, in my next paper, with what I am able to show of Orycteropus in this; for the Cape Anteater lies somewhere between the Armadillos and that most perplexing, most generalized Insectivore. Looking at the Mammalia, generally, and bearing in mind that Birds with the largest skulls (Crows and Songsters) have no interparietal, it seems evident that that bone comes in to help the parietals in roofing in the enlarging brain of the Mammal. In a young Ornithorhynchus, the size of a new born kitten, with the hairs just appening, the parietals form one thick continuous mass, as in the Ophidia, and the large bilobate ossification of the supraoccipital cartilage, is fast growing to its hind margin. I see, also, the same thing in the Echilna at a little later stage. Some things, no doubt, in the Edentata are due to degeneration, or suppression, but I feel sure that they were never higher in the scale of the Mammalia, on the whole, than they are now, and strongly suspect that they arc a sort of metamorphosed Monotremes, in which the Marsupial stage was got through rapidly.

MDCCCLXXXV. 
the nostrils with a rounded rim, and a small valvular process; they open laterally. The premaxillaries $(p x$.) can be seen in this view, on their outer edge, without any ascending or facial plate, looking no larger than the 1st maxillary tooth.

The maxillaries ( $m x_{0}$ ) are small relatively to the skull, generally, and they have their infraorbital foramen $\left(V^{2}\right.$, see fig. 1) rather inferior than lateral; there is a small hole in front of the main passage; the bone generally is curiously ribbed and wrinkled.

Over it we sec the edge of the nasal (n.), and under the contiguous parts of the nasal, frontal, and maxillary, the smallish, thick, perforated lacrymal $(l$. $)$ comes in to form the foremost part of the orbital margin; the canal (l.c.) opens on its edge. The jugal $(j$.$) has as well-formed an orbital margin as the frontal, above, and they with$ the lacrymal make a rim about the eye-socket for all but its hinder fourth. Even there the postorbital process of each bone is thick and tends to cover in this part; we shall see that this nascent perfection of the orbital rim is only temporary (see Plute 9, fig. 3), so that the early skull, only, can be said to look towards that of a Lemur; here, it is evident, we find signs of degeneracy, or retreat, from the more norrnal Mammalian type of skull. That the great peculiarity of the jugal bone is not something new in the existing, dwarfed Bradyporlidre is evident, for in this species this early stige shows its great peculiarities best; they are softened down afterwards. *

Below the neat orbital rim of the jugal, the bone is obliquely attached to the maxillary; thence it is free, and ends in a postorbital, a zygomatic, and an infrajugal process; together, these processes give a great depth to the bone; behind the middle and lower snags we see the coronoid process of the mandible.

Over the orbit the frontal rises - until at the vertex it is very high-as the roof of a very large skull cavity. The orbital plate of the frontal is large, but is imperfect below at present. The parietal $(\eta)$ ) is larger than would seem from the upper view, for it runs well down behind the auditory capsule, between it and the supraoccipital. The lower margin forms a sinuous line over the inside of the huge, open temporal fossa, and only at its middle, most projecting part does it reach the top of the squamosal (sq.). Besides the fontanelle at the vertex (fo.) there is another on each side, where the frontals and parietals diverge behind the orbits. Ihis is, at present, several times as large as the upper open space, and as far as superficial bones are concerned, it reaches from that divergence above, and the junction of the squamosal and parietal behind, forwards, to the bottom of the orbit in front. In its fore half it exposes the large orbitosphenoid $\left(0_{.} s_{0}\right)$, and in its hiuder half the long band of cartilage (s.t.c.), which runs on to join the top of the auditory capsule,

* If this figure of the skull of the early embryo of the Unau be compared with ReinHARDT's splendid plates of Coluton (Copenhagen, 1878), and Gryptotherium (Copenhagen, 1879), it will be seen how remarkably the jugals correspond. In the latter (plate 1) there is the appearance of a small hole above and in front of the infraorbital foramen, which evidently corresponds with what I have figured in the embryo of the Unau; this small hole is also to be seen in the half-grown Ai. 
is seen passing upwards and backwards along the middle of this hinder membranous tract,

We shall see, afterwards (Plate 9), how completely this space is filled in by the frontal and squamosal; the latter is now a large ear-shaped scale of bone with a thick horizontal part, capped with the glenoid facet (see fig. 1). The temporal fossa, widely opening into the orbit, is but slightly walled in externally by the projecting articular part, and its small zygomatic process. The inner plate of the squamosal reaches further forwards than the outer; behind, the bone ends in a round posttemporal lobe, which overlaps the massive ear-capsule up to the junction of the anterior and posterior semicircular canals (a.s.c., p.s.c.). The occipital plane is very wide and transverse (see fig. 4); here, in the side view, little save the edge of the arch, with its ossifications $($ s.o. e.o.), and the condyle (oc.c.), are seen. At present, the mandibular ramus $\left(d_{0}\right)$ is very slender, not much stouter than that of Tutusia; the absence of teeth makes the fore part narrow (Plate 8, fig. 3 ; and Plate 9, fig. 9). But the coronoid, articular, and angular processes are large, and largely cartilaginous; the first of these is long and distinct, the next solid and wide, the next a large rounded lobe.

The annulus tympanicus ( $a$ ty.), although narrow and simple, is quite ossified already; MEckeL's cartilage $\left(m k_{0}\right)$ is seen in front of it ; the head and manubrium of the malleus $(m, m l$.$) , are seen between its obliquely placed crura; and behind the$ head of the malleus the cartilaginous junction of the ear-capsule with the epihyal is seen, behind which the facial nerve (VII.) is emerging. The hyoid arch is short, and the segmentation below what is normal even for a branchial areh; not only is the ceratohral (c.hy.) not re-segmented, but it is continuous with the epihyal. The hypohyal (h.hy) is a longish curved tongue-shaped piece, pointed in front, where it nearly meets its fellow, and articulated loosely with the fore parts of the $U$-shaped basal piece $\left(b . h . b r_{0}\right)$, for the thyrohyals $\left(t . h y_{0}\right)$ are not segmented off from it. The only bony doposit is a sheath to the main part of the ceratohyal.

The end view (Plate 9, fig. 4) is roughly oval, the long diameter being across, and tho lower margin least convex and with several sinuosities. The upper view (fig. 2), which fails to show the full size of the parietals $\left(\rho_{*}\right)$, is corrected by the side and end views (figs. 3 and 4). Here they are seen with gently sinuous margins, and meeting at a right angle to overlap the upper margin of the occipital arch and the hind part of the auditory capsules. Below these, right and left, just the thin slightly inturned hind edge of the squamosal (sq.) comes into view, binding over the place where, within, the ampullæ of the anterior and horizontal canals lie. For so early an embryo the supraoccipital (s.o.) is a very large osseous centre; it has, recently, become one by the union in most of its lower half of two centres of bony deposit; much of the suture is seen above, and a little of it below. The part next the two parietals is nearly a rightangled triangle; on each side the lower angles lie on the auditory capsules. Below them the bone, keeping to its own proper chondrocranial field, has a short concave 
edge, touching the top of the two united canals (tig. 4, p.s.c.). The angle between this short oblique side and the concave line of the base of the bone dips somewhat into the oblique deep fossa, which at this part divides each capsule from the proper occipital cartilage. The projecting points of each bone, on each side of the lower remnant of the suture, come within a short distance of the neatly circular, large foramen magnum (f.m.). Between the convex, ear-shaped condyles (oc.c.), below, the basioccipital is seen (b.o.), and over, and outside the condyles, the squarish exoccipitals (see fig. 1, e.o.) are seen, creeping upwards towards the supraoccipital and outwards into the quite inconspicuous paroccipital region. Outside that tract the epihyals and facial nerves (e.hy., VII.) are shown, and above thein the oblique, massive, unossified auditory capsule, swelling with the large canals (op.,p.s.c.). Already, so rapid is the ossification, the broadest part of the supraoccipital bone (s.o.) is marked by an arched ridge for muscular attachment right and left of the mid-line; these ridges are parallel with the lower margin of the bone.

A vertically longitudinal section of this most instructive skull (Plate 15, fig. 5) shows the height of the skull cavity, whilst the embryo is still very immature, and the continuity of the marginal part of the cartilaginous skull-basin is still complete. As in the sicle view, the frontals, parietals, and squamosals $\left(f_{\cdot}, p_{.}, s q \cdot\right)$ are seen, just meeting in their most projecting parts, but they fail to wall-in the skull. Already, in front, the frontals are very thick, and the nasals $\left(n_{0}\right)$ also; the middle vomer $(v$. $)$ is short and stout, and the anterior paired vomers $\left(v^{\prime}\right)$ are small, thin, curved, clavate bones.

The septum nasi and perpendicular ethmoid (from a.l.n. to p.e.), together, form but a small, low, triangular wall, whose blunt apex is a little behind the middle, and scarcely rises into a cartilaginous crista galli. Altogether, this part of the skull is less developed than in the Armadillos. Between the partition of the snout and the proper septum nasi, there is a small oval fenestra (i.n.f.), with its long axis lengthwise.

The thick hind margin of the vertical ethmoid (p.e.) is grooved for the olfactory nerves, but the cribriform plate (cr.p.) is but little seen in this view; between it and the orbitosphenoidal band (o.s.) there is a semicircular fenestra. The roof-cartilage is cut away ( $a l . n$. to al.e.), and also the alinasal ( $a l . n$.$) itself, but its thickness is$ shown; the base of the whole septum is thickened below by the great intertrabecula. This is shown as cut away from the presphenoidal region (p.e., to b.s.), for in the hind half the section is in the middle, but in the fore half the basal part is left complete.

Where the alinasal region ends, there the cartilage gives oft' a curious spoon-shaped retral process, the recurrent cartilage (rc.c.); this is concave outside and convex towards the septum nasi; it protects JACoBson's organ, and so, also, does the little additional vomer $\left(v^{\prime}\right.$.) seen on each side in this region. These parts are better seen below (Plate 15, fig. 6), which shows the broad, symmetrical floor of the snout and the lateral nostrils $(n . f ., e . n$.$) . The floor is elegantly alate behind, and from each$ 
ala, on its imner edge, arises a recurrent cartilage. Together, in this view, these look like a lanceolate leaf, with convex halves, like that of Magnolia grandiflora. 'The walls are developed into the inferior turbinals (i.tb.; see also Plate 8, fig. 9 , in Bradypus); the inner part of the floor is developed behind them. Between the halves of the nasal floor the middle vomer $\left(v_{0}\right)$ is seen; it is short, notched behind, carinate, and has its fore end, which is blunt, hidden by the recurrent cartilages; behind the romer, the widening basis cranii is scen where the vertical ethmoid passes into the presphenoid (p.e., p.s.). This latter region (fig. 5) is still unossified; it passes insensibly into the perpendicular ethmoid in front, and on each side grows into a large wing, the orbitosphenoid (o.s.), which is perforated at its base by the optic nerve (II.). In this stage the cartilage ascends and becomes a large plate, continuous by its fore corner with the margin of the rhinencephalic fossa, floored by the cribriform plate (cr.p.). Below that junction there is a crescentic fenestra between the two legions, then the orbitosphenaid rises inside the orbital plate of the frontal $\left(f_{0}\right)$, and then dips again beneath the hind lobe of that bony plate. Across its widest part the orbitosphenoid is nearly equal to the great internasal partition. After a little irregularity of margin the cartilage runs on, rising upwards again as a narrow band, and then loses itself in the wide supratemporal lamina, which, in its turn, passes into the supraoccipital $\left(s . \alpha . c ., s_{.} o_{0}\right)$; the upper edge of the supratemporal tract is crenate, and so is its front margin, where it forms the postero-superior margin of the huge oval lateral fontanelle. That space is as wide as the auditory capsule, and wider than the orbitosphenoid ; it is covered in, externally, all but its anterior and upper margin, by the alisphenoid ( $a l_{.} s_{\circ}$ ) below, and the squamosal (sq.), still further outwards, above.

That peculiarly Mammalian character, the out-thrust of the alisphenoid, is well seen here; this "ala" is now ossified as a thick bilobate mass, which leans backwards on to the tilted auditory capsule; it is still separate from the basisphenoid (b.s.); this bony deposit does not reach the low, transverse postclinoid wall, At present, I see no proper foramina in the alisphenoid ( $a l . s$.$) , but the branches of the 5th nerve$ $\left(\mathrm{V}^{1,2}, \mathrm{~V}^{3}\right.$.) evidently pass through mere fissures. Over the notched top of the alisphenoid we see part of the squamosal (sq.), and the 3rd branch of the 5 th nerve $\left(\mathrm{V}^{3}.\right)$ escapes, at present between that bone and the alisphenoid $\left(a b_{\text {. }} s_{*}\right)$, in the chink between its lobes, whilst the 1 st and 2 nd branches $\left(V^{1,2}\right.$.) emerge through the sphenoidal fissure; this bone is very rudimentary at present.

The rest of the endocranium, proper, is well distinguished from the auditory capsule, which is tilted back at an acute angle to the basis cranii. The whole capsule is onethird larger in outline than the fenestra in front of it; the cochlear portion is jammed in between the basal beam and the infero-laterul walls (see also Plate 8, fig, 1), whilst the upper and hinder margin is ribbed all round by the thickening outside the anterior and posterior canals (a.s.c., p.s.c.) ; this thickening is increased and turned downwards where the two canals are fused into one "sinus." Behind the ampullar region of the anterior canal there is a notable aperture, seemingly for the facial nerve (VII.), but 
it is in front of the great archway for the branches of the facial and the auditory nerve (VII., VIII.). There is a lesser aperture under the anterior canal, where the concavity is shallow, as in the Dasypodidx, and not deep, as in the Insectivora and many other Eutheria; hence the "flocculus" must be but little developed in these Edentata. The endocranial "setting" of the capsule is about two-thirds the breadth of the imbedded sense-organ which bulges, inwardly, and is, although confluent with the capsule here and there, yet everywhere well marked off from it.

The relation of the three osseous centres - the hasi-, ex-, and supraoccipital (b.o., e.o., s.o.) is well seen; the basal piece is one-third longer than the cartilage in front of it, twice the length of the basisphenoid $(b . s$.$) in front of that. There are four$ holes in the short exoccipital; the largest of these, behind, is evidently the posterior condyloid foramen, the rest would appear to let out the hypoglossal (XII.) in three strands; externally (Plate 8, fig. 1), it only has one passage for its exit. The deep oblique passage for the larger post-auditory nerves (IX., X.) is shown in this figure.

The imer vicw of the double mandible (Plate 9, fig. 9) shows some extremely important morphological points. The primary mandible runs from a point near the fore end of the secondary ramus to a point considerably behind it; it is therefore the longer of the two; moreover, it is in two parts, a short proximal, and a long distal, segment. The true swinging point of the primary mandible-the "pedicle" or" "orbital process," such as we see in the Ovipara-is suppressed in the Mammal; hence the incus (or quadrate) has merely the secondary or hinder point of attachment, above, the short crus (s.c.i.) or "otic process." The line of segmentation or condyloid face is sinuous or saddle-shaped, and the specially Mammalian process-the long crus (l.c.i.), with its inturned neck and flat orbicular head for articulation with the topmost segment of the hyoid arch - is well developed. The solid condyloid region of the main or distal segment, the head of the mallens, overlies the scooped tract that gives off the blunt "posterior," (p.ag.), and long foreturned "internal angular process" (manubrium mallei, m.ml.); this latter part is slender, pinched in the middle and pointed at its end. The main shaft or Meckel's cartilage ( $m k$.) is pinched on its inner face proximally and then runs its course, gently arching downwards, and thickening in the middle as a strong terete rod. Where it joins its fellow, there a small basal rod $(b, m n$. $)$ is given off" which lies in the symphysis of the superficial rami. The outside part $(d$.$) has$ already been described as seen from its outer side (Plate 8, fig. 3) ; here, in front of the dentary canal, a flange of bone is given off from the alveolar wall, which overlies MEcKeL's cartilage; this tract is the continuous counterpart of the distinct splenial and coronoid of the Ovipara.

The stapes (Plate 9, fig, 9, st.) or topmost segment of the hyoid arch is shown as dissected away with the double mandible; its oval proximal head is seen sideways as a thick rim to this short flat rod. The length of the rod (not a stapes but a "crlumellet") is equal to the breadth of this proximal plate; its hind margin is concave, and its front convex. 'There is a short distal neck, with a circular flat head, 
for articulation with the incus, and in the tendon of origin of the stapedius muscle $(s t . m$.$) there is a round "interhyal" (infrastapedial) nucleus of cartilage (i.hy.).$

Besides the superficial dentary bone $(d$.$) , with its splenial and coronoid tract, there$ is only one other osseous centre shown in this figure; that is the first rndiment of the malleus $(m l$.) - as a bone - and it is the homologue of the "articulare externum" of the Ovipara.

Slull of un embryo of Bradypus (Arctopithecus) _— sp. (5 inches long). - Second Stage.

We must in these comparisons keep in view the fact that we are dealing with modifications of growth in the individual, and also with specific, and even generic differeuces ; these latter are not very great, and can easily be allowed for.

This skull of an embryo, almost twice as advanced as the last, looks more embryonic than it, for the face is shorter, and the cranium swells up above, giving it an almost Simian character (Plate 8, figs. 5 and 6).

The lower view (Plate 8, fig. 5) is curiously like, and yet in several things unlike, that of the earlier embryo of the Unau (Plate 8, fig. 1). The nostrils and alinasal region $\left(e_{.} n_{0}, a l_{0} n_{0}\right)$ are quite similar in both, but behind them the premaxillaries $\left(p x_{0}\right)$ are smaller, but have longer palatine processes. The anterior palatine foramina, exposing the openings of JACOBson's organs $\left(j \cdot v_{0}\right)$, are better enclosed as two lanceolate spaces, for the maxillaries $(m x$.) have closed in, in front, and bind on both the palatine processes behind, and the feeble dentary tract of the premaxillaries.

The hard palate is not a squared oblong tract here, but is elegantly urceolute, for the fore half forms an outline of more than half a regular ellipse, then it narrows gently, and then widens again, to grow out into haudles or horns, where the palatine bones ( $p a$.$) take their part in its formation.$

The whole maxillary region is well flattened out; a pair of middle palatine foramina end the submedian grooves, which bend outwards near their fore end. One-fourth further back the palatine plates are cut away, in a semi-oval manner, to make room for two wedges of bone, the fore part of the palatines. The rounded end of the alveolar tract of each maxillary rests against the thick outer part of the palatine, and the sockets, with their teeth, scarcely enlarge from the fifth, forwards, to the third ; the second is the largest tooth, and swells the bone out there to its greatest convexity. The first tooth is less than a fourth the size of the second, and lies midway between it and the front convergence of the bone.

Outside the second and third teeth the maxillary enlarges outwards, so as to hide the infraorbital foramen in this aspect; this squarish outgrowth gives a horned appearance to this part of the skull, so viewed. The hind part of this tract articulates with the jugal $(j$.$) , being rugged where that bone fits in, and then there is a$ rounded notch between this short jugal process, and the outer alveolar wall. Each large jugal $(j$.$) stretches outwards and backwards to its free but notched end; the$ 
right is larger than the left. Longitudinally, in the hard palate, the palatines ( $p a$.) are half as long as the maxillaries, but their semicircular hind inargin is but a short distance from the end of the alveolar tract of the maxillary. The thick outer part, forming a wall to the naso-palatine passage, projects outwards, and is notched behind for articulation with the pterygoid $(p y)$. The upper transverse flange of the palatine, which articulates with the presphenoidal cartilage $(p . s$.$) , is followed by a similar plate,$ belonging to the pterygoid, which binds upon the bony basisphenoid. The descending part of the pterygoid is nearly parallel with its fellow; the two continue the naso-palatine wall, but are not so solid-in this species-as the corresponding tract of the palatines; the hook or "hamular process" is blunt, free, and capped with hyaline cartilage.

Through the badly-enclosed orbital space the orbital plate of the frontal can be seen, but much less than in the Unau embryo (Plate 8, fig. 1). Outside, the large squamosals $(s q$.$) flank the greater part of the hind skull; they have a considerable$ temporal tract binding on the alisphenoids ( $($ l.s.), outside which there is a large glenoid facet $\left(g l_{f} f_{0}\right)$, protected externally by a thickish zygomatic process, which projects forwards more, and is sharper than that of the other kind (Plate 8, fig. 1). Behind the glenoid region the squamosal bulges outwards, greatly increasing the strength of the auditory region; it reaches, behind, to a point over the stylomastoid formmen (VII.). Abutting against this posterior tract of the squamosal are seen the two backwardly-turned horns of the large annulus tympanicus ( $(a . t y$.$) , a bone which, even now,$ is a broadish shell, with a dentated inner margin. Both really and relatively, these "rings" are much larger than in the other kind; in both they are large, relatively to the size of the skull; but in this kind they cover the cochlea (chl.) much better. Much of the endocranium is visible in this uspect. In the fundus of the orbit the unossified top of the orbitosphenoid and the optic nerve (o.s., II.) are shown, then the sphenoidal fissure $\left(\mathrm{V}^{1,2}\right.$ ), followed by the large, thick, ossified alisphenoid, notched, above, for the third branch of the 5 th nerve $\left(\mathrm{V}^{3}.\right)$. In the middle, the broad basisphenoid (b.s.), notched in front and concave behind, lies behind a tract of cartilage, which narrows forwards; this is the presphenoid (p.s.). The synchondrosis is less than half the extent of the basisphenoid; then comes the basioccipital (b.o.), one-third Jarger than that bone, imperfect in front, and alate and sub-triangular behind. The apex of the triangle is notched, for there the bone forms a small part of the outline of the foramen magnum $(f . m$.$) . The rest of the occipital arch is but little seen in this$ aspect; but the large condyles (oc.c.), the postauditory and condyloid foramina (IX., X., XII.), the interspace of cartilage between the basioccipital and the exoccipitals $\left(b .0 . e_{0 .}\right)$, as large as these centres, right and left, and the edge of the supraoccipital cartilage $(\because .0$.$) , behind the foramen magnum, are clearly shown.$

A widish crescentic tract of cartilage, the inner face of the cochlea (chl.), is seen inside each "annulus;" and, opposite the fore end of the basioccipital, the Eustachian opening (eu.), a lipped, crescentic slit in the inner and front face of the tympanic 
cavity, is also shown. MeckeL's cartilage $(m k$. $)$ is cut off where it is ready to enter the Glaserian fissure, and obliquely across the nembrana tympani the manubrium mallei $(m . m l$.) runs inwards and forwards, stretching the drum parchment.

The side view (Plate 6, fig. 6) shows a skull still more in contrast with that of the long-faced Edentata than that of the Unan (fig. 3). The simian shortness of the face, as compared with the bulk of the swelling skull, is very noteworthy; for the Ai has gone off" on one way, as far as the Ant-bear on another. *

The small snout, with its rounded lateral external nostril (e.n.), sumounded by a valvular growth, is followed, in this view, by the maxillary below, and the nasal above $(m x, n)$, for the premaxillary is too small to be seen laterally.

The short broad nasals (n.) just overlie the facial plate of the short but broad maxillary ( $m x$.$) ; at the postero-superior angle, however, the frontal \left(f_{0}\right)$ comes in, and below its angle the lacrymal (l.) lies in a notch on the maxillary; it is a small seedlike bone perforated on its most projecting part (l.c.). A little below the lacrymal, another notch in the hind margin of the maxillary receives the large falcate jugal, which forms the lower margin of the orbit. This bone sends downwards a spur behind its middle, where it broadens considerubly; the free hind part ends opposite the lower angle of the parietal (p.). The bone on the right side (fig. 7 ) is larger than that on the left (fig. 6), and has a deeper and wider descending process; its postero-superior part is also notched in a shallow manner. Even on this side the descending process is not equal to that of the embryo Unau (fig. $3, j$.).

Measured along the lower border, the frontal is found to be one-fourth shorter than the parietal $\left(f, p_{0}\right)$, but the depth of the frontal exceeds that of the parietal on account of the large size of its concave orbital plate. The upper fontanelle is not quite covered, the lateral membranous space seen in the embryo Unau (fig. 3 ) is in this covered by the meeting together of the frontal, parietal, and squamosal (sq.).

The large roof-bones are very convex above, their suture-the coronal -is sinuous, the frontal margin being convex above and below and concave in the middle, and the parietal the contrary to this. The squamosal, beginning even now to form its large air-cavity, forms a roughly oval, convex shell of bone. It has a stout zygomatic process, behind and within which is the glenoid facet ( $g l . f$, see also fig. 5$)$; the cranial plate runs further forwards than the zygomatic spur, which latter part is some distance from the end of the jugal.

The upper margin of the squamosal, in the large open temporal fossa, is convex, the lower is sinuous, dips downwards, and is somewhat notehed, behind, where it overlaps

* If Nature, who "innovateth gently," can show us such results as these-can in process of time grow the $A i$ and the Ant-beur from one common "root-stock" - we need have no misgivings about the divergence of any primary radical type, whatever. As to sndden variations which may develop into important modifications, divaricating this way or that, I shall be able, when I come to the Insectivora, to show polymorphic types that suggest possibilities of all sorts. 
the opisthotic region (op.). An oblique view is had, also, of the annulus tympanicus $(a . t y$.$) with its related parts.$

The mandible (fig. 6) is shorter and stouter than in the embryo Unau (fig. 3), the coronoid process $\left(c p^{2} p_{0}\right)$ is not so sharply divided from the articular or condyloid process (cd.p.), and the angular (ag.p.) is much deeper, further forwards, and has a larger crescentic notch between it and the condyloid part; the middle of these processes, only, is still capped with cartilage.

Of the parts of the endocranium to be seen in this view, the snont ( $a$ l.n.) has already been described. Inside the orbit, the orbitosphenoid $\left(0 . s_{0}\right)$ is partly seen, with the optic nerve (II.) emerging; the upper border of this plite is indicated by dots along the orbital plate of the frontal. MEckeL's cartilage and the manubrium of the malleus $\left(m k_{0}\right)$ are seen, and behind the large investing bones the massive occipital arch. The large supraoccipital ( $\left.s_{0} o_{0}\right)$ looks like a contimuation of the roof plates; below it, the tract of cartilage is large, for the exoccipitals (e.n.) are small at present, they are creeping round the outside of the projecting condyles (oc.c.). Where the epihyal passes off from the opisthotic region (op.) there some bony deposit has begun; then the bar suddenly lessens and ossifies as the ceratohyal (c.hy.), which is short, onejointed, and is articulated to a shortish, thick, unciform hypohyal (h.hy). That segment is attached by its narrow distal and to the front of the $U$-shaped unossified basal pair; the thyrohyals $(t . h \%)$ are mere spurs, the crura, of the $U$-shaped piece, as in the Unau.

The end view of the skull (Plate 13, fig. 10) is much like that of the younger embryo of the Unau (Plate 8, fig. 4), and as in the latter the ossification is nearly as far advanced as in this much older embryo, it follows that the ossification is more rapid and intense in the other kind-the Unau.

Signs of median subdivision are still evident in this large, roughly semicircular centre (s.o.), which has thoroughly ossified all the upper part of the large occipital plane. The lower angles are cut away, as it were, the shortened outline then running inwards and downwards; thence the lower outline, sharply marked of from the cartilage, has a small median and two large lateral concavities. Here the foramen magnum $(f . m$.$) is$ pyriform, the narrow part being above; the condyles (oc.c.) project well, and are flanked by the small exoccipitals (c.o.); a very small tract of the basioccipital (b.o.) is seen in the fore margin of the great opening. The epihyals (e.ly.), as they pass inwards and forwards, cover part of the shallow and narrow paroccipital region; above, and outside them, the opisthotic region (p.s.c., h.s.c.) is seen from behind. Covering the whole top and sides we see the parietals and squamosals $(p$., sq.).

Part of a rertical section, taken left of the great septum (Plate 8, fig. 8, p.e.), shows this wall as a short low triangle, shorter than in the Unau, but higher (Plate 15, fig. 5.). A small fenestra (i.n.f.)-very common in low Eutheria-appears near the end of the snout, dividing the septum nasi, proper, from the septum of the snout, where the alinasal tract $(a l . n$.$) ends below; thence the cartilage grows backwards as the$ 
spatulate recurrent cartilage (rc.c.), right and left; it is hollow on its outside, convex within, and hides the fore part of the short median vomer (vo). 'The whole septum (p.e.) is moderately thick, and has the roof $\left(a l_{.} s p_{0}, a l_{\text {. }}\right.$. $)$ cut away. Behind, the outline of the septum is arched, but there is no special crista galli. Further back, and below, the presphenoidal cartilage $\left(p . s_{*}\right)$ passes into the basisphenoidal $\left(b_{.} s_{*}\right)$, which is ossified. The naso-palatine canal is rather deep, and is divided along the midline for some extent into two channels by the vomer $(v$.$) About this time the small$ hinder lateral vomer appears right and left of the forks of the vomer: it was not noticed in this specimen. Part of the frontal, nasal, maxillary, palatine, and pterygoid are seen in this view. The small front paired vomers (see in the Unau, Plate 15, fig. $5, v^{\prime}$.) are probably already fused with the palatine processes of the premaxillaries. A large tract of the other half of this vertical section (Plate 8, fig. 9), with the orbitotemporal wall-bones - frontal, parietal, and squamosal ( $f ., p ., s q$.$) , partly drawn, shows,$ also, the inside of the nasal labyrinth, with the lower, nasal, middle, and upper turbinal folds (i.tb. line wrong, n.tb., m.tb., u.tb.). The orbitosphenoid (o.s.) has lost its front and hinder fastening bands (see Plate 15, fig. 5), but it is still much larger than the alisphenoid (above b.s.), its angles, from which the bands have been absorbed, are rounded, and the upper margin is concave. Less than the antero-inferior fourth of this tract is ossified, and this centre lies in front of the optic formen (H.), which is bounded behind by a very narrow tract of cartilage, soon to be absorbed! 'The lesser' alisphenoid, and also its base (b.s.), is quite ossified; it is a roughish, thick bilobate wing of bone, the hindel narrow lobe being separated from the broad front part by a deepish notch, under which is a small formen; the notch is the beginning of the foramen ovale $\left(\mathrm{V}^{3}\right.$.), not finished on its outer side (see the Unau, also Plate 15, fig. 5). The internal carotid artery enters in at the notch between the alisphenoid and its base, and the 1 st and ind branches of the 5th nerve $\left(V^{1,2} \cdot\right)$, pass out of the sphenoidal fissure between the two "alie;" afterwards a bar of bone divides the passage for the second branch of the 5 th nerve from the sphenoidal fissure, thus anticipating the human foramen rotundum, - a very inconstant passage in the Mammalia, generally. The solidity of the bones at this part is shown by a transwerse section of the alisphenoid, basisphenoid, and pterygroid (Plate 13, fig. 11, al.s., b.s., p.g.).

An inner vicu of the double mandible instructively follows that already described in the Unau (Plate 9, figs. 8 and 9). Here the superficial "ramus" (fig. 8, d.), shows a great difference between the two types, as alleady described; but the endoskeletal or more archaic parts are not so much unlike; part of the difierence here, namely, the lessening of MEcKEL's cartilage $(m k)$, and the ossification of the "ossicula," is due to age. The splenio-coronoid region of the ramus has thrust MEckel's cartilage down to the lower edge of the mandible, and bent it into a curiously sinuous rod. The basal rod $(b . m n$. $)$ is large and quite perfect yet. The mallear portion ( $m l$.) has a less lobular head, und a more dilated manubrium $(m . m l$.) than in the other kind, for there is well seen, from the inner side, a consider- 
able flange or crest to the thick lower edge of this "internal angular process." The incus (i.) and the stapes (st.) are much alike in both species; the latter is seen edgewise in this, and flat in the other. There is a definite cartilaginous nucleus-the interhyal $(i . h y$.$) , in the beginning of the tendon of the stapedius muscle (s t . m$.$) . *$

\section{Skull of young Unau (Cholopus Hoffinanni), 8 inches long.- Third Stage.}

Taking such materials as come to hand, I now get a third stage in a very young Unau of the species that has only six cervical vertebre. In interpreting the adult skull of this type, this stage alone is of great importance, the ankylosis of that massive skull being so intense.

A lower view (Plate 9, fig. 1) of this strongly built skull, already very solid, shows, in front, a very small tract of the snout, with its lateral openings $\left(a l_{.} n_{.}, e_{.} n_{\text {. }}\right)$. Behind it, the two wings of bone, meeting in front at a very obtuse angle, are the edentulous dentary regions of the premaxillaries $\left(p_{0}\right)$; they are quite inferior (see fig. 3) in position. They slightly overlap the maxillaries (mx.), and close to the mid-line send backwards a small styloid palatine process; between the two there is a rounded notch, and this forms the front border of the anterior palatine foramen, with the aperture of JACOBSON's organ $(j .0$.$) seen in it; each maxillary is$ cut away, as it were, obliquely, to form the hind margin of this space; the two foramina open into each other, behind.

'The whole of the bony palate, solid from side to side in the first three-fifths, and then strongly enclosed, right and left, but exposing a spatulate tract of the endocranial base, is a most remarkable architectural growth. The huge first tooth - a doubtful "canine"-is fixed in a large swelling socket; thus this part of the face and palate is greatly widened. There is then a rounded interspace, large enough for another tooth equal to those that follow; there are four of these, the second is the largest, and the last the smallest of the series. These curious mammillate teeth, resembling the degenerate teeth of the Walrus, but devoid of enamel, make their outer alveolar wall sinuous; it draws in, backwards. The alveolar "flange" in the hard palate is onethird wider than the submesial part of each bony plate; the ragged groove, right and left, is nearly straight, and the two are almost parallel.

The zygromatic process of the maxillary, opposite the second tooth, projects further outwards than the socket of the first, an oblique suture with few "teeth" is seen running backwards and inwards, between this process and the jugal bone $(j$.$) . The$ palatines $(p a$.$) scarcely form a tenth part of the hard palate; they run in, behind$

* If these two mandibles, belonging to such closely related types, be compared with those of the Dasypodida, already described, and with that of the lesser Ant-eater (Plate 10), and of its lunge relative the Ant-bear, then the most easy passage is seen from type to type; during growth, the mandibles of the two sorts of Sloth approximate very considerably (see Plate 9, figs, 3, 8, and 9).

t I owe this specimen, and many others, to my lamented friend, Mr. W. A. Forlies. 
and between the palatine plates of the maxillaries, which together have a convex margin outside and a concave margin at the middle, answering to the curved line of the fore edge of the palatines. The notch bounding the naso-palatine canal-as seen in the skull-is rounded, but each palatine projects a little where it meets its fellow. Outside, the palatines do not form a third of the wall, which is finished by the pterygoids ( $(2 \%)$; both of these bones are diluted into a subcranial flange above. The pterygoids look like short clubs; they ore, in reality, rough shells of bone, and open in front into the naso-palatine canal. Being so large, they hide much of the alisphenoids, which are clamped by them up to their antero-inferior margin, and are, themselves, notched to let the 3rd branch of the 5 th nerve $\left(V^{3}.\right)$ pass out of the foramen ovale. Behind that passage they unite by suture with the squamosal, inside and in front of the glenoid facet $\left(g l . f_{0}\right)$. Along this line of junction with the squarnosals the pterygoids are grooved; insicle that groove they swell into a large bilobate mass, which reaches further backwards than the fore edge of the basioccipital $\left(b_{0} o_{0}\right)$, close in front of the Eustachian openings (eu.).

Outside the hard palate, in the distance, we see the orbital plates of the frontals $(f$.$) , and nearer the eye, the jugals (j$.$) . These latter bones are large shells, convex$ infero-externally, and concave above; the inferior margin is cut away in its hinder two-fifths, and ends as a free rounded lobe some distance in front of the aborted jugal process of the squamosal (sq.); the right jugal reaches much further backwards than the left. This want of facial symmetry I have already described in the Ai, also (Plate 8, figs. $6,7, j$ ). The great extension of the squamosals, fore and aft, is seen in this figure, as well as in the side view (fig. 3.) ; for these bones bulge forwards, under the parietals, close to the back of the orbit. Hence a considerable tract of each bone is seen inside in front of the large uncinate, reniform glenoid facet $\left(g l \cdot f^{*}\right)$, with its protecting stump of a zygomatic process. Binding obliquely against the side of the hinder half of the skull, each bone forms an eave over the tegmen tympani, between which and the top of the ear-drum there is a large fissure, the postglenoid passage into the pneumatic cavity of the bone (see also fig. 3, sq.). 'The imperfect annulus (a.ty.) surrounding the exposed drum-membrune is fustened, like a horse-shoe, under this eave of the temporal bone; it is less developed than in the Ai, but is a strong bone notwithstanding.*

Outside the palatine, the exposed part of the orbitosphenoid (o.s.) can be seen with the optic nerve (II.) emerging. 'Then the alisphenoid, with its special Mammalian out-thrust is seen behind the orbital wing and the sphenoidal fissure $\left(\mathrm{V}^{1}.\right)$; close to the edge, the formen rotundum $\left(\mathrm{V}^{2}\right.$.) can be seen. Then this thick outstanding wing

* Many and most instructive parts of the endocraniun come into riew here, and this skull, so like that of the extinct MIegatheroids (see REINHaRDT, op. cit.), can be scen to havo a most remarkable conformity with that of the great Ant-eater-the little Cycloturus serving as an interpreter between these two skulls, whose outward form is so dissimilar. No one, however, who is familine with the structure of Birds-especially the Ratita, and the Carinate Gralla-will be surpriscd at this. 
binds down upon the fore part of the squamosal, and its oval hole $\left(\mathrm{V}^{3}\right.$. $)$ can be seen, where the pterygoid also underlies the alisphenoid. Between the palatines and pterygoids the basal parts of the two sphenoids are shown. At their base the orbitosphenoids (os.) are fast meeting each other, presenting each to each a convex edge; there is no bony presphenoid. The interspace of cartilage here enlarges into a roundish tract, bounded, behind, by the basisphenoid (b.s.), the descending ribbed margins of which touch the orbitosphenoidal bones by their tore ends. The suture between the alisphenoids and their basal piece can be seen outside these crests.

From the presphenoidal cartilage (p.s.) to the foramen magnum (f.m.) the basis cranii is scooped, or concave, and widens, gradually, to the end. The basisphenoid (b.s.) is one-third longer than wide, and is notched in a rounded manner at both ends. The cartilage between it and the basioccipital $\left(b_{0} .0.\right)$ is a transversely oval tract, and the two bones nearly touch by their outer margins. The rudimentary crests growing down from the edges of the basisphenoid are the homologues of the wings, so fumiliar to us in the Insectivora, that assist in the formation of the ear-drun. The much larger, thick, diverging ridges that grow from the edges of the basioccipital, are the exact counterparts of the ridges to which the elongated pterygoids are attached in the Ant-eaters (see in Cycloturus, Plate 10). Here the shortness of the palatines, and the arrest of the dilated pterygoids in front of the basioccipital, makes all the real difference there is in these parts between this Sloth and an Ant-eater (Myrmecophaga, Cycloturus). These outgrowths of the basioccipital of the Unau might have served the same purpose as the tympannic wings of the basioccipital in the Insectivora, or the alisphenoidal outgrowths in the Marsupial. Here they serve no auditory purpose, but are used as strong points of attachment to muscular bands. Narrowing, again, from the ends of these ribbed edges, the basioccipital runs now nearly to the convex condyles (oc.c.), and has a deeply emarginate hind margin against the foramen magnum (f.m.). In front of the reniforn condyle there is an oval mass of cartilage, and beyond it the exoccipital, pierced by the 12 th nerve (XII.), and forming a low paroccipital ridge (p.oc.) against the auditory capsule. As the occipital plane leans forward, above, the supraoccipital $(s .0$.$) is only seen at its lower edge, bounding$ the foramen magnum, behind. Right and left of the basioccipital the auditory capsule is seen here and there, hidden largely by the drum-ring and membrane. Here the ossified manubrium (m.ml.) is seen, and opposite it is found the long-lipped Eustachian opening (eu.). 'The opisothotic region (op.) is seen outside the paroccipital, and running from, and through it, the epihyal, and facial nerve (e.hy., VII.).

The upper view (Plate 9, fig. 2) shows a strong, smooth, oval roof, composed mainly of three pairs of bones that lessen, forwards: these are the nasals, frontals, and parietals $(n ., f ., p)$. 'Together, the nasals have scniewhat of an hour-glass shape, but they are pointed in front and spread out belind, at their frontal suture. The

* The ront of the "tympanic wing" in the Marsupial is a direct untgrowtlo of the alisphenoid; the hinder part is the "os bulla," anchylosed to that root. 
frontals begin wider than the nasals at the suture, and then are cut away gently in an arcuate manner over the orbits. This crescentic rim is rounded, and beyond it there is, towards the frontal suture, a gentle crescentic hollowing of the surface. The postorbital process is rounded and short, and the last third of the bone behind it widens up to the parietal. Longer than the nasal suture, the frontal and saggital sutures are nearly equal, and the wide swelling parietals $(p$.$) gently dip towards the$ temporal and supraoccipital regions. In the latter place, from above, the endoskeletal keystone of the back skull $\left(s . o_{0}\right)$, is just seen as a transversely spindle-shajed tract. Laterally, the squamosals (sq.) can just be seen flanking the parietals.

In front the alinasal porches $(a l . n$.) can be seen, more than from below; and, in the distance, the top of the dentary region of the premaxillaries $\left(p x_{0}\right)$ comes into view. But behind, and outside these parts, the maxillaries and nasals $(m x, n$, neet with no premaxillary process intervening; thus there is a deep triangular notch right and left. Outside that notch is the swelling first tooth-socket, then a deep rounded indentation, and then a hinder swelling of the maxillary, where it binds upon the small burrowed lacrymal $($ l. l. l.c.) ; these strong round knuckles of the maxillaries give the skull a remarkable form. Behind these parts, in the distance, the jugals $(j$.$) show$ their scooped upper or suborbital face, with their thickened outer edge.

The side view (Plate 10, fig. 3) shows many parts with their relations not well seen in the other aspects. The circular narial cartilage and hole $\left(a l . n_{.}, c_{n} n_{\text {. }}\right)$ is seen in front of the recess caused by the suppression of the facial process of the premaxillary $\left(p x_{0}\right)$, which is just seen, below. The nasals are seen, now, to be, not one-fourth shorter than the frontals (fig. $2, n ., f$ ), but only one-seventh; the outer and hinder lobe of the bone, also, shows well, wedging in between the froutal and maxillary, over the lacrymal $(l$. of which we have got, here, the best view. It is not so small as the other aspects suggest, but has a good oblong facial tract, thus forming a thick perforated rim to the orbit, and it runs inwards as a smill antorbital plate. Then, the maxillary (mx.) below, also, takes a good piece from the fore edge of the scooped orbital plate of the frontal by running up inside the fore rim, and joining the small antorbital plate of the lacrymal. This tract appears to me to be a very unusual antorbital growth of the maxillary, preventing any appearance of the lateral ethmoid as a "pars plana."

The outer part of the maxillary is a large high plate, worked well in to the lateral notch of the nasal, and carrying on its scooped descending hind edge the lacrymal and jugal. Its last tooth-socket and tooth can be seen, here, inside the notched jugal ; three more teeth are seen, in their convex sockets, and then a gap before we come to the swelling socket of the large tusk. About two-thirds of the orbit is rimmed with bone, and the lower half of the rim is formed by the free-ended notched jugal $(j$.$) . Over its$ margin is seen the orbital plate of the frontal, under the short thick supraorbital eave; it is notched twice, below, and the ophthalmic nerve $\left(\mathrm{V}^{1}\right.$.) takes its remarkable course under the front notch, below which some unossified orbitosphenoid (o.s.) is still to be seen. Under and in the other notch that plate is ossified, and deep in, under the 
jural, the optic hole (II.) can be seen. The temporal region of the frontal is gently marked off from the orbital, and here a large triradiate suture can be seen; it is formed by the squamosal ruming backwards and forwards from the coronal suture; both of these are very long seams.

The coronal suture runs downwards and forwards, and the squamosal backwards and downwards; these plates of bone, thus stitched together, swell towards the temporal space and muscle, and that space is but little enclosed, outwards, by the stunted zygomatic process of the squamosal. Over those parts the parietal forms at larger front, and a lesser hind, convexity, and ends against the supraoccipital in a straightish line-half the lambdoidal suture (see fig. 4). The squamosal is twothirds the size of the parietal ; it is a roughly uval plate, narrowing backwards.

Before and behind its edge is fretted away, or toothed, below; between its ends the bone grows outwards, swelling behind into an air-cavity of unusual size, in front it grows out into the condyle and small zygomatic spur $\left(g l . f_{0}\right)$.

Under the notched fore edge we see the alisphenoid standing out from the orbitosphenoid, and between the two sphenoidal fissure $\left(\mathrm{V}^{1} \cdot\right)$. Close under and behind this notch the enclosed foramen rotundum $\left(\mathrm{V}^{2}\right)$ is seen, and peeping out between the lower edge of the squamosal and the upper edge of the pterygoid $(\mathrm{pg}$. the formen ovale $\left(\mathrm{V}^{3} \mathrm{.}\right)$.

Between the latter rough, hollow bone, and the last tootl-socket $(m x$.), we see the edge and ascending part of the limited palatine $(p a$.$) .$

The annulus, manubrium, and metnbrana tympani (a.ty., m.ml.) come into view under the postglenoid part of the squamosal, and under its hinder toothed part, the

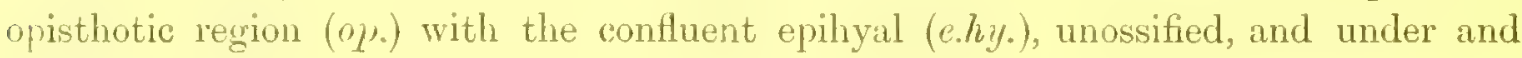
behind the junction, the facial nerve (VII.). Just the edge of the occipital arch with its condyles (s.o., e.o., oc.c.) are seen in this aspect.

The external view of the mandible (fig. $3, d$.) shows what development has taken place since the first stage (tig. 9, d.). I spoke of the first tooth or tusk as doubtfully conine; in the upper jaw, in the first stage (Plate 8, fig. 1), it is the first tooth, but in the lower jaw there is one in front of the rudimentary lower tusk-five in all; it is very small, prematurely developed, and early lost (see Plate 9, figs. 3 and 9). Thus the tusk, at most, can only represent the first premolar of the normal Mammalian dentition.

The coronoid process (cr.p.) is now separated by a large semicircular notch from the condyle (cd.p.), and that by a shallow notch from the angular (ag.p.), which is not very deep in this genus.

The fore end of the mandibles is narrow (figs. 3 and 5) and the sutural symphysis of a considerable extent; seen from below, the mandibles are as curiously swollen to form the socket of the tusk, as the face is above; the sockets of the hinder teeth are directed strongly inwards. Here we see how soon the dentition affects the form of the mandible (figs. 3 and 9), and the loos of tecth is taking place, here, before one's eyes. 
The end view of the skull (Plate 10, fig. 4), shows the strength of the wide and high occipital arch. The foramen magnum (f.m., see also fig. 1) is round above, notched below or in front, and it widens out over the condyles.

The supraoccipital (s.o.) is roughly semicircular and extends, without an "interparietal" over it, from the well-arched parietals to the formen magnum. A hookshaped wedge of cartilage still separates it from the exoccipitals (e.o.). The muscular impressions in the main piece are well marked; the outer and lower edge of the bone is flanked by the squamosals (sq.), and the lowest comer is pierced by a vessel. 'The exoccipitals (e.o.) are roumdish, and in this aspect are separated by a considerable band of cartilage from the opisthotic bone out of which we see the facial nerve (VII.) proceeding, and to which the epihyal (e.hy.) has grown. Below, the anmuli (a.ty.) are seen in the distance. 'The proper or anterior' condyloid foramen (fig. 1, XII.) must be seen from below; here, the posterior condyloid foramen $\left(p . c . f_{\text {. }}\right)$ is seen outside each condyle.

An inner view of the ossicula anditus, removed, and freed from the remains of MECKEL's cartilage (fig. 6), and an outer view (fig. 7) of those parts attached to the capsule, and with the tympanic remant of the primary bar, show some very instructive things.

The main part of MECKEL's cartilage has been used up-partly ossified and lost in the ramus, and partly absorbed. 'The head of the malleus, the osseous matter of which runs forwards as the styliform "processus gracilis" ( $2 \cdot g r$ ), has, in front of it, yet, a large tract of the primary mandible. This thick semiosseous hook (mk.) curves itself, after it becomes detached from the rest of the main bar, round the front of the tympanic cavity. The distal third is still unossified; this bony tract is, essentially, a second "articulare internum," such as is seen in the Holostean Ganoids, Lepidosteus and Amia; (see Bridge "On the Skull of Amir," Joum. of Anat. and Phys., Vol. 11, Plate 23), and the writer's paper "On the Development of the Skull in Lepidosteus," Phil. 'Trans., 1882.

But this tract has a greater interest for the morphologist even than this, for such a further remmant of the nomal mandible is often present in adult Marsupials (see Doran, 'Ossicula Auditûs,' plate 64), and for a time-during the first autumn-the Mole has a similar malleus, as I shall show in my next Part.

More than that-in a similar malleus of a young Koala (Phascolarctos cinereus) of the same size, nearly, as this young Unau-I find two smallish, but well-defined membrane bones in this premalleal tract; these are seen at once to be the same as the "supra-angulare" and the "angulare" of the Oviparous types. One such bone is seen in this case, the angulare (Plate 9, fig. 7, ag.), an oblong splint, pointed at both ends.

When this temporary mass is removed (fig. 6) then the processus gracilis $\left(p \cdot g r^{\circ}\right.$ ) is seen to be no larger than the manubrium $(m . m l$.) and parallel with it, but pointed and grooved, above, instead of being terete like that process. 'There is an evident elbow, or posterior angular process ( $p . o g$.$) , to this masked and arrested proximal end of the$ mandible. The lamina uniting the manubrium to the head of the bone is thin and 
splintery, and hollow on the inside (fig. 6). Over this plate the head of the malleus grows like the hood of the Monkshood flower, a remarkable semioval growth of bone. The simuous, saddle-shaped condyloid facets of the malleus and incus form, as the figures show, a very strong joint, and the latter bone is equal in size to the head of the former.

Both the crura of the incus are short, but well formed, the short crus (s.c.i.) has an oval facet for articulation with the cupped space in the tegmen tympani, and the long crus (l.c.i.) has a nearly circular and flat facet for the head of the stapes (st.). This latter bone is shown in situ from the outside (fig. 7), and, detached and dislocated, from the inside (fig. 6). The little nucleus of cartilage representing the interhyal (i.hy., see fig. 9) is now a small spur on the neck of the short columella; now by absorption of the centre of the flat stem, a veritable stapes. Here again we are on the Metatherian level; the Marsupials have a "pharyngohyal" which, in different types, oscillates between the columella and the stapes (see Doran, 'Ossicula Auditûs,' plate 64). The secondary perforation of the "columella," making it into a sort of stapes, is seen also in Birds (see Doran, plate 64, figs. 44-46). In this figure (fig. 7), little except the cochlear part of the auditory capsule is drawn, with the fenestra ovalis ( $f$ s.o. ) occupied by the stapes, and the fenestra rotunda $(f . r$.). 'This well ossified mass must be considered as a thick section, cut oft from the part that contains the canals, and from the opisthotic angle, behind (figs. 1, 3, 4, op.).

I am satisfied that in the Sloths the periotic bony deposit is generalized, as in the Armadillos-and in certain anurous Amphibia.

The epihyal (fig. $3, e . h y$ ) is still cartilaginous, and is followed by a single ossified ceratohyal segment (c.hy.), and then by an unusually long hypohyal (h.hy.), now largely ossified. The $U$-shaped basal piece $\left(b . h . b r_{0}\right)$ is also getting a bony centre in each thyrohyal horn $(t . h y)$.

Skull of half-groum Common Three-toed Sloth (Bradypus tridactylus, Linn.).-Fourth Stage.

A dry skull of the half-grown young of this species has served to make many things plain to me in this type.

The side view, with the olfactory, auditory, and most of the occipital, region removed (Plate 13, fig. 5), shows the roof bones $(n ., f ., p \cdot)$, the nasals, frontals, and parietals, supported behind by the large supraoccipital (s.o.), and below by the sphenoids $\left(\mathrm{V}^{1}\right.$, to $\mathrm{V}^{3}$ ) and the superficial squamosal $\left(s q_{*}\right)$. 'The nasals $\left(n_{0}\right)$ are short, the frontals $(f$.) have but an indefinite supraorbital rim, and the parietals have a sinuously swelling general surface. The squamosals $(s \%$ ) are less produced forwards and backwards than in the Unau (Plate 9, fig. 3, sq.), but have a more well-marked postglenoid process; the zyomatic process also is longer.

The thick short palatine ( $\left.p a_{0}\right)$ and the long swollen pterygoid $(p g$.$) are seen in$ 
situ; over them, the orbitosphenoid and alisphenoid $\left(V^{1}\right.$. to $V^{3}$.) are partly seen. Many nerve passages are shown in this part, namely, the optic (II.), which opens into the sphenoidal fissure, through which, besides the orbital nerves, the ophthalmic or 1.st branch of the 5th nerve $\left(\mathrm{V}^{1}\right.$ ) passes. This also enter's the skull ayciin by one of the more marked orbital foramina $\left(\mathrm{V}^{1}\right)$, in the anterior angle of the orbital plate of the frontal $\left(f_{0}\right)$. Behind the palatine $\left(p \alpha_{0}\right)$, the foramen rotundum $\left(\mathrm{V}^{2}\right.$ ) is seen close to the sphenoidal fissure, and where the alisphenoid, squamosal, and pterygoid meet, the foramen ovale $\left(\mathrm{V}^{3}\right.$.) is seen.

This latter is really a foramen; in this disarticulated skull, a thin, narrow, postneural lamina of the alisphenoid lies on the top of the hind part of the pterygoid; the 2nd branch of the 5 th nerve burrows the alisphenoid in fiont of the foramen ovale for the 3rd branch, runs over the top of the pterygoidal sinus or "antrum," and then escapes through its very forwardly placed foramen rotuudum. As far as I can see, this is the behaviour of the branches of the 5 th nerve in this type; but this is not all. I mentioned that the optic formen (II.), opened into the sphenoidal fissure; this is clearly shown in the hinder end vieu of this preparation (Plate 13, fig. $7,0_{.}$. .). In this aspect the orbitosphenoids are seen to be quite ossified, and nearly confluent; but the post-neural band of cartilage (Plate 8, fig. 9, 0.s.), still larger in the much younger embryo of the Unau (Plate 15, fig. 5), has not been ossified, but has been absorbed.

Here, again, we are on the level, so to speak, of the Marsupials; this is a thind Metatherian character; and it is acquired by osseous degeneration, correlated with degeneration and loss of the dental series.

The alisphenoids ( $a l . s$. ) are seen in this end view, bulging out beyond the orbital plates; the end view of the basisphenoid (b.s.), shows a middle part, faced with the cartilage of the spheno-occipital synchondrosis, and, outside this, the rough ends of the ridged sides of the bone, notched for the internal carotid artery (i.c.) on their outside.

In the distance, below, the two palatines $(p a$.) are seen to meet at the mid-line; and outside these, nearer the eye, the swollen pterygoids $(p \%)$. Outside and above these the squamosals (sq.) show their large pneumatic opening.

The under view (fig. 6 ) shows the lower face of the nasals (n.), and the frontals $(f$. with their approximating orbital plates resting upon the ascending process of each palatine ( $p a_{\text {. }}$, see also fig. 5). A very small tract of the parietals comes into view here in the postorbital region, but these bones $(p$.$) and their "lambdoidal" suture$ with the huge supraoccipital (s.o.) are seen behind. Externally, the squimosals (sq.), with their pneumatic foramen, hollow glenoid facet, and short zygomatic process, are seen. In the middle we have, at a distance from the eye, the fiused orbitosphenoids forming a presphenoidal region (p.s.) by their confluence.

This part is underfloored and flanked by the ascending parts of the palatines ( $p a$.$) ,$ in front, and by the like parts of the pterygoids $(\mathrm{pg}$.$) , behind. The proximal region of$ each alisphenoid $\left(V^{1}-V^{3}\right)$, is hidden in this view by the pterygoid, but the base (b.s.)

$$
\text { is } 2
$$


can be seen with its thickened sides, growing backwards as rudimentary "tympanic wings," and wedging forwards under the uniting orbitosphenoids. The distal part of the alisphenoids comes into view outside the pterygoids, and the foramen ovale, formen rotundum, and common passage for the orbital and optic nerves $\left(V^{3}, V^{2}\right.$, $V^{1}$., II.) cin all be distinguished in this aspect of the skull.

Here the large unique pneunatic pterygoids show their communicating passage with the great naso-palatine canal, and therefore, also, with the whole system of air-galleries in the nasal labyrinth.

I have mentioned the parallelism of the Unau and the Mole in the peculiar temporary pretympanic process of the malleus; here in the Ai (Plate 13, figs. 8, 9), the outer and inner aspects of the tympanic annulus are almost precisely like those of the Hedgrehog, and of the young Mole; they have a considerable concavity, a large amount of ossified floor, and strong, incurved cornua, the front horn being deeply and obliquely notched for the processus gracilis.

\section{MYRMECOPHAGID.E.}

Foung of Cyclotums didactylus; one with head $1 \frac{1}{4}$ inch long, and another $4 \frac{1}{2}$ inches long from snout to root of tail, and head $1 \frac{1}{2}$ inch long.

I shall treat these as one stage; they correspond well with the larger specimens of the Amadillos, and with the third stage of the Sloth. 'This small arboreal Anteater' comes in well after the Sloths; the difficulty of comparison of these two Families is lessened considerably in this case.

Once well understood, the same stage in each type-Sloth and Anteater-can be put side by side, and then the special adaptive modifications may be accounted for and the true radical kinship of these two, apparently so diverse, forms, can be demonstrated. I have found that by putting them alongside of each other, and carefully removing their special "marks," the evidence for" a common descent is very great. We have a similar comparison to make between the toothed and toothless Anteaters of the Old World-Orycteropus and Manis and also, indeed, between the Omithomynchus with its homy "snccedanea" for teeth, and the absolutely edentulous Echidna. Nowhere can the modifications produced by the gradual abortion, and the complete suppression, of teeth in the higher. Vertebrata be better seen than in the Edentata or Bruta. In the Chelonia the massive horn-covered jaws are less modified than might have been expected; the strong shears that serve as a makeshift for teeth, ask for as strong a setting as the normal teeth of a Reptile.

So also in Birds, to a greater or less degree, as may be seen by comparing the skulls of the toothed Birds (so ably described and exquisitely figured by Dr. Marsi) with those of the existing toothless types.

But, in the Mammalia, we are so familiar with the huge dental appaxatus seen in this or that high Futherian-jaws answering to teeth, and teeth to jaws-that any 
perfectly toothless type of Mammal seems to be a monster; and to be sans teeth is to be sans everything.

In the Snapping Turtle or the Macaw the massiveness of the face makes no difference in the morphology of the type; here also, in this little toothless arboreal Anteater, the bird-likeness of the face is a very thin mask to its true nature as a low Eutherian Mammal; the whole result is but a faint and feeble imitation of the face of the feathered and winged Edentate.

Yet the result of this slow secular "drawing" of the teeth is very curious and instructive (see Plate 10), and the result in this quasi-senite creature is to form a skull like a small gourd or a flask. But this lageniform skull is flat on one side, and bent downwards towards that flattened side. That is the uncler surface (Plate 10, fig. 1); here we see a small, short snout, with lateral nostrils $\left(a l_{0} n_{\circ}, e_{.} n_{0}\right)$, quite like that of the Sloths, but more slender.

The basal part of the premaxillaries $\left(p_{0}\right)$ is a small subtriangular tract; the right and left bones are separated by the width of the base of the nasal septum (fig. $7, s_{0} n$.). Where they diverge, behind, there the maxillaries $\left(m x_{0}\right)$ begin to converge; in the fore part of their palatine plate there is then left a lozenge-shaped interspace, and here we see the two front paired vomers, small pyriform ossicles (fig. 10, $v^{\prime}$ ), lying parallel with their pointed end forwards. The hard palate is very much sculptured and perforated, two-thirds of it belongs to the maxillaries, and one-third to the palatines $(p a$.$) 'This under region widens a little backwards, and narrows again towards$ the end of the perfect floor: That perfect part runs to the middle of the skull, the rest is indeed well marked oft and hedged in with solid bone, but the floor is merely a strong "aponeurosis," and not a bony tract right across, as in the large Ny/mecophagida; the naso-palatine canal, however, is quite perfect in this little kind, and opens close under the junction of the head and neck.

The sharp-edged, toothless alveolar region of the maxillary ( $m x_{0}$ ) sends inwards the usual flange, and this only leaves a small tract for the higher submesial part; the two tracts are separated by a deepish groove. About three-fifths of the underview of the maxillaries is palatine, the rest belongs to the facial walls, which spread out on each side of the inferior infraorbital formina ( $\mathrm{V}^{2}$.) into an ear-shaped lobe, and then the bone contracts suddenly, and rums inwards to bind on to the middle of the side of the rest of the hard palate. This part answers to the socket of the upper "wisdom tooth" in man.

Fine threads of bone are seen extending backwards into the jugal region from the outer lobe of the maxillaries; these are the starved, abortive jugrals $(j$.$) .$

The orbits are less enclosed than ever in this type; in this aspect the inturned orbital plate of the frontals $\left(f_{0}\right)$, and the antero-inferior cornu of the parietals $(p$.$) can$ be seen, folded over the two pairs of wings of the "sphenoid bone." The palatine hinder third of the hard palate is quite like the part in front of it, and at the line of junction of the two palatines, behind, this floor is emarginate, angularly. 
This takes up three-fifths of the large palatines, the remaining part merely helps to wall in the great naso-palatine canal. Each bone diverges backwards and leaves an interspace wider than each bar, at the top of which, on the inner side of each, the palatine bone is seen to clamp the basis cranii by a dilated plate.

Then the pterygoids ( $p g$. ) begin ; they run forward, a little, inside the palatines, and these, in turn, run backwards outside them, fastening together, obliquely.

Each bone has, away from the eye in this view, an upper plate embracing the skull, a flange, as in the palatines - which runs on to the last fourth of the basioccipital (b.o.). Up to the spheno-occipital synchondrosis $($ b.s., b.o.), the two pterygoids form the margin to a lanceolate space, the sides diverging and then converging; but in their last third the pterygoids diverge again, and then their upper plate is well seen. At their middle these bones spread out, doubling their breadth and becoming rugged and notched; they thus form an angle which wedges strongly in between the immermost part of the squamosal and the foremost part of the annulus tympanicus $(s q ., a . t y$.$) . In the angle, here, the foramen ovale (figs. 1$ and $9, \mathrm{~V}^{3}$.) is seen. At their rounded ends, which are cut away somewhat, externally, the pterygoids are capped with cartilage, as in the embryos of most of the lower Eutheria, which have this sign or remembrance of the great pterygo-quadrate bar, or endoskeletal upper jaw of the Ichthyopsida.

The double sphenoidal region is largely displayed in this view; outside the unfloored part of the palatines, the orbitosphenoids and optic nerves (o.s., II.) are seen, and behind these a large, lozenge-shaped tract of each alisphenoid ( $a l . s$.), behind the sphenoidal fissure, through which both the 1st and and branches of the 5th nerve $\left(\mathrm{V}^{1,2}\right)$ pass. Opposite the junction of the pterygoids and palatines there is a semi-oval tract of cartilage, separating the presphenoidal region from the basisphenoidal bone $\left(p . s ., b . s_{0}\right)$, for here the orbitosphenoids (o.s.) meet and coalesce, and the cartilage has, necessarily, a convex form at their junction. In front, where it runs on over the hard palate, it becomes the unossified perpendicular ethmoid (fig. 7, p.e.). The large, and unusually long basisphenoid (b.s.) has a small pituitery hole at its front third, and is longer, contrary to rule, than the basioccipital, that is, measured along the mid-line.**

This is correlated with the great length of the pterygoid bones $(p g$.$) , which are one-$ third the length of the bony cranio-facial base, and even in the Unau (Plate 9, fig. 1) are only one-fourth, with its relatively much shorter skull. The external descending ridges of the basisphenoid (b.s.), like those in the Unau (Plate 9, fig. 1), are hidden by the junction with those of the backwardly extended pterygoids. Only the prepituitary part of the basis cranii is convex along the middle, in the notochordal region;

* In the Unau at the same stage (Plate 9, fig. 1) the basisphenoid is one-third shorter than the hasioccipital; here the bony basal tracts, measured along the middle in my younger specimen, are as follows:-presphenoidal region 2 2 millims.; basisphenoidal 4.5 millims.; basioccipital 4 millims 
behind the middle of the basisphenoid, it is gently concave, as the roof of the hind part of the very long naso-palatine canal.

The rest of the basal region, formed by the basioccipital (b.o.) is very large, and between pentagonal and orbicular in shape; and like that of the Unau (Plate 9, fig. 1) has a very Sauropsiden form and size, but still more so than in the Sloth. As in that type, the bone has strong "basipterygoid processes" (figs. 4 and 9, b.pg.), which functionally correspond to the parts so named in the Sauropsida, but are, here, the outgrowths of a hinder bone. Here they reach within a short distance of the rim of the foramen magnum (figs. 1,4), and are, indeed, as strong and well-developed as any of their analogues in Reptiles or Birds."

In the sides of the hind skull, as seen in this under aspect, the parietals $\left(p_{0}\right)$ come into view, outside the squamosals $(s q$.$) , a rare character, and one that can only occur$ in such a curious gourd-shaped skull as this, or in the similar skull of the Pangolinnext to be described. Inside them, the abnormally small squamosals (figs. 1 and 9) make a better figure in this under face of the skull than they do as seen from the outside (fig. 3). The zygomatic process is very stunted, and behind it we see the small pyriform gently concave glenoid facet $(g l . f$.$) , with its narrow end forwards and a$ little turned outwards.

The postglenoidal part of the bone curls inwards, but is notched in the middle, iust in front of the tegmen tympani and ossicula auditus, and where the hollow bone has its pneumatic passage opening into the cavum tympani. A large sinuous under and inner flange runs fiom the convex outer part of the squamosal, and strongly undergirds the alisphenoid; it almost reaches the basicranial plate of the pterygoid $(p g$.$) , and is, in turn, itself undergirt by the fore horn of the large bony annulus$ $(a . t y$.$) , and also by the large spatulate processus gracilis of the malleus (fig. 9, p.gr.).$

A small vascular foramen is seen at the posterior angle of the squamosal (see also fig. $3, s($.$) .$

The tympanic annuli (a.ty.) are quite comparable to those of the embryo of the Ai (Plate 8, fig. 5), as to their large, relative, size. The side view (fig. 3 ) shows them, but not so well as this; their aperture is wide, and obliquely turned outwards and forwards, and is occupied by the manubrium and ear-drum skin (m.m., m.ty.). The part round the rim of the opening is smooth, convex, and is taking on the wellmarked bulliform character seen in the adult. All round the horns and convexity, externally, they are notched, or toothed, in a remarkable manner. Behind these bones, the ossified auditory capsule (op.) comes into view, with the opening for the 9 th and 10th nerves $(\mathrm{IX}, \mathrm{X}$.). This skull is somewhat more advanced as to its

\footnotetext{
* The quasi-embryonic arrest of the hinder hard palate in this kind is very instructive; a little more energy of growth would have given this dwarfed, arrested, Antenter, with its long pretensile tail for the service of its timid, arboreal life, a palate equal to that of its larger congeners (compare fig. 1 with Professor FLoweR's figure of the basal view of the skull in the Ant-bear'; 'Osteol. of Mammalia,' fig. 65, p. 2006).
} 
lower arches than that of the young Unau (Plate 9), for the fixed part of the hyoid arch (epihyal, e.hy.) has formed a "tympanohyal" ossification (fig. 9, between f.r. and IX., X.) in front of the stylomastoid foramen (VII.), separate from the opisthotic (op.); the rest of the arch (fig. 6) has become free.

The occipital arch, the base of which has already been described, is here seen, showing a semi-inferior, almost circular foramen magnum ( $\left.f . m_{0}\right)$, convex sub-reniform condyles (oc.co), exoccipitals with a low par-occipital riclge, and the lower edge of the large supraoccipital (s.o.). All the bones, here, are separated by a moderate tract of cartilage; in front of that which runs sinuously inwards and forwards, between the basal and side pieces, we see the hole for the hypoglossal nerve (fig. 9, XII.) lying in a notch of the exoccipital (e.o.).

The upper view (Plate 10, fig. 2) shows the form of the skull best, in its resemblance to a small gourd, the nasal labyrinth merely forming the neck to the bulbous cranium.

Here an unossified endoskeletal tract of the snout $(a l . n$.) finishes the upper end, and an ossified tract, the wide superoccipital (s.o.), finishes the lower; all the rest, as seen in this view, is composed of pared investing bones.

The emarginate space in front of the nasals shows a considerable amount of the double narial tube, ending near the fore end in the lateral nostrils (e.n.).

The nasals ( $n$, line too short), notched in front, widen, wing-like, at their frontal end, and are somewhat pinched at their sides. Just the top of the feeble facial plate of the premaxillaries $\left(p x_{0}\right)$ can be seen here, followed by the ascending part of the maxillaries $\left(m x_{0}\right)$, into which is set the small perforated lacrymal $\left(l ., l_{.} . c_{\text {. }}\right)$, and from which grow the feeble threads that remain of the jugals $(j$.$) .$

'The frontals $(f$.) are notched at their fore angle by the lacrymal wedge; they then expand a little, and contract again, to finish the "neck" of the "gourd."

From this neck, or waist, at the front third of the badly enclosed orbits, the whole cranium swells into its bulb, with but little injury to its neatly oval form, until we come to the gentle median projection of the supraoccipital.

There is but little difference in the length of the frontal and sagittal sutures (see also fig. $\left.3, f_{.}, p_{.}\right)$; but these bones are not finished where they should pass into each other; there the sutural teeth are large enough for a very much larger type, just as we find in the Caducibranchiate Salamandrians (see. Trans. Limn. Soc., ser. 2, vol. 2, plate 18, Cynops; plate 21, Spelerpes and Desmognathus). Here, in this dwarfed arboreal type, the fontanelle $\left(f_{0}\right)$ is bilobate, and fills in slowly, reminding the observer of the numerous dwarfed arboreal kinds of Anura (Tree-frogs) that abound in the same primaval forests, the companions of this very type.

But the side view (fig. 3) shows some of the most remarkable things in this arrested type of skull; this may be compared with the similar figure given of the embryo Unau (Plate 8, fig. 3); such a comparison will show a likeness between the two that is very remarkable.

One thing may be stated here, namely, that the length of the basifacial axis, from 
the front of the presphenoidal region to the end of the snout, and of the basicranial, from the former point to the foramen magnum, are nearly equal; so they are in the embryo, and in the new-born, Unau.

But in the great Ant-bear the front measurement is about three times the length of the hinder; hence I call this little skull quasi-embryonic-the Mymecophagine specialization of the face is arrested, and it is, very probably, the descendant of a much larger type, with a much longer face.

The fore part of the face is bent downwards in a mamner that is abnormal for this advanced stage, although it would be quite normal for an early embryo. The snout $\left(a l . n_{0}\right)$ is compressed and the nostrils (en.) lateral; the premaxillaries ( $x_{0}$.) are very small angulated bones just touching the nasals above, and followed by the maxillaries, which for them, have a starved appearance; they are wrinkled, and hollow extermally, without much convexity in the alveolar region. The infraorbital foramen is oval, and the bone over this passage swells somewhat, but has a notched upper margin where the lacrymal (l.) rests upon it. The maxillary is notched again, twice, in its suborbital region, and then ends in an ear-shaped jugal process, with fine threads of bone -remnants of the jugal $(j$.$) - attached to it.$

The lacrymal $\left(l_{0}\right)$ is a thin shell of bone, perforated for the duct (l.c.), and hollow towards the eye-ball; it has both a facial and an antorbital region. The frontals are almost Oplidion; together they nearly form a cincture by the large development of their orbital plates, which leave no space for any "pars plana" of the ethmoid, or allow more than a small patch of the low orbitosphenoids (o.s., see fig. 7) to be seen in the base of the orbital region.

These orbital plates come down to rest upon the palatines (figs. 1 and 3, pa.), and form a moderately concave wall to the very indefinite orbit. 'The supraorbital region is marked by a convexity having the shape of an hour-glass, the "waist" of which is part of the general constriction of the skull round the enclosed ethmoids.

The greatest concavity of the deep orbital plate is just below the second supmorbital swelling; it is then a little convex, and then hollows out backwards and downwards, the hollow ending in the principal orbital foramen, for the ophthalmic (orbitonasal) nerve $\left(\mathrm{V}^{\mathrm{l}}\right.$ ). There the orbitosphenoid $\left(0 . s^{\circ}\right)$ is exposed, and in it the optic passage (II.) is seen.

Behind the sinuous imperfect coronal suture the parietal (p.) stretehes backwards to the occipital arch, and, below, comes down towards the floor of the skull nearly as well as in the Snake.

Thus the temporal fossa is merely a part of the general face of the skull, inferolaterally, the parietal being scarcely at all hollowed to form it; here, at the lowest front angle, the parietal sends forwards a large round lobe that binds down upon both the wings of the sphenoid just over the sphenoidal fissure $\left(\mathrm{V}^{1}, 2\right)$.

Looking towards the mid-line, below, we see the undergirders of the sliull-the palatines and pterygoids $\left(p a_{0}, p g_{0}\right)$; they show, from this aspect, their ribbed edge, and 
the manner in which the infero-lateral parts of the endocranium are built upon them. Over their junction, and over the exposed part of the pterygoid, the alisphenoid is seen, partially, with its formen ovale $\left(\mathrm{V}^{3}\right.$.) in its middle, fitr forwards from the primary normal place for the escape of the hinder division of the trigeminal nerve."

The squamosal (fig. 3, sq.) is a very narrow, low-lying scale, a lateral or temporal scute, differing but little from that of the Frog, but specialized in another manner. In that Amphibian the onter or obliquely descending process binds upon a massive quadrate region, the hind part of the endoskeletal upper jaw. In this case, that of the Mammal, the outer process binds over the much arrested quadrate (=incus) at its proximal part, but the free end acquires a cartilaginous facet for articulation with the detached fore part of a compound mandible. The upper edge of the squamosal is gently convex, there is a small notch near the end, and the bone then forms a sinall angular process which fits in between the parietal and opisthotic (op.).

Below that junction, in fiont of its squared end, the bone is perforated for a vessel; it is then lobate, then notehed over the fiont crus of the tympanic (a.ty.), and, in front, on the inside of the short jugal process and glenoid hollow, it ends as a rounded angle behind the descending lobe of the parietal (see also figs. 1 and 9). The obliquity of the ammulus $\left(a . t y_{0}\right)$ is well seen here, and the large size of the drum-membrane and the manubrium $\left(m_{0} . y_{\circ}, m_{\circ} m_{l}\right)$. A convex, roughly pentagonal mastoid region (op.) is displayed in this side view, and over it the edge of the huge supraocipital (s.o.), dovetailed by the lateral occipital (o.), behind which the condyle (oc.c.) is hardly visible. The projection of the crown of the occipital arch is well shown in this view; the general relation and direction of these parts is very similar to what is seen in the early embryo of the Unau (Plate 8, fig. 3), whose squamosal (sq.) is probably very much like that of the little Anteater at the same stage. In the latter the parietal overgrows the squamosal; in the Unau (Plate 8, fig. 3; Plate 10, fig. 3) it is the squamosal that becomes so greatly developed, becoming half the size of the parietal, whereas in this case it is about one-tenth the size. ${ }^{+}$

In the Unau, whilst the teeth are thin caps of dentine on small rudimentary pulps (Plate 8, fig. 3), the mandibular ramus is not more unlike that of this edentulous type (Plate 10, figs. 3, 31) than it is to that which it will become in the ripe embryo (Plate 9, fig. 3). The edge of the ramus is curiously denticulated where the outer and inner lamina should form the alveolar walls. This is very similar to what is seen in

* The position of the formen ovale in the Mammalia is correlated with many remarkable specializa. tions that are diagnostic of the skull in this class; one of these is the extreme obliquity, or tilting, of the auditory capsules, and another is the out-tbrust of the alisphenoids, themselves, which now in the Mammal, for the first time, are pushed clean outwards from the general endoskeletal wall.

† I am satisfied that if a perfect series of embryonic Unans and Anteaters-small or large-conld be obtained, we should find that these two extremely specialized forms of low Entheria would be found to approximate more and more when thus studied downurds and dackuads; thus they would be scen to repent, in their prenstal state, their secular birth and growth. 
other edentulous types, as for instance in a remarkable Neotropical Passerine Bird-Phytotoma reve (Trans. Zool. Soc., vol. 10, plate 46, figs. 8-10); and in a gigantic Toad (Bufo agua, Phil. Trans., 1881, Plate 36, fig. 2) from the same region, whose palatines (normally edentulous in existing Anura) show signs of an old tooth-surface in the form of sharp osseous denticulations.*

In this slender mandible, decurved like the snout end of the upper jaw, the coronoid process $(c r . p$.$) is a good wide hook, separated from the round condyloid process (cd.p.),$ with its clearly marked neck, by a large semicircular notch; a shallow notch seprarates the latter from the less marked angular process $\left(a g \cdot p^{2}\right)$, which is slightly incurved. The inner face of the ramus (fig. 3A) shows tracts or regions of bone that correspond most accurately with the coronoid and splenial bones of the Oviparous Vertebrata; the rapid ossification of the ramus from the main bone, or dentary, does not allow of distinct centres for these parts; at least, as fur as I have seen, they are only partially distinct.

The end wen of this skull (fig. 4) is as important as the other aspects, which have to be corrected, visually, by this. The fundus of this tlask-shaped skull is subcircular' and gently convex; the perfect semicircle, above, is finished in its ontline by the deep parietals $(\mu)$; the rest of the outline is made more irregular than it would be by the appearance, in the distance, of the hinder swellings of the tympanics $(a . t y$.$) . 'The$ supraoccipital (.$\circ$.$) is reniform, with a concentric muscular ridge, but the lower edge,$ besides its "hilus" over the large, nearly circular foramen magnum ( f.m.), is notched, right and left, by the squared upper" end of the exoccipitals $\left(\iota_{0}.\right)$; the upper and outer junction of these bones is sinuous, the outer and lower margin fitting against the opisthotic (op.) is rounded. A notch separates the outer lobe, with its thick paroccipital edge, from the reniform condyle, and between the right and left condyles the basioccipital comes into view. Here we see the extraodinary development of the "basipterygoids" of the basioccipital (b.p. ) like those of the Unau (Plate 9, fig. 1), but larger, and carrying the ends of each pterygoid bone (p\%.). The lower face of each pterygoid is flat, but oblique, the outside being the deeper part; the interspace between the two bones is not greater than the width of each; this is floored by a strong membrane, and thus the circular hind part of the naso-palatine canal (n.p.co) is completed, a little in front of the formnen nagnum. A membranous interspace is seen between ench tympanic and the opisthotic (a.ty., IX., X.); outside the broad outer opisthotic part we see the hind margin of the narrow squamosal (s\%), and over the tympanic the epihyal (e.h.y.), and right and left in this region the nerve passages for the facial, glossopharyngeal, vagus, and hypoglossal (VII., IX., X., XII.).

'The external views (figs. 1-;) were taken from the smaller dry skull, with the belp of the larger spivit-specimen; the sectional vien's (figs. 7 and 8), the hyoid (fig. 6), and

\footnotetext{
* 'The cmbryology of the Myrmecophagide and of the Mamida would possibly show us rudimentary teeth in both families.
} 
the romerine bones and cartilages (fig. 10) are from dissections of the latter, more developed, young; this will account for some differences of form in the parts.

'The complete longitudinally vertical section, made a little to the left of the mid-line, shows almost perfect ossification of the endoskeletal part of the skull, proper, with no appearance of bone in the internasal region. That region is very short in proportion to the long cranial cavity, which, itself, is remarkable for the large development of the supraoccipital (s.o.) and for the peculiarly low position of the whole of the double sphenoid, reminding the observer of the skull of Serpents. The delicate decurved snout has the familiar fenestra $\left(i_{.} n_{0} f_{0}\right)$ in the fore part of the septum nasi $(s . n$.) between the external nostrils. The JAcoBson's, or recurrent, cartilage $(2 \text { c.c. })^{*}$ is cut across on the left, but that of the right side is seen under the septum nasi (see also fig. 10). The whole septum $(p . e ., s . n$.) is rather high in proportion to its length; its thick intertrabecular base has an arched or concave outline, but the top of the crest or partition is convex for some distance, and then drops rather suddenly towards the snout. The descending margin of the middle ethmoid (p.c.) is somewhat crested (the crista galli) and grooved by the olfactory filaments; the cribriform plate (below cr.p.) cannot be seen in this view; the partition hides it. Here the presphenoidal bony tract $(p . s$.$) is now almost complete through the fusion of the orbitosphenoids, which$ have long ago lost their large upper cartilaginous tract joining on to the supratemporal crest, and the supraoccipital.

The upper part of the orbitosphenoid only can be seen, and half the optic formen (II.); that wing has its margin first descending and then rising into a short lobe in firont of the sphenoidal fissure $\left(\mathrm{V}^{1} \stackrel{2}{2}\right)$. The alisphenoidal ( $a l .$, read ul.s.) lies still further out of sight, being thrust outwards as well as downwards (see fig. 1); its upper edge is notched gently, here, and the formen ovale $\left(\mathrm{V}^{3}.\right)$ is below the angular process that divides the notches (see also fig. 9).

The cartilage between the pre- and basisphenoids $\left(p_{.} s_{\circ}, b_{.} s_{\circ}\right)$ is longer than that between the basisphenoid and basioccipital $\left(b_{0} o_{0}\right)$; and the latter tract is high, being part of the postclinoid wall. 'This is thick now, being composed of part of two bones and the intervening cartilage, but in the adult the "sella" becomes more scooped, and the postclinoid wall is thin and curls forwards. The shorter presphenoidal tract of bone is twice as thick as the basal pieces behind; the basisphenoid is the longest of the thee. The internal carotid artery (i.c.) enters the skull nearer to the mid-line than in Eutheria, generally, but its entrance is normal; its internal continuation, forwards, is large, and lies in a very definite groove over the junction of the base and ala.

'The exoccipitals (c.o.) have a considerable parting of cartilage, yet, between them and the basal plate $($ b.o. $)$; the latter is notched in a crescentic manner, twice, first for the cochlea, and then for the exoccipital. A definite tract of cartilage still separates

* The line from rc.c. is wrongly clirected to the premaxillary; the anterior vomer (see fig. 10, $v^{\prime}$.) is not lettered. 
the latter bone from the great keystone piece $(s . o$.$) , which is notched in a triangular$ manner for the upper angle of the exoccipital.

The rounded, projecting, rather obtuse angle of the great supraoccipital is not in the middle, but below it, for the bony section along the top is one-fourth longer than that which leans over towards the spine, behind. Here, as in the Monotremes, the hind brain lies in a great hollow recess, formed by the ossified chondrocranium, and does not simply lean against a moderately concave wall. If the fore angle of the supraoccipital had been sharply pointed, and the frontals more developed backwards, we might have had what is seen in the highest physoclystic 'leleostei, namely, lateral parietals, and the supraoccipital meeting the frontals. Here, the cut edge of the occipital "tegmen" is longer than the inner edge of the parietal, where it neets its fellow to form the sagittal suture.

The tilting of the auditory capsules has been so great that their hind border lies almost flat upon the exoccipitals and basioccipital. The capsule is rather small, well ossified, and from the smallness of the space, and its immaturity, the form or the exquisite labyrinth within has been retained in the bony capsule. The anterior' canal, with its ampulla (a.s.c.), is seen arching over a very definite recess for the flocculus; and also its junction with the posterior canal (p.s.c.). Over both these canals the bony capsule becomes angular, to fit into the interspace of the neighbouring bones. Across, below the swelling of the vestibule, where the ampullio open, the archway of the meatus internus shows the normal passages (VII., VIII.) and, antero-inferiorly, below these, the coils of the cochlea.

A part of the exposed lower surface (fig. 9, chl.) shows a very tumid proximal coil, with $n$ o definite mark of the further turns of the helix. "This figure clearly shows how the squamosal, where it opens into the air cavity of the drum, helps the "tegmen," forming an eave over it, and that under this eave the top of the 1 st and and visceral arches are sheltered. The secondary fenestra ovalis, and the mimary fenestra rotunda (inside st., and $f_{0} r$.) are here shown, the former closed by the proximal part of the hyoid arch, or stapes (st.). The sub-proximal part of that arch, the epihyal (c.hy.), is confluent with the opisthotic region (op.), and has formed the bony "tympanohyal" of FLower-the proximal endoskeletal part of the so-called "stylohyal."

The remainder of the hyoid arch is shown separately (fig. 6); the ceratohyal (c.hy.), as in the Sloth, is undivided, and is followed by a longish hypohyal (h.hy.); this is pointed at its distal end, and joined, lightly, to the basal piece; it is slightly ossified. The ceratohyal is largely ossified; flattened above, and united, there, by fibrous tissue to the epihyal; below it is thick, and presents a flat fice to the flat face of the hypohyal, where there is a joint cavity.

The basihyobranchial $($ b.h.br) is $\mathrm{U}$-shaped; the median part is a thick wedge of cartilage, the diverging horns are solid, round, bony rods, tipped with cartilage-the thyrohyals $(t . h y$.).

* According to the excellent researches of Professor Alexanoer Fraser. 
The structures seen under the tegmen (fig. 9) are the incus, malleus, and stapes (see also fig. 5), where they are shown as detached, and from the outside, the stapes clislocated from the incus. The malleus has a large manubrium (m.ml.), with a strong elbow (posterior angular process, p.og.), turner towards the membrana tympani. The whole of the process is set on to the head of the malleus at more than a right angle; but, fiom the round bulbous fore part of the head, the processus gracilis $(p \cdot g)^{2}$ ) is continued straight forwards; that part is a long spatula, dilating forwards as it runs towards the Glaserim fissure. It has been much larger, 1 have no doubt (see in the Unau, Plate 9); afterwards it is absorbed up to its root (see Dor ss, plate 64, fig. 13).

The mutual sinuosities of the two bones at their junction give the hinge of the malleus with the incus an angular appearance (fig. $5, i ., m l$ ); a good face of cartilage remains at this part. 'The top of the short process and the disk of the long process of the incus (s.c.i., l.c.i.), are still mossified; the long process is well elbowed before it turns inwards, near its dilated end; this part is quite normally Mammalian.

But the stapes (st.) is not normal; the hole is absent; this element is a short flat "columella," with apex and base still mossified; afterwards (DorAN, op., cit.) a feehle vertical fossa forms along the shaft where a groove is shown. Now and then this hone becomes almost " "stapes." Heie we are on the level, or height, so to speak, of the Metatheria. There is a small interhyal (i.hy.) on the neck of the stapes.

Retuming to the large vertical section (fig. 7) and its partial comnterpart (fig. 8) we see that the nasal lahyrinth is quite nommal and not badly developed; the nasal, inferior, middle, and upper turbinals (fig. $8, n . t$. , i.tb., m.tb., u.tb.) are all well formed, although the complication of the last two regions-parts of the true olfactory region -is not great; these coils of cartilage are quite unossified, so that my largest specimen must have been very young.

In the main section (fig. 7 ) the roof bones (n., f., p.) are shown to be rather solid; the masals overlap the frontals, which cover the olfuctory region by their fore part (see also fig. 2). But the orbital region of the frontal, and the temporal region of the parietal bones are developed downwards in an almost Ophidian manner, so that a little firther ingrowth of the former wouk have given us a perfect frontal cincture-a state of things not absent firom some of the high Eutheria. 'The parietal comes down and lies on the low alisphenoid $\left(a l, s_{0}\right)$ by a broad emarginate process, behind which a small oval intercranial tract of the squamosal $(s \%$ ) is seen; as small as in the average Bircl. The right jointed palatine beam is seen reaching from the back of the snout to the fiont of the formen magnum, the series forming this many-pieced "balk" of" bones is as follows: the premaxillary, maxillary, palatine, and pterygoid (px., mx., pa., pa. read $p g$ ) ; these form the floor of a continuous canal, which opens freely into that of the other side, all along.

There is a small bone, the fiont paired vonner (figs. 7 and 10, $v^{\prime}$.), right and lefi over the fore part of the double channel-the naso-palatine canal, and behind it a groover bone, the vomer $(v$.$) , as \operatorname{long}$ as the palatine plate of the maxillary; right 
and left of the hind part of the vomer there is a bony plate; these are hind parred vomers (fig. 10, v."); they serve to unite the vomer, proper; with the ossifying ethmoidal masses, afterwards; the principal or proper vomer is not camate below either in this type, in the Armadillo, or in the Sloth (see Plate 2, fig. 1; Plate 3, fig. 9; Plate 5, fig. 6; Plate 6, fig. 9; Plate 8, fig. 8.).

When it is carinate below, the romer, resting upon the hard palate, keeps up the subdivision of the nasal passages, so far back; whereas in these Neotropical Edentates these passages open into each other close behind the snout. Now this state of things is not seen in the Palaotropical kinds, as I shall soon show, and as these latter agree in this respect with the Insectivora, and also, as in one of their Old World forms, the Aard-Vark, we have the exceptional "interparietal"--so large and miversal in the Insectivora-it seems reasonable to suppose that we have in the Old and New World Edentata two "sucker's" from some old "root-stock," that separated from each other long since, diverging and breaking up, each into its own special subdivision, of which sub-division we have only two genera, representing two, fumilies in the Old World, and many genera and several fimilies-especially it we take in the extinct kinds-in the New World.*

\section{MANIDA.}

My materials for working out the skull in this family were as follows :-

First Stage. Embryo of Munis,__- sp. ; $2 \frac{1}{3}$ inches long, snout to root of tail; tail itself $\frac{2}{3}$ inch long (Plate 1, figs. 3, 4). †

Second Stage. Embryo of Hanis brevecudata (from Ceylon; procured for me by Mr. WARD); $4 \frac{2}{3}$ inches long, snout to root of tail ; head $1 \frac{2}{3}$ inch long; tail $2 \frac{1}{5}$ inches (Plate 1, figs. 5, 6).

Thind Stage. New-born young of Munis Temminckii; head $2 \frac{1}{4}$ inches long. Fourth Stage. Adult Pangolin's skull, Manis,_- sp.

First Stage.—Embryo of Manis,--_-? sp.; $2 \frac{1}{3}$ inches long (Plate 1, figs. 3, 4).

The skull of this very immature embryo (Plate 11, figs. 1-6) differs very greatly from anything I have as yet seen in the Mammalia; it has its endocranial parts as abortive as its ectocranial.

* In the present state of my slow work 1 scarcely can lint at the relation of these Old aud New World Edentata to the groups below and around them; I feel sure, however, that the Aard.Vark is the nearest to the Insectivora, of any in the Order; and that the New World kinds, generally, and the Old World Pangolins, also, are nearer to the Monotremes than to the Marsupials.

$\dagger$ The youngest Tatou (Tutusie luybritu) was only $1_{3}^{2}$ inch long from snout to root of tail (Plate 1, figs. 7, 8), but its development was twice as much advanced as this; the Pangolins, like the Aard-Vark, are very large at the time of birth. This embryo of the Pangolin, for which I am indebted to Dr. GUNTHER, is therefore my proper starting-point in the stady of the skmll in the Edentata. In the Insectirora, Marsupialia, \&c., I shall describe much earlier stages than this. But if time and materials serve, I hope, some day, to add an appendix to the present paper, giving earlier stages. 
I have been able to compare it with the early skull-twice as advanced, and yet with at very perfect chondrocranium-in the Armadillo and the Unau, amongst the Edentata.

But in types that have yet to be described, especially the Marsupials and Insectivores, I find early crania differing in various ways, but quite normal, and with a well-developed chondrocranium.

In the Monotremes I have the most important, because most radical, types for comparison; but in both genera-Omithorhynchus and Echidna-in young two or three times as advanced as this embryo, the chondrocranium is most massive and well developed-almost Dipnoan.

Both in the early skull of the Marsupialia and of the Insectivora I shall be able to show how gentle the modification is of a Mammalian skull at this stage, from that of the embryo Crocodile. Even if that good, practically fundamental type of skull of a well-developed Amniote (see Trans. Zool. Soc., vol. xi., plate 65), be compared with those of the Tatou and Unau just described (Plates 2 and 8), it will be evident that we have in the chrondrocranium of that Reptile everything we want, in a generalized form, out of which to frame (mentally) the much more specialized skull of a normal Mammal.

But there are other Sauropsida whose skulls have undergone, in various ways, the uttermost degree of specialization-I refer to the Ophidia and Carinate Birds.

In explaining this early skull of the Pangolin and also its latter stages-even that of the adult-I shall have to show a parallelism in several things between the skull of this low Eutherian, and of those two extreme forms of the Oviparous Amniotesthe Snake and the Flying Bird.

The earliest skull, worked out by me, of the Ostrich (Phil. 'Trans., 1866, Plate 7), being at the same stage, is very profitable for comparison; yet, when all is done, and the likeness of this skull to any or all of these Sauropsidan types has been shown, there will still remain all that is strictly and absolutely Mammalian, the result of a transformation of various parts that suggests a true historic metamorphosis which once lifted up the Mammal, when just emerging from its low laval form, far above the platform of the other Amniota - the Sauropsida, - whether scaly or feathered.

The lower view of the skull (Plate 11, fig. 1) shows that the nostrils $(e . n$.) are large, and obliquely inferior in position; they are roofed over by dilated alinasals (al.n.), which have a wide base $\left(n . f^{\circ}\right)$.

All the beginnings of the ectoskeletal tracts are fine bony films, and are very far from investing the parts they are intended to cover.

The premaxillaries $\left(p x_{0}\right)$ are small, $\mathrm{V}$-shaped bones, with their rounded angle foremost; their proper dentary tract is no larger than their palatine process, which is short at present; afterwards (fig. 8) it is long, having received the addition of the small corresponding anterior paired vomer (fig. 1, $v^{\prime}$.).

Each maxillary $\left(m x_{0}\right)$, as seen from below, is a leafy lanceolate bone, with a notched hinder end and an inferior ridge. This ridge is the closed alveolar region; it 
is arched outwards, and rums from end to end of the bone, its hind part being continued into the inner fork of the bone. From this ridge a scooped plate runs inwards as a palatine flange to the main bone; its outline, on the inside, is symmetrical with that of the alveolar vidge. The right and left lanceolate palatine plates are separated by a space nearly their own individual width; the first third of this space is taken up by the palatine processes of the premaxillaries and the front paired vomers, the hinder two-thirds is occupied by the vomer, proper $\left(v_{0}\right)$, the outer edges of which rest upon the corresponding palatine plates of the maxillaries. The vomer is split in front, keeled all along, and somerwat trilobate behind; it, is a stout, shortish bone. The nusal capsules are seen inside and around these bones-side, septum, and terminal recesses (al.s.p. al.e.); the septum is first seen where it begins to rum over the fore part of the vomer, and the proper olfactory region, after swelling outwards beyond the maxillaries, runs inwards over the sharp forks of those bones, to end right and left of the presphenoidal region (p.s.).

As far as the maxillaries are concerned, this skull is now perfectly "schizognathous;" so it is as regards the palatines ( $p a$.), which are in a very primitive, quasi-reptilian condition. Each bone is falcate, and arched inwards; it is thicker forwards than behind, is a sharp wedge in front, binding obliquely on to the inside of the inner sharp process of the maxillary, whilst, behind, it runs outwards as a fine point of bone, binding over the pterygoid $(p g$.$) . Behind the vomer (v \circ)$, the palatines are, at their nearest, nearly their own width apurt, whilst, further back, they expose the whole width of the basicranial beam.

The palatal series is completed by the pterygoids $(p g)$; these bones are only twothirds the length of the palatines, of the same thickness, on the whole, and are wider apart, for at their middle they elbow out, like two pieces of "knee-timber." 'The fore end of each bone is sharp, and runs obliquely insicie the palatine, the hind converging part is rounded, and is capped by a truly cartilaginous remnant of its mother-tissue. This cartilaginous hamular process is common in the embryos of low Entheria. It is a slight re-appearance of the old "pterygo-quadrate" of the Ichthyopsida. The rest of the superficial bones seen in this view are the frontals $(f$ ), and the squamosals (sq.); the former are turned in under the suborbital ridge, and over the orbit, and the latter are applied to the endocranium opposite the pterygoids. 'The frontals are very partial, however, in this region, and only partially invest the arrested orbitosphenoids (o.s.). Behind these endo- and exo-skeletal laminæe there is a large lateral fontanelle, which takes up most of the posterior region of the orbital space (see also fig. 3). The squamosals are distinguishable from those of a Chick by the presence of a small, flattish, pyriform tract of cartilage attached to their jugal process; in the Chick this process serves for muscular attachment merely; here, in this low Mammal, we have the "glenoid" facet for the special Mammalian mandible, at its lowest state of development.

The floor and sides of the chondrocranium are largely seen in this view; I have MDCCCLXXXV. 
already spoken of its nasal or olfactory territories. 'The hind part of the perpendicular ethmoid (p.e.), and all the rest of the basis cranii, is displayed; but the edges of the bar, in front, are hidden by the inbent palatines; just in front of their middle, the presphenoid (p.s.) begins, and this is halfway, exactly, between the end of the snout and the fiont edge of the foramen magnum $\left(f_{.} m_{0}\right)$. If the postclinoid wall could be seen, it would be found to be half way from the end of the former to the foramen magnum; the open pituitary space $\left(p y_{0}\right)$ is a little in front of it.

A little in front of that primary opening, the basicranial beam is composed of three bars melted into one; the lateral bars are the trabeculæ, and they end between the widest parts of the ethmoidal swellings and the middle of the vomer; thence the basiseptal mass is formed of the azygous intertrabecula.

The orbitosphenoids are trabecular crests, as the great internasal partition is an upgrowth of the intertrabecula.

In the Crocodile and Alligator (see Trans. Zool. Soc., vol. 11, plate 64, fig. 2, $t r .$, o.s.) the orbitosphenoids, are seen growing directly upwards and outwards, from the paired trabecula. After the great intertrabecular crest is well developed, and the trabecula become thinned out on its sides, right and left, some transverse sections show a discontinuity between the orbitosphenoids, perched at the top of the crest, and the flattened trabeculæ from which they sprung (ibid., plate 67, figs. 2, 3).

In Serpents (Phil. 'Trans., 1878, Plates 28-31) there is no intertrabecula, and the nasal roots dip down, and coalesce with the trabeculre, which become fused in the internasal region. But in the interorbital region the trabecula persist as free terete rods of cartilage, and both the orbitosphenoids and alisphenoids arise in the wall of the membrano-cranium as small, free patches of cartilage. This is a curiously abortive and arrested condition of these parts.

Here in this little skull, which is abortively developed, both within and without, the very feeble orbitosphenoids, small and with very imperfect angular extensions, above (compare figs. 1 and 3 with the skull of the embryo of Tatusia, Plate 2, fig. 1), are articulated to, or distinct from, the proximal part, ending above it in a bilobate process. There is, however, evidence here that this is the abortive development of a type above the Marsupials, for the optic nerve (II.) passes through a ring of cartilage, and not through a common optico-sphenoidal fissure, as in them.

The rest of the sphenoid, excluding the abortively developed orbitosphenoids, is a remarkable structure. The basal beam is very wide, and has, for a Mammal, an unusually large and almost Sauropsidan pituitary hole; opposite that unfinished space the base grows out into a pair of thick rounded ears of cartilage, thicker and a little wider than the lateral processes of the presphenoid, which are perforated for the optic nerve. A rounded notch is seen both in front of and behind these small auriform alisphenoids (al.s.), and these notches are actual foramina, through the membranocranium; the foremost is the sphenoidal fissure $\left(\mathrm{V}^{2}.\right)$, and the hinder is the foramen ovale $\left(\mathrm{V}^{3}\right.$.), only a forcmen as it respects the membrane, not the cartilage. But the 
hinder of these passages is a great distance from the mid-line, and has a considerable (proximal) part of the alisphenoid between it and the proper basis cranii. 'The breadth of the investing mass or parachordal tract behind the pituitary opening is nearly equal to that of the cochlere $\left(c h l_{0}\right)$-those diverticula of the huge anditory capsules. The notch for the formen ovale $\left(\mathrm{V}^{3}.\right)$ is against the inmer third of the cochlea, the squamosal reaches the outer third, and then increases the size of the tegmen tympani (t.ty.), the incus is shown in that space overlapped by the squamosal. The bulbous cochlex (chl.) have the appearance in this view of being only composed of two coils, for the proximal coil is very large, and the distal is not marked off' from the second. 'The outline, even in the inner face, is evident, but the cartilage of the capsule has for some distance coalesced with the basal plate (b.o.), that is, along its inner edge, from the foramen ovale $\left(\mathrm{V}^{3}\right.$.) to the opening for the internal carotid artery, and then again on to the fissure for the ath and loth nerves (for X., XI., read IX., X.). 'The stapes (see also figs. 3 and 6 ) has been removed from the fenestra ovilis and from the incus $\left(i_{0}\right)$, and from the latter the primary mandible or malleus ( $m l$ ) has been removed. Thus in this figure the pier of the primary mandibular arch, the quadrate-or, speaking specially of it as a Mammalian element, the incus-is seen inside the posterior radiations of the squama temporis $(s \%)$. Its position here in this very simple kind of Mammalian skull is well worthy of consideration.

If we take the short crus of the incus as the equivalent of the "otic process" of the quadrate, and the long crus as a special Mammalian modification of the incus for articulation with the head of the stapes (=extra stapedial process of the columella, see in Chameleon, 'Trans. Zool. Soc., vol. xi., plate 16), and remember that in the Mammal the "orbital process" is suppressed, we shall see clearly what these things mean. In all essentials, everything is the same, here, as in the Fowl (Phil. 'Trans., 1869, Plate 81).

'The body of the incus, which articulates with the primary mandible, is opposite the middle of the cochlea; the long crus runs inwards to join the stapes-or columella in this case (see fig. 6) - and the short crus or otic process runs backwards over the stapes and fenestra ovalis, so as to get behind the ampulla of the horizontal canal (see fig. 3 , h.s.c.; and in the Fowl, op. cit., Plate 81, fig. 5, \%., h.s.c.). 'The fenestra rotunda, in this figure, is hidden from sight by the small rounded epihyal (e.hy.) which is alieady confluent with the capsule; behind it the facial nerve (VII.) escapes through the stylomastoid foramen, giving off in its escape the chorda tympani to join the 3rd branch of the 5 th nerve inside the primary mandible. In spite of the intrusion of the auditory capsules, and their tilted position, the cranial nerves make their escape in a very orderly manner. Here the facial nerve (VII.) although thrust far outwards-having to bore its way through the forepart of the capsule, from the meatus internus, and then travel backwards, under the tegmen tympani, yet manages to escape into the face a considerable distance in front of the 9 th and 10 th nerves (IX., X.).

The opisthotic rergion (op.) behind and outside the cochlea is very large, and the 
canals (see also figs. 3 and 4), are very conspicuous, shining through the hyaline cartilage. Outside the innermost lobe of the capsule, the ampulla and ascending part of the arch of the posterior semicircular canal (p.s.c.) is seen, and in front of it, more outward, the hind part of the horizontal canal (h.s.c.), which arches over the incus.

At present, the hind skull is a funnel-shaped structure, as though it were a detached and enlarged part of the spinal column. Along its wide floor, the basioccipital region (b.o.), the notochord (nc.) still persists, and runs more than half way to the pituitury hole $(2 y)$; it enlarges somewhat whilst in the parachordal channel, and then ends in a point. Right and left of its hind part, at a moderate distance from each other, the occipital condyles (oc.c.) are seen to be sub-crescentic thickenings of the infero-lateral margins of the chondrocranium; above and behind them, the roof (s.o.), imperfect behind, is ossified by a median osseous centre.*

The lateral occipital region $(c .0$.$) is but little raised as a paroccipital ridge; it$ is notched for the 9th and 10th nerves (IX., X.) -the formen being in the interspace of the arch and the auditory capsule-and perforated a little further backwards and inwards for the 12 th nerve (XII.). This would have been a pure chondrocranium but for the premature, single supraoccipital centre (s.o.).

The upreveru (fig. 2) shows the wide alimasal region (al.n.) followed by the more contracted double tube of the aliseptal territory (al.sp.), and this gradually widening into the aliethmoidal (al.e.), which swells on each side of the face in front of the orbits, and contains the upper and middle turbinals. The pyriform cranium has the broad, partly ossified supraoccipital (s.o.) for its base, and shows the deficient chondrification (s.o.n.) over the foramen magnum (see also fig. 4). The fore margin of this convex wall is sinuous, concave right and left of the middle, but with a convex margin, there, on each side. 'The ethmoidal and supraorbital regions are covered with bony films; and also the right and left third of the most swollen part in front of the supraccipital. Three pairs of these centres are visible from this aspect, the nasals, frontals, and parietals $\left(n_{0}, f_{\circ}, p_{0}\right)$.

The very small, short, nasals, are both in form, position, and relative size like those of a Bird, being deeply notched in fiont. But, in a Bird, these forks embrace the upper part of the extemal nostril, and between the nasals the premaxillaries send, each, a long lathy process-the nasal process (see in the Fowl, Phil. Truns. 1869, Plate 86, fig. 15). The Mammal has that process arrested, and the premaxillaries run under the outer edge of the nasals, and only have that extra-nasal process, large in certain types, e.g., the Hare and Rabbit.

'The frontals (fig. 2,f.) here lie over the orbital region, looking like the dislocated valves of a Bivalve; they do not meet in the middle, above and in front; beyond their

* A rare claracter-normal in Reptiles, but as rare in Birds as in Mammals; I have only, as yet, found it in one genus of Birds, namely, Turdus-the Thrushes (see Monthly Mieroscopical Journal, 187s, plate 9, pp. 10:-107).

In this figure of the skull of the embryo Pangolin (Plate 11, fig. 1, s.o.) the roof with its bony tract is figured as it appeared in the flutlened prepremation; figs. 2-4 correct this. 
middle they diverge rapidly, so do the parietals $(p$.$) behind them, but they are$ separated by a much wider space, almost equal to their own width. Hence the fontanelle $\left(f_{0}\right.$ ) is very large, has a narrow median limb in front, and a postorbital, and a supraoccipital pair of trusverse limbs; above, the median part is, over the vertex, dilated as a wide lozenge-shaped space.

But these things are secu also in an instructive manner in the side view (fig, 3). The narrowish snout is but little tumed downwards, it very suddenly passes from its short aliseptal region into the swelling ethmoids ( $u l . e$.). In front ( $a$.e.) the alinasuls form a crescentic portico over the sub-inferior nostrils (e.n.). Behind these parts-the snout, proper-the swelling caused by the inferior turbinal at the side, arches upwards and outwards from the semicylindrical upper tract ( $a l . s p$.), which contains the nasal turbinal; behind this is the bulbous olfactory region (al.e.), the narrow end of which ( $m . t b$.$) can be seen in the fore part of the orbit, below. 'The swall forked nasal ( n$. ) is seen to be a long way behind the external nostril (e.n.), and a good distance from the ascending toothed edge of the maxillary "scale" ( $m_{x}$.), in front of which is the narrow, oblique, ascending part of the premaxillary $\left(j x_{0}\right)$.

The frontal $\left(f_{\circ}\right)$ is moulding itself upon the orthital recess, and has a neat, superorbital edge; the bone is pinched in in front of that pirt. The toothed edges of these osseous scales-the frontals and parietals-nearly touch in the postorbital region. Under the inturned part of the frontal, the cartilagre (o.s.') lines the orbit, and just shows itself beyond, at the edge of the temporal region. Below, in the postero-inferior recess of the orbit, the optic nerve (II.) can be seen emerging through its ring of cartilage $\left(o_{.} s_{*}\right)$; it rests upon the thickish palatine bone ( $\left.\mathrm{po}_{0}\right)$. A large lozenge-shaped space is seen between the frontal, parietal, and squamosal $\left(f_{.}, p ., s q.\right)$; the latter hardly reaches the parietal in the temporal region, and is altogether a very jagged plate. Its jugal process runs outwards and forwards and shows its small pyriform glenoid facet $\left(g l_{.} f_{\circ}\right)$; its posterior part rus, splintery, over the face of the auditory capsule, hiding the ampullw of the anterior and horizontal canals (a.s.c., h.s.c.). But the hinder part of the latter, and the junction of the anterior and posterior canals ( $\left.2 . s_{0} c_{0}\right)$ - the latter displaying its ampulla-all these are clearly seen in this view, and also that the capsule itself' is not much tilted, at present. 'The cochlea (chl.), with its coils, and the pterygoid ( $p g$.) with its cartilaginous cap, are seen under the squamosal. Behind the swelling capsule, the large occipital arch shows an unusual amount of its surface in this aspect; it is a short, wide tube.

Above, the bony supraoccipital ( 8.0 .) is partly seen; laterally, this broad arch shows its sinuous edge behind the parietal, coming down to unite with the capsule above the junction of the two upper canals $(\alpha . s . c, p . s . c$.). The two parts of cartilage are confluent along the hind margin of the capsule, and here the exoccipital region (c.o.) is thickened obliquely, upwards and backwards, into a low paroccipital xidge; the condyle (oc.c.) is here seen in its upper part.

The incus (i.) is seen just peeping from under the postero-inferior comer of the 
squamosal; the malleus (ml.) has been dislocated from it, and also the new ramus from its zygomatic or glenoid ficet (figs. 3 and 6 ; in the former these parts are seen from the outside, in the latter more magnified figure, from within). 'The superficial secondary mandible $\left(d_{0}\right)$ is lesser than the deep primary rod $(\mathrm{mk}$.) ; it is applying itself to the upper and outer fuce of that rod, and in front is composed of two delicate tracts of bone, the inner and lower of which (sp., line too short) corresponds to the separate splenial of the Ovipara. But the main part of the ramus is a thickish lanceolate tract of hyaline cartilage; an "inferior labial," part of which tract has already become segmented off to form the glenoid facet.

MEcKEL's cartilage ( $m l_{\text {: }}$ ) has united with its fellow in front, and the two have an azygous rod in front of them, a basimandibular ( $6 . m n$.$) . The whole rod is sinuous,$ and thickens gradually backwards; the last fifth is behind the "ramus," and is the part which becomes the malleus $\left(m l_{0}\right)$. Then the rod is arched uprvards, and thence swells into a head, or articular portion, with a saddle-shaped condyle; from the head there arises a long and a short process-internal and posterior angular processes, which become the manubrium mallei $(\mathrm{m} . \mathrm{ml}$.). The long process forms an acute angle with the main rod, and ends in a slight dilatation in the middle of the developing membrana tympani (m.ty.), in the fore margin of which a slight are of bony cells is seen, the annulus (a.ty.). Under the proximal part of the rod a fine tract of membrane-bone is seen, the first appearance of bone to form the malleus $(=$ the ectosteal "articulare" of the Ovipara).

The quadrate or incus $\left(i_{.}\right)$is a quadrilobate segment of cartilage, binding against the malleus by the two front lobes, articulated to the tegmen tympani by the posterosuperior, and applying its inturned postero-inferior lobe, which has an orbicular facet at its end, to the head of the stapes. The latter part (st.) is oval in its base or proximal part, and then its short solid stem dilates in an orbicular manner to articulate with the incus.

That is the pharyngohyal; the epihyal is seen from below as a small lobe of cartilage, confluent with the ear-capsule, and forming a small bridge for the facial nerve to pass over (fig. 1, e.hy., VII.). The next segment is the ceratohyal (fig. 5, c.hy.), it is fibrous above, and instead of having an extra segment, above, and a hypohyal, below, as in most Mammals, there is but one piece altogether. 'The basal piece $(b, h . b r$.$) is also very rudimentary, being a bent U$-shaped rod, with very short continuous crura $(t . h y$.$) .$

Now in such an aberrant and feebly developed face as this, we can the better compare the Mammal with the Bird. In the latter the epihyal (=stylohyal) cartilage is also short; it does not, however, form an adhesion with the auditory capsule, but with a slender outgrowth from the neck of the columella (=stapes) (see "Bird's Skull," Part II., 'Trans. Limn. Soc., ser. 2: Zool. vol. i., Plate 20, figs. 7, and 8-11). That outgrowth-the infrastapedial band-is represented in Fishes by the interhyal, a segment which re-appears in the Mammal, and becomes wrapped up amongst the 
fibres of the tendon of the stapedius muscle. In the Bird the stapes, or columella, has not a flat head, but a tongue-like process (extrastapedial), which sends upwards at its base a forked spike (suprastapedial).

The ceratohyal is not distinct, in the Burd (as in Manis), from the hypohyal, but this feeble distal rod does not end abruptly and articulate with a transverse basal piece; it runs forwards into the substance of the tongue, meeting its fellow, there, at an acute angle; whilst the basal piece is longitudinal, and fits into the sharp re-entering angle formed by the two ceratohyals. The long basal piece is divided into what represents two basibranchials; and where the two segments meet, there is given off a large, segmented, gill-less 1 st branchial arch.

In the Bird the distal basibranchial forms the support for the thyroid cartilage; in the Mammal it is supported by, and articulated to, the paired hypobranchials of the aborted $3 \mathrm{rd}$ arch (=1st branchial).

The end view of this skull (Plate 11, fig. 4) is suborbicular-sinuous belowgently convex, and leans forwards above where the suproccipital joins the parietals $(s . n ., p$.$) . These latter are just seen, above, and so also are the squamosals (s q$.$) at$ the sides. The foramen magnum $(f, m$.$) is large and oval, with the long diameter$ vertical; it has a small deficiency in its upper outline, which leads to a circular membranous space-" the median occipital fontanelle" so familiar in certain Birds, e.g., Pigeon, Owl, \&c. (see 'Trans. Zool. Soc, vol. v., plate 34, fig. 2; plate 35, fig. 1; and plate 37, fig. 6, m.o.f.). Over this, from edge to edge, the cartilage has become ossified, by the azygous supraoccipital (s.o.), which is two-winged above, and forked below, the forks holding the fontanelle, like pincers. The rest of the occipital cartilage $(c . o$, b.o.) is free from bony deposit; in the middle of the basal plate, under the foramen magnum $\left(f m_{0}\right)$, the notochord $\left(n c_{\text {. }}\right)$ can be seen lying on the upper part of the thickness of the floor. The exoccipital region is very slightly raised into a paroccipital ridge, right and left, and is well marked off from the auditory capsules, in which are seen the posterior and horizontal canals (p.s.c.,h.s.c.). Underneath, in the distance, the cochlex (chl.) swell the bottom of the skull, right and left.

Second Stage.-Embryo of Manis brevicaudata; $4 \frac{2}{3}$ inches long, from snout to root of tail (see Plate 1, figs. 5, 6).

The under view of the skull at this stage (Plate 11, fig. 8), which is twice as advanced as the last, shows a great approach to the permanent condition.

The inferior nostrils (e.n.) are protected by a rounded but quite simple alinasal fold, and they approach each other more closely now, right and left of the alate floor. Part of the aliseptal region can be seen right and left of the front bones of the face-the premaxillaries $(p x$. $)$. These bones $(p x$. ) are very feeble, and are composed of an outer and an inner stalk; in the rounded re-entering angle, formed by the two stalks, the opening of "JACobson's organs" (j.o.) can be seen. The narrow 
fore part of the bone in its toothless alveolar region runs with its fellow close up to the alate alisnasal floor; it broadens to send upwards and backwards (see also fig. $7, p_{x}$ ) its falcate ficial plate. The palatine processes, once very short (fig. 1), are now extremely long, they have evidently made their hind part from the paired front vomers (fig. 1, $v^{\prime}$.). Two-fifths of the palatine plate of each maxillary (mx.) comes short of the mid-line, and exposes the long styles running backwards from the premaxillaries. The rest of these plates is complete, the termination of them behind is in sharp wedges that run between the palatines $\left(p u_{0}\right)$. The region between the thick edentate margins of the palate is elegantly lanceolate, and is more than a third of the general width of the face as seen from below; it is also high or arehed, for the fore palate in this type is very hollow. The arched alveolar ridges turn inwards to clamp the fore part of the palatines ( $p a_{0}$ ), and outside the ridges the bone is seen, right and left, expanding in a roughly convex manner to form the large facial plate (see also fig. $7, m x_{0}$ ). That plate swells suddenly over the lateral ethmoidal masses, and in the widest part is burrowed below for the 2nd branch of the 5th nerve $\left(V^{2}\right)$. The ridge from the infraorbital opening of that burrow runs backwards and outwards, and ends in a short, free, blunt zygomatic process, on which, in this stage, I find no trace of a jugal bone. The palatines $(p c$.), as seen from this aspect, are as long as the palatine region of the maxillaries. A considerable right-angled space divides the two bones behind, and a more acute-angled gap receives the maxillaries in front.

'They are somewhat pinched in, laterally, are slightly bevelled, externally, in front, and form a low ridge outside; each bone is gently hollowed towards its fellow; the two unite and carry on the median suture of the hard palate, which is half the length of the basis cranii, including the snout. This view only gives half the extent of the palatine bones (see fig. $7, p($.$) which have a large orbital develop-$ ment. The pterygoids $(p g)$ have only the average development, their external outline is concave as in the case of the palatines; their lower edge is thick, and they have a free hamular process, capped, still, with cartilage; they are two-thirds the length of the palatines; they still overlap the cochlere (chl.). T'wo large bony tracts can be seen on each side, the orbital plates of the fiontals $\left(f^{\circ}\right)$, and the zygomatic and postglenoid regions of the squamosals $(s q$.$) . The hind part of the nasal capsules$ (m.tb.) are still uncovered in the inner part of the orbital floor, the infraorbital nerve $\left(\mathrm{V}^{2}\right.$ ) is seen running under this tract right and left. The pyriform glenoid fincet $\left(g l_{f} f_{.}\right)$in the back of the zygomatic stump of the squamosal (sq.) is now large, and the bone, after swelling to enclose the facet, contracts into a neck, and then, hollow within, overarches the auditory capsule; the bony eave reaches back beyond the stylomastoid foramen (VII.) Inside the orbital plate of the frontal a large exposed part of the osseous orbitosphenoid $\left(o_{*} s_{0}\right)$ is shown as a rounded wing right and left. The optic nerve (II.) is escaping from its inner part, and its edge in front is notched for the re-entering orbitonasal nerve, which emerges from the 
skull at the sphenoidal fissure with the 2 nd branch of the 5 th $\left(V^{1},{ }^{2}\right)$. The presphenoidal region $\left(p_{.} s_{0}\right)$ is still unossified; it can be seen between the direrging palatines. The posterior sphenoid stretches across the whole inter-glenoidal region, outside and inside the pterygoids. The basisphenoid (b.s.) has ossified three-fourths of its proper territory; it is emarginate both before and behind. Nearer the eye than the orbital wing $(o . s$.$) , each alisphenoid \left(\mathrm{V}^{1}, 2\right.$ to $\mathrm{V}^{3}$ ) reaches the squamosal in front, and is then deeply notched for the 3rd branch of the 5 th nerve $\left(\mathrm{V}^{3}\right.$.). 'This notch is protected by bone behind, which runs between the nerve and the atiditory capsule $\left(c h l_{0}\right)$; on the outside the foramen ovale is finished by other parts, it merely notches the outer edge of the alisphenoid bone. In this figure the left annulus and its related parts are shown; whilst on the right side of the head-left of the figurethe lower face of the capsule is exposed.

The annulus $(a . t y$.$) is a wide U$-shaped tract, thickened at the end of its inturned cornua; the foremost of these is notched to let MEckeL's cartilage ( $m k_{\text {. }}$ ) pass. This is drawn as cut across. The narrow anmulus leaves a wide and exposed drum membrane (m.ty.), in which we see a long manubrium mallei proceeding from the head of the malleus $\left(m l_{0}\right)$, which articulates with the incus (i.) under the double tegmen formed by the squamosal (sq.) outside and the capsule within. The cochlea is exposed on the inner side of the annulus, and where the pterygoid $(p g$.) overlaps these parts, there the Eustachian aperture opens into the throat. The cochlea and vestibule (chl., op.) are large and normal; they are quite unossified; the fenestra ovalis $\left(f s_{.0}\right)$ is large; outside it is the passage for the 7 th nerve (VII.), which escapes through the stylomastoid foramen behind the small epihyal $(e . h \%)$; the rounded part behind that opening $(o p)$ contains the ampulla of the posterior canal. A band of cartilage separates the fenestra ovalis ( $\left.f s . o_{0}\right)$ from the fenestra rotunda $\left(f r_{0}\right)$, which is seen behind the first or proximal coil of the cochlea (chl.). A deep groove runs between the occipital arch and the capsule, and on the inner side of the vestibule both parts are notched to make a common passage for the gth and 10th nerves (IX., $\mathrm{X}$.). Behind and within this is another passage or hole in the occipital arch within the exoccipital bone (e.o.), which is creeping forwards; this is for the large hypoglossal nerve (XII.). Thence to the edge this part is ossified; and the bony matter runs right and left, up to and over the convex arcuate condyles (c.oc). But a very wide band of cartilage is seen continuous with, and in front of the condyles, margining the foramen magnum $\left(f \cdot m_{0}\right)$, and ending in a concave margin, where the basioccipital bone $(b .0$.$) has broadened out to twice its interauditory region. That bone is rather$ pinched in towards its fore end, where it is notched, and has a fine tubular process in the notch which runs much of the distance between this bone and the basisphenoid (b.s.); that process is the ossified sheath of the fore part of the cranial notochord $\left(n c_{0}\right)$

The upper view (Plate 12, fig. 1) shows how greatly the investing bones have developed since the early stage (Plate 11, fig. 2). The facial region is very small MDCCCLXXXY. 
compared with the cranial; the whole outline is pyriform. The nasal capsule is still considerably exposed, the whole alinasal, half the aliseptal, and part of the aliethmoidal parts (al.n., al.s.p., al.e.) still being visible. But the forked, ornithoid nasals (n.) have more than doubled their size, and outside them the premaxillaries and maxillaries (px., mx.) just show their upper edge.

The nasals and frontals $(n ., f$.) now fairly meet in the middle, and the frontal suture is now of considerable extent; behind it the lessening fontanelle ( $f \circ$.) is a four-rayed lozenge of membrane. 'The postorbital part of the frontal and the contiguous part of the parietal $(p$.$) are too convex to allow the squamosal to be seen in this view, yet it is$ a large bone (see Plate 11, fig. 7, sq). There is a fontanelle in the lambdoidal region, three-rayed, and half the size of the other; the parietals then meet for about half their inner margin to make the sagittal suture. 'The hind skull lessens one-third to form the occipital cincture $(\because .0$.) which is largely ossified in its upper part-more than half of the part exposed in this aspect; about a third in reality (Plate 12, fig. 2, s.o.).

The side view (Plate 11, fig. 7) has gained a more normal form than that of the early stage (fig. 3), the greater development both of the deep and of the superficial parts has brought this about.

The large, nearly inferior, circular nostril $\left(e_{. n}\right)$ is seen covered by a crescentic roof $(a l . n$.$) and the beginning of the roof and side of the great nasal tube ( \alpha$ l.sp.) is seen in front of the oblique falcate facial plate of the premaxillary $(p x$.) which is pedate in front, where it forms the aborted alveolar region. The nasal is seen over the olfactory capsule just reaching the frontal $\left(f_{0}\right)$ and the arched top of the facial plate of the maxillary $\left(m x_{0}\right)$, which thickens below to form the edge of the jaw, and sends backwards a free zygromatic process, the root of which is perforated by the 2 nd branch of the 5 th nerve $\left(V^{2}\right.$.). The top of the maxillary does not reach the frontal, but the nasal wall (al.e.) outside the upper turbinal (u.tb.) is exposed for some extent there, and in the antorbital region, showing there an unossified "pars plana" (m.tb.). There is no lacrymal bone, a rare character in a Mammal, as far as my experience goes. The well formed upper and orbital plates of the frontal $(f$.) give form to the upper half of the orbit, in which this bone forms roof and wall, the latter is a large rounded tract. The upper region of the frontal has a very large postorbital extension, and the large membranous tract seen there in the immature embryo (fig. 3), is here covered by the frontal and squamosal, the parietal in this type being kept well out of the temporal fossa. Thus in this side view the parietal (p.) looks scarcely larger than the squamosal (sq.) which reaches nearly as far backwards, and much further forwards, than the great upper plate.*

The squamosal is notched behind the orbit to give form to that space, and is scooped over the hinge for the mandible; the rest of the bone is evenly convex; it euds behind, like the parietal, in a rounded outline. Under the orbit the Iarge

* I fail to understand this modification, the opposite of what is seen in the Little Anteater (Plate 10), which has a far more perfect lower jaw than the Pangolin. 
ascending plate of the palatine $\left(p a_{0}\right)$ is seen; it helps the maxillary to form the antorbital bony wall.

The hind skull now leans backwards, above; it is very convex, and has its upper and middle part ossified (s.o., e.o.); the exoccipital, a broad band, runs across and then downwards behind the crescentic convexity of the opisthotic--which encloses the posterior canal (p.s.c.) - and the reniform occipital condyle (oc.c.). The articulated mandible and the ear-drum hide parts seen in the other side view (fig. 3); the annulus $(a . t y$.$) runs inwards and downwards.$

The outer and inner mandibles (here seen from the outside, but shown in their innes: aspect and more enlarged in Plate 12, fig. 4) are very instructive in this type, at this stage.

Even now the superficial ramus is a very small sinuous bar, with a considerable amount of cartilage in its hinder fourth, into which the dentary $\left(d_{0}\right)$ runs, ending in a point. The condyle (cd.p.) is a convex pyriform tract, lying lengthwise, and with the narrow end forwards, it is quite similar to that of the Echidna, but the ramus itself ( $=$ dentary) is less developed than in that type, although stouter; it has now no rudiments, even, of the coronoid and angular processes.

In this figure (Plate 11, fig. 7) the parts are shown in situ that correspond with what we see in the embryo Sauropsidan, the incus or small quadrate $\left(i_{0}\right)$ is just seen in front of the epihyal (best seen in fig. 8, e.hy.), ander the tegmen tympani; also the long internal angular process $(m . m l$.$) , with a rudiment of the posterior spur,$ running along the membrana tympani, and MECKEL's cartilage running under and within the dentary, which, however, has been made largely out of cartilage.*

Meckel's cartilage (Plate 12, fig. $4, \mathrm{mk}_{\text {* }}$ ) is slenderer, relatively, its thickest part, now, being near the symphysis; there, meeting with its fellow, it forms a considerable basimandibular (figs. 4 and 5, b.mn.).

As in the Green Turtle (Chelone vinidis) the ectosteal articulare (=superficial bony centre of malleus), appears first, and the endosteal centre afterwards-in that Reptile several years afterwards. The head of the malleal end of the Meckelian rod is solid and convex; the manubrium $\left(m . m l_{0}\right)$ is slender and more arcuate than in the early embryo (Plate 11, fig. 6), and the lesser posterior process is more indistinct. The large incus (i.) and the short, columelliform stapes (st.) are unossified, as yet; the

* I have never found an "inferior labial" cartilage in a Reptile; in Birds, howerer, it has turned up; in $1843 \mathrm{I}$ found and figured a tract of this kind, of an oblong shape, orer the midale of the mandible in the Coot (Fulica atra), and twenty years afterwards I dissected out the same thing in anuther of the Rallidx, namely, Gallinula chloropus. Now one thing is noticeable in this comparison, and that is that in the Sauropsida, as far as I have seen, MECkEL's cartilage simply shrinks and dies out in the main part of the mandible in front of the "articulare," and does not ossify and become a direct addition to the jaw. Nor can I find any actual endosteal ossification of MEcKEL's cartilage in the distal part in tho Edentates, although the part that is ultimately absorbed directly in front of the malleus (= articulare) is separately ossified in the Unau (Plate 9, fig. 7); but in che Insectivora, and cren in Man, a large tract of MECKEL's cartilage ossifies, and then unites with the ramus. 
interhyal has not appeared, up to this time; but abortively developed parts are often late. The inturned neck of the incus is curiously alate. The base of the stapes is very thick.

The distal parts of the hyoid arch (Plate 12, fig. 3) have undergone little change except as to size and solidity (see Plate 11, fig. 5); but the thyrohyals (t.hy.) are more incurved, for clasping the larynx.

The end view (Plate 12, fig. 2), as compared with the same aspect of the skull in the early stage (Plate 11, fig. 4), shows considerable progress in development.

The thick parietals $(p$.$) almost meet to finish, with the supraoccipital, the$ lambdoidal suture. The squamosals (sq.) now show considerably from the end; they have gained much substance, and are large convex plates.

The upper half of the face of the great occipital arch has its middle third occupied by a supraoccipital bone (s.o.), shaped roughly like an hour-glass; it does not yet reach the formen magnum ( $f . m$.), but the fenestra (or fontanelle) over that doorway is now a mere notch in the lower edge of the cartilage.

Nearly half the space from the lower edge of the bony supraoccipital to the occipital condyles (oc.c.) is occupied, below, by the large spreading exoccipitals (e.o.). 'Their upper margin is sinuous, their' outer rounded, and the large outer margin runs over the opisthotic convexity. Below, each bone runs in as an uncinate tract, between the opisthotic and the condyle; the thickish, convex, outer edge of the tract is the low, indistinct paroccipital process. The opisthotic tract, which has taken the form of the enclosed posterior canal, must be conceived of as lying some distance from the eye (see also Plate 11, fig. 8), and the bulbous cochlese (chl.) as still further off.

This stage is further illustrated by a vertically longitudinal section, made a little to the left of the mid-line in the fore half (Plate 13, fig. 12).

We see at once in this figure what is also seen in the side view (Plate 11, fig. 7), namely, that the snout and fore part of the nasal capsule is considerably curved downwards. I only see that in this stage and in this species, and am not sure whether there is some specific modification in this case; at any rate, this skull thus repeats a character seen well in Cycloturus (Plate 10, fig. 7).*

'I'he ethmoseptal or front half of this skull is one-fourth longer than the proper basiscranii or spheno-occipital region. In the early stages they were equal.

Nowhere is the intertrabecula, or thick base of the great partition (p.e., s.n.), more distinct and massive than in this; but for its crest, it would be almost Cetacean. ${ }^{\dagger}$

* These lesser modifications, both as seen in species and in stages, are almost endless, and yet none of them is without signitication. The two nine-banded Armadillos differ in this respect, for Tatusia pebu (Plate 5, fig. 6) has a very straight snout, whilst the closely related Tatusiu hybrilu has it considerably decurved (Plate 2, figs. 1 and 8 , and Plate 6, fig. 3).

$\uparrow$ See Frciluchit's figure of the skull of an embryo of Balana japonica in a posthnmus paper published by the late Professor Bmingarnt: "Ni Tavler til Oplysuing af Hvaldyrenes Bygning," tab. ii., Copenhargen, 18li:) 
The alinasal fold $\left(a n_{*} n_{*}\right)$ runs well round the end of the septum $\left(s_{*} n_{*}\right)$, which shows the usual fenestra at this part $\left(i . n f_{.}\right)$; behind the snout the alr nasi give off from their base the usual spoon-like recurrent cartilage (rc.c.) for the protection of "JAcobson's organ."

Two bones protect most of the top, but, below, the middle part, only, is supported by bone. The upper are the nasals $\left(n_{0}\right)$, and fiontals $\left(f_{*}\right)$, the lower the vomer $\left(v_{0}\right)$; I did not find the "postero-lateral vomers" developed in this stage; when they do appear" they do not remain distinct, for long: the antero-lateral vomers had evidently already coalesced with the premaxillaries (Plate 11, fig. 8). The floor of the deep olfactory recess, or cribriform plate $(c n . p$.) has been cut across; but it will be seen that this section leaves a large triangle of cartilage above and behind, making the recesses appear much deeper than they otherwise would do; this forms a large cartilaginous "cristi galli" or proximal solid part of the falx cerebri (see also in Tatusia hybrida, Plate 2, fig. 1, cr.g., where, however, it is not so large as in this type.) *

The hemispheres are lodged in a strong box, already; the fontanelle $\left(f_{0}\right.$.), and the triradiate suture between the frontal, parietal, and squamosal $\left(f_{.}, \eta_{0}, s q.\right)$ are clearly seen, and the growing thickness of the bones, especially of the parietal, where it forms an attachment for the "tentorium cerebelli" in front of the anterior semicircular" canal (a.s.c.). The falcate cartilage over the low bony orbito-sphenoid (o.s.o, o.s.) still shows its distinctness and is still a considerable distance behind the cribriform plate, below. The bony orbitosphenoids (o.s.) are obliquely oblong and are turned forwards and outwards; the large optic foramen (II.), well surrounded by bone, lies low down; the basal bar (p.s.) is not ossified. A considerable fenestra (or fontanelle) still exists over the sphenoidal fissure $\left(V^{1}, 2\right.$. ), not yet covered over by the firontal and squamosal. Under the latter the alisphenoid ( $a l . s$. ) lies outwards, and leans forwards, letting the nerve of the lower jaw $\left(\mathrm{V}^{3}\right.$.) pass over its edge at the hinder fourth; a snag of bone protects the nerve behind, but above, it escapes through a notch. 'The basisphenoid (b.s.) is separately ossified, and has taken up much of the cartilage of its own territory; then comes a tract of cartilage three-fourths as long, and then a tract of bone, the basioccipital (b.o.).

The latter bone comes far short of the foramen magnum (sce Plate 11, fig. 8). The fore part of the spheno-occipital synchondrosis is thick, forming the low postclinoid wall. In the large "formen lacerum" between it, the alisphenoid, the squamosal, and the round end of the large cochlea, the internal carotid artery enters. The large auditory capsule is separated, above, from the supraoccipital (s.o.) by a deep groove that contains the "lateral sinus," and is partly overlapped by the posterior (tentorial) edge of the parietal, and lower down by the posterior edge of the squamosal.

* If the presphenoid $(p . s$.$) were crested, like this part, in front, then we should hare a cartilaginous$ septum to the orbits, as in the Bird (see Phil. Trans, 1869, Plate 81, figs. 3, 4, 5); in that case the cartilaginous crista galli would be an additional crest on the antero-superior edge of this vertical orbital septum. 
Thus the swelling cochlea (chl.) has made itself a very accurate "nest" in the inferolateral region of the skull, and the posterior canal (p.s.c.) rising up from its junction with the anterior (a.s.c.) pushes itself into the antero-internal face of the exoccipital (e.0.). The whole arch of the anterior canal is seen, and the fore part of the space under it is well scooped for the "flocculus." The great multiperforate "meatus internus" (VII., VIII.) is arched over by a convex tract of cartilage; below, the entrance is floored by the swelling cochlea.

The whole capsule is large and normal, both as to the parts shown, and also, as to the degree of tilting it has undergone during growth.

The hind part of the wall formed by the occipital arch, is as large as the large preauditory region, walled in by the parietal and squamosal. In this internal side view the supraoccipital bone (s.o.) looks less than it is, but the band of cartilage below it shows its full breadth. The middle third of the wall-nearer the bottom than the top-is formed by the exoccipital (e.o.) which is somewhat of an hour-glass shape. It is notched, below, for the large 12th nerve (XII.), and in front of and below it the common nick for the 9 th and 10 th nerve (IX., X.) is seen. The cartilage between the basioccipital and exoccipital $($ b.o., s.o.) is narrower than the tract above, but widens out behind, to lose itself in the large convex condyle (oc.c.).

\section{Thind Stage.-Newly-born Pangolin (Manis Temminckii), South Afirica; head $2 \frac{1}{4}$ inches long.}

This young Pangolin was born in captivity in its native country, and died the next day (see Proc. Zool. Soc., 1878, pp. 632, 633). I am indebted to Dr. Sccater for this very valuable specimen.

This type, like its neighbour the Aard-Vark (Orycteropus, next to be described), becomes very large and well developed before birth, and the skull promises, even then, the strength it ultimately attains to.

The lower view (Plate 12, fig. 6) shows the sutures and synchondroses very clearly, and the remarkable shape of this toothless skull.

The alinasal region $(a l . n$.$) in front of the premaxillaries \left(p x_{0}\right)$ is short, and but little seen in this aspect; the nostrils $(e . n$.$) are now more lateral. The premaxillaries$ have recovered some strength and size, now; their marginal and palatine parts are stronger; between these the notch for the opening of JACOBson's organ is rounded. The maxillaries $\left(m x_{0}\right)$ soon expand into broad shoulders, laterally, after which the general convexity of the outline of the skull only lessens slightly, a little behind the junction of the maxillaries with the frontals $\left(f_{0}\right)$, and, again, behind the auditory capsules, where the occipital cincture retains its great similarity to the skeletal segments that follow it. The alveolar ridge is now a sharp balk between the general convexity of the upper face, and the general concavity of the hard palate, which is imperfectly developed, but in a manner very different from what we see in Marsupials and 
Insectivores, where this floor fills in well, at first, and then suffers large absorption in the part where the maxillaries and palatines join. If we compare this with the two previous stages, and with the adult, we shall see that there is a steady attempt to pass from the normal primary schizognathous condition to the normal secondary desmognathous state, and that in this curions toothless type the latter is never attained toit comes short of the mark of the high and perfect Mammalian hard palate.*

Only in the hinder thind do the concave palatine plates of the maxillaries approximate, and then not perfectly; in the front third they fail to hide the palatine spikes of the premaxillaries which run, as a wedge, far into the angle formed by those bones. In the middle third they are divided by the protruding ridge on the fore part of the vomer. The scooped part of the maxillaries inside the sharp alveolar edge is twice as large as the second and still more scooped part near the mid-line; where the bones nearly meet behind their thin edge is thickened. That thickened edge ends in a point, and the corresponding palatine sends its pointed fore end between that point and the outer flange of the bone which runs backwards and outwards. The outline of the maxillary is then notched, then bulbous, and is then obliquely cut away, where it articulates with the frontal; the infraorbital foramen $\left(V^{2}\right.$.) has but a small bridge under it, but from it there runs a considerable fossa upwards and forwards. Behind the bridge the jugal process is very stunted.

On each side of the vomer, the maxillaries are most concave; that bone $(v$. $)$ is thick and split at its fore end. This exposed part is of great interest to the morphologist; it corresponds with the enlarged dentigerous fore end of the bone in osseous Fishes, which in their extreme specialization have acquired a median vomer; and also with the flat infero-anterior' part of the vomer of the Green Turtle (Chelone viridis) ("Challenger Series,' vol. i., Zool., plates 10 and 11); and of certain Birds, e.g., Falco, Dicholophus (Trans. Linn. Soc., ser. 2, Zool., vol. i., plate 24). Odd enough, one of the strongest and most perfectly specialized of the skulls of the Eutheria-that of the Cat-shows a trace of this very plate, where the maxillaries fail to meet in the hard palate.

The palatines ( $p a$.$) form a squarish tract; they make about one-third of the hard$ palate, which ends with them; and, indeed, they fail to produce the plate in their hinder fourth, and the hind margin of the hard palate is cut away in a crescentic manner. The submarginal groove of the maxillaxy palatine plate runs on under the palatine, but soon turns outwards and is lost. The palatines form one-third of the wall of the great nasopalatine canal behind, and the pterygoids ( $\left.p g_{0}\right)$ two-thirds; these bones, like the palatines, have a broad basicranial flange, and this upper dilatation of these vertical bones overlaps the basioccipital. The wall or vertical part is deeply notched behind, and thus the hamular process (see also fig. $8, p g$ ) is large and free.

* To me this seems to suggest that whilst the Pangolin has suffered degeneration and relapse, as it were, as regards the teeth, and with the teeth the size and fulness of the jaws, yet that this abortion and snppression began when the type itself was very low, and only very imperfectly desmoguathous. 
The whole series of palatine bones in this scarcely perfect hard palate is a narrow, oblong tract, with the sides gently bowed out, and the ends gently converging. Opposite the end of the hard palate the fronto-squamosal suture, which is very large (see fig. 8), runs across, and the strong, concave orbital plate of the frontal takes up all the orbital space here, except at the inner edge.

There we see part of the orbitosphenoid (o.s.) notched at its anterior margin where the ophthalmic nerve $\left(V^{1} \cdot\right)$ is re-entering the skull through the orbital foramen. The optic passage (II.) is out of sight; but the sphenoidal fissure $\left(\mathrm{V}^{1,2}\right.$. $)$ comes into view, followed by the deeply notched, oblong alisphenoid (al.s.), notched deeply in the middle of its outer margin by the 3rd branch of the 5 th nerve $\left(\mathrm{V}^{3}.\right)$; it does not finish the foramen ovale, and emerges far in front of the auditory capsule (chl.). Those wings and these capsules are both walled in, externally, by the huge squamosals (sq.) that have pushed the parietals away from their frontal attachment, below (see fig. 8), and continue the general ovoidal convexity of the skull up to the paroccipital prominence $(e .0$.$) . Each bone has a pneumatic cavity opening behind the stunted zygomatic$ process (see also Plate 13, fig. 1 -for $\times 2$, read $\times 3$ ), with its oval glenoid facet, which reaches, in this specimen, nearly to the fore end of this arrested process. Then the whole lower part of the bone in the postglenoid region is hollowed out to form an upper chamber to the "cavum tympani" hence the great convexity of the squamosal in its hinder half (see also fig. 8). The whole line of junction of this great bony scale with the infero-laternl parts of the hind skull is well worthy of remark (Plate 12, fig. 6, and Plate 13, fig. 1). A strong flange from the glenoid region, inside the postglenoid pneumatic foramen $\left(p, n, f_{.}\right)$, binds on to the outer edge of the alisphenoid, running in with an angular process to complete the imperfect foramen ovale $\left(\mathrm{V}^{3}\right.$.) and then, after leaving the hinder half of the alisphenoid, clamping the antero-external margin of the auditory capsule (chl.). Here this "flange" becomes scooped and runs upwards until it ends in the general hollowing of the bone above the tympanic cavity. In its hinder part the bone strongly closes in under its own pneumatic cavity and interdigitates with the rough, grooved opisthotic, and the small epihyal bridge (op., c.hy.).*

Since the last stage (Plate 11, fig. 8, p.s.) the presphenoidal region has become bony and the bar (Plate 12, fig. 6, p.s.) looks like that next behind it (b.s.), but I strongly question the independence of it, as an ossification; it was most probably formed by the confluence of the orbitosphenoids in the middle cartilage.

The next basal piece, the basisphenoid (b.s.) is an independent centre; it is oblong, nearly as long as the broad (reptilian) basioccipital, and is separated by a moderate tract of cartilage from the other two basal bony plates. In this species there is, now, a small pituitary hole $(p y$.$) at the front third of this flat bone. The huge oval$ basioccipital, behind it, is everywhere surrounded by cartilage except where it binds

* I am satisfied that anyone wishful to compare the skull of an adult Pangolin with that of any high nomal Mammal, will not complain of these details, nor make light of the pains I have taken to pull this puzzle to pieces to get at its meaning. 
against the cochlere (chl.), and behind; there it has thick-ribbed edges, which make the middle part of the bone concave; this is like what is seen in the Unau (Plate 9, fig. 1); this is shown still more where these ridges are functional, as in the Anteater (Plate 10, fig. 1).*

The oval basioccipital (b.o.) is notched a little where it forms the front boundary of the foramen magnum $\left(f_{0} . m.\right)$; on each side of that end the large occipital condyles are seen (oc.c.); theil' direction is infero-posterior. The exoccipitals (e.o.) r'un well outwards to the grooved and rough opisthotic $(o p)$, which is wedged in between the squamosal and the gently convex paroccipital ridge.

The large hypoglossal (condyloid) foramen (XII.) is partly finished insicle by cartilage, and the exoccipital bone only partially surrounds that nerve and the 9 th and 10 th $\left(\mathrm{IX}, \mathrm{X}_{\text {. }}\right.$ ) at their exit; the cartilage here is half as broad as the bone outside it. The bony tracts seen in the distance behind the foramen magnum are not parts of the supraoccipital but an extension of the lateral bones (see also fig. 9, ?.0.2 s.o.) The moderately broad annulus tympanicus has been left in situ on the left side (Plate 12, fig. 6, (.$\left.t y_{0}\right)$; on the right side of the skull this bone and the ossicules were removed (see also Plate 13, fig. 1). This imperfect ring has doubled its breadth since the last stage (Plate 11, fig: 8), but it fails to run along the meatus externus, and leaves the large membrana tympani exposed in this view.

The well and roughly ossified auditory capsule (Plate 12, fig. 6; and Plate 13, fig. 1, chl., op.) runs obliquely inwards and forwards, warty, as it were, and riddled with holes and passages. The facial nerve (VII.) runs through a bony canal, and appears on the roof of the tegmen tympani to escape again through the stylomastoid foramen, which is bridged over by the small confluent epihyal (e.hy.) (see also Plate 11, fig. 8, e.hy., VII.), which has become confluent at its once free end with the highly ossified capsule, behind the obliquely seen fenestra rotunda $(f \cdot r)$. Another small bridge of bone at right angles with the inner end of the epihyal bridge separates the fenestra rotunda from the fenestra ovalis $(f s . o$.$) . In front, the ossified$ wall of the cochlea $(\mathrm{chl}$.) fits into digitations of the alisphenoid ( $a$.s.) by knobs of bone; and, behind the stylomastoid formen (VII.), the opisthotic region, is divided into two rough convexities by a considerable groove. On the inner face, where the cochlear and opisthotic regions unite, there the bony mass is notched twice, to let out the 9 th and 10th cranial nerves (IX., X.).

The pyriform shape is well seen in the upper vieu of the skull (Plate 12, fig. 7 ). The snout $\left(a l . n_{0}\right)$ is twice as much seen here as in the lower view (fig. 6). The only additional parts that come into view as compared with the last stage (fig. 1) are the squamosals $(s q)$ that can be just seen flanking the parietals (1).). The premaxillaries $\left(p x_{0}\right)$ are seen in front, and the maxillaries $\left(n x_{0}\right.$ ) can also be seen flanking the frontals $\left(f_{0}\right)$; the partly ossified supraoccipital $\left(s_{0} .0\right)$ finishes the structure behind, The still-notched, but improved, nasals $\left(n_{0}\right)$ run well back between the frontals,

* This character reappears in normal tooth-bearing Mammals, e.g., in the Marmot (Aretomys monax).

IDCCCIXXXV. 
which pinch in very little over the orbits, and cover as much surfice above as the parietals (p), for what they lack in breadth they gain in length. The sutures are now well finished and dentate, the lambdoidal takes an arcuate turn forwards, in the middle, and retreats at the sides, where the parietals are only flanked by the unossified margins of the supraccipital plane.

The side view (Plate 12, fig: 8) shows well the feebleness of the short straight fuce, and the fruit-like roundness and general convexity of the skull, proper, to which no thick-bellied muscles are attached, and over which a strong horny helmet has grown.

A thin wedge of bone, the facial part of the premaxillary $\left(p x_{0}\right)$, runs its point between the nasal (n.) and the maxillary (mx.), above; this is bounded in front by the snout, with its cresentic fold over the almost lateral nostril (e.n.). The square-topped maxillary takes up much of the outer edge of the nasal, and then runs downwards and backwards, where the lacrymal should be, and barely covers the nasal capsule. The antorbital, as well as the lower edge, is thick, and the infraorbital foramen and fossa $\left(\mathrm{V}^{2}\right.$.) are seen in front of the round, stunted rough zygomatic process in which, in this specimen, I can find no distinct rudiment of a jugal bone. A small vascular formen is seen above the main passage $\left(V^{2}\right)$ in the hind margin of the fossa. The supraorbital part of the firontal ends below in an arcuate line, which is roughly semicircular, and straightish in the middle; the orbital plate is nost hollow, almost angular, where it runs downwards to the orbital foramen for the re-entrance of the 1st branch of the 5th nerve $\left(\mathrm{V}^{1}.\right)$. The lower edge of the orbital plate ends in a line parallel with its upper edge; in the notch the orbitosphenoid (o.s.) is seen, and the oblique, but large, optic hole (II.). Below the frontal, and behind the maxillary, the palatine ( $\left.p c_{0}\right)$ is seen edgewise as it runs upwards to form its basicranial flange, and forwards to assist the maxillaries and frontals to finish the antorbital wall. This is done imperfectly, and a considerable lanceolate curtilaginous "pars plana" is to be seen between the maxillary and the palatine. At the fore end of that tract I have looked in vain to find a lacrymal foramen. The and branch of the 5th nerve $\left(\mathrm{V}^{2}\right.$.) strongly grooves the outer face of the palatine on its journey from the sphenoidal fissure to the infraorbital canal.

Most of the hind-skull, as seen in this view, is composed of two nearly equal tracts of bone, the parietal and squamosid $\left(p_{0}, s q_{0}\right)$. The coronal suture ends on the highest angle of the squamosal, which is not scooped out to form any definite temporal fossa, all the space answering to that valley is to be seen in that part of the squamosal which has caught the notched hinder margin of the frontal. This is made into a small space for the temporal muscle by the ridge which runs down to form the stunted zygomatic process, in the infero-internal face of which the glenoid facet lies. Behind this ridge is the pneumatic foramen $\left(\mu^{\prime} . f^{\prime}\right)$, then a gentle hollow, and then the general convexity over the large air cavity that forms the chamber over the cavum tympani. 'The hamular process of the pterygoid (pq.) and the annulus (a.ty.) are just to be seen, away from the eye, below, and the margin of the occipital plane, behind. A gentle concavity is seen between the external or paroccipital edge of the exocci- 
pital (e.o.), and the thickened rim formed by it to the foramen magnum. The bony and cartilaginous parts of the supraccipital are just seen, and also the condyle (oc.c.), below.

The lower jaw (Plate 12, figs. 8, 10,11, $d_{\text {. }}$ ) is a mere sinuous bar of bone, capped. at its posterior-superior part by a condyloid facet, in front of which a slight elevation is all that appears of the coronoid process $\left(c^{2} \cdot p_{0}\right)$, and under which there is no angular process, whatever. The symphysial face is oval and rough, and the dentary edge is sharp and roughly dentated; between that part and the aborted coronoid process the upper outline sinks into a gentle curve, answering to the convex outline below. Inside the hind part of the ramus the bone is scooped away for DIEckeL's cartilage and the burrowing nerve $\left(\mathrm{V}^{3}\right.$.), and vessels. The secondary mandible is now onefourth larger than the primary, for the fore part of MEckel's cartilage $\left(m k_{\text {. }}\right)$ is lost, and the rest is a sinuous rod partly in front of and partly behind the persistent ramus. 'This sub-proximal part of the primary rod is only attached to the ramus in front of the bony processus gracilis, behind, by ligamentous fitmes. The proximal part, now the ossified malleus ( $\left.m l_{0}\right)$, is quite normal, with the curved manubrum ( $\left.m . m l_{0}\right)$ and is equal to the processus gracilis. The incus ( $i$.) is now quite ossified, and its short crus is relatively larger. The stapes (figs. 11 and 12, st.) is still merely a columella, with a ragged hinder margin to its flat rugous stem, and a small interhyal in the tendon of the stapedius muscle (i.t.y., st.m.).

In this species, at this stage, there is a small second upper ceratohyal (fig. 13, c.lly.), and the rest of the bar $(c . h y)$ is ossified in its middle part; the basal bar, with its horns (b.h.br., t.hy.) is still unossified; its shape has not changed since the last stage.

The occipital rigion, as seen from behind (Plate 12, fig. 9), shows great progress in ossification since the last stage (fig. 2); and in this more finished ovoid the superficial bones $\left(s y ., p_{0}\right)$ come more into view in this aspect. The notch above the foramen magnum (s.0.n.) is as large here, as in the smallest specimen (Plate 11, fig. 4), the lateral cartilaginous tracts failing here for some distance. The three bones that are forming this face of the skull $\left(\because . \circ, e_{0} . o_{0}\right)$ wre still separated by a considerable amount of cartilagre. The basal bone (b.o.) just comes into view. The paroccipital margin $(p . o c$.$) of the lateral bones (c.o.) forms a definite ridge on each side, separated from the$ condyle (oc.c.) by a gentle vacuity.

\section{Fourth Stage.- Skull of adult Pangotin. (Manis — ? sp.).}

Some things worthy of notice appear in the skull as it becomes adult. In the lower vicw of the adult skull, with the hinder part removed (Plate 13, fig. 2), we see the strength of the roof-bones, and that they are strongly marked, inside, by the brain; these digital immessions of the inner table are very clear. So also is the bony tentorium (t.tm.) strong, and strongly fixed to the supraoccipital (s.o.) as its key-stone; outside that ingrowth the great tympanic recess in the squamosal (sry) is laid bare. In fiont of this the postglenoid pneumatic foramen ( $p m f)$ is seen, and in 
front of it the strong stunted zygomatic process with its small oval, glenoid facet $\left(y l_{f} f_{*}\right)$ on its innel face in fiont. The basisphenoid $\left(b_{.} s_{*}\right)$ was cut across near its front margin, and only part of the alisphenoids are shown-just to the notch for the 3rd branch of the 5th nerve $\left(\mathrm{V}^{3}.\right)$. Then we see the sphenoidal fissure between the two wings $\left(\mathrm{V}^{1,2}\right.$ ) ; the optic foramen (II.), the orbital foramen $\left(\mathrm{V}^{1}\right.$. $)$, and the orbital tunnel $\left(\mathrm{V}^{2}\right)$.

'The palate is much like that of the newly born specimen (Plate 12, fig. 6), but the palatines $\left(p a_{0}\right)$ are relatively longer, the palatal portion of the hard palate being nearly as long as that of the maxillary ( $\left.m x_{0}\right)$, which is very imperfect in front, and shows the long (borroued) palatine processes of the premaxillaries $\left(p x_{0}\right)$, and the forked anteroinferior part of the vomer ( 2.$)$. The alveolar flange of the maxillary ( $\left.m x_{0}\right)$ is perforated in two or three places, and the right palatine has lost its bony floor in one place, just as in Marsupials and some Insectivores, but not to the same extent. A small seed-like jugal $(j$.$) is now to be seen on the angle of the maxillary-its jugal process-but there$ is no lacrymal, and the place where that bone and the bony "pars plana" should be seen is merely an enlargement of the very open suture-like a mere crack-which runs, above, between the frontal and maxillary, and then, below, between these two bowes and the palatine, where it rises into the floor of the orbit, in front.

The hind view of the fore skull (Plate 13, fig. 3) shows the strength of the frontal cincture, the concavities ("cligital impressions") of the inner table, the enormous size of the ethmoid with its cribriform plate $(c r .1 \%)$, and the strength and depth of the "crista galli" (cr.g.). The optic foramina (II.) are surrounded by bone, and the whole anterior sphenoid (o.s.) is about equal to that of Man-relatively to its size. The sphenoidal fissures $\left(V^{1}, 2\right.$ ) are large oval passages, and the nasopalatine canal (n.p.c.) is large and subcircular. The manner in which the squamosal grow downwards to form the hollow zygomatic processes is also seen in this view, and the thinness of the floor of the sella turcica (l.s., read b.s.). The pterygoids ( $p g$ ) are anchylosed, to a great degree, to the posterior sphenoid.

A fiont view of the nasal end of the dry skull shows that the septum nasi (fig. 4, s.n.) in front of the vertical ethmoid is unossified, but that the nasal and inferior turbinals $\left(n . t b ., i_{0} . b_{0}\right)$ are quite bony, and anchylosed to the nasals $\left(n_{0}\right)$, in one case, and to the maxillaries (mx.), in the other:

\section{ORYCTEROPODID E.}

Nealy ripe embryo of Aard. Vark, Orycteropus capensis (Plates 14, 15).

Here, if anywhere, we have a generalized type, evidently very archaïc. Figures of the adult suggest the idea that this is an ancient, primordial, unarmed Armadillo.*

* The figures (Plate 1, figs. 9-11) given of the head in this nearly ripe embryo (belonging to the Insemm of the Royal College of Surgeons) are suggestive of the new-born young of several types of 
I have, moreover, to begin the description of this type of skull under an impression, which I believe is not prejudiced, that Orycteropus comes nearer the Marsupials and the lower Insectivores, and is further from the Monotremes, than the other Old World Edentates-the Pangolins. The whole of the New World Edentates, whether toothless, or with an imperfect dentition, appear to be like the Pangolins, upgrowths from the Monotremes.

Unfortunately, I cannot bring the evidence for these views forward, now ; but the papers on the skull of the Insectivora and Marsupialia will follow, next, upon the present.

The complex structure displayed in the lower view (Plate 14, fig. 1), if traced out point by point, will show how much unlikeness there is between the only two remaining types of Old World Edentates. The fice is long, the measurement, even now, of the base shows the tract in front of the fore margin of the presphenoidal territory to be twice the extent of the tract behind that point. Here the development of the jaws hardly suggests any change from that of the ordinary typical Mammals, with their well-developed sets of teeth, all round. The alinasal cartilages and nostrils $(a l . n ., e . n$.$) are very peculiar, and quite unlike what I have lately been describing.$

Here the nostrils are anterior, and the intervening alie, after spreading out into projecting folds and processes, suddenly narrow in, and then project again right and left, the projection being caused by a peculiar and large narial valve (n.v.). A deep fissure-not a solution of continuity of the cartilage-runs across, below, arching backwards a little in fiont of the premaxillaries $\left(p x_{0}\right)$; and a median groove runs forward from this part to the end of the snout, the converging folds of the floor in this front part being elegantly crescentic-back to back. The part behind the transverse arched groove soon opens out, right and left, where it gives oft the recurrent cartilages (fig. 5, re.c.); I shall describe these parts soon.

In this developing skull there is a palatal character seen at once, which is permanent in the curiously arrested skull of the Pangolin, this is the imperfect desmognathism of the palate, in front, exposing the vomer $(v)$. As to the character of the bones covering the endocranium, they are very unlike those of Armadillos, Sloths and Pangolins, not thick and cellular, but thin and fibrous, very much like those of the Insectivora. The premaxillaries $\left(j x_{0}\right)$ have retained their normal size, notwithstanding their loss of teeth; the alveolar edge is a thick tract, with a lanceolate outline, and higher Mammalia, e.y., Lamb, Calf, \&ce. ; but on my first, and very casual, look at the British Museum spirit-specimen, of the same age as this, I mistook it for the young, from the pouch, of some large kind of Kangaroo.

The head, only, of this single stage, as worked out here, will be fruitful of suggestions of relationship, which point to quite other quarters than those just mentioned, which are, manifestly, somewhat fanciful.

There are two species of this isolated, unique genus, namely, $O$. capensis and $O$. cethiopicus (see Proc. Zool. Soc., 1869, p. 431, and 1870, p. 669; also "List" of the animals of Zool. Soc. 1883, p. 192, fig. 35, and p. 193, fig. $33^{3}$ ). The differences between these two, external and internal, are not great, but are worthy of note. 
it is separated from the palatine process by a deepish concavity; the two processes reach backwards about the same extent. The re-entering angle between the two processes is rounded for the opening of JACobson's organ (see also fig. 5, j.o.), and the wedge-like end of the maxillary $\left(m x_{0}\right)$ reaches up to this passage.

The maxillarics are nearly half as long as the whole basal line, from the fore end of the suout to the foramen magnum, and their alveolar tract is really large, behind, where the two last teeth, with their subdivided pulps, take on somewhat of a Zeuglodontic character.

The first of the simpler front teeth-there are five, in all, at this stagre-would answer to the second or third premolar, of a Hedgehog or a Mole; all those that should be in front of this part are suppressed, and yet the jaw-bones have suffered but little by this suppression.

The palatine plates of the maxillaries certainly do resernble those of the Armadillos (see Plate 2, fig. 2), for inside the steep alveolar wall the great palatine flange, at first scooped, rises into a ridge, and is then separated by another concave and grooved tract from the lesser submesial tract of bone. This tract is deficient, both before and behind; in front it lets us see the fore part of the main vomer $(v$. $)$ and the small front paired vomers ( $\varepsilon^{\prime}$, see also fig. 5). The main part of the maxillaries ends a little in front of the palatine end ( $p a$.) of the hard palate, but at present the last alveolus is not walled in. The shoulder of the maxillary, its jugal region, extends outwards nearly as far as any part of the skull, the only wider part is the glenoid region $(g l . f$.$) .$ The infraorbital canal $\left(\mathrm{V}^{2}\right.$.) is one-fourth the length of the maxillary, and its opening in front is infero-lateral.

The total length of the palatines $\left(p a_{0}\right)$ is half that of the maxillaries, but they form less than one-third of the hard palate; that tract lums in between that of the maxillaries, leaving those bones only a narrow flange, there, inside the inner alveolar wall. The two plates do not meet well together, especially in front, and each forms, in this part, a rounded leafy plate of bone, fitting against a large, rounded notch on the imner angle of each maxillary plate.

The margin of each palatine, behind, is rounded, and has a strong rim, which is distinct from the thickened outer rim of the bone at its articulation with the end of the maxillary. Under that outer rim, which forms a bridge, there is a large oblique oval passage, or subway, and from it, in front, a groove runs forwards, along the outer third of the flat plate. The unfloored part of each palatine is only two-thirds as long as that which helps to form the hard palate; it is thick-edged below, and that edge does not project so far outwards as the hinder rim of the completer part; above, it is oblique, with a shortened upper margin, to which there is scarcely any basicranial Hange.

The pterygoids (behind pa.) continue the wall to the nasopalatine canal, they are as long as the palatines, and have a broader basicranial flange, which runs backwards, and is emarginate in front of the Eustachean opening (cu.). The short thick hamular 
process is but little free at its end (see also fig. 3., $p g$. ) ; the fore part of each bone, above, rums inwards over the palatines and the two bones are toothed where their thin edges touch.

Outside these bones, we see, in the distance, the orbital plate of the frontal $(f)$ with its large vascular hole, and at the margin of this space the jugal $(j$.$) , a considerable$ bone, broadened out where it overlaps the maxillary. It is, in turn, overlapped by the squamosal (sq.), whose jugal process passes a short distance beyond the jugal, and then, on its inside, at its root, we see the rather large glenoid facet $\left(g l_{0} f_{0}\right)$ which is oval, the long axis forwards, but the fore part emarginate, having there a deep rounded notch.

The squamosal can be seen a little in front of the glenoid cartilage; laterally, it runs from its jugal process, backwards, until we see it, after forming four gentle convexities and slightly converging, lie over the auditory capsule, ending beyond the stylomastoid foramen (VII.).

The thickened postglenoid edge is separated from the beginning of the hollow, and somewhat pneumatic, part that covers the tegmen tympani. The inner margin is scooped, thin, and then thickens again before it ends as a scaly tract over the swelling in the ear capsule caused by the horizontal semicircular canal (see fig. 3, h.s.c.).

Another superficial bone is seen inside the squamosal; this is the tympanic $(a . t y$.$) ,$ it is a thinnish $U$-shaped tract, with a foot-shaped flange, in front, for protection of the processus gracilis of the malleus. This imperfect ring leaves a large space of the auditory capsule only covered by membrane on its immer side, and the rim of the bone lies a good distance behind the Eustachian opening (eu.). The membrana tympani $\left(m . t y_{0}\right)$ is much exposed, and the unossified manubrium ( $m . m l_{0}$ ) is seen running obliquely across it.

The proximal, ossified part of the orbitosphenoid $\left(0 . s_{0}\right)$, can be seen in the fundus of the orbit, with the optic nerve (II.) rumning through, and the maxillary nerve ( ${ }^{2}$.) behind, it. A considerable tract of each alisphenoid ( $a l_{\text {.s. }}$ ) is seen between the pterygoid and squamosal $(s q$.$) , and the large inferior branch of the 5th nerve \left(\mathrm{V}^{3}.\right)$ passes through a very large foramen ovale, which lies in the centre of the plate, but which is not quite bound in with bone on the outside.

The large median beam, with the presphenoidal region unossified, the basisphenoidal centre (b.s.), the basioccipital, and the whole occipital cincture will be describer soon, as parts of the separated endocranium (Plate 15, figs. 1, 2). There is in this figure a small scale of bone seen in front of the stylo-mastoid formen, and on the proximal part of the epihyal cartilage $\left(e . h y_{0}\right)$; this is the proper perostecl stylohyal bone (st.h.), answering to that of Man, and of the Rabbit.*

I have not found this superficial ossicle in any other kind of Edentate, and

* Professor F'Lower's "tympano-hyal" answers in a general way to this bone, but it lies deeper, and soon forms the ectosteal plate of a small pateh of bone which is added to the "opisthotic," but belongs to the proximal part of the hyoid arch, where it has hecome confluent with the capsule. 
therefore must add it to the list of characters in which this type comes nearer to the normal Mammal than its congeners.

The upper view of the cranium (Plate 14, fig. 2) shows, in front, the remarkable form of the snout, the roof of which suddenly pinches in, in front, after dilating as suddenly on emerging from beneath the nasal bones (n.). The roof $(a l \cdot n$.) ends in front, like the nib of a pen, and the sides are swollen, and then scooped away in a crescentic manner, making the nostrils look forward. Close beneath this expanded front lies the root of the curious long twisted narial valve (n.v., fig. 3) which projects in front, right and left of the contracted fore end of the snout.

The difference between the general outline of this skull, and that of a nearly ripe Tatusia hybrida, is considerable; moreover, although larger relatively at the time of birth, it is not nearly so much developed (compare Plate 14 with Plate 6).

The Edentate diminution of the jaws is much less than in the Tatou; indeed, the skull is fairly intermediate between the skull of that kind of Armadillo and that of a large and important Insectivore from the East Coast of Africa, namely, Rhyncocyona type to be described in my next paper.

In both these nearly mature embryos the basifacial length is twice that of the basicranial, the point taken being that where the vertical ethmoidal and the presphenoidal regions meet. But the Aard-Vark's head is much the longer and narrower of the two-more like that of an Anteater, in this respect, and yet more like the skull of an Insectivore than that of any of the Myrmecophagidæ. Looking at the main roof bones the nasals are now only one-tenth shorter than the frontals and are one-tenth longer than the parietals $\left(n ., f_{0}, p_{0}\right)$. This is a very different proportion to what we see in Tatusia, and yet the general form is very similar, for the frontals have to swell and broaden over huge ethmoidal masses in both cases (Plate 15, figs. 1, 2; and Plate 5, fig. 1). Thus, in both cases, the antorbital and postorbital regions are of equal breadth, except in so far as the latter is widened by the squamosals in the glenoid region. The general frontal convexity seen in Tatusia (Plate 6, fig. 2), and still more in Dasypus (Plate 7, fig. 2), is exchanged in Orycteropus for a considerable median hollowing of the roof, which affects even the hinder part of the nasal bones. So that, as we shall see in the next figure (3), there is a very peculiar "beetling" of the brow in this type, the convexity of the frontals being only lateral and not general. But the skull rises well in the coronal region; yet there, at present, it is unfinished, a large diamond-shaped fontanelle $(f \circ$.$) still persisting. Here$ we gain that which the Armadillos are deficient in, namely, a good postorbital process to the frontal bone, as the end of a good, clean, well arched supraorbital rim. That ridge and process is very short and abortive even in the Unau (Plate 9), which has also some suprafrontal hollowing, but in Cycloturus, Tutusie, Desypus, and Hanis, all this is absent.**

* We shall see this Echimnine feebleness of the skull in many of the Insectirora, also, so that this impreffection of the orbit must not be taken as a necessary correlate of the suppression or abortive 
Here the nasals (n.), narrowing steadily forwards, have their edge cut away from without, inwards, and not notched as in Manis. The upper part of the facial plate of the premaxillaries and maxillaries $\left(p_{0}, m_{0} x_{0}\right)$ can just be seen, and also the lacrymal; (see fig. $3, l_{\text {. }}$ ) under and outside the well-formed orbital rim, the jugal $(j$.$) can be$ seen, and behind it the most projecting part of each squamosal (s\%.).

The front two-thirds of the frontal suture, and the hinder third of the sagittal, are complete; behind the latter, the temporal fossa is evidently gaining somewhat upon the postero-external part of each parietal. The lambdoidal suture is in two limbs, as it were, in front, running forwards in the middle, and backwards, behind, between the two parietals and the one large, wide, bracket-shaped intraparietal (i.p.); and behind, having a similar curve, and separating the intraparietal from the projecting endoskeletal supraoccipital (s.o.). Outside the latter this plane is unossified, and part of the projection is opisthotic, the swelling caused by the posterior canal being just caught by the eye.

The side view (Plate 14, fig. 3) shows many things well, that are only partly visible in the other aspects.

In fiont, the curious snout, with its alæe, valve, and opening (al.n., n.v., e.n.), are shown, and these are followed by the oval face-plate of the premaxillary $\left(p_{0} x_{0}\right)$ with its pedate lateral enlargement, below. The remaining three-fourths of the alveolar edge belongs to the maxillary $\left(m x_{0}\right)$, but the foremost third is edentulous. Surmounted by the long nasal ( $n$.) this bone forms most of the side of the large, long face; its upper margin ascends, at first gently, and then suddenly, its lower edge descends gently and sinuously back to the jugal $(j)$. The highest part contributes to the bony investment of the swelling ethmoidal mass (al.e.) which it fails to cover, not meeting the frontial $(f$.$) at that part.$

The hinder half of that preorbital tract is, however, covered by bone, but not by either of these ; the lacrymal $(l$. $)$ comes in here as an antorbital wedge. It is a pyriform bone about the size of the face-plate of the premaxillary, has a straightish edge above, against the frontal, but dips into the maxillary below. The large canal is behind this rounded lobe; then the bone flattens inwards to form a small orbital plate, and thickens, below, where it places a solid foot upon the fore part of the jugal.

The hind part of the maxillary, the direction of which is forwards and upwards, is scooped for the broad overlapping fore end of the jugal $(j$.$) , so that the zygomatic$ part of the maxillary is almost half its hind border; this is burrowed by the upper maxillary nerve, which comes out at a moderate distance from the jugal, at the infraorbital foramen $\left(\mathrm{V}^{2}\right.$.). Thence, forwards, the face-plate of the maxillary is grooved twice-under the great swelling, and just above the alveolar margin; a vascular foramen is seen in front of the great nerve passage, in this lower groove.

development of the teeth. Rhynocoyon and Orycteromus come very near each other in this character; the former, indeed, lies, in this respect, between the Shrews and Moles on the one hand, and the almost Lemurine Tupaia on the other.

MDCCCLXXXY. 
Here the form of the frontal is well seen, and can be compared with the same view in the Tatou (Plate 6, fig. 3). Here the swelling in front of and above the orbit makes the skull at this part almost as bulky as it is in the region of the upper fontanelle $(f \circ$.$) , and in this side view the frontal seems to be made of two parts,$ separated by a deep, oblique valley. The supraorbital ridge does not extend so far buckwards as the wall-plate of the bone, which runs back there, and notches the fore edge of the parietal, on the lower part of the coronal suture. Thus the parietal is of a more normal size, and the squamosal does not dominate this part of the skull as in Pangolins and Sloths.

Below the notch, the parietal $(p$ ) forms a round lobe which rests upon both the cartilaginous top of the orbitosphenoid $\left(o_{.} s_{*}\right)$, and the wholly ossified alisphenoid (al.s.), and firther back it forms the upper part of the temporal fossa, its whole lower edge being somewhat concave, and the outline both there and behind is somewhat emarginate, to receive the arched margin of the squamosal and intraparietal (i.p.). The latter bone is about one-third the size of the parietal, and it reaches back over the outer edge of the unossified part of the occipital plane.

The squamosal (sq.) is quite normal, it is much smaller than that of a Sloth or Pangolin, and much larger than that of Cycloturus.

The temporal squama has an arched upper edge; the hind margin of the bone is broad and emarginate; the outer face is moderately convex for a moderate pneumatic cavity over the drum cavity, and both there, where the glenoid cartilage ( $g l_{\text {. }}$.) has grown on to it, the margin is notched; the zygomatic spur is well developed.

From the peculiar manner in which the overlappings, or imbrications, of the parts that form the inner wall of the orbit are developed, the mind at once refers to the skull of the Insectivora. The orbital plate of the frontal $\left(f_{0}\right)$ is a thin hollow shell of bone, the hind margin of which is one large crescentic notch, inside which a semicircular tract of the semiosseous orbitosphenoid is exposed; the optic nerve (II.) escapes through the proximal part of the bony base of this tract, and the ophthalmic nerve $\left(V^{1}\right.$ ) re-enters the skull near the junction of the bone and cartilage in that plate. The rounded corners of both the frontal and parietal bones overlap the cartilage postero-superiorly, and, behind, its cartilaginous part is notched in the same crescentic manner as the orbital plate of the frontal, and is then overlapped by the semicircular fore edge of the alisphenoid ( $a l_{.} s_{\text {. }}$ ), which round edge is nearly parallel with the hind margin of the orbital plate of the frontal. This outstunding fore edge of the alisphenoid forms the hinder boundary of the sphenoidal fissure $\left(V^{1,2}\right.$. $)$; its inner boundary is formed by the orbitosphenoid $\left(o . s_{0}\right)$. The palatine ( $\left.p t_{0}\right)$ crops up in the anteroinferior part of the orbit; the pterygoid $(p g$.$) can be seen below the jugal arch.$ Below the tegminal notch of the squamosal the tympanic (a.ty.) and manubrium can just be seen. The supraoccipital bone (s.o.) bends down behind the intraparietals, behind which the thick wide convex unossified part is seen. Behind the lower lobe of the end of the squamosal a small convexity is seen; this is formed by the hori- 
zontal canal (h.s.c.); behind this the larger crescentic swelling is due to the posterior canal (p.s.c.). The exoccipitals (e.o.) margin the foramen magnum (see also fig. 4, e.o.); below, the occipital condyle (oc.c.) is shown, and outside this the low paroccipital ridge $(p . o c$. )

The facial nerve (VII.) is seen escaping below the horizontal and posterior canals where they meet, and in front of the nerve the epihyal (.$h \%)$, with its obliquely oblong splint, the stylohyal (st.h.). The cartilaginous bar is elbowed and enlarged; it then runs downwards and forwards into the upper ceratohyal (c.hy.) without segmentation. Then comes the lower ceratohyal half as long as the main bar, and then, less than half as long as the lower ceratohyal, the hypohyal (h.hy.). 'That little hillock of cartilage dilates to articulate with the fore part of the $U$-shaped basal bar (b.h.br.), a very regular semi-ellipse. The sides (or horms) of which are the continuous thyrohyals $(t . h y$.$) .$

When the hyoid bar becomes segmented from the cranial part, then this will be quite a normal hyoid arch, except that the thyrohyals are continuous. But in the Edentata the hyoid arch is most variable, and that not only as to Families, but the genera Dasypus and Tatusia do not agree in the structure of this arch.

The smallness and imperfection of the teeth has given rise to a great reduction in the size and bulk of the fore part of the mandible; this is a much larger "ramus" than that of Tatusia (Plate 6, fig. 3), for the hind part is very large, the coronoid process $(c r \cdot p \cdot)$ being of great extent and rather wide. The articular or condyloid part (cd.p.), with its oval condyle, runs downwards and forwards till it meets the overlapping thick part where the vessels and nerves enter. That thickening corresponds to the distinct coronoid bone of the Ovipara, and the gently convex inner wall of the ramus to the splenial bone. Below the foramen, the ramus forms a second lobe similar to the rounded angular process $(a g \cdot p \cdot)$ behind.

The end view (Plate 14, fig. 4) shows the occipital plane, still largely mossified. The investing bones $(i . p ., p ., s q$.) can be seen overlapping the whole of this hind wall, and the auditory capsules (op.), swollen here with the posterior canal (p.s.c.), are seen planted into a deep oblique notch, right and left; below these the facial nerve (VII.) and the epihyal $(e . h y$.$) come into view. The rest is occipital, and here we see, as a$ correlate of the development of the large intraparietal, a decrease in the size of the subcircular supraoccipital (s.a.); see also in Totusia (Plate 6, fig. 4). By this we know that we are further from the Monotremes, and from the rest of the Edentata. A large sinuously transverse muscular ridge runs across this bone already, so that here, as in the temporal region and lower jaw, we see that we have to do with a strong and muscular animal. The subcircular foramen magnum $(f . m$.$) his the outer part of$ its arch and upper half occupied by the rounded exoccipitals (e.o.); their depth, the depth of the cartilage between them and the supraoccipital centre, and the depth of the occipital condyles (oc.c.), are all nearly equal. Outside the condyles, the arch projects as a quite distinct, though not large, paroccipital ridge and process (p.oc.) : a 
good normal Mammalian character. The concave hind margin of the basioccipital (b.o.) is seen in the distance.

The ossicula auditûs (Plate 15, fig. 4) are, like those of the Armadillos (Plate 6, fig. 6 and 11 ; and Plate 7, fig. 6), intermediate between those of the more aberrant Edentates and those of ordinary Entheria.

Already in this relatively, and really very large, embryo, these parts are well formed, and the rest of the primary jaw is gone. The inner view (Plate 15, fig. 4) shows at reniform sinuous condyle, on a large hear, which is convex externally, and scooped on the inside. The large styliform processus gracilis $(p \cdot g r \cdot)$ is a little longer than the styliform manubrium ( $m . m l$.), which is still cartilaginous. Doran's figure (op. cit., Plate 64, fig. 14) shows a still smaller manubrium and a still larger processus gracilis, even in the adult.

The quite normal incus $(i$.$) is ossified, but the stapes (st.) has it facet and neek$ still cartilaginous; in the adult (Doran, op. cit.) the long crus of the incus has become slenderer and the hole through the high stapes somewhat larger, and more circular. I see no interhyal nucleus in the tendon of the stapedius muscle (st.m.). One more point may be noticed, namely, that the base of the stapes is convex, and projects inwards beyond the rim, as in the Mole (Tulpe europeca); but not to the same extent.

In the lower vicw of the peeled inner sluml (Plate 15, fig. 1), the eye is almost confused with the number of parts to be described. If these figures be compared with figures already given by me in other papers of the endocranium, - of Selachians ('Trans. Zool. Soc., vol. x., plates 34-42), and of the larvæ of the Urodela and Anura (Phil. 'Trans., 1877, Plates 21-29; Phil. Trans, 1876, Plates 54-62 ; and ibid., 1881, Plates 1-44; Linn. Trans., ser. 2., Zool., vol. ii., plates 14-21)--it will be seen that the interpretation of the Mammalian skull is no easy task. But there lie, obliquely between this marvellously specialized skull and the skull of the Ichthyopsida, the yarious kinds of skulls to be seen in the oviparous "Amniota," or Sauropsida.

To see the meaning of what lies before me, here, in the skull of this somewhat abnormal, low Eutherian, I find it necessary to remember the structure of the skull in every division of the great groups just mentioned, that is in Serpents, Lizards, Tortoises, Crocodiles, and Birds.

But the best of all these is the Crocodile, an ancient type, and one on which the loss of parts by degenerative specialization, is much less than in the other Sauropsida, for the living members of those other groups are manifestly more modified than the Crocodile.*

This lower view (Plate 15, fig. 1) shows, behind the exposed part of the snout

* Now, and for the future, I must aroil the use of the term Reptitian, qualifying it by the prefix quasi,-for what is low in a Mammalian skull; if some Paloontologist were to stumble npon a fossil Mypotherian it would be a great gift of fortune, then one could nse that term as an adjective. That such a type once esisted I feel certain-as certain as that I myself have had a scries of ancestors. 
(al.n., e.n.) already described, that the double nasal canal, after narrowing in a little, enlarges only gradually in the aliseptal region ( $a l . s p$.$) . But in the aliethmoidal (al.e.)$ or proper olfactory territory it widens out rapidly, and forms a large bulbous structure which reaches backwards to the anterior sphenoid (o.s., p.s.). This broad end of the pyriform labyrinth is not finished by cartilage below, and the internasal desmos which binds side to side is the main vomer $\left(v_{0}\right)$. But the septal region, above the front half of the hard palate, and which is supplied by the ophthalmic or orbitonasal branch of the 5th nerve, is open, now that the lower bony floor has been removed. The thick base of the alinasal region behind the crescentic groove soon opens out, right and left, like curtains folded back, and the aliseptal wall behind the snout, for an extent which is half the length of the whole labyrinth, tuns inwards very little below. This open part is divided into two lanceolate spaces by the septum nasi (above $v^{\prime}$.), and its grooved bony rest-the vomer (v., see also Plate 14, fig. 5).

But the nasal canals are not open towards the hard palate more than by narrow chinks ; for there are two pairs of folded cartilages in this general open space-two on each side-one, the internal, half the size of the other, the external, fold.

From above the inner part of the selvedge of the closed floor of the smout, close to the septum nasi, right and left, a rod of cartilage-the recurrent cartilage or the cartilage of JACOBson's organ-grows backwards, and before it passes inside the opening of that organ $\left(j .0^{\circ}\right)$ it sends a curling process half way round the front of the passage. The marrow stem, beyond the opening of the organ, soon expands, and then the cartilage becomes lanceolate, and ends opposite the middle of the outer coil, or inferior turbinal (i.tb.). Below, the recurrent cartilage is convex; seen from the side (Plate 15, fig. 3, rc.c.), it is seen to be scooped on its supero-external face. The inferior turbinal arises opposite the thickening part of the lesser tract; it also has the same lanceolate form with a convex under face, like the other, but is twice as large. 'This "maxillary," or" "inferior, turbinal" is not fixed by its fore end ; its root is from the side ; it is an ingrowth of the aliseptal wall (al.sp.). The thin lamina which grows inwards is concave below, it runs half-way across the gap in the floor towards the vomer, and then forms an upper and a lower secondary fold. These are coiled over from their common free face, like the leaflets of Cycas revoluta, but to a greater extent.

The nasal turbinals cannot be seen in this figure; they are similar in all the Edentata, and dip down from the cartilage that underlies the nasal bones, just as the inferior turbinals grow in from the cartilage that lines the maxillaries (see in Tatusia, Plate 3, figs. 9 and $10, n_{.}(b)$.). In the figures just referred to, and in figures, soon to be described, of these parts in the Hedgehog', a fiee section of cartilage is seen right and left of the septum nasi $\left(s_{0} n, p_{\text {. }} c . c_{0}\right)$. They are a little displaced by the razor, and should lie nearer the base of the septum. This dissection of the nasal labyrinth of the Aard-Vark gave me the interpretation of those sections of the nose of Tutusice and Ermaceus.

'The lanceolate form of the gap right and left of the septum (Plate 11, fig. 5, and 
Plate 15, fig. 1) is finished on the inside in its hinder half, by a precurrent cartilage, which overlaps the recurrent tract (pc.c., re.c.). This stoutish rod, which ends in a point in front, is a direct ongrowth from the inner edge of the nasal floor, over which floor the copious folds of the so-called "middle turbinal" are to be found. Behind these precurrent spikes, the proper olfactory floor, formed by a large ingrowth of the aliethmoidal fold (al.e.), is a wide sinuous tract, convex towards the inside, and at the outside, but convave along the middle. This wide part is divided, by a renewal of the concavity, into two lobes, the inner of which lies on a lower plane than the outer, and reaches a little further back. The inner part of the imner lobe is hollowed out, the nasal floor running upwards, in a concave manner, to reach the vomer. The outer and higher lobe is rather uncinate, hooking a little towards the orbitosphenoidal region; it is the lower face of the great lateral ethmoidal mass, seen from above in fig. 2.

The main median investing bone, the vomer $(v$.$) , and the small paired anterior bones$ $\left(v^{\prime}\right)$, were not peeled off with the rest of the superficial bones, when the preparation, here figured, was made. The large parosteal tract $(v$. $)$ has been dominated by two very distinet endoskeletal structures, namely, the intertrabecula, and the floor of the double nasal labyrinth. This large, long vomer reaches by its hind forks as far as the labyrinth, whose halves it mites, below; in front, it runs nearly as far as to

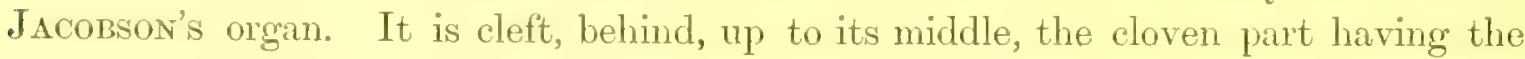
keel divided, which has run back from the fore half. In the foremost part the bone is simply rounded, running thence to its grooved upper face, on which the front partition wall rests.

This very remarkable foliacious vomer (Plate 14, fig. 5 ; Plate 15, figs. 1 and $3, v$.) is roughly pointed in front; then at the beginning of its second third it gives off a narrow wing, right and left, and these wings widen up to the median slit; a little behind it they end. Overlapping them, another pair of wings arise, right and left, twice as wide, and then another pair wider still, which run on to the diverging end of the forks, behind; the left middle wing is perforated.

The vomer is pinched in under the first and last wing, which are thinnish, as is usual in the edges of the Mammalian vomer (Plate 15, fig. 3, side view); but the middle wing is a solid mass with an oval outline.

This lobe or wing did not peel away easily, like the other, as is usual with a parostosis in its relation to the underlying cartilage, but had to be broken away, there being no line sharply dividing the bone-cells from the cartilage-cells. Thus the vomer is here grafted on to each moiety of the cartilaginous nasal capsule at the inner edges of its floor, as in Passerine Birds, *

* Sce Nitzsce, article "Passerine," in Ersch and Grüren's "Encyclopædie,'1840; "Ueber die Familic der Passerinen," Zeits. fiir die gesammten Naturwiss., 1862; Huxlex, Proc. Znol. Soc., April 11, 1867, pl. 450-454; and my papers on the Egithoguathous type of skull, Trans. Zool. Soc., vol. 9, plates 54-69, and vol. 10, plates 46-5: Trans. Limn. Soc, ser. 2, Zool. vol. i., plates 20, 21; and Monthly Micros. Jouru., 187:2, plates $31-39$; ind, ibit., 1873, plates 8-10. 
I may have missed this peculiar structure in some of my dissections; this is the last skull at which I have worked-if so this character will not easily escape me again. It appears to me to be a new and rare thing, and one of many remarkable cases of the conformity of the Mammalian skull with what is to be found in the Oviparous types-high and low.

Afterwards, I have no doubt, the bony matter transforms still more cartilage, that bone soon becoming anchylosed with the ossified tracts of the rest of the lateral ethmoids. Whether "posterior paired vomers" appear or not I camnot say, possibly the hindmost lobes or wings of the main bone become distinct for a time, and then unite with the bone forming within, so as to complete the compound desmognathism of the Mammalian upper face.

The anterior paired vomers $\left(v^{\prime}\right.$ ) are very small in this type; they are club-shaped, convex below and towards the septum, and hollow towards aAcoBson's organs, of which they are the bony correlates. 'They lie right and left, a little in front of the main vomer.

The skull proper is composed, now, of about equal parts of unossified and ossified cartilage. The anterior sphenoid shows no basal piece below; the whole of the thick beam, from the basisphenoid (Plate 15, fig. 3, p.s., p.e., s.n.) to the end of the snout, being cartilaginous.

That beam shows lateral wings where it passes into the alisphenoids, but for the rest of its extent, as seen from below, it is simply convex, lessening forwards (Plate 15, figs. 1 and $\left.3, p_{.} s_{.}, s_{.} n_{0}\right)$.

In this large embryo the orbitosphenoids $\left(o s_{*}\right)$ have lost their ethmoidal and supraauditory attachments, but the wide outer half is still unossified. Their rounded fore edge comes short of the retiring margin of the lateral ethnoids, only membrane flooring the front part of the cranial cavity there. The ear-shaped upper part of each orbitosphenoid runs backwards inside the alisphenoids (fig. 2), but the two broad wings of bone at the proximal part are in front of the alisphenoids, and these form the front boundary of the sphenoidal fissure, through which the 1st and and branches of the 5 th nerve $\left(V^{\perp} \cong\right.$. ) escape. The orbitosphenoidal bones are thick, below, fore and aft of the optic foramen (II.), and the front thickening nealy touches the vomerine fork on one side-the right in the figure-and overlaps it on the left, the concave margin of the bone fitting against the rounded inner lobe of the great nasal capsule. The hinder thickening of the bone, below, rests upon the ossified angle of the proximal part of the alisphenoid ( $a l . s$.$) .$

The posterior sphenoid is about equal now to the anterior, which it imbricates, behind, clearing itself well, outwards, from the rest of the skull wall.

The bony basisphenoid $\left(b_{*} s_{*}\right)$ occupies about three-fourths of its own territory; the whole of this subpituitary part is thick and convex, showing no sign of the primary deficiency in the cartilaginous floor. The sides (al.s.) have united, already, with their keystone piece, but a groove below marks the old line of division 
of the bony centres. The alæ are not ossified up to their root in front, but the bone reaches the front of the unfinished basisphenoid bone (b.s.); behind, they overlap it. The hollow under the junction of the base and alre is the place where the pterygoids clamped the skull (Plate 14, fig. 1); here the alisphenoids are bevelled; beyond that part they are strongly convex, as they grow first outwards, and then upwards. All their three free edges are crescentically emarginate; the notch in front forms part of the wide sphenoidal fissure $\left(\mathrm{V}^{1,2}{ }_{2}\right)$; on the outside a suture is seen ruming from the concave edge to the large foramen ovale $\left(V^{3}{ }^{*}\right)$. The alre being measured fore and aft, is in the middle of the bone, but it comes near the outer edge. Here, again, we have that remarkable character of the alisphenoid which we have just seen in the Sloth, Pangolins, and in the genus Dasypus (Plate 7, fig. 1), but not in Tatusic (Plate 5, fig. 1), where the alisphenoid, freed from the general cranial wall of the chondrocranium, is slow in developing-see especially in Manis (Plate 11, fig. 1, al.s.) -and thus the huge trigeminal nerve sends its hindmost branch over the edge of the ala. Normally, the 3rd branch of the 5th notches this hind margin of the alie (see in Tatusia, Plate 5, fig. 1, $\mathrm{V}^{3}$.), the "foramen ovale" being completed afterwards by a postneural bar of bone. But in the Mole (Talpa curopace) it perforates the primary cartilage, and the 2nd branch does the same, so that in that type the "foramen rotundum" is also a primary foramen of the chondrocranium, and not a notch completed afterwards by a bony bar.*

The large outer and hinder lobe of the alisphenoid binds in front of the "tympanic recess" of the squamosal, and then the hind margin rapidly running forwards, this bone closes upon that great auditory outgrowth, the cochlea (chl.). Between the cochlex the basal beam keeps on widening backwards, behind the bony basisphenoid $(b, s$.$) . There is a tract of this widening cartilage three-fourths the extent of the bone;$ behind this the basioccipital is twice as long as the cartilage, and reaches to the front (or lower) edge of the foramen magnum ( $f \cdot m$.).

This latter bone (l.o.) is six-sided, has a straight front margin, a concave side margin lying against the convex cochlee, a slightly concave margin followed by cartilage, postero-laterally, and its emarginate end is at the foramen magnum. The condyles (oc.c.) are short, convex, and ear-shaped; the small exoccipital bones (e.o.) are close in front of them, and end against the hypoglossal (or condyloid) foramen (XII.). The fore part of the foramen magnum has the bone and cartilage raised into a protecting

* If we lose patience over these details we shall miss the best things in this minute morphology. In the normal freedom and ont-thrust of the Mammalian alisphenoid, and in the rery varied manner of eseape of this inferior maxillary nerve-through, or over, or beinind the als-we have specializations that must be compared with the modification of this part of the general cranial wall to be seen in Serpents, Lizards, and Tortoises, where what is one continuous growth in Sharks, Frogs, \&c., is in one case a little patch, in the next a narrow "upright," and in the third case, the Chelonian, it has suffered complete suppression. (See Trans. Zool. Soc., vol. x., plate 38, fig. 2; Phil. Trans., 1881, Plates 1-4.; ibid., 1878, Plates 27-33; ibid., 1879, Plates 37-45; and 'Challenger Reports,' vol. i., Zoologg, plates 1-13.) 
rim. Outside the condyles a definite low convex paroccipital ridge is seen (po.c.), outside this the cartilage is opisthotic (op.). Beyond and behind the condyles, there is a narrowish tract of cartilage, and there the lower edge of the bony supraoccipital (s.o.) is seen bulging backwards.

The ovoidal cochlear region of the auditory capsule (chl.) lies ench in its own oblique, well-made socket; the rest of the capsule seen in this aspect is the tegmen tympani outside, and the opisthotic region (op.) postero-extemally. Outside the tegmen the large pneumatic foramen of the squamosal (tr.c.) is drawn in outline, and under the tegmen the ficial nerve (VII.) is seen passing to its place of exit, the stylomastoid foramen. In front of the nerve the small stylohyal bone (st.h.) is seen, and inside it the epihyal cartilage (e.hy.) Further inwards, in the enlarged occipito-auditory "foramen lacerum posterius," the 9 th and 10 th nerves (IX., X.) are emerging a little in front of the 12th (XII.). In fiont of this semicircular chink, the fenestra ovalis and fenestra rotunda $\left(f_{*}, o, f_{0} \%\right)$ are shown in the fundus of the nut-shaped cochlea (chl.), the proximal or hinder part of which is more convex than the rest.

The upper view (Plate 15, fig. 2) of the endocranium shows what a long tract there is of the nasal labyrinth before we come to the dilated, and most complex, true olfactory region; the cartilage roofing and walling all the regions in may still retau the old terms of alinasal, aliseptal, and aliethmoidal ( $a$ l.n, al.sp., al.e.). The whole structure, as seen in this aspect, is more like the parts of a flower than the fore end of a skull; the vestibular fluted part is very elegant, with its two pairs of semicylindrical tracts, gradually enlarging backwards, and then appearing to end, in each, in a point. Between these pointed ends, of which the submesial go furthest back, the roof (al.e.) is sinuously and gently concave, and then ends in a perforated triangular tongueas in Birds-that tongue-like growth being the top of the moderately developed cartilaginous "crista galli" (cr.g.).

Right and left of the crista galli-which is the concave free, posterior, macliastinal edge of the perpendicular ethmoid (see also fig. 3, p.e., cr.g.), the large, hollow, burrowing olfactory fossæe are seen floored by the multiperforate cribriform plate (cr.p.). This porous roof over the "midrle turbinals" is itself the floor of the fore skull, and these two pre-cranial orens are themselves roofed in front and at their sides by the arched edges of the upper turbinal regions of the olfactory capsule. The copious growths of the upper turbinal ( $u . t b$.) are indicated right and left in the great pillow-shaped lobes of the ethmoid. On the inner edge of each of these there is a small angular tag of cartilage, and at a moderate distance behind the round swelling end of these upper turbinal masses, the round fore end of the cartilaginous, outer part of the orbitosphenoid (o.s.) is seen; the tag is the remnant of the bond that did hold the much larger orbitosphenoid to the olfactory capsule.

The cribriform plate is margined behind by a thick rim of cartilage-very thick inside and below the tag; but nearer the middle the cartilage is still more solid, form- 
ing a remarkable structure right and left of the axial crest, which is hollow between these two sessile berries of cartilage, and then thickens as it passes into the presphenoidal region (p.s.).

We must cross over into the territory of another" group of the "Amniota' to get an explanation of these parts, which appear to be rather for ornament than use, but which are really most important in their morphological signification.

In the chondrocranium of the Crocodile and Alligator (see Trans. Zool. Soc., vol. xi., plates $63-67$, and especially plate 67 , fig. $1, i . t r ., c . t r$.) we have the explanation of this right and left berry-shaped swelling of the hind part of the ethmoidal region. They are the swollen ends of the paired trabecula-the "cornua trabeculre," so familiar to us in the Ichthyopsida.*

A large unciform lobe of the orbitosphenoidal cartilage $\left(o_{.} s_{0}\right)$ is seen lying upon the bony alisphenoid $\left(a l . s_{*}\right)$, but it is now two-thirds its own length from the front edge of the large superauditory (or pterotic) cartilage (s.a.c.), with which it was once continuous. The hind margin of the still large orbitosphenoid is a great semicircular noteh, the fore margin is wavy, up to the rounded front and outer margin. The first and largest rounded notch of the orbitosphenoid fits against the berry-like cornu trabeculæe (c.tr.), and the inner angle of the bone is separated from the same part of the other side by cartilage, the hindmost part of the perpendicular ethmoid (p.e.). Nearly in the middle of the inner margin of the bony part the oblique optic passage (II.) is seen well margined by bone behind (see also fig. 1), but in this aspect this margin of bone is pressed upon by a mass of cartilage. Between the two bony tracts-orbitosphenoids (o.s.)-there is a short, thickish wedge of bone with notched sides; this is the presphenoid $\left(p . s_{0}\right)$, it is doubtfully independent, but is well marked off by a right and left groove. $\dagger$

The cartilaginous tract between the pre- and basisphenoidal ossifications is also elevated into a sort of double berry; here with no stem between. Here we have the trabecula behind the intertrabecula, with the thickening at their origin, showing here most on the upper side, whereas this is seen most on the lower in the Crocodilia (op. cit., Plate 65, figs. 1-3). The large bony alre (al.s.) lie down low and are well scooped; they have a sharp raised ridge on their inside, and this is separated from the now confluent basisphenoid by a groove which is open at both ends; in the hinder space the internal carotid artery (i.c.) enters, and then runs along the groove. In front, the basisphenoid projects between the roots of the trabeculæ; behind, it is notched thrice

* The reader is also referred to the sections of the skull of the embryo Turtle (Chelone viridis) ('Challeuger Reports,' Zool., vol. i., plate 5, especially fig. 7, i.tr., $t r$.). If these figures be compared with those of the like sections of the skull of the embrgo of Struthio camelus (Phil. Trans., 1866, Plate 10, figs. 2-5, s.n.), and of the skull of the Chick (Phil. Trans., 1869, Plate 81, fig. 6, s.n., and itrit., Ilate 83 , fig. 4, s.v. $l_{\text {. }}$ ), the meaning of these things will be evident.

$\dagger$ The presphenoid is very rarely an independent ossification; it attains to that special condition most perfectly in the Marsupials and Rodents; but in that remarkable Insectivore, Rhyncocyon, the presphenoid has evidently had its own longitudinal centre of ossification. 
to receive the three convexities of the parachordal tract. 'The bone is gently hollow for the pituitary body, and this "sella turcica" is finished behind by the triple rising, very slight, of the postpituitary wall, the fore part of the cartilaginous tract in which the basisphenoid and basioccipital (b.o.) will ultimately meet. The three convexities of the cartilage are due to the manner in which the thick parachordal tracts met, and united, over the narrowing cramial end of the notochord.

Below (fig. 1), the investing mass, or parachordal cartilage, was finished into bone right and left, by the basioccipital (b.o.); above, the sharp edges that lie against the nut-shaped cochlere (chl.) are unfinished, the rest corresponds with what is seen below.

The cochler (chl.) look broader in this aspect than fiom below; they overlap the out-thrust alisphenoids, somewhat; their arched inner porch or meatus internus (VII., VIII.) is seen in this view, and also the widened chinks for the 9 th and 10 th nerves (IX., X.). The bulging supraoccipital centre (S.o.) has the outer third, on each side, occupied with a large convex inturned crest of cartilage, which runs forwards in front of the hinder angle of the alisphenoid; that foremost part is the remnant of the great continuous band that did run into the orbitosphenoid. It is mainly the hinder" third of the sides of the "tegmen cranii," and is supraoccipital behind, and "pterotic" at the sides. *

This "demonstration" will be finished when I have described the great septum of the nasal labyrinth in its lateral aspect (Plate 15, fig. 3). The whole of the large crest of the intertrabecula is rather low, its basal or primary part is very round and solid. A large oval fenestra $(i, n . f$.) lies in front of the crest, surrounded by the alinasal growths $(a l . n$.$) .$

These are figured as cut away, but from the lower part there is given off the recurrent or JACOBSoN's cartilage (rc.c.), a long, hollow-faced spatula, with a small vomerine bone $\left(v^{\circ}\right)$ above its dilating part, in front. The aliseptal fold (al.sp.) is thin, but where the hinder part of the roof is cut through the aliethmoid (al.e.), there the cartilage is very solid. Behind it the cartilaginous crista galli (cr.g.) stands like a reversed "rostrum." The margin of the septum then forms one large, nearly semicircular notch along the thin end of the intertrabecular septum (p.e.). Concentrically with this, a little lower down, the thick, cribriform plate (cr.p.) is cut through. Behind the fossæ, the stem of the cornu trabeculæ (see fig. 2, c.tr.) is cut through, and then comes the orbito-presphenoidal bone (p.s.) grooved laterally in the attempt to form a distinct median centre. Much cartilage is still unused, below and behind; then the basisphenoid (b.s.) shows itself through the thickness of the basal beam. The

* This lateral tract is ossified separately in the Osseons Fishes as the "pterotic" (see "Salmon's skull," Phil. Trans., 1873, Plates 5-8). In the Mole and Shrew the ossification of this part (as I shall presently show) takes place in a remarkable manner. The opisthotic rapidly ossifies nearly all the walls of the labyrinth, but the prootic arises in its normal place, and then, pushed upwards, so to speak, by the huge opisthotic, runs into this superanditory crest, forming a ptero-prootic bone. 
hind part of the septum is marked with hills and hollows that correspond with the folds of the middle turbinal.

\section{Summary and Conclusion.}

In the present state of my research I can make but little use of comparisons, and draw very few deductions. Most of the work already done is still in the form of figures, with no written descriptions, and that is only about a fifth of the work laid out for me in the Mammalian Class.

Nevertheless I am much mistaken if the knowledge already obtrined in this Order of the Edentata, alone, is not of considerable value; the living types composing it are so far removed from each other by specialization that they, evidently-Family after Family-represent large groups of forms that must have existed in the past.

As placental Mammalia, these types come, of necessity, into Professor Huxley's highest group - the "Eutheria;" and yet in both the skull and the other parts of the organization worked out by me, namely, the shoulder-girdle and sternum, they come nearer at times to the Prototheria than the Marsupials themselves-that middle group, the Metatheria.

Therefore it occurs to me, and the author whose terms I have just used will, I believe, agree with me in this view, namely, that these Edentata are the direct children of the Prototheria. That they passed through a Metatherian stage is a thing not to be controverted, but I believe that it was not, in most cases at least, utilized-it was an abbreviated prenatal stage; they lost their Marsupial bones and never acquired any Marsupial modification of their abdominal skin. A great satisfaction now arises to me from the fact that my very narrow line of research brings me to the reiteration of Professor Flower's views of the Edentata, inter se.

The Old World types are sharply divided from those of the New World; but types so different in appearance and habits as the Sloth and the Ant-bear can be shown by embryology, as well as by their general anatomical structure, to be, in reality, closely related. Adaptive modification has done its utmost in these two cases; but it has only masked, it has not destroyed, the essential fundamental conformity of these two grotesque and aberrant types of Mammals.

I need not repeat here what I said in the Introduction as to my change of views since the publication of my paper on the Pig's skull (Phil. Trans., 1874, Plates $28-37$ ), as to the general homology of the "ossicula auditûs." The researches of Balfour, Salensky, and Fraser have caused me to think over this question again, and to doubt the conclusion that Professor Huxley first, and I afterwards, had come to on this question; if further research shows that the views of to-day are untenable, I shall be ready to receive that fresh light.

When the developinent of the skull has been worked out in Family after Family in the Orders that compose the whole Class, then will be the time for a general 
Summary, and we shall then be better able to appreciate the fragmentary nature of the existing groups of Mammalia, and to imagine, in some degree, with the help of Palæontology, what the lost kinds were like.

In working out this Order I have had constantly to refer to the structure and development of the skull in the Sauropsida, and at the same time to be careful not to call any modification of a low Mammalian type of skull Reptitian or even Sauropsidan. I want a term of wider import than even Professol Huxley's title for the Mammalian root-stock, namely, "Hypotheria," as that would only lie under the Prototheria, and not under the Reptiles and Birds too. Proto-Ammiota occurs to me, but unfortunately the second existing group of Mammalia, the Marsupials or Metatheria, are themselves proto-Ammiota, having both that important foetal membrane and its correlated sac, the allantois, in a primary, or at least an arrested, condition.

At present, therefore, I use a term which, I think, cannot be misunderstood, namely, quasi-Reptilian, as its use does not suggest the idea of the possessor of such a character being derived from a Reptilian stock.

Using this precaution, I freely, from time to time, refer the reader to my published figures of the parts of the growing skull in Serpents, Lizards, Crocodiles, and Birds, because that, in some things, these highly specialized modern oviparous Ammiota retain certain structural characters that are manifestly archaic, and that can be easily compared with their counterparts in the skull of the gill-bearing tribes.

Out of the great number of parts that are in conformity with what is seen in the other Classes, especially in the Sauropsida, I have been anxious to eliminate and put into prominence, characters that are peculiar to, and diagnostic, of the Mammal. Some of these are as much so as the hair, and mammary glands, and are therefore of great interest to the Morphologist. Yet the most striking and important of these have to be plucked out of the very fire of controversy, so that the survey of a wider and still wider field is urgently necessary; that survey, fully made, will be the work of years.

When speaking of these low forms-the Edentata-and asserting that they are archaic, or arrested, or abnormal, I am, of course, thinking of such normal forms as the Insectivora, and of the higher types that ascend above them-Lemurs, Carnivora, Ungulata, \&c. Happily, everyone is familiar with the structure of the skull, in the adult, in these groups; and although these high forms have their own highest or culminating type-yet that which is highest in a Mammalian skull, as such, can be approximatively ascertained.

Suppression, or even abortive and abnormal development of, the teeth is always attended with abnormal development of the extensive facial structures; these, it is evident, modify the outward form of the head much more than any difference that can arise in the form, or proportional size of the skull proper, so far as it is a mere box to contain the central nervous system.

These remarks, it will be seen, have their bearing on the modifications to be seen in 
the skull of the Edentata. But for what is seen in Orycteropus, I should leave the Marsupial type of skull out of question in the present comparison. All the New World kinds, and the Pangolins of the Old World, may be considered in relation to each group - to the Monotremata below them, and to the Insectivora above, or rather outside, them.

As far as I can see at present, the parietals coalesce very early in the Monotremes, and the large supraoccipital grows over to meet this quasi-reptilian roof, and form the lambdoidal suture.

In the Edentati the parietals do not meet and coalesce early; but the supraoccipital region is very large, turns over towards the parietals, and ossifies early, and has no interparietal separating it from the parietals.

This takes place in all but Orycteropus, which has one of the largest interparietals I have seen, and thus agrees with Marsupials, Insectivora, and the Mammalia, generally, that have normal teeth.

The premaxillaries are very small in the Edentata, especially those that are absolutely toothless; Orycteropus has the best developed premaxillaries of any of the members of this Order. The maxillaries have the best development in Orycteropus, and the feeblest in the Pangolins; and they and the little Anteater (Cycloturus), have only the rudiment of a jugal. That bone, although large, does not make a finished zygomatic arch in the Sloths; it does in the Armadillos; it is quite normal in Orycteropus. The most Crocodilian development of the hard palate takes place in the Ant-bear and the 'Tamandua; in Cyclotums the pterygoids go quite as far back as in the large kind, and are attached to strong basipterygoid processes of the basioccipital bone. In the Sloths, especially Cholopus didactylus, C. Hoffmanni, and Bradypus tridactylus, the pterygoids are very large and long, and in the last kind form a great "antrum" on each side. The basioccipital bones have considerable basipterygoid processes with no bones attached to them.

In Dasypus, the Manidx, and in Orycteropus, the pterygoid bones are quite normal, but in the genus Tatusia, anongst the Dasypodidæ, the short, thick pterygoids add somewhat to the hard palate.

The lacrymal is absent in the Pangolins, huge in the Aard-Vark and Armadillos, and smallish in the Anteaters and Sloths.

'The squamosal is pneumatic in all these types, adding' a considerable upper gallery to the tympanic chamber; this agrees well with what is seen in Marsupials and Insectivores.

The os tympanicum is feebly developed in all the Edentata, about equal to what we see in Marsupials and Insectivora, but in none is there any such enlargement of the drum cavity as is seen in some Marsupials, and a few Insectivora, formed by a growth of the alisphenoid and a large "os bullse;" nor from a special wing of the basisphenoid, as in the Hedgrehog and Tenrec.

Where there are several teeth, as in Armadillos and the Aard-Vark, then the stapes 
is normal; in the Sloths with fewer teeth, and in the toothless Anteaters and Pangolins, the stapes is a short columella ; in the lesser Anteater and in the Sloth a slight perforation may take place after ossification, but this element is imperforate in the cartilaginous stage. I cannot find that the fore part of MECKEL's cartilage forms any part of the "ramus," as Insectivora and other normal Mammals; it seems simply to become absorbed, as in the Sauropsida. The angular and coronoid processes of the lower jaw are well developed in all except the Pangolins; in them these parts are more aborted than in the Echidna.

Also in the early embryo of the Pangolin the chrondrocranium, instead of equalling that of a Frog or a Skate, as it does in most kinds both of this Order and of the Mammalia, generally, is very feebly developed, almost as much so as in Serpents and Lizards, and, as in the Serpent, the orbitosphenoidal plate, at least its upper part, is a separate patch of cartilage.

In the osseous stage, the Armadillos of the genus Tatusic have their alisphenoid in two pieces, like the two separate tracts of the cartilaginous orbitosphenoid of the Pangolin, and in this genus, contrary to the rule of the Edentata, but according to the rule of the normal Mammalia, the 3rd branch of the 5th nerve notches the hind margin of the alisphenoid.

In the others it primarily notches the outer margin of that frec-edged plate, although it often becomes enclosed in bone, afterwards, thus, passing, in the adult, through a well-formed foramen ovale. Only in the Sloth do I find a har of bone enclosing the space through which the 2nd branch of the 5th nerve passes out, thus forming the foramen rotundum.

And only in the Sloth do I find the foramen opticum, which begins as a perfect passage, surrounded by cartilage behind, converted afterwards into a mere notch, thus opening into the sphenoidal fissure. This is primary in Marsupials, and exceptionally so in Sorex vulgreris anongst the Insectivora; in that type the nerve may or may not have a bony bar formed behind it, afterwards. This variation may occur in the same individual, the right and left sides differing. But in Marsupials, as in the Sauropsida, there is, normally, no postneural cartilaginous bar, either in the cartilaginous or the bony stage.

I shall refer to this imperfect list of modifications of the skull of the Edentata in my next and following papers. 

II. On the Structure and Development of the Shull in the Mammuliu... Part III. Insectivore.

\section{By Williaji Kitchen Parker, F.R.S.}

Received January 15,- Read Jaunary :29, 1885.

[Plates 16-39.]

TuE skull in this low group of placental MIammals (Eutheric) is of great interest, and, knowing this, I lave lost no opportunity, for many years past, of procuring specimens of all sorts, and of all ages and stages. The native kinds, nanely, the Hedgehog, Mole, and Shrew, form perhaps, on the whole, as instructive a group as could be found anywhere; they are related, and yet distantly, and the Mole comes in well between the generahsed Hedgehog and the very specialised Shrew.

I have been able to follow the Hedgehog and the Mole through a large series of stages, and the Shrew in fou--so that these native kinds will now have the history of their skull fairly written ont. But the exotic kinds of Insectivora do not yield a jot, in interest, to those familiar to us here; these I have been less fortunate in procuring. Yet I think that I can now offer to the Society a sufficiently detailed account to serve, by the help of the more exhaustive account of the skull in the native kinds, to give a clear idea of the morphology of the shull in the more important Families of this most instructive Order.

Any chance of my ever staying my hand from working at the Insectirora, and getting to work at other Orders, has simply arisen from failure of further materials, as to embryos and early young, so absorbing did the study of these types become.

The materials" for this present paper have largely poured in during the last three or four years; although I have been collecting, as opportunity has served, for a long time, many of my specimens have been waiting for twenty years, and some were prepared forty years ago.

Yet I feel now, more than ever, that any attempt at working out the morphology of the Mammalian type of skull would have been premature if I had not devoted much time to the lower types of skull seen in the oriparous Vertebrata.

* My hearty thanks are due to my friends for these, namely, to Messrs. Carplater, Cunnimginam,

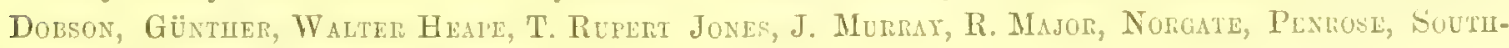
Weli, G. IVEst, and Professor Moselex.

MDCCCLXXXY. 
For although, of necessity, none of these lie directly below the Mammal, yet they are of great profit to the student of Mammalian descent, when the mask of their own particular specialisation has been resnoved, and that which is essential to the Vertebrate is seen in each "platform," lower and still lower, so as to help the mind to form some useful, if inadequate, idea of the lost types that did underlie, and indeed give rise to, the existing Mammalia.

The Common Hedgehog, besides being more easily obtained than most kinds, is, I feel certain, one of the most generalised types in the Order: it has escaped further from the Metatherian border than some (e.g., Rhymchocyon), that nevertheless show much greater signs of advance towards the higher Eutheria. Thus the various characters seen in Erinacens are none of them so low as some to be seen in the type just mentioned, whilst none are so high as others. On the whole I look upon this genus as most normal, for the Order itself, as well as a good instance of a low Eutherian type, with which to compare any of the higher and more specialised kinds-a sort of useful supra-marsupial norma.*

\section{BIBLIOGRAPHICAL LIST.}

Almañ, Professor George J., F.R.S. "On Potamogale." Trans. Zool. Soc., vol. vi., 1869 ; plates $1,2$.

Atston, G. R. "On an undescribed Shrew from Central America." Proc. Zool. Soc., 1877 , pp. $445,446$.

Andersov, John, M.D. "On the Osteology and Dentition of Mylomys." Trans. Zool. Soc., VIII, Art. XIII., pp. 453-467; plate 64; 1874.

Austen, N. J. "On the Habits of the Water-Shrew" (Crossopus foctiens). Proc. Zool. Soc., 1865, pp. 519-521.

Barboza du Bocage, Dr. J. V. "Sur quelques Mammifères rares et peu connus d'Afrique Occidentale qui se trouvent au Muséum de Lisbonne." (Bayonia velox.) Proc. Zool. Soc., 1865, pp. 401-404.

Brandt, J. F. "On Solenodon." "Memoirs of the Imperial Academy of Sciences of St. Petersburg,' 1832-3.

Coues Elisott. "Precursory Notes on American Insectivorous Mammals;" with description of new species. U.S. Survey.

Dossor, G. E., F.R.S. "A Monograph of the Insectivora." London: 1882-3.

Gil., Theodore. "Synopsis of Insectivorous Manmals." "Bulletin of the Geological and Geographical Survey of the Territories;' No. 2, Second Series. Washington; May 14, 1875.

* The Metatheria (Marsmpials) are now in hand; an acconnt of their skull will form Part IV. The Prototheria (Monotremes) will not be delayed longer than is absolutely necessary; if possible, their skull will be deseribed in Part $\mathrm{V}$. 
Gray, J. E. "A Revision of the Species of Golden Moles" (Chrysochloris). Proc. Zool. Soc., 1865, pp. 678-680.

Günther, Dr. Alibrt, F.R.S.

1. "Description of a New Species of Chrysochloris from South Africa." Proc. Zool. Soc., April 6, 1875, plate 43, p. 311.

2. "Remarks on some Indian, and more especially Bornean Mammals." Proc. Zool. Soc., May 16, 1876 (Tupaic), plate 36, pp. 424-427.

3. "Notes on some Japanese Mimmmalia." Proc. Zool. Soc, June 1, 1880 (Urotrichus and Talpa), plate 42, pp.440,441.

4. "Notes on the Speciess of Rihynchocyon and Petrodromus." Proc. Zool. Soc., 1881, pp. 163, 164, plate 14.

Heape, Walter. "On the Development of the Mole (Tulpa Europaca)."

'Quarterly Journal of Microscopical Science,' July, 1883.

Mivart, Professor St. George, F.R.S.

1. "Notes on the Osteology of the Insectivora." Journ. of Anat. and Phys., I., 1867, pp. 281-312; II., 1868, pp. 117-154.

2. "On Hemicentetes, a new Genus of Insectivora, with some additional Remarks on the Osteology of that Order." Proc. Zool. Soc., 1871, pp. 58-79.

Parker, W. K. "Shoulder-girdle and Sternum." Rity Soc., 1868 ; plates 27, 28, pp. 210-213.

Peters, W.

1. "Neue Säugthiergattungen aus den Insectenfressern und Nagern." Monatsber. Akad. Wissensch. Berlin : 1846, 257-259.

2. "Ueber die Säugthiere-Gattung Solenodon." Abhandl. Akad. Wissensch. Berlin : 1863-64, pp. 1-22; plates $1-3$.

3. "Ueber die Classification der Insectivora" (besonders Eviculus, Echinogale und Potamogale). Monatsber. Akad. Wissensch. Berlin : 1865, 286.

Sundevalu, C. J. "Ofersight af slïgtet Erinaceus." K. Vet. Akad. Handigr., Stockholm, 1841, pp. 215-240. Isis, 1845, pp. 273-280.

Thomas, Oldfield, F.Z.S. "Description of a New Genus and two New Species of Insectivora from Madagascar." Jour. of Linn. Soc. (Zoology), vol. xvi., pp.319-322. (Read March 2, 1582.) 
The following are the stages worked out in Erinaceus curopans:-

First Stage. Embryo of Emanacus curopous, about two-thirds ripe; $1 \frac{1}{4}$ inch long. *

Second Stage. The same species, about three-fourths ripe; $2 \frac{1}{4}$ inches long.

Third Stage. New-born young of the same species; $2 \frac{1}{3}$ inches long.

Fourth Stage. Young Hedgehog, two weeks old, or thereabouts; 3 inches long.

Fifth Stage. Young Hedgehog, about a month old; head $1 \frac{1}{2}$ inch long.

Sixth Stage. Young Hedgehog, two-thirds grown.

Seventh Stage. Young Hedgehog of first winter.

Eighth Stage. Adult Hedgehog, nearly, or recently-not old.

First Stage of Erinaceus europæus; cmbryo two-thirds ripe; $1 \frac{1}{4}$ inch lony. (Plate 17, figs. 1, 2.)

In this solid little embryo, with the "panniculus" formed, the prickles beginning to project (Plate 16, figs. 8, 9), the chondrocranium (Plate 17, figs. 1, 2), is no longer pure cartilage. ${ }^{+}$

\section{a. Dissected endocranium.}

The floor and sides of this skull-barge are well formed, except that large cracks or fissures show themselves below; it is almost as fully formed of cartilage as that of a young Skate of the same size, but shows some very remarkable modifications that are diagnostic of the Mammal. For instance, the nasal capsule runs along the whole extent of the rostrum, or intertrabecula. The sicles of the barge-like structure have given way, right and left between the ear and the eye, or between the anditory capsule and the orbitosphenoid (o.s.); thus the alisphenoids are syueezed, as it were, outside the rest of the structure, as if part of a wall should bulge out and break away from the "coping"stone."

To those two characteristics I may add the extensive plate of perforated cartilage ("cribriform plate") for the multitudinous nerves proceeding from the "rhinen"Nhiatia." "+

'This irregularly pyriform chondrocranium is a very extensive and complex structure, through the union, with the cranium, proper, of the fore and hind sense-capsules.

* In all the mensurements I exclude the tail, unless it is specially mentioned; the length is from the snout to the root of the tail, the length of the head and body, separately measured, being added together.

f In my next instance-the Nole-I shall give an account of that earlier stage, before any bony deposit has appeared. (See Plate 25, figs. 1, 2.)

+ The only other type that shows a cribriform plate is the Myxinoid (see Phil. Trans., Vol. 174, Plate 17, fig. 4, p. 401); in that case, however, only five nerves pass out on each side, through a perforated membrane. 
The front pair, or olfactory capsules, are half the length of the skull (fig. 17, al.n., (ll.e.); the hind pair, or auditory (chl.), take up much of the skull in its hinder part, aborting, by their implantation, a large amount of the inferolateral walls in front of the occipital arch. The ron is so largely open, when the investing bones have been removed, that the sides and base can be studied as well from the upper, as from the under, face.

On the under face of the skull (fig. 1) I have figured three bones of the vomerine series, although they belong to the investing bones; this is because of their peculiar relation to the olfuctory capsules, and especially the parts called "JAcosson's organs."

Beginning at the snout (fig. $1, a l . n$.), we see that the external nostrils $\left(e_{. n}\right.$.) are at present inferolateral in position, being seen better on the lower (fig. 1) than on the upper face (fig. 2). Their direction is oblique, and they are extensive open spaces. The rounded and emarginate fore end of the snout is followed by the coils that surround the nostrils, which widen out and are marked off by a groove; behind these coils, the snout enlarges on the under surface into two large flaps, that meet in the middle at an obtuse angle, which, however, is cut away, so to speak, and made acute by the sinuosity of the selvedge of the flaps. Here the labyrinth has its walls pinched in, before it expands to form the swollen olfactory or ethmoidal region. The margining hind flaps of the snout are only partially free, yet they overlap (or rather grow under) the two pairs of cartilaginous growths into which they are developed, backwards. The outer pair of cartilaginous growths simply form the general wall of the capsule, here called aliseptal $(a l . s p$.$) ; the sides of the capsule which are con-$ fluent with the septum nasi, above (fig. 2), are tucked under, below; and inside their edges another tract of cartilage is seen of, apparently, the same width as this arrested floor. This submarginal tract is the inferior turbinal (i.tb.) and is really very extensive, as we shall see in the sections (Plate 18); it arises as a longitudinal outgrowth from the inner face of the outer wall, and is half the length of the entire labyrinth

There are also two submesial cartilages, three-fourths the size of the inferior turbinals; these are retral developments of the snout, and I call them simply the "recurrent cartilages" (vc.c.); they are, however, very important, being the proper capsules of JACoBsox's organs. 'These tracts only partially close in above, forming a sort of trough in which the organs of $J_{\Lambda \text { COBson }}$ lie. 'They are elegant, somewhat sigmoid, long, revolute leaves of cartilage, with their convex face looking outwards and downwards.

Each leafy part is supported by a bone, the form of which they dominate, so that each tract is also hollow on the face that looks towards the curved inner edge of the cartilage; it lies on the inside, back to back to its fellow: these are the front, paired vomers $\left(v^{\prime}\right)$, and answer to the paired vomers of the Snake and Lizard among Reptiles.*

* In the two latter these paired vomers are very curiously modified, and have over them an extra pair of bones (septo-maxillaries), the two bones on each side forming a capsule to the organ of JAcorson, 
Between these front paired vomers, the proper azygous vomer $(v$ ), which only appears in highly specialised types - as Teleostei, Chelonians, certain Birds, and Mammalspasses its fore end between and above the paired bones, and then becomes carinate to rest upon the hard palate; it widens behind to support the olfactory capsule, where are developed the so-called "middle turbinals."

The aliethmoidal, or the olfactory region (al.e.), is divided right and left into a large antero-superior lobe and a small postero-inferior. The latter contains the hinder part of the middle turbinal folds $\left(m . t b_{0}\right)$, and the former the whole of the upper, and the fore part of the middle turbinals. A deep, sinuous valley is seen between this bilobate swelling, right and left, and the great orbitosphenoidal wings $\left(o . s_{\text {. }}\right.$, whilst, laterally, the cranium is narrowed behind the lateral ethmoidal region, and then swells out still inore in the orbitosphenoidal. All the sinuosities of the lateral outline of the endocranium are gentle and very elegant; there are several in the auditory and occipital region, where the "stern" of the barge-like skull narrows in.

The nasal labyrinth, on its lower aspect, shows some of its complexity through its fissures; where the floor of the capsule is bound by the vomerine forks $\left(n . f_{.}, v_{0}\right)$, there it is seen to run forwards, right and left of the vomer, as a spike of cartilage.

This will be seen in its full size in the sections; I have called it the "precurrent cartilage" (see fig. 8, pc.c.); it may reach the recurrent cartilage (rc.c.), as in Orycteropus ; here, however, it does not quite reach it. In the hooked angular space between the larger and lesser swellings of the ethmoid the foremost outgrowth of the middle turbinals $(m . t b$.$) can be seen.$

Between the forks of the vomer the basicranial beam shows itself; here it is composed of all the three prepituitary rods, trabecula, and intertrabecula; its anatomical numes here are perpendicular ethmoid (p.e.), between the forks of the vomer; presphenoid (p.s.), for a short distance behind the forks; and basisphenoid (b.s.) still further back, where it is perforate; a primary, oval, pituitary opening being left at this part. Right and left of that space we see the "sphenoidal fissure," which allows a number of cranial nerves to escape-third, fourth, part of the fifth, and the sixth.

The great orbitosphenoid (o.s.) has its moderately broad base or proximal part divided off from the presphenoid merely by an inferior groove; it curls round behind the ethmoidal masses (ul.e.), widening, expanding, and becoming convex. Nearly half-way towards the outer margin is seen the optic foramen (II.), which lies nearer the hind than the front edge of the band. The free upper edge of the orbitosphenoid $(o . s)$ is not seen in this figure (see fig. 2), but it can be seen that the wide upper part is continuous with the nasal capsule (al.e.) in front, and with the supra-auditory region of the side wall of the skull (s.a.c.), behind.

In this early vegetative state of the endocranium there is something very flower-like in its various parts, both as to their shapes and their development. Right and left of which is only partly supported by the feeble, and sometimes detached, recurrent cartilage. The fact is that these curious and enignatical organs dominate different skeletal parts in different types. 
the widening skull-beam (b.s.), now becoming parachordal, and also osseous, there is a. large leafy growth, a broad petaloid, ear-shaped tract; this is the free, outlying alisphenoid (al.s.). This "wing" is broadly falcate, the havelle being made by the cutting away of its proximal part to widen the sphenoidal fissure; the blude has its antero-external, sharp edge equal to a quadrant; its point is somewhat rounded; and its back, looking towards the auditory capsule (cht.), is gently concave. This hinder wing does not quite reach to the margin of the continuous skull-wall (o.s., s.(l.c.). Half-way from the pituitary opening $(p . \%$.$) to the edge, and nearer the hind than the$ fore margin of the wing, we see the foramen ovale for the third branch of the trigeminal nerve $\left(\mathrm{V}^{3}\right.$ ), but there is no separate passage, as yet, for the second-the forctmen rotundum.

One-third of the hind margin of the alisphenoid is ossified; the bony matter forms a selvedge both to the foramen and the hind edge of the wing. Also behind the pituitary hole there is a pyriform ossification as large as the two alisphenoidal centres together; its broad fore end is perforated-part of the pituitary space; this bone is the basisphenoid (b.s.).

Behind this bone the basis cranii shows three wide convex tracts, margined by a lesser concavo-convex tract, right and left. The least convex of the three main parts is cut away, so to speak, right and left, in a perfect semicircle, by the more convex masses, each margin being bevelled down to a sharpish edge. This region is the "spheno-occipital synchondrosis," which gradually becomes less and less until the basisphenoid bone (b.s.) meets the basioccipital (b.o.).

The large swollen part and the lesser sinuous margins, right and left, both belong to the auditory capsule, the inferior surface of which is well displayed in this aspect. The cochlea $(\mathrm{chl}$.$) shows three coils, in front of which there is a fissure through which vessels$ pass, and also the 7 th nerve, which runs inside the eave or outer thickening of the earcapsule under the tegmen tympani (t.ty.). That archway is ended by the epihyal $(e . h y$.$) in its confluence with the opisthotic region of the ear-capsule, and under it the$ 7 th nerve (VII.) runs, and behind it this nerve escapes; its exit is through the stylomastoid foramen, and before its exit it gives oft its returning fork, the chorda tympani. In front of the epihyal the fenestra ovalis $\left(f s_{0}.\right)$ is seen, behind it the fenestra rotunda $\left(f^{*} \%\right)$, and inside that the enlarged fissure for the 9 th and 10 th nerves (IX., X.)

Behind this cranio-auditory chink, the occipital arch is perforated a little nearer the mid-line, for the hypoglossal nerve (XII.), and behind the epihyal that areh has a definite paroccipital thickening of an oval shape.

Here the lateral ossification (e.o.) has taken up much of the tract between the paroccipital swelling and the condyle (oc.co); it reaches the condyloid foramen (XII.). The enlarged cartilaginous tracts, right and left, that form the condyles give the hind margin of the basis cranii an emarginate outline; into this emargination under the 
formen magnum $(f . m$.$) the notochord (nc.) still projects. It is embedded in the$ middle of a roughly pentagonal bony plate, the basioccipital (b.o.).

'The structure of this fundamental and most instructive skull will be still better' understood by referring to the upper aspect (fig. 2).

Here the snout $(a l . n$.$) is seen to be much shorter than below, and partly pinched off$ from the next or intermediate nasal region, the aliseptal ( $a l . s p$.), which, in turn, passes a little suddenly into the enlarged olfactory region, proper, the aliethmoidal (al.e.).

Here all is finished, the crested intertrabecula being confluent with the nasal roofs throughout their whole extent; a peculiarly Mommalian structure. The hind margin of the double labyrinth, above, is elegantly bracket-shaped, the proper roof ending thick-edged, in front of the huge lozenge-shaped, perforated, secondary roof, or cribriform plate (cr.p.). The partition wall, septum nasi $\left(s . n_{0}\right)$, in front, and perpendicular ethmoid $\left(p . e_{*}\right)$, behind, is, at first, scarcely apparent, above; then in the aliseptal region it thickens out considerably, and the tract between the upper turbinals does this again, but to a lesser degree. 'This top of the wall thickens out in front of the cribriform plate, to fill in the space between the retiring roof; it then, in the rhinencephalic fossa, narrows considerably, to swell out again as the presphenoid (p.s.). The perforations for the olfactory nerves are simply countless, two crescentic rows lie back to back, close to the septum, and then about five more valleys, full of holes, rum forwards and inwards from the postero-external margin of the great fossa. On a higher level than this valley full of holes are the roots of the orbitosplienoids $\left(o_{.} s_{0}\right)$ which are not so broad as the basal beaw from which they arise, the presphenoidal region (p.s.); these frond-like growths of cartilage run up co, and beyond, the most bulging part of the skull in front, and form a good floor and wall to the region of the fore-brain.

Confluent with the edge of the cribriform plate in front, they are free behind, and have a thrice-notched margin there; their selverge looks upwards, and, in front, melts into the general ethmoidal roof; whilst, behind, it is continuous with the large pterotic or supra-auditory crest (s.a.co), which in turn passes insensibly into the supraoccipital (s.o.). 'The roof of this skull, therefore, althongh open, or only covered by the investing bones, rests upon a complete rim of curtilage, from the top of the perpendicular ethmoid, in front, to the middle of the supraceipital cartilage, behind.

But the mid-brain rests upon the bulging, broken wall of the hinder sphenoid, and the alisphenoidal plate, right and left $(a l . s$.$) , is seen, in this view, away from the eye$ and partly hidden by the orbitosphenoid (o.s.). Down in the floor we see the optic passages (II.), the sphenoidal fissure for various nerves $\left(V^{1,2}.\right)$, the foramen ovale $\left(V^{3}.\right)$, and the fissure between the cochlea (chl.) and the alisphenoid, through the inner part of which the internal carotid artery enters.

Then in the auditory capsule itself the sicue for the 7 th and sth nerves (VII., VIII.); between the capsule and the skull the posterior lacerated formen for the 9 th and 10 th nerves (IX., X.); and through the contiguous exoccinital tract the proper foramen for the liypoglossal (XIL.). 
Likewise we see the three posterior sphenoidal osseous centres ( $a l . s ., b . s$.$) , the three$ lower centres of the occipital arch $(e .0 ., 6.0$.$) , and, also, the two upper centres that form$ this subsequently single keystone piece or proper supraoccipital (s.o.) - as distinct from the interparietal which may coalesce with it.

Over the atuditory capsule the pterotic band (s.a.c.) is notched; behind that notch, looking downward, we partly see the recess under the arch of the anterior canal for the "flocculus cerebelli."

\section{Visceral arches of First Stage.}

The mandibular arch of this stage (Plate 22, figs. 1, 2, ml., mk., b.mn.) is a remarkable structure, being composed of both an outer and an inner "ramus." Part of the epibranchial element of the first arch will afterwards be described as the pterygoid cartilage, the only remnant of the huge overgrowth of this part seen in Selnchians. The quadrate region is greatly masked in this case-that of the Mammal-for the orbital process or "pedicle" is suppressed, and the small pterygoid remnant is far off, forwards, whilst the small reduced quadrate segment is thrown into the same line, along the under face, as the large, well-developed lower segment, the ceratobranchial element, or articulo-Meckelian rod. Moreover, comparing the upper segment (incus or quadratum) with that of a Newt we see that its attachment to the skull is simply by the "otic process," close in front of the ampulla of the horizontal semicircular canal. Also this segment turns inwards below, behind its articulation with the free nandible, and has a narrow-necked, dilated process to articulate with the dilated remnant of the extrastapedial (the flat face on the head of the stapes).

The articular region of the endocranial mandible is already a "malleus," and already the "processus gracilis" is there as a delicate ectosteal plate under the neck of the malleus, where the long, rounded part, or MEckEL's cartilige, begins. 'The special development of the Mammalian skull, with its much-tilted, auditory capsule, and closely-fitting lower face, makes that hinge vertical, which is horizontal in all the Oviparous types. A short process on the inside of the cartilaginous malleus answers to the "posterior angular process" of the mandible of the Bird; whilst the "internal angular process" of the Bird, especially that of the Fowl-tribe (Gallinacex), is largely developed, but tethered to the centre of a radiating plate, and acted upon by one special mandibular adductor muscle, now called the "tensor tympani." The rim of this radiating plate is becoming cartilaginous, and is part of the jointed, cartilaginous lining of the ear-passage (meatus), but is ready to become bone, even now ; it does quickly become the "annulus tympanicus." Here, at present, the mandible, proper, or MEckeL's cartilage, becomes more and more solid, forwards, and somewhat flattened; it is well-nigh equal, at this stage, to that of a Selachian. It becomes alate or dilated near the end, and then, in a peculiarly Mammalian manner, unites with its fellow, and the two are finished off in front by a long basimandibular spike (figs. 1, 2, b.mn.). But this huge main rod already lies in a groove on the inside of a rapidly ossifying MDCCCLXXXY. 
cartilage, which has, already, the form of the maxilla inferior of a Mammal, for the coronoid, condyloid, and angular processes (cp., cd.p., ag.p.) are present, although not yet ossified. 'The rest of this superficial tract will be described in the palatal aspect of the skull as the glenoidal facet for the articulation of this superficial and secondury mandible.

The pharyngohyal element of the 2 nd arch is already specialised into a stapes by growing as a ring to the stapedial artery, which traverses the auditory capsule exactly where this little, free nucleus, formed in the topmost part of the hyoid facial fold, is fitting itself into the sccondary fenestra of the auditory capsule much as a Bird's femur sets itself into the widely-perforated "acetabulum." The next or epihyal tract $\left(e . h y_{.}\right)$is already confluent with the auditory capsule (Plate 22, fig, 3, e.hy., au.), close below the ampulla of the horizontal canal; the facial nerve (VII.) runs under the bridge formed by this junction.

The ceratohyal (c.lly) is divided through its middle, but is continuous with the epihyal above; and this tape-like structure divides again near its base, developing a short subcrescentic segment, the hypohyal (h.hy.).

The dilated, semicircular basal element $(b . h .6 r$. ) rather belongs to the 3rd, or 1st proper branchial arch than to the hyoid; it carries not only the hypohyals, but also the thyrohyals $(t . h y$.$) , short out-bent, thick-ended rods, that articulate with the$ thyroid cartilage, and are the distal remnants of the abortive $3 \mathrm{rd}$ visceral arch.

When once we are well assured of the points just given, all the rest of the Mammalian facial metamorphosis becomes easy to follow, and the "new things" thus produced become the most valuable diagnostics of the normal Mammalian fice and jaws.

Amongst the low Eutheria no better type than this can be found; as a Mammal, the Hedgehog is very normal, yet it is much less specialised thin several of its congeners, especially our other native Insectivora.

\section{First Stage (continued).-Vertically-transwerse sections.}

This stage will now be illustrated by a complete series of vertically-transverse sections through all the tissues of the head.

1st Section (Plate 18, fig. 1). - This is in fiont of the septum and catches the projecting parts of the alie nasi $\left(u_{0} n_{0}\right)$, and the openings of the external nostrils $(e . n$.$) .$

2nd Section (Plate 18, fig. 2). - This is close behind the extemal nostrils in the narxow beginning of the nasal passages $\left(n \cdot p_{0}\right)$. The septum liere $(s . n$.$) is but little due$ to the fore part of the crested intertrabecula, it is mainly formed by the confluence of the alinasal folds ( $u$ l.n.), back to back. This projecting part of the snout is grooved, above and below, through this union of the convex faces of the cartilages, which have inade a partition thick above and thin below. Close to the openings of the nose the aice are most complete at the sides, and the lower parts are tucked in where they 
support the lower part of the deep uncinate chink, the nasal passage (n.p.). Over the out-turned hook of the section a mucous crypt, one of the many small distinct nasal glands (m.g.), are formed between the cartilage and the Schneiderian membrane.

3rd Section (Plate 18, fig. 3).-This is from the hind part of the mobile, rooting snout, and here the upper lips begin to show themselves as depending lobes, the hollow of the palate now being more definite. Here the intertrabecula is as round as in an embryo Bird or a Shark; but here there has tiken place what is not seen in the projecting part, the "rostrum," in those very diverse Ovipara, namely, that the alinasal folds $(a l \cdot n$.) are confluent with the foremost part of this precranial rod, which now takes the name of septum nasi $(s . n$.$) . Here cach nasal tube is surrounded by$ cartilage, the alinasals having developed each into an almost complete tube, the lower part of which projects downwards far below the low wall of partition; the two folds rise again, back to back, although they do not touch. Each sweeping fold of cartilage is indented infero-laterully, in correspondence with the form of the nasal passage, which is now trilobate; a mucous crypt (see also fig. 2, m.g.) is seen outside the upper lobe.

In several sections, between this and No. 2, the lower part of the alie nasi had joined back to back, and the whole suont was thus confluent in all its parts and formed a complete double tube, or non-segmented proboscis; sections of other types (Mole and Shrew) well show this.*

4th Section (Plate 18, fig. 4).-This is from behind the flexible snout, and now the investing lones, most of which were removed from the endocranium (Plate 17, figs. 1, 2), are seen in section as thin films of bone. The solid intertrabecula, with its crest, and the confluent aliseptal folds of the nasal labyrinth ( $(a l . s p)$.), now form a strong septum nasi $\left(s_{. n}\right.$.). The alie are now fiee at their lower edge, but are enlarged there into a pedate process, which thrusts the lining skin inwards as a rounded lobe, looking downwards; this is the first appearance of the inferior turbinal (i.tb.) - its fore end. The lower parts of the cartilage, towards the middle, are now free from the base of the septum (s.n.), their section is a hook, the lamina just bending outwards, then inwards, below, turning round to supjort JACoBsos's organ (..o.); here seen at its fore end.

These curious submesial retral outgrowths of the alie nasi are the "recurrent cartilages" ( $\left.{ }^{\prime} c \cdot c.\right)$. Between these are the fiont paired vomers ( $\left.v^{\prime}.\right)$, the bony part of this locally modified skeletal structure; they converge below, and are thin uncinate splints (see Plate 17, fig. 1, $\imath^{\prime}$ ).

'The enlarging nasal passage (n.p.) gives off' from its main, vertical part, two outer, and one inner, "horn," the lattel turning inwards, below; here and there a mucous crypt is seen.

The nasals (n.) and the premaxillaries (px.) now come into view. Below, the fore part of the lower face is cut across, in front of the dentary, but through the basimandibular cartilage (b.mn.), here nearly circular in section, a tooth-pulp $(t$.) is cut

* The dotted line in fig. 2 , shows where the cartilage is complete in the next scction 
across on each side of the cartilage, and in the lower skin the bristles show their bulbs.

5 th Section (Plate 3, fig. 5).-Here the septum $\left(s_{0} n_{0}\right)$ is deepening, and its intertrabecular base is less bulbous. The nasal labyrinth has thicker walls, and besides the expanding rudiment of the inferior turbinal $(\dot{i} . t b$.$) , further up, the pointed fore end of$ the nasal turbinal $\left(n . t b_{0}\right)$ is cut across; a crypt is seen below it, and below the inferior turbinal. 'The skeletal parts that protect JACOBson's organs (j.o., rc.c, v.') are larger here, and the cartilage forms a complete tube for a short distance; above are the nusals (n.); at the sides, the bony lamince belong to both the premaxillaries (pr.) and maxillaries.

Below, the basimandibular cartilage (b.mn.) is depressed; close in front of the Meckelian rods, right and left, a tooth-pulp ( $\left.t_{0}\right)$ is seen.

6th Section (Plate 3, fig. 6).-The septum $(s . u$. ) is now much higher, and the bulb at the base much less; the side wall is very thick, for here the nasal turbinal inside (al.sp.) is beginning to clear itself of the wall; below it the inferior turbinal rudiment is still seen. Here and there a mucous crypt is seen, and here JACobson's organ (j.o.) lies in a fold of the recurrent cartilage (ic.co), behind the closed part, and behind the front-paired vomers. 'The nasals and maxillaries $(n, m x$.$) now show more clearly,$ and the latter are developing the diploè, and are giving off the palatine plate.

Below, the dentary $(d$.$) appears, outside the distinct large oval section of each$ Meckelian rod ( $m k$.).

Th Section (Plate 3, fig. 7). - This section shows several new things. The deep septum $(s . n$.$) is cut through at the junction of the septum nasi, proper, and the$ perpendicular ethmoid, the part that becomes solidly ossified in Mammals, in the true olfactory region. Under it the median vomer (v.) is seen, and JACoBson's organs are small at this their hind part. The nasal passages (n.p.) are now becoming rery complex or labyrinthic; this is due to the greater development of the various turbinal folds, now that the section is through the proper olfactory region. The nasal turbinals $(n . t b$.$) are, here, sharp and turned outwards at their free edge, whilst at the sides the$ wall is giving off new buds, and the inferior turbinal (i.tb.) is dying out. A remarkable free cartilage $(m . t b$.$) , oval in section, is seen in the principal cavity, covered with$ a mass of tissue, like the rest of the mucous and submucous lining. 'lhis is a process which grows forwards from the lower part of the labyrinth, from the region of the middle turbinal. It is large, here, but much larger in Orycteropus (see Plate 15, fig. 1), in which I have called it the precurrent cartilage (pc.c.). The romer $(v \cdot)$, the nasals and maxillaries $(n, m, x$.) are well seen here.

8th Section (Plate 18, fig. 8). - In this partial section the labyrinth is cut through just in front of the grent olfactory fossa; the perpendicular ethmoid (p.e.) has a submoniliform outline, due to three successive bulgings. The rudiments of the turbinal outgrowths are seen here, namely, the upper and middle turbinals $\left(u, t b ., m_{0} t b_{0}\right)$, and outside the latter, and just distinct from it, the thick trihedral 
mass-the precurrent cartilage (pc.c.) at its hind part; in the next section (fig. 9) it forms the front projecting part, inwards, of the middle turbinal $\left(m_{0} . t.\right)$.

'The vomer $(v)$ is here cut through its middle, where it is roughly carinate; afterwards, this part will rest on the palatine plates of the maxillaries. These bones $(m x$.$) have here developed a large alveolar cavity, and a tooth-pulp is seen in the$ alveolus; the nasals have their place taken by the frontals ( $f$.). In the last, and in this, the mucous crypts (m.g.) are abundant, especially below. The large oval section of MEcké's cartilage ( $\left.m h_{*}\right)$ is now overgrown with the diploë of the dentary $\left(d_{*}\right)$, which also is developing an alveolus, with its tooth.

9th Section (Plate 18, fig. 9).-Here another partial section is given through the forepart of the eye-ball $\left(e_{0}\right)$, and the middle of the rhinencephalon which is giving off its fibres through a mainly membranous cribiform plate $\left(c r_{0} p_{0}\right)$. Here the septum $(p . e$. is much lower, and beneath it the vomer $(v$. ) is beginning to divide into its hind forks.

The folds of cartilage are, here, confluent, so that the nasal passage is now in several sections, and at the lower part a section of the space is growing towards the cavity of the other side ready to form the proper "nasopalatine canal." 'The maxilluries and dentaries ( $m x$., d.) have here large alveoli with their tooth-pulps; the superficial bone, above, is the widening frontal.

10th Section (Plate 18, fig. 10).- This is another partial section, made through the middle of the eye-ball (e.), and the hind part of the nasal labyrinth, with the huge olfactory lobes (rhinencephala) overlying a membranous cribriform plate. The nasal wall now forms a protection to the "fossa," and beneath the floor $\left(n_{\text {. }} f\right.$.) the cartilage runs nearly up to the low dividing wall (p.e.). Here the labyrinth is reduced to two passages (n.p.), besides the common nasopalatine canal (n.p.c.) at the midline, below. Here the forks of the vomer $\left(v_{0}\right)$ are cut across, and at this part the maxillary meets the palatine ( $p a_{\text {. }}$ ) on the palatal floor; outside, the former bone ( $m x_{0}$ ) shows its large alveolar plates, as does the dentary (d.), below. At this part the frontal is in reality in two pieces, as the next stage will show; the orbital plate being separate from the upper part $(f$.$) .$

11th Section (Plate 18, fig. 11). - This section is through the back part of the eyeball $\left(e_{0}\right)$ and the front third of the hemispheres $\left(\mathrm{C}^{10}\right.$ o. . Here the true cranium comes into the section, for the basal beam is now the presphenoid $\left(p_{\circ} s_{*}\right)$, and the wall right and left is the orbitosphenoid (o.s.).

The back of the olfactory labyrinth (n.w.) is cut through, and these limited tracts of cartilage lie between the two regions of the anterior sphenoid $\left(0 . s_{.}, p_{0} s_{0}\right)$, and are confluent with the basal mass. So, also, is the orbitosphenoid confluent, above, with the top of the olfactory wall (see Plate 17, figs. 1, 2). 'The relation of the orbital plate of the frontal $\left(f_{0}\right)$ to the orbitosphenoid $\left(o_{.} s_{0}\right)$ is well seen here; below, the bones of the palate are thick tracts, dividing on their imner edge into an upper and a lower plate to embrace, and protect, the nasopalatine canal (n.p.c.); these are, now, the pterygoids $(p g$.$) .$ 
Below, outside the tongue $(t g$.$) and mouth cavity (m.) the compound lower jaw is$ seen to be composed of three tracts of cartilage and two of bone; the latter answer to the dentary and splenial, but these are not actnally separate bones, at this part. 'Then there is MEckEL's cartilage, or the primary mandibie, and two points of cartilage belong to the superficial cartilaginous "ramus."

12th Section (Plate 18, fig. 12).-Here the razor has cut through the anterior sphenoid (p.s.), continuously, missing the small optic foramen (see Plate 17, figs. 1, 2, o.s., p.s., II.), most likely cutting in front of it. Thus the crunial cavity and membranous cranium is more than half engirdled by this tract; the upper deficiency is, at present, only partially made good by the frontal bone. Here we encounter cartilage right and left, below the flat presphenoid (o.s.), for the pterygroids are cut through here, and they are largely preformed in cartilage (see in next stage, Plate 17, fig. 3, pg., pg.c.). 'These bones only form a wall, on the right hand, and on the left, to the nasopalatine canal (n.p.c.), and do not form a bridge, beneath it, as the palatines do. The mandible is growing up, here, towards its coronoid process, above, and its angular process (ag.p.), below; the inner rod ( $m k$.) lies in a groove of the ramus, near its lower part.

13th Section (Plate 18, fig. 13). - This section will be understood if reference is made to the dissected skull (Plate 17, figs. 1, 2). The basis cranii is cut through at the hind part of the presphenoid (p.s.), just where the basisphenoidal region begins. Here the two trabeculæ are cemented together by the wedge-like end of the intertrabecula. The large sphenoidal fissure is cut through, and several nerve-bundles (V.) are seen in the interspace; because of the sinuous form of the margin of the orbitosphenoid (o.s.) that cartilage is cut through twice, immediately in front of the alisphenoid, which lies in a lower plnne. The bulk of the pterygoid is still cartilaginous, and so is the "ramus" of the mandible (d.) at this part, where the coronoid and angular processes $\left(c r^{2} . p_{0}, c d . p\right.$.) are cut across; Meckel's cartilige (mk.) forms a large oval section at this part, and the dentary is spreading over it; the frontal $(f$.$) is$ seen outside and above the orbitosphenoid (o.s.).

1.4h. Section (Plate 18, fig. 14).-This is a very instructive section and should be compared with the dissection of the same and of the next stage (Plate 17, figs. 1, 2, 3). The cranial cavity with the included brain $\left(\mathrm{C}^{12}\right.$. $)$ is here very large, and the basal part of the skull is cut through where the floor is incomplete $(b . s ., p \%)$, so that we have here the exact form of the trabecula behind the intertrabecula; they are oval, with the long axis horizontal. On each side, in a deep fossa, the great Gasserian ganglion $(V$.$) is seen, supported by the alisphenoid (ul.s.) which lies outside and below the$ general pline of the skull floor and wall; it is ossified at its postero-external margin, and its hollow upper face forms the floor of the trigeminal fossa. 'The orbitosphenoid (o.s.) is narrowing towards its posterior band, and it is supported outside by the orbital part of the frontal $\left(f_{*}\right)$, which runs far down into the hind part of the orbit, almost touching the alisphenoid.

'T'wo rods of cartilnge, oval in section, but with their' long axis vertical, are seen 
under the basis cranii and protecting the narrow nasopalatine canal (n.p.c.); these are the pterygoils (m.c.) in their unossitied free part ("hamular process"). Outside, and below, we see a part of the squamosal, its zyomatic region on the jugal $(j$.$) ; and$ inside it the glenoid facet (gl.c.) is cut along its whole transverse extent. A little below it a section of cartilage appears, thick above and below and narrower in the middle; this is the main part of the great superficial slab, a segment of which is given off to form the glenoidal facet. 'The ruper' part is the condyle of the lower jaw $\left(c l_{.} p_{0}\right)$, the lower is part of the angle $\left(a g \cdot \eta^{\prime}\right)$; the inside of the cartilage is becoming bony; in the concavity, on the lower part of the inner side, Meckel's cartilage $\left(m k_{0}\right)$ is still full-sized.

15th Section (Plate 18, fig. 15).-- Here the fore brain $\left(\mathrm{C}^{1 a}\right.$. $)$ is cut through near the infundibulum, but the pituitary body $(p \%)$ is seen as a large separate quasi-glandular mass resting upon the basis cranii near the beginning of the parachordals or investing mass (b.s.). These are flattish and oroidal in section, the interspace between them being the primary pituitary space at its hinder part. On the side, the orbitosphenoid (o.s.) is still seen as a considerable band of cartilage; this is near the junction of the frontal $\left(f_{0}\right)$ and parietal bones. The Gasserian ganglion (V.) is cut across in its hinder part, and the razor has caught the cochlea (above i.c.) in its fore margin. This is behind the hinge of the secondary mandible, and through the part of MEcKEL's cartilage where the bony lamina that forms the ossifying centre of the malleus ( $\mathrm{ml}$.) has appeared. Outside this the postglenoid part of the squamosal ( $s \%$ ) is seen, and, between the two, the foremost part of the tympanic cavity (c.ty.). 'The internal carotid artery (i.c.) is seen entering the skull between the cochlea and the basisphenoid (b.s.), and under it the Eustachian tube $\left(e u_{0}\right)$ is laid open as it is passing towards the fauces or back part of the oval cavity ( Whas.); it opens into that cavity between this and the last section (fig. 14).

Under this tube the cartilaginous lining of the first cleft is seen to extend (eu.c.); this Eustachian cartilage is the innermost part of the purtly segmented cartilaginous tube which expands extemally as the "concha," and which, in the part next outside the Eustachian cartilage, becomes ossified, early, as the anmulus tympanicus.

Four arterial branches are seen, here, cut obliquely across, one of them close beneatl and outside an oval section of cartilage, the ceratolyal $(c . h \%)$. The one above it is that part of the "common carotid" which gives off the "stapedial artery," to inosculate with the artery of the lower jaw.

At the mid-line, below the palatonasal cavity, the pharynx is laid open, and right and below it the hypohyal cartilages $(h . h y$.$) . Outside and in front of the cerato-$ hyal the chorda tympani (VII".) is cut across, and outside and below these the main facial nerve (VII.).

16 th Section (Plate 18, fig. 16).-This is through the widest part of the hemispheres $\left(\mathrm{C}^{1 n}.\right)$, and also cuts across the lurge glandiform pituitary body (m\%). Several large nervous masses are cut through (VII., VII.), close to the top of each cochlea (chl.). 'The 
basisphenoidal cartilage $(b, s$,$) has a film of bone in it above and below; its outer edges$ are beginning to coalesce with the cochlea, which are laid open. The orbitosphenoidal band $\left(0 . s^{\prime}.\right)$ is still large, and is separated by a large space from the inferolateral parts. The processus gracilis has still a solid cartilage lying on it $(\mathrm{ml}$.$) ; outside this is$ the postglenoid part of the squamosal. The meatus auditorius externus is partly laid open, and the Eustachian cartilage (m.c.) is still seen under the cavum tympani (c.ty.), which is here still partly the Eustachian tube. Beneath the middle of these parts the epiliyal (e.hy.) is cut across, and outside it the chorda tympani $\left(\mathrm{VII}^{a}\right.$. $)$, with the main facial nerve (VII.) lower down, is exposed. The larynx is below the pharynx $(l x$, p phx. $)$, and there is seen a film of bone outside, the ramus $\left(d_{0}\right)$; a part of the cartilaginous framework of the larynx is seen in section.

17 th Section (Plate 18, fig. 17).- This is another important slice, showing many things. It is in front of the junction of the orbitosphenoid with the crest on the top of the auditory capsule; the cochlea (chl.) is near its widest part, it is just in front of the proximate coil. We are now behind the great trigeminal nerve, with its roots, ganglion, and branches, but the nerves proceeding from the ganglion geniculatum (VII., VIII.) are cut across, and the ficial nerve (VII.) has entered its "aqueductus." The same nerve (VII.), and its inosculating anterior branch, the chorda tympani, are seen outside the epihyal (e.hy. VII.)." Here the great meatus externus (m.a.e.) is fairly laid open, and it is seen to be lined with cartilage throughout; it is indeed one more or less segmented tube, from the opening of the Eustachian tube, within, to the conchal expansion, without. The pituitary body $(m y$.$) is cut through in its hind part; the malleus, or dilated end of Meckel's$ cartilage $(m l$.$) , is partly seen, its head and the tip of the manubrium (m b$.); the rest of that process is indicated on the right side by a dotted line. 'The archway over the facial nerve (VII.) is the fore part of the tegmen tympani, inside the head of the malleus. The postglenoid part of the squamosal is seen, and on right and left of the pharynx ( $\left.p h h_{0}\right)$ the hypohyals $(h . h y$.$) .$

Isth Section (Plate 18, fig. 18). - This section is through the basis cranii where the sphenoidal $\left(b . s_{\text {. }}\right)$ and occipital regions meet. The orbitosphenoidal cartilage has here passed into the supra-auditory (s.a.c.), where this great crest is continuous with the top of the auditory capsule. The left side of the figure is from a point in front of the right, so that this section serves instead of two. 'The left side is through the base of the cochlea (chl.), but in front of the cavity of the vestibule. The cartilage lining the meatus externus (m.c.) is seen both in the outer opening and under the dagger-shaped section of the cavum tympani (c.ty.); a small cavity at present lying in the midst of a mass of indifferent tissue. The solid cartilage of the "pterotic" region, close in front of the anterior semicircular cinal (see the other side (t.s.c.), is not perforated until we come to the beginning of the aqueductus for the facial nerve (VII.), which is cut across twice on the right side, both where it 
perforates the capsule, and where it begins its course under the tegmen, which is imperfect here in its front part. At some distance below this auditory eave the head of the malleus ( $m l_{0}$ ) is seen in section along the whole course of the manubrium on the left side. Under the tympanic cavity and its cartilaginous floor the epihyal (e.hy.) and its accompanying nerves, the chorda tympani and facial trunk (VII ${ }^{a}$, VII.) are seen cut across, and the hypohyal and thyroid cartilage $\left(h . h y ., x_{0}\right)$ at the mid-line, below. On the left side the cartilage above the cochlea (chl.) is perforated by the facial and auditory nerves (VIII.), and the right side has part of the auterior canal (a.s.c.) visible.

There the tegmen is perfect, and the main part of the incus and its long crus is cut through, the manubrium mallei $(\mathrm{ml}$. ) appearing beyond and below it. The hyoid and its nerves are similar to what is seen on the other side, for the obliquity of this section is very slight.

19th Section (Plate 18, fig. 19).-This partial section is one of the most important in the series. The parietal $\left(p_{0}\right)$ is seen outside the pterotic or supra-auditory cartilage (s.a.c.), but the squamosal which was seen in the last (fig. 18) is not figured. The arch of the anterior, and the ampulla of the horizontal, semicircular canals (a.s.c., h.s.c.) are cut through, besides several other spaces in the vestibule and proximal part of the cochlea. The wall of the cochlea is cut through in front of the band of cartilage that divides the fenestra ovalis from the fenestra rotunda, a band which in the Sauropsida is uniformly ossified by the opisthotic centre; in Mammals that centre is much more potent, and may, as in the next instance ( $T a l p a)$, ossify nearly all the proper capsule. 'The auditory nerve and its ganglion ( $g$. cochleare, VIII.) are seen in the meatus internus, and externally the stapes (st.) by its base fills the fenestra ovalis. 'The articular part or head of the stapes, which was nearly in view inside the long crus of the incus on the right side of the last section (fig. 18) is now cut clean through, and the stapedial artery (st.a.) is seen traversing the foot-hole of the stapes, on its way to the inside of the maxilla inferior. 'This section is at the back part of the meatus externus, and at the end of the tympanic cavity, so that here the epihyal (e.hy.) is seen already confluent with the hind part of the tegmen; the formen stylo-mastoideum is laid open and the facial nerve (VII.) is seen rumning downwards behind and outside the epihyal, and the cavity of the tympanum $($ c.ty.) is seen inside, close to the artery. The larynx (lx.) is seen below at the mid-line, and the basioccipital floor $\left(b_{0} .0_{0}\right)$ under the hind-brain $\left(\mathrm{C}^{3}\right)$.

20th Section (Plate 18, fig. 20).-Here the supra-auditory cartilage (s.a.c.) is close to the supraoccipital, and the film of bone outside belongs to the squamosal (sq.).

The anterior and horizontal canals (a.s.c., h.s.c.) are cut across, and the hind part of the vestibule at its junction with the cochlea.

The head of the epihyal is seen finishing the tegmen (t.ty.), behind, and the narrow hind part of the cavum tympani $(c . t y$.$) is shown, here, for the last time. The flat form$ of the parachordals (b.o.), inclosing the notochord, is seen under the hind-hrin $\left(\mathrm{C}^{\prime}\right)$.

MDCCCLXXXY. 
21st Section (Plate 18, fig. 21). -The anterior canal (c.s.c.) is here cut through where it joins the posterior, and the horizontal canal $\left(h_{\text {..s.c. }}\right)$ is seen where it opens into the cavity of the vestibule (lower part of $v b$.) ; the wall is imperfect on the inner side (see also next stage, Plate 17, fig. 7). The lowest part of the posterior canal, and its ampulla, is close behind this part. The posterior lacerated foramen (IX., X.) is here cut across, and also the condyloid formen (XII.); the basis cranii (b.o.) is large, here, and partly ossified.

22nd Section (Plate 18, fig. 22). - The thick opisthotic region of the auditory capsule is cut across, here, and the posterior canal at its beginning, above, is one with the anterior canal (a.s.c.); below, it is close to the horizontal canal (h.s.c.). On the inner face the cartilage is thin, and there is a small vestibular cavity $(v b$.). The supraauditory cartilage (s.a.c.) is so cut across as to be sone distance from the top of the capsule; this is due to the slight obliquity of the sections. The vagus and liypoglossal nerves (XI., X.) are still seen outside the bent basioccipital plate (b.o.). This section is in front of the sides and condyles of the occipital arch, and is behind the hole for the 12th nerve (XII.).

Second Stage of Erinaceus europreus. Young, three-fourths ripe; $2 \frac{1}{4}$ inches long; head, $\frac{3}{11}$ inch.

This larger embryo serves well for showing the development of the ectocranium as well as for the advancement made in the endocranium (Plate 17, figs. 3-8). Beginning with the roof (fig. 4) we find a very orderly series of bony scutes along the mid-line; there are four pairs of these sub-median radiating centres that have all the appenrance of belonging to the same category, namely, a double row of subcutaneous scales growing towards each other along the top of the head.

The foremost of these scutes, the nasals $(n$.$) , are the smallest, they are the tiling of$ the cartilaginous nasal roof, and the septum nasi $(s, n$.) is seen between them. Like shell-valves, with a pointed end, forwards, and a rounded broud end, behind, these bones just cover the hinder half of the nasal labyrinth.

The nest pair are four times as large, these are the frontals $(f$.$) ; they are narrow$ in the middle and dilated at each end; they scarcely reach the nasals, in front, and only touch the parietals $(p$.$) , behind, by their convex margin. There is a long$ fontanelle ruming between them and the parietals up to the nasals, in front, and to the sujraocipital (s.o.), behind; this is dilated in three places, especially in the coronal region. The concave outer edge of the frontal does not run as far as to the suproorbital ridge; this part and the orbital roof are covered with a distinct bone (see also fig. 5, s.ob.). This single supraorbital scale bone is new to me in the Iammalia, but fimiliar enough in the Oviparous forms--the Ganoid Fishes, below, up to the Tinamous and some higher Carinate Birds, above. In all these, however, it is broken up into two or more pieces. 
The parietals $(p)$ are nearly twice as large as the frontals, and, behind them, the interparietals $\left(i_{.} p\right)$ are not much larger than the nasals $\left(n_{0}\right)$.

Besides the supraorbitals, the lateral and infero-lateral bones seen in this view are the premaxillaries, maxillaries, lachrymals, jugals, and squamosals ( $p x$., mx.; see also fig. $3, l_{.}, j ., s q$ ), these are better seen in the other views (figs. 3, 5, 6).

In the side view (fig. 5) the premaxillaries $\left(p x_{0}\right)$ are seen to be of normal size, mounting upwards obliquely, and wedged in between the nasals and maxillaries above. The outer or facial part of the maxillary is large, with its very large infraorbital foramen $\left(\mathrm{V}^{2}\right.$ ) and its long concuve preorbital and suborbital edge. Over the former part the fore end of the supra-orbital (s.ob.) fits, and inside, below this, the smallish perforated lachrymal scale $(l ., l . c)$. The jugal $(j$.$) is a small thickish style, and is over-$ lapped both by the jugal process of the maxillary and of the squamosal ( $\left.m x_{0}, s q_{0}\right)$. Where the uncinate supraorbital $(s, o b)$ and the swollen parietal $(p)$ meet in the postorbital region there the squamosal is seen, the fore part of its temporal plate, which walls in the temporal fossa, it begins there, and the bone, clilating gently backwards, is trifid behind, in its postglenoid end, where it just hides the ampullax of the anterior and horizontal canals (r.s.c., h.s.c.) The parietals and interparietals (p). ip).) meet over the arched junction of the anterior and posterior canals (a.s.c., p.s.c.).

But the peculiarly normal Marnmalian state of the superficial bones is best seen in the lover view (Plate 17, fig. 3).

Here the increasingly perfect desmognathism of the skull and the great development of tooth-pulps, asking for large suckets, are the factors that make the normal Mammalian palatofacial structures so different from their comterparts in the Ovipara, grenerally. Add to these the metamorphosis of the mandible, giving the last finish to a face with limited motion, and we get the reasons for much that is novel in this type of skull.

The premaxillaries $(p x$.) are largely hollowed out for the teeth, and their palatine processes are, at mesent, short and small. The maxillaries (mx.) send inwards a large flange from their inner alveolar plate; beyond this, to the mid-line, another equally large tract has been developed, the palatine plate; it is joined to the outer plate by a broadish isthmus, and is never quite distinct from it. The palatine plate of the palatine $\left(p c_{0}\right)$ is three-fifth the size of that of the maxillaries, and is perforated behind its midclle. The two bones wedge in between the maxillaries at the mid-line, and at their hind part are deficient there. Outside they are thick, where they ascend to the basis cranii.

The pterygoids $(p \%)$ are merely small ectosteal tracts fustening upon and transforming the thick, short, rounded pterggoid cartilages (pg.c.), and spreading above them to plaster the basisphenoid (b.s.) with a thin bony tract.

The lower edge of the jugals and squamosals $(j ., s q$.$) are seen in this aspect, the$ latter is largely hidden by the wide three-lobed glenoid facet (gl.c.), which is placel transversely to the axis of the skull. 
The end vieu (Plate 17, fig. 6) shows the roughly-oval interparietals, and the hind part of the parietals and squamosals $\left(i . p ., p_{.}, s q.\right)$ as they fit on to the auditory and occipital regions of the endocranium.

But a lower view of the upper palate, after the hard palate has been removed (Plate 17, fig. 8), shows three more investing bones, namely, the front paired vomers $\left(v^{\prime}\right)$, and the vomer, proper $\left(v_{0}\right)$.

These paired bones are quite distinct from the palatine processes of the premaxillaries, and are delicate, narrow laminæ, with an outside hook in front; they are placed vertically inside the recurrent cartilages ( $\left.{ }^{\circ} . c_{0}\right)$ and JACoBson's organs.

Wedging in between their hinder part we see the narrow, bifid fore end of the main vomer $\left(v_{0}\right)$, which is roughly carinate in its fore half, and then flattens out, and is alate in its hind half where it is applied, right and left, as an ethmoidal splint, serving to bind the right and left floors of the nasal labyrinth together, as in Passerine Birds; this upper junction of the right and left halves of the face has been called "Egithognathism," because of its peculiar development in Passerine Birds.

\section{Endocranim of Second Stage of Erinaceus europæus.}

In the figure just referred to (Plate 17, fig. 8) we see the lower view of the alinasal cartilages $\left(a l . n_{*}\right)$ and the outer nostrils $\left(e_{. n}\right)$. Constricted suddenly, these parts give off the neck of the curious, tongue-shaped recurrent cartilage (rc.c.), which at its fullest part grows quite round JAcobson's organ (see Plate 18, fig. 5). Behind these the floor of the rasal capsule, under the "middle turbinals" (pc.c., the "precurrent cartilages"), is partly shown, and then the narrow, unossified mesethmoidal (p.e.), and presphenoidal region $\left(\mu . s_{0}\right)$, and the very wide, ossified basisphenoidal $\left(b_{0} s_{*}\right)$. This bony plate is transversely oral and is perforated in front; this hole is the pituitary space $(p y$.$) .$

In the lower view (Plate 17, fig. 3), behind the hard palate, the endocranium is well shown; it is a broad osseo-cartilaginous structure. At the mid-line the presphenoid and basisphenoid (p.s., $b s$, also shown in fig. 8) come into view, but the latter is partly hidden by the pterygoids ( $p \%, p g . c_{\text {. }}$ ), outside which the base of each alisphenoid (al.s.) swells into an egg-like process (e.p.g., or "external pterygoid"), much more distinct, now, than in the first stage (fig. 1).* Outside this swelling the cartilage is largely ossified as the alisphenoid (al.s.), which is perforated nearer its hinder, than its fore, margin, by the 3rd branch of the 5 th nerve $\left(V^{3}\right)$; the rest of this nerve $\left(V^{1,2} \cdot{ }^{\circ}\right.$ escapes through the sphenoidal fissure.

The onter part of the orbitosphenoidal bony centre (o.s.) is just seen in front of the

* This part is similar to what is seen in the embryo (uterine) of Didelphys, and the counterpart of which docs develop even in some Insectivora (e.g., Rhyncocyon, Plate 36, fig. 5) into an "anterior tfmpanic recess," or alisphenoidal bulla; this, however, in the Hedgehog becomes the external pterygoid plate; a part which, in Kingaroos, co-exists with the tympanic wing of the alisphenoid. 
fissure; these parts will be better shown in the section (fig. 7). Where the wirle posterior sphenoid joins the auditory capsules (see also fig. 1) there we see a wide transverse territory of cartilage, which, at its middie part, is the very extensive sphenooccipital synchondrosis.

Externally, it is notched, here, where the permanent "foramen lacerum," or jagged passage, will be ; and nearer the mid-line it is perforated, right and left, by the internal carotid artery (i.c.). Although the cochlex (chl.) show their form well, their cartilage is confluent with that of the skull, proper, except behind, where the "foramen lacerum posterius" will be, which is now a large oval hole formed by the 9th and 10 th nerves (IX., X.). The notched space in fiont of the capsule allows of the exit of the facial nerve (VII.), the proximal part of which is not drawn in the figure; it is seen further back under the tegmen tympani (t.ty.), and then passing under the epihyal ( $\left.e_{.} . y_{0}\right)$ to escape through the stylomastoid foramen. On the side of each cochlea the stapes (st.) is seen in situ, and behind the cochletr the foramere roundum $(f \%)$. Behind this the occipital arch shows a. swelling, a rudimentary "par prcipital." Inside that eminence the 12th nerve (XII.) passes through the condyloid formen, which is almost surrounded by the rudimentary exoccipital celiwe. Thie'sioccipital (b.o.) is very Reptitican, being roughly pentagonal; it is still marked by the notochord (nc.).

The occipital condyles (oc.c.) have a very Butruchiun appearance, not being very prominent, and very wide apart.

From the upper view (fig. 4) not much of the endocranium is seen, but the alinasal region $\left(a l_{.} n_{0}\right)$ is seen to have developed into a projecting snout, much longer than in the early stage (fig. 2). Behind, the supraoccipital bone (s.o.) has become single, and right and left of it the cartilage passes into the supra-auditory crest, and the proper auditory capsule with its canals (p.s.c., h.s.c., c.s.c.).

In the side view (fig. 5) the projecting snout and nostril (al.n., e.n.) is seen, and the valvular folds covering the nostril. In the orbit the lower frontal (s.ob.) ossicle fails to cover the orbitosphenoidal cartilage (o.s.) with its orbital plate. Below, the thick bulbous process of the alisphenoid (e.p $g$.) and the pterygoid nucleus (pg.c.) are seen, and, behind, the outer face of the auditory capsule, with its canals (a.s.c., h.s.c., p.s.c.) is well shown, and also the tegmen tympani, and part of the cochlea (chl.). The epihyal (e.hy.) is confluent with the capsule behind the tegmen, and the facial nerve (VII.) emerges behind it. Behind this stylomastoid formen, the paroccipital eminence, the condyle (oc.co), the exoccipital (e.o.), and the supraoccipital (s.o.) come into view.

So do those parts in the end view (fig. 6), where, however, they are displayed more fully; here especially we see how large the great foramen ( $\left.f^{\circ} \mathrm{m}_{0}\right)$ is, as compared with the hind skull, even with the investing bones (p., i.p., sq.) still in place.

But the most instructive view of the endocranium is to be had by bisecting the skull, vertically (fig. 7).

Now we see what a mere tube this skull is, even in the embryo, and also that the 
chondrocranium is nearly as perfect as in a Skate. Yet every true Mammalian character is to be seen, well developed, and diugnostic.

The cranio-facial axis has two bones in its hinder third, not much larger than the "synchondrosis" that separates them; these are the basioccipital and the basisplhenoid (b.o., b.s.); all the rest forward is pro-chordal, and composes the presphenoidal, ethmoidal, and septal regions of the skull (p.s., p.e., s.n.).

The septum runs forwards, between the folds of the alinasal cartilage ( $a l \cdot n$.) in front, a roundish part, perfect, or nearly so; then a narrow isthmus unites this part with the proper septum nasi $\left(s_{. n}\right.$.), which passes, at present, without change into the perpendicular ethmoid (p.e.), and this into the presphenoid (p.s.). This large partition wall is a low triangle, the apex of which forms the rudiment of the crista galli $(c r . g$.$) . The fore part, above, is continuous with the nasal roof (al.e., al.sp., al.n.);$ the hind part divides the two great olfactory : finssie, with their hollow, cribriform floor (cr.p.). The basal part of to " great wall is thick, this arises from the primary solidity of the intertrabecula. Where the alæ nasi $(a l . n$.) seem to end below, there they give off the recurrent cartilagf's (rc.c.), and these are strengthened by their special splints, the anteriur paired vomers (fig. $8, v^{\prime}$.) ; behind these, the intertrabecula is supported by the large grooved vomer, proper $(v$.$) . From the crista galli (cr.g.) to$ the formen magnum there is one continuous growth of solid cartilage, the fore part of which becomes the crest of the orbitosphenoid (o.s.). Up to the sphenoidal fissure $\left(\mathrm{V}^{1,8}\right.$ ) the cartilage runs from the base to the top without any break save the foramen opticum (II.), which passage is now enclosed in the wedge-shaped orbitosphenoidal hony centre (o.s.). This beginning of a large plate takes up all but the lowest part of the stem of the great orbital wing, but only reaches one-third of the way to the sinuous upper edge of the cartilage. Hence, a full fourth of the whole side wall hes. given way outwards, and the top of the cartilaginous wall reduced to one half its depth, forms an elegant archway over this breach; it is a very perfect arch, but leans a little forwards. This doorway is only partly shut above by the alisphenoid (al.s.), the part which has been thrust out; the lower half of this halfopened valve is ossified, and the lower edge of the bony part has a large notch in it, behind the middle; this notch is finished by cartilage, and is the foramen ovale $\left(\mathrm{V}^{3}.\right)$. The basisphenoid (b.s.) is growing into this tract of cartilage, and reaches further backwards than the alisphenoid.

The cartilaginous side wall has then a second great archway larger than that caused by the out-thrust of the alisphenoid; here there is an actual suppression of the wall, but the space, which looks a little backwards, is filled in by the large ovoidal cartilaginous auditory capsule. Over the capsule the cartilage is thimned out by pressure of the lateral sinus $(l . s$.$) , which forms as perfect an arch as that over the alisphe-$ noid. Under the arched swelling caused by the anterior and posterior semicircular canals, which meet above, there is but a shallow concavity for the flocculus cerebelli. Behind this hollow, there is an unciform opening, with its convex margin behind; this deficiency is caused by the "recessus labyrinthi." 
The multiperforate meatus internus, further forwards, and the swollen proximal part of the cochlea $(c h$.$) , are well seen in this view, over the long spheno-occipital syno-$ chondrosis. Between these tracts the bony and cartilaginous parts of the occipital arch (s.o., e.o., b.o.), the passages for the postauditory nerves, and the occipitai condyle (oc.c.) are seen.

\section{Visceral arches of the Second Stage.}

The compound mandible has developed considerably since the last stage (Plate 22, fig. 4), the dentary bone (d.) having grown round MEckeL's cartilage (mk.) for some distance, in its middle part, and the upper edge of the bone is now hollowing out to form the tooth sockets. In front, the basimancibular $(b . m n$.) is less, and it is now well defended by bone on its outside. Behind, the trilobate, semicartilaginous "ramus" has assumed its permanent form, although the coronoid and angular processes are equally cartilaginous with the condyloid or articular part. Under the latter, MEсKEL's cartilage is being let into the bony plate; behind this part it arches upwards, and below the arched part the ectosteal malleal centre $\left(m l_{0}=\right.$ articulare externum) is enlarging. 'The malleal part of this primary mandible shows a small but distinct posterior angular process $\left(p_{0}\left(r g_{0}\right)\right.$, as the elbow of the manubrium (mb.), or internal angular process. The incus ( $i_{\text {. }}$ ) and the stapes (st.) are still quite unossified, but they are assuming their permanent form.

The annulus tympanicus $\left(a_{0} t y_{0}\right)$ is a crescentic band of not very solid cartilage, which is becoming bony along the middle; this bony tract will use up all the cartilage, not leaving any to form a "bulla."

\section{Third Stage of the Skull of Erinaceus europaus; new-born young, $2 \frac{1}{3}$ incheslong.}

In the "endocranium" at this stage we find a considerable advancement in growth; seen from below (Plate 19, fig. 1), and from above (fig. 2), it is roughly pyriform in ontline, gradually enlarging up to the auditory region, and then suddenly lessening. 'The short snout (fig. 1, al.n.) has the nostrils (e.n.) Iitteral; this region has a definite bracket-shaped selvedge where it comes in contrat with the premaxillaries, and from the submesial part of this hind edge the recurrent cartilages (rc.c.) are given off; these are large tongue-like tructs, convex infero-laterally and concave on the upper and inner face, where, for a short distance, they form a perfect tube round each J Aconsov's organ. They are supported on their inner face by the dagger-shaped front paired vomers $\left(v^{\prime}\right)$, whilst the vomer, proper $\left(v_{0}\right)$, runs in between them in front. That bone, overlapping these parts in their hinder third, runs backward to the end of the right and left subcranial recesses of the nasal labyrinth; it is widely forked in its hinder, and strongly carimate in its niddle, third.

The aliseptal region (al.sp.) narrows in at its middle, and then expands again to become aliethmoidal (ul.e.). 
The inferior turbinals (i.tb) arise from its inner face, and can be seen in the space right and left of the vomer. Where the vomer forks, there each fork supports the inturned nasal wall, now the floor $\left(n . f_{0}\right)$, which is finished by the vomer. In the front of this part the inturned walls give off" the "precurrent cartilages," already described. At present, the hinder region of the nasal labyrinth forms merely part of a scroll, and has not yet closed in to finish the hinder recess. The very solid basal bem is seen between the forks of the vomer, first as perpendicular ethmoid (p.e.), and then as presphenoid (p.s.). The proximal part of the orbitosphenoid is hidden by the recesses of the nasal labyrinth, the bony centre $\left(0 . s_{0}\right)$, can, however, be seen in its upper part.

On a lower plane, the large alisphenoids $(a l . s$.$) , with their oblique sinuous onter$ margin, are seen now to be largely ossified; these bony plates are perforated by the 3rd branch of the 5 th nerve $\left(\mathrm{V}^{3}\right)$, for they have a large foramen ovale a little behind their middle. Between these wings and the basisphenoid (b.s.) there are still two remarkable tracts of cartilage, one of these is the large synchondrosis between the ala and the base, and the other is a button-shaped projection (e.pg.), between the pterygoid $\left(p g \cdot, p^{\prime} y_{0}.\right)$ and the foramen ovale $\left(\mathrm{V}^{3}{ }^{*}\right)$, but a little in front of both.

This projection is the cartilaginous rudiment of the external pterygoid plate, which in this broad-floored skull is in its normally Mammalian position, namely, a good distance outside the correlated pterygoid, with its independent cartilaginous nucleus.*

In this type, and in many of its Insectivorous congeners, the basisphenoidal bony centre $\left(b . s_{\text {. }}\right)$ runs behind, largely, for some distance, into the alisphenoidal cartilage $\left(a l_{.} s_{*}\right)$; this is a most important diagnostic of a true, normal, Insectivore. It is, however, a very gentle modification of that which is diagnostic of the skull of the Marsupials, namely, a "tympanic wing," which grows backward from the alisphenoid. Here, the rudimentary tympanic wing arises from that part of the alisphenoid which is ossified vicariously from the basal centre; thus the further growth of the tympanic wing is merely a shelllike flange of the basisphenoid. Hence the bone which develops round the tympanic air-cell in the typical Insectivora, assisting the superadded annulus tympanicus, is basisphenoidal. The alisphenoidal centre, in Marsupials, which forms the front part of their drum-cavity, is supplemented by a large, crescentic "os bullæe, which ultimately becomes ankylosed, in most cases, to the alisphenoid. Moreover, the extensive pneumaticity of the basis cranii of the Insectivora, at this part, is very Sauropsidan, and these types have also a considerable upper tympanic recess inside the squamosal bone, as in Crocodiles, Birds, Marsupials, and Edentates. At present the basisplienoid (Plate 19, fig. 1, b.s.) does not reach so far forwards as the ali-

* In the typical Ruminants, and still better, in the genus Caria among the Rodents, this sphenoidal outgrowth is seen to be manifestly the homologue of the "basipterygoid process" of the Sauropsida, growing as it does from the side of the basal beam. Its viscernl corrtate, the pterygoid cartilage, which, indeed, dominates it, has uudergone most remurkable structural modifications in the types in which it re-ippears, e.g., in Chelonia, Crocodilia, Passerine Birds, aud, lastly, in the lower Mammalia. 
sphenoids, but it goes further backwards, yet there is a considerable tract of cartilage separating it from the basioccipital.

A groove in its lower face leads to the still unclosed pituitary space (see fig. 2, py.); whilst right and left it has a deeper groove filled by the terete pterygoid (p\%.) with its cartilaginous terminal nucleus (jo.co). Behind the pterygoids, and in front of the sinuous wedge-like growth of bone in the middle, there is a definite rudinent, as an oblique ridge, of the future tympanic wing.

The broadest part of the skull is behind the posterior sphenoid; here the huge cochlere (chl.) display their coils, and outside them the broad tegroen tympani has on its inside the groove for the fitcial nerve (VII.), which escapes from the skull behind the edge of the alisphenoid. This groove is protected behind by the confluence of the epihyal $(e . h y)$ with the auditory capsule; the nerve escapes behind it, through the stylomastoid foramen. In front of the epiliyal, the fenestra ovalis $\left(f_{s} .0.\right)$ is seen obliquely, and the fenestra rotunda (f.r.) mesiad of it. Behind the fenestra rotunda, and further inwards, the large passage for the 9 th and 10 th nerves (IX., X.) is seen, and behind that passage the lesser hole for the 12th nerve (XII.) The basioccipital (b.o.) is roughly hexagonal; the exoccipitals (c.o.) are developing in the hollow between the paroccipital convexities and the condyles (oc.c.).

The upper view of the endocranium of this stage (Plate 19, fig. 2) is shown with the upper part cut away for the better display of the fundus cranii. 'The crenate hinder' margin of the nasil capsules is almost transverse, only a little concave, and is so thoroughly pre-cranial as to display nearly all the large cribriform plate (cr.p.). The top of the septum nasi $\left(s_{0} n\right.$.) and perpendicular ethmoid $\left(p_{0} e_{0}\right)$ is seen at its junction with the alæ or roof $(a l . s p ., a l . e)$; the middle part of the continuous partition is thicker than the end. The upper part of the capsule is constricted twice, so as to form a front, a middle, and a hind, enlargement. The lateral part is constricted, gently, once. There is no definite cartilaginous crista galli (cr.g.), but merely a gentle rising of the wall in front, directly behind the end of the roof:

The cribriform plate has floored the whole fussa, and this tract, as well as the lateral walls, are confluent with the fore edge of the anterior sphenoid. 'The broad short presphenoid (p.s.) is unossified, and it has in its middle a hollow, showing the double nature of the bar. The orbitosphenoids (0.s.), are ossifier, proximally, close to the base, in their hinder margin; the fore part and the whole of the main wing still remain sott. This pyriform centre is perforated by the optic nerve (II.), which escapes near the hind margin, half-way up the ascending bony tract. The intumed upper edge has been cut away, but the band is shown to run backward to, and to be confluent with, the auditory capsule.

The hind margin of the orbitosphenoid (o.s.) is sinuously crncuve and hides the more distinct alisphenoid ( $a l_{\text {.s. }}$ ) at its fore edge. The basisphenoid (b.s.s) occupies the hind half of the small open pituitiry space $(\mathrm{m} y)$; it is separated by a large tract of cartilnge, as yet, from the basioccipital $($ b.o.). Both before and behind, that centre is MDCCCLXXXY. 
seen, even above, to be creeping into the alre, the bony centres of which just touch the foremost of these extensions of the basisphenoid. But more than a third of the hind part of the alie is still cartilaginous; the posterior external part dips below the auditory capsule, just as the front margin does under the orbitosphenoid.

The sphenoidal fissure $\left(\mathrm{Vl}^{\mathrm{l}} \curvearrowright\right.$. ) is an oblique reniform foramen, and to it a groove for the 2 nd branch of the 5 th nerve runs from the lirge foramen ovale $\left(\mathrm{V}^{3}.\right)$. A small sphenotic flup of the auditory capsule overlies the alisphenoid, externally; between this part and the coiled cochlea the facial nerve (VII.) escapes, rumning first under a bridge of cartilage from the foremost hole of the meatus internus (VII., VIII.). 'The swellings outside the wall-which has been cut away horizontally-are due to the horizontil and posterior semicircular canals (h.s.c., p.s.c.), the arch of the anterior canal (a.s.c.) is cut away and its cavity exposed. The hollow for the flocculus is not well shown in this view; behind it, the opening of the "recessus labyrinthi" is seen.

Patches of bony cells are now to be seen, the beginnings of the extensive opisthotic bone (op.). These are at the hinder margin of the cochlea in the lower view (fig. 1). 'This bony deposit is to be seen, inside, in front of the large foramen for the 9 th and loth nerves (IX., X.). This foramen and the condyloid (XII.) in front of it are seen in the upper view with the exoccipital (c.o.) creeping up to the latter; the large six-sided basioccipital (b.o.) still lies in the centre of the large multiangular basal cartilage, flanked, outside and behind, by the occipital condyles (oc.c.).

\section{Visceral arches of Third Staye.}

The outer and inner elements of the mandible (Plate 22, fig. 5) are still bound up together, and are nearly equal in bulk. The new condyle on the "ramus" is at no great distance in front of the primary morphological condyle-the short crus of the incus (i.). This suspensorial segment is still unossified, and so is the stapes (st.) or uppermost part of the next arch; but the inalleal bony centre $(\mathrm{ml}$. $)$ is working into the cartilage. 'The dentary (d.) hiss grown over Meckel's cartilage (mh.) in one place, and is converting that part into bone; in front of this ensheatled part the rod is very solid; its basal bar (b.mm.) is well formed, and tums upwards somewhat. The cartilaginous ends of the three hind lobes of the ramus keep growing, pari passu, with the rest; the annulus tympanicus $\left(x_{0} t y.\right)$ is now ossified.

The hyoid arch has been cut away where the epilhyal (Plate 22, fig. 6., e.h...) is confluent with the auditory cupsule (see fig. 3). The cartiliginous segments are solid and strong, but are at present quite unossified.

Fourth Stuge of the Skull of Erinacens europaus; young specinens, 2 weeks old; 3 inches long.

This stage shows but little difterence in the general form and condition of the endocrunium; but the osseous centres are much more advanced (Plate 19, figs. 3-5). I have 
figured the upper aspect as a perfect object, not having cut away the rim and roof of the chondrocranium.

The general description just given of the third stage may serve on the whole for this, but the bony tracts will be especially noticed 'The large front paired vomers ( $v^{\prime}$.) protecting the recurrent cartilages (Nc.c.) and JACoBson's organs are still separate. 'I'he proper vomer (v) is becoming very strong, and its keel is now double, in front. On each side of its forks, behind, there is a small bony tract; these are the bones which help to unite the two sides of the nasal labyrinth to each other and to the vomers; they are the hinder paired vomers $\left(v^{\prime \prime}\right.$.) The folds of the middle turbinal $\left(m_{0} . t.\right)$ are seen to be undergoing ossification; the hinder pair of these centres is close to the precurrent cartilaginous spikes, which run forwards on each side of, and above, the middle keeled part of the vomer. The hinder part of the nasal labyriuth is opened out somewhat, artificially, for display.

The large orbitosphenoidal bones $\left(o_{0} s_{0}\right)$ are running upwards towards the marginal band; below, they are beginning to ossify the basal tract, or presphenoidal region (p.s.). The posterior sphenoid is now almost completely ossified, but the bones of the alwe and base (al.s., b.s.) are distinct. The external pterygoid process (e.pg.) is still unossified. The three bones, measured across the foramina ovalia $\left(V^{3}\right.$.), are of equal width; but, further backwards, the basisphenoid is the widest of the three, having taken in part of the cartilaginous alw. Here the hole, right and left, for the internal carotid artery (i.c.) is fairly enclosed by the bony deposit of the basisphenoid. This shows that we are not far from the Marsupials, and this agrees with what I have just shown, namely, that the tympanic wings of the posterior sphenoid are basal, in the Hedgehog, instead of being alar, as in the Marsupials, through the special posterior dilatation of the basal bone in this type. The pituitary hole (py.) is now enclosed by bone $(b . s$.$) ; this hole is in the fore part of an inferior groove, right and left of which$ the pterygoids $(p g$.$) , left in situ, have developed an upper dilated part, by which to$ stick, like Limpets, to the basisphenoid; their cartilaginous nucleus (pg.c.) is not jet all ossified.

The ossification of the auditory capsules is progressing rapidly. The opisthotic centre (figs. 3 and 5, op.) reaches from the passage for the 9 th and 10 th nerves, above the inner margin of the cochlea; it encompasses the fenestra rotunda behind (fig. $3, f . r$. ), and runs up to the fenestra ovalis; above (fig. 5 ), it is growing round the meatus internus. The prootic ( m.o.) is a much smaller centre; below (fig. 3), it is growing over the groove for the facial nerve at the inner edge of the tegmen tympani (t.t.y.), and above (fig. 5) it is rumning along under the anterior canal (a.s.c.) into the recess for the "flocculus." The basioccipital (b.o.) is increasing in size, but it is still in the midst of a wide tract of cartilage; the exoccipitals $\left(e_{0} o_{0}\right)$ are just enclosing the condyloid foramina (XII.); the supraoccipital is widening over the foramen magnum $(f . m$.$) .$

In the upper view (fig. 4), the fore part is seen to be quite unossified, but the 
orbitosphenoids reach their own cartilaginous base (p.s.). The well-ossified alisphenoids $(a$.s.) are seen articulating with the wide, extensive basal bone, " which shows its pituitary hole in front, and has a low postclinoid ridge running across behind the middle, it has, in front of it, a very shallow "sella." The hinder part of the floor is shown in the partial figure (5); but the huge supraoccipital tegmen, with its wide, angular ossification (s.o.) overlapped in front by two interparietals (i.p.), are to be seen in the main figure (4). All the canals (a.s.c., h.s.c., p.s.c.) can be seen in this view where the large auditory capsules project outwards, like short ears, from the sides of this curious cranial "vessel." The exoccipitals (e.o.) can just be seen rising right and left towards the postero-external margin of the supraoccipital osseous centre (s.o.).

\section{Visceral arches of the Fourth Stage.}

About one-third of Meckel's cartilage (Plate 22, fig. 7, mk.) is now enclosed in a canal formed by the dentary $(d)$. In front of this buried part the cartilage rises and swells into a thick mass, up to where it meets its fellow, from which junction the basimandibular (b.mm.) grows forwards, and a little upwards.

The condyloid mass of cartilage is now much larger than that which still remains unossified on the ends of the coronoid and angular processes. The parts that form the ossicula ( $m l ., \quad i$, st.) have merely become enlarged without any noticeable change; the amnulus $(a . t y$.$) is also increasing in size.$

\section{Fifth Stage.-Slull of Erinaceus europaus; 1 month old; head $1 \frac{1}{2}$ inch long.}

a. Inresting bones. - The superficial parts of the skull have been worked out and figured in this stage (Plate 20, figs. 1-3), as in the second (Plate 17, figs. 3-5), and in the sub-adult (Plate 21, figs. 1-6).

In the upper view (Plate 20, fig. 2) we see what a strong roof the investing bones now form to the very solid endocranium. The nasals $(n$.) are small, narrow bones, and diverge in front; the frontals $(f$.$) are almost as large as the parietals \left(p_{0}\right)$; they are now in one piece on each side.

The large convex parietals have the frontals running in between them in the coronal suture, and the double interparietal (i.p.) fits on to their concave hinder margin. The sides of the hind skull are well buttressed by the squamosals (sq.), and the fore part of the skull by the huge maxillaries ( $m x$.$) , and the middle-sized premaxillaries$ $\left(j x_{0}\right)$; the jugals $(j$.$) are smallish; the lachrymals are not well seen in this view.$

Int in the side view (Plate 20, fig. 3) the lachrymals (1.) are seen to be intraorbital; they are oval, have a large opening (l.c.) in front, and are very thin. The imbrication of the subcutaneous scutes that invest the endocranium is well seen in this view. 'The jingal was removed in the preparation figured, to display the interior of the orbit, the imner wall of which is composed of the lachrymal, orbital plate of the frontal, and maxillary, in front; and behind, by the frontal, parietal, and squamosal; it is a very 
open space. The postglenoid part of the squamosal $(s q$.$) is short, the hind part of$ the squama, in the end of the temporal fossa, is perforated. The facial nerve (VII.) is figured, and also its chorda tympani branch (VII ${ }^{\mathrm{a}}$ ), passing to the large inferior branch of the trigeminal $\left(\mathrm{V}^{3}.\right)$. The 1st and 2nd branches of that nerve $\left(\mathrm{V}^{1} . \mathrm{V}^{2}.\right)$, are seen emerging from the sphenoidal fissure, the former re-entering the skull through the main orbital foramen, and the latter running forward through the great maxillary canal, and emerging through the supraorbital foramen.

The optic nerve (II.) is seen between the forks of the trigeminal ( $V^{1}, V^{2}$ ), emerging from its own foramen opticum.

The investing bones, as seen from below (fig. 1), show the finishing of a very fine piece of architecture; the hinder superficial pieces, the tympanics, were removed to display the proper cranial structures. This individual was just cutting its teeth; the huge sockets for which are shown with but partially developed dissepiments.

The premaxillaries have a large dentary part, and a small, short palatine process; over this, however, the anterior pailed vomer $\left(v^{\prime}\right)$, is seen, which afterwards makes that process of the normal size.

The maxillaries ( $m x_{0}$ ) are enormous, being gravid with many large teeth, and, as the palate is very wide between the tooth-rows, the concave palatine plates are of great extent. There is, here, as in many of the Edentata, a sign of some distinctness of the inner, from the submarginal, part of this bony roof. The inner part is wedged in between the rami of the premaxillary $\left(a . p_{.} .{ }\right)$in front, and then an oblique ridge, running backwards, and a little inwards, up to the posterior palatine foramen, marks the inner part off from the outer. The outer part of the hard palate is a concave tract, forming a lanceolate flange to the internal alveolar wall. The hinder part of the alveolar tract is unfinished; the jugal process is short and sharp.

The palatine bones $\left(p \alpha_{0}\right)$ are very elegant, and quite Metatherian in iheir characters; their palatal plates are sharp wedges, ruming forwards, together, between the palatal plates of the maxillaries. An irregular subreniform fontanelle is seen in each plate, near its middle, behind the thickening inside the posterior palatine foramen $\left(p \cdot p_{.} .{ }^{\circ}\right)$. Each bone has a thick subarcuate margin, as the finishing, behind, of the palatal plate; these ridges are turned a little forwards as well as outwards. Part of the subcranial tract of each bone is seen behind the hard palate, bounding the nasopalatine canal; this is clamped by the pterygoid $(1 \mathrm{~g} \%$ ); outside this, the palatine bone spreads into a hooked wing, which bends round the front of the oblique, oval, small external pterygoid plate $\left(e_{. p g}\right)$. The distinct upper vertical tract of the palatine ends a little behind the anterior sphenoid $\left(0 . s_{0}\right)$, then the wall is continued a short distance further back by the pterygoids $\left(p g_{0}\right)$, which are not distinct, now, but have already coalesced with the sides of the wide basisphenoid bone (b.s.); the lower part is terete, and ends in a short, free hamular process, which has, now, used up all the cartilage.

The tympanics are not given in this figure; they have been removed, with the ossicula anditîs, to display the auditory region. 
The jugals $(j$.$) are flat styles; the squamosals (s q)$, riding over them, are seen to swell out into a convex shell of bone clamping the parietal, and then to grow inwards to be covered with the broadly-reniform glenoid facet (gl.c.). Thie postglenoid tract is here seen to bend in to the mastoid region of the ear-capsule, and to end in three tooth-like processes.

Both the end vicw (Plate 19, fig. 6), and the inner view (Plate 19, fig. 8), also show the investing bones from their aspects.

\section{Endocranium of the Fifth Stage of Erinaceus europaus.}

The verticul section (Plate 19, fig. 8) shows the whole of the craniofacial axis up to the presphenoid (p.s.); behind, that the axis was cut along the middle, and only half the skull was figured; this part is only two-fifths of the whole length. 'The round snout has its own septum marked off from the proper septum nasi $(s . n$.) by a considerable inferior notch, in which the JACosson's, or recurrent cartilages (rc.c.) are seen to arise. These folded leaves are tubular in their most perfect part, and then are open along the side.

Over the notch the intertrabecula (i.tro) is very thick, but it diminishes very little all along the base of the great ethmonasal wall (s.n., p.e.); itis ossified behind by the orbitosphenoids $(o . s)$, in the presphenoidal region; there is no separate median bone there.

'The front paired vomer, and the vomer, proper, $\left(v^{\prime}, v_{0}\right)$, are shown in situ; the masals and frontals $\left(n ., f^{\circ}\right)$ lie over the roof $(a l . s p ., a l . e$.$) .$

The short descending side of the low triangle formed by the great partition is notched by the numerous olfactory filaments, and the cribriform plate $\left(c r \cdot p_{*}\right)$ is seen to the right of this crested tract, which has a small, special elevation, above-the crista galli (cr.g.).

The anterior sphenoid is still continnous with the nasal labyrinth, in front, by the fore edge of the great orbitosphenoidal cartilage (o.s.); the lower third of this tract is ossified, and is perforated by the optic nerve (II.) near its hind margin, below.

The rest of that sinuous margin, passing into cartilage above, is now abruptly free, the rest of the band, over the alisphenoid, and along the supra-auditory region (see figs. 1-4) having been absorbed.

Thus the sphenoidal fissure $\left(\mathrm{V}^{1,2}\right.$.) is now very steep, and perfect; it is bounded below by the cartilage still remaining between the fused orbitosphenoids (p.s.) and the distinct basisphenoid $\left(b_{.} s_{0}\right)$. The low-lying alisphenoid (al.s.) is free, in front, and bulges outwards; it is only notched in front by the and brar ch of the 5th nerve, but is perforated by the 3rd branch $\left(\mathrm{V}^{3}{ }\right)$, which forms a large formen ovale near its hind third; this is much the smaller wing, even now. The basisphenoid is both long and wide; over its hinder half the cochlea is seen; the pituitary hole (see fig. 4) is present, but the sellar depression is slight. 
The auditory capsule is largely ossified, especially on this, its inner, fuce ; the "crest" of cartilage is not quite gone, nor quite ossified. The recess for the flocculus $(f l . r)$ under the arch of the anterior canal $\left(\alpha_{.} s_{.} c_{\text {. }}\right)$ is about the size of the meatus internu; or vestibular eave leading to the foramina for the 7 th and 8 th nerves (VII., VIII.). The other foramina (IX., X., XII.) in front of, and through, the occipital arch (s.o., e.o., b.o.) are seen in this section.

Part of the outer view of the hind skull (Plate 19, fig. 9) shows the normal division of the petromastoid into prootic, epiotic, and opisthotic centres ( $\left.p r . o_{0}, c p ., o p.\right)$, but the wedge-like epiotic is not a very distinct tract; it is bound to the rest of the main centre-the opisthotic-on its inner side.

There is still unossified cartiluge over the anterior canal, and outside its ampulla, and that of the horizontal canal; the paroccipital process $\left(p_{.0 c}\right)$ is still cartilaginous, and also the stem of the epihyal $\left(e . h y_{0}\right)$.

These parts are also seen in the end view (Plate 19, fig. 6), which displays the occipital arch perfectly, and the auditory capsules partially; the broad cartilaginous tracts, here seen, give the whole structure depicted a diagrammatic distinctness.

In the lower view of this perfect skull (Plate 20, fig. 1) the broad snout in front, and the broad basis cranii, behind, are displayed, fore and aft of the large investing bones of the upper face and palate.

The hinder part of the anterior sphenoid $\left(0, s, p . s_{0}\right)$ is seen behind the hard palate, in the roof of the nasopalatine canal, in the middle, and, right and left, in the wall of the orbit. 'The top of the orbitosphenoid (o.s.) is still unossified, and the presphenoid has been formed by the fusion of the proximal parts of the ossified tracts, right and left, of the two orbitosphenoids (see also Plate 19, fig. 8).

But the posterior sphenoid is freely displayed in this aspect, covered, however, in one part, by the small pterygoids $(p g$. ) that have coalesced with it by their subcranial tlange.

The suture, right and left, between the alse and the base $\left(a l_{,} s_{\circ}, b_{0} s_{0}\right)$, is fist disappearing, so that the whole tract which forms so large a part of the base and lower wall of the cranium, proper, is now practically one bone. The well-formed temporal squama (sq.) forms a slightly squamous suture with the outer edge of the alisphenoid (al.s.), which, in turn, lies some distance outside the orbitosphenoid (o.s.). But in this view the squamosals are seen only to form a thin clamp to the alisphenoids, which stretch across the wide tract that intervenes between the hard palate and the auditory capsules. In front of the squamous suture the alisphenoid is notched and uncinate at its antero-external angle, and then has a somewhat notched, thick maryin bordering the sphenoidal fissure $\left(V^{1}, V^{2}\right)$. Behind this fissure the palatine bone is seen to hook itself round the front and outside of the small, oval, oblique "external pterygoid plate" (e.pg.). A moderate fossi is seen between this piece of carpentry and the ankylosed pterygoid bone ( $p \%$ ), behind which a small foramen is seen. The formen ovale $\left(\mathrm{V}^{3}\right.$ ) forms a conspicuous opening, behind, and further outwards, than the 
external pterygoid plate. Behind the foramen the outer margin of the alisphenoid is notched, gently, and then grows outwards again to form a wedge, which is strongly jammed in between the squamosal and the petrous bone. Leading from the external pterygroid plate to this wedge, inside the foramen ovale, is an elegant crest of bone, concave, extemally, and lying below the rough, dentated, hinder edge of the alisphenoid. This is the boundary line of the junction of the basal and alar osseous centres, and it is this tract which corresponds with the alisphenoidal part of the bullir of a Marsupial, the root of its so-called "tympanic wing:" 'This and the rest of the basisphenoid (b.s.) form a very peculiar structure, quite diagnostic of an Insectivore, and, when suppressed, tells of a departure from the normal skull of this Order. The fore part of the basal tract is pinched in so as to form a very narrow passage; the hind part widens into a semioval concave space. Right and left of this space the busisphenoidal tympanic wings grow out; these are square tracts, notched and uncinate behind, and hollow, externally, where they add to the general drumcavity. These hinder outgrowths of the basisphenoid are separated by a notch, externally, and by a groove contimued from the notch, internally, from the pretympanic wing which has its homologue in the Marsupial. 'The cochlear part of the opisthotic (chl.) articulates on its inner side with the basisphenoid, and in its outer is margined by the grooved tegminal tract which contains the horizontal semicircular canal (fig. 3, h.s.c.). Here the fenestra ovalis (fs.o.), fenestra rotunda (f.r.), and the hinder opening of the groove for the facial nerve (VII.), bridged over by the epiliyal $($ e.h..$)$, are all displayed.

The cartilaginous projection that contains the two front ampulla is separated by a bony tract of the opisthotic from the next cartilaginous swelling-the parocipital $\left(p . o c_{0}\right)$; behind this the condyle (oc.c.) forms a third cartilaginous convexity. The broad, short occipital ring has its trunsversely oblong basal piece (b.o.) separated, still by a widish tract of cartilage, fiom the exoccipitals (e.o.); these are bored by the 12 th and notehed by the 9 th and 10 th nerves (XII., IX., X.).

The upper view (Plate 20, fig. 2) shows but little of the endocranium; but a dissected skull, shown in its lowe aspect (Plate 19, fig. 7), as far as the first third of the basisphenoid, displays several parts not yet described.

In this preparation several of the lesser splint bones were left, $i n$ situ, and figured; the premaxillaries ( $p x_{0}$ ) are shown cut through their alveoli, horizontally, and we see that their palatine process is, at present, very short. But the front paired vomers $\left(v^{\prime}.\right)$ are close behind, and above, the sub-median part of those bones; they are long splints, a little scooped on their outside, and are in close contact with the pointed fore end of the vomer proper $(v)$, which runs in above them. Right and left of the paired bones $\left(v^{\prime}\right.$.) we see the large cochleate recurrent cartilages (r.c.c.), and, outside these, the ossified inferior turbinals (i.tb.). The fore part of the upper and middle turbinals $(u . t b ., m . t b$.$) is ossified; but the greater part of the wall and floor of this large bulbous$ labyrinth is still mossified. The vomer (vo) is carinate behind its pointed fore end, 
and the keel is grooved; the hinder two-fifths is in two forks, that run back and gently bend in between the bisal beam (p.e.) and the postero-infexior recesses of the basal labyrinth. Here the winged divisions of the vomer serve to bind together the right and left tricts of the nasal floor, under the fore half of the middle turbinal region. 'Ihis second upper binding together of the right and left face, making the skull douldy desmognathous, is assisted by a pair of oblong splints, the posterior paired vomers $\left(v^{\prime \prime}.\right)$, which run from this great opening between the inferion and middle turbinals up to the oval hinder recess, right and left, of the presphenoid. When the middle turbina] is well ossified in its lower as well as in its front part, then the three vomerine bones and the ossified floor and turbinals all become an indistinguishable tract of bone. This preparation is only figured up to the hind margin of the foramina ovalia $\left(V^{3}\right)$; the optic, ophthahnic, and maxillary nerves (II., V1., Vº) are figured, emerging from the optic foramina and sphenoidal fissures. The rest of the skull in this aspect is seen in the entire palatal view (Plate 20, fig. I).

\section{Viceral arches of the Fifth Stage.}

The lower jaw (Plate 22, fig. 8) is now almost complete, but there is a little cartilage still left on the coronoid and angular processes. The latter (ay $\%$ ) is somewhat incurved. The fore part of MEckel's cartilage and the basimandibular rod (mk., b.mn.) are still present, but the freed part of the bar is now ossified as a linge spatulate processes gracilis ( $\left(m \cdot y_{0}\right)$, much larger than the manubrium $\left(m p_{*}\right)$.* The incus and stapes $(i ., s t$.$) are now ossified, and are seen in situ, so also is the annulus (a.ty);$ all these parts are shown from their inner face.

The hyoid arch (Plate 22, fig. 9) has acquired all its bony centres, but the thick, crescentic hypoliyals $\left(h . h y_{0}\right)$ are only ossified in their middle, and the upper ceratohyal (c.hy.) only half-way up. The epihyal (Plate 20, fig. 1, and Plate 22, fig. 9, e.hy.) is ossified in the upper part directly from the bony substance of the opisthotic (op.); it has no separate proper centre ("tympanohyal"), nor splint ("stylohyal").

\section{Sixth Stage of Skull of Erinaceus europreus; young; two-thirds grown.}

These large young are profitable for study, because, although well ossified for the most part, nearly all the sutures are very visible; a iertical section at this stage (Plate 20, fig. 4) is very instructive.

In the fore part we see the rounded form of the snout, and the complete septum that has grown forwards from the proper septum nasi between the alinasal folds (al.n.). The whole partition wall, from the front of the snout to the fore-edge of the presphenoid (p.s.), is two-thirds the length of the whole craniofacial axis. The highest, or hinder part, is ossified as the perpendiculur ethmoid (1.e.), and this reaches forwards for nearly a third of the length of the wall behind the snout. 'The bone runs further forwards above than below; laterally, behind, it is now confluent with the partially

* The letters of reference should have been mb

MDCCCLXXXV. 
ossified cribriform plate $\left(c r . \nu_{0}\right)$; behind, it gets to be a low thick wall between the retral recesses of the nasal labyrinth. The septum $\left(s_{0} n\right.$. ) is moderately thick from above, where it gives off the aliseptal folds $\left(a l . p_{0}\right)$ to the thick base; that part shows its thickness as a solid rod with a flat crest, from the low hind part to the equally low foremost part of the septum nasi proper. There, the septum is notched, below, and right and left of the notch the base of the alinasal folds gives off the recurrent cartilages (rc.co), large spatulate processes, tubular, proximally. The palatine process of the premaxillary $(p, p, x$. ) is seen in its thick part, the rest, separate, for some time, as a front vomer, is given in outline in the tigure, showing that it is inside the cartilaginous process. 'The vomer $(v)$ is seen supporting the thick intertrabecular base of the partition, and under this we see the thick inner edge of the palatine plate of the maxillary (mx.) ; these bones are united by suture, and now we see why the median vomer should have its keel double (see Plate 19, fig. 7, v.), for it articulates with two plates beneath it, and these bones, doubly sutured together, divide the right and left nasal passages from each other. This division ceases where this suture ceases, and this is half-way between the external and posterior nasal openings; the latter open out behind the soft palate, which is strengthened right and left by the descending plates of the palatine and pterygoid bones ( $p a, p q$.). The cranial cavity is roofed, and largely walled in, by the frontals, parietals, and interparietals $\left(f_{.}, p_{.}, i . p_{.}\right)$, the ossified remains of the endocranium lying low down in the floor of the skull. A round notch makes the orbitosphenoid bilobate; above the front lobe is a thin lagged tract lining the orbital plate of the frontal. Where these join there the 1 st branch of the 5th nerve ( $V^{1}$., ophthalmic) has entered (see also Plate 20, figs. 3 and $5, V^{1}$ ), it is seen in this section riding over the outeide of the cribriform plate to gain the nasal cavity. 'The longer, more regular hinder lobe of the orbitosphenoid (o.s.), passes inside the alisphenoid ( $\left(l_{. s .}\right)$; these parts lie so low down that neither the optic formen, nor the foramen lacerum anterius, or sphenoidal fissure, are seen in this directly lateral view. The parietal $(p$.$) passes so well down the$ skull wall that the squamosal-as in the Ostrich-is not seen, or scarcely at all ; in this inner view the elegant curve of the lateral sinus $\left(l_{.} s_{0}\right)$ is seen near the lower edge of the parietal.

The alisphenoid ( $a . s_{0}$ ) is here visible as a strong concave shell of bone, hidden, however, in front, by the orbitosphenoid, and below by its own large basal beam (b.s.); its thick ear-shaped hind part rides over the front of the cochlea, and the great oval foramen $\left(\mathrm{V}^{3}\right.$.) is seen opposite its front third; behind this part of the base the sella turcica is seen as a shallow concavity, and the posterior clinoid wall as a mere thickening of the base; behind that thickening the postelinoid region dips downwards -a normal state for this and the rest of the base (b.o.).

A solid tract of cartilage still exists between all the three basicranial bones, the first of these $\left(1, x_{0}\right)$ is high, but it is not an independent presphenoid; it is only formed, as bone, by the juncture and ankylosis of the right and left orbitosphenoids. 
The ossified auditory capsule is seen over the second synchondrosis; it is obliquely fixed, large, and full of hills and hollows on this aspect. 'The supra-auditory tract of cartilage has been largely absorbed, but its base was ossified, and that remains as a rough crest to the capsule. Below this, in front, the anterior canal (a.s.c.) is seen with its ampulla; an oblique rib of bone ascends from the cochlea to the crown of the arched canals, the anterior and posterior. 'This arch and its hivder enlargement behind the hollow for the flocculus $\left(f_{0} r_{0}\right)$ is not formed by the posterior canal and its ampulla, but by the growth of a tubercle of bone inside that arch, bounding the Hoccular recess behind, as the nblique ridge does in front.

The meatus auditorius internus (VII. VIII.) is a large archway, between which the petromastoid bone swells into the fore part of the deep sulcus for the posterior sinus, and for the exit of the 9 th and 10 th nerves; the hollow for the sinus opens below into the foramen lacerum posterius. Behind that opening the lesser hole, or condyloid foramen (XII.) is seen in the substance of the exoccipital (e.o.); the condyle (cc.c.) is seen behind, the basioccipital (b.o.) in front, and the supraoccipital (s.o.) above it.

'The large rough wings of the basisphenoid are seen below the basal section and behind the pterygoid bone ( $p g$.$) .$

The inner view of the nasal labyrinth (Plate 20, fig. 5), obtained by removal of the perpendicular ethmoid and septum nasi, shows the complex folds of the nasal, inferior, upper, and middle turbinals $\left(u_{0} t b_{0}, i_{.} t b_{0}, u_{0} t b_{0}, m_{0} t b_{0}\right)$, and here the ophthalmic nerve $\left(\mathrm{V}^{1}.\right)$ can be seen in its course along the interior of the labyrinth. Below the cribriform plate (cr.p.), the right recess of the lindermost part of the nasal cavity is seen running by the base where the ethmoidal and presphenoidal regions meet.

Seventh Stage of the Shull of Erinaceus europreus; young; three-fourths grown.

I have merely figured the outer auditory bones in this, a somewhat more advanced stage than the last, as they are now in a very instructive state a state retained only for a few months longer, after which much absorption and modification of bone will take place.

The outer view of the ear-drum and its chain (Plate 22, fig. 10), shows a condition quite comparable to what is found in subadult and adult Marsupials. Moreover the annulus $(a . t y)$, now rapidly strengthening its thickening inner edge, and has there a row of small osseous points quite similar to those that are the only rudiments of the tympanic ring in the Bird; that feeble chain of bones is best seen in the Corvidæ.

The processus gracilis of the malleus is several times larger than the manubrium $(p . g r ., m b$.$) ; it is at strongly ribbed bar, which, appearing in front of its tympanic attach$ ment, there shows a rudiment of the pretympanic hook so large in many Marsupials. The body of the malleus is large, and the "prosterior angular process" ( $p$.ag.), behind the manubrium, is a semioval convexity. The short crus of the stout ond well-made 
incus (s.c.i. ) is unusually short; the long crus (l.c.i.) is also short, but is well inturned, and has an oval fiacet for the head of the stapes.

That bone (st.) is rather high, has a long oval base, narrow, and somewhat snaggy sides, and has a tuberele on its neck, in which is a very rudimentary interhyal $(i . h y$.$) , rooted in the base of the stapedial muscle's tendon (st.m.).$

\section{Eighth Stage of the Stinll of Erinaceus europæus; nearly adult.}

This skull is, conceivably, a very gentle modification of the type we are familiar with in the Marsupials; it is just farly within the Eutherian margin. The upper and side viems (Plate 21, figs. 2, 3) show that most of the sutures are still present, and that where the sagittal is dying out, there a crest is forming between the top of the large temporal muscles. Also a lambdoidal crest is seen behind the wide interparietal (i.p.), which, however, is confluent with the proper supranccipital $\left(f i g .4, s_{*} n_{*}\right)$. The coronal suture is $\mathrm{W}$-shaped, the bones being strongly dovetailed into each other. The large, long nasals (n.), narrow behind, take up about a third of the gently arcuate dorsal line of the skull; the frontals $\left(f_{\text {. }}\right)$ flank them in front, but do not reach the large ascending plate of the premaxillaries $\left(p_{x} x_{0}\right)$, the much larger maxillaries $(m x$.$) intervening. An oblique ridge separates a deep fossa above from$ the large lachrymal passage $\left(l c_{0}\right)$ below; this passage is on the edge of the orbit, but most of the bone, now largely fused with the maxillary, is inside the orbit. The orbital space opens freely into the temporal fossa, and the outlines of the bones that form the whole of this concavity can be well seen for the most part, the fusion of the lachrymal with the maxillary being exceptional. Down at the buse of the orbit the orbitosphenoid can be seen passing within the alisphenoid, and some distance outside the former the alisphenoid and maxillary meet and form a narrow longitudinal bridge orer the thick edge of the palatine bone ( $p a$.$) .$

The infiarbital foramen $\left(\mathrm{V}^{2}\right.$ ) is large, and so is the canal that runs backwards into the skull through the hinder part of the sphenoidal fissure, for the alisphenoid (Plate 20, fig. 6, al.s.) is deeply grooved for this large 2nd branch of the 5th nerve.

The jugal $(j$.$) is moderately strong; it reaches the glenoid fossa, but is sharp$ there; it does not dilate, terminally, as in the Marsupials. Part of the basis cranii and the auditoly ring can be seen from the side view, but the lower view (Plate 21, fig. 1), alone, displays these parts well. The premaxilluries and maxillaries $\left(p x_{0}, m x_{0}\right)$ at their palatal junction leave a considerable space $\left(\alpha . p_{\text {. }}\right.$. $)$, right and left, through which the recurent cartiluges and JACOBson's organs can be seen. The palatine processes of the premaxillaries are long but lie above those of the maxillaries; they have added to their substance and length, the antero-lateral vomers or splints of JACoBson's organs. The palitine plates of the maxillaries form a fine large concive roof; they are followed by the imperfect plates of the palatine bones ( $p t_{0}$ ). The fenestra seen in each bone in the 5 th stage (I'late 20, fig. 1, $p x_{0}$ ) is now a deep notch open in front, for each palatine bone is now formed in its lower part and fore half into a flat fork with long ragged "tines:" 
the inner being the larger and uniting by a "harmony suture" with its fellow of the opposite side. The ascending part of the palatines is strong and has coalesced" with the external pterygoid plates (e.pg.) on the outer side; they have not united with the pterygoids $(p g$.$) . The hind margin of the hard palate, formed by the palatines, which$ have not united with the maxillaries, is an elegant archway with a strong upper lintel over it, formed by a thick rib on each of the palate bones; these ribs meet at the mid-line at a very obtuse angle.

The elements of the basis cranii behind and below are fast coalescing with each other; the sutures of the hind skull, however (fig. 4), are most of them visible.

The paroccipital processes (p.oc.) are thickish and somewhat foliaceous; they finish a semioval occipital plane, with its large convex obliquely pyriform condyles (oc.c.). But in front of the occipital arch the mastoid processes (fig. 4, op.) project like wings and are there strongly sutured to the postglenoid process of the squamosal (sq.), which is pneumatic, and has its own foramen. There is a large foramen lacerum posterius for the 9th and 10th nerves, and a lesser formen condyloideum for the 12 th (fig. 1, XI.).* The ossified anditory capsule has alrendy been described (6th Stag'e, Plate 20, fig. 4), but the posterior sphenoid, and the turbinal folds of the nasal labyrinth, with the interior sphenoid can be well studied in this scarcely adult stage, whilst the parts are still capable of being taken to pieces to a considerable degree.

The posterior sphenoid shown in its upper aspect (Plate 20, fig. 6), is a large winged bone, with a ragged outline and a multiperforate surface.

The large foramen ovale $\left(\mathrm{V}^{3}\right.$.) is at the hinder and the midclle third of each great wing $\left(a l . s_{.}\right)$; the and and 1st branches of the 5 th nerve pass with the lesser orbital nerves out of the sphenoidal fissure.

The fore part of the bone does not fit itself to the linder part of the anterior sphenoid (Plate 21, fig. 7, O.s., p.s.), except at the middle; the pointed fore end of each large wing grows outside, free of the orbitosphenoid. The onter and hinder part of each wing is rounded, and this upper surface is broken; it is strongly grooved where the 2nd branch of the 5 th escapes from the 3rd and runs forwards and inwards to the great fissure. The narrow front part of the basisphenoid lies some height above the wings, and the bone has several small perforations at this part. The hinder broad part of this bar is very gently hollowed for the pituitary body, and the postclinoid wall (p.cl.) is extremely low.

The lower surface of the bone shows the greatest number of diagnostic marks of a typical Insectivorous skull. The inferior wings, external pterygoid processes (e.py.), and pterygoid bones $(p g$.), are well developed and have a good fossa between them. 'The latter are distinct from the palatines, but have come away, in disarticulation, with the basisphenoid, having already become anchylosed to it, above. Between these internal plates the bone is sharply grooved, but, behind, between the tympanic wings, the basisphenoid has a lirge cup-shaped recess which might have lodged some such body as

\footnotetext{
* For XI. read XII. in this figure.
} 
the pituitary. This recess is bounded, behind, by a snag from each tympanic wing. 'These wings are deeply notched in front, on their outer side, and in front of the notch the alisphenoid has a strong rib of bone running with its concave outline forwards to join the extemal pterygoid process. 'This rib is itself notched in the young, but in old specimens this notch is converted into a formen. Here in this immature specimen the hole is finished only on the left side-right in the figure.

The same parts are seen from the hinder aspect of the bone (Plate 20, fig. 8).

The anterior sphenoid (Plate 21, figs. 7,8) is less than half the size of the posterior; it has coalesced with the compound ethmoidal bone, behind the extensive olfactory fossa with the underlying cribriform plate $\left(c r \cdot p_{0}\right)$. The sinuous wings $\left(o . s_{*}\right)$ are deeply srooved, transversely, near their hind margin; these grooves lead to the optic forainina (II.). These wings are formed by the ossification of only the proximal or luwer part of the original cartilage (see Plate 17); they lessen, forwards, like the large wings, and grow down into a keel on each side before they unite to form the short presphenoidal bar.

This skull is doubly desmognathous, for the vomerine series of bones unite the two halves of the nasal labyrinth into one common complex structure (Plate 21, figs. 7-9); this is very common in the Mammalia; and is sometimes seen in Birds (e.q., Gymnorhina - the Piping Crow of Australia), where the maxillary palatine floor has an ethmovomerine floor completed above it.

The antero-lateral vomers have coalesced with the palatine plates of the premaxillaries, lengthening them considerably; and the postero-Jateral plates have coalesced with the outside of the forks of the main vomer (Plate 21, figs. 7-9), the latter is a long thickly carinate bone, bluntly pointed in front.

That which is most important to remark upon in the ossified nasal labyrinth itself is that the various turbinals-nasal, inferior, middle, superior $\left(u_{*} t b_{\text {. }}, i . t b_{\text {. }}, m_{\text {. }} b_{\text {. }}, u . t b_{\text {. }}\right)$-are transformed into a light and porous kind of bone, but when the investing bonesnasals, frontals, \&c-are peeled oft them the wall is found to have been absorbed; the succedaneum to this wall is the outer investing plate. Hence, these coils, when stripped before they are anchylosed to the investing plates, have large vacuities between them, displaying their folds. This is due to the fact that the secondary folds or turbinals, ossify first, and only so much of the primary wall becomes ossified as gave origin to these out-growths; the intermediate spaces are absurbed, being pressed upon and defended by the superficial bony plates.

The me-olfactory region occupied by the inferior or maxillary turbinal (Plate 20, figs. 9, 10, fiont and side views) is very large, and this part is exceedingly complicated, as indeed it is in most of the Eutheria; in the Rabbit and the Dog, as well as in the Iredgehog.

The lower jaw (Plate 21, figs. 5, 6) is fuirly intermediate between that of a Marsupial and that of a high Mammal; the three proximal processes are all large and well formed, and the lower, or angular, is sounewhat inflected as well as thickened. 
The incus and stapes have altered very little since the last stage ('late 22, figs. 10, 11, i., st.); but the malleus (Plate 22, fig. 12) has lost all its large (metatherian) foregrowth, only a fine, sharp, processus gracilis $(p \cdot(y)$ ) now remains.

The hyoid arch (Plate 22, fig. 14) is well ossified, now ; the epihyal (e.hy.) is continuous with the ear-capsule, above, and is joined to the upper ceratohyal (c.hy.), below, by a tract of non-segmented cartilage. 'The lower ceratohyal (c.hy'.) is about equal to the upper in size, and the hypohyal $(h . h y$.$) is unly lalf as long, but broader;$ all these as well as the basal piece and thyrolyyals $\left(b_{0} h . h_{0} \eta_{0}, t . h y_{0}\right)$ are united by joints, mostly with a perfect joint-cavity. The "annulus" (Plate 21, fig. 1, a.hy.) has all its irregular bony nodules confluent with the main bax.

\section{On the Skull of the Common Hoie (Talpa europar).}

My materials for working out this type have been very copions; my work links itself on to that of Mr. W ALter Heape (Quart. Journ. of Micr. Sc., July, 1883), to whom I am indebted for some of my best specimens.

These materials are divisible into arbitrary Stures, as follows :-

Stage 1.-Embryos of Mole, $\frac{1}{4}$ of an inch long; (this and the next were measured round the curve formed by their head and body, the tail not being reckoned; the rest were measured first from snout to occiput, and then from occiput to root of tail, and these were added together to give the full length, of course, excluding the tail).

Stage 2.-Embryos of Mole, $\frac{1}{3}$ of an inch long.

Stage 3.-Embryos of Mole, $7 \frac{1}{2}$ and 8 lines (twelfths of an inch) long.

Stage 4.-Embryos of Mole, $\frac{3}{4}$ and $\frac{4}{5}$ of an inch long.

Stage 5.-Embryos of Miole, 1 inch long.

Stage 6.-Embryos of Mole, $1 \frac{1}{3}$ inch long.

Stage 7.-Embryos of Nole, $1 \frac{1}{2}$ inch long.

Stage 8. - Ripe young of Mole, $1 \frac{2}{3}$ inch long.

Stage 9.- Young Moles, three or four ditys old; $1 \frac{3}{4}$ and $1 \frac{1}{5}$ inch long.

Stage 10.-Young Moles, 3 inches long:

Stage 11.--Young Moles, two-thirds grown.

Stage 12.-Young Moles, three-fourths grown.

Stage 13.-Adult Moles.

$$
\text { First Stage.-Embryo of Wole, inch long. }
$$

This stage (Plate 16, fig. 1) is, here, merely studied from its onter aspects ; it is very profitable for comparison with the corresponding stage in other Mammalia and in the Vertebrata, generally; it is nearly hulf as long as a similar embryo of a large Mammal would be.

About twenty-eight somatomes can be made out; the heart is still seen in a large 
pouch that projects from the ventral aspect of the embryo. The fore limbs are large flat buds behind the middle of the larviform embryo, and the hind limbs are much smaller and are curved inwards on each side of the rudimentary tail. The mesocephalic flexure is well marked, and the cerebral vesicles very large; the long, lobulate lind-brain is covered with a very thin layer of tissue. The pineal elevation is to be seen between the fore- and mid-brain, and the fronto-nasal process against the former vesicle. Between these parts the notch which contains the rudimentary olfactory organ is seen; this is bounded, above, by a band which runs into the large naxillo-palatine lobe. This lobe is separated by a sharp notch, the oral opening, from the rudimentary mandible, behind which is the hyoid fold, and the first branchial fold; these are separnted by clefts.

Over the maxillo-palatine lobe the small eye-ball is seen, and over the hyomandibular cleft the oval auditory sac.

\section{Second Stage.-Embryo of Mole, $\frac{1}{3}$ inch long.}

I have had sections" made of the embryos at this stage; these have been studied, but not figured, as the tissues of the skeleton were in an indifferent state, and it is not part, of my plan, as a rule, to give histological figures.

The external form, however, in this stage is very important (Plate 16, figs. 2-4), as the influence of heredity, which had begun to show itself in my first stage (fig. 1), in the large size of the rudiments of the fore limbs, is here very evident indeed.

The limbs are now, evidently, pentadactyle; but the fore limb is also very large, and close to the head.

The folds of the outer skin are now perfecting themselves, we see the eye-ball in its circular setting, the external meatus of the ear is formed, and the outer nostril, with its rim complete.

\section{Third Stage.-Embryo of Mole, $7 \frac{1}{2}$ and 8 lines long.}

In an embryo two-thirds of an inch long (Plate 16, fig. 5) the fingers and toes are distinct, and the small pig-like creature has got a distinct circular eyelid; the meatus externus is very small, and encircled with a fold, and the nostrils are now well fashioned.

The true hyaline cartilage is now differentiated, and in this stage I shall give a description of the sections made from a specimen scarcely two-thirds of an inch ( $7 \frac{1}{2}$ lines) long. The dissected figures of the skull of the nest stage ( $\frac{3}{4}$ inch long, Plate 25, figs. 2, 3) will serve, like a ground-plan, to explain both the sets of sections: namely, those of the same stage, and those of this earlier embryo.

From about 200 exquisitely sectioned and perfectly stained slices of this small

* These and most of my sections were made for me by my son, Professor W. N. Parker; those of the next stage were made by, and belong to, F. PExrose, Escl. 


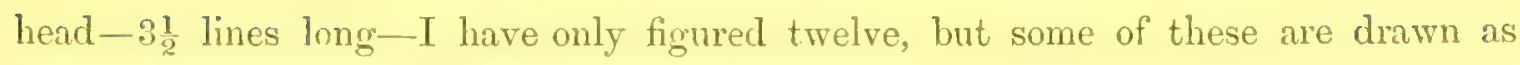
separate half sections; they were somewhat oblique.

Section 1 (Plate 23, fig. 1).-This is close to the hind part of the alinasal region (al.n.), at the beginning of the aliseptal. The nasopalatine canal is open below, and here, behind the narial valves, the cavity is high and simple. "The septum nasi and alinasal folds $\left(s . n_{.}, a l . n.\right)$ are well developed; the thickness of the former, below, is due to the size of the intertrabecula, and the cartilaginous walls are thickening above to form the nasal turbinal, and below to form the inferior turbinal.

In the thick mass of tissue below the septum the recurrent cartilages (rc.c.) are seen, they are placed subvertically, and are thick above and thin below; outside them JAcobson's organs (j.o.) are shown, and inside them the palatine processes of the premaxillary $\left(p \cdot p x_{0}\right)$.

The hind part of each premaxillary $\left(p x_{0}\right)$ is cut through laterally, there are two lamina of bone meeting, above, at an acute angle; below, in the mucous membrane, a tooth-pulp ( $p$.$) is shown; the nasals (n.) are forming, above.$

Sections 2 and 3 (Plate 23, figs. 2 and 3).-These, which were one oblique section, show, on the deepest side (fig. 3), the remarkable manner in which the rudimentary nasal turbinal (n.tb.) encloses an oral space; below that space the cartilage grows inwards, and is pedate; this is the inferior turbinal. Here, inside JACoBsos's organs (j.o.), the recurrent cartilages (rc.c.) are thick throughout, and the little vomerine bones are not apparent. The maxillary $(m x)$ comes into the section here, and the nasals (n.) are seen, above. In this, as in the last, mucous crypts are seen here and there between the lining of the nose and the cartilage; the whiskers are cut through in the outer skin, and a tooth-pulp is shown below.

Sections 4 and 5 (Plate 23, figs. 4 and 5).--These, which were one oblique section, were made through the middle of the eye-ball $(e)$ on one side, and on both through the olfactory lobes $\left(\mathrm{C}^{1 b}\right.$.). It also takes in the lower face, with the tongue $(\mathrm{tg}$.$) . The$ mass of soft tissue under the olfactory lobes will be differentiated into the cribriform plate, the olfactory nerves passing through its meshes. This is behind the roof of the nasal labyrinth, and thus the septum, here, the perpendicular ethmoid (p.e.), has a free upper edge- the region of the crista galli.

In the side which is the foremost part (tig. 4), the nasal wall passes a little over, above, and under, below, and sends inwards a large plate of cartilage, which is bifurcated and very thick at its imer part Here we have the rudimentary middle turbinals $(m . t b$.$) . The same is seen on the other, or hinder, side, but above; the$ section is near the orbitosphenoid, or fore part of the cartilaginous cranium, for it is continuous with the nasal labyrinth ( $\left.a l_{.} . e\right)$; the frontal bone $\left(f^{\prime \prime}\right)$ is seen outside it. Also, below the bulbous base of the middle ethmoid, formed here of all the three trabecula, the hinder forks of the vomer $\left(v_{0}\right)$ are to be seen; whilst below, on the palatine ridge, the palatine plate of the palatines $\left(p a_{0}\right)$ is cut across. Below, outside the base of the tongue ( $\left.y_{0}\right)$, the dentary (d.) and Meckel's cartilage (mk.) come into view. 
Section 6 (Plate 23, fig. 6).-This large partial section is through the back of the eye-bulls $\left(e_{0}\right)$, the front of the cercbral hemispheres $\left(\mathrm{C}^{1 a} \cdot\right)$, and the hind part of the nasal labyrinth. The perpendicular ethmoid (p.e.) is, as in the last, a wall standing alone, rounded, but thinnish above, thick and bulbous below; at present, the whole roof of the labyrinth, or floor of the cranial cavity at that part, is void of cartilage ; there are two nasal passages (n.p.) on each side, and between them the rudimentary middle turbinal is growing. The floor of cartilage is imperfect below; the wall (al.e) passes into the orbitosphenoidal lamina, above, and there is a fissure more than half-way down. The raphe formed by the meeting together of the right and left palatal laminæ is strengthened, still, by the palatine plate of the palatine (pa.); a wide, but not deep passage (n.p.c.) is seen above this second floor. 'The root of the tongue (tg.), tooth-pulps, and the dentary bone (d.), with Meckel's cartilage ( $m k_{\text {. }}$ ) inside it, are all shown in the lower part of this section.

Section 7 (Plate 23, fig. 7).-Here the cerebral hemispheres $\left(\mathrm{C}^{1 a}\right.$.) are large, and the wide orbitosphenoids (o.s.) form the floor of the cranial cavity; they are continuous with the presphenoidal bar (p.s.), which is oval, with the long diameter transverse. 'The wings themselves (o.s.) are thinner and then thicker, twice over. This section is diagnostic of a Eutherian skull; the alisphenoid ( $a l_{.} \varepsilon_{\text {. }}$ ) comes into the same section with the orbitosphenoid (o.s.) lying outside it, and they have the Gasserian ganglion (V.) between them. Here the pterygoid bones $\left(p y_{0}\right)$ are cut across, and the little nodule of cartilage, which becomes the pterygoid (pg.c.). We also see the undiminished Meckelian rod $\left(m l_{0}\right)$ with the growing ramus of the lower jaw $\left(d_{0}\right)$ outside it. The large nasopalatine canal is constricted in the middle, and has the ceratohyals (c.hy.) in section below it.

Section 8 (Plate 23, fig. 8).- This section is through the fore part of the basisphenoidal bar $\left(b_{s} s_{*}\right)$, close behind the presphenoid; here it has been formed by the three trabecular bars, the hind part of the intertrabecula wedging in between the paired trabeculæ.

The angle of the orbitosphenoid $\left(o s^{\prime}\right.$.), and part of its lower hind margin, has been cut through ; this latter band is, however, fur from the basal beam; it lies over the huge Gasserian ganglion (V.), the fore part of which is here seen in section; this mass lies on the out-thrust alisphenoid (al.s.) which is hollow above, and has a thick upper edge. On the inside of each alisphenoid the upper part of the corresponding pterygoid is cut across, and below the alisphenoid is the lower jaw or dentary $\left(d_{\text {. }}\right.$ ) developing outside MEcKEL's cartilage ( $m k_{0}$ ) ; it is an oblique long oval tract, hollow in the inside where the rod of curtilage lies. The wide nasofaucial passage is constricted at its middle; below it, part of the larynx is seen, and on the outside the ceratohyal (c.hy.).

Section 9 (Plate 23, fig. 12). * - This section is directly in front of the pituitary body and sella turcica; and here the alisphenoid is cut across, where it runs near the

* The re-arrangement of most of these figures as half-sections, so as to get them into a smaller space, has produced some confusion; the figures do not always follow in regular succession on the Plates; but the numbers give the correct order, except in this instance. 
basisphenoid (b.o.), * the tympanic wings of which are seen as projections, below. A small tract of each wing is seen above the internal carotid (i.c) entering the skull, and the orbitosphenoidal band $\left(o . s^{\prime}\right)$ is also seen at one-third of the height of the side-wall. The inner margin of the huge Gasserian ganglion (V.)-lere cut across its middle-- lies in the bend of the artery, it reaches more than halfway outwards and upwards to the orbitosphenoidal band.

The angle of the outer mandible (mn.) is cut through, and below, and further inwards, Meckel's cartilage $\left(m k_{0}\right)$.

Over Meckel's cartilage the curved section of a considerable tube is seen, and also under it and nearing outwards a much larger space; the upper cavity is the beginning of the Eustachian tube, and the lower the tympanic cavity. Outside the latter a patch of cartilage is shown; this is part of the meatus. Under the inner edge of the tympanic cavity the epihyal cartilage (e.hy) is cut off close to its junction with the ceratohyal; and towards the mid-line the hypohyal $(h . h y$.$) is severed near$ the larynx (lx.), part of the cartilage of which is laid bare.

Sections 10 and 11 (Plate 23, figs. 9 and 10).-'These two half sections show the pituitary body ( $p y$.) above and in front of the ascending postclinoid cartilage, in the upper surface of which we see the point of the notochord. The auditory capsules (chl.) are cut across; they lie a considerable distance from the basisphenoid (b.s.). 'The orbitosphenoidal band $(o . s$.$) is present here, it soon becomes the supra-auditory crest.$ Over the anditory capsules the Gasserian ganglia (V.) are seen cut across in their hind part, and below them the geniculate ganglia (VII.).

In fig. 9, the tympanic cavity is cut across; outside and below it the meatus cartilage is shown. The small upper piece is outside the head of the malleus $(\mathrm{ml} .)^{)},+$ below which the body of the incus is seen, whilst its long crus is shown as turning inwards towards the capsule; the fenestra ovalis is cut across at its front margin in fig. 10 , but the stapes is massed.

Section 12 (Plate 23, fig. 11). - In this partial section we see the basilar artery $(b \quad a$. cut across obliquely over the hind part of the basioccipital (b.o.); here the large hind part of the cochlea (chl.) touches the basisphenoid, ready to coalesce with it. The orbitosphenoidal band $\left(0 . s^{\prime}.\right)$ is now very deep, close in front of its supra-auditory continuation.

The geniculate ganglion is still seen, and also under it the passage in the top of the auditory capsule for the facial nerve (VII.), which enters its canal at this place. The outer wall of the auditory capsule is deficient in two places here; the upper deficiency is partly filled up by the base of the stapes (st.), it is the fenestra ovalis ; between its base and apex the stapedial artery $\left(s t . c_{0}\right)$ is seen as it passes to the inside of the mandible. The other space, not stopped up by cartilage, is the fenestra rotunda : the outer part of the capsule with its tegminal projection (t.ty.) is seen external

* The letters of reference slıould have been b.s., and only one line to i.c.

$\dagger$ The line of reference to the figure is made too low down. 
to the stapes, and the epihyal $\left(e . h y\right.$ ) growing from it; the notochord ( $n c_{0}$ ) is compressed in the middle of the basal cartilage.

Section 13 (Plate 23, fig. 13). - This partial section is near the last, and shows actual fusion of the capsule with the basis cranii (b.o.), and the inferior position of the notochord (nc.). The lateral band $\left(o s^{\prime}\right.$.) is not yet continuous with the auditory capsule, which is, here, cut through at the meatus internus. The tegmen tympani (t.ty.), is severed near part where the short crus of the incus is articulated, and the stapes (st.) is cut through behind the middle, so that the stapedial artery has been removed. The two fenestræ have a convex tract of the capsule between them.

Section 14 (Plate 23, fig. 14).--The top and bottom of the section are left out, and the capsule is drawn with the investing basal cartilage (b.o.). Under this sinuous thinnish plate of cartilage the notochord is seen, and above it the basilar artery. 'The crest of cartilage is now the supra-auditory, and the recess outside it at its junction with the capsule will be filled in by the squamosal bone. The tegmen tympani is cut through behind the incus; but the fenestre $\left(f s_{0} .0, f_{\text {. }} r_{0}\right)$ are still in view, the anterior and horizontal canals (a.s.c., h.s.c.) are also seen.

Section 15 (Plate 23, fig. 15).-The supra-auditory cartilage (s.c.c.) is deficient below, where it passes into the supraoceipital. From the great obliquity of the

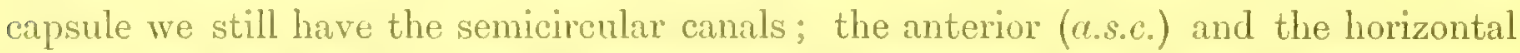
(h.s.c.) are here seen to be imbedded in solid cartilage; part of the vestibule is seen below and within. The capsule is separated by a considerable space from the basal cartilage (b.o.), which is thick and bracket-shaped; the notochord (n.c.) has again retched the upper fince of the investing mass of cartilage ; the vagus and glossopharyngeal nerves (IX., X.) escape through the interspace, right and left, between the capsules and the basis cranii ; the foramen for the hypoglossal (XII., f. condyloideum) has been laid open. 'These sections of the newly chondrified skull will be better understood after I. have described the next series.

Thind Stage (continued). - Dissection of the visceral arches of an embryo Nole; $\frac{2}{3}$ inch lony.

An inner view of these parts, in connexion with the auditory capsule, is shown as drawn from an outspread preparation; the osteoblastic tracts had been removed from Meckel's cartilage (Plate 28, fig. 1). The part of the capsule containing the semicircular canals (a.s.c., h.s.c., p.s.c.) is in its natural relation to the arches, and shows their extreme obliquity. The capsule is cut arvay so as to show the base of the stapes (st.) in the fenestra ovalis. That part of the hyoid arch which corresponds to the epibranchial the epihyal (e.hy.) - is seen to be outside the stapes, and to be confluent with the capsule a little above the insertion of the head of the pharyngohyal (stapes). The junction of the inturned end of the long crus of the incus (l.c.i.) is liom the eye in the figure, and is hidden by the base of the stapes, the perforated stem of which is at a right angle to that part of the incus. Looking upon the short 
crus of the incus (s.c.i.) as the morphological equivalent of the "otic process" of the quadrate of a Bird, Reptile, or Amphibian, and remembering that the "orbital process" is suppressed in this Mammalian suspensorium, we see by this figure that the incus is well in front of the auditory capsule. Indeed, it is as definitely in front as in the embryo of any of the Samropsida, in some of which the otic process, ultimately, runs backwards to be articulated with the fore edge of the occipital arch, beyond the auditory capsule, altogether.

The body of the incus (i.), as well as its two crura, is already of the normal shape, and so also is the malleal portion of the primary mandible, witl its bulbous head, and its large, forwardly-turned manubrium $(m l, m b$.). The large, terete, sigmoid Meckelian rod $(m k)$, after uniting with its fellow of the opposite side, runs into a basimandibular spike $(b . m n$. $)$.

Here, normally for a Mammalian hyoid arch, but not for a branchial arch, as such, there are three segments below the flat, rounded epihyal (e.hy.), which is not united with its own uppermost segment, but with the auditory capsule. Nor is it united with the next segment, or upper ceratohyal (c.hy.), by cartilage, for that next lower piece is fibrous above.

The two next segments are the straight lower ceratohyal (c.hy.), and the curved hypohyal $(h . h y$.$) ; this is the stoutest of all the segments. 'The common rudiment of$ the basihyal, basibranchial, and first hypobranchiais $\left(b . h . b r_{.}, t . h y_{0}\right)$, is a stout, well. formed $U$-shaped piece, with the front edge of which the two hypohyals are articulated. Over the tympanic cleft, the tympanic annulus $\left(\alpha_{0} . t y_{0}\right)$ is seen, formed of a crescent of tender bone round the membrana tympani $(m . t y$.$) .$

\section{Fourth Stage.-Shull of embryo of Hole; $\frac{3}{4}$ and $\frac{4}{5}$ of an inch long. \\ Dissection of the chondrocranim of an embryo Mole, $\frac{3}{4}$ inch long.}

The basal view of this skull (Plate 25, fig. 2) shows the distinctness of the olfactory and auditory sense-capsules from the cranium proper, and the upper view (fig. 3) displays the large amount of cartilaginous "tegmen," in spite of the cruciform fontanelle. The general outline of the skull is pyriform, the narrow nasal end being the stalk; this is dilated, in front, over the inferior external nostrils ( $\left.e_{\text {.n. }}\right)$, and again where the alinasal region $\left(a l_{0} n_{0}\right)$ ends, opening below at the beginning of the aliseptal region $(a l . s p$.$) , where the inferior turbinals (i . t b$.$) are given off. At its middle the$ nasal labyrinth swells out, suddenly, so that it is itself pyriform, and ends in front of the orbitosphenoid $\left(o_{.} s_{\text {. }}\right)$ in a large and somewhat bilobate cushion; the right and left masses are separated by the perpendicular ethmoid ( $\gamma_{0}$. .) which passes into the septum nasi (s.n.). The long alinasal region is closed below, except at the sides, in front; and the hinder fourth of the main labyrinth is also perfectly floored with cartilage. The open space between these two floored regions is largely filled up by the huge recurrent lobes ( $r c . c$.) which support JACoBson's organs; these tongue-like tracts are three-fourths the length of the long open space, and are themselves supported 
on their inner face by the anterior paired vomers, which are very slightly separated from the palatine processes of the premaxillaries (p.px.); the whole of these bony tracts has been figured here, $i n$ situ. In the dilated front end of the lower opening the inferior turbinals $\left(i . t b_{0}\right)$ are seen, and the folds of the middle turbinal $\left(m_{0} t b_{0}\right)$ in the hinder rounded space. Where the floor turns inwards and upwards towards the septum $\left(p_{\cdot} e_{0}, s_{.} n_{0}\right)$, there it gives oft' a spike of cartilage which nearly reaches the recurrent lobe; this spike is the precurrent cartilage. The line of junction of the proper cranium with the nasal labyrinth $\left(0 . s_{.}, a l_{.} e_{0}\right)$ is quite visible; the orbitosphenoidal region of the cranial wall and roof is very wide, and has a convex outer face. The stem of each tract is narrow, and becomes, after ossification, the permanent, small orbitosphenoid. Each band winds round behind the corresponding lobe of nasal labyrinth, and is not flush with it, below; the two bands are continuous with the presphenoidal regrion of the prepituitary basal beam.

That beam is thickest where these bands join it; it is mainly formed of the intertrabecula, for the paired trabeculæ are flattened against the merlian part, and then cease between the hinder part of the right and left nasal floors. The chink between the convex hinder edge of the orbitosphenoidal stem (o.s.) and the concave edge of the alisphenoidal lobe (al.s.) is ear-shaped and curves backwards, and is large and round against the basal beam; this is the large sphenoidal fissure for the ophthalmic and orbital nerves $\left(\mathrm{V}^{3}\right.$.). The small optic foramen is oblique, and is hidden in this view by the alisphenoid (see fig, 3, II.). 'The basal cartilage is very narrow between the orbito- and alisphenoids, and then expands suddenly, to remain wide to the end of the skull. Here, as in all typical Insectivores, the basis cranii in the early skull is extremely wide, ready to become pneumatic in relation to the auditory function. Even where the large cochlex (chl.) push their coils right and left against the basisphenoidal, at its junction with the basioccipital, region, it is still nearly four times as broad as at the point where the presphenoid and basisphenoid neet.

The stem of each alisphenoid scarcely becomes pinched in, but its margins are both concave, having the emerging orbital nerves in front of it and the swelling cochlea behind. Just where the latter concavity is seen, there the sub-basal cartilage swells out into a mammillate mass, which looks outwards and forwards, reaching threefourths of the distance ta the sphenoidal fissure. These solid masses, which look like the basipterygoids of a Lizard or Bird, are the chondrocranial form of the "tympanic wings;" when ossified, they become pneumatic.

The alisphenoids $(a l . s$.$) are very remarkable; their broadest part is proximal, but$ they dilate again at their outer, free edge, after becoming narrowed in by one-fourth at their middle. Their front margin, which helps to form the sphenoidal fissure, is concave, and their postero-external edge is cut away, so to speak, by the large pupiform cochlen (chl.), around which the posterior edge of the alisphenoid is carefully bound, The hind margin is a large right-angled notch; the outer edge is sinuous, rounder, and looks forwards and inwards; all this onter part is swollen, but perforated, 
equidistantly, in two places, by the 2nd and 3rd branches of the 5th nerve, thus forming the foramen rotundum, and foramen ovale $\left(\mathrm{V}^{2}, \mathrm{~V}^{3}\right.$.). The thick semicircular inner nargin of this outer lobulated part stands off from the main plate, and the whole of the outer part lies below, free of, and at a distance from, the orbitosphenoid, which it overlaps considerably. This very diagnostic Mammalian alisphenoid is follower, postero-externally, by a large fenestra, a space totally devoid of cartilage, but which is being filled up by the squamosal bone; it is the upper part of the tympanic space, and is traversed by the ossiculu auditus. Round it, like a bow, the orbitosphenoidal band $\left(o . s^{\prime}\right.$.) is bent, passing, behiud and above, into the supra-auditory cartilage (s.a.c.); below, this band forms the fore part of the tegmen tympani, and the incus articulates, by its short crus, at the junction of this lateral band with the auditory capsule. These capsules, in their hasicrunial setting, are very elegant structures; they stretch from the tympanic lobes of the basisphenoid, anterointernally, to the feebly-expressed paroccipital ridge, right and left, posteroexternally. The cochlex $\left(c h l_{\text {. }}\right)$ show their three coils, and the fenestrx rotundx $\left(f . r_{0}\right)$; these are very large, and well seen from below.

The fenestru vestibuli is closed by the stapes (st.), a small irregular ring of cartilage. Up to the passage for the 9 th and 10th nerves $(\mathrm{IX}, \mathrm{X}$.) the capsule is very distinct from the chondrocranium, but in the mastoid region below the semicircular canals, and where the posterior canal is imbedded, there is more or less fusion of these parts The very large relative size of the occipital arch reminds one, at once, of that of the Echidna; here the chondrocranium is as complete as in the Skite.

The notochord (nc.) is seen from below, up to the point where it rises into the postclinoid wall (see fig. $3, n c ., p . c l$.), in which the proper, primary axis of the animal ends, and beyond which everything is of the nature of an outgrowth. *

An elegant narrow waist is formed to the basis cranii by the pressure of the large cochler; behind this part the parachordal tract expands sinuously, and runs upwards into the side walls. The whole hind part is very smoothly rounded, and the condyles (oc.c.) are very flat, and have a sulcus across them; the foramen magnum $\left(f . m_{0}\right)$ is very large; the f. condyloideum (XII.) is small and far outwards, nen the concave edge of the arch.

The upper view (Plate 25, fig. 3) shows the roof of the nasal labyrinth, with its long fore part, and its lateral lobular expansions right and left of the deep, multiperforate rhinencephalic recess $\left(c v^{\prime} p\right)$. The crested intertrabecula, at its junction with the hind part of the nasal roof, above, shows a small crista galli (cr.g.); the wall below this part is thin above; it is the top of the perpendicular ethmoid (p.e.), which widens, gently, to pass into the presphenoid (p.s.). The narrow, backwardly-curved

* There are tro ways of looking at the prochordal tracts of the skull-the trabecula and intertrabecula; some see in these parts a highly modified, first visceral arch; I confess that, at present, they merely seem to be angronths of the proper axis to finish the new, highly expanded fore part of the skull; made necessary, in the Vertebrata, by the great expansion, even in the lowest kinds, of the neural axis. 
stems of the orbitosphenoids (o.s.) show their optic perforations (II.), close behind the outer margins of the cribriform plate; thence the cartilage expands rapidly, and curves over the sides of the root as far inwards for some distance as the lateral ethmoidal lobes (al.e.); the line of union between these parts is still visible. Narrowing from before backwards, and bowing ontwards, the cartilage runs so as to become, first, the supra-auditory (s.a.c.), and then the supraoceipital region (s.o.)

The neat, rounded selvedge of this cranial wall and roof (tegmen cranii) forms the outline of a huge cruciform upper fontanelle, through which, the membrane being removed, we see the floor of the cranial cavity. Much of what has been described in the lower view is seen here from its upper face, but the low postclinoid wall (p.cl.) and the large multiperforate meatus internus (VII., VIII.) are only to be seen on this face. Also the general smoothness of the gently concave inner surface of the chondrocranium is to be noted, and, over the top, the manner in which the supraauditory part of the tegmen cranii flanks the fore edge of the occipital roof $\left(s_{0} o_{0}\right)$, a sulcus marking the distinct regions.

Fourth Stage (continued). - Visceral arches of the slull of an embryo Mole; $\frac{4}{5}$ inch long.

A somewhat more advanced embryo than the last yielded me a very important stage in the development of the visceral arches. The deep and the superficial jaw are shown in relation, with the hinge-piece (incus) attached to the fore part of the auditory capsule. In this inner view (Plate 28, fig. 2) the ampulla of the anterior and horizontal canals (a.s.c., h.s.c.) are laid bare, and the short crus of the incus (i.) is seen to be attached close in front of these parts of the membranous labyrinth; that process is very short and obliquely attached; and in this shortness and obliquity it shows an intermediate stage between the normal Mammalian incus, on one hand, and the curiously arrested incus of a Monotreme, on the other. The long crus, however, is well developed, and is articulated by its inturned discoidal end, with the head of the stapes (st.), the base of which is turned towards the eye. The malleal end of the deep mandible is well developed, and the fore-turned internal angular process lies in the centre of a thick cushion of soft stroma-the future membrana tympani (m.ty.). This is partly enclosed by a delicate lunule of bone, the annulus tympanicus $(\alpha . t y$.$) . The posterior angular process of the malleus is almost suppressed.$ The main part of MEckEL's rod ( $m k_{\text {. }}$ ) is evenly terete and sinuous, but it is largest near the head, and near the distal end; there it is continued into a median process, the basimandibular (b.mn.), into which both the rods end. The only bony matter in this primary mandible, as yet, is a short ring, or shaft, close behind the thick part, close to the median rod. Morphologically speaking, this is a hypobranchial bony segment. Outside all but the malleal portion there is, already, a well-formed superficial jaw, bony in front and cartilaginous behind, and having a groove, on its inside, between its condyloid and angular processes (cl.p., ag.p.) for the descending Meckelian rod, the bony matter $\left(d_{0}\right)$ begimning to run up the unciform coronoid process (c.p.). Here, if there 
were a coronoid bone, like that of a Reptile, this postero-superior part of the dentary would be distinct. The inner alveolar plate corresponds to the splenial bone; an angulare, a supra-angulare, or an articulare would have to be sought for on the malleal part of the deep or primary mandible.

The stapes (st.) was dislocated out of the fenestra ovalis in making this preparation. I did not figure the rest of the hyoid areh.

Fourth Stage (continued). $-A$ series of vertically-transwerse sections of the head of an cmbryo Nole, $\frac{3}{4}$ inch long from snout to root of tail.

During the time that the embryo of the Mole grows from $15 \mathrm{~mm}$. to $18 \mathrm{~mm}$., the tissues gain much increase of solidity; this is, indeed, the best stage for studying the structure and relations of the chondrocranium, and the superficial bony plates which it draws to itself for increase of strength.

The long snout (see Plate 25, figs. 2, 3) admits of being sectioned into a large number of slices; I have, however, only figured a moderute percentage of those that were made in this case (Plate 23, figs. 16-19), which was an embryo of the same size as that which was dissected to show the chondrocranium (Plate 25, figs. 2 and 3).

The 1st Section (Plate 23, fig. 16) is in front of the outer nostrils; here the upper part of the section is the narrower; the lower is the narrow part further back. Here the septum nasi (s.n.) is perfect, and is dilated both above and below; the alre (al.n.) are thick above, turn inwards below, and the thick growti below turns upwards. Part of the folded part below is so curled round as to appear in this section as a distinct segment.

2nd Section (Plate 23, fig. 17).-This is close to the nostrils, and the nasal passages are seen projecting outwards, right and left. The septum nasi $\left(s_{0} n.\right)$ is thinnest at this part, and here the alæ nasi (al.n.) turn inwards abruptly, whilst the folds that form the floor $\left(n_{i} f_{0}\right)$ are reaching further upwards.

3rd Section (Plate 23, fig. 18). - Here the narial tubes are surrounded by cartilage, for the floor has reached the roof $\left(n f_{.}, a l_{\circ} n_{0}\right)$, and now the septum $\left(s_{.} n_{0}\right)$ is very thick above, and of considerable thickness below the most dilated part.

4th Section (Plate 23, fig 19).-- Here the roof and floor are confluent at the sides, and in this section it is seen that the floor has turned inwards so as to project, laterally, by its proper end, into the nasal passage, the fold uniting with the dilated septum $(s . n$.$) -or intertrabecula - by its upper face.$

Here the mandibles are cut across in their fore part, and the basimandibular rod (b.mn.) unites the two Meckelian rods ( $m k$.).

5th Section (Plate 23, fig. 20).--This is behind the snout, in the front part of the proper nasal labyrinth, which is now open below. Here the nasal septum is seen to be merely the round intertrabecula - like that of an embryo Bird-with the nasal roofs, however, united to it. The only remnant of the floor, so large and perfect in the MDCCLXXXY. 
last section, is a retral trast of cartilage, convex on the inner face, where it touches the septum, and concave extemally; this is the "recurrent curtilage" (re.c.) developed for the support of JACoBsox's organ. Here the upper lips are seen, and have a hollow palatine part between then; below, the Meckelian rods (mk.), are distinct in the mass of the lower jaw, over which the tip of the tongue is seen. 'The pulps of the whiskers $(v i b$ issce are cut through in the outer thick skin.

6th Section (Plate 23, fig. 21).-Here the septum nasi is deeper, and the bulbous part less; the aliseptal folds (al.sp.) turn inwards below; the inturned part is the rudiment of the inferior turbinal. The recurrent cartilage (rc.c.) was tubular between this and the last section; but it is now open again to the end; here it has JAConsoN's organ (j.o.) in its concavity. The pulp of an incisor is seen, and MEckEL's cartilages are getting some distance apart.

Th Section (Plate 23, fig. 22).-This is a remarkable section, and very instructive. It is behind JACOBsox's organs and cartilages, and is seen to be girdled with bony tracts-the nasals ( $n_{\text {. }}$ ) and maxillaries $(m x$.), with their palatine plates; the base of the deep septum $(s . n$.) also is supported by the main vomer $(v$.$) . The septum becomes$ thin above, as it passes into the broad and solid nasal roof ( $a$ l.sp. $)$, which is convex right and left and in the middle. 'The wall as it becomes floor' turns inwards to form the pedate rudinent of the inferior turbinal, which projects upwards so as to lessen the nasal passage below. Below each shallow valley on the roof, a large lamina of cartilage grows downwards and a little outwards, dividing the nasal passage into a larger inner, and a lesser outer, space, both subvertical and somewhat pinched in at the midlile.

This is the "nasal turbinal" ( $\left.n . t b_{0}\right)$, which for a short clistance, fore and aft, and for " short time during derelopment, forms a complete secondary nasal septum on each sirle of the septum proper $(s, n$.$) .$

8th Section (Plate 23, fig. 23). - This is immediately in front of the olfactory fossre, and through the fore part of the eye-balls (e.); this is the widest part of the complete masal labyrinth. 'The septum is now perpendicular ethmoid (p.e.), and the roof is in the aliethnoidal region. 'The maxillary $\left(m x_{0}\right)$ is cut through close in front of the orbit, and again in the palatal region, right and left of which there is a tooth-pulp ( $t$.). The vomer $(v)$ is cut through its middle, and over it the deep septum (p.e.) thickens twice; it also grows so as to lift the roof over it into a low rounded ridge. Inside, near the septum, and at the upper part of the wall, there are small rudiments of the upuer turlinal folks (u.tb.), and half way down the wall grows inwarts as a large mass of cartilage, pedate in section; this is the common rudiment of the middle turbinal folds ( $m . t b$.$) . 'The floor is cut through behind the inferior' (properly anterior) turbinal,$ it encts fir fiom the mid-line. Below, the dentary (d.) is cut through; over it, outside, is a tooth-pulp, and further inwards MeckeL's cartilage ( $\left.m k_{0}\right)$; the tongue (tr.) is now developing its fremum. 'The palatine plate of the palatine begins to be seen in section. 9/h. Section (Plate 23, fig. 24). - The olfactory lobes $\left(\mathrm{C}^{16}\right.$.) are cut through the 
middle in this section, and also the eye-balls (e). Here we have apparently an open Hoor to the brain, which is the roof to the nasal labyrinth, for the cribriform plate is not yet chondrified. The solid septum (p.c.) is still convex in two places, it stands quite by itself in the section, for the lateral ethmoidal structures at this part, are far fiom it, right and left; it is supporterl, below, by the vomer. There is still a small upper turbinal rudiment, and the midlle tubinal ( m.th.) is in two folds; the floor is strong, it is still at a great distunce from the mid-line. Over the eye (c.) the frontal $\left(f_{0}\right)$ is seen, and the maxillary palatine plates, those of the palatines, and the jugal bones $\left(p a_{*}, j_{0}\right)$ are seen in the roof and silles of the mouth. The tongue $\left(t g_{0}\right)$ is cut through its middle; and the lower juw is seen as a cruciform section of the dentary (d.) holding a tooth-pulp (t.) above, and Neckel's cantilage (mk:) below.

10th Section (Plate 23, fig. 25). The cribriform plate (cr.p.) is here a lirge membranous tract, right and left, hollow alouve and convex below.

The perpendicular ethmoid (p.e.) has lost one-thircl of its height, and is much thimmer above; the floor $\left(n_{i} f^{\prime}\right)$ has now reached it, and each plate articulates with its bulbous base. The wall and the list fold of the middle turbinal (m.tb.) are thick plates, free above, and having their concave fuces looking towards each other; the nasal cunal is thus subdivided into two passarges, the outer oval, and the inner unciform, in section. Another cartilage has appeared above the low wall, and at a short distance from it; this is the orbitosphenoid (o.s.); it is thicker below tham above, and convex outside; at a small distance outside it a much larger part of solid tissue is cut through, this is the frontal $\left(f^{*}\right)$, which, however, only forms a wall-not a roofto the huge hemisphere $\left(\mathrm{C}^{1 *}\right.$. $)$. The romer $\left(v_{0}\right)$ is still seen in section, and the palatines ( $\left.p a_{0}\right)$, with it, almost complete the fence round the bilobate nasopalatine passage. Below, the dentary $\left(d_{0}\right)$ is thickening over Mecrel's cartilage (mk.).

11th Section (Plate 24, fig. 1).-This section is through the hind part of the nasal labyrinth, and the nasal passage $\left(n . p_{0}\right)$, right and left, is single, large, and heart-shaped. This is the last section through the membranous cribriform plate (cr.p.), and the perpendicular ethmoid ( $\left.\eta_{\text {.e. }}\right)$ is but little above half its original height; the nasal wall, being cut through obliquely to its plane, looks extremely thick. 'The ascending floor' is still articulated with the bulbous middle wall. Here the orbitosphenoid $(o . s$.$) is$ larger, and is sharp both above and below; it almost reaches the nasal wall. 'The frontals $(f \circ)$, the palatine $\left(p_{0}\right)$, and the forks of the romer (v.) are seen in section; also Meckel's cartilage ( $m k_{\text {. }}$ ), and the dentary (d.) below.

12th Section (Plate 24, fig. 3).-This and the next section have been accidentally transposed: the back wall of the nasal labyrinth is here seen and the fore part of the Gasserian ganglion (V.).

This part shows a very deep orbitosphenoid (o.s.), resting by its thick base upon a cartilaginous fold growing out from the back of the nasal labyrinth; although the orbitosphenoid (o.s.) was cut through, the small optic foramen was caught in this section. The presphenoid $(p . s)$ is almost trilobate, and is composed of the 
three trabecular hars-the trabeculae right and left, and the intertrabecula above. the fore edge of the alisphenoid is not yet renched, but the fore part of the Gasserian ganglion (V.) is shown. On the side of the wide, oblong nasopalatine canal (n.p.) the pterygoid bone and cartilage $(p g ., 2 g . c$.$) are cut across, and below we have still$ the dentary with MEckEL's cartilage ( $m k_{0}$ ), and also with the superficial cartilage that forms the condyloid and angular regions; the ceratohyals (c.hy) are also seen in this section.

13 th Section (Plate 24, fig. 2).--This partial section shows the orbitosphenoid (o.s.) in two parts, the postero-superior band, and the hind margin of the stem; the basal part (p.s.) is fusiform. Below the stem of the orbitosphenoid, at a considerable distance, the alisphenoid ( $\iota_{\text {. s. }}$ ) is seen as a thickish plate, curved downwards, and beaded at its outer edge. Its concavity makes a nest for the large Gasserian ganglion (V.), which is protected above by the orbitosphenoid. 'Two thick rods of cartilage are cut through between the alisphenoids, one on each side of the broad nasopalatine passage, they turn inwards and downwards, and are capped with a film of bone above, these are the pterygoid cartilages, with the growing pterygoid bones (see fig. 3). Below we see the maudible as one large folded tract of bone (d.) embracing three cartilages; the middle of these is the Meckelian rod (mk), the others are the condyloid and angular parts of the superficial slab. Below the oral cavity (m.) the ceratohyals $\left(c . h y_{0}\right)$ are seen.

14th Section (Plate 23, fig. 4).-Here the same parts are better seen, than in the last, in a more symmetrical figure.

15 th Section (Plate 24, fig. 5). - Here only the posterior band of the orbitosphenoid $\left(o . s^{\prime}\right.$.) is seen, for the basal part (b.s.) now runs into the alisphenoid (al.s.), which is cut through proximally, at its postero-external angle. The Gasserian ganglion (V.) still lies on it, at its proximal part, the cartilage dipping considerably to form a nest for it. Here the basisphenoid (b.s.) is formed of the outspread and coalesced trabecule, this part being somewhat in front of the pituitary space. The squamosal $(s q$.$) is seen outside the angle of the alisphenoid, and MEckEL's cartilage (mk:),$ the latter, the end of the angular, and part of the articular cartilage ( $m n$.), are also cut atrens.

There are three cavities laid open, namely, the masopalatine (n.p.c.), the mouth $(m$.$) ,$ and the larynx $\left(l_{0}\right)$; the Eustachian tubes are also laid open in their inner half, continuously with the nasopalatine passages. Besides the cartilage of the larynx, the epihyal, and hypohyal (c.hy., h.hy.), are cut through.

$16 t h$ Section (Plate 25, fig. 6).- This is from a little further backwards than the last, and takes in part of the meatus auditorius externus, with its lining cartilage (m.a.c.). 'This partial section is below the orbitosphenoidal band, and behind most of the ailisphenoid (al.s.); outside the proximal part of that wing, which is cut through below the Gasserian ganglion (V.), MEckEL's cartilage (mk.) is seen high in position, and large in size. Whe Eustachiun tubes (eu.) are laid further open than in the last 
section, and besides the hyoid rods $(e . h y ., h . h y$.$) , the thyroid cartilage, as well$ as the arytnoids $\left(l x_{0}\right)$ are cut across.

17 th Section (Plate 24, fig. 7).-This section is through the basisphenoid (b.s.), close behind the edge of the alisphenoid (al.s.), which, however, is caught further outwards, still bearing the Gasserian ganglion $(V$.$) . The hinder edge of the soft palute is cut$ through, and the nasopalatine canal (n.p.c.) is nearly continuous here with the mouth

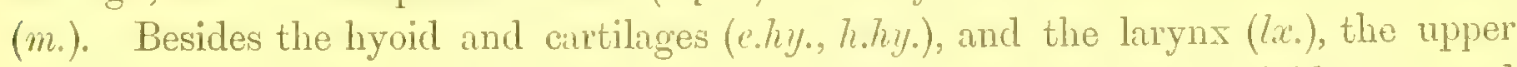
tracheal rings are seen in section. The tympanic cavity (c.ty.) is laid open, and also the inner part of the Eustachian tube (eu.); here the meatus curtilage (m.c.) is thick. MECKEI's cartilage is now thick: it is the fore part of the head of the malleus ( $m l_{0}$ ) that is seen at this point; above it a small tract of the tegmen tympani (t.ty.) is ilso brought into view; outside these cartilages the squamosal is shown.

18th Section (Plate 24, fig. 8).-This section is behind the alisphenoid and through the ganglion geniculatum (VII., VIIT.); also, besides a small piece of the teginen tympani, the fore part of the cochlea $\left(c h l_{\text {. }}\right)$ is cut across. In this and the list section the basisphenoid $\left(b . o_{0}\right) *$ is concave below, this is because the mammillary processes that form the foundation of the "tympanic wings" are cut through (Plate 25, tig. 2, 6.s.). In the hollow we see the large faucial passage ( $/ h x_{0}$ ), which opens into the larymx (lx.). The laryngeal and tracheal cartilages are similar to those of the last section, and so are the hyoid $\left(e . h y_{.}, h_{0} h_{y_{0}}\right)$; heneath the epihyal, the chorda tympanic nerve (VII ${ }^{a}$ ) is seen in section. Inside the squamosal, and under the tegmen tympani, the whole head of the malleus, with its manubrium, is shown; the latter pushing the membruma tympani before it; this is behind the Eustachian tube.

$19 t h$ Section (Plate 24, fig. 9).-This section of the cranial basin is oblique and may serve as two; the right side is from a point in front of the left; and from the somewhat sinuous direction taken by the razor, some things on the left side belong to points in front of the parts shown in the last (fig. 8).

The orbitosphenoidal band and part of the parietal $\left(o . s^{\prime}, l^{\prime}\right.$. $)$ are cut across, above; whilst the squamosal (sq.) and the meatus (m.a.c.) are seen lower down. Here, again, the head of the malleus ( $m l_{0}$ ) is seen in its whole extent, capped by the tegmen tympani, and with its manubrium pushing inwards the membrana tympani. Over the malleus, the ganglion geniculatum (VII., VIII.) is seen, and under the tympanic cavity (c.ty.) the ceratohyal (c.hy.). On that sicle the cochlea (chl.) is just laid open, on the other it is cut across its middle. Between the two, the basisphenoid (b.o.) † has becomes thicker and narrower, and it is still concive below; it carries, here, the pituitary body $(p y$.$) . The obliquity of the section is shown by$ the form of the upper part of the fauces ( $h h_{x}$.) below the basis cranii.

The left side is very instructive, for it shows the other elements of the earchain behind the malleus. This is the front view of the section, and thim as it is, the

* The letters of reference in this and the next figure should be $b .{ }^{\circ}$

+ The letters of reference should liave been $t$.s. 
incus $\left(i_{0}\right), *$ is seen to be nearer to the eye than the stapes, the fore margin of which lay somewhat back. Here part of both the parietal and squamosal ( $p ., s(y)$ are shown and also the orbitosphenoidal band, now the supra-auditory, where it rests upon the crest of the auditory capsule. Below that crest the thick outer edge of the capsule is seen forming the tegmentympani (t.ty.) under which the body of the incus (i.) is shown, in front of the stapes. The canal for the facial nerve (VII.), is cut through, ontside the cochlea (chl.), and under the cochlea part of the vestibule is laid open just at the fore end of the fenestra ovalis. Under the incus ( $i$.) a small cavity is seen, this is the hind part of the tympanic cavity which is very small even further forwards; there is very much soft tissue filling in the spaces here. Under the auditory capsule, on the outside, the epihyal is seen (see also Plite 25, fig. 2, e.hy.), and to it is articulated the top of the ceratolyal $(e . h y) .$.

20th Section (Plute 24, tig. 10). - The description just given may serve for the next section, but this being a little further back the lole in the stapes (st.) has been reached. In this the ficial nerve (VII.) was found in two places, besides the one above, owing to the curve it takes in its course. The cochlea is most open on the left side, and on the right it is cut through at its proximal part, and the vestibule is opened through the fenestra ovalis.

21st Section (Plate 24, tig. 11). - This next oblique section shows the malleus (ml.) on the right side, behind its manubrium; below it is the tympani cavity (c.ty.) and the ficial nerve and geniculate ganglion (VII., VIII.) are seen above it. There is still a considerable space between the auditory capsule (chl.), and the thick oblong section of the basis cranii, now the basioccipital (b.o.). The lhyod bar (e.hy.) is cut through obliquely, and uncler it the fincial part of the seventh nerve (VII.) is shown. On the left side the supri-auditory cartilage (s.c.c.) is continuous with the capsule, and so also is the basioccipital plate (b.o.). Here the razor passed through the meatus internus (VIII.), and the fenestra ovalis; in the litter the stapes (st.) is shown exactly through its middle, with the stapedial artery (st.a.) threading it. The top of the epihyal only is shown at the back of the tegmen $(t . t y$,$) , just where the short crus of the incus is$ articulated. Under the stapes a small cavity is seen, part of the tympanic (c.ty.).

22nd Section (Plate 24, fig. 12). - This also is oblique, but is two or three sections further back than that shown on the last figure. Here the right side shows the stapes (st.) cut across with the stapedial artery (st.a.) threading it; here, however, we get a section of the anditory capsule showing both the fenestrx, the oval and the round $(f s . o, f . r)$, and this also shows the meatus internus (VIII.). The tegmen tympani $(t . t y$.$) \neq is deeper here, and the inner edge of the cupsule (chl.) is seen to come down$ upon the basal plate $($ b.o.) to unite with it. This plate is fusiform in section and has the basilar artery (b.a.) upon it, and the notochord (n.c.) grooving its lower

: The line of reference in this figure is too short and does not reach the incus.

† In this figure for i read chy., and for e.hy. read c.luy.

* the line of reference passes down wards instead of across. 
face; the plate passes directly into the cartilage of the capsule on the left side. There the vestibule $\left(2 . b_{0}\right)$ is laid open and the lorizontal canal (h.s.c.) is exposed.

23rd Section (Plate 24, fig. 13). - 'This is only a little more than half the floor of the skull. The supra-anditory cartilage (s.c.c.) is now passing into the supraoccipital, and is again free from the capsule. The horizontal canal (h.s.c.) is cut across its arch, the posterior canal (p.s.c.) through its ampulla, and the anterior canal (a.s.c.), above. The large space between the capsule and the basal plate allows the 9th and 10 th nerves (IX., X.) to pass, and the large size, and the thick edges of the basal plate $($ b.o.) is due to the fact that the condyles are cut across. The notochord (n.c.) is now directly benenth the basilar artery (b.a.); it is seen again in the attached wedge of the axis ( $\alpha_{x}$ ) ; the condyles of the atlas (at.) are also seen.

24th Section (Plate 24, fig. 13).--The basilar plate and condyles (oc.c.) are cut across in this section in the fore part of the foramen magnum. The roof-cartilage (s.u.c.) lies upon the auditory capsule. 'This latter shows inside it the hinder part of the horizontal canal, and the neck of the posterior carial (p.s.c.) close to the ampulla. In this, as in the last, the cartilage is very solid above and behind the canals.

The 1st, 2nd, and 3rd vertebre.(1rt., rx., and below it, a small nucleus), are partly shown.

Fifth Stage-Dissection of the lower fuce and throat of an embryo llole; 1 inch long.

There is very little difference between these parts in an embryo an inch long and the same in one four-fifths of an inch (Plate 28, figs. 3 and 2). But in the larger embryo I was able to get a side view of the stapes (st.). It is shown in the figure dislocated from the incus $(i$.$) , and thus the triangular form and the round hole are$ shown. The incus also has its discoid articular ficet for the stapes turned towards the eye. The facial nerve (VII.) is seen in its canal, and in front of it the epihyal (c.hy.)* is seen to be confluent with the auditory capsule (au.), but only connected with the ceratohyal (c.h.y.) by ligamentous fibres. The extremely thick and soft membrana tympani (m.ty.) is just beginning to have an osseons deposit in its rim, and its fibres radiate from the front of the manubrium mallei $(\mathrm{mb}$.). The distal ossification on MECKEL's cartilage ( $m k^{\prime}$.) is elongating, and the dentary bone ( $l_{\text {. }}$ ) is creeping up the coronoid and condyloid processes of the superticial cartilage (c.p., cd.p.). There is no malleal ectostosis, at present.

\section{Sixth Stage.-Dissection of lower fuce and throat in an embryo Nole; $1 \frac{1}{3}$ inch lony.}

In an embryo a little more advanced than the last there are several things in the facial arches worthy of notice. 'The superficial mandible (Plate 28, fig. 4) has not only increased its bony matter, but the cartilige has become much more solid and in larger quantity; the middle process ending in the condyle (cd.p.), especially, is a thick rounded mass; the glenoid cartilage (yl.c.) is seen capping the condyle. The hypobranchial element of the arch-the distal Meckelizn ossification-is now larger, and

* In the letters of reference the hinder c.lly. should have been e.hy. 
under the proximal part of this rod, where the malleal enlargement is, there is a small ectosteal tract; the future bony centre of the malleus. Also in the thick soft outer disk of the tympanum there is a crescentic deposit of bone-the annulus. In this, as in the rest, the short crus of the incus $\left(i_{0}\right)$ is small and bent downwards; its symplectic facet, the orbicular region of the long crus, is shown with the outline of the base of the stapes (st.) round it ; this is the inner view of these parts. The epihyal $($ (chy.) is diawn as cut away from the auditory capsule; its lower end is connected with the pointed top of the ceratohyal $(c, h y$.$) , the long upper piece of which is$ heginning to ossify; the lower piece (c.h.y'.) is no longer than the hypohyal (h.hy.), which is thick and curved. The basi-thyrohyal piece $(b . h .6 r ., t . h y$.$) is thick and$ roughly $U$-shaped, with its angles squarish.

\section{Seventh Stage. - A similar dissection to the last of an older embryo 1. Iole; $1 \frac{1}{2}$ inch long.}

This fifth inner view of the visceral arches (Plate 28, fig. 5.) shows another sign of advanced growth; the distal ossification of MECKEL's cartilage is almost surrounded by a splenial growth of the dentary $\left(d_{0}\right)$, forming the inner face of the mandible. The dentary is also growing well round the thick trict that ends, above and behind, in the condyloid process (cd.p.); this is capper by the glenoidal tract (gl.c.), a part derived firm the same superficial source. The soft disk round the membrana tympani (m.ty.) is a more developed crescent of bone-the annulus (a.ty.). The head, both of the malleus and incus $\left(m l_{\text {. }}, i\right)$, is smooth and rounded, and in each case has a very condyloid appearance; the stapes (st.) is detached from the orbicular facet of the incus ( $i$.$) ; it is a$ stout cartilage, with a small circular hole, a distinct neck below its incudal head and facet, and a thick rim to its base, or proximal plate. I see no interhyal ( = intrastapedial) nucleus of cartilage in the tendon of the stapedius muscle $(s t . m$.$) .$

\section{Eighth Stage.-Vertical longitudinal section of the head of a ripe embryo Nole; $1 \frac{2}{3}$ inch long from snout to root of teil.}

In this preparation the interior of the right half of the skull was displayed with the whole of the ethmoseptal part of the cranial axis.

The figure (Plate 25, fig. 1) will help to a proper understanding of the skull in its earlier stages, both the sections and the dissections (Plates 23-25). The endocranium is now undergoing ossification. The nasal region, from the back of the cribriform plate to the front of the snont, is exactly of the same length as the cranium, measured from the former point to the top of the foramen magnum. 'T'he great internasal septum $(s . n .$, p.e.) is twice as high behind, at the crista galli (c).g.), than in front, between the nostrils; the dorsal line of this wall is sinuous; its lower edge is gently concave; behind the presphenoidal region ( $1 \% . s)$, the lower line of the skull is gently cunvex.

Between the nostrils, the floor and wall together form a sinuous tract; behind this part the calinasal artilage gives off the recurrent (or J $\Delta$ CoBson's) cartilage, right and left (rce.). The great intertrabecular bar thickens the septum all along, giving its 
sections a bulbous form, below. The cartilaginous crista galli (cr: $\left.g_{0}\right)$ is a mere retral point of the great septum; below that point the outline is coucuve, and between the large cartilaginous cribriform plates $\left(c r . p_{0}\right)$, it rises up at the meeting of the presphenoidal region with the perpendicular ethmoid.

From the middle of the presphenoidal tract (p...), to the foramen magnum, the skull is drawn as cut along the mid-line; the front part is left entire. Right of the presphenoidal, the orbitosphenoid $\left(o . s_{0}\right)$ is seen helping to wall in the orbital region; its stem is ossified, and near the hind margin of the bony trict the small optic foramen (II.) can be seen. Above the bone the stem broadens suddenly into an axe-blade of cartilage, which reaches to the top of the skull in front, and also to the top of the side wall, further back.

Then from the hind margin of the stem to the middle of the auditory capsule there is an elegant archway of cartilage nearly equal to the orbitosphenoidal stem in width. Over the junction of this arched band with the auditory capsule the cartilage -supra-auditory (s.a.c.) - more than equals the great blade of the orbitosphenoid in size. In reality it is twice as large, but the hinder two-fifths of this large crescentic crest is ossified as the supraoccipital $(s, o$.$) . The roughly oval space below the orbito-$ sphenoidal archway is filled up, in its antero-inferior third, by a small ruptured and. out-tumed part of the side wall-the alisphenoid (al.s.); the angle between this auriform flap and the cochlea (chl.) is filled by the huge Gasserian ganglion (V.).

The upper two-fifths of the space under the archway is void of cartilage, and is finished by the investing bones-frontal, parietal, and squamosal. There is no presphenoidal bone; the orbitosphenoids will meet to finish that region; the basisphenoid (b.s.) is already present as a short tract in the middle of its orvn region. 'The small lobulate alisphenoid is not ossified, it has two large foramina near its upper part, the $f_{\text {. orcule }}\left(\mathrm{V}^{3}\right.$.) and the $f_{0}$ rotundum $\left(\mathrm{V}^{2}.\right)$. The auditory capsule is relatively very large and extremely oblique in position; it stretches from the hind margin of the alisphenoid upwards and backwards to the lower edge of the supra-occipital. The large archway for the 7 th and 8 th nerves (VII., VIIT.) - the meatus internus - is very near the great orbitosphenoidal archway, where it becomes supra-auditory. 'I'he pupiform cochlea (chl.) lies in a clearly-margined space, right and left of which the basioccipital and basisphenoidal regions meet. The anterior canal (a.s.c.) has its crom looking backwards as much as upwards; it arches over a consideruble fossa for the flocculus cerebelli ; it is arched over by a very elegant crescentic channel for the lateral sinus, which makes the cartilaginous crest very thin at that part. The gap (foramen lacerum posterius) for the 9 th and 10 th nerves (IX., X.) is large, and the small hypoglossal formen (XII.) is seen close behind it in the occipital arch. Above that hole the exoccipital bony centre $\left.\left(e_{0} .\right)_{0}\right)$ is seen to occupy about a third of the side of the arch, between the supra- and basioccipital centres $(s .0 ., b .0$.$) ; the latter is a large$ lozenge-shaped tract.

Various investing bones are seen in situ, namely, the nasal, frontal, parietal, interMocCCLXXxv. 
parietal, squamosal, part of premaxillary, maxillary, palatine, and vomer (Plate 25, fig. $\left.1, n_{0}, f_{*}, p_{0}, i_{0} p_{*}, s q ., p_{*} x_{*}, m_{*}, p_{*}, v_{0}\right)$.

\section{Ninth Starge.-Dissections of the stull of young Noles, 3 or 4 days old; $1 \frac{3}{4}$ and $1 \frac{4}{5}$ inch long.}

Dissections of the skull of the larger of these young ( $1 \frac{4}{5}$ inch long) serve to interpret the adult skull as well as any of the stages.

'The form of the skull is wedge-shaped (Plate 26), the widest, part being very near the end, and the whole skull structure narrowing forwards to the growing snout. Seen from above (Plate 26, fig. 1), the normal investing bones are shown to increase in size from before backwards, very remarkably. The oblong nasals ( $n_{0}$ ) are of considerable width, but they are not so long as the uncovered snout in front of them; they are flanked by the premaxillaries and maxillaries $\left(m x_{0}, p x_{0}\right)$. The small convex frontals $(f$.$) added to these six bones of the face do not cover so large a surface as the$ two parietals $\left(p_{.}\right)$; which, togrether, form half a large ellipse.

A considerable fontanelle (fo.) still exists along and across the skull in the frontal, coronal, sagittal, and lambdoidal regious; the last of these is the largest space, but it is partly filled up, behind, by a small semi-amnulus of bone-the interparietal (i.p.). Looked at from the side (Plate 26, fig. 3), other splint-bones come into view. In this view the premaxillary $\left(p x_{0}\right)$ is seen to have considerable facial tract, interdigitating with the maxillary (mx.) and reaching up to the nasal (n.). The maxillary is notched by the frontal $\left(f_{.}\right)$and has the small heart-shaped lachrymal $(l$. ) set into its orbital edge, where, also, the canal (l.c.) is seen just on the outer margin of the orbit. The canal for the 2nd branch of the trigeminal nerve $\left(V^{2}\right)$ is not finished, and behind and below the groove, first the jugal $(j$.$) is seen as a small style, followed by the styloid jugal process$ of the small, oblique, multilobate squamosal $(s q$.$) . That bone is very peculiar in this$ small wedge-shaped skull, which is bent downwards, behind, at a considerable angle; nearly all the hinder half of the skull is unprotected by superficial bones, and the squamosal, thereby, forms a small adherent scale on its antero-inferior surface. Scarcely reaching the lower edge of the parietal in front, it recedes, downwards, from that bone, leaving a large triangle of the endocranium bare; it is marked off into two regions, one in front and above, narrow and forked, and the other behind and below, wide and semi-ovate.

The broad upper tract in front of the proper squamous part has a sharp point, the jugal process, which overlies the jugul bone $(j$.$) ; under this fore part we see the$ glenoid cavity (gl.c.). The lower and hinder lobe reaches by its rounded end nearly to the stylomastoid formmen (VII.) and quite to the ampulla of the anterior and horizontal canals of the ear (a.s.c., h.s.c.). 'The lower edge, rising forwards, forms the eave of the tegmen tympani; under it is seen another superficial bone, the annulus tympanicus ( $\left(u_{0} t y_{0}\right)$, better seen from below (fig. 2). The frontal $(f \cdot)$, half the size of 
the parietal $\left(p_{0}\right)$, shows the foramen for the ophthalmic nerve $\left(V^{1}\right)$ on its lower margin; its orbital plate leaves much of the endocranium (o.s.) naked; it shows no signs of distinctness from the roof-plate of the bone, such as is seen in the Hedgehog.

The parietal is a fine shell of bone, and is the largest in the skull. The frontal and parietal clamp each other mutually in the postorbital region, but the latter imbricates itself on the frontal in the coronoid region; from the top of that suture to the top of the lambdoidal, the convex dorsal outline of the bone forms a large and accurate arc.

The compound superficial mandible $(d$.$) is almost perfect, but the coronoid,$ condyloid, and angular processes $\left(c_{\cdot} p_{.}, c c_{\cdot} p_{*}, a g \cdot p_{.}\right)$are still cartilaginous; they are rounded and sub-equal.

In the lower view (Plate 26, fig. 2) the surface is only invested with superficial bones in the narrow palatine region; the occipital, and most of the sphenoidal, regions are left bare.

Each premaxillary, carrying three teeth, is well developed, but the palatine processes ( $p \cdot p x_{0}$ ) are largely hidden by those of the maxillaries ( $m x_{0}$; see fig. 5 ); the antero-lateral vomers, also, are not seen, they have a very temporary and doubtful existence independent of these processes of the premaxillaries. The vomer (v.), also, is only partly seen, but is really very large and typical (fig. 5, v.), being wide, carinate, pointed in front and forked behind, and has a semidistinct postero-lateral vomer $\left(v^{\prime \prime}\right.$.) attached to the outside of each fork.

The hard palate is well developed, three-fifths of it belongs to the maxillaries ( $m x$. and the rest to the palatines $\left(p a_{0}\right)$, which have their palatal plate very large, perfect, and typical; yet the fore part of the median suture even of these bones is imperfect, and the vomer $(v$.$) is partly exposed; the maxillaries meet each other nowhere, at,$ present. The hinder and upper part of each palatine is at thick lobe of bone turned outwards, behind, and bevelled on its inner face for the pterygoid bone ( $\left.p g_{*}\right)$. A clubshaped cartilage adheres to the inferior surface of this small bone, the pointed end is in front and the clubbed end is turned outwards, behind; this is the pterygoid cartilage (pg.c.), and is a genuine remuant of the endoskeletal upper jaw of a branchiate type. The broad hind skull is seen from this aspect, flanked and supported by the infero-lateral squamosals $\left(s q_{*}\right)$; the annuli $\left(\alpha_{*}, y_{*}\right)$ are seeu as $U$-shaped bones-right and left-with their crura looking outwards and backwards, and their arch almost touching the pretympanic boss of the basisphenoid. These are all the investing bones that I can discover at this stage.

The endocranium may now be described. I shall begin with the palatal (or basal) part first (Plate 26, fig. 5). Looked at, as a whole, this is a very solid cartilaginous structure, here and there undergoing ossification. The snout ( $\left(l_{0} n_{0}\right)$ with its inferior external nostrils $(e . n$.) has a length about a fourth greater than its breadth; it is quite a continuous structure. The snout passes into the proper nasal labyrinth, not only abore and at the sides, but the floor, also, sends backwards a remarkable tonguelike process - the recurrent or JACOBson's cartilage (rc.c.). This tract, right and left, is 
very large in the Mole, and is half the length of the proper labyrintl, reaching backwards almost as far as the inferior turbinals (i.tb.), here largely hidden by the inturned nasal wall (al.sp.).

The tubular part of the recurent cartilage is short; the rest is convex below and ontside, and concave on the other face, where it is in relation to JAcossov's organ. In froint of the terminal point of these processes the labyrinth expands rapidly right and left, and these moieties are then to be seen a pair of swollen cushion-shaped masses, that first bend outwards and then converge towards each other, having only the basal beam between them. Where that beam escapes from the vomer it is the perpendicular ethmoid (p.e.); a little further back it is the presphenoid (p.s.), and has the stem of each ala, or orbitosphenoid (o.s.) ossified; thence, to the top of the skull, these rapidly widening wings are cartilaginous. The posterior sphenoid is a rery remarkable structure; it is ossified in its median or basal part only, at present; the anterior sphenoid does not develop a median piece, but the basal beam receives its bony growth from the ossifying alæ.

The basal region of the posterior sphenoid is at present ossified for about threefifths of its length; this centre $\left(b_{0} s_{0}\right)$ is very broad, and is alate in front; it is not a mere ossified basal beam, for whilst the anterior sphenoid forms its base from its ala, the posterior sends its basal bony centre fir into the proximal part of its wingsright and left. Outside the hinder half of the basisphenoid, where it has narrowed in so as to vccupy but little more than the proper base (trabecular roots arising from parachordals) there, right and left, we see a large rounded boss of cartilage just in front of each cochlea (chl.). This swelling part, or process (lg.), at the junction of the ala with the base, is homologous with the cartilaginous "lingula" scen in the embryos of Crocodiles and Birds (Trans. Zool. Soc., vol. ii., part 9, plate 64; and Phil. Trans., 1869, Plate 82). It becomes ossified very variously in these different types, but its meaning is the same in all. It is the root of an enlargement for the tympanic cavitythe posterior sphenoid becoming pneumatic. Behind these bosses the basal part has an elegant "waist" and then broadens into large "hips," on which the cochlere (chl.) rest.

The alisphenoids (al.s.) are still unossified; they have a very broar proximal part, even beyond the cartilaginous bosses and the alre of the basisphenoidal centre; they expand so as to grow round the pupiform cochlee, and then are so notched behind as to leave a large oval space between their hind margin and the onter part of the auditory capsule (chl.). In front of this lateral fontanelle (or fenestra) each alisphenoid (als.) forms an ear-shaped free lobe, looking inwards and forwards; this lobe is biperforate for the 2 nd and $3 \mathrm{rd}$ branches of the 5 th nerve $\left(\mathrm{V}^{2}, \mathrm{~V}^{3}{ }^{\circ}\right)$.

There is a cartilaginous tract between the new basisphenoidal and basioccipital centres $($ b.s., b.o.) equal in size to each of these bones; the hinder centre $($ b.o.) is peculiarly reptilian, being at present polygonal, and broader than it is long. 'The chundrocranium is lugge in this part of the head; from the waist-like synchondrosis 
the basal region swells out into broad hips which end, behind, in the slightly convex but very large condyles (oc.c.); these are wedge-shaped and have a sulcus across them at their front third, they are almost pointed behind, when they reach nearly to the end of the enormous foramen magnum $(f . m$.$) , the fore part of which is a semicircle,$ whilst the hind part widens out irregularly. The fore margin of each condyle is gently emarginate.

The hinder or opisthotic region of each large auditory capsule is completely confluent with the corresponding side of the occipital arch; the paroccipital region is a mere gentle convexity. The exoccipitals (c.o.) can be seen outside the condyles as narrow tracts of endosteal bone; the supraccipital (s.o.) reaches the top of the foramen magnum.

Outside the front part of the condyle (oc.c.), the condyloid foramen (XII.) is seen, the 9 th and 10th nerves (IX., X.) are seen in the distinct foramen lacerum posterius, and the facial nerve (VII.) is visible in this view, emerging from the f. stylomastoideum, behind the epiliyal (e.hy.). The uppermost part of the hyoid archthe stapes (st.) - is shown, in situ, on the right side of the figure, and the incus and malleus, with a part of Meckel's cartilage $\left(i, m l_{0}, m l_{\text {. }}\right)$ on the other side. The "otic process" or short crus of the incus or quadrate-a secondary retral part of the suspensorium of the mandible in the Ovipara, and which in them often reaches beyond the auditory capsule to join the occipital arch-is here seen to be in front of the semicircular canals. Both the mandibular elements of the ear-chain lie, now, in a large vacuity of the chondrocranium, which is caused by the curious non-development of the alisphenoid at that part. All round the pupiform cochlea (chl.) the line of separation of the capsules and chondrocranium, proper, is perfect; and again, on the outside, the opening into the lateral sinus $\left(l_{.} s_{0}\right)$ marks off the epiotic region from the supraoccipital cartilage; but in front of the sinus-opening, laterally (fig. 3), and along the paroccipital region (fig. 5), the confluence of the two structures has been complete. The fenestra ovalis is filled by the stapes (st.), the fenestra rotunda $\left(f_{0} r_{0}\right)$ is seen on both sides.

In the lateral view (fig. 3), the supraoccipital, supra-auditory, and posterior orbitosphenoidal tracts of cartilage (s.o., s.a.c., o.s.), are seen to be confluent, and the whole hind part of the skull, strongly bent downwards, is composed either of cartilage or of cartilage-bone (endostosis). Over the foramen magnum the supraccipital is large, both high and wide, and the exoccipital (e.o.), is seen to be wider than the lower view would indicate. There is no appearance of bone in the auditory capsule, except over the fiont part of the anterior canal, (a.s.c.), and the sinus-opening; the labyrinthic part of the capsule is still cartilaginous. The oblique oblongo-crescentic tract of bone seen, already, in the sphenotic and pterotic regions, is the first of the two bony periotics formed in the auditory capsule in this type; notwithstanding its growth along the crest of the capsule, and the fact that it does not help to enclose the labyrinth, I consider it to be the "prootic," and the other, formed afterwards, the "opisthotic." 
The tilting of the canal-region of the capsule is well shown in the side view; the fore part of the large anterior canal (a.s.c.) Jeans backwards, under the prootic bone (pr.o.), at a right angle to the squamosal bone; its hinder half, below the sinus-canal is parallel with the outer edge of the occipital roof. The posterior canal (p.s.c.), which joins the anterior, is parallel with the general direction of the occipital condyle, and the horizontal canal (h.s.c.) runs downwards and backwards, from the end of the squamosal to the exit of the facial nerre (VII.).

But for the ossifications of the hind skull, and the continuation of the nasal roof cartilages to the end of the intertrabecular beam-a peculiarly valuable Mammalian diagnostic-the upper view of the skull (fig. 4) might have seemed to belong to a Skate. There is a large membranous fontanelle ( $f_{0}$.), but it is well surrounded by solid hyaline cartilage, and in several places the "tegmen cranii," or cartilaginous roof is well developed.

The large and long nasal labyrinth is practically divisible into three regions, namely, the snout, or alinasal ( $\left.a l_{\circ} n_{0}\right)$; the middle region with the nasal and inferior turbinals, and, like the snout, supplied from the 5 th nerve only $(a l . s p$.$) ; and the true$ olfactory region, containing the upper and middle turbinals - the aliethmoidal region (al.e.). The fluted roof becomes concave near the end, and then terminates abruptly, in an almost transverse line, at the middle of which there is a small projection-the crista galli (cr.g.). The wide, lateral, olfactory regions, with their hill-and-valley markings, reach backwards, right and left, beyond the end of the roof; the oblique postero-internal margin is confluent with the front of the tegmen tympani, a part which is continuous with the orbitosphenoid (o.s.). Its tegminal lobe has a sinuous inner margin, it ends behind, in the narrowish posterior band that runs from the posterior angle of the orbitosphenoid to the supra-auditory tract (o.s'., s.c.c.c); this band is convex on its outer, and concave on its inner, side. From the end of this band the cartilaginous tegmen is almost complete, but the supra-auditory tracts (s.a.c.) do not meet, they are separated at the middle by a large round notch, at the back of which there is already a smallish crescentic interparietal scale (i.p.). These tracts, however, send forward a thinner bilobate lamina, sharply marked off from the hinder main part by a crescentic line, whose convexity is behind; this line, and the thinning-out of the tegmen, is caused by the parietal bone. Behind the lateral band $\left(0 . s^{\prime}\right.$.) the supra-auditory cartilage is ossified, beyond the turning over of the roof, by the prootic (pr.o.). Answering to the great size of the occipital arch, the supraoccipital ( $s .0$.) is already more than a third the width of the widest part of the hind skull, its sides are bilobate, its extent, lengthwise, is from the fontanelle to the foramen magnum.

An upper view of the cranial floor (Plate 26, fig. 6), after the membranous fontanelle has been removed and the orbitosphenoids $\left(0 . s_{0}\right)$, lateral bands $\left(o . s^{\prime}\right.$ ), and the tegmen $\left(s_{*} a_{0} c_{0}, p^{\prime} . o^{\prime}, s_{.} o_{0}\right)$ have been cut down to the top of the rall, shows some things very instructively. The top of the great internasal septum (p.e.) projects backwards, as a small triangular crista galli (cr.g.), and below that ends as an oblique, 
rather thin, somewhat projecting wall-top, right and left of which we see the large cribriform plate $(c r . p$.$) . Each plate is perfect, is circular in outline-as cartilage,$ and is grooved obliquely, inwards and forwards; it is also riddled full of holes for branches of the olfactory nerve. The top of the presphenoid ( . s. $_{\text {. }}$ ) runs into the hind part of the perpendicular ethmoid ( $p . e_{0}$ ) which is broad behind, and has the thick crescentic top of each moiety of the nasal labyrinth pressing against it ; these curious curved lobes, which are thick and bulbous against the median cartilage, and thin externally, contain the hinder folds of the middle turbinal; they are separated from the orbitosphenoids $(o . s$ ) by a narrow chink. These latter tracts are ossified up to the thick middle beam $\left(p_{*} s_{*}\right)$; and the bony deposit is, now, complete for some extent, proximally, and then it merely strengthens the fore edge of the tract up to the anterior chink. At their inner third, and near the hind margin, these bony centres show a small foramen opticum (II.). The hind margin of the orbitosphenoidal stem is first convex, and then concave, and this sinuous line, the front boundary of the sphenoidal fissure $\left(V^{1}\right.$ ) is a good height above, and not behind, the fore edge of the alisphenoid; it crosses over the foramen rotundum ( $\mathrm{V}^{2}$.)

The rest of the alisphenoid $\left(a l . s_{0}\right)$ is seen, away from the eye, behind and below the orbitosphenoid $\left(0 . s_{0}\right)$; the basisphenoid $\left(b_{s} s_{0}\right)$ is, on this upper surface, of less lateral extent than below; it only passes for a small extent beyond its own boundary line.

The synchondrosis is large, and in it is seen the seat of the sella turcica ( $p y$.$) and the$ low transverse postpituitary wall $\left(p_{.} . l_{\text {. }}\right)$. The middle fissure, right and left, between the synchondrosis and the cochlea $\left(c h l_{0}\right)$ is wide; the "helix" projects upwards, but is not so well seen as below; the meatus internus (VII., VIII.) is wide and large. The fore margin of the auditory capsules runs almost transversely across the lower part of the base of the hind skull, and the outer two-thirds of this edge forms the hinder boundary to the great infero-lateral fontanelle. The separateness of the capsules from the chondrocranium, proper, is very perfect, especially on the anterior and inner side; but above, it is more apparent than real, for there the great sinus canal (l.s.) seems to part the crest from the tract containing the semicircular canals. The whole arch of the anterior canal (a.s.c.) shows its convexity here, and under the archway there is the large recess for the "flocculus" ( $H_{r} r$. ). The lower part of the occipital arch binds, sinuously, against the two huge capsules; in this view we see most of the exoccipitals (e.o.) and all the basioccipital (b.o.), the fore edge of which nearly reaches the post-clinoid wall $(p . c l$.$) . The cartilage is thick; it is perforated$ by the 12 th nerve behind the posterior fissure, and somewhat notched by the 9 th and 10 th nerves (IX., X.), in the margin, behind that fissure.

$$
\text { Ninth Stage (continued). - Visceral arches of a Young Mole; } 1 \frac{3}{4} \text { inch long. }
$$

I shall finish my description of the skull at this stage by an account of the inferior arches of a somewhat smaller specimen than the one whose main skull has just been treated of. The front fourth, and the linder half; of the mandible are shown from the 
inner side (Plate 28, fig. 6). Here we see that the deep and the superficial mandibles are both well developed; the basal cartilage (basimandibular, b.mn.) is still large at the symphysis, and the subdistal part of MEckEL's rod $\left(m k_{*}\right)$, although undergoing ossification $\left(m h^{\prime}.\right)$, and hidden partly by the splenial lamina of the dentary $\left(d_{.}\right)$, is still perfect up to its malleal end (ml.). That part $(m l ., m b$.$) is now undergoing endostis,$ answering to the ectostenl plate applied to it; but the incus (i.) and the stapes (st.) are still unossified. The annulus (a.ty.) is growing larger round the membrana tympani $(m . t y$.$) , but the fold of skin that lies outside that membrane is still very$ thick and spongy. The cartilage that pre-forms so much of the permanent mandible is very solid, now; on the articular or condyloid process the glenoidal facet (gl.c.) is figured, like a cap; it was derived from the same primary subcutaneous tract, and has the same morphological meaning, as the slab which is ossified by the dentary bone.

\section{Tenth Sturge.-Ioung Moles; 3 inches long from snout to root of tail.}

When the young are more than one-third longer than in the last instance we get a great advance towards the permanent condition.

In the side view of the skull (Plate 27, fig. 3) the jugal, squamosal, lower jaw, and most of the hyoid arch are left out.

The long, non-segmented, decurved snout $(a l . n$.$) reaches half-way to the badly-$ formed orbit. The valvular nostril $(e, n$.$) is almost terminal, and is scen best in the$ under face. The facial purt of the premaxillary $(p x)$ is half as large as that of the maxillary $(m x$.$) ; at present the canal for the maxillary nerve ( V^{2}$ ) is not finished externally. On the process above it the small crescentic lachrymal $\left(l_{\text {. }}\right)$ rests, and the canal (l.c.) is seen in front of the bone, on the face. The slender nasals ( $n$.) and the small frontals $\left(f_{0}\right)$ are still distinct from each other, and from the facial plates of the bones below them $\left(p_{0}, m x_{0}\right)$. The large parietal $\left(p_{0}\right)$ always keeps distinct from its surroundings: the interparietal (i.p.) is now a broad, transverse plate between the parietal and the supraoccipital (s.o.). The palatine ( $\left.p a_{0}\right)$ and the pterygoid ( $p g$.), with its terminal cartilage (pg.c.) still visible, can be seen below and behind them, the annulus $\left(a . t y_{0}\right)$. Behind the lachrymal $\left(l_{0}\right)$ the thin convex frontal shell $\left(f_{0}\right)$ is turned inwards suddenly in its orbital part. Near the hind comer of the orbital plate the opening for the ophthalmic nerve $\left(V^{1}\right.$ ) is large and oval. Below that bony plate the lateral ethmoidal mass (al.e.), and the cartilaginous top and bony lower part of the orbitosphenoid $\left(o_{s}\right.$ ) can be seen, as also the emerging optic nerve (II.). The alisphenoid, with its two large foramina $\left(V^{2}, V^{3}\right)$, is seen outside and behind the orbitosphenoid; below their foramina the broad basisphenoid (t.6.s.) is exposed. Over the drum of the car $(a . t y)$ we see the large four-sided, infero-lateral fontanelle $\left(f o^{\prime}\right)$, which is hidden in the perfect skull by the squamosal. Behind that membranous space a deep temporal bone is shown; it is large, convex, and has a polygonal outline; this is the prootic $\left(m . o^{\prime}.\right)$, which has rambled away from the labyrinth, to 
ossify the chondrocranial wall. Behind and below that bone, the large labyrinth, in this view, is unossitied, and in the cartilage the semicircular canals can be traced (a.s.c., h.s.c., p.s.c.). The epihyal (c.hy.) is seen descending, with the facial nerve (VII.) emerging behind it; and from the posterior fissure, and from the condyloid formen the 9th, 10th, and 12th nerves are escaping (IX., X., XII.). Parallel with the posterior canal (p.s.c.), and a little behind it, the junction of the opisthotic with the occipital cartilage can be traced, and a little behind that the growing exoccipital bone (e.o.); under it is the condyle (oc.c.). The gentle, general curve is formed by the parietal, interparietal, and supraoccipital bones $\left(p_{.}, i_{. p}, s_{.} . o_{0}\right)$; between the latter and its side bone, the exoccipital (e.o.), there is still much cartilage.

In the lower view of a skull at this stage, with most of the investing bones removed (Plate 27, fig. 2), we see how much advance has been made. The long snout (al.n.), with its infero-lateral nostrils $\left(c_{n} n_{0}\right)$, is followed by the labyrinth, proper, with the peculiar supporting and conjugating investing bones that lie beneath it or between its moieties. The premaxillaries $\left(p \cdot x_{*}\right)$ have very long laminar palatine processes $\left(p \cdot p x_{0}\right)$, (involving the antero-lateral vomers); these support JACOBson's organ and cartilages (j.o., rc.c.), and reach as far back as those tongue-shaped cartilaginous tracts. The vomer $(v$.$) is set between and above the palatine processes of the premaxillaries, and$ its pointed fore end is hidden by them; its keel begins in their angle, and is very short. The body of the bone first narrows and then suddenly widens between the converging floor-plates of the nasal labyrinth $\left(n f_{\circ}\right)$. In the chink right and left of the recurrent cartilage ( r.c.c) the inferior turbinals $(i . t b$.) can be seen; then the gap widens, and the upper and middle turbinal folds, now ossifying, are exposed $\left(u, t b, m_{\text {. }} t b_{\text {. }}\right)$. But where, as in Passerine Birds, the broad hinder part of the vomer connects the right. and left ethmoidal masses, there at each edge there is a small, additional postero-lateral vomer $\left(v^{\prime \prime}.\right)$, and outside it an osseous patch in the cartilaginous floor itself $\left(n_{.} f_{0}\right)$.

The lateral cartilaginous tracts-floor and side-wall-first become constricted, and then expand; becoming, indeed, the upper broad unossified part of the orbitosplienoid (o.s.). But the hind part of each half of the nasal labyrinth is seen to end, in a bulbous form, right and left of the forks of the vomer, above which the end of the perpendicular ethmoid (p.e.) passes into the short presphenoidal region (p.s.), still unossified. The orbitosphenoidal bony centres (o.s.) can only be partially seen from this aspect (see fig. 1), being hidden in front by the end of the nasal floor $\left(n f_{\circ}\right)$, and behind by the alisphenoids ( $\left.a l_{.} s_{0}\right)$.

The posterior sphenoidal regrion is now well ossified; it is exceedingly broad and thick.

Referring to the early chondrocranium (Plate 25, tigs. 2, 3, b.s., al.s.), we see that the basisphenoidal region, just where the parachordals pass into the trabecula under the pituitary body, is greatly dilated, right and left. If two imaginary lines be drawn obliquely backwards and a little outwards from the sides of the presphenoid to the side of the narrow waist in the base, between the cochlea, then we shall get the 
true width of the basal beam. Such a width is kept for the basisphenoidal ossification in the Marsupials, whilst all the part outside that definite bar is ossified by the alisphenoid, which also takes in the whole region that is left bare in the Mole between its alisphenoid and cochlea. Thus, in them, that thickening of the cartilage which is the foundation of the tympanic ala is ossified by the alisphenoid, and the tympanic wing has a large "os bullæe" attached to it, behind and towards the mid-line. Here, as in the Hedgehog, there is no os bullæ, and the dilated pneumatic part of the posterior sphenoid is ossified by the abnormally large median centre $(b . s) .$.

Behind the presphenoidal cartilage (Plate 27, fig. 2, p.s.) the ossified basal beam is seen to be flanked, right and left, by an outgrowth, which grows into a lower plane, ind stretches outwards as far as to the under and inner edge of the alisphenoid (al.s.). 'These suboval masses look inwards in front, and are notched in that part; their inner' margin is swollen and rounded, their outer and harder edge is sinuous. A large air cell is forming on the outer part of the under surface, and the whole mass is spongy.

This very ornithic condition of the dilated and pneumatic basisphenoid is only a modification of the parts quite similar to what I have just described in the Hedgehog, where, however, the bones are more solid, and are devoid of this peculiar spongy growth. Resting on this wide, pneumatic basisphenoid, we see the narrow oblongocrescentic alisphenoids with their large foramina-foramen ovale and formen rotundum $\left(\mathrm{V}^{3}, \mathrm{~V}^{2}\right.$ ) ; the outer front corner of each bone lies under the corresponding orbitosphenoidal cartilage $\left(o . s^{\prime}.\right)$. The rest of the cranium proper, is seen wedged, in between, and expanding behind, the large auditory capsules. The synchondrosis is lessening fast, and the rest of the parachordal region is occupied by the very Reptilian basioccipital (b.o.). This relatively large plate is polygonal, has a notched fore edge, a coneave hind margin, and roughly-sinuous sides; it is concave, right and left of the mid-line. Behind it we see the huge, flattish condyles (oc.c.), which are reniform, having a large notch on their inner edge; outside these we see the creeping ossification of the exoccipitals $(e .0$.$) , and outside these a very low and narrow paroccipital$ tract ( $p . o c$.). The perforating foramen condyloideum (XII.), and the hinder foramen lacerum (IX., X.) in front of, the occipital arch, are here seen.

The deeply notched antero-lateral margin of the great ear-capsule is bounded externally by the rambling bony growth of the prootic $\left(p r . o^{\prime}.\right)$. The inner edge of that rounded notch, and the rest of the opisthotic region behind it, and behind the cochlea (chl.) is still unossified, and shows in this aspect the horizontal and posterior eanals (h.s.c., p.s.c.); shining through its semitransparent sulstance. The cochlea and the contiguous part of the vestibule (chl.) are well ossified; the fenestra are at right angles to the general basal plane, and are not well seen in this view. From the outer

\footnotetext{
* In this remarkable pneumaticity of the basal and sub-basal parts of the skull, in relation to the tympanic arr-cavity, the fundamental structure is quite similar in the Crocodile, Bird, Marsupial, aud Inscetivore: the after-modification gives the diagnostic, in each case.
} 
edge of this opisthotic centre the bony matter has run forwards, and a little ontwards, to the front of the cartilage, inside the antero-lateral notch.

An upper view of this dissected skull-peeled of most of its investing bones (Plate 27, fig. 1) shows the continuity of the elongated nasal labyrinth with the large orbitosphenoidal wing (o.s.). The long unjointed double nasal tube is but little enlarged, although sinuous, up to the proper olfactory region (al.e.); there, in the swollen part, the marks of the turbinal folds are seen outside. The fore brain and large olfactory lobes overlie the hinder part of the labyrinth, and then the roof ends abruptly, a long way in front of the end of the floor; there we see the large cribriform plate (cr.p.) between the roof and floor, in two hollows, greatly perforated, and separated by the perpendicular ethmoid (p.e.), which gives off a short cartilaginous crista galli (cr.g.), above. The partial ossification of the turbinals, within, is shown in the lower view (fig. 2); in this figure the cribriform plate and mesethmoid (cr.p., pr.e.) have a small centre, in the middle. Behind, the ethmoidal wall thickens, and right and left of it the end of the capsules is swollen in front of the orbitosphenoidal bony centres. These two bony tracts (o.s.) are subareuate, narrow at their origin, and broader above; where the cartilage enlarges suddenly, there they end near their hind margin; half-way outwards they are perforated by the small optic nerve(II.). The short and narrowish presphenoidal tract $\left(p_{0} \varepsilon_{0}\right)$ is not ossified by them at present. Behind these parts the basisphenoid (b.s.) is altogether abnormal, as compared with that of a Marsupial; it reaches nearly as far outwards as the orbitosphenoids, and has the small ear-shaped, biperforate alisphenoids ( $a l . s_{.}$) placed on its edges.

From side to side the basisphenoid is marked oft into three nearly equal regions; the two outer of these have a rounded hind margin; behind the fossa marking them off from the middle the cochlew $(c h l$.) wedge in. Between the cochlere and the alisphenoids there is a membranous space; and between the basisphenoid and the basioccipital (b.o.) there is a considerable tract of cartilage; here, at its narrowest, part, the basis cranii is very broad. Right and left the great misplaced prootic $\left(2 r^{\prime} o^{\prime}.\right)$ is as well seen as in the lower view; it has a vertical position, for the cartilage further back turns inwards at its inner edge ; the opisthotic bony centre has crept ontwards from the well ossified cochlea (chl.); its elegant coils are seen in this view, and behind them the archway and recesses for the 7 th and 8 th nerves (meatus internus, VII., VIII.). Backwards, and a little outwards from that passage, the huge anterior canal (a.s.c.) is seen, and has its walls bony, but the recess for the flocculus $(f l . r)$ ) and the cartilage round and behind the great canal, are still unossified. In this view the basioccipital (b.o.) appears still broader and more reptilian than on the lower aspect; its fore part is still notched, where the bony cephalostyle was formed by the ossification of the cranial notochord. Right and left of the notched hind margin of the bone we see a large tract of cartilage separating the basal from the lateral bones--the exoccipitals $\left(c_{.0}.\right)$; the supraoccipital (s.o.), and the surrounding cartilage, has been cut away to expose the cranial floor. 


\section{Tenth Stage (continued). - The visceral arches.}

Notwithstanding the more specialised nature of the Mole, as compared with the Hedgehog, some things in it are much more like what is seen in the Metatheria than anything to be found in that larger and more normal Insectivore.

In these large "nestlings" the three lobes of the lower jaw (Plate 28, fig. 7, c.p., $c$ c.p., ag.p.) are still largely composed of cartilage. Meckel's cartilage ( $\left.m l_{*}\right)$ is to a great extent lost in the general dentary ossitication $(d$.$) , but it is seen behind, wedged$ in between the condyloid and angular processes of the jaw. The ossicula are now largely ossified and the bony deposits forming the malleus ( $m l_{\text {. }}$ ) are exceedingly instructive and very Metatherian. Besides the ordinary ectosteal tract, which has set up endostosis in the head of the malleus, there is an almost distinct splint under the neck of the malleus, which is the true counterpart of the os angulare of the Ovipara. The manubrium ( $m b$.) is mainly cartilaginous, but there is a fusiform epiphysis in the middle of this process; this is very noteworthy; for in Lepidostcons and in Amia the "articulare" is ossified by two centres; and this is manifestly the additional centre cropping up once more.*

The three most projecting parts of the incus ( $i_{0}$ ) are still unossified; the short crus (s.c.i.) is very small. The stapes (st.) is merely indicated in outline; so also is the annulus; the epihyal (e.hy.) is confluent with the auditory capsule (au.) where the ficial nerve (VII.) emerges. A short ligament connects that second segment of the hyoid arch with the top of the subdivided ceratohyal $\left(c . h y_{0}\right)$; this is a gently curved rod, occupied by a shaft of bone for half its extent. 'The next segment (c.hy'.) is only two thirds the length of the upper, and is one-third thicker" it is just beginning to ossify. So also is the still shorter and stonter hypohyal (h.hy.) which fits obliquely on to the basi- and thyrohyals (b.h.br., t.hy.); these rods are ossifying, but the distal half of the paired rods is soft. The annulus (Plate 25, fig. 13, a.ty.) and the imperfect cartilaginous tuhe of the meatus (m.c.) show the normal type of the outer ear, with arrest of the concha; it has four rudimentary rings.

\section{Eleventh Stage- Toung Mole; two-thirds grown.}

The side view of the skull at this stage (Plate 27, fig. 4) is very similar to that of the last (fig. 3). I have, however, figured the squamosal, in situ, in this; the malar or jugal, is left out, here, for the better display of the fundus of the imperfect orbit. 'The length of the figures is nearly the same, those of the larger specimen being somewhat larger, although they are magnified much less.

The bones are much stronger and more polished, and the cartilage is rapidly disappearing; the snont $\left(a l_{0} n_{0}\right)$ is relatively slenderer. The irabrication of the

* In the Green 'Turtle there are two articular centres: one the endosteal, dereloped late, and the other the ectosteal, developed enry, and just like the other-bony plates around it; these, however, are merely the two elements of one ossification. 
investing bones is now seen to be that of the one behind on the one before it; had they taken up more of the cutis verce they would have differed but little from the bony scutes on a fish's hend. Below, there is now a more evident angle where the premaxillary uneets the maxillary; in this latter bone the infroorbital formen $\left(\mathrm{V}^{2}\right)$ is still unfinished. It is covered over, in some degree, in the perfect skull, by the jugal (figs. $5,6, j$.$) . The frontuls (f$ ) have grown down well inside the orbit, but they are singularly free from the usual orbital processes; the upper part there forms a rounded eave over the retiring orbital plate. That plate has a very large oval foramen for the ophthalmic nerve $\left(\mathrm{V}^{\mathrm{l}}\right.$ ), and a lesser hole behind that in the extreme part. The gap in the wall of the skull seen in the last $\left(f i g .3, f^{\prime}\right.$.) is here shown as filled up by the small oblique squamosal (s\%), the thin, sinuous upper edge of which overlaps the antero-inferior part of the large parietal (see also fig. 3). There are three sharp processes growing from the slanting lower edge of the squamosal. 'I'he first is its own front corner, overlapping botl parietal and frontal; the next is the small, sharp jugal process; and the third is the postglenoid process. The hinder swollen part over the auditory region is bilobate; the temporal fossa is extremely small and ill-defined Over the roof, behind, the interparietal (i.p.) has grown so as to be, relatively, the largest, or nearly so, to be seen in the whole class; anteroposteriorly, it is only one-third the extent of the parietal, but seen cross-wise, or at the side, its extent is very large; it nearly reaches dorvm to the exaccipital (e.o.).

Below, the palatine $\left(p a_{0}\right)$ is seen a little, and the pterygoid ( $\left.p g_{0}\right)$ better; this has still a nodule of cartilage on its hook ( $p$ g.c.). Under the very perfect system of investing bones-which serve the purposes of "ashlar" in a building-the almost completely ossified endocranium is partly seen. The orbitosphenoid (o.s.) does not show its optic foramen well in this view (see fig. 8, o.s., II.), but the splhenoidal fissure, and the foramen rotundum and foramen ovale in the alisphenoid (al.s., $V^{2}, V^{3}$.) are displayed in this aspect. Under the alisphenoid, the broad, cellular. tympanic wing of the basisphenoid (t.b.s.) is quite visible in this side view. A remarkable amount of the very large skeleton of the auditory capsule is seen in this figure. In the somewhat obtuse angle between the parietal and interpirietals $\left(p\right.$. , i.p.) the polygono-ovoidal prootic wing $\left(m \cdot 0^{\prime}.\right)$ is almost entirely displayed; it is very convex, and, if shorter, is much broader than the squamosal, for which it might be taken in a cursory view of the adult skull. The opening from the lateral sinus is behind the prootic wall-piece; under that bone there is a large tongue-shaped epiotic tract (ep.), it is not a distinct centre, but merely a lobe of the opisthotic (op.). * Under it there is a foramen, above the large passage for the vagus and glassopharyngeal

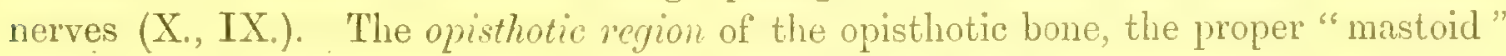
tract, is an irregular wedge of bone running from the post-temporal part of the squamosal to the exoccipital (e.o.), with its almost suppressed paroccipital ridge; that bone is, like the mastoid region of the opisthotic, an oblique, irregularly-oblong tract.

* There is a deficiency in the lines of reference to these parts in this figure. 
Over it is seen the large, smooth supraoccipital, and below it the flattish condyle (oc.c.).

At the fore part of the mastoid tract the epihyal and facial nerve (c.hy., VII.) are shown in relation, and the 9 th, 10 th and 12 th nerves are figured as they escape from the skull. There is still a considerable tract of cartilage between the supraoccipital, exoccipital, prootic, and opisthotic bones.

The upper view of this rapidly growing skull is shown in fig. 6 ; without the long cartilaginous snout ( $a l_{0} n$.) this view would have been very imperfect. That finishes this long, flattened, boring, wedge-shaped skull. Eight pairs of investing bones, and one single pair-the interparietal-finish the upper and lateral parts of the skull; they are so developed and imbricated as to increase their general breadth up to the auditory region, and then the skull ends in a somewhat irregular semicircle, not perfected by any superficial bone, but by ossification of the walls and roof of the chondrocranium $\left(s .0, p^{\prime} r^{\prime}, o^{\prime}.\right)$.

A lower view (Plate 27, fig. 5), with the tympanics and ossicula removed, shows the great progress in ossification and general development that have taken place, whilst the young Mole has rapidly become twice as heary as it was when only 3 inches long -the last stage. The dentigerous semicircle formed by the premaxillaries $(p x$. $)$ with their long palatine processes $\left(p \cdot p, x\right.$.), largely hidden by the maxillaries $\left(m x_{0}\right)$ is followed by the long sinuous dentary line of the maxillaries; several of the molars are only just cutting the gums with their sharp cusps. The palatine plate formed by the palatine bones ( $\left(\mathrm{m}_{0}\right.$ ) is shorter and wider than that formed by the maxillaries, for the suture between the two pairs of bones is very far forward; the Mole has a very perfect and normal hard palate. 'The openings of JACobson's organs (j.o.) are seen in the anterior palatine foramina, and the posterior foramina are large and wide apart, they are in the line of the laterul suture between the palatines and maxillaries. The palatine plates of the palatines have a beaded edge, and this thick or limbate margin, which turns inwards and backwirds to form the wall of the nasopalatine canal behind the hard palate, is, altogether, bracket-shaped. The palatines go twice as far back on their palatine plate, and are very solid and spongy where they embrace and support the base of the skull. On to them, the pterygoids ( $p g$.$) , are articulated, and they also$ have a pedate expansion above, supporting the skull; their hamular process is not quite ossified (pg.c.). The presphenoid (p.s.) is a long beam of bone, formed by fusion of the orbitosphenoids, and separated by a considerable synchondrosial tract from the basisphenoid (b.s.) ; this latter is a truly marvellous bony centre, and as far as my experience goes is, in this creature, relatively wider than in any otber type. In this aspect, the basisphenoid runs across the whole basal region up to the floor of the orbits, so that very little of the top of the skull can be seen right and left.

The fore edge is narrower than the hind margin; both are sinuous, and the outer margin is rounded, and almost semicircular. The anterior third, which is clamped by the cranial plates of the pterygoids, has its floor perfect, but the bone is burrowed, 
above the floor, there being a continuation there of the great pneunutic recess seen, right and left, in the hinder two-thirds of the bone. Euch recess occupies about halt the large hinder tract; the inner half is convex, and meets its fellow at the mid-line in a deep fissure or sulcus.

All this wide, spongy, pneumatic structure is merely a peculiar Talpine modification of the normal skull of an Insectivore, such as that of the Hedgehog, or the Tenrec.

The slender zygomatic arch $\left(j_{0}\right)$ is finished behind by the squamosal $\left(s q_{*}\right)$ with its glenoid facet $(g l, c$.$) ; this is close outside the tympanic recess of the basisphenoid. A$ character is seen here which is only partly shown on the side view (fig. 4), namely, that the squamosal after giving off its zygormatic process, and forming the sinuous plate for the glenoid cartilage, grows round and under the skull, strongly clamping and binding all the parts by a large squarish postglenoid plate, which grows obliquely inwards and a little backwards, and is notched on its imer edge. The two plates, right and left, hold the large auditory capsules as in a widely opened vice.

A considerable tract of cartiluge separates the basioccipital (b.o.) from the car-capsules; it runs backwards, and a little outwards ; it is almost straight, and passes nearly into the cartilage of the condyle. Behind the postglenoid region of the squamosal, and to some degree clamped by it, is the large prootic plate $\left(p 0_{0} 0_{0}^{\prime}\right)$. In the angle between the squamosal and prootic plate $\left(s q ., p r .0^{\prime}\right)$ there is an oblong tract of bone, subdistinct; this is the epiotic $\left.(e)_{0}\right)$; it is bounded within by the hinder part of the main opisthotic tract $(o p$.$) , which has left a considerable tract unossified behind, up to$ the small fusiform cartilaginous paroccipital ridge ( $\rho_{0} .0 c_{0}$ ). In front of that cartilage, up to the basisphenoid, there is a large irregular tract of the opisthotic visible below; this is beset with cranial landmarks. Close inside the front lobe of the under part of the squamosal the ceratohyal $(c . h y$ ) is seen, tied to the epihyal snag; behind this the facial nerve (VII.) emerges through the stylomastoid foramen. Inside the nerve, the hole for the internal carotid may be seen, and behind that, at a good distance, the formen lacerum posterius for the 9 th and 10 th nerves (IX., X.) is enclosed, nearly, by the opisthotic; behind it, over the border, is the hole for the 12 th nerve (XII.). There is also a crescentic hole under the notch of the squamosal. The use of this I did not discover.

The foramen magnum $(f . m$.$) has a neatly egg-shaped outline; in front of it the huge$ basioccipital (b.0.) has a subpentagonal shape. The fore edge is very extensive and gently sinuous, for this plate is notched and grooved in front, and this fore edge is thick and spongy, answering to the hind part of the basisphenoid. Then, behind each thickening, there is a round concavity, from which the bone becomes generally gently convex up to the semielliptical notch at the fore part of the foramen magnum. A large lozenge-shaped tract of cartilage, pierced on its outside by the hypoglossal nerve (XII.), is seen between each postero-lateral edge of the basioccipital and the condyles; these (oc.c.) rise but little in fiont, and are grooved, crosswise, at their fore third, and then on their hinder, narrower part, are more perfectly defined. Wedging 
in between the small cartilaginous paroceipital and the large condyle, the exoccipital $\left(e_{.0}\right)$ is seen, and behind the foramen magnum the crescentic lower edge of the supraoccipital (s.o.).

In the end view (Plate 27, fig. 7) some of these things are better seen; supplementing the large, smooth parietals (p.), the great transverse interparietal (i.p., see also fig. 6) stretches across the top of the occiput from one prootic plate ( $\left.m^{\prime} .0^{\prime}.\right)$ to the other. Under and behind that superficial plate the true supraoccipital is seen as a large and almost semicircular ossification of the endocranium; the lower transverse edge of the plate is notched over the formen magnum, and rises, and then falls, outside that archway. A little cartilage exists at its outer edge, between it and the prootic plate $\left(m^{\prime} . o^{\prime}\right)$, and this cartilage forms a short arched tract over each exoccipital, and then fills in a square space over the notched hind part of the mastoid bone $(o p$ ). . The hindermost projecting part of each squamosal (sq.) can be seen, right and left, away from the eye. Around the formen magnum the crescented exoccipitals, capped, behind, by the curious condyles-oval above, groored, and then transversely lobate; outside the exoccipitals, the small fusiform unossified paroccipital ridges (po.c.) are flanked by the mastoid bone $(o p$ ). .

A very instructive preparation was made of the inner face of the skull-floor (Plate 27, fig. 8); the nasal labyrinth was largely cut away. The top of the upper wall (al.e.) ends in the short, cartilaginous crista galli (cr.g.); behind this, the top of the ethmoidal partition wall (p.e.) and the contiguous part of the cribriform plate $(c r . p)$ are ossified as a trowel-shaped centre, with the handle below. The rest of this large, exquisite, double sieve, with its thickened rim, is still unossified. Behind, this structure is embraced by the gently concave front margin of the orbitosphenoids (os.), which now meet in the middle of the skull-floor and there lie upon the presphenoid, which they have ossified (see fig. 5).

They are very narrow plinks, bent backwards behind, forwards in front, and with a sinuous hind edge, the middle part being the narrowest. The small, oblique optic foramen (II.) begins at the inner third, and is behind the middle of the bony tract.

The posterior sphenoid is as remarkable from this view as from below ( $6 \mathrm{~g}$. 5). The alisphenoids $\left(a l_{.} s_{0}\right)$, with their two foramina $\left(\mathrm{V}^{2}, \mathrm{~V}^{3}\right.$ ), are about twice the size of the orbitosphenoids, they project beyond their basal plate in front as much as they fall short behind; there they are free and pointed; in front, they are rounded and turn under to the base of the skull; they are wide apart from the orbitosphenoid, and the sphenoidal fissure ( $V^{1}$.) between the two plates is large. The huge basisphenoid (b.s.) has a concave fore edge, and convex sides, and then ends behind in four large sharp cusps. The two submesial cusps reach much further backwards than the outer; between these pointed projections, externally, the whole bone is toothed and splintery, and is attached to the rough toothed fore edge of the cochlear region of the earcapsule by fibrous tissue.

In fiont of the deep lateral notch, the bone, right and left, is gently concave, as 
also is the middle part in front of the synchondrosis, but the sella tureica is badly defined.

The prootic plates $\left(p . v^{\prime}\right.$.) have been cut through; betreen them and the proper bony capsule there is a considerable tract of cartilage. The cochlea (chl.) is much masked by bony growths; the meatus internus (VIII.) is large and very near the inner edge; there is a special foramen for the 7 th (VII.).

The remarkable archway over the deep recess for the "flocculus" is ossified; the enlargement in front, on the outside, is due to the ampulla of the anterior canal (a.s.c.), and its arch is over the archway; the common sinus for the anterior and posterior canals runs, inside the thickening of this curious internal "porch," downwards and forwards, on the inner side; the appearance of an ampulla below, and in front, where it ends, is deceptive, that is due to a swelling of the vestibule (ib.).

The horizontal canal (h.s.c.) is not well seen from this aspect, its ampulla is only visible under that of the anterior canal. The posterior canal $\left(p_{0} s_{0} c_{0}\right)$ is seen in the postero-internal face of the porch where it meets the anterior canal, and where the two pass into the common sinus on the inner side. The ampulia of the posterior canal is formed after the arch has crossed and passed under that of the horizontal canal, just where the latter is entering the vestibule; these parts lie at the bottom of the bony labyrinth, just outside the passage for the 9 th and 10 th nerves (IX., X.). The basal, and part of the lateral, regions of the occipital arch (b.o., c.o.), are seen, also; in this figure, the hypoglossal nerve (XII.) is on the edge of the exoccipital ossification on this inner side; outside, or below (fig. 5), it is still surrounded by cartilage.

\section{Inferior arches of the young Mole in the Eleventh Stage.}

The malleus in this eleventh stage is thoroughly Marsupial in character。*

Seen from the inside (Plate 28, fig. 9) the head projects as a semiovil mass, having, behind, the saddle-shaped condyloid cartilage. Under the head there is a pneumatic recess bordered by a sloping, sinuous edge of bone, front which the manubrium ( $m b$.) is continued. That process is rather a round hook than an angular part, and the whole hind margin is sinuous, without showing on this face any very definite posterior process (ag.p.). The neck of the malleus is broad and irregular; it is followed by a rough, rounded, perforated lobe or crest. Then the bone dips and runs forwards as a straight "processus gracilis" ( $p \cdot g r$.$) . But this is only a part of the foregrorths of$ the malleus, for beneath the upper lobe there is a linceolate, almost distinct tract (seen also in fig. 7, tenth stage), and in front of this, ruming away from the line of MeckeL's cartilage (see fig. 7, mk), there is an elegant pretymponic sickle of bone, enlarged and split at its end.

* My own fignres of the Marsupial skull will show what I mean by this assertion; meantime the

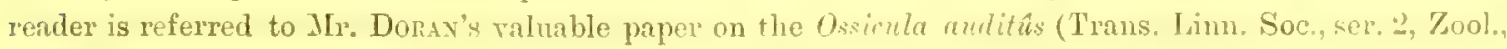
vol. i., plate 6t, tigs. 15-34).

MDCCCLXXYi. 
On the outer fuce (fig. 10) that process is well marked off, as if it had formed separately, and then became anchylosed to the straight process; here, also, the upper lobe has a rely distinct form and outline, behind, whilst the lower lanceolate tract is less distinct.

On this face we miss the pneumatic recess, but get a view of the remnant of the cartilage that separates the epiphysis in the manubrium (fig. 7, mb.) from the main part of the bone. It is evident that, about the time of weaning the young Mole is reveloping, in a rough, irregular, and abortive manner, the well-known "angulare" and "supra-angulire" of the Oviparous tribes, in addition to the "articulare externum," and the two endosteal articular tracts that are found in Holostean Ganoid Fishes. We shall soon see what becomes of all this effort to restore the old compound mamlihle.

The hyoul arch (Phite 28, fig. 8), when detached from its two upper elements (the epihyal and stapes), shows a considerable advance upon the last stage (fig. 7), all the hony shafts are rapidly developing along the cartilaginous rods; the articulations, also, are very distinct.

\section{Twelfth Stage.-Young Mole; three-fourths grown.}

Among my materials-gathered during the last forty years or more-I found the malleus of a somewhat older Mole than the last; it is of great importance, for it shows (Plate 25, fig. 4, inner view; fig. 5, outer view) the softening down, by absorption, of much that was rugged and irregular in the last stage. The processus gracilis is still very large, and is cochlente proximally; the crest and the pretympanic sickle are gone. But the cartilage separating the manubrial centre $(m b$.) from the main bone, on the outer side, is still evident. Of the same age also are the other ossicles here figured, the incus (Plate 25, figs. 6,7) and the stapes (Plate 28, fig. 11), and also the imnulus (Plate 25, fig. 11).

Both the orbicular facet for the stapes (l.c.i.) and the short crus of the incus (s.c.i.) are feebly developed and look towards the Monotrematous condition; the whole inner fice is open to the tympanic cavity.

The stapes (Plate 28, fig. 11) cannot be detached in this stage, as in the adults of some other Insectivores, e.g., Myogale moschata and M. pyrenaica (see Dorss, op. cit., p. 435).

This is a very remarkable modification (Plate 28, fig. 11, st.), and its transitoriness in this type is also noteworthy; the Mole gets beyond Myogale in this respect. This little bone is kept in its place by the ossification of the onter sheath of the stapedial artery (st.a.); a sheath similar to that which protects the outer part of the internal carotid in the Bird. There, the bony arterial sheath traverses the light diploë of the basis cranii between the basitemporal plate and the proper spheno-occipital skull floor. I am under the impression that this sheath is formed just as the stapedial artery becomes 
obliterated; then the bony sheath, itself, soon afterwards, is absorbed; these things are enigmas to us at present.

The annulus tympanicus is shown in the young Mole, three inches long, from tho side (Plate 27, fig. 3, $\alpha . t y$.$) ; and the curious flat, imperfect ring is figured in several of$ the earlier stages (Plates 26 and 28). In the adult it is wholly blended with the skull floor, but during the first summer it remains distinct; that of the right side, in this stage, is shown fiom its imuer face (Plate 25, fig. 11); it looks like a well-made amnulus that has been crushed into a flat coiled band of bone. The outer opening is roughly pyriform, quite pointed on the inner or lower side, and broad above, and having its margins dentated. 'The part nearest the opening, outside, is very thin; then the bone thickens up to the margin; on the inner face the edge is seen to be strongly ribbed by bony deposits. The anterior crus is rery large, and grows along the inside as a large rostral plate, looking backwards, and nearly meeting the sharp, inturned, hinder crus. Thus the great inner opening, which is thrice the size of the outer, is also transverse to it; it is a nearly finished oval, with the long diameter at right angles with that of the onter opening. 'The great rostral process of the front crus is grooved on the inside, outside its arched edge, for the still large processes gracilis of the malleus (Plate 25, figs. 4, 5, y.yr\%).

\section{Thirteentin Stage.-Skull of the adult Mole.}

I could have wished to have given figures fully illustrating the structure of the skull in the adult Mole, but considerations of space liare deterred me; I have, however, figured the ossicula auditûs (Plate 25, figs. 8-10), and the snout, in section (Plate 25, fig. 14). This latter part has been affected by the generally intense ossifi. cation of the skull, and not only the proper septum nasi (s.n.) has been well assified on from the perpendicular ethmoid, but that fore-growth of the septum (s.u') which divides the long alinusal region $\left(a l . u_{0}\right)$, in front of the premaxillaries, has acquired an endosteal tract, ahnost to its front end; the telcology of this structure is evident enough, but it comes in as a part of the general osseous modification of this type, which is everywhere intense.

The prootic plate, and the hinder or mastoid region of the auditory capsule, have sutures separating them from the surrounding bones. The parietals, also, are always free; they form a squamous suture with the frontals, which they overlap up to the middle of the interorbital region, but the true squamous suture, between them and the squamosals, is very slight; they keep their own mutual saggital suture perfect. With these exceptions the skull of a Mole has its bones as completely anchylosed together as in any Bird; and the structure of the base of the skull is as light and pneumatic as anything seen in any Passerine, or highest, kind of Bird. During the first summer there is but little promise of the exquisite polish of the bones nor of the excavated condition. they will soon attain to. Everything becones smoothed down, 
outside; the limmlar processes of the pterrgoids are small but perfect, and behind and outside them the whole of the wide hind skull is flattened, and bevellen, and polished to a marvellous degree. On the inside, also, the surface is exquisitely smooth, and the bone delicately cellular; the cochlew have their bony walls polished and thinned down so as to show the coils as if through a transparent medium, and the great porch for the "flocculus cerebelli" is the most remarkable piece of miniature architecture I am acquainted with. The bony tubes containing the semicircular canals strengthen the porch at its margin, and the intervening bone roofing it is extremely thin. The base of the skull now shows a shallow but distinct sella turcica, and behind it the postpituitary wall is well defined, although rather low. 'The cribriform plate is very large and abundantly perforated.

But the basal and basilateral regions of the skull, in its floor, although highly polished, is marvellously broken up into hills and holes, because of the extreme delicacy of the upper table of the bone; the supratympanic bony shell, the cochlex, the floccular porches, the pituitary cup, and postclinoid wall,-to say nothing of the foramina and fissures for nerves, vessels, and the like,-make this little skull, in its inside, a most admirable object for study and contemplation.

All this is true of the outside or lower surface, but the large flattened tympanic annulus, completing the unlipped bonv meatus externus, and thoroughly anchylosed to the surrounding bones; and the extensive air-galleries that are excavated inside the huge basisphenoid, and the small squamosals, may be mentioned.

The ossicula auditus are figured and will now be described, as they show the last specialisation of the inferior arches of the face.

The malleus (Plate 25, fig. 8, inner, and fig. 9, outer view) shows a very small processus gracilis $\left(p \cdot g r^{\circ}\right)$ and a small manubrium $(m b$.$) , whose axis forms one continuous curve$ with the body of the bone. In front, under the head, but most on the inside, a considerable pneumatic recess is seen, and outside the obtuse angle (p.ag.) of the manubrium, there is a loop-shaped ridge where the remnant of the last tract of cartilage was seen. In this malleus almost the whole of the attempted nandibular structures has been absorbed; and the Metatherian type, at its lowest grade, has been exchanged for the typical Eutheroun form.

The incus has lost much of its typical Mammalian character* (see Plate 28) ; its short crus (s.c.i.) has dwindled to a fine transverse style, the incurvation of the lower part of the long crus (l.c.i.) is almost lost, and the orbicular facet is a mere oblong condyloid tract.

Thus this little representative of the quadratum has lost, not only much of the "otic process" (= short crus), but also that special Mammalian character, the orbicular plate on an inturned narrow neck, has greatly suffered degradation. Now this relapse is

* I here include both the Marsupial and Placental Mammals, for in the former the incus has its highest development; the long crus and the obrieular plate being better developed than in the Eutheria, gencrally. 
in the Prototherian direction; if carried further, and the bone were fluttened out, we should have an incus very similar to that of a Monotreme.

The long crus is hollowed out into a pneumatic boat, its long opening looks forwards and outwards (fig. 9).

The stapes of the adult (Plate 25, fig. 10) is greatly altered from that of the larger young (Plate 28, fig. 11), at the time when it is fastened in the fenestra ovalis by the bony arterial tube.

Then it had narrow sides, and its incudal condyle had a rounder shape; now, that articular face is oblong, and the sides have become inflated, as also the base ; so that the whole bone is a sort of lagena, with an oblong apex and a bulbous base; whilst the flattened sides are perforated, one by a large, and the other by a small, oval fenestra. 'The sides of the base are neatly limbate, the rim being adapted to the edges of the fenestra ovalis. 'That there is nothing in the structure of the skull of the adult Mole that is not in harmony with the life and habits of the creature, I feel certain; but questions of that sort are of less interest than the correspondences seen in this terricolous Mammal with that we are familiar with in Reptiles (Crocodilia) and Birds. Besides the general pneumaticity of the whole hind skull, we have the hollow counterparts of the quadratum, articulare, and columella of those high Sumropsida.

\section{On the slutl of the Common Shrew (Sorex vulgaris).}

There are three native species of the Soricida-Sorex vulgaris, S. pygmous, and Crossopus fodiens. I have worked out the skull in the first of these, comparing it in its adult condition with that of the last, or largest, kind.

My materials yielded me four stages, as follows:--

1st Stage.-Embryos, $\frac{5}{6}$ ripe; $8 \frac{1}{3}$ lines long from snout to root of tail (Plate 16, figs. 10, 11).

2nd Stage.-Ripe embryos; $9 \frac{1}{2}$ lines long.

3rd Stage.-Young from the nest, 10 or 12 days old; $1 \frac{1}{3}$ inch long (Plate 16, fig. 12).

4 th Stage -Adult Shrews.

Besides these I obtained early embryos, with the somatomes weli formed, a little less developed than my earliest embryo of the Mole (Plate 16, fig. 1); these were merely examined externally.

'The First Stage here given was examined in sections, but as these corresponded very literally with those of the younger Mole, already described, they were not figured. In these almost ripe young the general form is such as one might imagine in some early Tertiary types, in which the characters of the Orders of Mammalia now existing had not been developed.

It is a simple pentadactyle form, very similar to my third stage of the Mole (Plate 16, fig. 4), but having smaller fore limbs that are further back from the head. 
Along the amnular folds of the outer skin the but-like hair-pulps are seen cropping up in corresponding rows, as though they had been planted by a farmer's "drill." The eyelids are developed, and closed over the eye-balls ; the concha auris is a kidneyshaped fold of skin, the snout is, relutively, no longer than that of a full-grown Mastift, and shows little promise, as yet, of its future length.

\section{Second. Stage. - Ripe embryos of Sorex vulgaris, $9 \frac{1}{2}$ lines long (about $\frac{3}{4}$ of an inch, or $20 \mathrm{~mm}$.).}

The chondrocranium (Plate 29, fig. 7), is undergoing ossification, but its general form is not altered, and absorption of those parts of the cartilage which do not ossify has scarcely set in; it serves well at this stage for comparison with the skulls of the Mole and the Hedgehog' at a similar stage of development (see Plates 17 and 25). In the Nole the choudrocranium is less massive, relatively, than in the Hedgehog, and in the Shrew less than in the MLole. The Hedgehog is the least modified and most primitive type. The Shrew is the most modified, and that mainly throngh dwarfing, so that some parts are arrested, and others actually suppressed-as if for want of room for them. They may ensily have arisen from one common stock, and the Mole comes in as a connecting link between the well-developed Hedgehog and the scant and stinted form of the Shrew.*

Therefore we may look for signs of that peculiar form of degeneration which arises from dwarfing. The cartilage may be expected to be scanty, and the number of osseous centres lessened.

In this ripe embryo of the Shrew the top of the nasal partition wall (Plate 29, fig. $\left.7, s . n, p^{2} . e_{0}\right)$ reaches half-way back to the front of the suprioccipital $(s .0$.$) ; at its crown$ it is much more than half the height of the skull; at its base, from the front of the snout $(a l . n$.) to the middle of the presphenoid (p.s.), it is twice as long as from that point to the foramen maguun.

The snout, itself, has only half the relative length it will have in ten or twelve days - next stage (Plite 29, figs. 1-4). The septum in front is perforated and circular; then it narrows to half its width in front, and is narrowest in the front part of the true septal region, behind the snout, proper. Thus between the large recurrent "II. JACOBson's cartilages (tc.c.) t the thick intertrabecular base of the whole partition wall (i.tr) is formed into a low arch, and is especially thick where it descends agrin, as it passes backwards towards the presphenoidal region. The thinner, main part of the frartition - septum uasi $\left(s . n_{*}\right)$, and perpendicular ethmoid (p.e.) - is very even, and forms in low triangle, the hinder side of which is the shortest, and is the dividing line between the two perforated (cribriform) plates $(c r \cdot p \cdot)$; that line is a little arched, the longer line in front, towards the snout ( $a l . s p$.$) is first convex, and then concave before$

* 'The pygmy Shrew (Sorex pymmous), is not only the smallest British Mammal; it is as nearly as may be the smallest beast in the whole Class of the Mammalia.

+ For tc.c. read re.e. 
it passes into the gently arched snout $\left(a l_{0}\right)$. The basal cartilage behind the cribriform plate and nisal labyrinth is thick, but from being high and narrow, becomes depressed and broad; thus the middle ethmoidal region passes into the short presphenoidal, and that into the fore part of the basisphenoidal territory (b.s.). 'That region is perforated and partly ossified (see Plate 30, fig. 18, b.s.). Here we meet, again, with the open pituitary space which we found in the Herlgehog (Plate 17, figs. 1, 2, py.), but did not find in the Mole (Plate 25, figs. 2, 3). Behind that passage the bisal tract thins out, becomes gently concave, thickens again, is again ossified, partly, as the basioccipital (b.o.), and then ends, with a narow cirtilaginous selvedge, at the formen magnum. The primary fontanelle is very large, for the band of cartilage connecting the great orbitosphenoidal wing $\left(0 . s^{\prime}\right.$.) with the equally large supra-anditory tract (s.a.c.) is narrow.

The upper orbitosphenoidal expansion is conthent with the nasal wall in tiont; it is sinuous, notched in a rugged manner, above, and its hind margin, both above and below the narrow posterior band, is concave; there is no optic formen through its stem. 'The optic nerve passes through the great sphenoidal fissure, in company with the orbital nerves, as in Marsupials. The skull is unprotected by cartilage for a very large space both above and below the narrow band; for that band, dipping a little, bounds a huge space below of an irregulurly oval shape, with its long diameter-which reaches from the cribriform plate to the meatus auditorius intemus (VII., VIIL.) -two-fiths the length of the whole cranial cavity. Below, this space is partly occupied, in front by the alisphenoid (ul.s.), and behind by the cochlea (chl.). The alisphenoid (see also Plate 30 , fig. $18, a l . s$.$) is a small ear-shaped tract of cartilage, notehed on its hinder$ margin near its upper angle for the 3rd branch of the trigeminal nevve $\left(\mathrm{V}^{3}\right.$.), and lying quite outside the pline of the orbitosphenoid.

Thus the optic, 3rd, th, 1st and and branches of the 5th, and the 6th nerves all pass through the gaping sphenoidal fissure. Some distance behind the proper alisphenoid the basis cranii becomes alate, and that small rounded wing is perforated and has its hinder margin adapted to the apex of the cochlen, on its inner side. The posterior orbitosphenoidal band (o.s') runs upwards and forms a sinuous ribbed edge to the supra-auditory plate (s.a.c.), the high upper margin of which has a convex outline, and passes into the supraoccipital region (s.o.), already ossifying.

That spheno-pterotic tract (s.u.c.) is as broad as the inner face of the huge, geniculate auditory capsule (chl.), its hinder half, and the capsule, form the very perfect semioval margin to the hincler part of the great lateral fontanelle. The archway formed by the upper cartilaginous wall (s.a.c., s.o.) for the setting of the oblique upper half of the auditory capsule, is much larger than is needed for that part; the whole margin is occupied by the large, and accurately semicircular" "latern. sinus" (l.s.).

There are three arched and convex tracts to be seen in the postero-superior part of the auditory capsule; the middle tract is nearest to, the hinder tract furthest from,

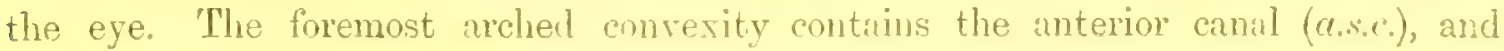


the middle tract, which bulges inmards, the "sinus" or conmon tube of the anterior and posterior canals. The latter is in the conresity that is just seen behind in the great space for the lateral sinus; the lollow oral space betreen the first and second arched curexity is for the "Howulus cerebelli." There the antero-inferior and posteri-superior regriors of the capsule meet, there, abore, the inner and outer opening" it the short immel for the portio dura (TII.) are seen.

Below these hales ite pertorations for the rirto mollis (TIII.) are seen in the sin thed mertus intertus. and the scace between the capsule and the basicovital leads to the tormen lacerm posterius. There the outline of the capule is gentr concure: in tivn of that part it swells again with the colls of the cochlea (cil.). and behind it with the galleries of the resthule (i\}.). The halred cecipital

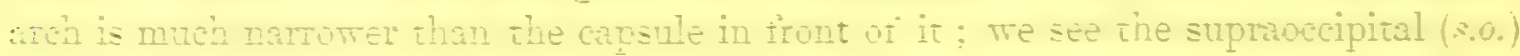
athi the excecipiol (n., alreadr large centres: the condrloid foramen (III.) and

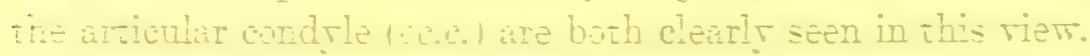

The irresting bunes are rapidr toming: the nesal (., ) abare the septum, and the vomer (a) below: and the maxillart and palatine (mat. pa.) below the nasopalatine

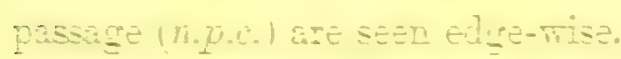

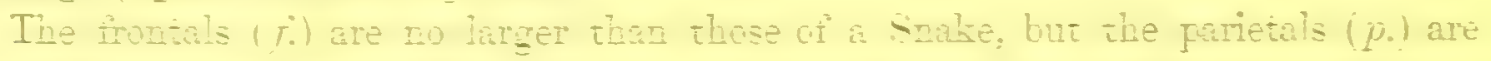
rert large; and projex from ine ontside, at the upper thimi of the tront lateral

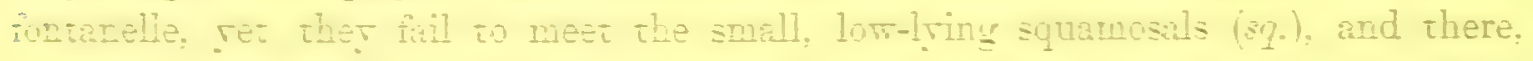
betrean ifen and behind the alsopenoid. there is a lare pritom tract entirel! unsuptored, eicher by curilage on bre.

In a disscaion of the basis cratil at this stage, seen trom ielote (Plare io, tig. Ij),

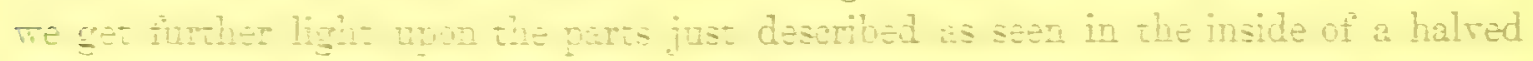

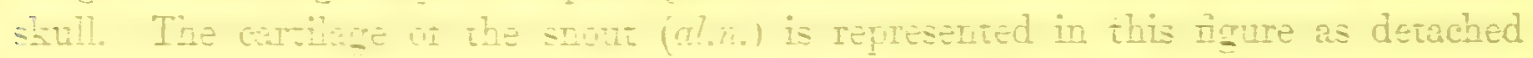

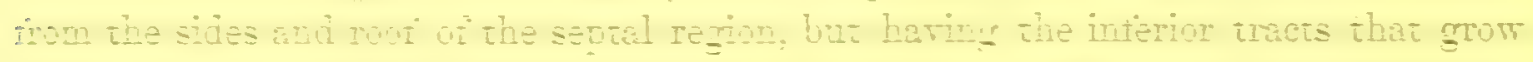

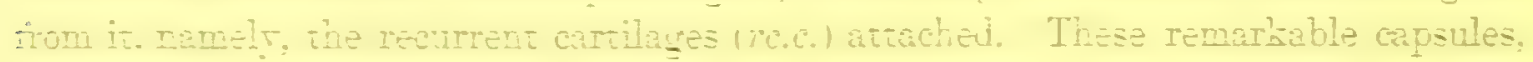

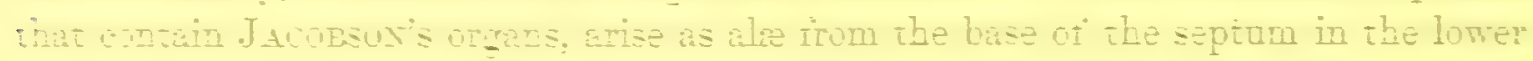

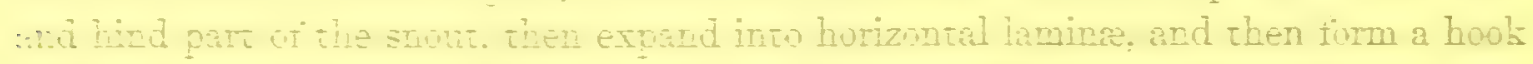

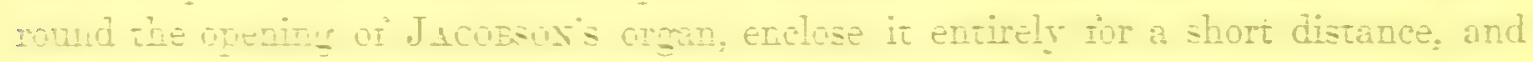

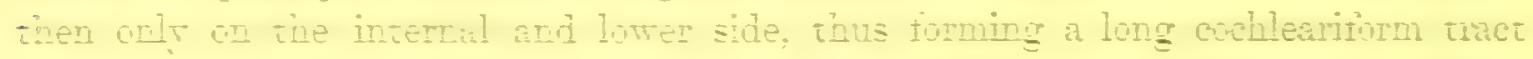

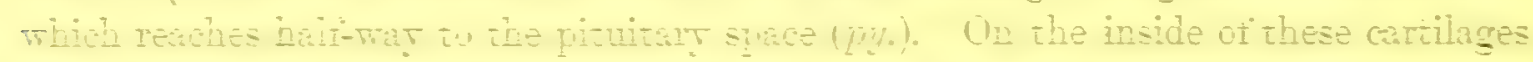

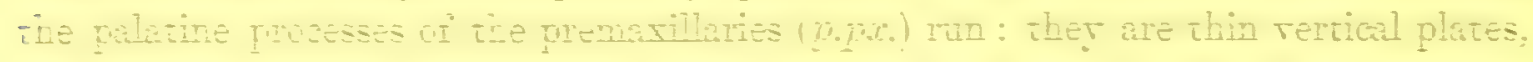

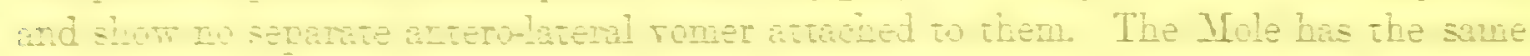

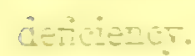

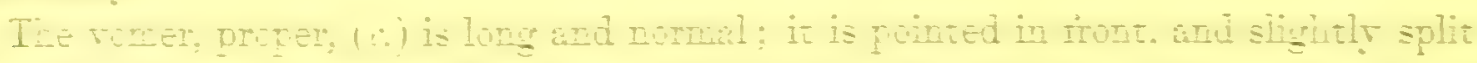

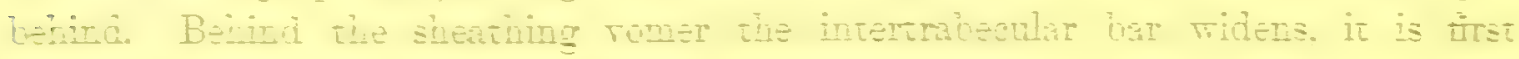

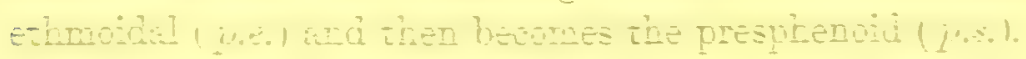

On exon sire I huve tigned the nind. dosing par of the lateral ethmoidal regions

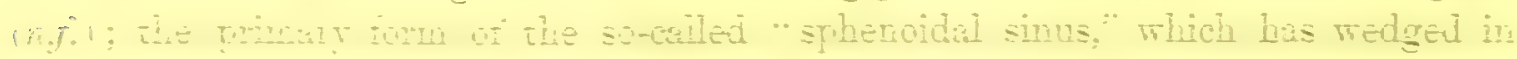

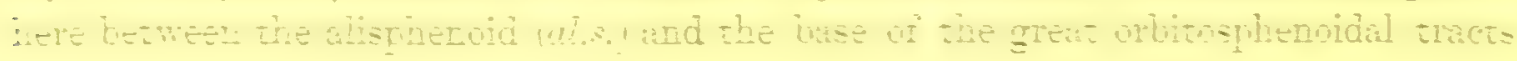


(o.s.). The narrow stalk of these great leafy growths of cartilage is out of sight; it is imperforate. A true Insectivorous diagnostic is seen in the sudden widening of the basisphenoidal region (b.s.), which is fice times as long, and three times as wide as the presphenoid, and has an open pituitary space $(p y)$ in its middle, in which it agrees with the Hedgehog and differs from the Mole. Around this hole the bony basisphenoid (b.s.) is forming; it is circular at present. The alisphenoids (al.s.) are small enr-shaped tracts of no greater extent than the cochlere (chl.), and having an oblique position, they look forewards as well as outwards, and are quite outside the plane of the orbitosphenoids. A round notch is seen between them and the base, in front; they are gently sinuous in front and on the outside, whilst, behind, they have a deep notch for the 3 rd branch of the 5 th nerve $\left(\mathrm{V}^{3}\right.$. $)$ near their outer angle. The base is clear of all alate growths in its middle part, but, behind, it gives off a small perforated crescentic wing which is applied to the fore end of the cochlen $\left(c h l_{0}\right)$; this, however, is soon lost, and the tympanic wing, so characteristic of the typical Insectivore, is aborted. The spheno-occipital region of the basis cranii is elegantly cut away, so to speak, to let in the rounded aper of the cochlen, right and left. The basioccipital centre $(b . \%)$, nearly reaches the formmen magnum, and is growing fast towards the lateral notches; it is polygonal and reptilian. A superficial tract of cartilage and of bone, forming the pterygoid $(p g . c, p g \%$ ) is shown attached to the base of the skull. The viscemal arches are well developed. I have figured the upper part from the inner side (Plate 30, fig. 16) of the tympanic region. The malleal end of MECKEL's cartilage $\left(m k_{*}\right)$ shows a well formed head, a deep and wide tract beyond the articular ficet, a very large "posterior angular process" and a short straight "internal angular process," or manubrium (m.ml.). The annulus (a.ty.) is already a considerable crescent of bone. The incus $\left(i_{0}\right)$ is quite normal and well developed, and so is the stapes (st.), the base of which looks towarts the eye in this figure.

Ossification has begun in the perichondrium of the neck of the malleus (ml.), below ; it is a thin ectosteal tract.

\section{Third Stage.- Young Shrews (Sorex vulgaris) from the nest; 10 or 12 days old;} and measuring $1 \frac{1}{3}$ inch in length, from snout to root of tail.

The dissected skull at this instructive stage, in its upper view (Plate 29, fig. 1), shors a cartilaginous snout ( $(l \cdot n$.$) , nearly as long as the long, and relatively large$ nasals (n.). The nostrils $\left(e_{0} n_{0}\right)$ are sublateral, and the snout itself is narrow at first, and then widens so as to become ventricose where it passes under the investing bones. Those bones are very thin at present, and show the elegant radiating lines of growth. The premaxillaries $\left(p \mu_{0}\right)^{*}$ run well up the face, wedging in between the much larger maxillaries ( $m x$.) and the nasals $(n$.) ; these two pairs of bones run backwards to about the same extent at present, widening backwards. The small, almost Ophidian frontals

MDCCCLXXXY.

$$
\text { * For pu, read pic. }
$$


(f.) are much shorter than the nasals and about twice as broad on their upper fuce; that fice is only one-third as large as that of the parietals, which are very large, have a strongly marked umbo, the primary centre, and liave a small diamond-shaped fontanelle between them and the frontals in which the coronal, sagittal, and frontal sutures meet. These bones elbow outwards, strongly, over the temporul region, and lie well over the squamosals (sq.), which are scarcely visible in this aspect. Behind, the parietals are largely suppressed, a space (fontanelle) existing there almost equal to a whole parietal; this is beginning to be filled in, behind, by a bow-shaped band of bone, the interparietal (i.p.), which forms a transversely-long beading to the well ossified and extensive supraoccipital bone (s.o.).

'The side view (Plate 31, fig. 10) shows the form and relations of the parts just described, and many other things besides. The snout ( $\left.\ell_{0} n_{0}, e_{0} n_{0}\right)$ is largely arched, and reaches half-way to the middle of the badly-defined orbit. Under the long thin nasals (n.) the premaxillaries and maxillaries $\left(p x_{0}, m x_{0}\right)$ are seen to form large thinwalled troughs, for the huge tooth-pulps; though which the sharp, red cusps shine, ready to cut the gums.

In front of the orbit there is a process of the maxillary which is beginning to form the nerve channel, but no separate malar bone; in an emargination of the maxil. lary, above, a small lachrymal, with its canal $(l ., l c$.$) , is seen.$

The roof plate of the frontal $\left(f_{0}\right)$ becomes convex at its edge, and then dips suddenly to form the thin, vertical orbital plate, under which the small, but bulging, alisphenoid (fig. 11, al.s.) can be seen; the orbitosphenoid is hidden by it, and by the frontal, in this aspect. The lateral extent of the frontal is only half that of the parietal, which is a vall, in this case as much as in our own skull. It lies over the frontal somewhat at its antero-inferior angle, close behind the coronoid process of the lower jaw (c.p.). I arge as is the parietal, it has two great deficiencies or emarginations, one above, alrearly described, aud one along the hinder lualf of its lower margin. In this aspect we see the squamosal (sq.) in its whole extent; and much as this bone is modified by the dwarfing of the skull, generally, it is normally Mammalian. It lies quite down at the lower edge of the skull, rising somewhat where it forms an abortive zygomatic process, in front of the condyloid facet $(c d . p)$. . The first two-thirds of the upper edge is concave where it fits over the lower edge of the parietal, and the last third is emarginate when it overlaps the prootic plate $\left(m m^{\prime}.\right)$. Behind, it interdigitates with that plate in some degree. The postero-inferior margin is convex, for a short extent, and then the lower edge looks quite straight, but is only partially seen, being curved inwards (Plate 29, fig. 2, sq.). Under the squamosal, the tympanic $\left(a_{\circ} t y_{\circ}\right)$ is just seen, and under the face the characteristic mandible. This latter structure for its fore two-thirds is a thin tooth-trough, behind which the large, elegant coronoid process (c.p.) ascends, vertically; its fore edge is two-thirds as long as the dentary part of the ramus. The condyloid lrocess $\left(c\left(l_{.} p_{3}\right)\right.$, on the other land, is very short; looks downwards and backwards, covered with its cartilaginous coat. The angulur process $(\alpha f \cdot p$. 
is, in the Shrews, very long and very slender, it runs backwards and a little inwards. Some parts of the endoskeleton are best seen in this outer side view; especially the prootic plate $\left(p r^{\circ}\right.$. .) and the proper mastoid region. The prootic plate, which takes the work here of the "sphenotic and pterotic" of Fishes, and does but little of its own, is a large shield-shaped ossification of the supra-auditory region of the cartilaginous endocranium. Its arched top does not yet reach the emargination in the parietal, nor the lateral sinus (s.c.), which now forms an elegant bow over the side skull, inside the parietal for the most part, but exposed, behind. The roughly dentate lower hinder edge of the prootic plate overlaps the ampulla of the anterior canal (a.s.c.) and in some degree that of the horizontal canal (h.s.c.) ; then this bone meets with the very extensive opisthotic (at h.s.c.). That bone can be seen behind the tympanic (a.ty.), and also creeping over the junction of the anterior and posterior canals (a.s.c., p.s.c.); much of that part of the capsule (epiotic region) is still cartilaginous; there is no appearance of a distinct epiotic bony centre. Part of the interparietal $\left(i . r_{0}\right)$ is seen in front of the supraoccipital (s.o.), and the occipital arch is seen edge-tvise; there is still cartilage between the supra-and exoccipitals (e.o.) and the latter run up to the auditory capsule, without forming any definite paroccipital process ; the condyle (oc.c.) is very large, and looks obliquely downwards and outwards. The whole hind skull is gently convex and very similar to that of the Mole, with which it agrees in laving the large mootic plate.

'The lower view (Plate 29, fig. 2) shows the large alveolas grooves, overfull of toothpulps, with cusps cutting the gums; thus the marginal part of the premaxillaries ( $x_{x}$. as well as of the maxillaries ( $m x_{0}$ ) is very wide and bulbous. The palatine processes of the premaxillaries are very long and slender, and continuous with each anterior paired vomer, right and left. The palatine plate of the maxillaries is large, and twice the extent of that of the palatines $\left(p a_{0}\right)$; the suture between these four plates is arched forwards, and the fore nargin of each palatine is deeply notched; there the anterior palatine foramen is open in front.

The merely vertical and upper part of the palatines is short and swollen, and the similar tracts formed by the pterygoids $\left(p g_{0}\right)$ are swollen aiso; the hamular processes are small, but sharp; they have used up the primary cartilaginous nucleus. Of the other investing bones to be seen in this aspect the squamosals $(s q$.) are the most striking; they are much larger than they seem to be from the side view, being curled round under the side of the skull in a remarkable manner. The postglenoid region is very large; the preglenoid a short free spike; the glenoid facet (gl.c.) looks forwards and a little inwards, and is, at present, a continuous selliform facet to the wide, thick infero-anterior lobe of the bone. Inside the hinder portion of the squamosal, the annulus tympanicus $(a . t y)$ is seen as a relatively large, very thin, imperfect ring of bone, bending upon the emerging primary mandible-MECKEL's cartilage ( $m k_{\text {: }}$ ) - and supporting a wide membrana tympani $(m . t y$.$) ; the hinder crus lias a widened part or$ blade at its free end, and the fore end is dilated, but to a less degree. The vomer $(v)$ is seen in its hind part, with its forks, supporting the perpendicular ethmoid (p.e.). 
Between the forks of the main vomer $(v$ ), behind the middle ethmoid (p.e.) a small, thick crescent of bone is seen lying crosswise with its convexity forwards; this is the independent presphenoid (p.s.), a bone not found in the Hedgehog and Mole.*

On this face the orbitosphenoids are not seen, or very slightly (see figs. $3,4,0 . s_{0}$ ); the basisphenoid $($ b.s. $)$ is separated from the presphenoid by a broad tract of cartilage; the bony trict is four times as long as that synchondrosis, and, in front, three times as wide. Behind, it is twice as wide, and so also is the spheno-occipital dividing cartilage; this is also somerwht more extended, axially, than the front tract. Here we have the abortive development of the large diagnostic Insectivorous basisphenoid; it is very large, has stout shoulders, on which the alisphenoids ( $a l . s$. ) rest, but it is not specialised for pneumatic purposes. The anterior fissura lacera ends in the rounded notch between the forwardly-thrust alisphenoid, and the narrow anterior synchondrosis. These parts will be understood better when we come to the disinvested endocranium (figs. 3,4 ); so also will the occipital arch and the anditory capsule.

'The side view (Plate 31, fig. 10) is still more intelligible when the divided skull is seen from the inside (fig. 11); this also gives us one of the three views of the endocranium, as distinct from its ectocranial investing scale-bones.

'This view of the skull of a Shrew, ahout the twelfth night after birth, should be compared with the counterpart figure of the skull of the ripe embryo (Plate 29, fig. 7); thus the decadence of the deep chondrocranium and the development of the superficial elements of the ectocranium will be understood. Measured along the basal line, the septal and ethmoidal (continuous) regions of cartilage are five-sevenths the length of the whole axial tract from the fore end of the snout to the foramen magnum; at birth that fore part was two-thirds the whole length. It is the snout which has lengthened most (relatively), as if to form a proboscis; but there is no segmentation of the cartilage enclosing the double tube. The basal line of the snout is strongly, that of the septo-ethmoidal region feebly, arched; nearly all the thick basal part is due to the development of that azygous median prepituitary (= pro-chordal) rod, the intertrabecula; for the trabeculie and cornua trabecula run but a short distance forwards and only meet at the mid-line in the region immediately in front of the sella turcica. Thus the middle element of the cranial fore-growths is as large as in the Selachian Fishes and the embryo Bird. The foremost part of the septum (s.n.) is perforite-a very common thing in Mammals, the ala nasi throwing themselves out from the middle wall, in forming the valvular nostrils. Up to the anterior palatine formina this wall is very low; it then gently rises up to the top of the rhinencephalic fossa, with the cribriform plate $\left(c r^{\circ} . p_{0}\right)$ as its floor; there is no crista galli projecting from the obtuse angle from which the great partition descends, twice as rapidly as it ascended, until it reaches the presphenoidal bony centre $\left(p . s_{0}\right)$.

The fan-shaped upper part of the great orbitosphenoid of the embryo (Plate 29,

* We shall sce this again in Rhynchocyon; and it is also present in some of the lesser Rodents (at any rate in Arvicola, Mus, \&c.). Nevertheless, it is a Marsupial character. 
fig. 7, o.s.) is now much lessened (Plate 31, fig. 11, o.s.); its posterior band has been absorbed, leaving only a point to the hind corner of the wing; the hind eilge is now ossified as the narrow orbitosphenoidal centre.

The oblique, notched, anteriorly-placed alisphenoid ( $a$ l.s.) is only partly seen in this view, because of its great out thrust; its base (b.s.) and the basioccipital (b.o.) are seen to be rather thick plates of bone. The other elements of the occipital arch (s.o., e.o.) are set in a crescent, whose convexity looks backwards; all the synchondroses are large, as yet.

There are only two periotic bony centres-the prootic $\left(2 r^{\circ} .0^{\prime}\right.$.) which forms the curious wall-plate, and the opisthotic; which builds-in the labyrinth.

The mastoid region behind, enclosing the posterior canal (p.s.c.), and the arch of the anterior canal ( a.s.c.) are still invested with cartilage, but the common sinus, behind the cerebellar fossa, has a bony inner wall. Everything in this skull, as in that of the Mole, conforms to the dominant idea of a skull to be manipulaterl, so to speak, into a smooth, elongated borer, so that it may resemble the head of a Weevil (Curculro). Thus all the investing bones are thin, gently convex, and so imbricated as to thrust out no projecting points, externally.

This section shows the nasal, frontal, parietal, and interparietal $(n ., f ., p ., i . p$.$) above ;$ and the premaxillary, maxillary, palatine, pterygoid, and tympanic ( $p x$, mx., pa., p $\%$, a.ty.), below. Infero-laterally, the trough-shaped squamosal (sq.) is seen from the inside as a narrow tract, arched above, but not reaching the rounded lower edge of the parietal, and the concave edge of the latter fails to reach the arched top of the prootic plate, thus there is a considerable lateral fontanelle or part formed of membrane only. Near the lower edgre of the parietal, the lateral sinus (.$c_{0}$ ) throws its elegant arch over the inside of the skull, from the auditory capsule to the orbitosphenoid.

When the endocranium is seen divested of nearly all its investing bones, from below (Plate 29, fig. 4), we have what seems to be a remarkably imperfect skull, even considered as a basin, and not as a box. What we see is a remarkable result of dwarfing and elongation; there is a thrifty use of every kind of skeletal material, and the substances used have been thinned out as far as could be done safely. Yet the skull of a Child at the same stage, similarly prepared, would show the same elements disposed in a similar manner, and there would be little difficulty in recognising most of the homologous parts.

The conchoidal narial region $(e . n ., c l . n$.), right and left, and the fluted double nasal tube, are seen to form a very perfect cartilaginous structure up to the part where the dentary region of the premaxillaries is attached. There the floor is cut arvay in a rounded manner, and the nasal labyrinth is open below, almost to its end, where its moieties do close in, independently of each other, right and left of the forks of the vomer $\left(a l . e ., v_{0}\right)$. This open region begins by forming the long retral tracts that help to encapsule J Acobsov's organs (figs. 4, 5, rc.c., j.o.) ; there is no Mammal in which I have, as yet, been able more satisfactorily to work out these parts than in this young 
Shrew; and this both in the dissections (Plate 2?, figs. 4, 5), and the sections (Plate 30).

Where the perfect narial floor ends, there on each side of the intertrabecular base of the septum (Plate 29, figs. 4, 5, s.n.), a gradually increasing wing is given off, which, on reaching the notch in the premaxillary-between the dentary margin and the palatine process - at once expands, hooks itself round the front of the opening of JACosson's organ, and then completely surrounds that organ for a short distance. The rest of the cartilage is like the bowl of a spoon, and protects the organ infero-externally. Along the inside of each retral tract the palatine process of the premaxillary $(p \cdot p x$.) runs as a vertical lamina, comate, apparently, as in the Mole, with the interior paired vomers. Between the hinder third of these laminx the fore part of the long, normal, main vomer $(v)$ is seen. The inferior turbinal is developed from the inside of the lower edge of the nasal wall (al.sp.); the upper and middle turbinals (fig. 4, al.e., m.tb.) from the inner face of the capsule in its dilated part. There, for some distance, the floor is very deficient, the wall, simply bending invards, with a sinuous selvedge underneath; at the end it finishes in a sort of pouch, right and left of the forks of the vomer.

Where a kind of secondary desmognathism is made by the vomer (as in Passerine Birds), there a small oblong tract of bone runs in hetween the main vomer and the ossifications already forming in the nasal wall and floor; these little bones are the posteriorpaired vomers $\left(v^{\prime \prime}\right)$. Behind the short exposed tract of the perpendicular ethmoid (p.e.) the small crescentic presphenoid $(p . s$.$) is seen, with its concavity looking$ backwards; a tract of cartilage, larger than this bony centre, separates it from the next bony tract-the basisphenoid (b.s.).

'The semiosseous orbitosphenoids are partly hidden in this view, but are fully shown in the upper (fig. 3). The posterior sphenoid is well displayed in this aspect. The basal bone $\left(b_{s} s_{0}\right)$ is inordinately large for a Mammal, but small and aborted for an Insectivore. It is, roughly, an equilateral triangle, with its hinder angle truncated, and its anterior side transverse to the cranial axis; the imperfect lateral margins are sinnous, so that there is a rounded lobe at each angle; this is the arrested "tympanic wing:" 'The alisphenoids $\left(\alpha l_{\text {.s. }}\right)$ are sutured to the fore edge of this lobe, right and left, and run forwards and a little outwards; their rounded fore angle is not quite ossified.

Each bone is a rough, notched, snaggy wedge; the notch is on the outer margin, just a little in front of the projecting hinder angle or lobe. This is the imperfect foramen ovale $\left(\mathrm{V}^{3}.\right)$; it is a large vacuity, as seen from below. The scarcely ossified fore end is rounded on its inside; it reaches to the middle of the incurved nasal floor (al.e.) much beyond, and some distance below, the orbitosphenoid (o.s.); the inner margin is notched both at this front part and at the hinder third. There is a considerable membranous space between the ala and the narrow fore part of the base, right and left. 
'Then there comes, behind and outside the posterior sphenoid, a very large space, in the dissected endocranium, which in the perfect skull (fig. 2) is only partly filled in by the squamosal (sq.). This was the case very remarkably even in the skull of the embryo (fig. 7), but the auditory capsule has not grown so much, since, as the rest of the skull and snout (figs. 3, 4); it scants very much towards the great semicircular. space developed for its reception. The small perforated ala of cartilage seen in the embryo growing right and left, from the basisphenoidal region (Plate 29, fig. 7 ; and Plate 30, fig. 18), and coiling round the front of the cochlea-helping to complete the setting-is now absent; it has evidently been used up in the ossification of the cochlea (chl.); it now exists as the toothed rim of its semicircular fore part. There is still some cartilage between the prootic plate $\left(p 0^{\prime}, o^{\prime}\right)$ and the main part of the capsule; and also behind the bony top of the epihyal (c.hy.), as well as on the inner face, above (Plate 31, fig. 11). The coils of the cochlea (chl.), the fenestra ovalis and fenestra rotunda $\left(f^{\circ} . o_{0}, f r^{\circ}\right)$, and the great fissure widening for the exit of the 9 th and 10 th nerves (IX., X.) are clearly seen in this lower view.

The wide basioccipital (b.o.) with its semicircular notch in front of the foramen magnum; the large reniform condyles (oc.c.) ; the exoccipitals (e.o.) separited by a large tract of cartilage from the base, and that tract perforated by the 12th nerve (XII.), are also shown. There is scarcely any paroccipital ridge to the exoccipital bone, which, above, is separated by a definite tract of cartilage from the large, shieldshaped supraoccipital (s.o.).

In the upper vicu (Plate 20, fig. 3) the nasal labyrintl is complete ( $(4 . n .$, al.sp., al.c.), and ends above, as below, in a rounded lobe right and left. The fluted top part is very uniform up to the proper olfactory region; that region is ossifying, rapidly, in its middle. The grooved top, formed by the septum $\left(s_{0} n_{0}\right)$ does not end in a cartilaginous crista galli ; from the median, notched part the margin of the nasal roof is first concave, and this swells into the lateral, teminal convexity.

The great perforated floor, or lamina cribrosa $\left(c r^{\prime} . p^{\prime}\right)$, has, outside, a sublobate edge; the rest is evenly semicircular; more than half of the plate, with the top of the perpendicular ethmoid, is ossified. In this curiously scanted skull there is a considerable membranous space between the cribriform plate and the orbitosphenoid; these tracts $\left(o . s_{0}\right)$ are remarkable in several ways, and are almost the least normal of any I have yet seen in the Eutheria. The top part is still fan-shaped, but the whole of the large posterior band (see fig. 7, o.s.) is gone. The sharp angle left is now ossified separately $\left(o . s^{\prime}.\right)$, and the stem $\left(o . s_{.}\right)$is also bony; it does not reach more than two-thirds of the way to the upper margin of the wing. The lower end is pedate, and is beginning to form a suture with the base (p.s.); it is then reduced to a mere rod, which curves forwards and backwards twice, becoming flat, but still narrow, above.

There is no optic forcmen, as in Marsupials; but in front of the main bar, below its middle, there is, in a notch, a separate spicule of bone $\left(0 . s^{\prime \prime}\right.$.), a third bony centre to 
this abortively developed orbitosphenoid. The sphenoidal fissure is a long space under the orbitosphenoidal bar, and over the alisphenoid; through it, not only the orbital, but the optic, nerves also pass. The hinder half of the alisphenoid (al.s.) only can be seen in this view; the bone is twisted over the notch for the 3rd branch of the trigeminal $\left(\mathrm{V}^{3}.\right)$. The notches and shoulder of the basisphenoid (b.r.) are well seen; there is scarcely any sellar concavity on its upper face. Much cantilage is still seen in the synchondrosis between the two basal bones and between the elements of the occipital arch; and also, above, where the auditory and supraoccipital regions mite. The cartilage in the auditory recesses (see Plate 31, fig. 11, (c.s.c., p.s.c.) are scarcely visible in this aspect, but the capsule appears to be almost wholly ossified; the base of the floccular recess, the holes for the portio mollis (VIII), and the bridge under which the portio dura (VII.) runs, are well seen. In front of the very shallow meatus intemus the capsule sends forwards a bony snag, which helps the toothed rim of the cochlear region to give some bony support to the largely membranous region in front of it.

\section{Thind Stage (continued).-Dissections of the visceral anches of the young Shrew.}

I have not figured the fore half of MECKEL's cartilage, which still persists, not larger, but not evidently lessened, inside the lower jaw (see Plate 29, fig. 2). 'Towards the malleus (Plate 29, fig. 6, mk:) it is seen as a solid terete rod, having a bony style supporting it further forwards than the manubrium (mb.) extends. But that primary style of bone has grafted itself upon, and set up extensive ossification in, the head of the malleus (ml.). 'This rambling bony tract has forced its way down to the neck of the manubrium, but has left a large core of cartilage in the middle of the head. The partly bony head of the malleus is quite normal, and has the tensor tympani (t.t.m.) attached to its inner face; but the manubrium and the posterior angle of the part from which it springs are very remarkable. The slender manubrium looks like the tube of a retort, the bulb of which is imitated by the angle; the main part of the head projects well, backwards, below the articular facet; the bony matter then forms a ring round a contracted tract, or waist; from this part the bulbous tract hangs, so to speak. 'Thus the bulbous head, the enlarged body, and the subglobular' "angle" form three enlurgements, all in one line, and that at a right angle to MECKEL's cartilage, and to the manubrium. The incus (i.) is rather small, and its articulation with the malleus is becoming indistinct; the short crus (s.c.i.) is very short; the long crus (l.c. $i$ ) is rather longer than ordinary; the head is unossified, and so also is the inturned orbicular facet.

'The stapes (st.) is large, relatively, and has a perfectly stapedial shape; it is nearly all bony, the top and base being still soft; I could not find any separated interhyal in the tendon of the stapedius muscle $(s t . m$. $)$.

The short crus of the incus fits into a little cup close above the part where the 
epihyal (c.hy.) has fused with the auditory capsule; here the bone (au.) extends; but the main part of the unusually well-developed epihyal is still cartilaginous, and is continued without any segmentation into the unossified part of the ceratohyal (Plate 29, fig. 6; and Plate 31, fig. 12,c.hy.). Half the upper ceratohyal is ossifiedits middle part; then comes a joint, and then the short, lower ceratohyal (c.hy'.), which, in turn, articulates with the short, ossifying hypohyal ( $h . h \%$.).

The latter, in turn, articulates with the almost straight, transverse, nearly ossified basihyal (b.h.br.), which has, articulating with it, the ossified, short thyrohyal rods $\left(t . h y_{0}\right)$.

\section{Third Stage (concluded).-Vertically transwerse sections of the Nestling Shreu.}

A description of these sections will throw further light upon the structure of the skull at this stage.

Section 1 (Plate 30, fig. 1). - This is through the outer nostrils (e.no), and shows how the roof $(a l, n$.$) turns inwards to form the narial valve, and how the floor, also, of$ the opening, is cartilaginous; many of the vibrisse are seen in section in the thick skin of the snout, in this, and in the following sections.

Section 2.-Here (Plate 30, fig. 2) the narial valve is seen in the hind part of each nostril; it curves downwards at its free end; the alre nasi $\left(\alpha l_{\text {.n. }}\right.$ ) are confluent, back to back.

Section 3.--In this (Plate 30, fig. 3) there is a definite tract of the septum nasi $(s . n$.$) with an enlarged-intertrabecular-base. The narial valve is gone, and the$ cartilage that formed it is now confluent with the floor, so that there are two perfect narial tubes $(n . p$.$) at this part.$

Section 4.-At this part (Plate 30, fig. 4) the floor and walls are separating, again; the floor, right and left, touches the lower part of the septum, which is carinate below its bulbous part.

Section 5.-The tubes now (Plate 30, fig. 5) are not surrounded, below, by cartilage, and the floor is in two short, oblique tracts; the almost vertical wall turns inwards below, and the septum, still carinate, is much thicker; these narrow floor-tracts are those that give oft' JAcoBson's (= recurrent) cartilages (Plate 29, fig. 5).

Section 6.-We are now (Plate 30, fig. 6) behind the snout, and through the premaxillary $\left(p x_{0}\right)$, with its thin walls, and its relatively luge incisor teeth (see also fig. $7, t_{\text {. }}$ just developing in these large, swelling pulps. The double tube is contracted here, the top is still flat, and the septum $\left(s_{.} n_{0}\right)$ is very thin above and thick below; the enlargement at the bottom of each inturned wall $(a l . s p$.$) is the rudi-$ ment of the inferior turbinal (i.tb.), at its very beginning, in front. 'The rods of the recurrent cartilages (rc.c.) are seen lying obliquely below the bulbous intertrabecula $(s . n$.$) ; below, the fore part of the lower lips are seen in front of the dentary$ bones $(m n$.$) .$

Section 7.-This (Plate 30, figs. 7, 7A) is through the fore part of JACoBsos's MDCCCLXXXY. 
organs (j.o.) and the perfect part of the cartilage. The roof ( $a$.sp.) is now arched, with a very small median groove; this roof is very thick for some distance, and then thins out below, where it is bulbous. The upper three-fifths of the septum $(s . n$.$) is of the same thickness as the main part of the roof, and then suddenly$ swells into a large bulb, with a flattened basal outline. Here the cartilaginous capsules of JAconsox's organs (rc.c.,) are at their perfect part. They are solid above, and nearly vertical where they fit obliquely to the septal base; then they curve outwards to form an oval cavity (for JACoBson's organ, j.o.), and are keeled and turned inwards below. In the middle of the pyriform space between them the thin palatine plate of the premaxillary is seen to rest obliquely on the top of the inner face of the tubular part. The nasal passage opens into the palatal space below; the nasals (n.) are cut through above, and the fore part of the maxillaries $(m x$.$) with a$ tooth and its pulp (t.) on each side. Three mucous follicles (m.s.) are seen in the interspace between the mucous membrane and the aliseptal cartilage. This part is close behind the anterior palatine foramina, and here the palate is rugous and subcarinate in the middle.

Section 8. This (Plate 30, fig. 8) is through the open part of the recurrent cartilages (rc.c.) and the hind part of the palatine processes of the premaxillaries. 'The thick aliseptal wall has now formed a definite rudiment of the nasal turbinal $\left(n_{*}+b_{0}\right)$, but the rudiment of the inferior turbinal $\left(i_{0} t b_{0}\right)^{*}$ is still very imperfect. The nasals were present, but not figured, and part of the maxillaries $(m . x)$, with a pulp, are cut across and the fore part of the vomer $(\%)$. Also, below, the dentaries and their teeth-pulps $(d$.$) are seen.$

Section 9.-Here (Plate 30, fig. 9) the vomer (v.) comes fully into view behind the palatine processes of the premaxillaries (see Plate 29, figs. 1, 2, 4, 5). The nasals (no), and the maxillaries ( $\left.m x_{0}\right)$, with their palatine plates ascending to articulate with the vomer, are all clearly seen. Also the dentaries $\left(d_{0}\right)$ below, with their teeth. Here the nasal and inferior turbinals $\left(n_{0} t b ., i_{0} t b.\right)$ have good rudiments. The front of the tongue $\left(t_{g}\right)$ and the lower jaw $\left(d_{\text {. }}\right)$ have been cut through, below.

Section 10.-Here (Plate 30, fig. 10) the nasal labyrinth is widening towards the true olfactory region; the septum is deeper and less bulbous below. The inferior turbinal rudiment is no longer seen, but the nasal (n.tb.) is still in view. The nasals, maxillaries, and dentaries ( $\left.m x ., d_{0}\right)$ are still seen in section.

This section is behind the angle of the mouth; the tongue (tg.) is now at its middle.

Section 11.-Here (Plate 30, fig. 11) the eye-balls (e.) are cut through their front part, and the nasal labyrinth, largely osseous, is cut across where the nasal, upper, and middle turbinals $\left(n, t b, n_{0} t b_{0}, m_{0} t b.\right)$, can all be seen; the floor is ossified at this part. The nasals, vomer, maxillaries, and palatines $\left(n_{0}, n x_{0}, p a_{0}\right)$ are here cut through, and the dentaries (d.) below. In the last (fig. 10) the nasal passages 
were separate, here they communicate, below, under the vomer; here the middle of the palatine skin is keeled again; it was flat in the last two sections

Section 12., In this section (Plate 30, fig. 12) the fore part of the olfactory lobes $\left(\mathrm{C}^{16}\right.$.) are cut across as they lie in the large fossie upon the ossifying cribriform plate $(c r . p$.$) . Part of the roof-cartilage is seen right and left, and from the walls and floor$ copious turbinal growths $\left(u_{0} t b ., m_{0} t b_{0}\right)$ are seen. Here, the frontals $\left(f_{0}\right)$ are perfect and roof the whole over, whilst below, the palatines and vomer $\left(p c_{0}, v_{0}\right)$ are seen in section, protecting the small, square naso-palatine passage (n.p.c.).

Here the perpendicular ethmoid ( $\left.p . e_{0}\right)$ is spear-shaped above, and clubbed below; it is very thin for the most part. The jugal process of the maxillary $(j$.$) is seen, the$ mandibles and teeth $\left(d_{0}\right)$, with tongue, below.

Section 13.-This (Plate 30, fig. 12 1 ) is fiom a little further back behind the general roof, and where the firontals $(f)$ do not meet in the middle; one description may serve for both of these sections.

Section 14.-This (Plate 30, fig. 13) is through the hemispheres ( $\mathrm{C}^{1 /}$.), the great fontanelle, at the back part of the frontals $\left(f^{*}\right)$, and the large orbito-sphenoidal wings (o.s.) ; the basal part, here, is behind the middle ethmoid, and is the front of the presphenoid. The cribriform plate still comes into section in its lindmost part; this is where the skull-walls (o.s.) are united to the olfactory capsules. This is behind the

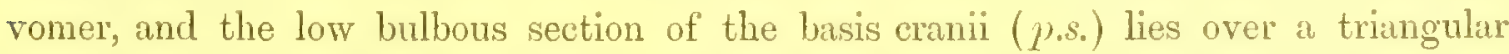
section of the nasopalatine passage. The bony alisphenoid ( $\left.u l_{.} s_{0}\right)$, is seen outside the nasal wall.

The palatines and pterygoids overlap at this part, and here the frontal $\left(f_{0}\right)$ gets well under the skull in the imperfect orbit.

The articular and angular processes of the lower jaw (cd.p.) and MEckEL's cartilage ( $m k^{\circ}$ ) are cut across, close in front of the ear-drum.

Here the nasal cavities are small, oblique, and reniform in section, in this, their retral subcranial part. The wall, although well coiled round the cavity, does not completely wall it in; the median cartilage (p.s.) is some distance from the walls.

Section 15.-In this partial section (Plate 30, fig. 14), the basioccipital (b.o.) is cut across in its front part; on the side, at some distance, the cochlear and part of the vestibular region of the auditory capsule are cut through; the wall, very thin, is ossified. The prootic plate $\left(m \circ o^{\prime}\right)$ is seen in section, with the hind part of the squamosal (sq.) outside and below it. The ossifying opisthotic region, outside and below the vestibule, shows the facial nerve (VII.) in its whole course-infia-cranial, auditory, and extra-cranial-escaping close behind the sigmoid hyoid arch (e.hy., c.hy); the stapes (st.) is partly scen, and also the folds of the concha auris (mc., m.t.e.).

Section 15.-In this still more limited section (Plate 30, fig. 17) the ossifying auditory capsule is cut through across the fenestra ovalis $(f s . o$.$) and the bar between it and the$ fenestra rotunda. The well-formed stapes (st.) is seen in situ; its head and neck and

* The line in the figure is too short.

2 E 2 
its base are still cartilaginous, and the long crus of the incus $\left(l_{0} c . i_{0}\right)$ has its distal part attached. The opisthotic and epihyal (e.hy.), at their junction, are cut through, and the continuation of that bar, unossified, into the ceratohyal (c.hy.). The facial nerve (VII.) is seen escaping from the foramen stylomastoideum.

Section 16. - In this section (Plate 30, fig. 15) more than half is figured; it shows the basis cranii (b.o.) cut through in the fore part of the foramen magnum; the fore part of the condyles (oc.c.) are in section; and the atlas and axis (at., ax.) also come into view. The occipital roof (s.o.) is ossified above, and below, runs (s.a.c.) into the top of the auditory capsule over the anterior canal (a.s.c.). Below, the posterior canal (p.s.c.) is cut across; the thin, inner wall of the vestibule is ossified; the thick outer part is still cartilaginous.

\section{Fourth Staye.-The shull of the adult Shrew (Sorex vulgaris).}

The interpretation of the skull in its perfect state will now be easy, in spite of its great unlikeness to that of an ordinary good-sized Mammal, or even of that of a typical Insectivore.

Seen from above (Plate 31, fig. 1) the peculiar tenuity of this small skull is shown; the long bi-tubular snout $\left(a l_{0} n_{0}\right)$ is half the length of the dorsal line of the ossified cranium. Laterally, however, the projecting premaxillaries $(p x$.) protect the cartilage in its hinder third. The preorbital region and half the orbital, together, from one continuous bony growth; faint signs only of the sutures between the nasals, frontals, premaxillaries, maxillaries; and lachrymals $(n ., f ., p x, m x, l$.) being visible. The toothsockets make the sides sinuous, and they only diverge, increasing the breadth very gently, up to the jugal processes of the maxillaries.

The foramen infraorbitale $\left(V^{2}\right.$. ) is very large, and well seen in this aspect; the space between the frontal and the jugal process of the maxillary is a sharp notch. From that notch to the general swelling of the hind skull the cranium enlarges but little; the upper part of the coronal suture runs straight across the middle of the skull-waist; it is well-toothed and somewhat squamous, the frontals $(f$.$) being imbricated by the$ parietals $(p$.$) . The frontals are but little larger than in a Snake; but in that Reptile$ the frontals remain distinct, whilst the parietals coalesce-just contrary to what takes place in this little Mimmal. The parietals $(p$. ) cover about four times as much space as the frontals, they are far from each other, and from all the surrounding bones, except the squamosal, in front. The saggittal and lambdoidal sutures are welltoothed, like the coronal; the general surface of the bone is smooth-polished, as it were-and gently convex. The fore part, helping to form the orbits, is narrow; the rest becomes almost twice as wide. Flanking the frontals the squamosals can just be seen, giving additional width to the temporal region. The middle half of the lambdoidal suture has, set in it, a transverse plate of bone which projects forwards into the notehed parietals in front, and lies straight along the fore margin of the supraoccipital (s.o.), behind; this bone, which is slightly crested, is the interparietal (i.p.). 
The interparietal is small for an Insectivore, but the true supraoccipital (s.o.) is unusually large, and suggests at once a Monotrematous relationship. The thriceconvex hind margin is wide, but the fore edge runs across the skull to the post. temporal region, and is nearly as wide as the two parietals, together, at their widest part. Moreover, the tract covered by the supraoccipital tegmen is almost as extensive as that which is covered by the frontals.

In the side view (Plate 19, fig. 3) the peculiarities of the Soricine skull are well shown; a Mammalian skull, truly, but reduced to its utmost tenuity. There is a general parallelism in the downward and forward curve of the various parts; the snout also is thus followed by the premaxillaries $(p x$.$) , with their notched and ferru-$ ginous teeth-like the mandibles of a Beetle-and the elements of the skull, further back, dip in firnt, in like manner.

Back, as far as to the coronal and squamous sutures, which are largely persistent, there is no sign, in this view, of composition; the badly formed orbit has the frontal coming well down on its inside, but it merely dips inwards a little, it forms no brow; nor is there any definite post- or preorbital wall or outwork.

For such a snout the maxillary nerve $\left(V^{2}\right.$.) has to be very large, for the lips are thick, and the vibrisse well developed; the canal, therefore, is very large, and it is perfected by the maxillary, which has a stump of bone in the jugal region ; the canalwall for the infraorbital nerve is itself perforated. 'The lachrymal $\left(l_{\text {. }}\right)$ is melted into the fore edge of the maxillary, and the sphenoidal wings, frout and hinder (o.s, al.s.), are all confluent with the overlying membrane-bones; so also are the palatine bony tracts with the bones above them. In the inner and lower face of the undefined orbit, the sphenoidal fissure (II., $V^{1,2}$ ) is seen as a large channel, opening obliquely; this is due to the fact that the alisphenoid (al.s.) embraces the orbitosphenoid (o.s.), growing freely outside it.

The curious, low-lying, oblong squamosal (sq.) opens in front as two short blunt blades, which seem to bite the outspread alisphenoid; this is due to the fact that, whilst the jugal process is aborted and has no jugal bone to lie upon, the condyle (glenoid cavity) has become subdivided into two tracts of articular cartilage, one above and one below. Thus the two-fuced condyloid head of the lower jaw (figs. $3,4, c d . p$. ) is really held between the two blades of the squamosal. In the crescentic hollow behind these blades the normal pneumatic toramen is seen; the bone there is narrower, then broadens somewhat, and then, dipping gently, ends as arounded $0 r^{\prime}$ ear-shaped lobe in the re-entering angle formed by the prootic plate $\left(2 \% 0^{\circ}\right.$. $)$, and the mastoid region of the ear capsule (op.). Under its concave edge-greatly turned inwards (see fig. $2, s q$.) - the tympanic $\left(a_{0} t y_{0}\right)$ can just be seen. 'The structure of the skull in the temporal region is very elegant; the larger hind skull is finished by the large parietals $(p \cdot)$, which imbricate the frontals in the postorbital region, and throw themselves backwards and downwards, over the hinder auditory region, clamping all the parts with their toothed edge. They come down with a straight edge to the 
slightly overlapping squamosils, with which they partly coalesce, and then ride over the prootic plates, with a concave edge; then, as if for purposes of architectural ornament, the "lateral sinus" (s.c.) throws its low arch over the whole of these temporal sutures; three foramina are seen close to it, one in front, one in the middle, and another over it, near its hind part.

Wedged in between the parietal and squamosal, the curved prootic plate $\left(p r^{\circ}, o^{\prime}.\right)$ is seen; its fore-part is like a pruning knife; its hind part passes insensibly into the epiotic and opisthotic regions, where the three canals (a.s.c., h.s.c., p.s.c.), by their burrowing, mark the outer face of the bone, which is very thin over them. The occipital condyles (oc.c.), are large, bold, and pyriform in outline; between them and the opisthotic region (op.) the ex-occipitals $\left(c_{0} o_{0}\right)$ are wedged, scarcely forming any definite paroccipital process. Over the whole, like half a clome, the great supraoccipital $(s .0$.$) is seen.$

The lower jaw (seen from the inside) is rery small, but strong; it is hinged half way between the front of the nasal bones and the occiput. The coronoid process (figs. 3, 3a, c.p.) is high, vertical, and scooped on its inner face; the articular process $(c d . p$.$) is sub-triangular, thick, and has a two-faced condyle (gl.c.); the angular process$ $(a g . p$.$) is long, terete, and incurved at its end; the dentary canal (neuro-vascular passage)$ begins under the muscular fossa of the coronoid process. The teeth, here, as above, are curiously minetic of the mandibles of Coleopterous Insects-the food, especially of the Shrew, who, himself, is less than some of the members of the Beetle Family.

In the lower view (Plate 19, fig. 2) the snout ( $\left.a l_{0} n_{0}\right)$ is partly supported by the protruding incisors; and the bony palate, between the fine dental armature, is a high triangle, whose short base is behind; this boundary is directly transverse, but somewhat bracket-shaped, and is strongly limbate. The longitudinal extent of the premaxillaries $\left(p x_{0}\right)$ is one-seventh that of the whole hard palate; they are very partially distinct from each other, and from the maxillaries ( $m x_{0}$ ); the anterior palatine formina $\left(\alpha \cdot p^{\prime} f_{0}\right)$ are small. So also are the posterior formina $\left(p \cdot p_{0} f_{0}\right)$, and they are some distunce in front of the persistent palato-maxillary suture. The fused maxillary plate is subcarinate in its middle third, under the junction of these bones with the vomer; the fore half of the middle palatine suture persists, and that part of the hard palate has four small formina; its fore margin wedges in between the maxillaries, and yet its extent is less than half of the plate formed by the latter bones.

The jugal processes of the maxillaries projecting beyond the last tooth-socket make the narrow-waisted part, next following, very remarkable. In the distance, the orbital plates of the frontal and the rounded supraorbital edge are seen beyond the open region of the palate. The thick, spongy walls of the nasopalatine passage (n.p.p) are equal in width to that passage; and the roof, where the forks of the vomer $(v$.) end, is perforated with holes and slits.

The pterygoids and palatines $(p g, p a$.$) are thoroughly fused together, and are$ equally confluent with the posterior sphenoid (al.s., b.s.). The hamular processes 
of the pterygoids are small, terete, short, parallel, and unusually near together. Behind them there is a small foramen, right and left, and still further back, another pair of holes, wider apart, near the junction of the basisphenoid with the basioccipital (b.s., b.o.). The basis cranii, from the perpendicular ethmoid (over the thick hind rim of the hard palate) to the foramen magnum, is a peculiar structure; in front it is narrow, but behind the pterygoid hooks it widens out rapidly into two triangular wings, where the ali- and basisphenoid are anchylosed together. The basal plate then narrows gently and sinuously up to the middle of the basioccipital region, and then gently widens to the end, until it becomes just half the width of the widest sphenoidal part. The median part is made into a broadish and rather shallow groove by a thick, ribbed part, the rudiment of the hinder part of the tympanic wing of the typical kinds; these thickenings run up to the occipital condyles; but they do not enlarge the tympanic cavity. The inner (and also lower) facet of the glenoidal cavity (gl.c.) turns inwards and lies under the foramen ovale - now perfected by a bony hinder bar; - so that this hole is not seen, either laterally (fig. 3) or from below (fig. 2); the longitudinal direction taken by this nerve passage is indicated in both figures by a bristle ( $V^{3}$.). The inner edge of the squamosal, where it curls under the skull, is sinuous; it diverges from the outer edge of the basis cranii, so as to leave a large space, the hind margin of which is finished by the opisthotic region of the auditory capsule (op.). This pyriform space, with its wide end behind, is as large as the dilated posterior sphenoidal region of the basal and basilateral parts of the skull; it is largely finished by membrane-a permanent basilateral fontanelle. 'This space in the macerated skull occupies nearly all the side of the hinder or postorbital part; it is heart-shaped, being filled in somewhat in front by the postglenoid wing of the squamosal (see fig. 3). In the undisturbed state of the parts where the huge auditory capsule is kept in its place by ligamentous tracts, the hinder and outer part of each great fontanelle is filled in by that complex, intercalated labyrinth.

But on the lower face, between the squamosal and the basis cranii, this fontanelle is only partially latticed across by the small anmulus and the ossicula, which, with the drum-membrane, only half hide this great gap. In this under aspect the cochlea (chl.), that part of the vestibule which passes into the tegmen tympani and overarches the facial nerve and ossicula, and the part containing the horizontal and semicircular canals (h.s.c., p.s.c.), are all well seen. The large, pyriform condyles (oc.c.) and the oval foramen magnum $(f \cdot m$.$) surrounded by the elements of the occipital arch$ $(s . o ., e .0 .$, b.o.), are shown in this view.

When the auditory capsules have been loosened out by maceration, and are examined separately (figs. 4 and 5; oblique views of the imner and outer side), then we find that the capsule has used up and carried with it, in its ossification, a large amount of the primary endocranium, not properly belonging to the capsule. Not only is there a pterotic and a sphenotic tract of this kind, but, as I have already shown, the small alse that originally grew from the basis cranii behind the pituitary region, have been 
ossified by the corresponding opisthotic centres, and made to serve as a rim to the cochlea."

Seen obliquely from the outside (fig. 5) there is, above and in front, the shell-like prootic plate $\left(m \cdot o^{\prime}\right)$, and below it a similar, but lesser wing-like growth of bone. The cochlea (chl.) is also crested, the crest running forwards into a sharp point. A notch still persists where the two bony centres meet in front; below that notch the canal for the facial nerve (VII.) is seen at both ends, and below and outside its foramen of exit (stylomastoid) a thick, hooked club of bone runs across between and outside the two fenestrx-fenestra ovalis, and fenestra rotunda $\left(f_{s . o}, f_{.}.\right)$; the clubbed part is the stump of the epihyal $(e . h y$ ) confluent with the capsule.

The anterior canal (a.s.c.) shines through the thin bone, and the posterior and horizontal canals (p.s.c.,h.s.c.) project from the surface of the opisthotic region.

On the inside (fig. 4) the anterior canal stands out as an elegant arch over the deep and large flocular recess, which is bounded behind by a sharp crest of bone inside which is the common sinus of the anterior and posterior canals. Three convexities are seen below the recess; these are, from before backward-the ampulla of the horizontal canal (h.s.c); that of the anterior (a.s.c.) and the third rising is formed by the vestibule $(v \%)$. Below these mammillary risings the great porchway for the auditory nerve (VIII.) and the bridge over the facial (VII.) are shown; and there is a small tube behind, on the edge of the capsule: in front of these foramina the coils of the cochlea are partly hidden by the limbation of its margin, rumning into the anterior sharp process.

The small, strong annulus (figs. 6, 7, a.ty.) quite enclose an oval space, although the crura do not coalesce; the hinder crus has a broad, bilobate end, which overlaps the somewhat pointed end of the front crus, and from the outside (fig. 6) partly hides the manubrium mallei $(m b$.). The fore part of the annulus projects, being also dilated considerably; below, and at both ends, the outer fice is convex; the upper crus is ridged and grooved below the ridge. On the inside (fig. 7) there is but little concavity; this is for about a third of the imner rim, in front of the sharp groove on which the processus gracilis of the malleus $\left(p \cdot g r^{\circ}\right)$ lies.

That process is styloid, slightly decurved, and diverges from the manubrium, which runs straight along the long axis of the elliptical space formed by the annulus for the membrana tympani; it traverses three-fifths of that axial line; and is very slender and straight, with a gently bulbous free end. The neck of the malleus ( $m$.) is flat, and rises suddenly into the rounded head, which is confluent with the liead of the incus (i.). Half-way down below the condyloid region the bone projects as an obtuse

\footnotetext{
* There is nothing new in the morphology of the skull; in the Frog each of the three great lateral bony centres that harden the chondrocranium takes up both a sensory and a cranial tract; thus we have a "sphenethmoid," a "prootico-alisphenoid," and an "opisthotico-exoccipital." In osseous Fishes the semicircular cauals run far into proper chontroctuninl regions, and are ossified by tracts that have a double morphological significance-e.g., the "sphenotic " and the "pterotic."
} 
angle, the hinder edge is then notched twice, and then comes the solid bulbous "posterior angular process" (p.ag.) of this highly modified "articulare." "The main part of the malleus has ribbed erges, is limbate, and the neck is flat and thin; on the inside the root of the manubrium is thick and rough.

The incus (i.) shows signs of degradation, being fused with the malleus and reminding the observer of the arrested and, in the adult, fixed state of that segment of Echidna. The short crus (s.c.i.) is a mere snag; the long crus is very long, feeble and bent forwards; the neck of the orbicular condyle is well bent, very thin, and carries a well-made circular facet for the stapes. That bone (fig. 8, st.) is a miniature model of a stirrup, thoroughly normal, and unusually perfect in form. The hyoid arch, proper (Plate 31, fig. 9), has become much stronger, and yet more slender, than in the young stage (fig. 12). The cartilaginous continuation of the epihyal, from its bony stump (fig. 5, e.hy.) to the top of the upper ceratohyal (fig. 9, c.hy.), is a complete band of cartilage; the next trict is slender and curved, and is unossified in its lower third; the lower ceratohyal (c.hy'.), the hypo-basi-and thyrohyals are largely ossified; the latter $(t . h y$.$) are much longer now, and are bent outwards in the$ middle.

The interior of the skull was not figured; nor any of the figures made from an old specimen. The cribriform plate is very large, oblique, and richly perforated; the median ethmoid, between its halves, is thin, but strong; all the parts, inside the front of the cranial cavity, are well ankylosed together. The orbitosphenoids have very narrow edges to the hind margin of the cribriform plate; the basisphenoid has a very slight sellar depression. In old skulls the parietals coalesce with the frontals and with the fore half of the upper part of the squamosals; so that the sutures left are the hinder main part of the sagittal, that between the parietal and interparietal, and the hind part of the squamous suture.

Yet these remains of sntures, the independence of the extensive anditory capsules, and the general thinness and elasticity of the larger bony tracts defending the brain, all help to make this small skull more or less flexible under accidental pressure.

I have not added certain figures made from the skull of the adult Water Shrew (Crossopus fodiens); it merely differs fiom that of the Common Shrew (Sorex vulgaris) by its larger size, greater robustness, and a somewhat more intense ossification generally. The orbitosphenoids are wider, and the "foramen ovale" is quite visible on the lower aspect of the skull ; in the common kind (Plate 31, fig. 2) the bristle ( ${ }^{3}$.) is seen to pass over the incurved louer glenoid process; there is a notch between it and the hind corner of the alisphenoid (al.s.), and then a bridge of bone between this notch and the fore-end of the great infero-lateral fontanelle. In Crossopus fodiens the emerging nerve is bounded in front by a tract of bone, where the notch is in the lesser third; here it appears to pass through the neck of the lower glenoid process ; as a matter of fact, the foramen is made by the confluence of the alisphenoid with that part of the squamosil. 


\section{On the skull of the Centetidie.}

My materials for working out the structure and development of the skull in this peculiarly Mascarene Family of the Insectivora are as follows :-

A. Stage 1.-An embryo of the largest kind-Centetes ecaudatus - 7 lines long, (head 3, body 4), (Plate 16, fig. 13); this is intermediate between my 1st and 2nd Stages of the Mole (Plate 1, figs. 1, 2, 3).

Stage 2.-A three-fourths ripe embryo of Centetes ecaudatus, $1 \frac{11}{1}$ inch long.

Stage 3.-Young individuals of Centetes ecuudatus, $3 \frac{1}{4}$ inches long.

B. Almost adult specimens of Iemicentetes madagascuriensis and H. nigrescens.

C. An adult Ericulus nigrescens.

D. An adult (or nearly) Miciogale longicandata.

\section{Stage 1 (Plite 16, fig. 13).}

In the smallest embryo the snout is just beginning to project from the front of the face; the brain vesicles $\left(\mathrm{C}^{1 / \alpha}, \mathrm{C}^{2} ., \mathrm{C}^{3}\right.$ ) are very large; the eye-ball is very small, and surrounded by a circular lid; the concha auris has commenced its folds; the limbs are mere flaps; and the tail is, relatively, longer than in the more advanced specimeus; the head is very large, relatively.

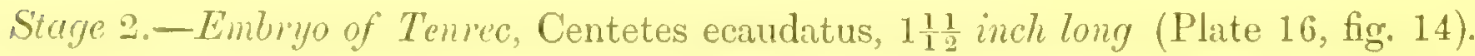

'The head is still (and always will be) very large in proportion to the body; the tail is a mere stump, the limbs are well-formed. The eyes, and their lids, are very small, and so are the outer ears; the snout is now a considerable structure, running in front of the lips.

'The skull (Plate 32) has acquired a large amount of solidity from ossification, both extemal and internal; the whole structure is very evenly conical, with the snout as its obtuse apex.

\section{The investing bones.}

Seen from above (Plate 32, fig. 1) the endocranium only comes into view at the two ends; behind, it is largely ossified. 'The scale-like superficial bones of the roof, the nasals, frontals, and parietals $\left(n, f_{0}, p_{0}\right)$, show their radiating lines of growth; as to size, the nasals are broader, the frontals much longer, and the parietals much shorter than in the Mole and Shrew; they are more normal in this type. A large fontanelle $(f o$.$) still exists above, it spreads into sharp wings, right and left, in the$ coronal region, and in the lambdoidal to a less degree, where it runs back as a large semicircular notch in the huge, roughly crescentic interparietal (i.p.). Here this superficial cranial element that is absent from all the Edentata except Orycteropus, but constant in the Insectivora, as in the Marsupials beneath them, attains its highest 
relative develupment. The premaxillarics and maxillaries $\left(p x_{0}, m x_{0}\right)$ are not well seen in this view.

In the side view (fig. 3) the premaxillaries $\left(p x_{0}\right.$ ) are of the average size, and show a diamond-shaped oblique fucial plate, which wedges in between the nasal and maxillary on each side. The maxillaries $\left(m x_{0}\right)$ are nearly half the lengtio of the whole bony skull; the postero-superior angle runs somewhat into the orbit, and inside this process, and the one below it, the small lachrymal and its canal (l., l.c.) are seen. That space is triangular, but under the sharp style that bounds it below, there is a deep chink along which the maxillary nerve ( $\mathrm{V}^{2}$.) passes; it is unprotected on its outer side; behind this chink the general alveolar roof runs for a considerable distince.

The frontals $(f \circ)$ have a thick supraorbital edge, and a lirge concave orbital plate. The growing parietals $(p$.$) run forwards obliquely under the postorbital edge of the$ frontals, just meeting the upper and front angle of the allisphenoid (al.s). Thence, each parietal runs backwards to the antero-external edge of the azygous interparietal (i.p.); the obtuse re-entering angle formed by their junction exposes the huge auditory capsule.

There are no jugals; each squamosal (sq.) applies its small squamous plate over about a third of the lower edge of the parietal, rather in front of its middle. The jugal process does not reach so far forwards as the squamous; it only serves to carry the glenoid facet (gl.c.); the postglenoid process is very small, and the posttemporal plate small; its sharp hinder angle reaches half-way over the horizontal canal (h.s.c.) Under the squamosal the annulus (u.ty.) is just seen, and the pterygoid (m\%.) with its cartilage (pg.c.) behind the alveolar angle of the maxillary (m.x.).

The lower jaw $(l$.$) is well formed, and most of the curtilage on its three processes is$ ossified. The coronoid $(c . p)$ is twice as prominent as the angular (ag.p.), and the condyloid (cd.p.) is rounded, and definitely marked oft by a neck. The splenial region is seen in this imer view to be deficient inside MECKEL's cartilage (mk), (a part soon to be described), this is ossified, and fills a large groove all along the ramus.

The lower view (fig. 2) shows the superficial bones that form the hard palate; the premaxillaries (see also tig. $4, p x_{0}$ ) form the narrow fore part of a long ellipse, truncated behind. The dentary region is shorter and thicker than the palatine process. 'The two palatine processes together form a long lanceolate, leafy structure, with their flat, high suture, simulating a mid-rib. I could find no separate front paired vomers; as in the Mole and Shrew, these are probably connate with the premaxillary.

The short jugal process of the maxillary projects beyond the last large tooth-pulp; of these I find five large pulps in each maxillary, and three small ones in the premaxillary.

Inside the crenate alveolar wall the palatine plate of the maxillary is divided by a groove into two subequal narrow tracts. Each of these ends in front in a sharp spike, the outer binding on the inside of the alveolar plate of the premaxillary; and the inner on its puatine process; thus the anterior palatine foramina are very long slits. 
Butween the sides of the palatine plates of the palatine bones and those of the maxillares there is an oblique, fusiform fenestra. The former bones (pa.) are like two blades, they are closed, at their suture, which is nemly half as long as the maxillary snture, and have their handles behind the had palate. On each side, at their broadest part, they nearly tomeh the alveolar plate of the last tooth; they then bend inwards and become a mere oblique short tract of the wall of the nasopalatine passage. 'This wall is finished by the pterygoids $\left(p y_{0}\right)$, which aro bent inwards and downwards also, behind, where they are capped with a nucleus of cartilage (pq.e.); their basieranial flunge is moldente and continuous. 'There is no mesopterygoid centre. The tympanic (a.ty.) is a narow $U$-shaped bony staple, with its fore limb sinuous, and lobate at its end.

'The vomer (ligs $t$ and $6, r_{0}$ ) is an extraordinary structure; the main median bone is relitively smallest in the Mlarsupials, and largest in the l'enrec, if we except the abnomally long-faced Cetacea."

The low septum (fig. $6, s . n$.) and the largo thick vomer (v.) at once suggest the comparison with those of the Cetacea. This bone overlaps two-thirds of the recurent cartilages (rece), become's roughly carinate, pinches in a litcle, and then gives oft' an ala, right and letit of the shary split in its hinder end. 'The whole bone is rough and cellular, and in the hind part is undergoing absorption along certain lines, the meaning of which we shall see in the next stage.

\section{Second Stupe of Centetes ecaudatus (continued). - Endocranium and visceral arches.}

'The exposed part of the nasal labyrinth-the snout (al.n.) -is barrel-shaped; the nostrils are latero-terminal; the rest of the large labyrinth is not figured, but 1 have

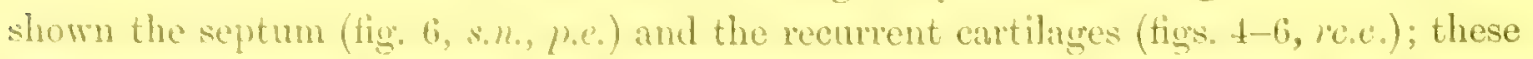
are tongre-shaped, seovped tracts, and are quite normal. The highest part of the perpendicular ethmoid (fig. i, p.e.), between the large oblique olfuctory tossa is in reality low, hut the septum nasi. proper $(\therefore n$ ), is a crest to the huge, thick intertrabecula, scaredy higher than that bar. Where the septum divides the snont, there it becomes deficient, and, inded, the partition in front of that oval fenestra is mainly formed by the fusion, back to back, of the alo nasi (al.n.); the snout is bent downwards considerably.

'The basis cranii belhind the perpendicular ethmoid (figs. $4,5,+\mu . e_{0}$ ) is beginning to ossify as the presphenoid, but the independence of this centre is doubtul in this case, as the orhitosphenoids (o.s.) have met over the middle bar (fig. 5) and are closely embrange it. These wings are about two-thirds the size of the alisphenoids (al.s.), alreaty they are quite ossified and have lost the large superlateral tract of cartilage,

* This spreies-Centetes cooudatus-is the one land Mammal that rivals the Whale in the relative length of the hend-it is one-third of that of the body.

t Figs. I and is are from the dissected endoeranium aftex it hat been pressed ont so as to display the pints. 
which did not ossify, but was absorbed. Each of these bony plates is widest above and narrowest in the middle, and the large optic foranen (II.) is well in the middle of the proximal part. When fully seen frorn abovo (fig. 5, o.s.) the hind margin has two emarginations, one large, in the middle, and one small, near the base; the projection between these notches has, on the right side, a small additional nucleus of bone (o.st.).

The posterior sphenoid is at this early stuge a single bone, for the base and the alre (b.s., al.s.) have already largely become confluent; the lower surface (fig. 4) is much larger than the upper (fig. 5), this is mainly due to the great tympanic development in the base; but the alae are partly overlaid both by the orbitosphenoids and the cuchlea $(0 . s ., c h l$.$) ; the alisphenoids are most remarkably out-thrust in these and$ oiher normal Insectivores. Half the cartilage between the basisphenoid and the presphenoidal tract of bone (fig. $4, b . s ., p_{.}$. o ) belongs to the former and half to the latter; also, behind, there is much cartilage between the basioccipital (b.o.) and the basisphenoid.

There the basal beam has doubled its width; but that is only two-fifths of the whole width of the basisphenoir, which has two crescentic wings, shell-like outgrowths, placed back to back, with their hollow fice ontside. In frorit, these tymparic wings only reach half way along the basisphenoid; behind, they overlap the basioccipital, so that they are retal in relation to their origin. The whole inferion surface of the posterior sphenoid is broken up into ridges, grooves, and holes. On each side, in front, there is a rough ridge parallel with the basul cartilinge and bone; these are for the fixation of the basictanial flanges of the palitines and pterygoids. Outside these, separater from them by a fossa, there is, right and left, a triangular wing, the external pterygoid process (e.pg.); the hollow is the pterygoid fossa; these wings spread further out than the tympanic wings, behind, and they resemble them in forn.

Outside the front of the curved tympanic wing there is a rough foramen $\left(f\right.$.ovale, $\left.V^{3}.\right)$ which on the inside (fig. 5) is a mere notch. Outside and in front of this is the hinder opening of the alisphenoidal canal (fig. 4, al.s.c.), and on the same oblique line, looking outwards and forwards, is a semioval fossar, its truncated end being at the edge of the great wing $(a l . s$.$) . On the inside this is not seen, and the bony wing has a generally$ concave face in front of and outside the foramen ovale $\left(\mathrm{V}^{3}.\right)$. The posterior clinoid wall (fig. 5, p.cl.) is low and broad; there is, lowever, a rery definite sellar depression.

The anditory capsules--here artificially squeezed outwards to display their partsare large and pyriform; they are quite normal in having two subecual osseous centres -the prootic and opisthotic (pr.o., op.). The latter, on the lower face (fig. 4),

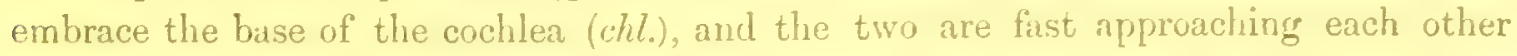
over the first coil. The prootic (pr.o.) is creeping backwards, and (fig. 5) along the front edge of the capsule.

The opisthotic is seen from below (fig. 4, op.) creeping round as an uncifurm shell, behind and under the cochlea and vestibule; it has already formed the familiar inter- 
fenestral bur between the fenestra ovalis and the fenestra rotunda $\left(f_{s .0 .}, f_{i}\right)$; above (fig. 5, op.) it has formed a roughly crescentic shell round the inside of the meatus internus (VII., VIII.). On the inside, the great anterior canal (a.s.c.) arches over the large but shallow fossa for the "flocculus" $\left(f l . r^{\circ}\right)$; the convexity behind this fossa is formed by the sims, common to the anterior and posterior canals. Below (fig. 4), the horizontal and posterior canals are seen. 'These views have, however, to be corrected by the other figmres (figs. 1-3) when the parts had not been subjected to pressure. Above (fig. 1), the top of the huge auditory convexity is seen, and then the posterior canal (p.s.c.) can just be seen where it has passed away from the anterior.

On the side (fig. 3) all the three canals (a.s.c., l.s.c., p.s.c.) are seen, showing through the hyaline cartilage, in their natural position, and leaning backwards: a normal state of things for a Mammal.

Below (fig. 2), in the undisturbed condition of all the cranial elements, the horizontal and posterior canals (h.s.c., p.s.c.) come well into view and meet at a right angle. But the ampulla of the horizontal canal is, here, hidden by the epihyal (e.hy.), which is confluent with the capsule, and by the facial nerve (VII.) passing through the stylomastoid foramen.

The occipital arch must be described from the figures of the complete skull (figs. 1-3) as well as from those of the outspread endocranium. 'The keystone (figs. 1, 2, s.o.) is very large, and its evenly emarginate fore edge is adapted to the hinder round edge of the still larger interparietal (i.p.). The cartilagre is wide between it and the exoccipitals (e.o.), and they are separated by a tract, half their own width from the polygonal basioceipital (b.o.) whose hind margin is notched to form the fore boundary of the large foramen magnum $\left(f_{.} m_{0}\right)$. The occipital condyles (oc.c.) are long-oval in size and shape, and are modcrately convex.

The foramen condyloideum (XII.) just behind the chink for the 9th and 10 th nerves (IX., X.) is through the thick cartilage in the lower edge of the ex-occipital.

The deep mandible $\left(m k_{\text {. }}\right)$ in its proper mandibular part, inside the superficial "ramus" is now invested, ronghly, with bone, possibly derived from the dentary (d.). Under the condyloid process of the ramus (cd.p.) the proximal part of MEckeL's cartilage has acquired a styliform ectosteal plate, and this is spreading over, and growing into, the head of the malleus $(\mathrm{ml}$.) nearly up to the articular condyloid facet for the incus. That facet is leep and selliform: below it, the hinder margin of the malleus is semicircularly notched, and has an unciform angle.

From this angle, and from the lower edge of the bony centre, the main enlargement grows obliquely forwards; it then dips to form a subglobular posterior angular process (p.ag.) from which the manubrium (fig. $7, m b$.), arcuate and dilated at its free end, passes forwards. The incus (i.) is perfectly normal; its straight, conical "short crus" (s.c.i.) is large, and its "long crus" (l.c.i.) is thick, well inturned, and has a short-oval orbicular plate for the stapedial head; the body of the incus is rapidly ossifying from the hinder concave margin. The stapes (st.) is very short, has an almost circular fenestra, and 
a very perfectly limbate margin, with a flat outer face all round, for insertion into the fenestra ovalis. I did not find any interhyal segment. 'The short round epihyal (fig. 2, e.hy.) is followed by membrane up to the equally small hypohyal (fig. 8, h.hy.).

The basal piece $\left(b . h_{*}, r_{\%}\right)$ is a longish transverse bar, narrow in the middle where it is beginning to ossify, and then where it reaches the hypohyals it is thicker; thence, at a very obtuse angle, the thyrohyals (t.h\%) grow outwards and backwards, without any sign of segmentation from the basal piece.

\section{Third Starge. - I vung of Centetes ecaudatus; $3 \frac{1}{4}$ inches long.}

\section{The incesting bones of the skull.}

At this stage, before the development of the crests and ridges seen on the hind skull in the adult, " the general form is like that of a Mlole, or still more of a Shrew, as there are no jugal bones. Very little of the great fontanelle is now visible at the junction of the parietals and frontals, and the whole investiture of bony plates is strong and smooth; ossification takes place very rapidly in this type, but not so rapidly as in the Marsupials, whose premature birth is provided for by precocious ossification of the skull. Behind the moderately long, and rather slender snout $(a l . n$.), the skull is at first narrow, and then widens gently to its orbital "waist;" the temporal region is the widest, notwithstanding the great size of the maxillaries with their large teeth and tooth-sockets (Plate 33, fig. 1). In the upper view, we see that the nasuls (fig. $2, n$ ), flanked by the premaxillaries and muxillaries $\left(p x_{0}, m x_{.}\right)$, art long, and already give promise of the intense ossification of the Tenrec's skull.

The notch between the nasals in front is followed by a suture dividing their fore third, and behind, there is a slight division; for the rest they are thoroughly confluent. The frontals $\left(f_{0}\right)$ are louger than the nasals, but their mutual suture-the frontal-is only two-thirds the length of the bones, as the nasals run their double wedge far in between them. The frontals, in turn, to a less degree, divide the parietals ( $p$.$) , and$ their strong suture-the sagittal-is only two-thirds the length of the frontal suture. There is a remarkable amount of mutual inter-wedging above, in the preorbital region, for the frontals divided by the nasals run forwards between the maxillaxies and the nisals, whilst the lesser premaxillaries do the same between the nasals and maxillaries, in front, so that the latter only rench the middle part of the nasals for a short distance.

The supraorbital region of the frontal passes very gently down into the orbital, and each bone gently widens out to the posturbital corner. From the $V$-shaped coronal suture the parietals widen at first very little, and then suddenly in the temporal region; they are bounded behind by the huge interparietal (i.p.), and divided from it by the lambdoidal suture.

The suture is, here, an inverted $V$, and is similar to the coronal; its crura are concave in front, those of the coronal are arched forwards. The dentation of these 
non-persistent sutures is very strong, as in the Salamander's skull. The hinder outline of the parietals and interparietals, together, is a very neat semi-circle, just flanked, and made to look irregular by the partial view, in this aspect, of the squamosal, auditory, and supraoccipital bones.

In the side view (fig. 3) the parts just spoken of as flanking the great roof-bones, come fully into sight, as also the bones of the upper face, so imperfectly seen from above.

Behind the deflected snout $\left(a l_{0} n_{0}\right)$, the strong, oblique, unciform premaxillary facial plate $\left(p x_{0}\right)$, is seen with its sharp and rather large teeth; over it the nasal $(n$.$) is seen$ somewhat; the maxillary ( $m x_{0}$ ) is nearly half the length of the whole bony skull, and is a notable prophecy of what this bone, with its heavy burden of teeth, will become in the great herbivorous Eutheria; from its rounded edge, closely fitted to the premaxillary, it runs backwards as far as the coronal suture, ending there as a flat, free jugal process. A low triangle, its posterior edge is shorter than its anterior, and that is the most irregular. That irregular edge bounds the front of the badly enclosed orbit; near its upper part, the squamous, perforated lachrynal $(l ., l c$.$) fits into a deep$ recess, and below this the great infraorbital foramen $\left(\mathrm{V}^{2}\right.$ ) runs on, forwards, as a large groove; it is very feebly finished, outside, by an arched bar which articulates with the lachrymal. Behind that suture the maxillary is seen as a large rounded lobe of bone, the outer alveolar wall of the two last molars, and the jugal process, ali in one tract. Even now the frontals and parietals have separate convexities, that of the former is the higher of the two. 'The orbital plate is notched where the 1st branch of the 5th nerve $\left(V^{1}\right.$.) re-enters the skull, and there the frontal, parietal, orbitosphenoid and alisphenoid, all approach each other. In the temporal region the parietal swells over the squamosal, whose scale-like temporal flange overlaps the lower edge of the former; it is sharp at its fore corner, where it lies on the projecting alisphenoid, and it turns upwards in its post-temporal region, to bind, tightly, between the parietal outside, and above, and the auditory capsule within, and below. The oblique retreating front margin of the squamosal is notched, and meets its outer oblique edge at an obtuse angle, beyond the glenoid cavity $(g l . c$.$) ; it scarcely projects at all as a jugal process.$ The lower postglenoid facet binds upon the canal-region of the auditory labyrinth by its ollique, toothed, and notched posterior margin. This side view shows the interparietal (i.p.), the pterygoid hook (pg.) and the annulus (a.ty.). At present, therefore, the temporal fossa is badly enclosed, and the sagittal and lambdoidal crests have no existence.

In this same side view the mandible is seen as an almost crescentic bone; the axis of the ramus and of the ligh coronoid process $(c p$.$) , being coincident. The three$ processes are almost equal, for the smallest of the three, the angular (ag.p.) is larger than it seems to be as seen from the side; seen endwise (fig. $3 \mathrm{~A}$ ) it has a thick limbate inturned edge, and is manifestly Marsupial. The condyloid process (cd.p.) is ovil, transverse, and has the narrow end inwards. The dentary canal can be seen 
from behind, protected by a wing of bone in the true coronoid region, and the remarkable thickness, roundness, and solidity of the ramus is also shown.

The lower view (Plate 21, fig. 1) shows a large pyriform tract, two-thirds of the whole inferior area, covered with superficial bones. The premaxillaries $(p x$.) bave a considerable dentary edge, and long, slender, compressed palatine processes. Each large maxillary ( $m x$.) shows on this face three tracts, first, the series of alveoli, expanding from before, backwards; then the outer part of the palatine plate wrought into subtransverse ridges, and hollow with perforations; and, close to the mid-line, a narrow tract, on a higher level. The two halves of the palatine plate end, in front, as spikes, the inner binding on the palatine process, and the outer on the dentary region, of the premaxillary. The inner tracts run short behind, the palatines ( $p a$. ) wedging in, in an irregular manner; the outer reach as far backward as the alveolar walls, binding strongly on the outer face of the open part of the palatines. The rough splintery fore part of the palatine plate of the palatines is split for some distance, and then towards the transverse ribbed edge, behind, shows the posterior palatine foramen $(p \cdot p . f$.$) . Where the nasopalatine passages open, there both at the middle part$ and the sides each palatine bone is thick and solid; and then, suddenly thinning out, they bind on the small subparallel blunt-hooked pterygoids (pq.); the pterygoid fossie are very indefinite.

Over the opening of the nasopalatine canal the vomer $(v$.$) is just seen in its$ hinder part; and on the right side of the figure the annulus $\left(\iota_{0} . y_{0}\right)$ is shown, with its thick twisted anterior, and its sharp posterior, crus. The orbital plate of the frontal $\left(f_{0}\right)$ is seen in the distance, and the squamosal (sq.) shows its obliquely oval glenoid facet (gl.c.), its stunted jugal process, and its short, strong, three-limbed postglenoid tract, with the postglenoid pneumatic foramen, close to the glenoid cartilage.

On the hinder face of the skull (fig. 4) we get an imperfect view of the parietals, interparietals, squamosals, and tympanies ( $p_{0}, i . p_{0}$, sq., a.ty.).

On the inside of the skull, with the septum (s.n., p.e.), perfect, and shown from its left face, we get an instructive view of the investing elements of the skull. In front we see the nasals ( $n$.) above, and the palatine process of the premaxillary $\left(p \cdot p x_{0}\right)$ severed from its body below; and behind it, at the lower edge, the palatine plate of the maxillary and palatine $\left(p_{0} m x_{0}, p^{\prime} a_{0}\right)$, and the free retral hook of the pterygoid (pg.), growing from its ascending plate.

Above, the frontals $\left(f_{0}\right)$, at their edge, and in their orbital region, and the parietals and interparietals (p., i.p.) ; the imbrication of the parietal over the frontal is very great; that of the squamosal $(s q)$ below, over the parietal, is very moderate; over this latter squmous suture the elegant furrow for the lateral sinus (s.c.) is well seen.

But the most remarkable of all the investing bones still remain to be described, and are best seen in this view; these are the large vomers (Plate 33, fig. 5, v., $v^{\prime}, v^{\prime \prime}$.). In the earlier stage (Plate 32) I failed to tind a distinct anterolateral vomer; this bone appears to be comnate with the palatine process of the premaxillary, as in some other MDCCCLXXXV. 
kinds. It is represented here (Plate 33, fig. 5) by the rising on the upper edge of the palatine process of the premaxillary $\left(p \cdot p_{0} x_{0}\right)$ close in front of the foremost vomer $\left(v^{\prime} \cdot\right)$.

Here the posterolateral vomers that bind the hind part of the main vomer $(v$ ) to the lateral ethmoidal masses (Plate 33, figs. 5 and $8, v^{\prime \prime}$.) are well developed but not large.

The main vomer of the unripe embryo (Plate 32, fig. 6,v.) was shown to be extremely large, thick, and spongy; now (Plate 32, figs. 5, 8) it is in three pieces; and these are not arranged on one plane, as in the Marsupials (which, as I shall show in my next paper, have many separate vomers) but the large upper bone (v.) lies in the trough of the two lower pieces. These occupy about the first and second third of its length (see also fig. 8, showing the hind part of the second lower piece ( $v^{\prime}$.), and the hind third of the main bone v).

The subdivision of a primarily single centre is much more frequent in the higher Vertebrata than I had imagined, a process curiously in contrast with that more familiar phenomenon-ankylosis of primarily distinct bones.

This special peculiarity of the Tenrec, and of the Centetidre, generally, as I shall soon show, is, after all, merely a modification of the Marsupial type of structure, and it is not the only instance in its skull of a now Insectivorous character formed by a very gentle modification of an old Marsupial one.*

I have already referred to the only other splint-bone to be noticed, namely, the annulus tympanicus (figs. $1,3,4$, a.ty.); this, as seen from the inside, separated from the skull (figs. 6 and 7, (a.ty.), is an imperfect ring of bone, convex on its outer side, ribbed at the edge and then scooped on the inner side; it is irregularly crenate on its inner, growing edge; its elongated front limb binds strongly on the outer side of the huge processus gracilis of the malleus $(p \cdot g r$.$) .$

\section{Third Stage (continued).-On the endocranium of the Young T'enrec.}

By a comparison of what is shown in the various figures just referred to we shall be able to understand the structure of the inner skull; the younger stage (Plate 32) will help us in the interpretation of its parts and regions.

The snout (fig. 3, al.n.), as seen from the side, leans over at the fore end; the nostril (e.no) is large, oblique, and well surrounded by a valvular fold; it is also made more complex by an internarial lobe, above. The fenestra in the fore part of the septum, seen in the last stage (Plate 32, fig. 6, s.n.), is now filled in with cartilage,

* The process itself, by which a thick spongy bone splits into concentric laminæ, is quite like that which is scen in the bark of the Plane tree (Platanus). Considored architecturally, in the building of the skull, it is oddly unlike anything wronght by art or Man's device; and as a mode of the imbrication of bony sentes, everywhere, from the Ganoids to the highest Mammals, so familiar to us, this is (apparently) nuique. The greater part of the huge rounded septo-ethrnoidal base, or intertrabecula, lies over one large semitubular balk, which is, itself, sheathed by two similar but smaller semitubular pieces. 
and the great partition is complete from front to back (Plate 33, fig. 5, (l.n., s.n., p.e.); that tract, now partly bony (p.e.), is clmost three-fourths the length of the whole basicranial axis, for a time, in this young suckling. The liuge rounded intertrabecular base of the septum is, in the figure, largely hidden by the vomers, whose swelling form, however, tell of the bulk of the mass of cartilage covered by them. The septum nasi $\left(s . n_{0}\right)$ is low, and the perpendicular ethmoid (p.e.) rises to no great height between the large cribriform plates $(c r . p$.$) . Theze is no cartilaginous crista galli;$ from the free margin of the partition, a little forwards and then backwards, two-thirds of the way to the presphenoid $(p . s$.$) , the perpendicular ethmoid is bony, already.$ Bone is now seen in the base between the two orbitosphenoids; this is the presphenoidal region $(p . s$.$) , doubtfully or only partially independent as a bony centre.$ The orbitosphenoids (o.s.), and alisphenoids ( $\left(l_{\circ} ._{\circ}\right)$ are scarcely seen at all in this internal sectional view, they lie down so low, infero-laterally. But their upper margin is shown, and in the other lateral view (outside, fig. 3) their structure and relations can be seen.

The optic nerve (tig. 3, II.) emerges above and inside the wide sphenoidal fissure $\left(\mathrm{V}^{1}, 2\right)$; its passage through the middle of the proximal part of the orbitosphenoid was shown in the last stage (Plate 32, fig. $5,0 . s_{.}$, II.). The orbitosphenoid is also seen-min the distance--in the lower view (Plate 33, fig. 1, o.s.) bound upon by the orbital plate of the frontal $(f$.$) .$

The posterior sphenoid forms a very large part of the endocranium, and attains here its fullest development as a special (Insectivorous) type. The overlapping of the orbitosphenoid by the alisphenoid is seen well in the side view (fig. 3, o.s., al.s.), and in that aspect the formen ovale $\left(\mathrm{V}^{3}\right.$. $)$ and the additional hole or hind opening of the alisphenoidal canal ( $a$ l.s.c.) in front of it also; the front overlapping lamina mounts up, and is seen under the junction of the frontal parietal and squamosal; the external pterygoid process is aborted. Below (fig. 1), the posterior sphenoid is seen to extend from the place where the maxillaries overlap the palatines in front, to the foramen lacerum posterius (IX., X.), behind; thus this great region ends, behind, opposite the middle of the basioccipital $($ b.o.). This extreme front and hind extension is peculiar to the typical Insectivora, and is due to the forward growth of the alisphenoid at a good distance outside the orbitosphenoid, so making the sphenoidal fissure a side passage to the skull; whilst, behind, the tympanic wings of the basisphenoid grow beyond their root, and thus extend that bone, backwards.

There is still some cartilage at the mid-line in the fore part of the presphenoidal region (fig. 5, \%.s. ), but where ths two orbitosphenoids have met further back the bony base is complete, and that tract has already coalesced with the fore part of the independent basisphenoid $\left(b_{. s}\right)$ (see also Plate 32 , figs. 4, 5, p.s., b.s.), the basisphenoidal region is full twice the extent of the presphenoidal. The remarkable hollow under the fore part of the basisphenoid of the Hedgehog (Plates 17, 20, and 21) is also seen here, and the pituitary floor (sella turcica) is perforated; this hole,

$$
242
$$


however, appears to be secondary and not primary as in the Hedgehog. I did not see it in the embryo (Plate 32, figs. 4, 5, b.s.), so that this character is not primary, as in the Hedgehog.

The tympanic wings $\left(t . b . s_{0}\right)$ are more clearly marked off from the main basal bone than in the Hedgehog; and thus a clue is got to their real nature; they are mere periosteal outgrowths, and, had they arisen independently, their homology with the "ossa bullæ" of the Marsupial would have been seen at once; they are the morphological equivalents of those bones. These tracts are roughly in the shape of the shell of a bivalve Mollusk, but they grow inwards; in front, the right and left processes meet. Behind this junction only a small triangular space of the basisphenoidal bone is seen, it is somewhat apiculated; at the middle, the synchondrosis is still present. These shells (or wings) grow outwards and backwards some distance beyond their root.

The alisphenoids are confluent with their common key-stone piece (al.s., b....), they are very large, reaching from the fore-third of the tympanic wings (fig. 1) to the bottom of the coronal suture (fig. 3). Thus they lie over the large tympanic cavity in its front-third; they also, like their basal piece, have developed a large tympanic wing (t.al.s.) in front of the tympanic cavity; this wing has converted the hinder angular notch (Plate 32, figs. 4, 5; and Plate 33, figs. 1, 3) into a foramen-the forctmen ovale $\left(V^{3} \cdot\right)$.

The hole through the alisphenoid, further forwards, is the hinder opening of the alisphenoidal canal (al.s.c.); the 2nd branch of the trigeminal escapes through the sphenoidal fissure. The subdistinct tympanic alæe of the basisphenoid, the very large alisphenoids, and their tympanic wings, are all characters that are Marsupial, or nearly so.

But the internal carotids do not enter the skull ihrough the basisphenoid ; there is no foramen rotundum; there is a hollow recess under the basisphenoid, and the alisphenoids have broken away from the general skull wall, far outside the orbitosphenoids. In Marsupials, however, this does not take place, but the planes of these alæe are coincident, and the alisphenoid, as well as the orbitosphenoid, ossifies upwards into the great supero-lateral band of cartilage.

All these things are intelligible; these low Eutheria are developing typical characters, which are curiously mixed up with certain archaic characters inherited from the forms on a lower level (Metatheria), from which these Insectivores once sprung.

The auditory capsules are relatively less now than they were in the umripe embryo (Plates 32, 33), only the supra-auditory crest-running into the supraccipital, where it is joined by the exoccipital - is still cartilaginous.

The cochlex (fig. 1, chl.) are well formed, and their position is almost transverse; the tegmen tympani is burrowed by the facial nerve (VII.), which emerges behind and within the stunted epihyal (e.hy.); behind the stylomastoid foramen) 
the opisthotic region grows into a distinct mastoid process. The fenestra ovalis ( fs.o.) is seen inside the canal for the facial nerve, and the large fenestra rotunda $\left(f_{.} . r_{0}\right)$ is reniform, being notched somewhat in front. A considerable tract of the bony capsule is seen behind the squamosal (figs. 3,4$)$; the canals ( $($ s.s.c., h.s.c., p.s.c.) mark this part, but the anterior canal is best seen on the inside (fig. 5), in front of the recess for the "flocculus $\left(f l . r_{0}\right)$." Behind this moderate hollow the thickened bone contains the common sinus of the anterior and posterior canals. The large meatus internus (VII., VIII.) is oblique, going backwards and downwards; the passage for the facial nerve, in front, is well marked. The occipital arch has its elements still separated by considerable tracts of cartilage; the basioccipital (b.o.) is a sinuous, transversely polygonal plate, sharply notehed in front, where the notochord ran, and having a concave margin behind, at the foramen magnum. The supraoccipital (s.o.) is a large shield of bone, thickened and convex along its middle, and arching over the foramen magnum by its lower edge. The exoccipitals $(e .0$.$) form a very small paroccipital$ ridge behind the mastoid process; the foramen condyloidem (XII.), close behind and within the posterior lacerated foramen (IX., X.), is large. The whole arch is small relatively to the rest of the skull, and this is Eutherian in this respect.

Meckel's cartilage (figs. $3,6, m k$.) is being lost in the mandible in front; where it has become free behind, tracing it backwards and uprwards, it is still quite thick and is endosteally ossified, continuously with its proximal part, the malleus (ml.). T'The primary ossification (Plate 32, fig. $7, m_{\text {. }}$ ) is ectosteal, and now, on the inside, this in roughly and imperfectly subdivided into three bony laths, binding the front of the head of the malleus, which is now well ossified throughout, the endosteal tract seen in the early state (Plate 32, fig. $7, m l_{0}$ ) having used up all the cartilage except the selliform condyle.

Here we have the counterpart, first, of the endosteal or inner articulare of the Sauropsida; and then the outer articulare, the supra-ingulare, and the angulare of the endocranial mandible, in a state of imperfect differentiation.

Below the condyle the malleus projects towards the incus $\left(i_{0}\right)$, the head is then bent on itself, growing obliquely forwards; it gives off two processes, manifestly equal to the internal and posterior angular processes of the Bird; the latter is represented here by a rounded knob ( $\left.\operatorname{cg} . p^{\prime}\right)$, and the former by the long striight, slender manubrium (mb.). On the outside the inalleus is strongly tied by the anterior crus of the annulus (figs. 7 and $8, a . t y$.$) ; behind that bar the malleus grows into a crescentic$ foliaceous plate and is concentrically grooved to a less degree in front of the condyle, and much more in front of the foliaceous outgrowth. All these things admit of no Teleological interpretation, but show that the hinder third of the Sauropsidan type of mandible is here aborting itself, so to speak, into an Eutherian malleus.

The incus (fig. $6, i$.) is well formed; the short crus (s.c.i.) straight and conical, and the long crus (l.c.i.) is short, eapped with an orbicular facet where it turns inwards to articulate with the stapes. 
The stapes (st.) is thoroughly typical, having an unusually large foot-hole. I see no interhyal in the hinder of the stapedius muscle (st. $m$., see also Plate 32, fig. 7).

The very Marsupial os hyoides (fig. 9) has small, unossified hypohyals (h.hy.) on a transverse basihyal $\left(b . h . b r_{0}\right)$; this is ossified now, and so are the thyrohyals $(t . h y$. which are now segmented from it; they were not in the last stage (Plate 32, fig. 8).

Going back again to the olfactory region, we find that the nasal, inferior, upper, and middle turbinals (fig. $10, n_{0} t b ., i . t b ., u_{.} t b ., m_{.} t b$. ) are large and well developed, but at present they are cartilaginous.

For a description and figures of the adult skull the reader is referred to Dr. Dobson's invaluable work (Part I., p. 72 ; and Part II., plate 8). The whole structure is as much modified from what I have shown in the young (Third. Stage) as that is from the skull of the unripe embryo (Second Stage). Its great length, and the large size of its transverse and longitudinal crests, make it one of the most remarkable skulls in the whole Order.

\section{On the skull of Hemicentes (sub-adult).}

For figures and a description of the adult skull of this type the reader is referred to Prof. Mivart's Paper (Proc. Zool. Soc., Jan. 17, 1871, p. 58), and for a further account of this type to Dr. Donson's Monograph (Part I., p. 69).

Fortunately, my specimens--one of $H$. madugascuriensis (Plate 34, figs. 1-5), and another of H. nigrescens (Plate 34, figs. 6-9)-were not quite full-grown, and therefore yielded me better results for my special work than older skulls would have done.

\section{On the investing bones of the shull of Hemicentetes.}

This extremely elongated skull gains its great length, as in most other Mammals with a long head, not by elongation of the premaxillaries, as in longirostral Birds, but by the great length of the maxillaries and nasals.

The upper view (Plate 34, fig. 2) shows that the nasals $\left(n_{0}\right)$ are more than half the length of the bony skull; they are much separated in front, and their suture only reaches to the middle; in their hinder half they are completely anchylosed. The fore part of each is a mere style of bone; the united hind part is a convex lanceolate tract, overlapped at its edges by the thin internal edge of the divaricated frontals $\left(f_{0}\right)$. The facial plate of the premaxillaries ( $p x$.) is about a fifth of that of the maxillaries $(n x$.$) , but the upper margin is extended backwards between each nasal and maxillary,$ so as to keep those bones apart for the front half of their related edges. Each maxillary shows two regions laterally, the lower or alveolar is seen in the distance in this view, but the upper is in full view, it runs well up to the badly defined orbit; the whole of this upper facial tract is a long, gently convex lath of thin, but strong, bone ; it reaches a little further backwards than the nasals, and, below and behind, shows between itself and the alveolar part, the infraorbital opening $\left(\mathrm{V}^{2}\right.$.). 
'The frontals and parietals $\left(f ., p_{0}\right)$ have a nearly equal uxiul length, but the former' are far inferior to the parietals in width.

The frontal and coronal sutures are perfect, at present, and are semi-squamous; the two frontals mutually overlapping each other, in this place and that, and the parietals overlapping the frontals laterally.

Where the frontals are wedged in between the nasals and maxillaries there they are very thin, sharply angular in form, and splintered at their edges.

Behind, they run in between the parietals, with strong dentations; their orbital edge is rounded and smooth, and has a gently arcuate outline. 'The parietals ( $p^{\prime}$ ) r'un as far forwards, below, as they retreat, above; inside the gently concave temporal fossæ, they swell together, into a dome-like structure, which is divided by the sagittal suture. This is larger than the general convexity of the frontals; but it is enlarged still more by the subconcave part which extends into the temporal fossæ. 'The squamous suture with the squamosal (sq.) is not well seen from above; the wedgelike fore part of the interparietal $(i . p$.$) is more clearly defined than its narrow,$ extended outer wings; it is rather a large bone, and is convex above, where it fits to the fore margin of the supraoccipital (s.o.). It there forms the lambdoidal crest; but the sagittal crest has not any existence, at present, and there is a shallow concavity running across the skull where the parietals and interparietals meet, which connects together the two temporal fossie.

The side view (Plate 34, fig. 3) brings ont things that are not well seen from above; it shows a dorsal line gently sinuous, with even fewer interuptions than the lateral outline which is broken by the hind part of the maxillaries; compared with normal skulls it looks as though it had been artificially elongated whilst in a plastic state; the great distance of the teeth from each other increases this appearance. 'The dentary edge of the premaxillary $(p x$.$) is only one-fifth the extent of that of the$ maxiliary $\left(m x_{0}\right)$; the whole line is gently sinuous, convex in front and behind, and concave in the middle. The nasals (n.) are scarcely seen from this aspect, but the maxillary is well displayed, with its upper facial plate, its infraorbital hollow passage and narrow bridge $\left(\mathrm{V}^{2}\right.$.), and the liils and hollows caused by the series of teeth. The maxillary ends, behind, in thin lobes, the upper of these is broad, and overlaps the small angular lachrymal $\left(l_{0}\right)$ with its canal $\left(l_{0} c_{0}\right)$ in front, in the notch between the upper and lower outer lobes; the lower lobe is sharp and upturned, it is the end of the alveolar region. The third lobe is a Hattish tridentate tract, further inwards, and binds upon the palatine $\left(p \alpha_{0}\right)$. The orbital plate of the frontal $\left(f_{0}\right)$ runs down to the middle tooth of this inner lobe of the maxillary; its hollowest space is the shortish tract between the lachrymal and the overlapping parietal. The hinder and most convex part of the frontal where it passes under the parietal is not marked by any lines or grooves, but in front of that tract it is sinuous, rising and falling over the turbinal coils within, which shine through it, is through a thin plate of horn. The hinder margin of the orbital plate is notched, deeply, by the outstanding alisphenoid 
( $a l_{\text {s.) }}$, and behind this part the narrow fore corner of the parietal lies over it. The parietal, in this aspect, is seen as a fine shell of bone, with its hinder three-fourths overlapped by the squamosal. That scale is perforated at its hinder part, near the almost straight squamous suture.

The squamosal (sq.) is ribbed (or limbate), outside, the fore part of the thick edge being the rudiment of the jugal process, which however scarcely projects beyond the glenoid cavity (gl.c.). The thick, ribbed enge dips and forms the post-glenoid tract behind its middle; it then rises, and runs into the low lambdoidal crest, which is formed above by the interparietal $\left(i . p_{0}\right)$. The palatine $\left(p a_{0}\right)$ is hidden by the maxillary in this aspect, but the pterygoid $(p g$.$) is seen with its short, blunt hook; the tympanic$ $(a . t y$.$) also just comes into view.$

'The dentary zegion of the lower jaw $\left(l_{0}\right)$ is not much more than half the length of the ramus; it is as remarkable for its slenderness, as the hinder, shorter part is for its breadth. The coronoid process (c.p.) is small, and uncinate; it is separated from the large, well-formed condyloid process (cd.p.) by a round notch. The angular process $\left(a g . p^{\circ}\right)$ is separated fiom the condyloid by a round notch twice as large as the upper: it is twice as large as the coronoid, and also uncinate; hooking towards the coronoid hook. Below, the angular process is notched and another third sharp hook is seen; there (see also fig. 5) the bone is very thick, and both the thickening and the hook are curved inwards, as in Marsupials. The outer face of the broad divided part of the ramus is made concave by the outward leaning of the coronoid process (fig. 5).

The lower view (fig. 1) shows the peculiar lathiness of the palatal region, the bones having much the character of those investing the face of the embryo of a longirostral Bird.

The premaxillaries $\left(p x_{0}\right)$ show four parallel tracts; the two outer are the alveolar, and the two inner are the palatine regions, and these are separated by a deep cleft, ending in a round notch in front, where JACoBsos's organs (j.o.) open in the anterior palatine foramina. Right and left of the median suture each maxillary palatine plate is split half-way backwards to the palatine bone $\left(p a_{0}\right)$; the inner spikes bind on the inner spikes of the premaxillaries, and the outer splintery, interalveolar tracts bind against the alveolar tracts of the premaxillaries. Then each palatine plate of the maxillary is hollow at the mid-line, and against the alveoli, and convex along its middle, up to the palatine bone, which impinges upon the hinder third of the maxillary. This latter bone then divides into a short jugal and a long inner process. 'he hollow behind the last tooth is the infraorbital canal ( $\mathrm{V}^{2}$ ), and the small, bony bridge over it is seen in the distance. The palatines $(p a$.) are very long, nearly as long as the submesial part of the maxillary palatine plate; they run in under those tracts, first with an imner, and then with an outer spike; only their front two-fifths is complete up to the mid-line, for they soon form a thick short process, which meets its fellow at an obtuse angle over the open nasopalatine passage. Each palatine is there convex, and a little broader than the open space in the middle; the bone wideus to 
bend on the end of the maxillary, and is then cut away, so to speak, to receive the fore part of the ascending plate of the pterygoid $(p g$.$) . The latter spreads ont under the$ basisphenoid $\left(b_{.} s_{0}\right)$, and is ankylosed with it, some distance behind and above the hamular process or hook. In this view the orbital region of the frontal $\left(f^{\circ}\right)$ is seen in the distance, a large space existing between it and the bulging alisphenoid. On the right side of the figure the annulus $(\alpha . t y$.$) is shown; it is well formed, convex$ outside, has a retrcating, broad, notched, anterior crus, and a strong, crescentic hinder crus; both these crura are strapped on to a strong ridge of the squimosal, inside and behind the oval glenoid cartilage $\left(g l_{\circ}.\right)$. Round that facet the latter bone is thickened everywhere, though the inner and front part of that thickening is the stunted jugal process. The post-glenoid tract bends back against the bony auditory capsule and the inner edge is excavated, and united by a serrated suture with the tympanic wing of the alisphenoid (al.s.), thus helping to form the tympanic cavity, as well as to enlarge the tegmen tympani.

In the end view (fig. 5) the investing bones (i.p., p., sq.) are but little seen; a side view of the septum of the olfactory organs (fig. 8) shows the large and remarkable vomerine series of bones. These are quite similar to those of Centetes (Plate 33); there is a large upper semitubular vomer, proper $\left(l_{0}\right)$, and two lesser semitubular bones sheathing it $\left(v^{\prime}.\right)$. Behind, the main bone has attached to it a pair of posterolateral centres $\left(v^{\prime \prime}.\right)$; the antero-lateral vomers are not distinct from the palatine processes of the premaxillaries $\left(p x_{0}\right)$.

\section{The cndocranium of Hemicentetes.}

The snout $(a l . n ., e . n$.$) is straight and bulges at the end and below; the nostrils are$ surrounded, except below, by a valvular fold of cartilage, they look downwards and forwards, and the antero-inferior face of the snout is oblique. The fore part of the septum nasi (fig. $7, s_{.}$. .) is obliquely oval, answering to the form and direction of the snout; the rest is a very low crest to a very solid and well-narked intertrabecula (i.t.). Where the septum becomes ethmoidal there it rises into a low triangle, and is ossified as the perpendicular ethmoid (p.e.); it las a kidney-shaped swelling with the "hilus" looking forward, just in front of its free inter-olfactory crest. The whole septum is rather saddle-backed; it has a considerable cartilaginous tract behind, between the large bony plate and the presphenoid $(p . s$.$) . The latter tract is hidden from view in$ the lower aspect (fig. 1 ) by the main vomer $\left(v_{0}\right)$; the orbitosphenoids (o.s.) can be seen in the side view (fig. 3), they are perforated by the optic nerve (II.) as can be seen by looking forwards through the foramen magnum. In that figure the alisphenoids (al.s.) can be seen both above, where they form the curious thin dentate onter wall to the intersphenoidal passage, and also below, where the hinder openings of the alisphenoidal canal $\left(a l . s c_{*}\right)$ is seen a little in front of the foramen ovale (V.). That caual opens in front into the general cavity of the wide "sphenoidal fissure" (or passage). 
In the lowe view (fig. 1), the foramen ovale $\left(\mathrm{V}^{3}\right.$ ) is seen just inside the stunted jugal process of the squamosal and the glenoid facet $(g l . c$.$) , but the canal (al.s.c.) is$ hidden by a lamin of bone, and the extremely outward position of the thin shell-like alisphenoidal wall is seen, and the crescentic notch that emarginates its oblique front edge. The huge alisphenoid-nearly as large as in a Marsupial-forms, behind the foramen ovale $\left(\mathrm{V}^{3}\right)$, an oblique strongly dentated suture with the inner edge of the squamosal, and then becomes hollow over the tympanic cavity, outside the tympanic wing of the basisphenoid. The hinder edge of that supratympanic lamina is deeply notched, and terminates close in front of the cochlea (chl.).

The shell-like tympanic wings of the basisphenoid (t.b.s.) reach as far forward as the foramen ovale $\left(\mathrm{V}^{3}.\right)$ in front, and nearly to the fenestra rotunda $(f, r)$ behind; they are manifestly "bullee" that have lost their distinctness from the basisphenoid, whilst the hollow cavity of the greatly extended alisphenoid is, as surely, the counterpart of the tympanic wing of that bone seen in Marsupials. The hollow, in front, under the basisphenoid, is present, but it is not so much marked as in Centetes; the rest of the basisphenoid is of an hour-glass shape and is somewhat carinate; its hind edge is bracket-shaped and is separated from the basioccipital (b.o.) by a clear synchondrosis.

The auditory capsules are ossified; there is, however, some cartilage near the horizontal canal (fig. 1, h.s.c.); this is the small epihyal (e.hy.) in front of the foramen stylo-mastoideum (VII.). The cochlea (fig. 1, chl.) is well formed, and the fenestræ $\left(f_{s \circ}, o_{0}, f^{\circ}\right)$ are seen outside and behind it, also the chink and channel for the facial nerve (VII.) emerging, from the cranial carity. The horizontal and posterior canals (h.s.c., p.s.c.) are seen on the ontside, showing throngh their thin bony walls. Behind the posterior canal there is a bony ridge, and then a suture between that ridge and the short paroccipital process (p.oc.). The basi- and exoccipitals (fig. 1, b.o., s.o.) are confluent; the supraoccipital (figs. 1, 4, s.o.) is a very large distinct shield of bone, cut away in a semicircle, over the huge foramen manum; the condyles (oc.c.) are lare, pyriform, and wide apart.

The "ossicula," separately figured on a large scale and seen from within (fig. 9), attacher to the thick-rimmed middle-sized aunulus $(\alpha . t y$.$) , are worthy of note.$

The cartilage is gone in front and has left a large tongue-shaped processus gracilis (p.gr.), twice as large as the manubrium (mb.), and parallel with it. The body of the malleus is at a right angle with these handles, and is of great extent. Over and in front of its condyloid facet there is a large solid helnet of bone; behind that facet the hind margin projects backwards as a rounded elbow; and below the root of the manubrium there is a subglobular "posterior angular process" (ag.p.) - a familiar Sauropsidian remnant.

The incus (i.) and the stapes (st.) are large, well-formed, and quite typical.

A small hypohyal (fig. 6, h.hy.), equal to the epinyal (fig. 1, e.hy.) above, is attached to a transverse basal bar $\left(h, h, 6 v^{\circ}\right)$, and from this proceed the two short diverging thyro- 
hyals (t.hy., cornua majora-1st hypobranchials), separated from the base by cartilage, but not segmented off.

\section{Skull of adult Ericulus nigrescens. (Male.)}

The hinder half of the palutal view of the skull of this type has been figured (Plate 35, fig. 11); this is a very instructive skull, and typical of the Mascarene modification of the Insectivorous type; nearly typical, as respects the Order itself, in its modern development.*

'The palatines (fig. 11, pa.) end in a straight line at the end of the hard palate; they are behind the maxillaries, and have the well-formed pterygoids ( $p g$.$) attached,$ subvertically, to them.

In the roof, the vomer $\left(v_{0}\right)$ is seen sheathing the perpendicular ethmoid, and the forepart of the presphenoid $\left(p_{.} s_{*}\right)$; the orbitosphennids (u.s.) are not seen in this view, except a little in front of the great fissure $\left(V^{3} \%\right)$. Like the presphenoid, the forepart of the huge basisphenoid $\left(b . s_{*}\right)$ is of moderate width, and flat; it is rendered somewhat concave by its union with the pterygoids.

The sub-pituitary hollow is perforated, above, as in Centeles; behind it the basisphenoid broadens out, and behind, both it and the basioccipital (b.o.) for some distance are subcariuate; this ridge is due to the bulging of the earliest bone deposited round the notochord. The tympanic wings $(t . b . s$.$) are not symmetrical, that on the$ left side being much the lirger of the two; a notch separates these shells in front, from the equal and well-developed tympanic wings of the alisphenoid (t.al.s.). These, with a similar process of the squamosils $(s q$.$) , form the antero-extemal outline of the$ obliquely oval tympanic spaces. These spaces are roofer, in front, by the same bones, and, behind, by the oblique, well-formed cochler (chl.). From those helices, to the fore edge of the great sphenoidal side gallery, out of which the 1st and 2nd branches of the trigeminal nerve $\left(\mathrm{V}^{1}, 2\right.$ ) emerge, is a large space-half the cranial floor; it is an unmistakable Marsupial character. But the foramina are typical for an Insectivore; this formen ocale $\left(\mathrm{V}^{3}\right)$ is finished behind by the tympanic shell of the alisphenoid, and for a distance, in front, equal to its own width. Another oval hole of the same size is seen, but it has not its long axis outwards and backwards as in the foramen ovale, but inwards and backwards; this is the hinder opening of the alisphenoidal canal (al.s.c.); the anterior opening being made into the common sphenoidal fissure or side passage. The squamosal $(s q$.$) has a stunted zygomatic or jugal process, and a large$ oblique saddle-shaped glenoidal facet (gl.c.). Where the bone widens towards the tegmen tympani $(t . t y$.$) , and bounds the tympanic cavity, there is a short postglenoid$ tract and a small post-glenoid formen.

The external part of the ossified auditory capsule outside the tegmen has grown beyond its contained horizontal canal (compare with Microgale, figs. 1, 3, h.s.c.) into an

* The original skull from which this figure was made is in the Biological Laboratury. South Ḱonsington Museuu. 
ear-shaped mastoid process, not unlike, in size and form, the gienoid region of the squamosal close in front of it. The openings here are numerous; inside the postglenoid foramen and outer tympanic wall the canal for the facial nerve (VII.) is seen, and further backwards and outwards, behind a stunted and ossified (epihyal) (e.hy.), the same nerve (VIT.) escapes through the large stylomastoid foramen. Nearly opposite, but much further inwards the two fenestre - fenestra ovalis and fenestra rotunda $(f s . o, f r)$ are seen, and the large foramen lacerum posterius, or the common chink for the exit of the 9 th and 10 th nerves $\left(1 X ., X_{\text {. }}\right.$ ) in front of and further out than the foramen condyloideum for the 12 th nerve (XII.) in the exoccipital (e.o.).

'The supraocipital (s.o.) can be just seen behind the foramen magnum $\left(f . m_{0}\right)$; the lateral and basal tracts $\left(e_{0} ., b_{0} o_{0}\right)$ are ankylosed. The condyles (oc.c.) are roughly pyriform, with the narrow part in front; each exoccipital grows out into a large, thick, down-turned puroccipital process (p.oc.). This is unusually large and well developed for one of the lower Eutheria. The whole occipital arch is distinct from the auditory capsules in front of it.

\section{The skull of the adult Microgale longicaudata.}

The skull, and indeed the whole skeleton of this small, very long-tailed Tenrec, resembles, very closely, that of the Common Shrew (Sorex vulgaris, see Plate 31) * both in size and form. But there are very important differences between the two, and on the whole this dwarf kind is but little altered, except in form, from the Centetidre of a more normal size. The snout $\left(a l_{0} n\right)$ is somewhat shorter than in the Shrew; it is similarly deflected.

\section{Investing bones of the shull of Microgale longicaudata.}

In the upper view (Plate 35, fig. 2) the sutures are largely filled up, yet their place is seen in various markings. There is, however, one long, almost perfect, median suture fiom the snout to the lambdoidal suture, and the coronal is only filled in below. The premaxillaries $(p x$.$) are of considerable length, and are well wedged in between$ the nasals $\left(n_{0}\right)$ and maxillaries $\left(m x_{0}\right)$ above. The upper tract of the maxillaries is about equal to the nasal with which it is fused; they project over the lachrymal (fig. 3, l.) ; the alveolar part of the maxillary is seen in the distance. The boundaries of the frontals $\left(f^{\prime}\right)$ can be seen above, wedging in between the nasals and maxillaries in front, and between the two parietals behind; through their thin walls the ethmoid and its turbinal folds can be seen in the front half; the linder half, apiculate before and behind, is smooth and gently conves. Swelling to a width one third greater than that of the frontals, the parietals $\left(p_{0}\right)$ nearly lide the lateral parts $(s q ., c p$.$) . Each$ forms its own round convexity (see also fig. 5, p).), the sagittal surure lying in a finrow. The hracket-shiped lambdoidal sutural line has a remarkible setting of 
bones in a half-ring; these are undoubtedly the progeny of two primary interparietul scales that united at the middle and then broke up agin in fresh places. There are three main pieces, subcrescentic in form; the convexity of the middle piece being in front, and of the other two behind; these are embedded along this wavy line of suture, besides several small piecos, like the fragments of the larger tracts. This curious brecciu is very instructive; the median piece is the proper interparietal (i.p.), and the main lateral pieces (s.t.) are the counterparts of the familiar supernumerary temporal bones, or "supratemporals" of the Lacertilia. Bones so situated and so related are common enough in the Ganoid Fishes, and in those 'Teleosteans (Siluroids) that come nearest to them in their cranial scutes.

The side view of this skull is curiously mimetic of that of the Shrew (Plate 31), but the teeth are sharply diagnostic. Almost everything is revealed through the thin homlike bony walls in this most exquisite little skull; the roots of the sharp teeth show through the outer alveolar wall; there is no special jugil process beyond the last of the series. The maxillary overlaps the frontal above, and then has a round notch in which the lachrymal and its canal $\left(l ., l . c_{0}\right)$ can be seen, although this fine film of bone has lost its sutural enclosures. Then there is a sharp spur, under and inside which the bone is hollowed out, and becomes a canal for some distance, opening in front on a very large infiaorbital foranen $\left(V^{2}\right)$. Above the sloping postero-superior edge of the maxillary, which is parallel with that of the ethmoidal region, a large tract of the badly-defined orbit, half its upper, and most of its lower inner face, is marked by the rich turbinal folds-rniddle and upper-of the lateral ethmoids. In the middle of their hinder boundary, sloping downwards and backwards, there is a large vascular foramen; and the curled lower edge of the orbital plate of the trontal is notched in the middle, below and in front of the larger noteh, for the ophthalmic nerve $\left(V^{1}\right.$.). Here, at the postero-interior part of the open orbit, a lobular tract is seen, at the bottom of which the orbitosphenoid, pierced by the optic nere $(0 . s .$, II.), can be seen imperfectly.

Behind that oblique bony edge, which runs backwards and downwards, and is formed by the frontal, in front, the parietal above, and the squamosal behind, the lateral simus (s.c.), throws its exquisite arch, clearly shining through the diaphanous walls of the parietal in its temporal region. Half-way between the end of the arch and the supratemporal bone there is a rough vascular forumen, close to the ragged hind edge of the parietal.

The squamosal $(s q$.$) is about equal to that of the Shrew, but its temporal squama is$ higher, and is lobulate; it is confluent with the parietal in front.

The thick outer edge forks in front; and in the fork the glenoid facet (yl.c.) lies; the upper fork does not grow forwaris as a definite zygomatic process.

The ribbed outer edge then goes backwards and a little upwards, and then spreads into an oblique four-sided enlargenent, betore it ends, as a sharp spike below the 
hinder crus of the sinus canal (s.c.): the rest of the squamosal will be seen from below (fig. 1).

Here there is a real additional temporal scale-bone, or supratemporal (s.t.), but in those other dwarfed types-the Mole and the Shrew-the apparent second temporal bone was shown to be only a peculiar rambling of the prootic bone into the pterotic region - a part, in fact, of the chondrocranium, ossified by a periotic bony centre.

Here, the likeness of this, the smallest of the Tenrecs to the dwarfed Shrew, is seen to be largely superficial; they are very wide apart, zoologically.*

The slender hamular process of the pterygoid $(p g$.) can be seen passing backwards from the thick palatine wall, and the annulus ( $\left.a . t y_{0}\right)$ also comes imperfectly into view in this aspect. The mandible $\left(d_{0}\right)$ is long, gently arched downwards, sinuous above, through the swelling caused by the teeth roots, and gently convex below. 'The coronoid process $(c p$.$) is a blunt, high triangle; the condyloid (cd.p.) is neat and$ rounded; the angular process (figs. 3, 4, ag.p.) is slender (almost Soricine) and somewhat incurved, below.

'The lower view (Plate 35, fig. 1) shows a well-formed hard palate; the maxillary $(m x$.$\left.) fits by a sharply-pointed end against the premaxillary ( p x_{0}\right)$, and the palatines against the maxillaries by a transverse, deeply toothed suture, in front of which each maxillary has a small fenestra. In front of that suture there are two, and behind it one, strong subtransverse ridge. The maxillaries bind against the open part of the palatines by a vertical plate, and the latter, after forming a strongly ribbed end to the hard palate, finish as a thick spongy wall to the nasopalatine passage; this is enlarged behind, as it narrows in, by the pterygoids with their delicate hooks; all the parts, here, are ankylosed together, so that the upper flange of the pterygoids is not distinguishable from the sphenoid bones, or the palatines from the pterygoids. The hinder part of the main (upper) vomer ( $\left.v_{0}\right)$ is seen in the roof of the nasopalatine passage; the other vomers could not be exposed either in this skull or that of Ericulus (fig. 11) without injury to the preparation. I take it for granted that in these parts these two kinds agree with Centetes and Hemicentetes. The squamosal (sq.), like the alisphenoid (al.s.), is dominated by the middle part of the organ of hearing. The outer part of the roof of the drum-cavity is formed by a shell-like ingrowth of the squamosal, behind and within the reniform glenoid facet (gl.c.).

The annulus (figs. 1 and 7 , a.ty.) is strong, and well made for so small a beast, and has a considerable external convexity. Its rim is well-finished, its anterior crus binds upon and holds the processus grailis $\left(p \cdot g r^{\circ}\right)$, and its posterior crus is thickened where it is tied to the posterior angular process $(a g . p$.$) of the transformed articulare.$

The end vien gives the relations of the parietal to the interparietal and super-

* There is no Soricine type as large as the Great Tenrec (Centetes ccaulatus), with which that large Insectivore might be compared; but the largest that can bo found must be worked out, and the two compared together, if we would know how much in our. little Shrew, and in this litele Microgule, is due to their dwarting. 
temporals (p., i.p., s.t.), but it scarcely shows the squamosal (sq.); the form of the skull thus seen is reniform, with the hilus below, and is gently convex, with many sinuosities.

\section{Endocranium of Microgale longicaudata.}

I have no inner views of this skull, but through the huge foramen magnum (fig. $5, f . m$. ) the large cribriform plate is seen to have two deep antero-superior recesses; and the orbitosphenoids to be pierced by the optic nerves in the middle of their basal regions; the shallow sella turvica, and the deep recessus flocculi, in the auditory capsule, can also be seen thus, without injury to the prepared skull.

At this point and that the endocranium can be seen from without (Plate 35, figs. 1-5). The nonsegmented deflected snout, with its sublateral nostrils (al.n., e.n.), is exposed; but the form of the true olfactory region can be traced and seen through the semitransparent frontals. The orbitosphenoid (figs. 1, 3, o.s.) is seen but little in any of these figures; the optic nerve (fig. $3, \mathrm{Il}$.) is shown as emerging in front of the great sphenoidal side-passage, out of which escape the $3 \mathrm{rd}$ and 4 th, the 1 st and 2 nd branches of the 5th, and the 6th, nerves. The alisphenoidal canal (al.s.c.) is short and its anterior opening, although less perfect than in the Dog, is plainly shown by a deep notch in the front of the alisphenoidal wall (al.s.); the foramen ovale $\left(\mathrm{V}^{3}\right.$ ) is well seen both in figs. 1 and 3, laterally; the suture between the alisphenoid and squarnosil above (fig. 3, al.s., sq.) is indistinct. In the basal view (fig. 1) the whole posterior sphenoid is displayed, a structure equally elegant and instructive. The subpituitary hollow is obsolete, the basisphenoid running backwards as a rounded balk from the presphenoidal, up to the basioccipital, region (fig. 1, p.s., b.s., b.o.).

Behind, in the latter region, the exposed part of the bone is a mere chink, owing to the proximity of the tympanic wings of the basisphenoid, which almost touch, back to back, like the aliseptal cartilages of the nasal labyrinth. 'These shell-like periosteal outgrowths (exogenous "ossa bullie") are broad, notehed, and out-turned in front; behind, they are pointed, and the last third of the strong aponeurosis is not ossified; so that these wings (or shells) do not finish the floor of the large tympanic cavity, but a large membranous space is left, bounded by the annulus in front, the bony ala inside the occipital arch, behind, and the mastnid process (op.) externally. On the other. side, where the annulus has been removed, and the cochlea (chl.) exposed, the imperfection of the bony floor of the skull is seen. In front of the large auditory region the skull has a very fenestrate appearance, the two openings of the alisphenoidal canal (al.s.c.) and the large formen ovale $\left(V^{3}\right.$.) cause this. The alisphenoids do not cnd after letting out the $3 \mathrm{rd}$ branch of the trigeminal nerve; a thick bar of bone runs across behind the foramen ovale, this is continuous, now, with the basisphenoid within, and supplemented, externally, by a similar wing or bar of the squamosal (sq.). This bony boundary of the drum-cavity is contisued backwards by the outer (tegminal) edge of the squamosal, so as to form, ronghly, a quadrant, which ends close in front of the 
stylo-mastoid foramen (VII.). That tegminal edge of the squamosal runs inwards as a vaulted roof to the cavum tympani, nearly hali-way across. Inside, the cochlea fills up the space behind, but, in front, the retral growth of the alisphenoid (al.s.) fills in three-fiftlis of the remaining space and sends backwards a spur to the cochlea, which divides the rest into a large outer, and a small inner, fenestra, covered only by the dura mater. This structure is Soricine, but it is also Marsupial; it is much more Marsupial in character than that which is seen in the Shrew.

The suture between the squamosal and alisphenoid is nearly lost, but the former sends downwards a thin lamina of bone which shows where they have joined; close inside the glenoid cartilage the squamosal is bent inwards, and appears as a convexity in the fore part of the tegmen. The (Marsupial) alisphenoidal wing ( $\mathrm{al} . s_{\text {. }}$ ) is extremely thin, and coils over backwards as a sharp selvedge. The basisphenoidal wings (t.b.s.) are much deeper and more hollow than they appear at first sight, in the basal view (fig. 1).

Behind (fig. 1), the relatively spacious tympanic chamber is partly closed in, and filled up, by the remarkable auditory capsule, which is thoroughly ossified, and retains its distinctness all round its border; it is, however, not so loosely set in the skull as in the native Shrew, or as in our native Bat (Pipistrelle).

The tilting of the auditory capsules is shown in the side view (fig. 3), and the horizontal and posterior canals (h.s.c., p.s.c.), are seen in that and also in the posterior view (fig. 5), and in the lower view (fig. 1). 'There is no prootic wall-plate in front of the smoothly convex part, through the walls of which these canals are seen.

The facial nerve (VII.) is seen emerging close behind a small, separate epihyal bone $(e . h y$.$) ; inside these parts the fenestre of the capsule lie out of sight. Inside and in$ front of the posterior canal, and of that part of the labyrinth into which it opens, there is a convex oval enlargement of the postero-inferior face of the cochlea (chl.), hiding its fenestru, which opens in front of, and above, the oval swelling, and externally forms the front margin of the foramen lacerum posterius (IX., X.). The basal and lateral upper elements of the occipital arch (b.o., e.o.) are fused together; the basioccipital is short axially, and the lateral parts each form a small paroccipital process (p.oc.) close outside the large pyriform condyles (oc.c.). The supraoccipital (s.o.) is a large shield of bone, well in the back of the skull, and not lying over, as a hind tegmen, as in the Mole and Shrew. It is quite distinct from the auditory capsules, and is fused with the lateral elements of the arch (e.o.); lying over a very large foramen magnum, round, but with a recess in front, it is a relatively great shield of bone, with a large circular convexity in the middle, separated by two oblique fossa from a subcrescentic convexity, right and left.

The supratemporal pieces (s.t.) impinge upon the bone over each fossa; it arches very nccurately over each auditory capsule above and outside, where it has ankylosed with the exoccipitals (e.o.). 'The whole of the upper margin of the supraccipital is 
somewhat ererted (fig. 2); the exoccipitals are pierced by the hypoglossal nerve (fig. 1, XII.) ; as usual, these foramina are very wide apart.

The ossicula auditis,-hyoid arch, and meatus-certilage of Microgale longicaudata.

The malleus (fig. $7, m l_{0}$ ) is remarkable in this, and in other small Insectivora; here the transverse extension of its main part is carried to the extreme, and here also the posterior angular process $\left(a g \cdot p_{0}\right)$ is wrought into a very ornamental form, like a carved fruit-ornament; it is, as it were, suspended from the part which gives off the strong manubrium $(m b$.$) . The processes gracilis \left(p . g r_{0}\right)$ is about equal to the manubrium; they are very far apart, and diverge, evidently; each is a twisted and thick-edged blade of bone, the back of which is in the inner side. The head is less definitely hooded than in the larger Centetidx, but the large posterior margin is more elbowed; the condyloid face is deep and oblique, but not large. The incus and stapes (figs. 8, 9, $i ., s t_{\text {. }}$ are quite typical, relatively large, and very elegant in form; the short crus of the incus (s.c.i.) is larger than in the Shrew; the stapes, most neatly finished, shows no interliyal on its neck.

The hyoid arch has a separate epihyal above (figs. 1, 3, c.hy.), and has also an upper and lower ceratohyal (fig. $6, c . h y ., c h y^{\prime}$ ), the former is attached by ligament to the epihyal, above. The short hypohyals (h.h.y.) are articulated to a process of the basal bar $\left(b . h . b r_{0}\right)$, whose thyrohyals $\left(t . h y_{0}\right)$ are not distinct, but short, and diverge greatly.

Thus this small kind approaches our native Insectivora in the structure of its liyoid arch, which is much more perfect than in the kinds just described.

When the meatus externus is dissected, and the lining cartilage opened out (fig. 10), it is seen that there are three imperfect annuli, separated by deep notches, inside the continuous concha, the proximal edge of which has also two round notches.

\section{The skull of the embryo of Rhynchocyon cernei; 4 inches long from snout to root of tail.}

This is the largest of the Elephant Shrews of the African mainland, and is from the eastern part, near Zanzibar.

The Macroscelide, of which this is an outlying member and the largest of the family, are extremely unlike the insular forms from Madagascar, just described; this particular kind is the more interesting as being a native of that part of the African continent which lies nearest to that large and most remarkable island, which is not African. The Macroscelidæ, however, have a wide African distribution, continental and insular, and this large kind-Rhynchocyon-is somewhat aberrant.

So much does this type differ from the forms already described, namely, our native types and those from Madagascar, and also from those yet to be noticed, that, considered from the standpoint of their cranial morphology, I am surprised at the collocit- 
tion of such diverse forms into a single Order of the Eutheria. But in this, as in many other types of Vertebrata, the highly compound cranial region retains a large number of archaic characters that are suppressed or lost in the body, and especially in the soft organs.*

\section{The investing bones of the skull of the embryo of Rhynchocyon.}

In this apparently nearly ripe embryo the bones as seen from abore (Plate 36, fig. 1) form a nearly perfect roof to the rather long cranium. Of these the foremost, or nasals $(n$.$) , are only moderately long and broad; they are two-thirds the length$ of the frontals $(f$.$) , and of the same length as the sagittal suture. Rounded in front, they$ widen up to the triradiate suture, where they, the premaxillaries, and maxillaries $\left(p x_{0}, m x\right)$, meet; they are then somerwhat pinched, and widen a little, once more, to unite with the frontals.

In strong contrast with what we see in the Mole and the Shrew, the frontals $(f)$ are nearly as wide as, and nearly one-fourth longer than, the parietals $(\mu)$, and although, together, they have a well-formed mid-orbital waist, they are very wide even there. Towards the still open, four-cornered fontanelle $\left(f_{0}\right)$, the main upper part of these bones is gently convex; this convexity narrows, forwards, and there is a definite fossa marking it off from the supraorbital margin, which is very neat and finished, and quite unlike what we have just seen in the more typical Insectivora. Slightly overlapping the frontals, and wedging into their lower and hinder edge, the parietals $(p$. $)$ give a great breadth to the intertemporal region; their convexity, above, is greater, altogether, than that of the frontals. The conspicuous temporal fossa runs round them, on the side and behind, up to the large triangular wedge of bone that shortens the sagittal suture and separates the two bones from the supraoccipital; this triangle of bone is the interparietal (i.p.).

Laterally, the premaxillaries, maxillaries, lachrymals, jugals, and squamosals ( $p x$., $\left.m x ., l_{.}, j ., s q.\right)$ can be seen flanking the great, gently convex, pyriform roof; all these are better seen, however, in the side view (fig. 3).

Here we find that the premaxillary $(p x$.$) is one-fourth the length, and one-half the$ greatest beight, of the maxillary $\left(m x_{0}\right)$; its facial plate, thus seen, is notched in front, where it embraces the snout, and behind, when it is dinted by the maxillary; above, instead of wedging in between the nasal and maxillary, it is actually rounded off. The maxillary is swollen in front where it runs against the premaxillary; above, where it runs up to the frontal, still more; and below, under the lachrymal and jugal bones $\left(l_{0}, j.\right)$. That last swelling is the outer alveolar wall of the last tooth, and above it there is a large and deep fossa for the maxillary nerve $\left(\mathrm{V}^{2}\right.$.), but this

* Whilst very grateful for what the Zoologists send me, I feel no ways bound to their groupings of the types. Their zeal for Taxonomy is not always according to knowledge, and by their hard and fast lines they often put asumder what Nature has joined, and leave together types that are not elosely reliterl, but merely mimetic, or isomonphic. 
nerve has no maxillary bridge over it at present. The lachrymal $\left(l_{\text {. }}\right)$ has a large, pentagonal facial plate; its thick orbital margin is somerwat notched, and inside that notch is the canal; the thickness of the orbital margin, which helps the frontal and jugal to give finish to the orbital ring for nearly three-fourths of a circle, is so large as to hide the interorbital plate of the bone and its canal.

Lying between the aberrant Tupaice and the typical Erinaceus, this type tends to finish its orbital ring, especially in the perfection of the supraorbital rim of the frontal; there is, however, no free postorbital process, the ribbed edge merely rums back and binds upon the parietal. The frontal is perfect in the upper half of the huge orbital cup, but unfinished, behind; yet giving promise of the Lemurine orbit-a promise fulfilled in Tupaia, soon to be described.

Behind that very extensive hollow, thin orbital plate, the parietal ( $p$.) just comes in and divides it from the squamosal; the rest of the parietal is seen to be convex above, and gently pressed inwards over its lower edge, which has two large shallow emarginations; the one, in front, over the squamosal, and the other, behind, over the huge auditory capsule. 'The triangular interparietal (i.p.) is sinuously united to the parietal above, and hooks round its rounded hinder margin, lower down. From the middle of the lower edge of the parietal to the lachrymal the outworks of the skull are completed by two bones, the squamosal $(s q$.$) and the jugal. The latter bone \left(j_{0}\right)$ is strong for an Insectivore; it protects the maxillary nerve $\left(\mathrm{V}^{2}.\right)$, wedges into the lachrymal and maxillary, is grooved and broad in front, outside, and ends as a blunt style below the jugal process of the squamosal, some distance in front of the glenoid facet (gl.c.). The squamosal (sq.) just rests its spike upon the jugal, and then broadens out into the glenoid tract, which is covered with a subconvex oval cartilage looking inwards and somewhat forwards (see fig. 2, gl.c.), and into the oval, hollowed, temporal plate, which overlaps more than half of the lower edge of the parietal. 'The jugal spike runs into the thick outer part, whose upper edge is sharp and sinuous, first convex and then concave, where it runs up and meets the squamous or temporal edge. 'The lower margin has two concavities, the glenoid, and tympanic, and two processes, the post-glenoid and the post-temporal, the latter is the larger of the two; under these we just see the tympanic annulus $\left(a_{0}\left(y_{0}\right)\right.$.

The mandible ( $(l)$ is scarcely developed into distinct processes, behind; the coronoid $(c . p$.$) being very low; the rounded condyloid process (cd.p.) is separated by a$ rounded notch from the small, sharp, angular process ( $\left.\alpha g_{\cdot} p_{0}\right)$; the ramus, with its swollen alveolar space, and teeth just cutting the gums, is gently convex, below, and with a slightly arcuate outline runs forwards to its narrow, pointed fore end.

In the palatal view (fig. 2) there seems nothing, at first, to remind one of the Marsupial; in this, Rhynchocyon agrees with the two types next to be described, namely, Galeopithecus and Tupaiu. The general form of the palate is roughly oval, but emarginate at its narrow, fore end, and having a broken or dentate hind margin. 'The premaxillaries $\left(p x_{0}\right.$ ) are of short extent, being largely overlapped by the maxillaries

$$
2 \text { I } 2
$$


(mx.). The alveolar walls of the only upper incisor tooth are imperfect behind; this tooth is often wanting in the adult. The openings for JACobson's organs (j.o.) are far forwards, and the palatine processes of the premaxillaries are largely hidden by those of the maxilliries.*

The maxillaries ( $m x_{0}$ ) show three parallel regions in this view : the alveolar, with the large tooth-sockets and teeth just appearing; the submarginal, with oblique ribbings and hollows; and the sub-mesial, separated from the ribbed part by a crack, or sharp, roughish fissure, which looks very much like a suture. 'The outer part binds on the premaxillary, and the inner tract on its palatine process, hiding most of it. The submesial tract rises somewhat where it meets its fellow, so as to form a definite fossa; these two tracts fail behind, being aborted by the counterpart tracts of the pailatines.

These bones ( $p u_{0}$ ) form a very elegant winged part of the hard palate, for the posterior palatine foramina notch them, close behind the fissure, in the maxillary plate, and inside the foramen they each have a round lobe running forwards, and outside it another, which fits obliquely to, and extends beyond, the end of the maxillary.

In front, these palatine plates of the palatines are hollow where they meet, and then this shallow fossa runs obliquely outwards on each bone, leaving the middle part convex. The hind margin, as a whole, is transverse, but it is deeply crenate, there being two notches on each side the projecting ends of the bone at the median suture. The orbital, or ascending, part of the palatines is steep, hollow inside, and gently convex outside; the hind half of each plate embraces the side of the presphenoid, and, shightly diverging, is joined by the small subvertical pterygoid $(p g \cdot)$, which diverges still more, and has a nucleus of cartilage (as in the Hedgehog and Mole) on its hamular process. I find no trace of the mesopterygoid-a test-bone for Marsupial relationship. Nor does the jugal (malar-j.) come near the glenoid facet; here, agrain, this type is normally Eutherian. The squamosal (sq.) has a short, triangular jugal process, overlying that great bone, and behind it the concave glenoid cartilage has a pyriform outline and an oblique position-inwards and a little forwards, also.

The lateral and post-glenoid part of the squamosal is rather feeble, and is bound upon by the tympanic $(a . t y$.$) ; its processes are best seen in the sicle view (fig. 3);$ the hollow face of the wide orbital roof $(f$.$) is seen in this view, in the distance.$

The annulus (a.t. $)$ is like a large capital $G$ with the top looking backwards; it gives a wide space for the membrana tympani, has a large trowel of bone on its front crus, and has the hind crus inturned and blunt. The cartilage of the Eustachian tube (eu.) is large, as in Marsupials, and as in Marsupials, behind and outsicle it, but inside the proper thick annulus, there is a thin crescentic "os bullæ"

* The abortive development of the single apper incisor, and the perfect condition of the hard palate, car'y ns far away-upwards-from the Marsupial territory. These things foreshadow what will be seen in Bats, some Lemurs (Tepilemur), and, ultimately, in the Ruminants. 
$(o . b$.$) , exactly as in young Marsupials; the annulus thickens in front, just where it$ lies under the front crus of the os bullie,

There are here five vomerine bones, as in the embryo Hedgehog, and Armadillo; the main bone or vomer proper (fig. $5, x$.) is strong and carinate, and bluntly pointed at both ends; it is short for so long a skull, and its keel is very thick. The two anterolateral vomers $\left(v^{\prime}\right)$ are the largest I have seen, as yet, reminding one of their large cupped counterparts in the Ophidia and Lacertilia ; they are ovato-oblong, and sculptured in their infero-external face, and are like two chaff scales of the Oat. The fore part of the main vomer $\left(v_{0}\right)$ is hidden by these two bones; the recurrent or JAcobson's cartilages ( $(r . c$.$) are seen outside them.$

The narrow hind part of the main vomer ( $\left.i_{0}\right)$ is partly hidden by the two large pastero-lateral vomers $\left(v^{\prime \prime}.\right)$, which, as far as I know, are in this case relatively larger than in any other Eutherian; they are perfectly Metatherian in size and relations, nearly meeting in the middle, having there a ribbed edge, and sending outwards a large rounded lobe from their middle part; they are each nearly as long as the main vomer, and are twice as long as the antero-lateral pair $\left(v^{\prime}\right.$.). The hind part of each postero-lateral vomer $\left(v^{\prime \prime}\right.$.) just overlaps the base of the orbitosphenoid (o.s.) and reaches the presphenoid (p.s.). The above are the whole of the investing bones I bave been able to find in this type.

\section{Endocranium of Rhynchocyon cernei.}

The deep parts of this skull are as remarkable as the superficial; the diagnostic characters of several Orders meeting in one endocranium. That tract of the nasal libbyrinth which is in front of the proper olfactory region is very long (Plate 36, figs. 4-7), and is segmented in all but its foremost and hindmost part; there are thirty double rings, and this is as true a "proboscis" as that of the Elephant. So long is this proboscis that the completely closed part is half as long as the whole labyrinth, which, altogether, is twice as long as the basis cranii, proper:

The nostrils $(e . n$. ) are nearer the lower than the upper face of the snout, and are very near its end ; the valvular coil of the nostril is very complete, and terminates in a free outer process. There the double tube is very narrow, but widens gently to twice its first width, it is then constricted twice, and swells again before the definite enlargement for the middle turbinals begin. There is then a deep constriction, and then the whole structure swells out to almost tenfold the width of the neck of the double snout-tube. Those swollen bags of cartilage do not meet each other below (fig. 5); above (fig. 4), they are deeply excavated, behind a short, perfect roof-region to form the two large circular multiperforate olfactory fossa, each floored by the cupshaped cribriform plate (cr.p.). Above, the septum (p.e.) terminates in a bulbous, free "crista galli" (cr.g.), but the sloping hind margin of the wall continuous with the cribriform plate, and notched where the multitudinous branches of the olfactory nerve pass through from the cranial into the nasal cavity (see fig. 7, p.e.), becomes much 
thimmer than it is above. Abore (fig. 4) the inflated olfactory chambers turn round behind, and clasp the fore part of the orbitosphenoid (o.s.); there they are sharp or angular, but below (fig. 5), they end as rounded pouches, clasped by the base of the orbitosphenoids, and separated by the base of the perpendicular ethmoid (p.e.), where it is floored by the two linge postero-lateral vomers $\left(r r^{\prime \prime}\right)$. These huge olfactory ponches reach nearly as far outwards as the equally large auditory capsules (chl.), although these latter are separated by the mass of the hind brain. Where the palatine processes of the premaxillaries are given off, and in the space between them and the alveolar margin of those bones (figs. 2 and 5), there the floor of the snout is emarginate and soon ceases; its hind selvedge being elegantly bracket-shaped. In that emargination lies the openings of JACOBSox's organs $\left(j_{.} . o_{0}\right)$, seen in the anterior palatine foramina. For the rest there is a large ovato-oblong open space divided at the middle by the great septum and its splints. In front, the recurrent cartilages (rc.c.), are seen out= side the antero-lateral vomers $\left(r^{\prime}\right)$; for some distance, then, the inferior turbinals $(i . t b$. are also seen; but the nasal turbinals are out of sight, and the upper and middle are well within the great pouches. All these parts are cartilaginous at present; their detailed structure is quite like what I have already described in the Hedgehog and the Mole- by dissections and sections.

But the axial part of the nasal labyrinth (Plate 24, fig. 7) deserves special notice; it is mainly formed by the huge intertrabecula $\left(i . t v^{\circ}\right)$, which is as large relatively as in the embryo Bird, or in an average Selachian Fish. When we come to the long-faced Cetacea we shall see this element playing an important part-as in the embryo Birdin the formation of the face, serving as a model on which the liuge facial splints are laid; in them, however, the olfactory organs and their outer openings are drawn backwards, and this bar runs forwards independently of them; here, as is normal for a Mammal, the nasal roof is continued along its whole extent, and the alinasal part, runs round its front end.

In the rounded fiont of the snout the intemarial septum is fenestrate $\left(i_{0} . f_{0}\right)$, a common thing in low Eutheria; and at that part the septum itself is largely formed of the alinasal cartilages, that, placed back to back, have coalesced with each other as well as with the median intertrabecular bar. Now, here, for the whole length of the aliseptal region, this is the case, so that up to the true olfactory territory the intertrabecula itself, is only slightly crested, the top of the low septum is, in reality, merely the confluent ale, or roof cartilages. Hence, in this low wall, the first thee-fifth is septum nasi, part of it roofed by the alinasal and part by the aliseptal tracts; these tracts are, of course, continuous, but they are true morphological regions. Of the hinder two-fifths, the first half is twice as high as the septum in front of it; it is now the perpendicular ethmoid ( p.e.), then it lowers again, at first suddenly, and becomes a mere rounded bar, which passes insensibly into the presphenoid $\left(p \cdot s_{0}\right)$, most of which is already ossified. The roof has several regions, well marked out; beginning at the front of the snout, we see the ala nasi turned round and formed into the coiled nostril-valves, then comes a 
narrow neck; these parts are all in a continuous tract of cartilage. But fiom the middle of that narrow neck up to the part under the triradiate suture formed by the nasals, premaxillaries, and maxillaries (compare figs. 1 and 4), each nasal tube is segmented into narrow rings, all of which, except those at the end (fig. 5) are perfect below. Yet at the mid-line each ring loses its distinctness, being confluent, above and below, with the septum.

This is a true proboscis, quite like that of an Elephant, and like that of the Myxinoid Fishes, except that it is double instead of being single, as in those permanent laver, with their primordial "cribriform plate." A little in firont of the part which swells with the middle turbinals, these rings cease; there are thirty of" them on each side.

'The ossification of the proper cranium is very abruptly marked ofl' from the unossified olfactory labyrinth. The anterior sphenoid is but little less than the posterior; it is in three "centres," but little united as yet, for the presphenoid (n.s.) is here, as in Sorex and the Marsupials, as distinct an element as the basisphenoid $(b . s$.$) ; it is of the same length and not much narrower, but is somevhat hour-glass$ shaped. The orhitosphenoids have a large and pedate downgrowth proximally (fig. 5, o.s.), which fits close to the corresponding postero-lateral vomei (v".) by the fore part of its pedate process.

The orbitosphenoids lie well over the hind part of the olfactory fosse and their cribriform floor (cr.p.), and form a concave margin to that part, for they project far beyond their basal piece, fore and aft; most behind. 'Towards each other, right and left of the median ethmoidal wall-top, they are rounded and notched, and behind their junction with the presphenoid they have a large noteh-a quadrant. Their outer margin, directed backwards outwards and upwards, is crenate, and the hind margin is also sinuous; its inner part ending as a spur just inside the foremost angle of the alisphenoid (al.s.). Hence these alie do not, with their own basal piece, finish the "sphenoidal fissure;" it is completed by the posterior sphenoid, base and wing, with the help of the pre-basisphenoidal synchondrosis. The widened hind part of the presphenoid runs into the large oblique sphenoidal fissure, making it reniform, instead of oval.

The optic, as well as the orbital, nerves pass through this large, dilated fissure; there is no optic foramen; thus there are three Marsupial character's in this anterior sphenoid: (1) the orbito-sphenoid is only slightly overlapped by the alisphenoidthere is no gap, only a small squanous suture; (2) there is no optic foramen; and (3) the presphenoid is an autogenous bony element. The posterior sphenoid has about the same extent, axially; but laterally, it is one third larger, or nearly. The basisphenoid (b.s.) is as long as the presphenoid $\left(p_{.} s_{*}\right)$, and is about one-fourth wider, on its upper face (fig. 4). It has a small open pituitary space (as an Erinaceus and Sorex), but the seat of the sella is shallow; there are no tympanic alre. The alisphenoids (al.s.) are larger than they would seem to be, viewed merely from the upper surface (fig. 4); they are best seen from below (fig. 5). The 3id branch of the 5 th nerve $\left(V^{3}\right.$.) passes 
through a large round notch in the middle of the lind edge of the bone, and the bone grows under the nerve for some distance in its passage to the lower jaw. 'The alre are set on to the base obliquely, and the suture is on a level with the flatter upper face of the basisphenoid (fig. 4).

If there is no tympanic ala to the basisphenoid, that part being a separate "os bullæe" (fig. 2, o.b.), there is nevertheless a large tympanic ala (t.al.s.) growing from the hinder and under part of the alisphenoid; in form this hollow growth is like an ordinary tympanic annulus, being crescentic, and having a wide convex face and a ragged opening looking outwards. All this is truly Marsupial, and if these alæ coalesce with the ossa bullie in the adult the conformity is perfect.

The auditory capsules are extremely large, and the petrous region is well ossified; but the mastoid region is almost wholly cartilaginous. The fore margin is convex and bulbous, where the capsule, by its cochlear region (chl.) fits into the large interspace between the alisphenoid and exoccipital (c.o.); but higher up the fore margin is notched and sharp in front of the arnpulla of the anterior canal (a.s.c.), the upper margin is free, but the hinder has coalesced with the occipital arch, yet not so as to obliterate the boundary line. ${ }^{*}$

In the upper view (fig. 4) the coiled cochlear region (chl.), the meatus internus (VII., VIII.), and the base of the recess for the flocculus are seen, but the main part of that hollow is hidden by the subvertical part of the capsule, unossified, and showing the form of the arch of the great anterior canal (a.s.c.). In the side view (fig. 3) the large convex mastoid region shows the elegant sweep of the horizontal and posterior canals (h.s.c., p.s.c.), the latter giving a smooth, rounded form to the mastoid margin of the capsule, with no "mastoid process." Beneath (fig. 5), the prootic and opisthotic bones are wholly amalgamated, the fore edge of the capsule and the cochlea being one common tract of bone-probably never quite separate centres, but developed, as in many Mammals, in a generalised way, as also is frequently the case in the Anurous Amphibia. The 7th nerve (VII.) can be seen running in its canal, reappearing inside the tegmen tympani, and burrowing again, to escape through the stylomastoid foramen, close behind the epihyal $(c . h y$.$) . In this view also (fig. 5) the$ fenestræ $\left(f_{s, 0}, f i\right.$. ) of the auditory labyrinth are well seen, divided, as in Marsupials, by a wide opisthotic bony tract. Then comes the wide interspace, or foramen lacerum posterius (IX., X.), and the actually perforated exoccipital (e.o.) (XII.) for with the exception of the olfactory sieve, the hypoglossal nerve is the only one which passes through a proper endocranial foramen; the 7 th and 8th perforate a sense-capsule, and not a part of the true cranium.

The occipital arch follows the auditory capsule, finishing the skull in a smooth and

* This embryo was probably ripe, or nearly so, yet the development of bone in the skull is very remarkable, and quite like the early ossification of the Marsupial skull; the sharp free edges of the infero-lateral bones have been formed by arrest of the ossifying process, combiued with absorption of a large tract of chondrocranium. 
rounded manner; the paroccipital ridges of the exoccipitals are scarcely marked, and the supraoccipital $\left(s_{0}, o_{0}\right)$ is gently convex. The basioccipital $\left(b_{0} o_{0}\right)$ is large, and through the bulging of the bony sheath of the notochord (cephalostyle), subcarinate in front, below. The condyles (oc.c.) are large and obliquely reniform, and there is, besides these, much cartilagre still left between the bony centres of the arch; the foramen magnum $(f . m$.$) is very large, and pyriform in shape.$

The ossicula auditûs are already well developed, MEckel's cartilage being absorbed or used up in the lower jaw. The malleus (fig. $6, \mathrm{ml}$.) is almost completely ossified; the processus gracilis is still one-third larger than the manubrium (mb.), which is short and straight, and nearly parallel with the processus gracilis. The head of the malleus is bulbous and large, the posterior angular process (ag.p.) forms a small cartilaginous elbow to the manubrium. The hind margin of the bone is oblique and sinuous; altogether this malleus is very much unlike what is seen in the Mascarene types. The incus (i.) is quite typical, and has, for an Insectivore, a very large processus brevis (s.c.i.). The stapes (st.) is nearly typical; it is higher, however (or longer), and has a smaller fenestra than that of the typical Insectivora; it is fairly an intermediate form between the typical and the Marsupial stapes. Its neck and base are not yet ossified completely; I see no interhyal on the tendon of the stapedius muscle.

The slender epihyal (fig. 3, e.hy.) cartilage is continuous both with the auditory cansule above, and with the upper ceratohyal (c.hy.) below; that tract is now a slender bony rod, separated by a cartilaginous piece half its length from the lower ceratohyal (c.hy'.), which is straighter, shorter, and stouter. The bypohyal segment is solid, conical, short, and articulates by its base with the basal bar; it is, at present, unossified.

The thick basal hyoid is $U$-shaped, and has a bony centre on both the base, proper $(b . h . b r$.$) , and in the thyrohyals (t . h y$.$) .$

The emargination of the fore edge of the basihyal, and the general breadth of the whole of the hinder tract, makes this part, also, intermediate between the hyoid of a typical Insectivore and that of a Marsupial.

\section{On the skull of the Colugo (Galeopithecus).}

My materials for this type are as follows:-

Stage 1 (A).-A naked, but apparently ripe, embryo of Guleopithecus voluns (?locality), $5 \frac{1}{2}$ inches long from snout to root of tail, with the umbilicus thick and soft.

Stage $2(\mathrm{~B})$.-A young specimen of Galeopithecus philimpensis, 8 inches long to root of tail (well covered with hair).

Stage 3 (c).-A second young form of the same kind, one-fifth larger.

Stage $4(\mathrm{D})$. - Two adult specimens of $(r$. philippensis, which were taken with the two young individuals, in the Philippines, by Professor Moselex, F.Li.S., during the MDCCCLXXXV. 
"Challenger" expedition, and put into my hands by JoHs Murray, Esq.; and one dry skull of the same species; locality unknown. *

Stage 1, A. - The embryo of Galeopithecus volans; $5 \frac{1}{2}$ inches long.

The figures given of this embryo (Plate 16, figs. 15, 15A) at once show its utter unlikeness to the normal Insectivora; it belongs, undoubtedly, to their level or platform, but its relation to them is doubtful in the extreme. To the group below-the Marsupials-it is related, and to a group above-the Chiroptera-it is also related, as I shall show anon.

I shall not enter into either the zoological characters, or the visceral anatomy of this type, but speak of what I have found in the developing skull. Biologists can then deal with the evidence as to the Insectivorous or Chiropterous nature of this very archaic beast, at their leisure.

\section{Stage 1 (A).- Skull of Galeopithecus volans; embryo, $5 \frac{1}{2}$ inches long. a.-Iniesting bones.}

The general appearance of the dissected skull, with the investing bones complete upon it (Plate 37, figs. 1, 2; and Plate 38, fig. 1) is very similar to that of a young Phalanger, or Cuscus, of the same size, but about thiee months old, † but the form is in reality intermediate between that of the skull of those Metatherian types, and that of the young Pteropus, or Frugivorous Bat. By keeping these comparisons in mind we shall be able to see the meaning of many things in this type, which, however, has some unique characters; these are strange and unique, becuuse the kindred of the two Colugos are all extinct. This skull is very flat or depressed, and its great breadth across the middle gives it an almost oval outline; the short snout scarcely breaking such a supposed circumscribing line, and the occipital region being merely sinuous, instead of regularly arcuate. The roof (Plate 37, fig. 2, upper vicw) is mainly composed of three pairs of bones that form a very regular series; these are the nasals, frontals, and parietals $\left(n ., f ., p_{0}\right)$, and behind these is the single interparietal (i.p.), once, no doubt, composed of a pair of centres. The nasals ( $\left.n_{0}\right)$, flanked by the maxillaries and premaxillaries $(m x ., p x$.), are as long as the parietals, and nearly as long as the frontals. They are pointed in front and very broad behind, stretching outwards so as to be sutured to most of the fore margin of the frontals. Here, at once, we see the effect of the general depression of this peculiar skull, almost unique in the class, in its flatness and breadth. The frontals are well formed, and from the lachrymal to the parietal grow outwaxds as a neat supra-postorbital ledge; a large supra-

* The large size of the embryo which had, apparently, been taken from the utcrns-as there was no shrinking whatever of the umbilicus-and the remarkable differences, soon to be described, between it and the other kinds, satisfy me that this belongs to the large species, Guleopithecus volans.

+ At birth the Australian Marsupials range from the size of a new-born Mouse to that of a new-born liat; this larger size is what is attained by Mncropus major. 
orbital foramen is seen near the front of this bony selvedge. The postorbital processes seem to clasp the parietals behind; these, the largest of the series, carry on and increase the general, gentle convexity of the skull-roof; the frontals wedge into them before, and the interparietal $\left(i_{*} p_{*}\right)$ behind, so that the sagittal suture is searcely more than two-thirds of the length of the frontal. The fore edge of the interparietal (i.p.) makes the lambdoidal suture bracket-shaped; that transverse, oblongo-oval bone, raises a new convexity over the hind brain; at present, the parietals are scarcely imprinted at all by the top of the temporal muscle.

This skull, which reminds one of anything rather than that of an Insectivore-for the Colugo might be called a small primordial Herbivore, with a parachute-has pneumatic squamosals as in the Marsupials; the squamous suture is seen in this upper view, and also the swelling of the bone caused by large air-cells outsicle the temporal fossa. The short zygomatic process is also seen in this view, and the thick top edge and hollow inner face of the jugal or malar $(j$.$) which reaches far back, as we shall see in the other$ figures. Another thing is seen here in this marvellous little Herbivore, namely, the great backward extension of the maxillaries $\left(m x_{0}\right)$, with their large dentary region (see also figs. 1 and 3). We see also, obliquely over the growing hind sockets, the hinder opening of the infraorbital foramen or channel for the 2nd branch of the 5 th nerve $\left(\mathrm{V}^{2}\right.$.). ()utside that passage, in the antero-external part of the orbit, there is another large passage, this is the lachrymal canal in the lachrymal bone (l.c., l.), a large perforated shell of bone growing out upon the face, as well as forming a large part of the orbital cup in front.

All these things want supplementing by the lateral, lower, and end views of the skull (figs. 1 and 3 ; and Plate 38, fig. 1).

The side view (Plate 38, fig. 1) shows that the face is deflected considerably-an embryonic character-and that there is a definite hollow between the nasal and frontal regions above.

The orbital and temporal regions rum into each other, but the enclosure of the postorbital region is begun.

In the adult (Plate 39, fig. 3) the cranial cavity and the upper nasal region, from the end of the snout to the crista galli are equal; now (Plate 38, fig. 1), the braincavity measures nearly twice the upper nasal length; this is an early and also a Marsupial state of things, and would have been still more remarkable in an earlier embryo.

The nasals have a very convex dorsal outline, and dip where they slightly overlap the frontals laterally; they are in sutural relation with the deep facial plate of the premaxillaries and maxillaries $(p x, m x$ ) ; the upper edge of the former is extensive, being three-fourths as large as that of the maxillaries. Two-thirds of the exposed outer face of the maxillaries is suborbital; a hollow, beginning in the premaxillary, runs along the maxillary up to the lachrymal $(l$.$) ; near its end there are two small infraorbital fora-$ mina $\left(V^{2}\right)$; the first hole is small on both sides; they, however, are very variable, as in one adult Philippine Colugo, I find two openings on each side, and in another four on 
both sides. At present, the thickening of the orbital edge is formed by the lachrymal, and the maxilary is hollow up to it; below, the whole alveolar region is swollen but sinuous, it reaches to within a very short distance of the preglenoid convexity. The lachrymal is very large; its infraorbital plate was best seen in the last figure (Plate 37, fig. 2, 7.); there it is seen to carry on the orbital ring, forming at least a quadrant; its swollen outer facial part corresponds to the excavated infraorbital tract (see the upper view). Riding over and outside the last two alveolar swellings of the maxillary, the large jugal $(j$.$) begins narrowish and convex, and then forks, and becomes somewhat$ concave. The foremost upper fork tends to unite with the postorbital process of the frontal, and then to make a perfect orbital ring such as we shall see in the next type (the Lemurine Tupaia). This large jugal, like that of a Marsupial, grows over the fore part of the glenoid cartilage-a diagnostic Metatherian character. Most of the side of the skull is taken up by the enormous squamosal (sq.) which, measurement for measurement, is as large as the parietal.*

The squamous suture is very extensive; when seen from above (Plate 37, fig. 2) it is seen to be formed by overlapping the parietal, although it just touches the interparietal. The junction of the jugal with the zygomatic process of the squamosal is extensive, and its lower part is plastered by the glenoid cartilage; the glenoid cavity is deep and looks forwards and downwards, and is supported behind by a large postglenoid ridge. Behind that, the bone is cut away in a circular manner, with toothings over the eardrum; then from its postero-inferior angle it rises obliquely, being furthest backwards above, and has its thin rounded hind edge notched just below the middle, where it overlaps the mastoid regiou.

The suture with the alisphenoid (al.s.) in front is short and almost vertical; from it the temporal fossa runs backwards and upwards. The pterygoid hook ( $\left.p g_{0}\right)$ is just seen below the jugal and inside the small external pterygoid process of the alisphenoid $($ e.p y.). The annulus (a.ty.) is very instructively imperfect for comparison with the next stage (fig. 4), where it already forms a vertical opening or slit with bony lips. Ifure (fig. 1) it lies under the tegmen tympani as a shallow saucer-like bone, projecting in front, hiding its hinder and front crura inside the squamosal, and developing a rudiment from the hind crus which will become the hinder and lower part of the vertical bony meatus.

The mandible (figs. 1 and $2, d_{\text {. }}$ ) is decurved like the upper face, quite unlike the ascending "mentum" of Cuscus; so also the extended and out-turned angular region $($ (a.p.) is unique; it does, however, show an inflated inner face, as in Marsupials. The condyloid process $(c d . p)$ is not very sharply defined; the condyle itself is oval, with the long axis transverse; the coronoid process (c.p.) is small, oblique, and subuncinate; the whole ramus is sigmoid in its general outline.

* Here the skull of a young Cuscus maculatus, of the same size as this large embryo of Galeopithecus volans, comes in in a most timely way; that type is to me the most generalized Marsupial I hare seen, and the squamosal in it is only less than that of the embryo Colugo. 
The under view (Plate 37, fig. 1) is remarkable for its size, both in length and breadth; its length is considerably greater than that part of the basis cranii which lies behind it, and its breadth is equal to that part-the main part-which is formed by the maxillaries and palatines. The general form of the palatine region is oval, but irregular in front, and emarginate behind. Laterally the large alveolar tracts with their pushing teeth (some of them are cut) are very large; there are no teeth in the fore part of the premaxillaries, but two in each, on the side; these, however, are small. The fore margin of the premaxillaries is narrow, where they meet in a very obtuse angle; the lateral part of each bone projects forwards, and is subuncinate. The slender palatine processes of the premaxillaries $(p \cdot p x \cdot$.) are hidden, behind, by the maxillary palatine plates; when these are removed (Plate 39, fig. 1) then they can be seen as long, slender, areuate, compressed bars, having no distinct antero-lateral vomers attached to them; but these bones may have become confluent with them. Through the narrowness of the premaxillaries in front, and the deficiency of the maxillary plates towards the mid-line, the anterior palatine foramina are very large; they are oral, and show a considerable tract of the recurrent cartilages ( $\%$ c.c.), behind the opening of $J_{A C O B S O N ' s}$ organs (j.o.). Behind the emargination the maxillaries scarcely meet for some distance, but the last two-thirds of their suture is perfect; right and left of this part the bone is concave, but this hollowing of the roof is much less than that which is found in young Marsupials; the sides also are hollow, thus there is a general crescentic convexity along the middle of each palatine plate. The hard palate is not extended backwards more than one-sixth further by the palatines $\left(p c_{0}\right)$, but they are strong bones, and the whole hard palate shows nothing of that economy of bony deposit seen in Marsupials and typical Insectivores. The skull set up, and with the palate towards the eye, shows, here, a very elegant double archway to the two nasal passages. The thick, ribbed margin of the bones projects where they meet, so that the end of the hard palate is bracket-shaped; in front of each thickening the oblique posterior palatine foramen (p.p.f.) is seen. These narrow curved palatines lie like scales under the maxillary plates, and their curved thin fore edge retreats, laterally, and then turns a little inwards, where it is pressed against the alveolar wall of the two last teeth. The thick side wall of the open part still gently curves inwards; it is separated outside from the palatine portion by a large sharp notch. The shell-like orbital or ascending part of the palatines meets the hinder part of the main vomer $(v$.$) , almost reaching as far backwurds as its four terminal prongs.$ 'The small pterygoids $(p g$. ) also ascend, and below, where they are spliced obliquely to the palatine wall of the great nasopalatine canal, they end, behind, in the hamular process, which is small, flat, and turned outwards; it is supported, outside, by the equally small external pterygoid process (e.pg.). The pterygoid is very small, as in the Marsupials, and this comes from the fact that what is generally, in the higher manmals, the upper or basicranial flange, is here, as in the Marsupials, at long, tongueshaped mesopterygoid (ms.pg.). This flat bone is sharp in front, where it wedges in 
between the palatine and pterygoid, and blunt behind, where it partly hides the basisphenoid (b.s.); its front part hides the side of the presphenoid (p.s.); it is gently arcuate, the convex side being towards the mid-line. T'o see the rest of the splints of the fore part of the skull the palatine plates have to be cut away (Plate 39, fig. 1). The main romer $(v)$ is five-ninths the length of the whole bony skull, measured along its base. Its blunt point fits in between the hinder third of the palato-premaxillary bars; there it becomes subcarinate, widening gently; its broadest hinder part is distinctly keeled, and that keeled part is exposed in the open nasopalatine passage (Plate 37, fig. 1). The subcarinate part is strongly clamped by the bones of the hard palate, and thus the nasal passages are divided. The postero-inferior part of the nasal labyrinth is mnderfloored by lateral bones, behind the great inferior openings which have the maxillary plates as their floor; but for these plates the greater part of this region would be "schizognathous." Behind, however, the "desmognathism" is double-upper and lower; this is caused by the meeting together of the notched orbital plate of the palatines and the "postero-lateral vomers" $(v "$ ". -two triangular wedges of thin bone that by their most acute angle fit in between the vomer and recurrent cartilage in front, have their obtuse angle external, and their less acute angle wedged in between the vomer and palatines. These bones are larger than usual for even an Insectivore, but are not distinctly Metatherian-as in Rhynchocyon, where they nearly meet behind the median vomer: Thus the creature sways, so to speak, everywhere, between a normal Eutherian and one of the Metatheria. The strong jugals (j.) bind against the maxillaries in front and widen out; they then thicken, are hollow outside, and end obtusely just over the glenoid facet $\left(g l . c_{0}\right)$. ' The great pneumatic squamosals (sq.) show some of their most marked characters in this aspect, for both the hinge (gl.c.) and the pneumatic cavities are to be seen from below. The zygomatic process is short, the glenoid facet is concave, oval, and almost transverse, -it looks obliquely downwards, and forwards, and retreats a little at its inner end. The postglenoid ridge is large and thick, and the bone extends inwards beyond it, clamping the alisphenoid (al.s.), and nearly reaching the cochlea (chl.). The outer edge is tucked, as it were, under the skull and round the top of the tympanic cavity.

Behind, the squamosal embraces the mastoid part of the ear-labyrinth, and that elge is, close in front of the arrested and coalesced, epihyal (e.hy.). The roof of the tympanic cavity - tegmen tympani - is largely formed by the squamosal, and that roof opens into the air-galleries above, that give the sinuous appearance, and apparent thickness to the bone (fig. 2, sq.).

The tympanic ring $\left(a_{.} t y_{.}\right)$is in a remarkable state of development for an embryonic Insectivore; its development is equal to that of a Rodent or a Herbivore (Ungulate). But although large, the bone is shallow - a mere saucer, and the air cavity in it is very limited as to depth; but this is compensated by the extensive galleries that are developed in the squamous and mastoid regions (see in the adult, Plate 39). This tympanic clish (Plate 37, fig. 1, a.ty.) has a spout in front, an accurate round notch-the 
opening-on its outer edge, and a small unfinished part behind that noteh; its general form is round and gently concave above and convex below, but it runs into crenations at the postero-external margin, and also (Plate 38, fig. 1, a.ty.) is developing a process which is the rudiment of the compressed bony meatus externus (see Plate 38, fig. $4, \alpha_{.}$ty.).

The end view (Plate 25, fig. 3) shows the imbrication of the roof-plates as they fit upon the occipito-auditory region; the parietals, interparietal, and squamosals $\left(p_{.}, i . p ., s q.\right)$ are thus seen, and the latter show their sinuous enlargements, due to the excavations within them.

\section{Endocranium of embryo of Galeopithecus volans; 1 st Stage ( $)$.}

Many things belonging to the inner cranial structures can be seen in the dissected, but perfect, skull (Plate 37, figs. 1-3; and Plate 38, fig. 1) ; but only when the investing bones have been removed are the deep parts thoroughly visible.

Such further dissections are figured in lowen and upper vieus (Plate 39, figs. 1, 2), with some of the investing bones, left for the most part in outline, to be useful as landmarks.

The short, broad snout (al.no) has its nostrils (e.no) near the end, and rather underneath; the snout narrows in front, broadens behind the nostrils, and then is somewhat pinched in.

From the middle of the floor, which crosses over the premaxillaries $(p x$.$) , the$ recurrent cartilages ( $r c_{.} c_{0}$ ) are given off; these grow round the opening of JAcoBson's organs and then run along on their inner and under side as their proper, but imperfect, capsule. These eurious retral growths of the snout are twice as long in this species as is normal, a fact the meaning of which I cannot explain, but which will be understood when our knowledge of these parts is more advanced.

The inferior turbinals (i.tb.) are very feeble, but the foremost coil of the middle turbinal series $(m, t b$.) is very large indeed-both in width and in length; it extends forwards twice as far as usual: three other coils of this series are seen behind it.

Above (fig. 2), in this species, the olfactory labyrinth (al.e.) is seen to be short, and not very wide; this is partly due to age, and is partly a specific distinction. The whole fuce being shorter and broader in this embryo than can be accounted for by difference of age; the thick top of the septum (p.e.) does not end in a definite crista galli. The top of the great septum (p.e.) is very oblique, it is narrow, and has a sinaller perforated plate $\left(c \cdot \cdot p_{0}\right)$, right and left of it, than is usual in Insectivores. 'This cribriform plate is quite unlike that of the Hedgehog or the Mole, and is quite like that of a young Frugivorous Bat (Cynonycteris collaris), now before me. Its upper recesses are shallow, its size is small and sub-oblong-widest above-and its perforations are comparatively few; the Frugivorous Bat on one hand, and Cuscus on the other, gives us the two cribriform plates most like it. A tract of median cartilage is 
seen above, behind the cribriform plate, which is the end of the perpendicular ethmoid, and the beginning of the presphenoid. All the fore part of the basis cranii on the under surface (fig: 1) up to this point is hidden in the lower view by the vomers. In the upper view (fig. 2) the orbitosphenoids have lost their large cartilaginous upper part, and now form two oblique, four-sided wings (o.s.) that have met, and largely coalesced below, to form a long presphenoidal region, as in the Hedgehog and the Mole; the Shrew, as I have shown, agrees with the Marsupials in having an independent presphenoid; that is a rare thing among the Eutheria, but is seen in small Rodents. The optic formen (II.) is very large - a good Lemurine characterand the bar enclosing it, behind, is strong; here we are far away from the Marsupials. There is still much cartilage between the presphenoid and basisphenoid (b.s.); the fore margin of the latter is bilobate, and its sides show some remnants of the expanded parts that in typical Insectivores form the tympanic wings; there are two irregular knobs on each side. The alisphenoids ( $a$ l.s.) are still distinct from the basisphenoid, they are one-third larger than the orbitosphenoids, and overlap them by their inner and anterior angle much more than in Rhynchocyon and the Marsupials; this corresponds with what we see in Bats, but is quite unlike the peculiar overlapping growth of the alisphenoid in typical Insectivores. Each wing is ear-shaped, narrowing in behind, and so deeply notched for the 1st and and branches of the 5 th and the orbital nerves in front $\left(\mathrm{V}^{\perp}{ }^{2}\right)$, and by the $3 \mathrm{rd}$ branch $\left(\mathrm{V}^{3}\right.$.) behind, that there is only an isthmus of bone one-third the extent of the wing between the two great round notches; this is equally true of these parts in a young Pteropus. When the soft tissues are removed between the posterior sphenoid and the auditory capsules (fig. 2), then a very irregular middle lacerated foramen is seen, this is bounded posterolaterally by the squamosal (sq.). That bone covers nearly all the auditory capsule, externally (Plate 38, fig. 1, sq. op ). and below (Plate 39, fig. 1. op.), only a small mastoid tract is seen clamped by the squamosal, perforated by the facial nerve (VII.), and having in front of that foramen (stylomastoid), a very small rough bony elevation, the arrested and confluent epihyal (e.hy.). There the bony capsule is pinched, for the exoccipital (e.o.) nearly meets the squamosal in front of the epihyal knob. Then the auditory labyrinth expands, running inwards and forwards, and showing, from behind forwards, the heart-shaped fenestra rotunda, the oval fenestra ovalis, and the notch in front of the latter, through which the facial nerve (VII.) passes to get under the tegmen tympani (t.ty.); the whole fore and under part is the smallish, obtuse cochlea (chl.).

Above (fig. 2), the capsule is well displayed; it has a rough keel in front of the proximal cochlear eminence, behind which, running invards and a little backwards, are several holes. The porched meatus internus, on the inuer side, contains several of these, the outermost being for the facial nerve (VII.) and the other for the auditory or portio mollis (VIII.). 'The former passes under a thick bridge of bone, and then runs round and escapes through the notch in front of the fenestra ovalis (fig. 1, fs.o.,. 
VII.). Then comes the arched part containing the anterior canal (a.s.c.) bent over the hollow for the flocculus cerebelli; the arch runs backwards and inwards to meet the occipital arch, strongly clamped by the thick hollow squamosal (sq.). From the bridge over the facial nerve there is on the left side a short, and on the right side a long, spur of bone, ruming upwards towards the arch of the anterior canal. 'The whole auditory capsule is well ossified, just a little cartilage remaining in the mastoid eminence (op.) and along the epiotic margin, but the occipital arch has still large synchondroses (Plate 37, figs. 1-3; Plate 38, fig. 1 ; and Plate 39, figs. 1, 2). The supraoccipital (Plate 37, fig. 3, s.o.) is a large shield of bone, round above, notched below, and with sinuous sides; it was, evidently, double at first, is convex above, and along the middle, and is a little scooped for muscular attachment inferolaterally. Then comes a large triradiate tract of unossified cartilage, below which there is, outside, the mastoid bone (op.), and inside, the exoccipital (c.o.); the former ends in a small cap of cartilage. The curved exoccipitals are everted against the mastoid bone, but they keep well inside it, and form no definite paroccipital prominence. The condyles are long (deep) and roughly crescentic-broad above, narrow below-and help to enclose a large foramen magnum (f.m.).

The basioccipital (Plate 39, figs. 1, 2, b.o.) is twice as long as the basisphenoid, it is narrow in front, broad behind, subconcave above, and subcarinate below; it is separated from the lateral ossifications by a large tract of cartilage, and is perforated by the large hypoglossals (XII.), and notched by the vagus and glossopharyngeal (X., IX.).

So far advanced is the embryo before birth-equal to that of a young Marsupial eight months old - and the Marsupials ossify their skull earliest of all kinds-that the processus gracilis of the malleus (Plate 37, fig. 4) is already only half the size of the manubrium ( $m b$.$\left.) . The posterior angular process ( p_{.} a g.\right)$ is a distinct knob, but small; the head of the bone is bulbous. The incus ( $i_{\text {. }}$ ) is very bulbous, and is very similar to that of a very different Order of Herbivores, namely, the Ruminantia (Doras, plate 61, figs. 12-21). The short crus (s.c.i.) is very short and small, and the long crus (l.c.i.) although normal in form, is small ats compared with the bulbous body. The height and basal breadth of the stapes (st.) are about equal, the fenestra is small, as in those Marsupials that have this hole; the interhyal is arrested.

The ceratohyal (Plate 38, fig. 3, c.hy.) is in one slender subfilcate segment, with the lower part ossified; the hypohyal $(h . h y$.$) is less than half of the length of the$ ceratohyal, but it is thicker; it is not ossified. Nor is the $U$-shaped basal cartilage $\left(b h . b r_{0}\right)$ which has flat and uncinate thyrohyals $\left(t . h y_{*}\right)$, not yet segmented from the basal tract, which is small and narrow. This os hyoides is quite unlike the perfect arch of the British Insectivora and the East African Rhymchocyon; it is better developed than that of the larger Centetidæ, and is about equal to that of a Marsupial at the same stage of development. The small, simple conche (Plate 37, fig. 5), shows an imperfect segmentation of the annuli inside the dilated leafy growth of cartilage.

MDCCCLxixy.

$\because \mathrm{L}$ 
Stuge 2(B).- Young of Galeopithecus philippensis; 8 inches long from snout to root of tiil.

\section{The incesting bones of the skull.}

The sicle view of the skull (Plate 38, fig. 4) reminds one of that of an Ewe, or of a Llama, just as the incus, as we have seen, is like that of the Ruminants; the side view of the head in the embryo of the other species (Plate 16, fig. 15 $\mathrm{A}$ ) suggests the sane resemblance. Anyhow, whatever it is like, the skull is as unlike that of a normal Insectivore as it can wrell be. The centre of the orbit is at the middle of the length of the whole skull, including the snout; the facial part is much shorter in the embryo of the other kind (compare Plate 38, figs. 1 and 4). More than a third of this large orbit-Lemurine as to size-is unenclosed behind; it is more circular than in the young specimen. Through advanced growth, the hollow over the fore part of the orbits, and the deflection of the snout, are less marked. Now, the highest convex part, above, is parietal (p.), and the supraorbital ridge is higher than the upper face of the frontals $\left(f_{0}\right)$, and the convex dorsal line of the nasals $\left(n_{0}\right)$ is a little less rounded. 'The embryonic curve of the whole skull is now much less evident; but the straightening process is not finished yet. The premaxillary ( $p^{\prime}$.) runs further into the maxillary (mx.) in the facial suture, and the latter is much more outspread in the preorbital region, quite flush with the lachrymal $\left(l_{0}\right)$ The latter bone encloses a fourth of the orbit, and a third of its actual rim. Its canal is well inside the edge, as in the Hyrex, and not outside as in Bats, Lemurs, and most Marsupials. These latter, as a rule, have two canals-one in Phalangista. The facial part of the lachrymal is a large lunule and the orbital a thin polygonal plate. The small double infraorbital formen $\left(\mathrm{V}^{2}\right.$.) is below the convex preorbital margin of the maxillary. The developed orbital rim lides the inner opening when looked at in this aspect. The orbital edge and pustorbital process of the jugal $(j$.$) are better grown now, and the latter is not$ so far back; it is nearly over the middle of the well-developed cheek-bone. A triradiate concavity traverses the large orbital plate of the strong-browed frontal $\left(f_{0}\right)$; that shallow fossa ends below and behind in a rounded notch, which is made into a foramen (f. orbitale) for the re-admission of the ophthalmic nerve $\left(\mathrm{V}^{\mathrm{l}}\right.$ ) inside the skull-wall. The frontal bone interdigitates with the parietal ( 1 .) under and behind the postorbital process, and then that gently swelling roof-bone runs back to the transverse interparietal (i.p.). Behind the f. opticum (see fig. 1, II.), the large alisphenoid wedges apart the frontal, parietal, and squamosal; the latter (sq.) is squarish, and large enongh to hide most of the side of the loind skull; it corresponds with that of an Eastem Mirsupial; in Diclelphys it is much smaller; it is in remarkable contrast with that of Erinuceus and Rhynchocyon (Plate 20, fig. 3; and Plate 36, fig. 3); in I'teropus and Lepilemen the parietils throw the squamosul down to the side, and, in their much fuller growth, overshadow it. 
Here the zygomatic process, the glenoid cavity, the postglenoid ridge, the supratympanic notch, the temporal fossa, the tempora squama, and the post-tympanic angle are all in a high state of development. Below and inside the elegint sigmoid jugu-squamosal suture we see the internal pterygoid hook, and the small external pterygoid plate $(p g ., e \cdot p g$.$) . Built well into the deep rounded tympanic noteh of the squa-$ mosal, we see the strong compressed bony meatus externus ( $m$.a.e.), standing out from the general tympanic dish $(a . t y$.$) ; it is open above, as the squamosal is below ; together$ they make a vertical narrow bony-lipped passage to the shallow drum-cavity and its extensive upper galleries-that is, after the membrana tympani has been removed from the inside of this narrow porch. The lower jaw (figs. 4 and 5) has, already, nearly assumed the adult form, with its deflected mentum, its oblong dentary region, its small unciform coronoid process, its non-pedunculate condyle, notched behind, and its wide out-turned angular region, with an incurved inner edge.

The lower view (Plate 37, fig. 6) shows some contrasts with that of the embryo of the other species (fig. 1) that cannot all be put down to a further stage of development. Here we must make allowance for two causes of difference-age, and diversity of species."*

Here (Plate 37, fig. 6) the alveolar tracts are more nearly parallel than in the other kind (fig. 1), and this is not merely due to advance in growth, but is partly also specific. The fore part of the premaxillaries $(p x$.$) is slenderer, and the maxillary$ palatine plates have grown further forwards.

With this fuller development of the palatine plates, the hollowness of the palate in its middle - a remnant of the old Marsupial feebleness of this part-is almost gone, although the mid-line is hollow, and a shallow fossa runs right and left, cross-twise, near the hind margin of the maxillary plates. The palatine plates of the palatines ( $p a$.$) are like those of the other kind, but they are more extensive, and in this stage we$ have a complete sutural analysis of the peculiarly elegant archivays of the nasopalatine passages of the adult Colugo. The squamous suture of the maxillaries and palatines is arched, but runs transversely in this case, and the narrow fissure between the flat part and the ribbed edge is widened out into a very remarkable uncinate concavity, ending sharply, outside, in the posterior palatine foramen (p.p.f.). Here, again, we see the sharp angular space between the palatine part and the mere side wall, which turns inwards to join the feeble pterygoids $(\mathrm{pg}$.$) , which have a basicrnnial$ tract, ending in a toothed edge, between the orbital plates of the palatines and the long tongue-shaped mesopterygoids (m.s.pg.). These latter reach nearly to the basioccipital (b.o.).

* The difference is as remarkable as the similarity (Plate 37 , figs, 1 and 6 ); and if these two maifs can show such curious and notable modifications, although so close akin, there can be no difficulty in imagining a large number of similar but greater differences in structure in whole hosts of related forms, which may at one time have existed, and which were, probably, potent in species, genera, and even subfamilies. 
The splint bones that support the basis cranii, lying on a higher level, are the vomer and the "parasphenoid;" the former (fig. $6, v$.) is here seen to be the common keystone of this very perfect double archway of the masopalatine passages (n.p.c.). The keel of the vomer wedges itself in between the ribbed edges and the two palatines, and these complete the divisions of the common nasopalatine channel; its broad sides then unite by harmony with the orbital plates of the palatines, so that it is conjoined with those bones both in the middle and also right and left. These lateral flanges of the vomer end as free spikes under the presphenoid (p.s.), and the middle, shorter part is also split. But the other bone just mentioned-the "parasphenoid" -is not seen in the embryo of $G$. volans (fig. 1), nor, indeed, in any other Mammal examined by me, as yet.*

This small style of bone lies under the foremost two-thirds of the basisphenoid (b.s.), but is very distinct from it; it resembles, at first sight, the ridge often seen under the basioccipital, which is due to the ossification of the sheath of the notochord; but this tract is wholly pro-chordal. It is the exact comnterpart of the parasphenoid of the Lacertilia, which disappears as mysteriously in some kinds as in G. volans; in the case of two closely related Cyclodonts-Cyclodus nigroluteus and Trachydosaurus rugosus: in the latter it has been taken away, and in the former it has been left. Here the Marsupial condition of the well-developed jugal $(j$.$) is seen again (fig. 6, j$.$) ,$ and a still more extensive development of the equally Marsupial squamosal (sq.) with its thick, crescentic, hollow postglenoid process, its large pretemporal part clamping the alisphenoid $(a l . s$.$) and its extensive swollen post-temporal plate. The tympanic$ $(a . t y$.$) is, here, most instructive as to the interpretation of the thoroughly ankylosed$ adult skull (Plate 39, figs. 3-8). This bone, now well-formed, is a remarkable shallow dish with a most irregular outline, and a crescentic convexity in its deepest part, the convex outline of which runs close to the fissure for the exit of the grlossopharyngeal and vagus nerves (IX., X.).

Where, as a rough wedge, it runs forwards and reaches the mesopterygoid, there it has a considerable oblique foramen, the Eustuchian opening (eu.); this is surrounded by cartilage in the embryo (fig. 1). Externally it is jammed in between the postglenoid and post-temporal elevation of the squamosal (sq., see also Plate 38, fig. 4, a.ty.). Thus, since birth, it has finished the bowl of the dish and formed the deep two-lipped spout-the bony meatus externus.

In the end view (Plate 37, fig. 7) the parietals (p.) are seen with their lower edge forming the top of the temporal fossa, which half is sconped out of the squamosal $(s \%$.). The swelling of the post-temporal part of the latter bone (see also Plate 38,

* I shall have to describe a pair of bones found in membrane, and added to the basisphenoid, when I come to other and higher kinds of Eutheria; these have long been known in Man as the "lingulæe spitenoidales." I strongly suspect that they are the "basitemporals"-symmetrical remnants of the parasphenoid-so well seen in Birds and the Crocodilia (Phil. Trans., 1869, Plate 82, fig. 2, b.t.; and 'Irans. Zool. Soc., vol. 11, plate 66, fig. 3, b.t). 
fig. $4, s q$.$) , close to the large air cavities within, is also well seen. The interparietal$ (i.p.) has begun to develop the occipital crest so large in the adult (Plate 39, fig. 4).

\section{Stages 2 and 3 (B and $\mathrm{c}$ ).-Showing endocranium and certain of the investing bones of Galeopithecus philippensis.}

These two stages differ but little from each other, and for the advance of the endocranium may be taken together. In the longitudinally vertical section (Plate 38, fig. 7) the cranial cavity, and the nasal labyrinth are equal in length; the former overlaps the latter in front. The obliquity of the top of the perpendicular ethmoid (p.e.) is such as to make a very obtuse angle with the top of the general septum (p.e., s.n.), whilst it is almost in a line with the basis cranii behind, just rising a little at the crista galli (cr.g.). The recess for the olfactory lobe, lying on the oblique cribriform plate, is not large-very little in advance of the same in the Marsupials. Only about a fifth of the general partition (p.e.) is ossified at present; this is a long way from the presphenoid $\left(p_{. s}\right)$ and does not reach the bottom; the intertrabecula itself is hardly touched, only its crest.

This is a very long septum $\left(p, e_{0}, s_{0} n_{0}\right)$ for so short a snout; in most of the Insectivora it is that part which prolongs the septum, forwards; here, it is the elongated facial region itself, with but little alinasal addition. The deflection of the whole face is still evident, and the end of the septum is almost in a line with the general palatal tract. Behind that part the opening of JACoBsox's organ $\left(j . o_{0}\right)$ and the fore part of its cartilaginous capsule of the near side is shown; behind, where it is cut across, the vomer (v) is seen.

That long trough of bone is half the length of the cranio-facial base, reaching from the front third of JACoBsor's (recument) cartilage (rc.c.) to behind the middle of the presphenoid (p.s.). As it supports the intertrabecular base of the nasal partition, so it is itself supported by the bones of the hard palate $\left(p_{0}, m x_{0}, p \alpha_{0}\right)$ at their junction along the mid-line; thus the nasal cavities as they pass towards this hinder opening are kept distinct.

Over the septum nasi $\left(s_{0} n_{0}\right)$ the nasal $\left(n_{0}\right)$ is seen, and the frontal $\left(f_{\text {. }}\right)$ over the ethmoid, and over the cavity of the skull in front. At this stage the roof-bones are thick; the parietal receives the hinder angle of the frontal into a notch, laterally, and is partly overlapped by, and partly overlaps, the frontal. The well-ossified anterior sphenoid $\left(o . s ., p_{.}.\right)$is seen in this view, the wing rising into a rounded angle, and having the large optic foramen (II.) near its hind edge below ; the presphenoidal tract is rather thick, and is longer than the bony plate-basisphenoid (b.s.)-behind it. The alisphenoid ( $($ l.s.) leans against the orbitosphenoid, and rises to the same height; it overlaps it in front, and is then only partially visible in this view.

The short basisphenoid (b.s.) dips a little, but gets no postclinoid ridge again, behind; there is a small tract of cartilage between all these basal bones (p.s., b.s., b.o.). Under 
the basisphenoid the parasphenoid (pa.s.) is seen. Between the alisphenoid and the auditory capsule there is a large semi-oval space filled in by the squamosal (sq.), which is hollow inside, the concavity being a continuation of that formed by the parietal. Above the hind corner of the squamosal and over the upper and front part of the auditory capsule the parietal forms it thick and rough rudiment of the "tentorium cerebelli." Under that rafter-like bar the squamosal (sq.) shows a roughly triangular inner face, which lies outside the arch of the anterior canal (a.s.c.), and supports the lower half of the fore edge of the supraoccipital (so.); the re-appearance of the squamosal inside is due to its great height, especially behind. 'The auditory capsule is subvertical in position, and in this view shows the great arch over the recessus flocculi, the multiperforate meatus internus (VIII), with the bridge over the facial nerve (VII.) a thickening where the posterior canal (p.s.c.) begins, and a somewhat notched edge where the 9 th and 10 th nerves (IX., X.) emerge. The basioccipital $($ b.o.) is thick in front and thin behind; it is one-third longer than the basisphenoid (b.s.). By an obtuse angle it wedges in between the capsule and the lateral occipital (e.o.), which is a broad and high bone, having a large oblique hole for the hypoglossal nerve (XIT.) not well seen in this aspect, and a small posterior condyloid foramen (p.c.f.). The supraoceipital (s.o.) and interparietal (i.p.) now form one large shield-shaped bone, fuishing the postero-superior face of the skull, and articulating with the parietals and exoccipitals, but kept apart from the petromastoid by the large post-temporal part of the squamosal.

In the side view of the smaller young of $G$. phitippensis (Plate 38, fig. 4) the snout with its valvular opening $\left(a l . n ., e_{.} n_{0}\right)$ is seen in front, and the top of both the orbitosphenoid and alisphenoid (o.s., al.s.) laterally, in the fundus and back of the orbit. Here it is seen that the alisphenoid reaches much higher than the inner view (fig. 7) would seem to show. The occipital condyle (oc.c.) is seen in both these views, and some part of the mastoid (op.), the exoccipital (e.o.), and the supraoccipital (s.o.).

In the basul aspect (Plate 37, fig. 6) several important parts are displayed, not covered by the superficial bones. In front, the alinasal region shows with great distinctness the origin of the recurrent cartilages (rc.c.); the external nostrils (e.n.) are more teminal, as in Marsupials, than in the other kind. 'The presphenoid, basisphenoid, and basioceipital (p.s, b.s., b.o.) are displayed, with the parasphenoid ( $p a . s$. under the middle piece; the basisphenoids and basioccipitals are much wider in this space than in the other. 'The alre are not much displayed, and the alisphenoid is largely overlapped by the squamosal. The small mastoid process (op.), with the stylomastoid foramen and epihyal in front of it, and the exoccipital void of any distinct paroccipital process, are also well seen. The subcircular foramen magnum ( $f . m$.) is hordered by the large projecting semioval condyles (oc.c.), and, behind, the supraoccipital (s.o.) can be seen finishing the great doorway.

Part of another lower view in the larger young (fig. 8.) shows the foramen ovile $\left(V^{3}.\right)$, the chamel for the facial nerve (VII.), the fenestre-fenestra ovalis 
and fenestra rotunda $\left(f s_{0} ., f_{*}\right)$ - - in the auditory capsule, the outlet for the facial, glossopharyngeal, vagus, and hypoglossal nerves (VII., IX., X., XII.) ; a bristle shows the opening from the ear-drum into the labyrinth of air-cells in the squamosal (sq.).

The end view of the skull, younger specimen (Plate 37, fig. 7), shows the well-built occipital arch, with its elements distinct; the large foramen magnum, the outstanding condyles (oc.co), and the mastoid process (op.) all well set in under and within the great investing plates.

There is a remarkable difference between the hyoid arch in the lesser and larger of these young Philippine specimens (Plate 38, figs. 6 and 8).

In the former (fig. 6) this part is not so well developed in some respects as in the embryo of the larger species, for the hypohyal h.hy. is not segmented off from the ceratohyal (c.hy.), whilst the latter region is not ossified, but the hypohyal region has an oval centre. The busal and thyrohyal regions have now each a small bony tract.

In the larger young (fig. 8.) these parts are much more advanced, and the hypohyal is segmented off from the ceratohyal ; each of these is rapidly ossifying, and so are the basal piece and thyrolıyals; but these are continuous in the cartilaginous interspaces.

Stage 4, D.-On the skull of the adult Galeopithecus philippensis.

This is one of the most remarkable skulls to be found in the whole of the Eutherian division of the Mammalia; it is, thus, like the skull of a Serpent-a low type, arid yet specialized, in its own way, to the uttermost. Just now, I am only responsible for the skull; the structure of all the rest of its organization must be accounted for and argued about by others; but I must mention the size of its brain-cavity (Plate 39, fig. 3), as showing how small a brain this creature has. The proportion that the foramen magnum bears to the greatest intercranial breadth will serve my purpose, as I cannot go further into that matter. In the adult Galcopithecus philippensis and in the sub-adult Cuscus maculatus, that opening is two-fifths the greatest breadth of the skull inside; in Leprlemur mustelinus it is only one-third, and in Loris gracilis, and Pleropus medius, only one-fourth.

In the cranid characters that have been already described in the young specimens and embryo, I have shown that there are several things that are manifestly Metatherian, but these are not the same things as those that show a Marsupial attinity in the Hedgehog and its allies; they belong to another set of parts.

I have already spoken of the help the young of Cuscus maculatus-one of the lowest and most generalized of the Eastern Marsupials--has been to me in the study of the growing skull of the Colugo. I now find that with the adult skull of that species, and the adult skull of a great Fuggivorous Bat (Pteropus medius) I have the two extremes, with the skull of Galeopithecus half-way between them. Not but that this bizarre type has its own unique characters; this might have been expected, for it 
is left alone-at most with but one companion-the other species-and its proper. Family must have suffered very largely from causes of extinction. This is one of the lightest and most highly polished of all skulls-quite Bird like in this respect, and in the thorough fusion of all its cranial elements.

The impression that rises first is that it is a fotiaceous skull (Plate 39, fig. 4), as unlike other more familiar skulls, as the Leaf Insect is unlike normal Orthoptera. The temporal and nasal regions are about equal, the orbital one-third shorter; this opens into the temporal, behind. 'The general convexity of the upper surface is made gently sinuous by the special convexities of the various bony elements of which it is composed; these have just been described, and will enable anyone to understand the finished and fused adult skull, in which, instead of sutures there are fine, and often clear, depressed lines. There is a supraorbital fossa on each side, as in aquatic Birds, as though it had a pair of nasal glands; these end sharply behind, and lead to a supraorbital foramen, which is further forward than in Pteropus and its allies. Over the small hemispheres, as in Marsupials, the frontal region is lat, in front, and then rises gently; the whole brain cavity has its form revealed in this way by a definite convexity, the outworks being well marked off. The orbit has the posterior fifth incomplete, for the finely turned supraorbital ridge ends in a large uncinate leaf of bone, the postorbital process and the jugal has a clean edge, growing up towards the postorbital process of the frontal; the lachrymal projects invard in the preorbital region, and forms about a fitth of the actual ridge of the orbit; its canal is small. In front of the lachrymal and jugal there is the small, but double, infraorbital foramen. The ridges on this skull serve the purposes both of beauty and of use; the hind edge of the postorbital process curves forwards and then, at its sides, over the swelling brain-cavity, becomes the supratemporal ridge, which converges towards its fellow, getting within a half of the front distance, as they meet on the top of the interparietal. There the temporal fossa rounds itself, and is enclosed by the transverse occipital edge (Plate 39, fig. 4). This large oval enclosure, half as long again as the orbital territory, has then below it a low oblique wall which is very strong behind, and runs down over the meatus externus; and, with two rounded elevations, one small and the other large, the sharp boundary line passes into the hinder edge of the ascending uncinate postorbital process of the jugal bone. This outer boundary-orbital and temporal - is greatly bowed outwards in this depressed skull, in sharp contrast with the sime parts in the neat narrow skull of Pteropus. Along the middle of the extensive temporal fossa, for the wide origin of the huge temporal muscle, the convexity of the wall of the skull cavity is clearly seen. 'The side view of the temporal region in this skull shows nothing new to the student of the higher Mammalia, but the form and condition of the parts is both Marsupial and also unique. Only the narrow outer end of the large transverse glenoid cavity is seen in this ispect of the skull, but the large postglenoid process, the notch for the deep tympanic trough, and the part of the squamosal overlying the mastoid process are best 
scen in the side view. Then the post-temporal and mastoid regions are concare, turn obliquely, and are swollen and sinuous, with the great air-cells within, which are wellmarked on the outside, every cell marking its own convexity. The supraoccipital ridges, vertical and transverse, can be seen in this view, and the large projecting occipital condyle.

The end view (Plate 39, fig. 4) shows the gently hollow sagittal region (i.p.); the outspread, foliaceous postorbitals $\left(p_{0} .0.\right)$; the widely extended glenoidal part of the squamosals $(s q$.$) ; the post-temporal region of the same bones, overlapping the mas-$ toids $(o p$.$) ; the projections further forwards of the postglenoid ridges, and the free$ fore legs of the tympanic (a.ty.). The large foramen magnum is seen to be somewhat elliptical, with the long axis transverse; over it the supraoccipital forms a low arch, and on that bone, above, there is a keel, derived first from the interparietal; and from the top of the keel or crest a transverse ridge, right and left, enclosing the supraoccipital region.

The very large condyloid foramina (XII.) are well seen inside the foramen magnum, in front of the large subpedunculate condyles; then the occipital arch is constricted, and the paroccipital ridges are obsolete, but the mastoid grows inwards over that region, and forms a thin-edged floor to the passage for the $9 t h$ and 10 th nerves. The general form of the great hard palate in the adult is oblongo-elliptical, and it is half the length of the whole basal tract. The anterior palatine foramina are large and oval, the posterior palatine foramina are moderate, far back, and far apart, lying in the fossa of the palatine plate of the palatines, close to the junction of these bones with the maxillaries.

The general surface of the hard palate is gently hollow, margined by the edentulous part of the narrow premaxillaries, in front, by the large sockets and teeth laterally, and by the exquisitely wrought, thickened and ribbed edge of the nirrow palatines, behind. These plates grow backwards to receive the crest of the vomer, and then arching forwards, run round the posterior nares, curving in again to form a waist in the open part, and then ending in a sharp ridge, turned outwards, which ends in the small unciform extemal pterygoid process. Inside these alisphenoidal hooks there is a more delicate pair of hooks, the hamular processes of the pterygoids. 'The hinder" edge of each pterygoid is notched above the hook, and then runs backwards and ontwards in a sharp ridge, reaching the foramen ovale. The keel of the vomer ends between the pterygoids; then the skull is made carinate by - the slender acicular parasphenoid, is then gently convex along the middle, and becomes subcarinate in front of the foramen magnum.

The transverse well-margined glenoid cavities, underlapped behind by the thick incurved postglenoid process, might belong to some stout Camivore.

The neat foramen ovale lies between the glenoid facet and the cranial part of the pterygoid; behind and inside it is the ragged opening of the Eustachian tube, floorer by the sharp, rough fore lip of the tympanic bone. The keeled bottom of the deep,

HDCCCLXXXV. 
folded meatus externus wedges in between the postglenoid process and the mastoid; the latter is an oval, ear-shaped tract, subconcave below, with a limbate margin, and a narrower hole in its inner, proximal part; that hole is the stylomastoid foramen, and a small convexity in front of and outside it is due to the fusion, with the mastoid, of a small epihyal.

Behind and within the ear-shaped base of the mastoid process the smallish opening for the 9th and 10th nerves is seen. The opening for the 12th nerve, behind, and for the internal carotid arteries, further forwards, are very large indeed. Only half of the lirge strongly curved occipital condyles can be seen in the lower aspect of the skull.

A section of the skull of the adult (Plate 39, fig. 3) shows three convexities along the dorsal line: the first long, over the nasal labyrinth; the next somewhat shorter, over the front parietal region; and the third short, over the ear-capsules and hind brain. The great septum (p.e.) is ossified over all the proper ethmoidal territory and most of the proper septal; this latter is elongated in front by the partition of the snout (s.n., (l.n.), which hooks, downwards, in front. From it the recurrent or JACoBson's cartilage (rc.c.) proceeds, scarcely lessened in relative size since birth (Plate 39, fig. 1, rc.c.). 'The ridge of the perpendicular ethmoid (p.e.), behind and above, forms a very obtuse angle with its top in front, and a very acute angle with the axis of the skull, behind and below, thus the cribriform plate lies well down in front of the proper cranial cavity. 'The septum bulges downwards in the true olfactory region, and rises again where the perpendicular ethmoid passes into the presphenoid (p.e.,p.s.); inside that part the optic foramen (I.) and sphenoidal fissure $\left(\mathrm{V}^{\mathrm{r}, 2}\right.$. ) can just be seen. The nasals and frontals form the wall-plate of the great partition; below, the vomer ( $v$.) has become fused with the palatine plates ( $m_{0} x_{0}, p a_{0}$ ) dividing the nasal channels, below. Underneath, the right channel can just be seen, and further back the palato-pterygoid side wall $\left(p u_{0}, p_{0}\right)$, and the lip of the tympanic $\left(u_{0} t y_{*}\right)$ under the Eustachian opening. The basis cranii $\left(b . s_{.}\right.$, b.o. $)$is thin and sinuous, thickest behind, where it dips and forms the free fore margin of the foramen magnum. But little sellar depression exists inside the foramen ovale $\left(\mathrm{V}^{3}\right)$. Above, the frontal and parietal $\left(f_{\circ}, p_{0}\right)$ form a thinner roof than in the young (Plate 38, fig. 7); there is a rudiment of the tentorium cerebelli growing from the inner face of the parietal, and from the fore edge of the auditory capsule. The arch of the anterior canal $\left(a_{.} s_{.} c_{0}\right)$ is well marked, the prootic bone is crested, roughly, above it; below, is the deep floccular recess $\left(f_{0} r_{\circ}\right)$, and below that the multiperforate meatus internus (VIII.), and the bridge over the facial nerve (VII.). T'he large openings for the 9 th and 10 th (IX., X.) and the 12 th nerves (XII.) are also seen in this aspect. Above, the vertical and transverse ridges of the supraoccipital (s.o.) are seen projecting beyond the line of section, which was on the left of the middle.

In front of the auditory capsule the septa between the large air-cells shine through the inner table of the squamosal (sq.).

In the firont wew (Plate 39, fig. 5) the liuge foremost coil of the middle turbinal 
(m.tb.) is seen thrusting itself forward over the feeble inferior, and under the small nasal, turbinals $\left(i . t b ., n_{0} . t b.\right)$; here the cartilaginous part of the partition has been removed, and the front of the bony part $\left(s_{.} n\right.$. ) is towards the eye ; it is hollow below where it has not ossified, and rests upon the grooved vomer (v) in front of the palatine processes of the premaxillaries $(p x$.$) . A vertical slice of the skull in the region of$ the meatus (Plate 39, fig. 6, a.ty., m.a.e.), and through the glenoid cavity (gl.c.), shows the large air-cells of the squamosal (sq.) and their somewhat radiating arrangement.

In a part of the hind skull cut across horizontally (fig. 8) the air-cells of the squamosal and mastoid $(s q ., o p$.$) are shown; where these two bony parts have coalesced$ behind, there the cells are very regular and their septa for some extent radially arranged. In this figure the parasphenoid ( $\left.p \alpha_{.} s_{*}\right)$, pterygoid ( $\left.p g_{0}\right)$, external pterygoid process (e.pg.), and glenoid cavity (gl.c.) are shown. The tympanic lip, under the Eustachian tube (eu.), is not injured, but the dish itself is largely cut away and the small tympanic cavity (c.ty.) exposed, insicle and above which is the small melon-like cochlea (chl.) and the fenestrx $\left(f s .0, f_{i}\right)$, and also the opening for the 9 th, 10 th, and 12 th nerves (IX., X., XII.); the latter are very large, but are only seen obliquely in front of the occipital condyle (oc.c.).

The lower jaw of this beast might belong to some generalized Herbivorous Ungulate; it is indeed almost a miniature of that of the ITippopotamus. 'To say nothing of its unique pectinated front teeth, the general shape is very remarkable, with its depressed mentum, oblong ramus, short uncinate coronoid process, transverse, sessile condyloid, and deep out-turned angular, process, the edge of which is thickened inwards; its whole shape is half a circle.

The malleus (Plate 39, fig. $7, m l_{0}$ ) has lost all its processus gracilis ( $p . g r^{\circ}$ ), except one or two sharp prickles; the manubrium (mb.) is strong, curved, dilated at its end, and sinuous outside. The incus (i.), like that of the Ruminants, has a heavy, solid body, with short processes (s.c.i., l.c.i., ); the stapes (st.) is somewhat inflated and hollow behind, and at its base oval ; there is a minute interlyyal bone in the tendon of the stapedius muscle (i.hy., st.m.).

The hyoid bone (Plate 38, figs. 9 and 10) shows a hypohyal as large as the ceratohyal $(h . h y ., c . h y$.$) . The basal bar (b . h . b r$. $)$ is concave in fiont, and has a right and left tubercle behind; the thyrohyals $(t . h y$.$) are large, uncinate, and separate, as bony tracts,$ from the base; all these bones are flat and splintery.

\section{On the stull of the adult Tupaia Javanica.}

This is another very isolated form of the Insectivora; I can only mention here certain peculiarities of the structure to be seen in the adult skull, hoping at some future time to be able to describe its development.

The Tupaia is another instance to be added to Rhynchocyon and Galeopithecus, in which a clear prophecy of higher signs of development is combined with characters 
most unmistakably Marsupial; the sudden ascent, so to speak, above the general level in these types has been partial, and combined with a failure to free themselves from low and archaic characters derived from an ancestry belonging to an inferior grade.

As to the relative size of the brain this is evidently one of the highest of the Insectivora; it may be said in this to approximate at once to the Lemurs and the lower Carnivora. To the Lemurs it is comparable also in possessing a large and well developed orbital ring, rare in low forms, keeping its own special character in having a liuge oval fenestra in the jugal arch, where the squamosal overlaps the jugal bone.

'The hard palate is less complete than in Galeopitheous, but more perfect than is normal for an Insectivore. The extemal pterygoid approaches that of the adult Petrodromus, where there is a large oblique Iamina of bone outsicie the proper pterygoid. But in the embryo of the closely allied Rhymehocyon, at this part there is manifestly a shell-like tympanic wing to the alisphenoid, as in Marsupials. Here in Tupare there is a hole through the root of the external pterygoid process; this is evidently the counterpart of the alisphenoidal canal of certain Insectivora, Carnivora, \&c.; in siee, that process equals what we have in Marsupials. 'The supraorbital formen is very large, and is further forwards than in Galcopithecus; in Pteropus it is still further back.

But the annulus tympanicus and os bulle are not only well developed, they are also the almost perfect counterparts of what we find in the lesser Australian Marsupials, especially Petcurus sciureus; the greater degree of anchylosis, which has completely fused these two elements of the ear-drum, is the only difference I can find in the two types. The lower jaw is a good intermedium between that of a Marsupial and that of a normal Eutherian.

\section{Summary and Conclusion.}

Although this paper is confessedly only a fraction of what is necessary to be done in this polymorphic Order, it at least shows how difficult a group it is to hamdle.

For the Insectivora are set in the midst of the other Mammalia-low and high; they might be called the Biological stepping-stones from the Metatheria to the Eutheria.

One thing can be done, even now, with the present fragmentary knowledge of the structure and development of the Insectivorous types - we can assure ourselves that these types are immediately above the Marsupials; that they have the Bats (Chiroptera) obliquely above them; that their nearest relations must be sought for amongst extinct Eocene forms; and that lowly as they are-arrested and often dwarfed to the uttermost, so that Nature could not safely go further in that direction, 
they are, one and all, rich in prophetic characters that have come to perfection in larger and nobler types.

I think it will not be denied that, in the ascent of the types, the Chiroptera are above the Insectivora, and as it were a sort of special "new leader" from that stock, and that the Insectivora are more or less transformed modifications of what is characteristic of the Marsupials.

I suspect that the existing Insectivores just yield the Zoologist one of his groups of types classed together because he knows not what else to do with them; not forming a proper, clear, special branch, or "leader" of the Mammalian life-tree. They form one group, under one designation, just as the poor of this Metropolis form a group; their brand is simply lowliness; they differ, inter se, almost as much as the whole remainder above them differ. The higher forms, however, because of theil elevation can attord to be subdivided again and again, into Order after Order.

If we could descend and see the transforming and newly-transformed Placentalia of the Eocene epoch, then the Morphologist and the Zoologist would find common ground ; the Taxonomy of the latter, however, would be as useless as the titles and distinctions of modem society to some undeveloped race of savage men.

The evidently extreme specialization of the existing Monotremes or Prototheria, and their manifest close relationship to the Edentates - a strange, lowly group of Eutherians, almost extinct in the Old World, and not potent in genera and species in the Newmakes it necessary for me, in the present stage of my research, to leave them until I have mastered both them and the great Marsupial sub-class. Of the latter, however, I can speak already; and as no interpretation of the meaning of the parts seen in a Eutherian skull can be made until they are read in the light of the structure of the quasi-reptiticu skull of a Marsupial, I shall in this summary compare the two types together, using the lower and older as a measure of the higher and newer type of skull.

Anatomists are familiar with the charucters of the skull in adult Marsupials; to these may be added others that have turned up to me in the study of the development of that type. When these are seen in the light of the types outside and below the Mammalia, then that which is typical in a high Mammal, as such, can be formulated, and the spechalization of this great branch of the Vertebrate stock be understood.

I will therefore, here, give a list of the more important and striking cranial characters of the Marsupials, promising to bring forward, as early as possible, the figures and descriptions of the skull in various stages and in many kinds.

But before making this comparison of the characters of the skull in the Marsupials with what is seen in the Insectivora, I will state that in the latter-a mere "Order"the diversity is four-fold that to be found in the Marsupials, which are worthy to be put, not as a mere Order, but as a "Sub-Class." 
For in these, whether they be Eastern or Western types, the uniformity on the whole is very remarkable - as remarkable as the diversity seen in the Insectivora.

The problem put to the Morphologist, however, is to explain why the characters that distinguish a Marsupial from a high or Eutherian Nammal are, for the most part, characters which the former possess in common with the Sauropsida: the residuum of proper, unique Metatherian characters, neither to be found in the higher Mammals on one hand, or in the Sauropsida on the other, is but small.

Another crucial difficulty is this, namely, the Sauropsida, which of all others help ins most in the interpretation of the Marsupial skull, are not those to be found in low Reptilian, but in the lighest Avian, types.

Of all Birds the Passerinæ are the noblest and most marvellously specialized for their orm peculiar mode of life, having many accomplishments and high intelligence.

Yet it is from this Order of Birds that I have had most help in this matter, finding in their skull special structures which closely correspond with what is most remarkable in that of the Marsupials.

There are several characters in the superficial or investing elements of the skull of Mursupials that are unlike what we find in the highest forms of placental Mammalia, but which linger in the lower:-

(a.) The frontals are very small in proportion to the parietals, and the squamosals are relatively, especially in the young, inordinately large, as large as the frontals.

(b.) The lachrymals are not only large and have generally a facial plate, but they have, as a rule, two canals.

(c.) The palatine plates of the maxillaries and palatine bones form an extremely hollow or dome-like structure, and by the time the creature is full-grown much of their substance has been absorbed, so as to leave larger or smaller fenestræ; thus there is an attempt to return to the schizognathous condition of those parts seen in many Sauropsida.

(d.) The palatines are often formed of several pieces, very irregular patches of bone, and their irregular centres are largely absorbed or united with the main parts in the adult.

(e.) The pterygoids are very small, and their basicranial part limited, on account of the constant separate development of a large mesopterygoid.

$(f$.$) The main vomer is often relatively small; there is, nearly always, a pair of$ antero-lateral vomers, protecting the cartilaginous capsule of JAConsox's organs, and large postero-lateral, and other, or postero-medial vomers; these are very irregular and unsymmetrical in the young Cuscrs, especially, in which I find ten vomerine bones.

(g.) The floor of the tympanic cavity ossifies before the cartilage is ripe, but in two subequal centres-the annulus and "os bullæe" - inside the latter a larger folded cartilage protects the Eustachian tube, and outside the former the meatus externus is protected by a more or less segmented tube of cartilage, which ends outside in the continuous concha auris. 
(h.) The jugal (or malar) bone is large, and reaches back so as to lie over the cartilage of the glenoid cavity, thus helping to form the joint.

(i.) The angular part of the lower jaw is greatly incurved, forming a remarkable hollow inside.

In the endocranium there are some very curious structures, that differ from what we find in the high forms of Mammalia, but which mostly agree with what is seen in the Sauropsida :-

(a.) The nostrils are sub-terminal and give off large tongue-shaped cartilages to protect JAcoBson's orgins.

(b.) The whole nasal labyrinth is small, especially in the young, not more thais half as large as in an average Placental Mammal, and the cribriform plate is less depressed in front, and very limited in size, and is square in form.

(c.) The orbitosphenoids do not form the presphenoid by meeting together below, but the presphenoid is as independent as the basisphenoid.

(d.) There is no special optic foramen in the orbitosphenoid, but the optic nerve passes through the common sphenoidal fissure with the orbital nerves, and the 1 st branch of the 5th; the 2nd branch, like the 3rd, has its own foramen rotundum, as in Man, and many other Eutheria.

(c.) The next character is one of the most important: it is this, namely, that the orbitosphenoids are flush with the alisphenoids. The latter, which are extremely large, ossify a tract of the general cartilaginous side-wall of the embryonic skullthe highly developed "chondrocranium," - and not "fiec flep of cartilage, merely continuous with the basal bar, as in the Eutheria. For in these latter the more bulky brain pushes out the lower part of the side-wall of the skull, leaving for some time a band of cartilage, which rums free from the alisphenoid, passing on from the orbitosphenoid up to the supraoccipital. In front, the orbitosphenoid is confluent with the ethmoid, so that but for the breach in the wall, made by the alisphenoid, there would be, even in Placental Mammals, a chondrocranium very similar to that of the skull. This breach does not take place anywhere among the Vertebrate types until we get above the Marsupials. The other character just mentioned, namely, the absence of a special optic foramen, is of similar import; there never is such a foramen until we are among the Placental Mammalia.

(f.) The alisphenoid helps to form the drum-cavity by developing behind its small external pterygoid process a shell-like g'rowth, similar to the "anterior tympanic recess" of Carinate Birds. Thus, as the squamosal is a labyrinth of air-cavities, opening into the upper part of the drum-cavity, these and the tympanic recess in the alisphenoid greatly enlarge the space for air. Indeed, not only those parts, but the mastoid region of the auditory capsule, and the sides and top of the occipital arch, all became pneumatic-as in Crocodiles and Birds.

(g.) The internal carotid arteries pierce the basisphenoid submesially - that part of the basis cranii is not perforated in the Eutheria,--and the clinoid processes and the concavity for the pituitary body are but little developed. 
(h.) The limited, suberect, and tlattish cribriform plates, and the small frontals are the necessary correlates of" a small brain-cavity and brain. The occipital plane corresponds with those parts, being suberect: it forms but little more than a right angle with the general basicranial axis.

(i.) In the Mirsupials, as well as in the Monotremes, we see the "ossicula auditus" in making, so to speak. In all the three subdivisions of this class-NIonotremes or Prototheria, Marsupials or Metatheria, and Placentuls or Eutheria-the lower jaw is broken up, the larger front part becoming the persistent mandible, and the shorter hind part the malleus, whilst the starved and modified quadrate becomes the incus.

For a long while in the growing Marsupial the malleus is manifestly a compound bone; it is an "articulare" with an internal and a posterior angular process, as in the Forl. On it the "angulare" can be seen, and sometimes, as in the half-grown Koala (Phescolaretos), a "supra-angular" too.

'The working mandible attached to a new pier on the jugal and squamosal is composed of a sort of morphological mixture of a large inferior labial cartilage, a dentary bone, with coronoid and splenial regions, and the greater part of MEckEL's cartilage - the true primary rameus.

(j.) The topmost segment of the next arch (pharyngohyal) is often a "columella," and not a stapes. Tn the early young and embryo of the Marsupials it is V-shaped, its greater front fork enlarging above and forming the inverted base of the columella or stapes, and the lesser hind fork becoming, after a time, detached and then ossified, and forming the interhyal.

In Fishes, the uppermost element of a branchial arch (and the lhyoid is a branchial arch) often forks; in the Sturgeon these become two separate pieces, as in this particular case of the embryo Marsupial. There is not much to remark upon in the rest of the hyoid arch, the functional suspensory part.

For comparison with the Insectivora the existing Marsupials do not yield me all the archaic characters I want.

For the existing low Eutheria are, of course, the descendants of Metatheria that were much more generalized and archaic than any now existing; these latter, during the whole Tertiary period, must have undergone, on their own low platform, many adaptive changes that would make them look very strange beside the Marsupials of the Secondary epoch, if these latter could be restored for comparison.

'The best type of Insectivore for general comparison is the Hedgehog (Evinaceus curopeus), as it shows the least suppression of parts, and the best development of that which is diagnostic, so to speak, of the Order.

In it the greater investing bones of the skull are similar to those of the Marsupial, but the nasals and squamosals are smaller, and the frontals are larger. In the hard palate there is a considerable relapse, as in Marsupials, certain tracts of bone being absorbed, but it has no mesopterygoids, and only fice vomers; yet the antero-lateral jairs are well developed. 
Moreover the tympanic region has only one "annulus," the outer bone. There is no separate "os bullie." Instead of the latter there is a crescentic shell of bone which grows from the basisphenoid, greatly increasing the size of the tympanic cavity. In the endoskeleton, in front of the tympanic cavity, there is a remarkable ridge of bone growing outwards from the alisphenoid. That ridge is the remnant of the alisphenoidal tympanic wing of the Marsupial, and a shell of bone growing from the basisphenoid is the same morphological element as the separate "os bullie," but it has lost its independence. The higher Mammalian type is fully reached in the thorough freedom of the alisphenoid from the general cranial wall. This character, indeed, is intensified into the special diagnostic of an Insectivore, for it lies almost wholly outside the orbitosphenoid. Here the sphenoidal fissure-which in this case lets out the 1 st and and brunches of the 5 th, but not the optic, nerve, that nerve having its own foramen in the orbitosphenoid,-is not a mere gap, but a side passage, a sort of sphenoidal corridor, right and left.

In these things the Hedgehog is higher than the Marsupials, but in some others it is lower, or more archaic. These latter characters, which suggest an uprise from a more generalized type than the existing Metatheria, are-first, the development of a considerable rod of solid hyaline cartilage in the pterygoid region, a remnant of the pterygo-quadrate of the Ichthyopsida; and secondly, the presence of a persistent pituitary hole, which is connected with a curiously specialized structure, only seen in typical Insectivores, namely, a hollowing out of the basis cranii beneath the pituitary region.

A third archaic character, not seen in the existing Marsupials, is the huge relative size, long persistence, and separnte distal ossification of MECKEI's cartilage, so that in the embryo Hedgehog, and even in the Nestling, the primary lower juw is as large as in Fishes, grenerally, scarcely excepting the Selachians.

The ossicula auditûs are typically Eutherian; we have lost the imperforate stapes or columella, the interhyal is very small or absent, and the malleus and incus are much like what we find in the higher Mammals generally. The pneumaticity of the skull is much reduced; and the olfactory region is almost double the relative size of that of a Marsupial. In the head of another family of the Insectivores, namely, the Mole (Talpe europece), there is much that is in accord with what is found in its distant relation, the Hedgehog, but in it there are evident signs of degradation, or of relapse into what is Marsupial in character.

The nasal labyrinth is relatively immense, and the skull walls below, laterally, and behind, are as exquisitely pneumatic as in the Flying Marsupial (Pctcums), the Bird, or the Crocodile. The swollen basis cranii, all air galleries within, is so excavated that the hinder sphenoid, both base and wings, largely helps the flat single tympanic to form the drum-cavity.

The pituitary hole does not exist, but there is a considerable pterygoid cartilage; the ossicula, in the adult, are normal, but a curious special character is seen during ossification. In the young the bone grows along the sheath of the stapedial artery, MDCCCLXXXY. 
which for a time holds the stapes in its place; it is, however, absorbed afterwards, but remains in the related genus Myogale. In nearly half-grown young Moles the malleus is quite like that of the Marsupials, and it is an evident articulare, with copious wild growths of bone, sub-distinct and answering to the "angulare" and "supra-angulare" of a Reptile or Bird. This malleus in its articular part has two endosteal and one cctosteal bony centres. MEckes's cartilage, long continuous with the malleus, is nearly as massive as in the Hedgehog, and has a more distinct separate ossification in its subdistal part-a long independent, but temporary hypobranchial bone.

The Mole shorvs a most remarkable development of the endocranium, which, twenty years ago, suggested to me that its skull retained unmistakable Monotrematous characters. In the large young of the Echidna and Ornithorhynchus the solidity of the chondrocknium is immense-like that of a Chimceroid Selachian-and the investing bones are thin and splintery. I have not made out the mode of ossification of the inner skull in those types, but in spirit, if not in the letter the Mole agrees with them, that is in the great development and independence of the inner skull. The "opisthotic" bones ossify the normal petromastoid region, whilst the "prootic" bony centre begins in its right place on the front edge of the cartilaginous capsinle and then runs away from it into the wall of the skull; thus there is a large bony tract in the temporal region, between the small squamosal and the large interparietal, which is not one of the ordinary outer cranial hones, hut an endocranial bony tract, overshadowing and yet imitating the true temporal bone or squamosal. This bone is represented by three separate centres in Osseous Fishes, namely, the prootic, pterotic, and sphenotic, whilst their true auditory region is ossified by the epiotic and opisthotic; the epiotic is only subdistinct in the Mole.

If I am asked why I dive so far down for my illustrations instead of being satisfied with what Reptiles and Birds would show me, my answer is that those are often of no use for comparison, for they are as thoroughly specialized for their own mode of life as the Mammalia, generally, and are as completely, and often more completely, transformed from the original archaic type or types.

Thus the Mole, like most of the Edentata lately described by me, suggests as the root-stock of the Eutheria, generally, not Marsupials (Metatheria) as we know them, but Prototherian forms, in which, in nges long past, the existing Monotremes and Marsupials had a common origin.

The Shrew (Sorex mlyaris) represents another fumily of the Insectivores, the Soricila. It combines the characters of the Mole and Hedgehog with peculiarities of its own that are manifestly due to dwarfing; many things are suppressed, as if there was not room in so small a skull for their development. The pituitary hole re-appears, and the pterygoid cartilage-but the tympanic wing of the alisphenoid and of the basisphenoid are gone; the malleus does not show itself so ummistakably Marsupial, and MEcrer's cartilane is slenderer. 'The sheathing alisphenoids are well seen ; the squamosal is small, low down, and devoid of a jugal process; the jugal bone is suppresserl. 
So much for the British representatives of three fimilies of the Insectivora-tlio Erinaceidre, Tilpidie, and Soricidre. .

The Mascarene Insectivor are all so evidently related as to suggest at once a common origin; these are the Centetida, the largest of which is the Tenrec (Centetes ecaudutus); the other genera treated of in this paper are Eiviculus, Iremicentetes, and Microgale.

These are almost typical Insectivora, but they agree with the shrews in having the jugal bone suppressed; they are also more Marsupial than our native kinds.

In these types the normal characters of the shull of an Insectivore are combined with a remarkably Marsupial tympanic wing to the alisphenoid, but the os bullo is not free, it is merely an outgrowth of bone from the basisphenoid. The pituitary hole is present, and in the larger species the curious basicranial excavation; also the optic foramina; whilst the sphenoidal side passages are remarkably developed.

As in the genus Phalangista among the Marsupials, and Talpa and Sorex among the British Insectivora, the antero-lateral vomers are evidently suppressed, or have a very temporary independent existence. The postero-lateral vomers are rather small, as in the Hedgehog.

In the embryo the main vomer is relaticely as large as in the embryo Whale, and is curiously cellular or spongy.

In Nestlings this one primary azygous centre has broken up into three; vne, the largest, above, and two lesser, below, sheathing it, as it sheathes the base of the nasal septum. Now this multiplication of the romers, proper, is thoroughly Marsupial ; it is unique, as far as I know, in the mode of its subdivision into secondary bony centres.

In the African (Continental) Family of the Elephant, or Jumping, Shrews (Mascroscelidie), as illustrated by the largest forms-Petrohromes and Rhynchocyon-we have a curious mixture of Marsupial (Metatherian) and Eutherian characters, so that they are very abberant as Insectivores.

The Marsupial characters are most remarkable, these are: 1, the absence of an optic foramen; 2, the alisphenoid, scarcely overlapping the orbitosphenoid; 3, tympanic wings to the alisphenoid, well marked hollow shells in the embryo; 4, large antero-lateral vomers and postero-lateral vorners as large as in average Marsupials, and, as in many of them, meeting and uniting at the mid-line; 5, a large, distinct "os bullw", which makes a tympanic cavity as large as, and much like that of, Petaurus or Phascolarctos.

On the high Eutherian side we have, in the embroyo, frontals as large as the parietals, and, strangest of all anticipations of Mammalian specialization, a long proboscis, composed of thirty double rings of cartilage, a structure quite similar to the proboscis of an Elephant. The mesopterygoids are suppressed, but the pituitary hole is present.

Galeopithecus and Tupaia are manifestly annectent. I shall treat of them, again, when I come to the Bats and Lemurs. 


$$
\text { . }
$$


MR. W. K. PARKER ON THE SKULL IN THE MAMIIALIA.

\section{List of the Abrreviations.}

The Roman numerals indicate nerves or their foramina.

ay. Angulare.

ay.l. Angular process.

al.e. Aliethmoid.

al.n. Alinisit.

al.s. Alisphenoid.

al.s.c. Alisphenoidal canal.

al.sp. Aliseptal,

a.p.f. Anterior palatine foramen.

u.s.c. Anterior semicircular canal.

at. Atlas.

a.ty. Annulus tympanicus.

ax. Axis.

au. Auditory capsule.

b.a. Basilar artery.

b.h.br. Basihyobranchial.

b.mn. Basimandibular.

b.o. Basioccipital.

b.p)g. Basipterygoid process.

b.s. Basisphenoid.

C. Brain.

c.eu. Concha auris.

$c$ l.p. Condyloid process.

ch. Cochlea.

c.lly. Ceratohyal.

c.p. and cr.p. Coronoid process.

ci.g. Crista galli.

cr.p. Cribriform plate.

c.tr. Cornu trabecule.

c.ty. Cavum tympani.

d. Dentary.

d.c. Dentary canal.

C. Eye.

e.hy. Epihyal.

e.n. External nostrils.

c.o. Exoccipital.

'p. Epiotic.

e.pry. External pterygoid. ei. Eustachian tube.

f. Frontal.

f.m. Foramen magnum.

fl. $\lambda^{2}$ Floccular recess.

fo. Fontanelle.

f.r. Fenestra rotunda.

fs.o. Fenestra ovalis.

gl.c. Glandular crypts.

gl.f: and gl.c. Glenoid cavity or cartilage.

h.ley. Hypoliyal.

h.s.c. Horizontal semicircular canal.

i. Incus.

i.ay. Internal angular process.

i.c. Internal carotid.

i.lıy. Interhyal.

i.f.l. Inferolateral fontanelle.

i.n.f. Internasal fenestrin.

inf. Infundibulum.

i.p. Interparietal.

i.tb. Inferior turbinal.

i.ti. Intertralieculis.

iv. Investing mass.

j. Jugal.

j.o. JACOBson's organ.

l. Lichrymal.

l.c. Lachrymal canal.

l.c.i. Long crus of incus.

l.s. and s.c. Lateral sinus.

lx. Larynx.

m. Moutl.

m.a.e. External meatus

$m b$. and $m . m l$. Manubrium mallei.

m.c. Meatus cartilage.

m.g. Mucous gland.

mk. Mecrel's cartilage.

m. Malleus.

m. Mandible. 
ms.pg. Mesopterygoid.

mt.c. Mastoid cells.

m.ty. Nembrana tympanl.

$m x$. Maxillary.

n. Nasal.

no. Notochord.

n.f. Nasal floor.

n.p. Nasal passage.

n.p.c. Nasal palatine passage or canal.

n.tl. Nasal turbinal.

n.v. Narial valve.

o.b. Os bullie.

oc.c. Occipital condyle.

op. Opisthotic.

o.s. Orbitosphenoid.

1). Parietal.

pa. Palatine.

p.ag. Posterior angular process.

p.cl. Posterior clinoid.

p.e. Perpendicular ethmoid.

pg. Pterygoid.

pg.c. Pterygoid cartilage.

p.gl. Postglenoid process.

p.gr. Processus gracilis.

phox. Pharynx.

p.mx. Palatine plate of maxillary.

p.n. Posterior nares.

pu.f. Pneumatic foramen.

p.ob. Postorbital.

p.oc. Paroccipital.

$p \cdot p \cdot f$. Posterior palatine foramen.

$p \cdot p x$. Palatine process of premaxillary.

pr.o. Prootic.

p.s. Presplenoid.

p.s.c. Posterior semicircular canal. p.t. Post-temporal.

p.t.r. Posterior tympanic recess.

p.ty. Pretympanic process of malleus.

px. Premaxillary.

py. Pituitary region.

re.c. Recurrent cartilage.

$r . v b$. Recessus vestibuli.

s.c.c. and s.t.c. Supra-auditory cartilage.

s.ag. Supra-angulare.

s.c. and l.s. Sinus canal.

s.c.i. Short crus of incus.

s.n. Septum nasi.

s.o. Supraccipital.

s.ob. Supraorbital.

sp. Splenial.

sq. Squamosal.

sq.c. Squamosal cells.

st. Stapes.

s.t. Supratemporal.

st.u. Stapedial artery.

st.h. Stylohyal.

st.m. Stapedius muscle.

t.al.s. Tympanic wing of alisphenoid.

t.b.s. 'Tympanic wing of basisphenoid.

tg. Tongue.

th.c. Thyroid cartilage.

t.hy. 'Thyrohyal.

tr. Trabecula.

tt. Tentorium.

t.tm. Tensor tympani.

t.ty. Tegmen tympani.

u.tb. Upper turbinal.

u.t.r: Upper tympanic recess.

$v ., v^{\prime}, v^{\prime \prime}$. Vomerine bones.

vb. Vestibule. 
PLATE 1.

\begin{tabular}{|c|c|c|}
\hline Fignres. & & $\begin{array}{l}\text { Number of } \\
\text { times } \\
\text { magnified. }\end{array}$ \\
\hline 1 & Embryo of Unau (Cholopus didectylus); about half ripe & nat size. \\
\hline$:$ & The sime; front view . . . . . . . . . . . . . & ditto \\
\hline$\because$ & $\begin{array}{l}\text { Early embryo of Pangolin (Manis - ? sp.) (1st stage); } \\
\text { front view . . . . . . . . . . . . . }\end{array}$ & $1 \frac{1}{2}$ \\
\hline 4 & The same; sicle view . . . . . . . . . . & $1 \frac{1}{2}$ \\
\hline 5 & $\begin{array}{l}\text { Advanced embryo of Pangolin ( } 1 \text { Imis brevicandate), } \\
\text { from Ceylon (2nd stage); front view . . . . . . }\end{array}$ & nat. size. \\
\hline 6 & The same; side view . . . . . . . . . . . . & ditto \\
\hline 7 & $\begin{array}{l}\text { Embryo (one-third ripe) of Armadillo (Tutusia hybricla) } \\
\text { (1st stage); side view . . . . . . . . . }\end{array}$ & 2 \\
\hline 8 & The same; front view . . . . . . . . . . . . & 2 \\
\hline ! & $\begin{array}{l}\text { Head of nearly ripe embryo of Aard-Vark (Orycteropus } \\
\text { capensis); mpper view . . . . . . . . . }\end{array}$ & $\frac{1}{2}$ nat. size. \\
\hline 10 & The same; side view . . . . . . . & ditto \\
\hline 11 & The same; fiont view . . . . . . . . . & nat. size. \\
\hline
\end{tabular}




Partier
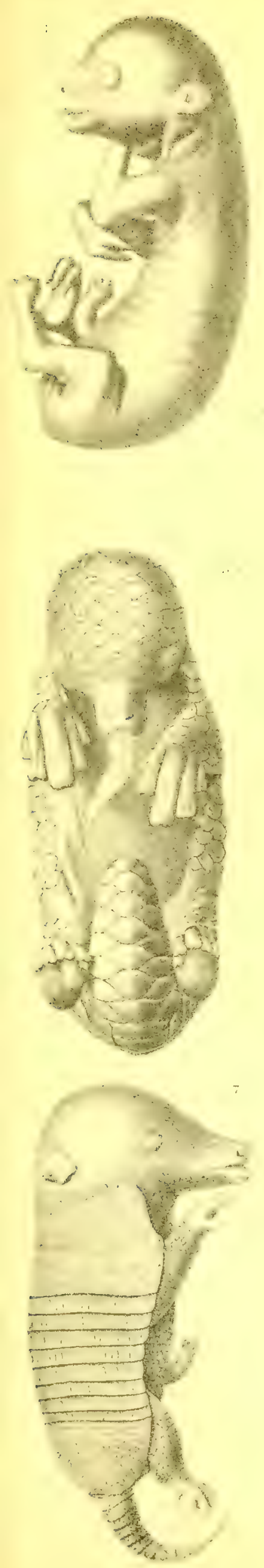
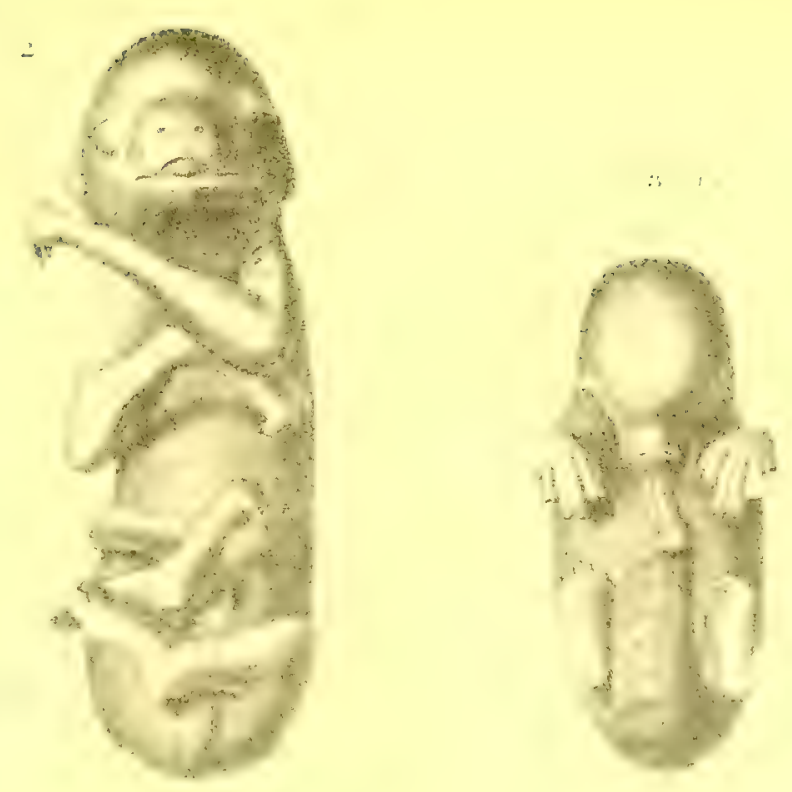

Thi2 Iinoms.1885 Plaie I
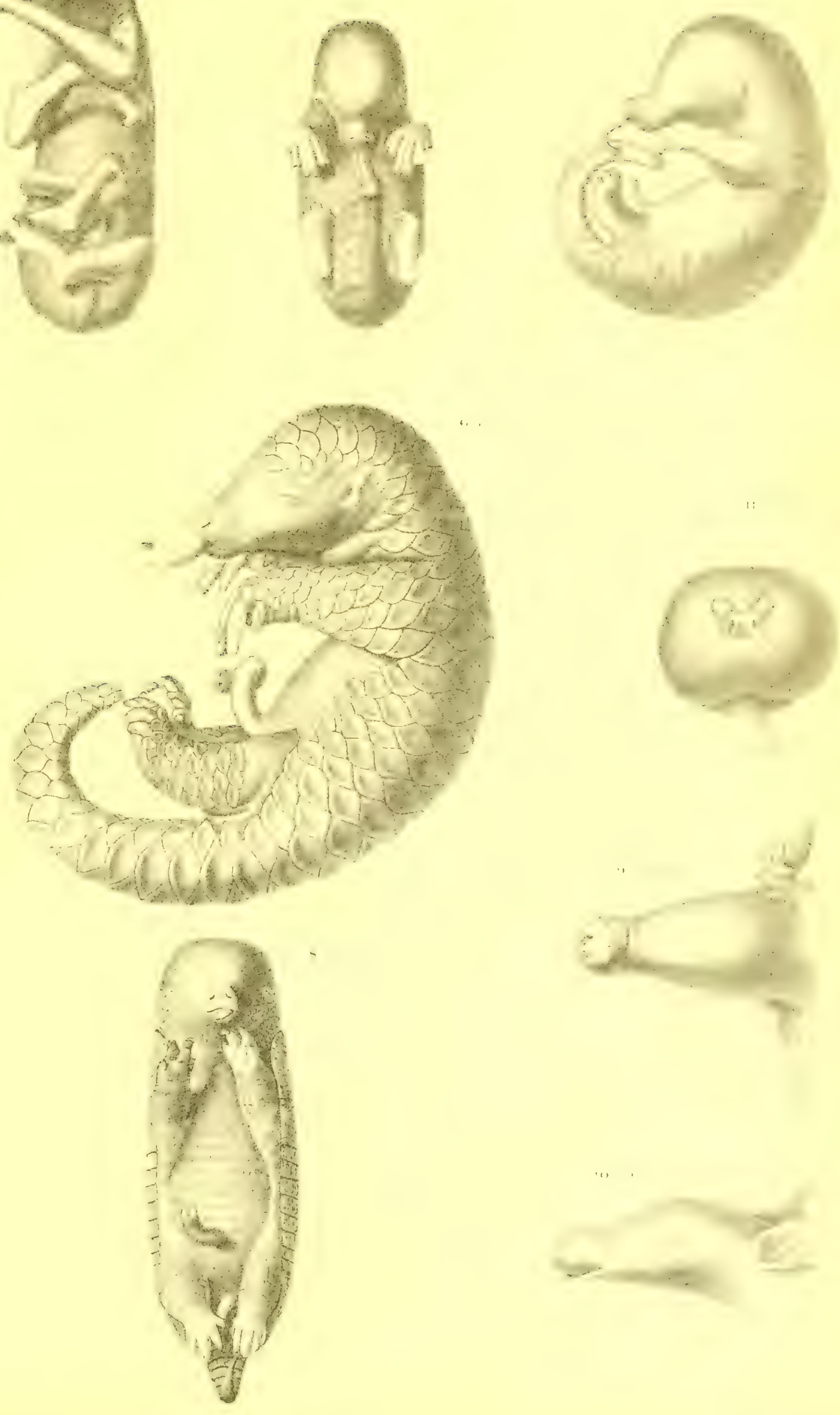


MR. W. K. PARKER ON THE SEULL IN THE MAMIALALIA.

PLATE 2.

\begin{tabular}{|c|c|c|}
\hline Figures. & & $\begin{array}{l}\text { Number of } \\
\text { times } \\
\text { magnified. }\end{array}$ \\
\hline 1 & $\begin{array}{l}\text { Tatusia hybrida (1st stage) ; embryo } 1 \frac{2}{3} \text { inch long (snout } \\
\text { to root of tail); section of skull; inner view. . . . }\end{array}$ & $7 \frac{1}{2}$ \\
\hline 2 & The same*; fore part of lower jaws; upper view . . . & $13 \frac{\pi}{2}$ \\
\hline 3 & The same; lower jaw; inner view . . . . . . & $7 \frac{1}{2}$ \\
\hline 4 & The same; auditory region; outer view . . . . . & $13 \frac{1}{2}$ \\
\hline 5 & $\begin{array}{l}\text { The same; part of ethmoidal region, with turbinals } \\
\text { exposed, and rudiment of cribriform plate shown . . }\end{array}$ & $7 \frac{1}{2}$ \\
\hline 6 & $\begin{array}{l}\text { Tatusia hybrida; } 2 \text { inches long (2nd stage); skull; } \\
\text { lower view . . . . . . . . . . . . . . }\end{array}$ & 6 \\
\hline 7 & The same; skull; upper view . . . . . . . . . & 6 \\
\hline S & 'The same; skull; side view . . . . . . . . . & 6 \\
\hline
\end{tabular}

* This figure is not numbered on the Plate; it is below fig. 4. 

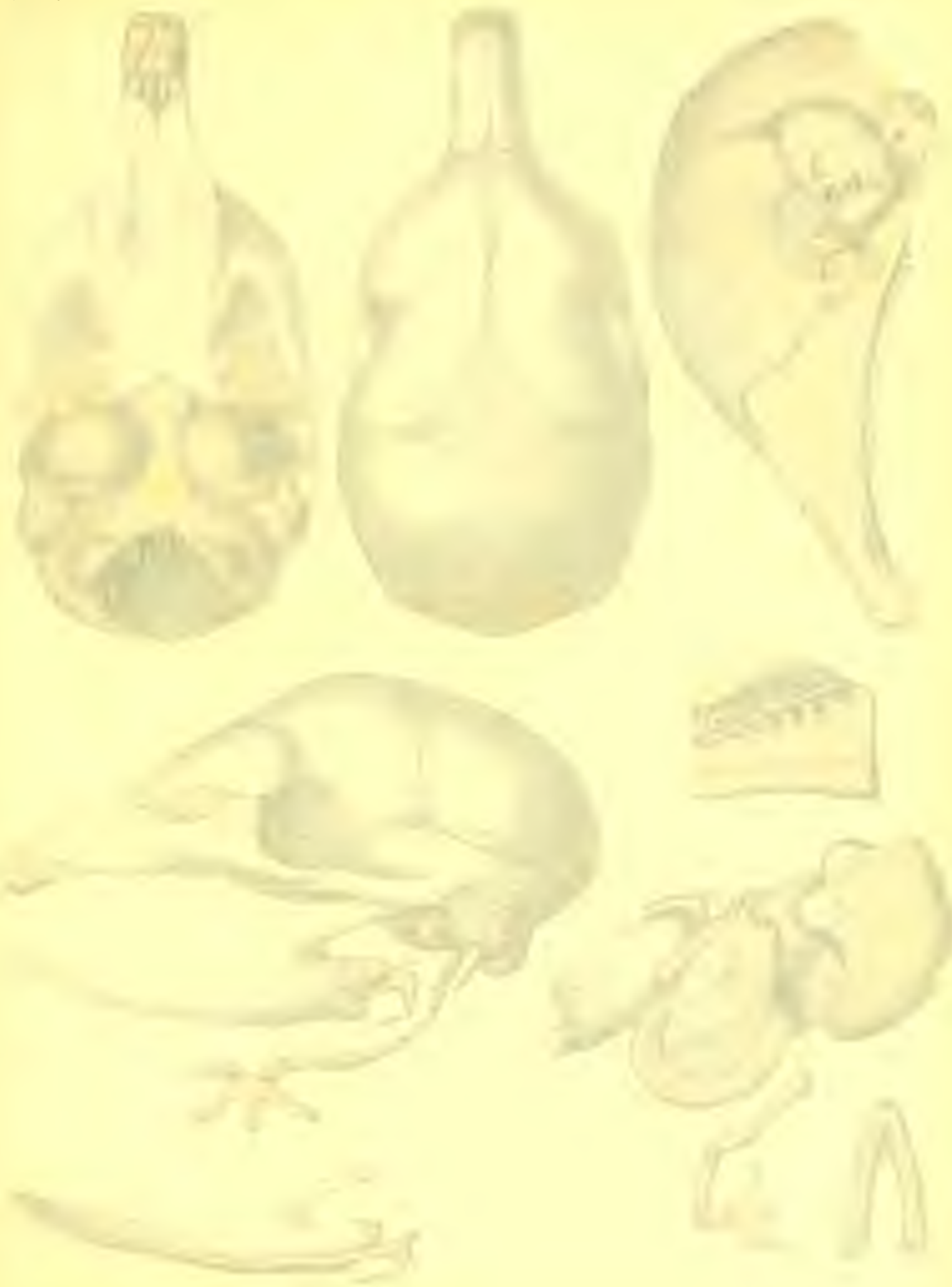


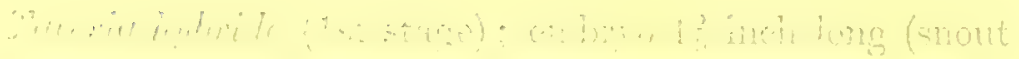

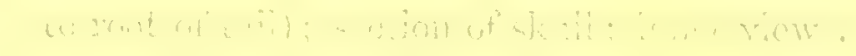

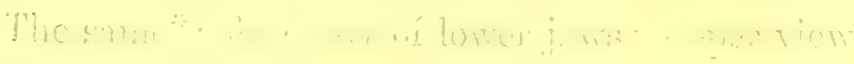

rilic $;$ in :

IIS. 


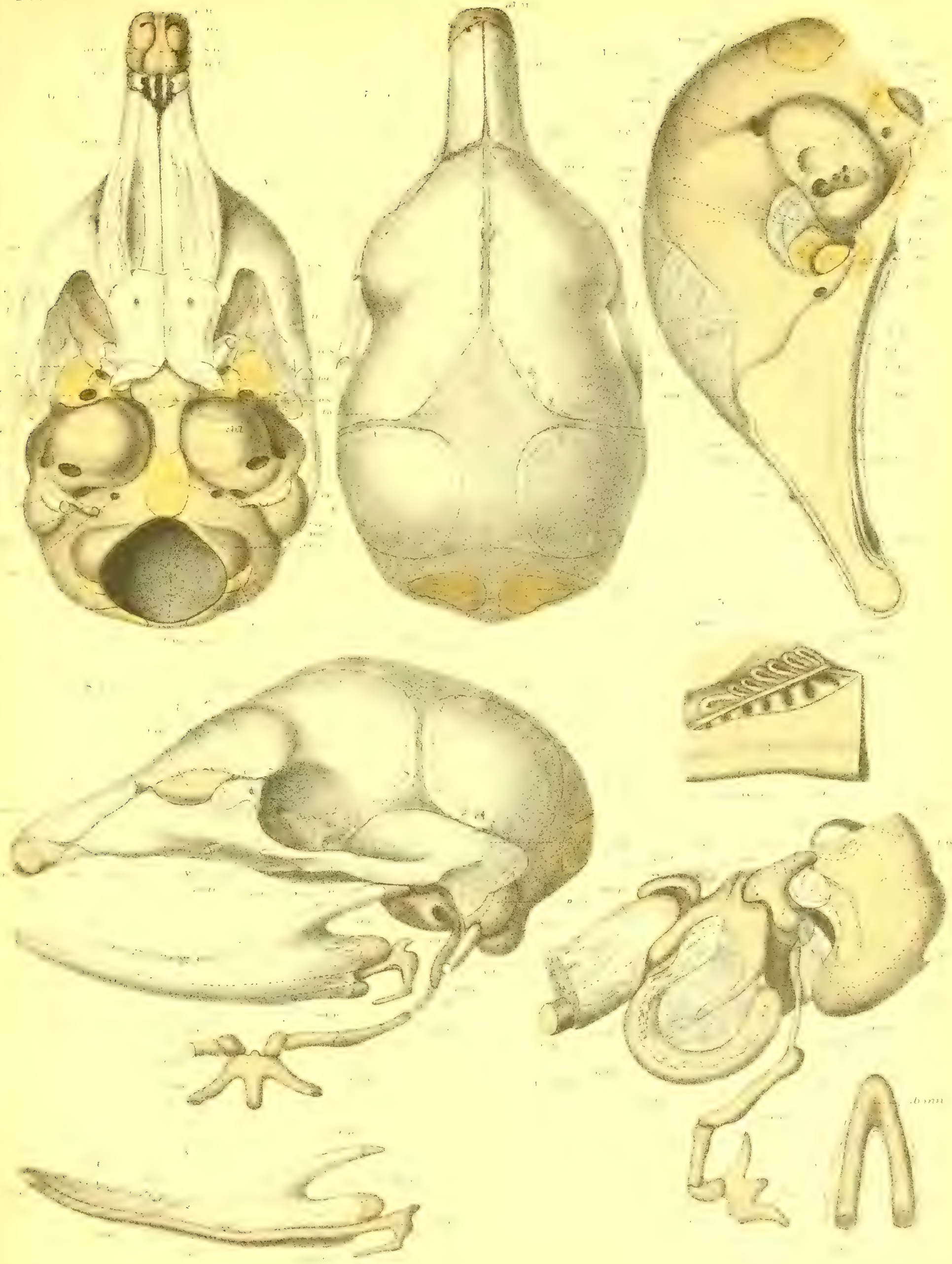



$+$ 
MLR. W. K. PARKER ON THE SKULT, IN THE MLAMMALIA.

PLATE 3.

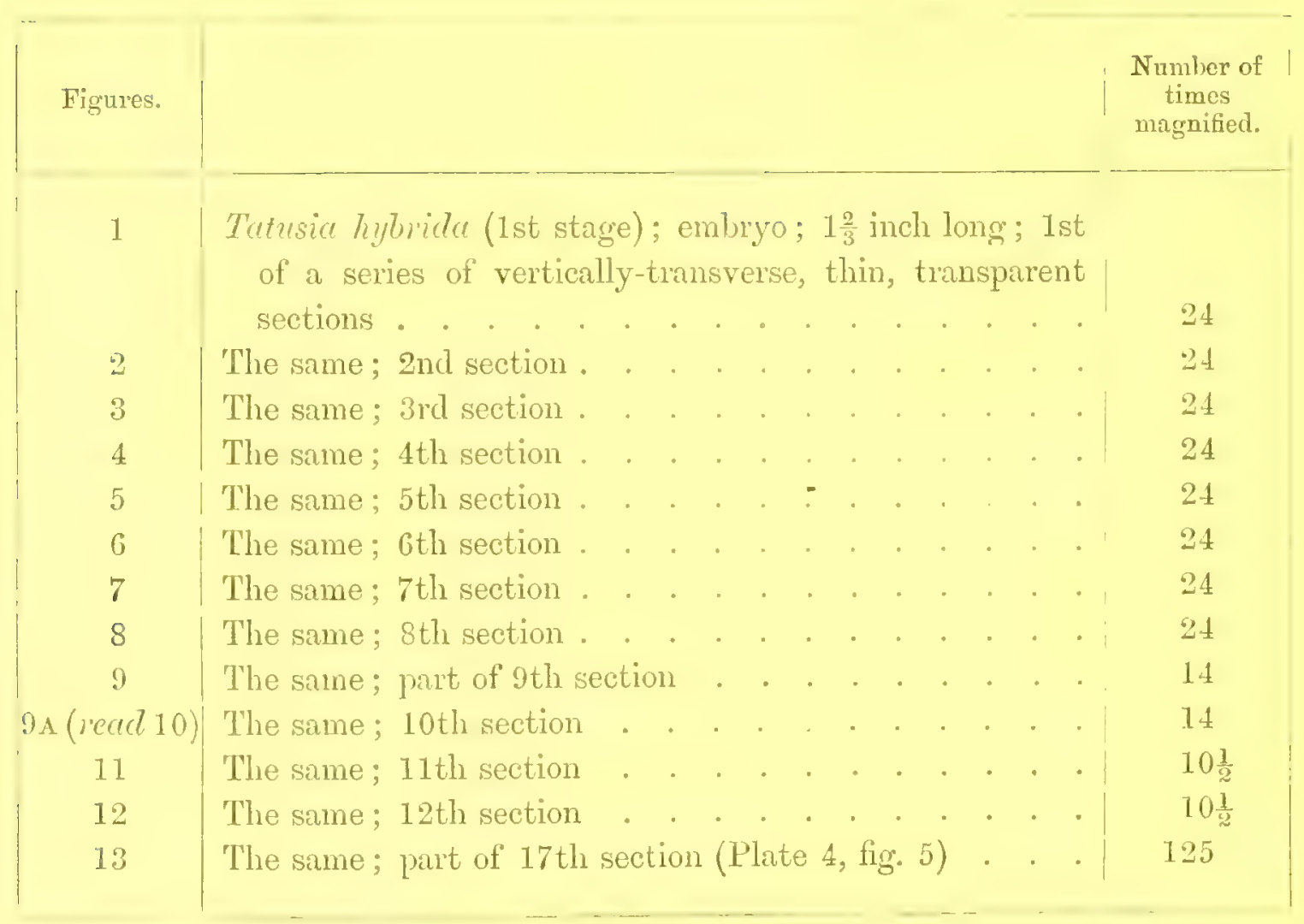



Phil.Trarts. 1885. Ptate 3

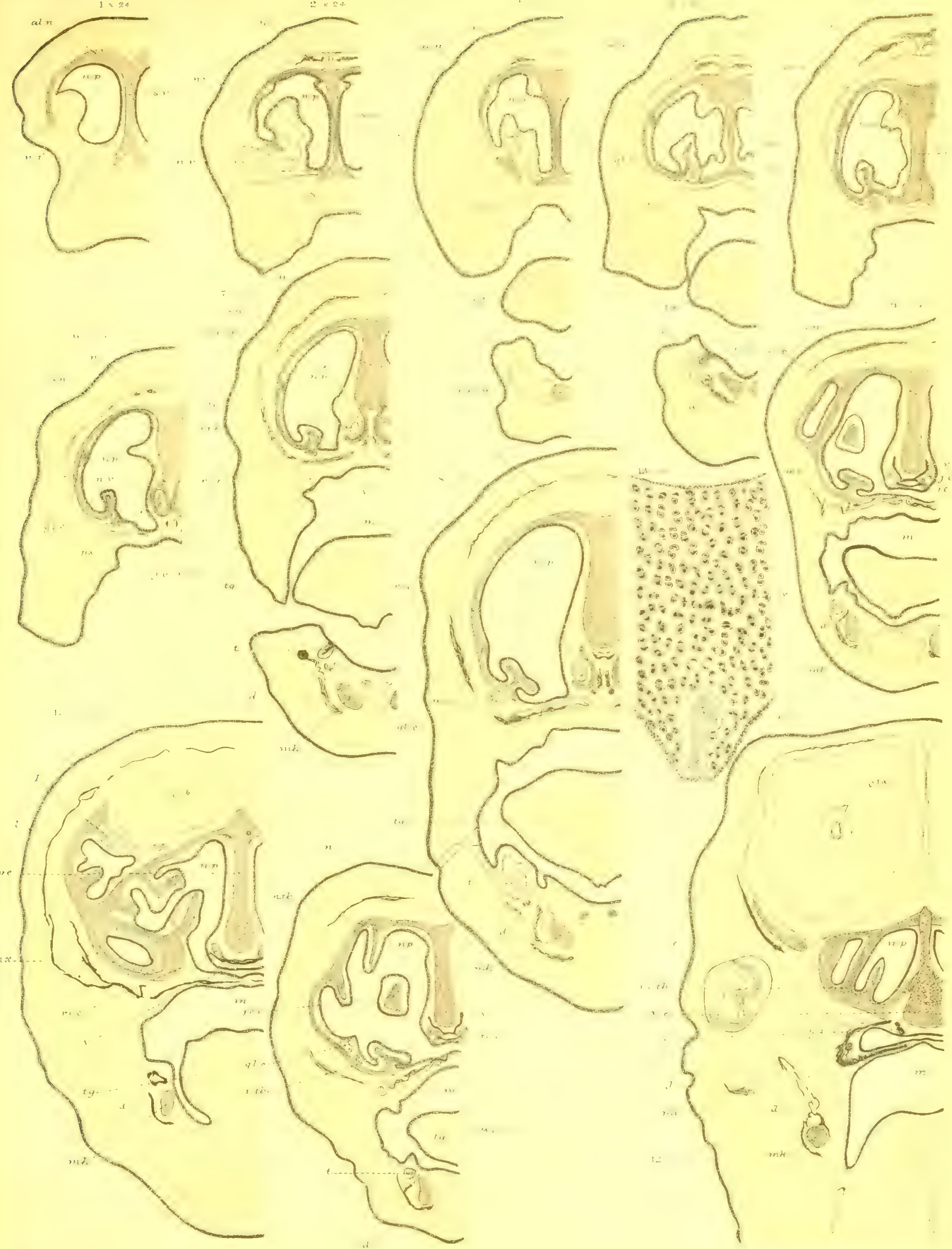




ILR W. K. PARKER ON THE SKULL IN THE MIAMMALTA.

\section{PLA'TE 4.}

\begin{tabular}{|c|c|c|c|c|c|c|c|c|c|c|}
\hline Figures. & & & & & & & & & & $\begin{array}{l}\text { Number of } \\
\text { times } \\
\text { magnified. }\end{array}$ \\
\hline 1 & (Continuation of same seri & ies); & ; 13 tl & h secti & Ion. & & . & . & . & $10 \frac{1}{2}$ \\
\hline 2 & The same; 14th section & . . & $\cdot$. & $\cdot$. & & & . & . & . & $10 \frac{1}{2}$ \\
\hline$: 3$ & The same; 15 th section & . . & . . & . . & . & . & . & . & . & $10 \frac{1}{2}$ \\
\hline 4 & The same; 16th section & . . & . . & . . & . & . & . & . & . & $10 \frac{1}{2}$ \\
\hline 5 & The same; 17 th section & . . & . . & . . & . & . & . & . & . & $10 \frac{1}{2}$ \\
\hline 6 & The same; 18 th section & . . & . . & . . & . & . & . & . & . & $10 \frac{1}{2}$ \\
\hline 7 & The same; 19 th section & . . & . . & . . & . & . & & . & . & 12 \\
\hline$s$ & The same; 20th section & . . & . . & . $\cdot$ & & . & & . & . & 12 \\
\hline 9 & The same; 21st section & . . & . . & & . & . & . & & . & 12 \\
\hline 10 & The same; 22 nd section & . . & . . & . . & . & . & & & . & 12 \\
\hline 11 & The same; 23 rd section & . . & . . & . . & . & . & . & . & . & 12 \\
\hline $1:$ & The same; 24th section & . . & . . & . . & . & . & . & . & . & 12 \\
\hline $1: 3$ & The same; 25 th section & . . & .. & .. & . & . & . & . & . & 12 \\
\hline
\end{tabular}




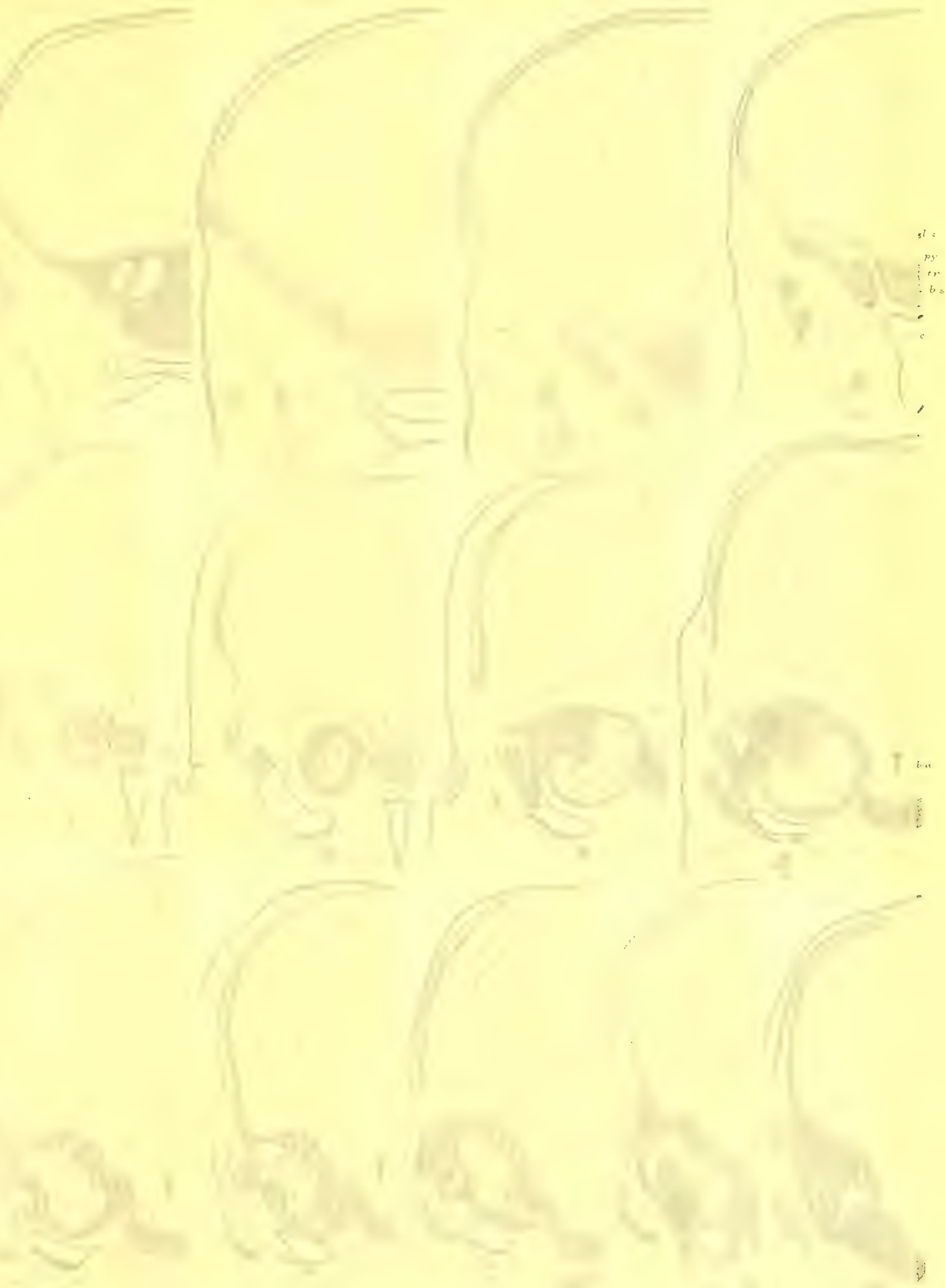




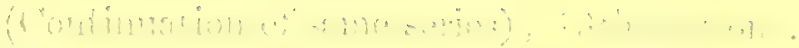

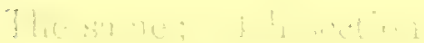

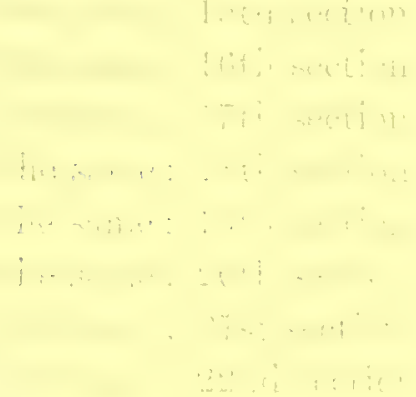

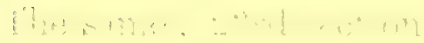

Thr,

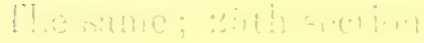



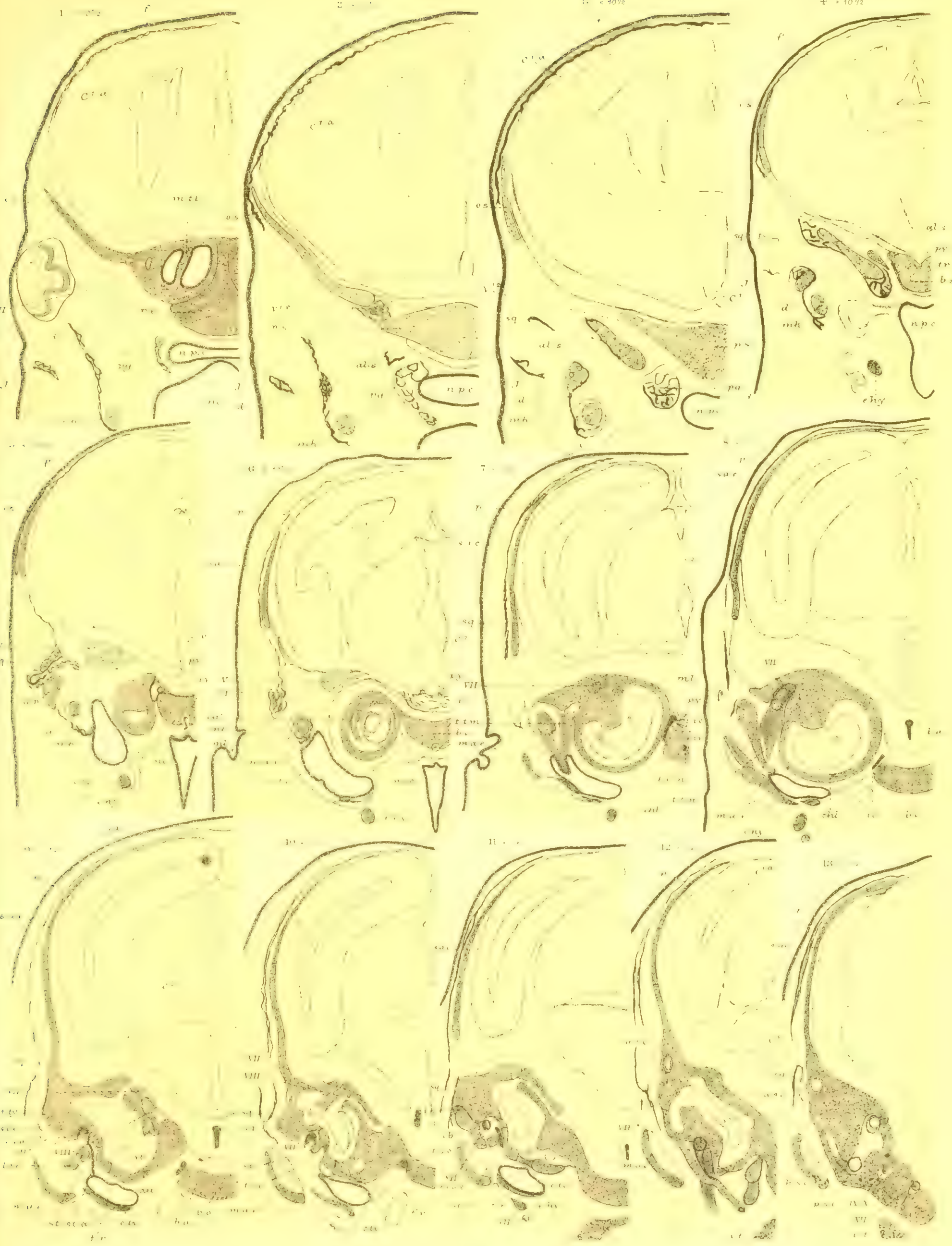

PLATE 5.

\begin{tabular}{|c|c|c|c|}
\hline Figures. & & & $\begin{array}{l}\text { Number of } \\
\text { times } \\
\text { magnified. }\end{array}$ \\
\hline 1 & $\begin{array}{l}\text { Tatusia higbrida; embryo; } 3 \text { inches long (3rd } \\
\text { endocranium; upper view . . . . . . . }\end{array}$ & stage) & $3 \frac{3}{4}$ \\
\hline 2 & The same; end view. . . . . . . . . . & . . . & $3 \frac{3}{4}$ \\
\hline 3 & The same; auditory region; outer view . . . & . . . & $13 \frac{1}{3}$ \\
\hline 4 & $\begin{array}{l}\text { Tatusia hylrida; embryo; } 2 \text { inches long (and } \\
\text { auditory region; outer view . . . . . . . }\end{array}$ & stage) ; & $13 \frac{1}{3}$ \\
\hline 5 & $\begin{array}{l}\text { Tatusia peba; embryo; } 3 \text { inches long (4th stage) } \\
\text { lower view . . . . . . . . . . . . }\end{array}$ & ; skull ; & $3 \frac{3}{4}$ \\
\hline 6 & The same; vertical section of skull; inner view & $\cdot \cdot \cdot$ & $3 \frac{3}{4}$ \\
\hline 7 & The same; skull ; end view . . . . . . . & $\cdot \quad \cdot \quad \cdot$ & $3 \frac{3}{4}$ \\
\hline 8 & The same; ossicula auditûs . . . . . . . & . . . & $11 \frac{1}{4}$ \\
\hline
\end{tabular}



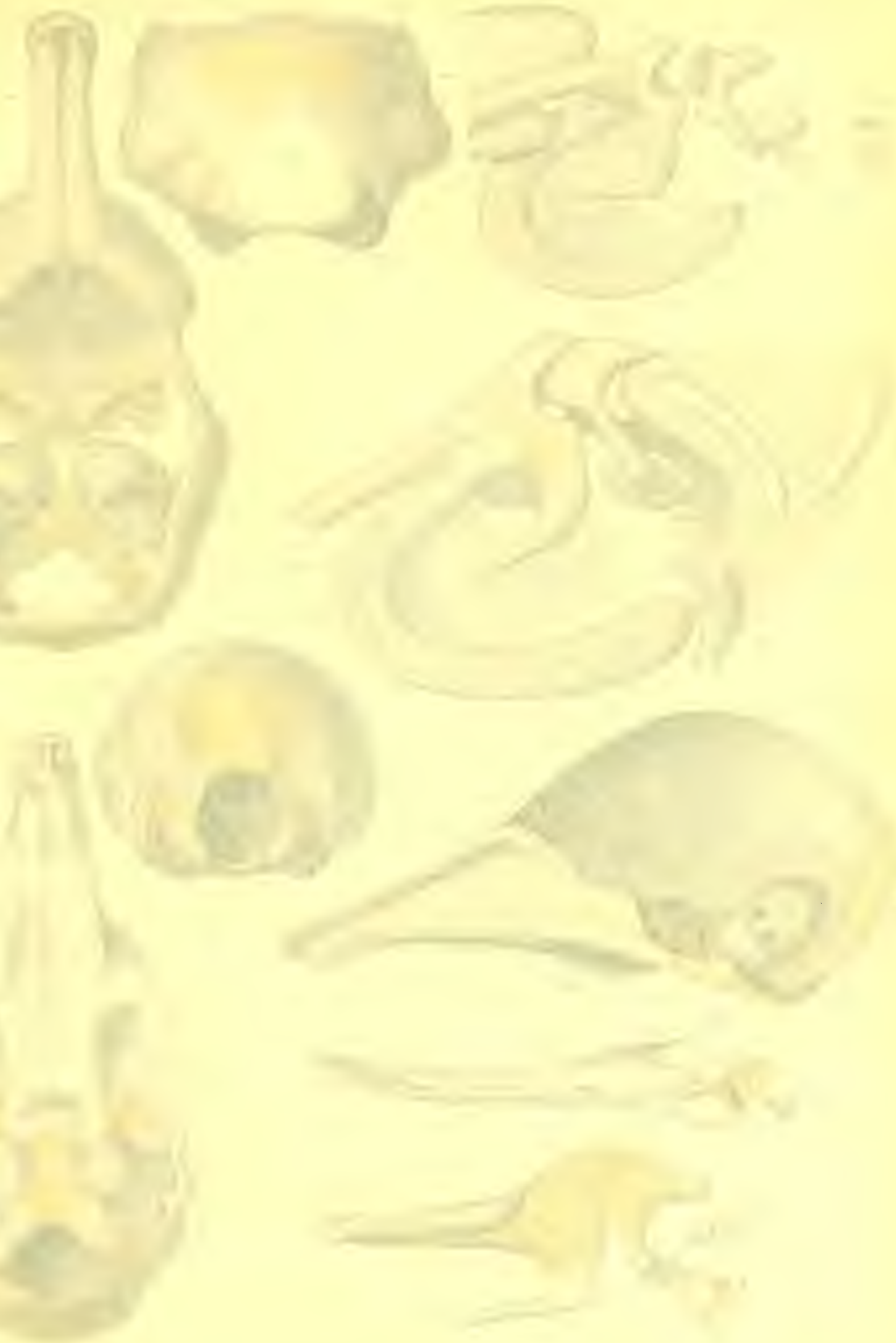


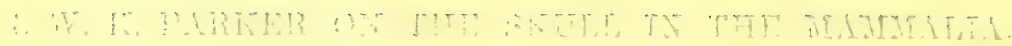

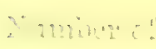

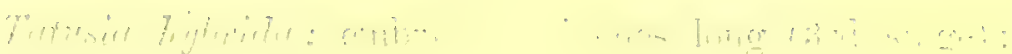

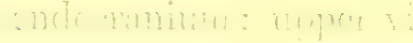

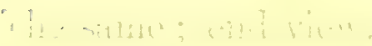

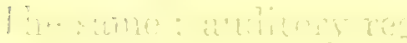

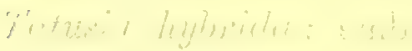

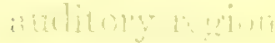

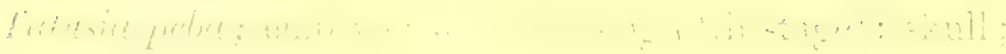

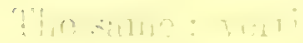

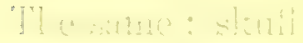

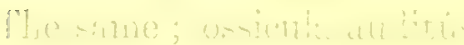




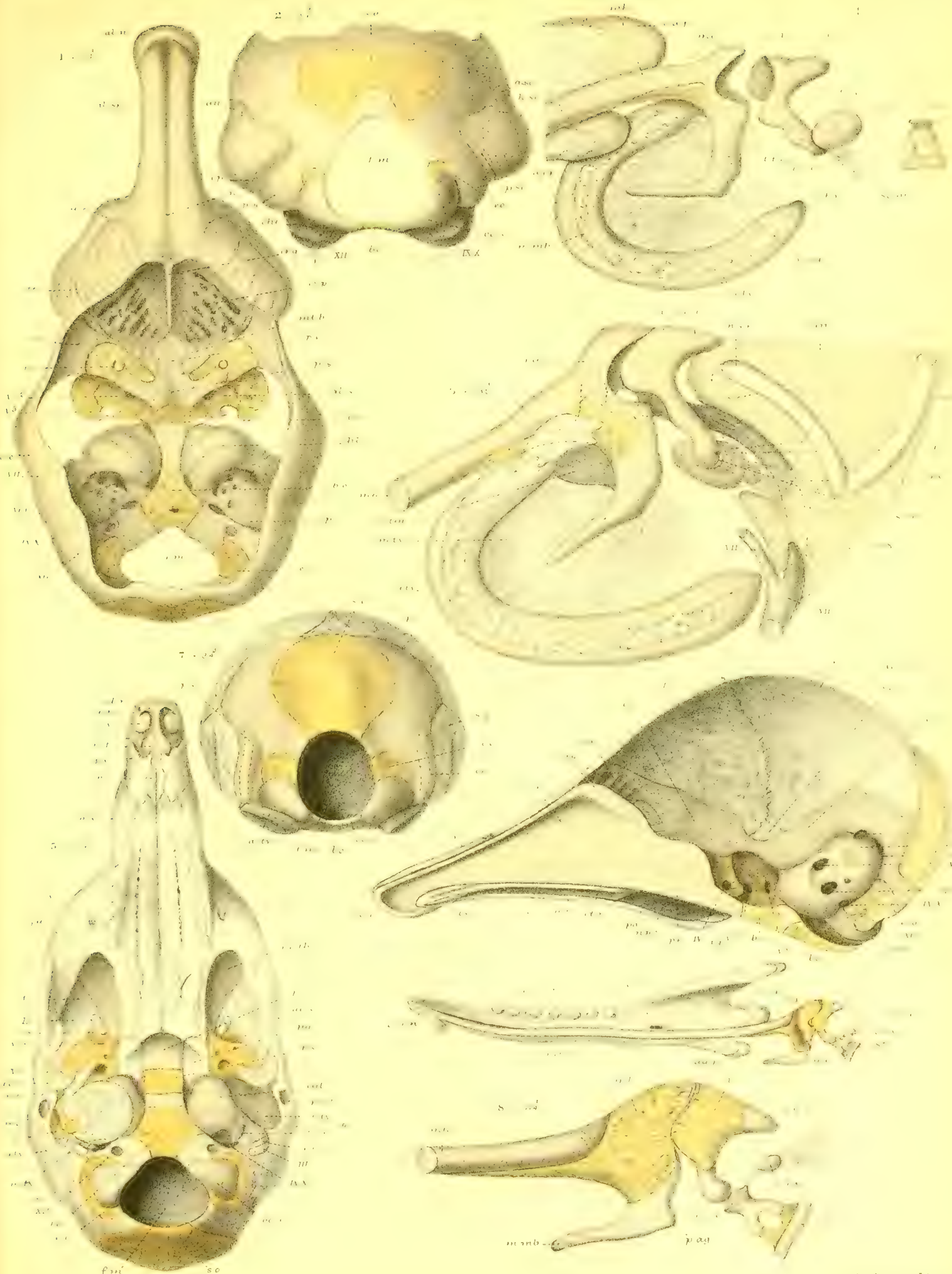





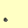


MR. W. K. PARKER ON THE SKULL IN THL MAMMALIA.

\section{PLATE 6.}

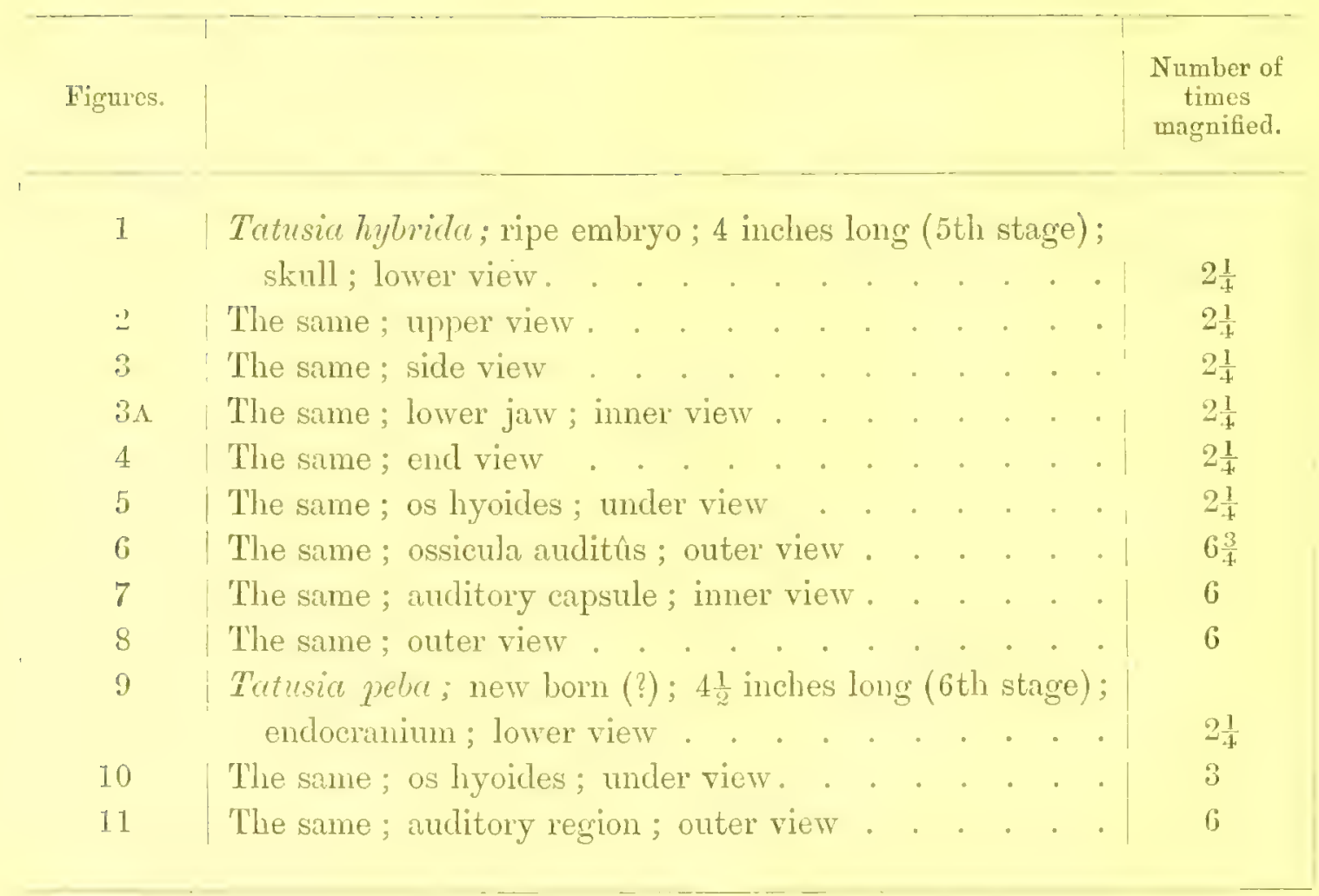



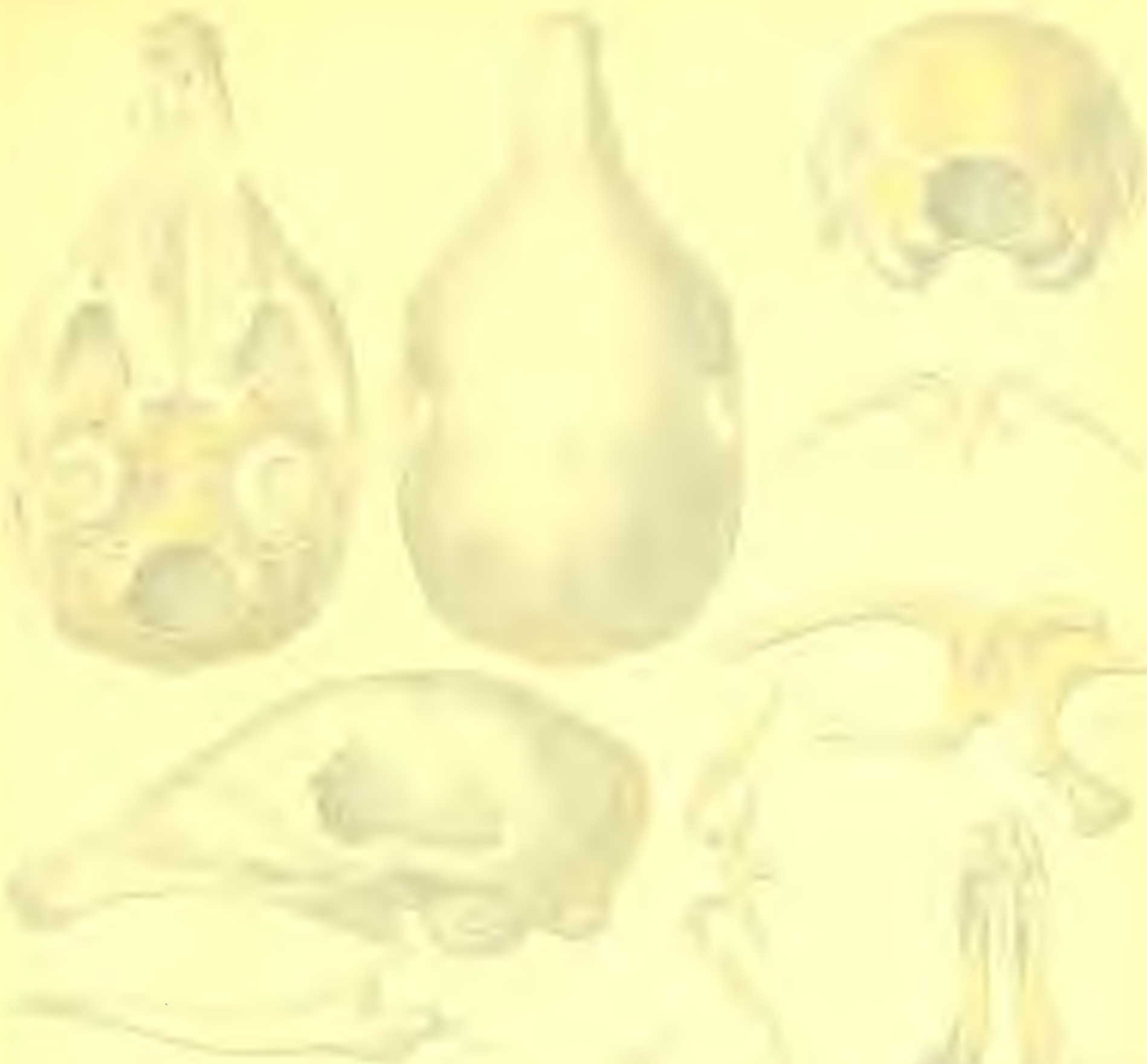


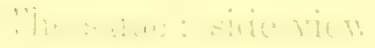




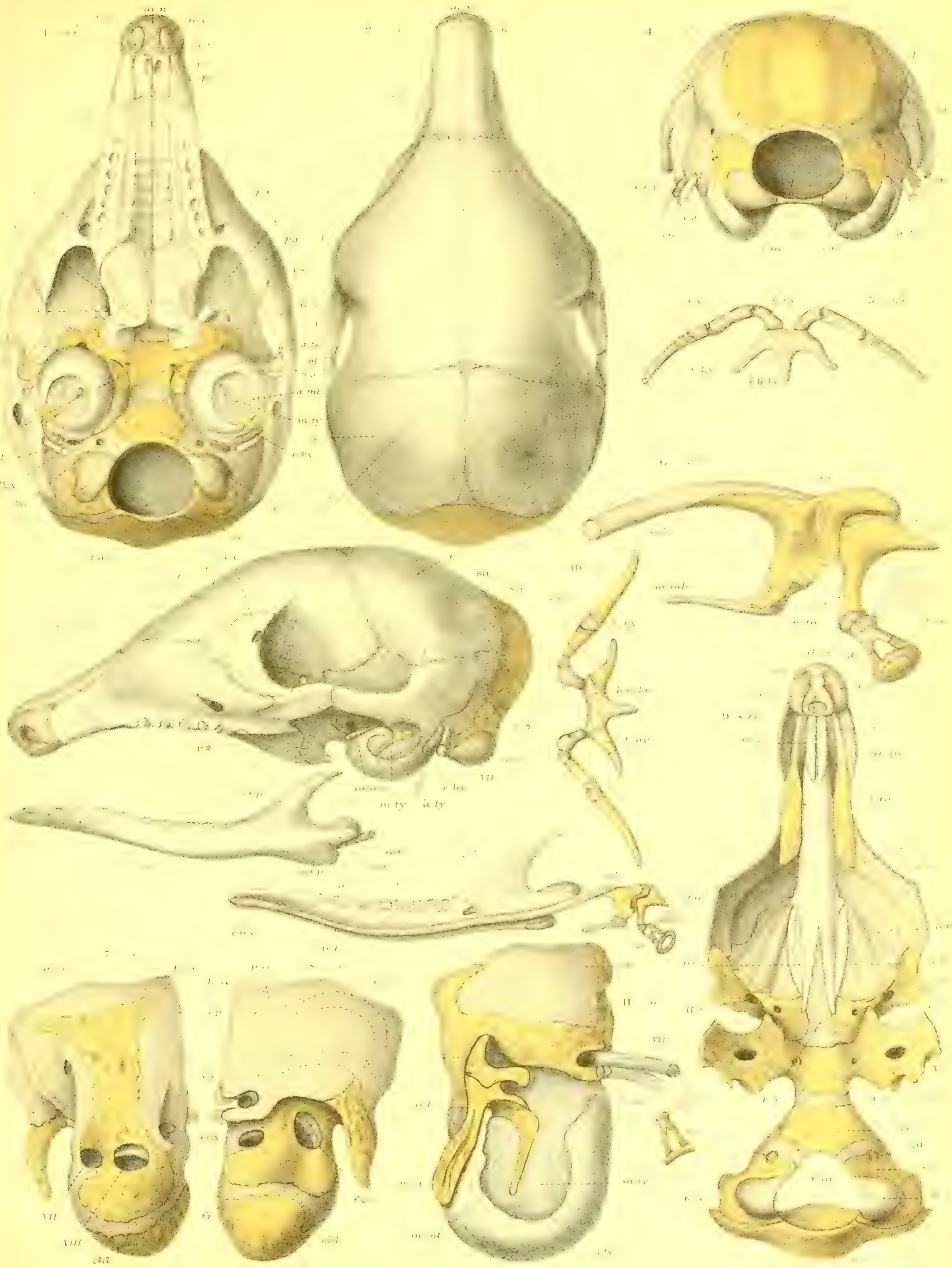




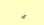




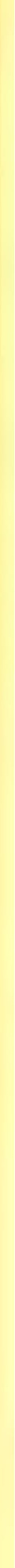


MR. W. K. PARKER ON THE SKULL IN THE MAMMALIA.

PLATE 7.

\begin{tabular}{|c|c|c|c|}
\hline Figures. & & & $\begin{array}{l}\text { Number of } \\
\text { times } \\
\text { magnitied. }\end{array}$ \\
\hline 1 & $\begin{array}{l}\text { Dasypus villosus; ripe embryo; } 4 \frac{2}{3} \text { inches } \\
\text { stage, continued); skull; under view . }\end{array}$ & $\operatorname{long}(5$ th & ; \\
\hline 2 & The same; upper view . . . . . . . . . & . . . . & 3 \\
\hline$\because$ & The same; side view . . . . . . . . . . & . . & 3 \\
\hline 3.1 & The same; lower jalw; inner view . . . . & . & $: 3$ \\
\hline 4 & The same; skull; end view . . . . & . & $\because$ \\
\hline 5 & The same; os hyoides; inner view . . . . & . . & 3 \\
\hline 6 & The same ; ossicula auditûs ; outer view . . & . . . & 9 \\
\hline
\end{tabular}



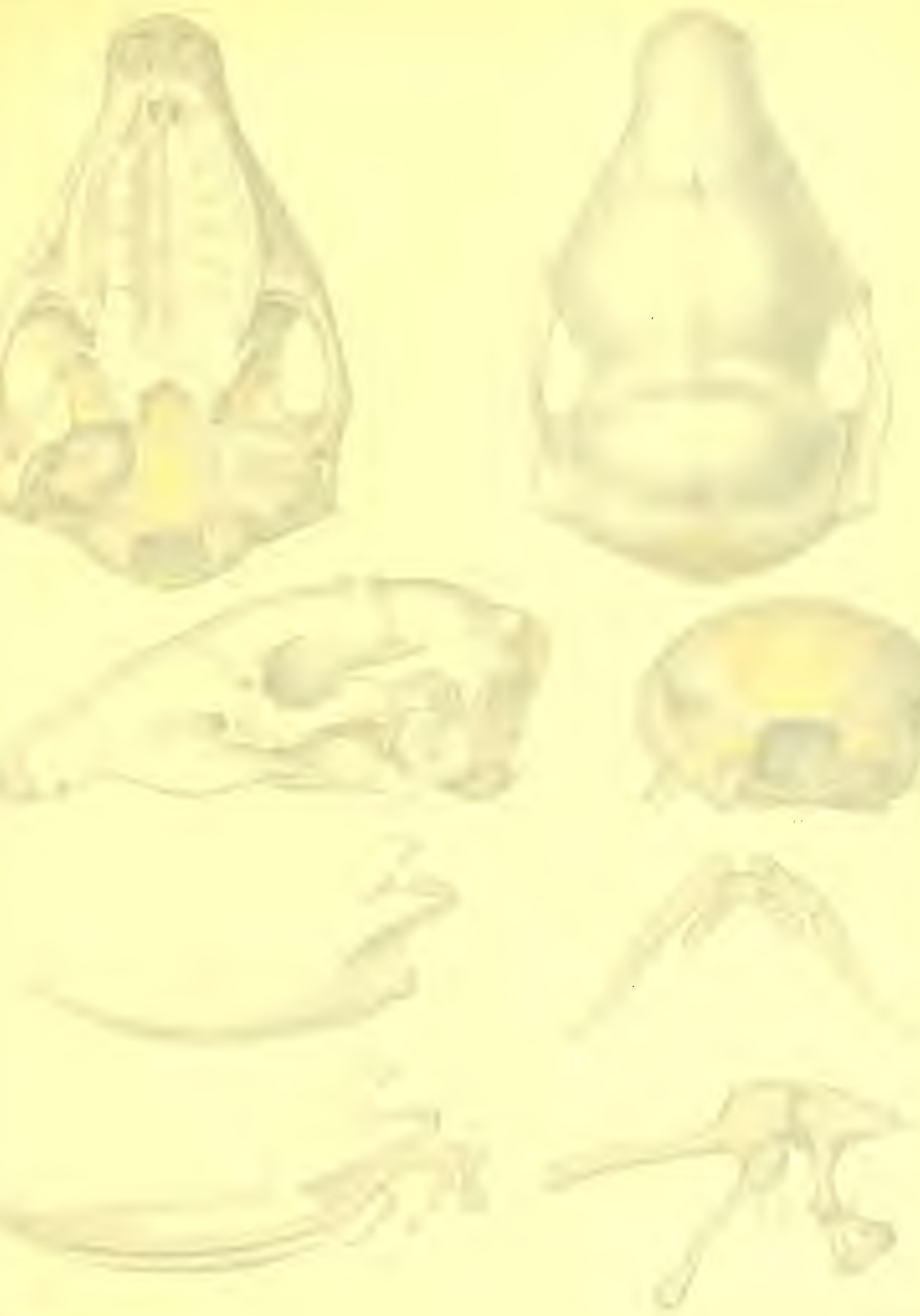


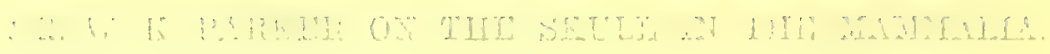

P.: $\%$

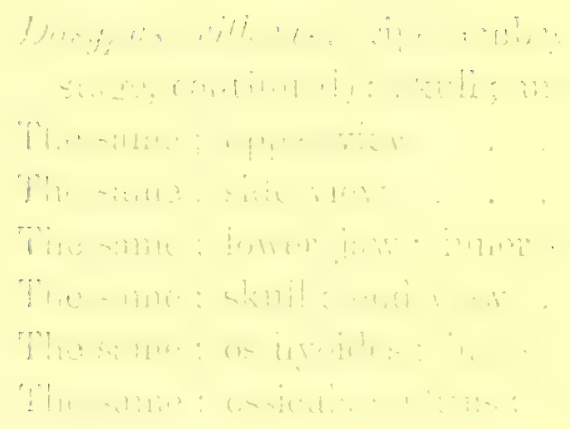



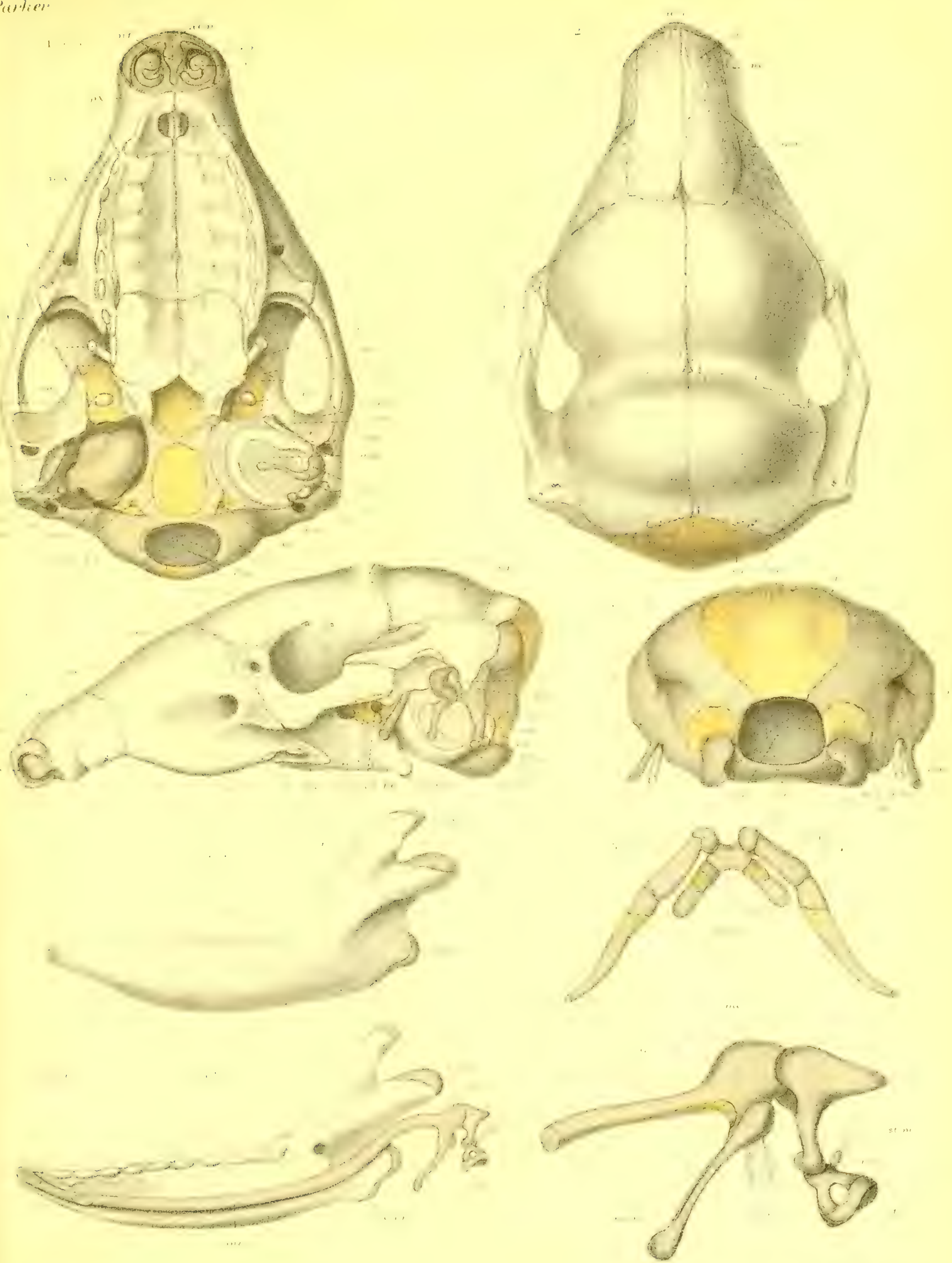




\section{PLATE 8.}

\begin{tabular}{|c|c|c|}
\hline Figures. & & $\begin{array}{l}\text { Number of } \\
\text { times } \\
\text { magnified. }\end{array}$ \\
\hline 1 & $\begin{array}{l}\text { Unau (Cholopus didactylus) (?) ; embryo ; } 3 \frac{1}{-1} \text { inches long } \\
\text { (1st stage); skull ; lower view . . . . . . . . . }\end{array}$ & 4 \\
\hline 2 & The same; upper view . . . . . . . . . . . . & 4 \\
\hline 3 & The same; side view . . . . . . . . . . . . & 4 \\
\hline 4 & The same; end view . . . . . . . . . . . . & 4 \\
\hline 5 & $\begin{array}{l}\mathrm{Ai} \text { (Bradymus, Aretopithecus, Gray, ? sp.) ; embryo; } \\
5 \text { inches long (2nd stage); skull ; lower view . . . . }\end{array}$ & 3 \\
\hline 6 & The same; side view . . . . . . . . . . . . & 3 \\
\hline 7 & The same ; right malar bone . . . . . . . . . . & 3 \\
\hline 8 & The same; nasal region of skull ; side view of septum . & 3 \\
\hline 9 & The same; showing turbinals. . . . . . . . . . & 3 \\
\hline
\end{tabular}



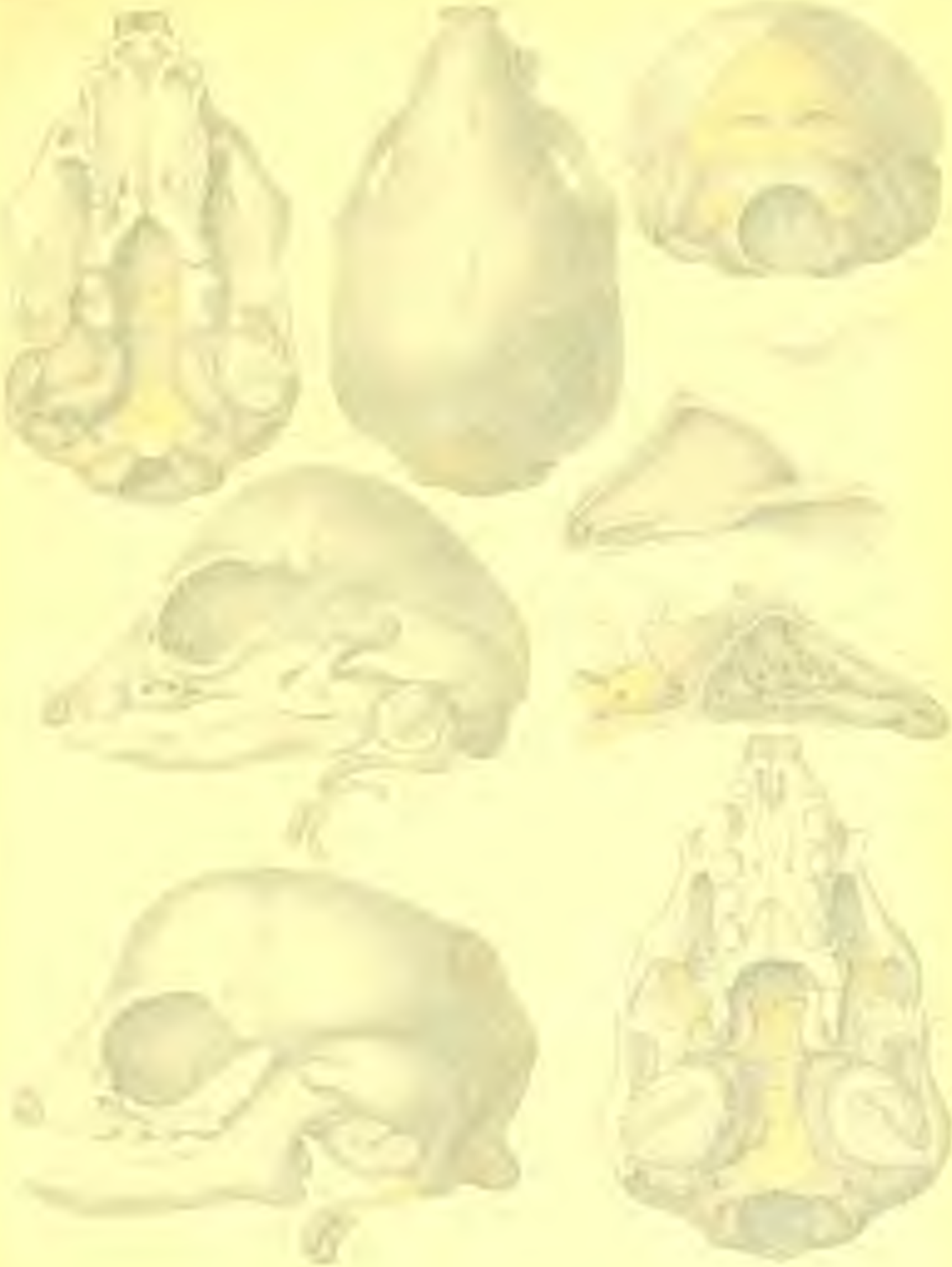


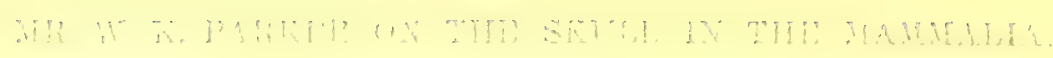

PY. AlY i-

(n)

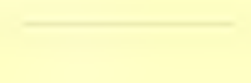

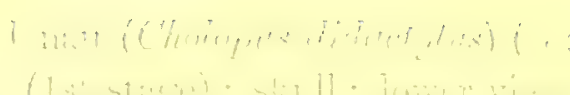

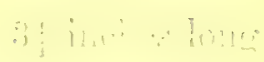

yhe

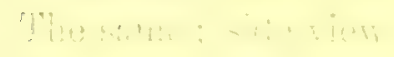

The one

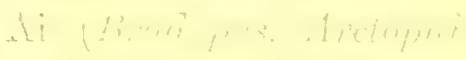

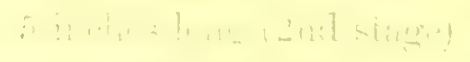

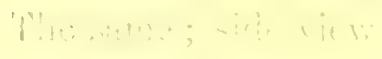

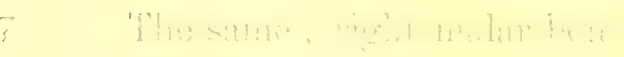

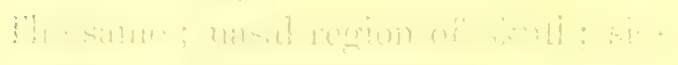

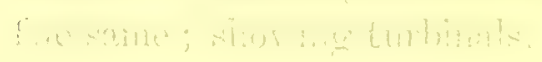




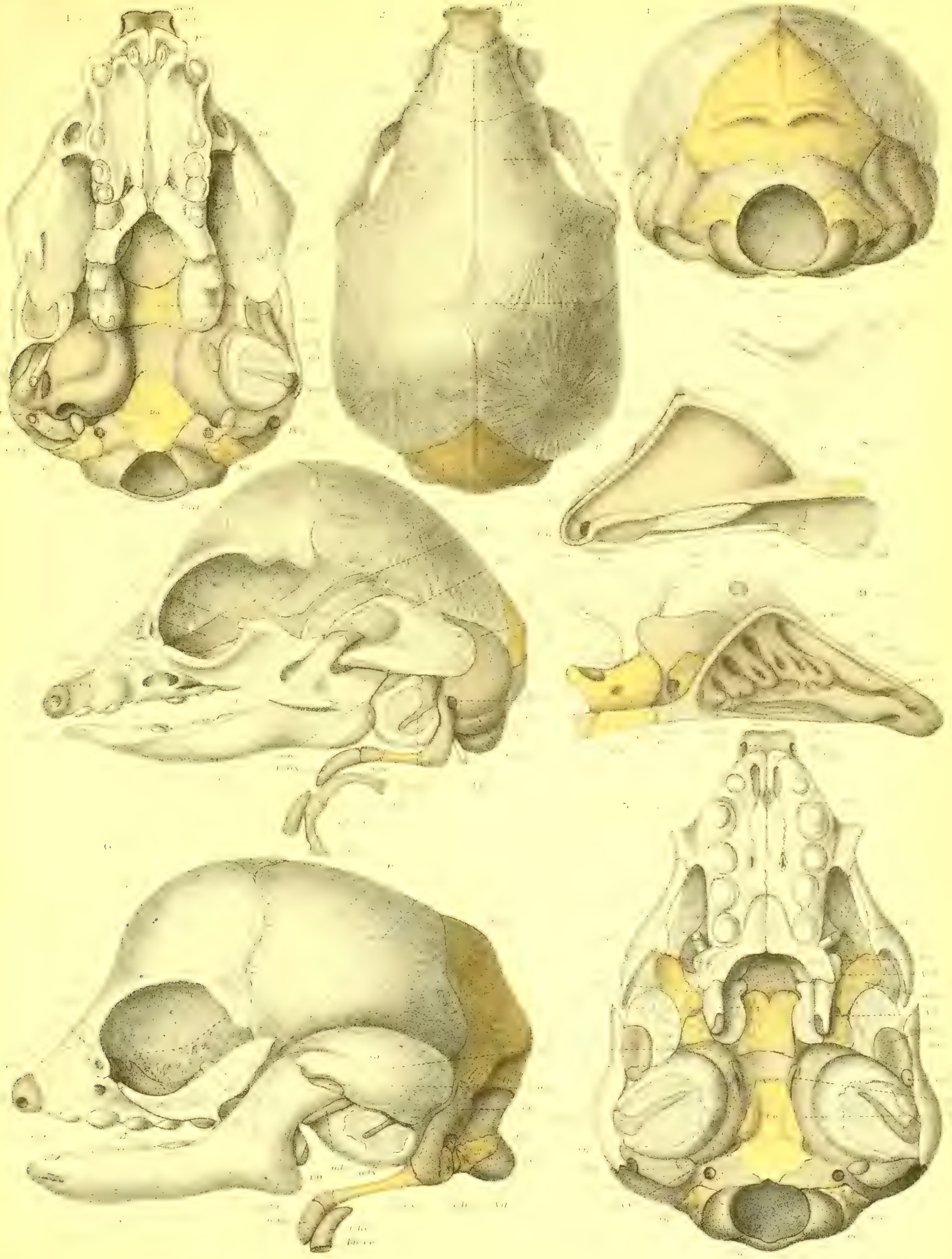





\section{.}


MR. W. K, PARKER ON THE SKULL IN THE MAMMALIA.

\section{PLATE 9.}

\begin{tabular}{|c|c|c|}
\hline Fignres. & & $\begin{array}{l}\text { Number of } \\
\text { times } \\
\text { magnified. }\end{array}$ \\
\hline 1 & $\begin{array}{l}\text { Cholopus Hoffmanni; young; } 8 \text { inches long (3rd stage); } \\
\text { skull ; lower view. . . . . . . . . . . . . . }\end{array}$ & $1 \frac{4}{5}$ \\
\hline 2 & The same; upper view . . . . . . . . . . . . & $1 \frac{4}{5}$ \\
\hline 3 & The same; side view . . . . . . . . . . . . & $1 \frac{4}{5}$ \\
\hline 4 & The same; end view. . . . . . . . . . . . . . & $1 \frac{4}{5}$ \\
\hline 5 & The same; lower jaws; under view . . . . . . . & $1 \frac{4}{5}$ \\
\hline 6 & The same; ossicula auditûs ; inner view . . . . . . & 6 \\
\hline 7 & $\begin{array}{l}\text { The same; ossicula auditûs and auditory capsule; outer } \\
\text { view . . . . . . . . . . . . . . . . . . . . }\end{array}$ & 6 \\
\hline 8 & $\begin{array}{l}\text { Bradypus (Arctopithecus) (2ud stage); lower jaw and } \\
\text { ossicula auditas; inner view . . . . . . . . . }\end{array}$ & \pm \\
\hline 9 & $\begin{array}{l}\text { Cholopus didactylus (?) (1st stage); the same parts; } \\
\text { inner view . . . . . . . . . . . . . . . }\end{array}$ & 6 \\
\hline
\end{tabular}



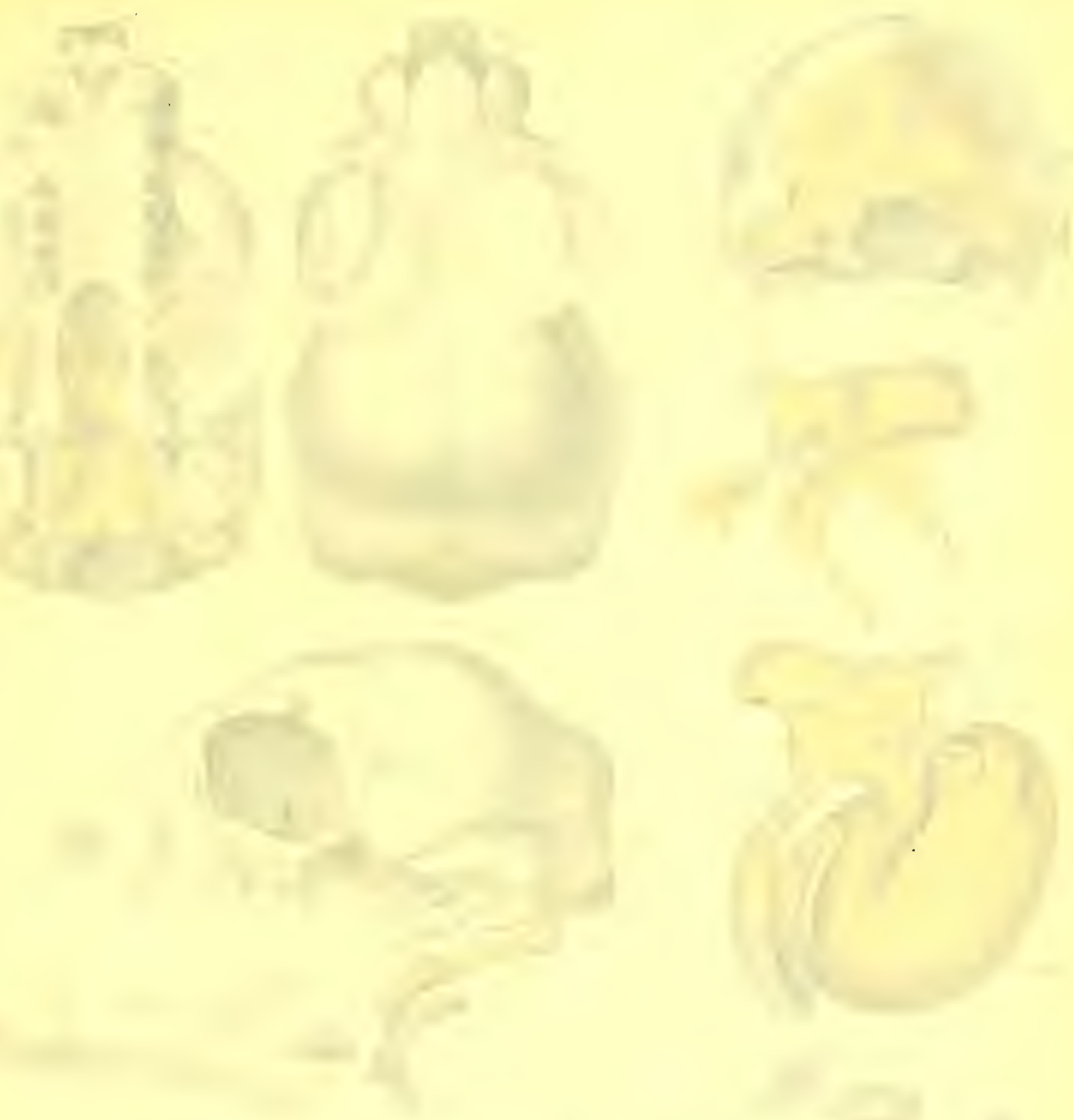


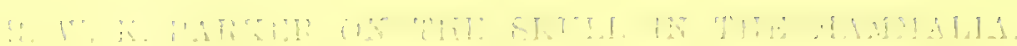

$[1,-1]^{-T H}$

ii)

sit

3n: 25

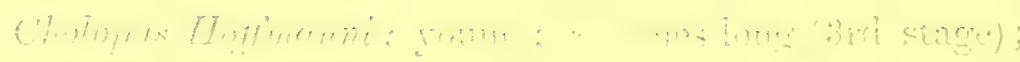

Holl will

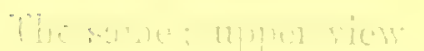

?i!l

?

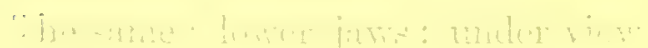

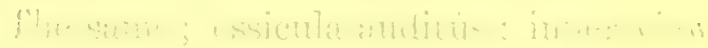

ind

Ii:

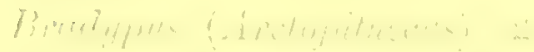

ansirule wicitus

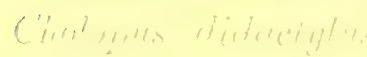

ins? 

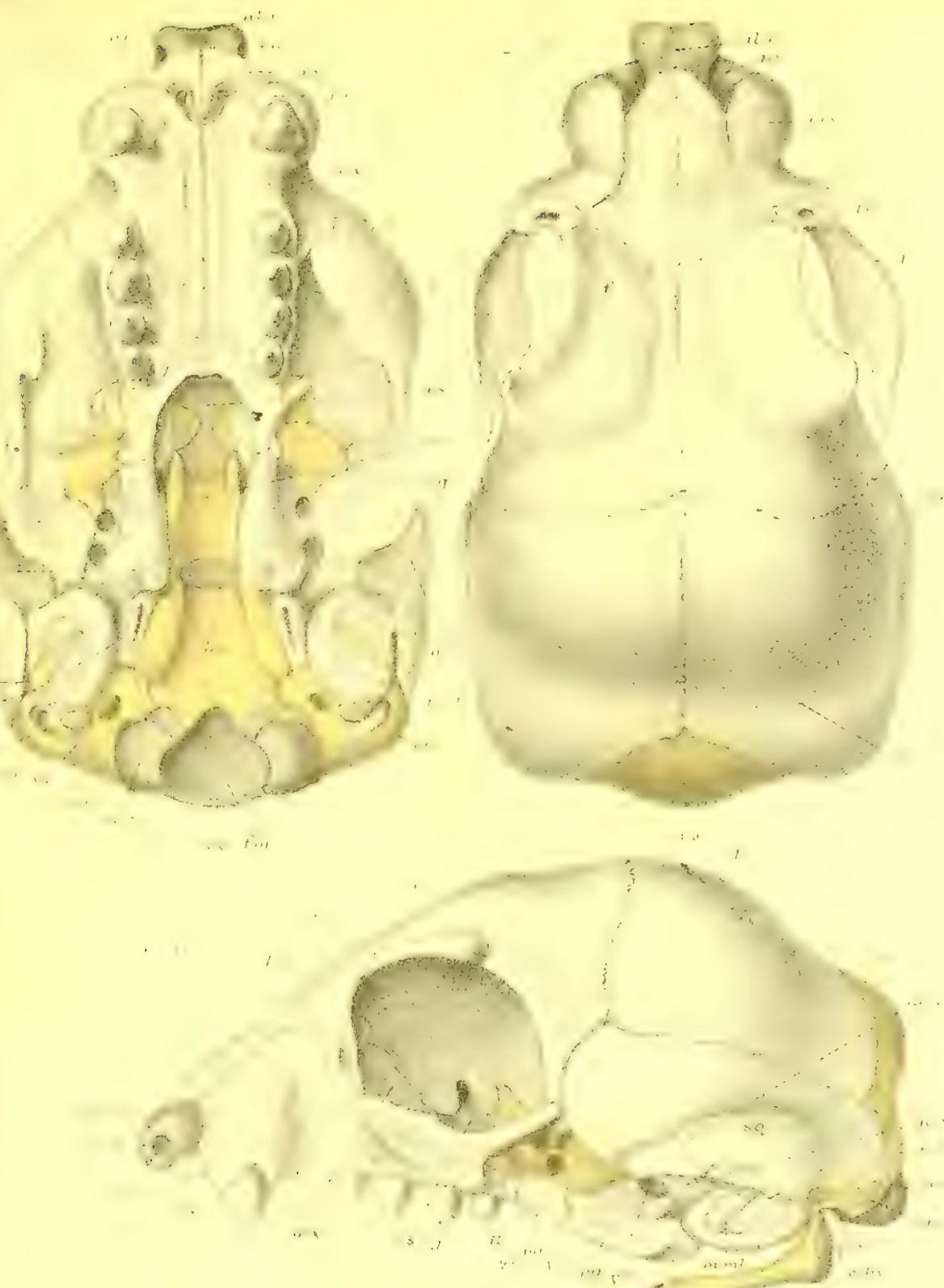

$1 \cdots 04$
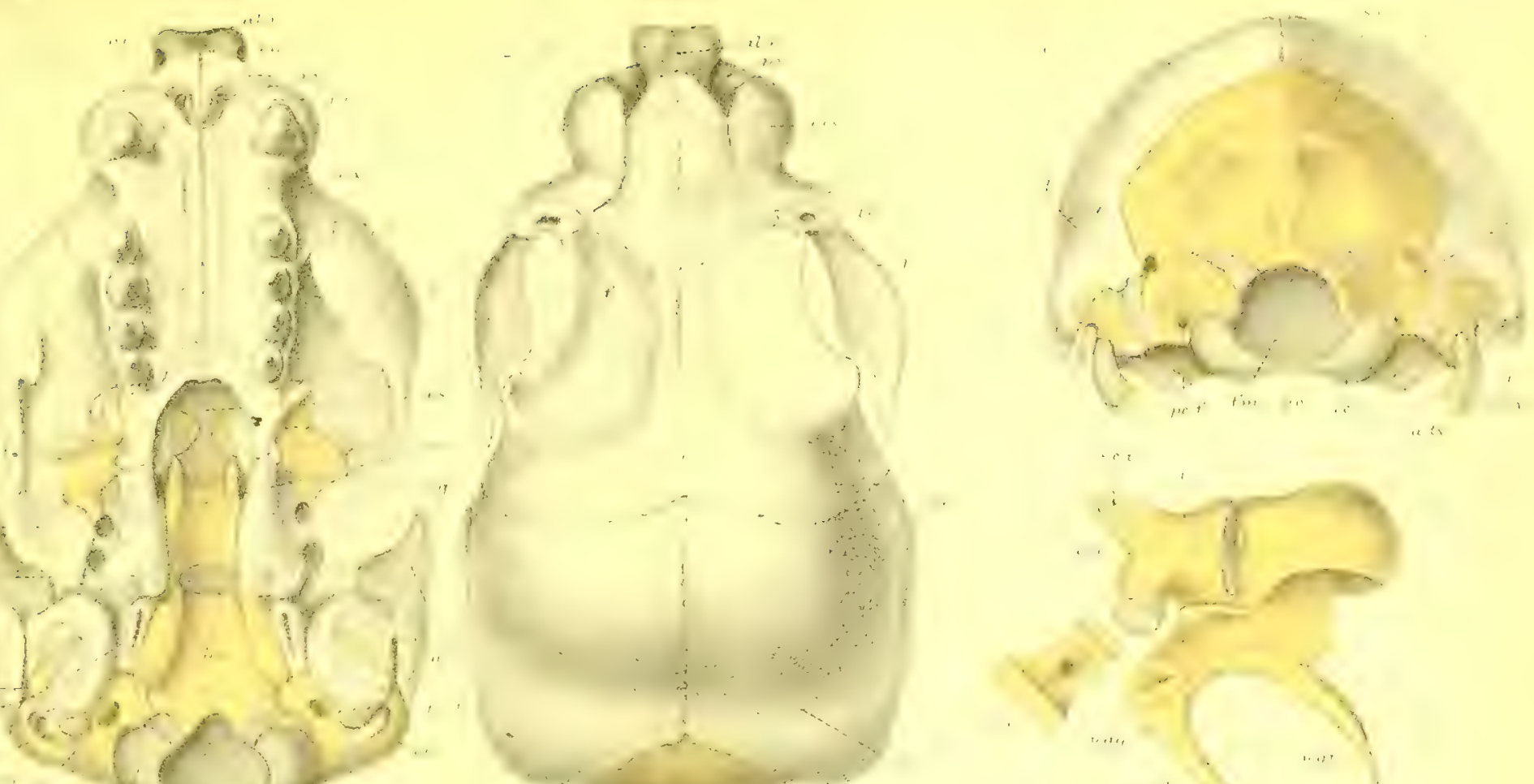

6
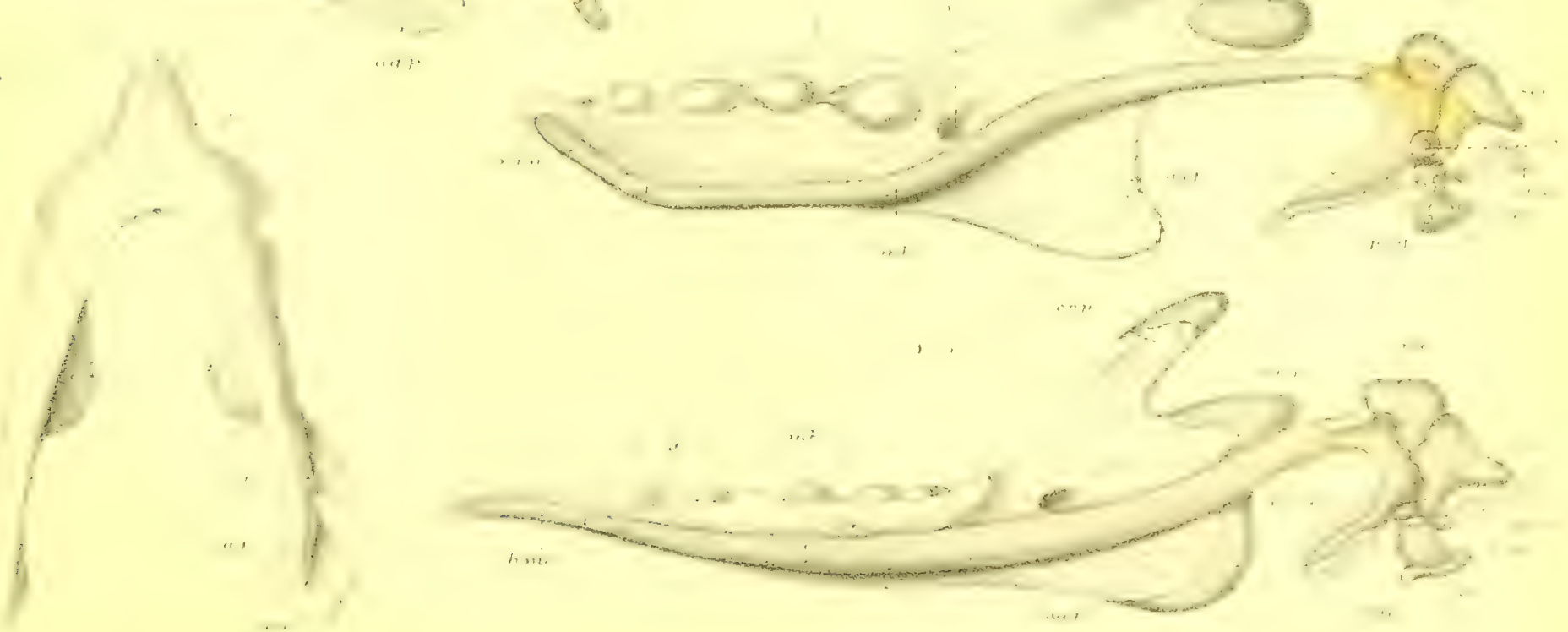




\begin{tabular}{|c|c|c|}
\hline Figures. & & $\begin{array}{l}\text { Number of } \\
\text { times } \\
\text { magnified. }\end{array}$ \\
\hline 1 & 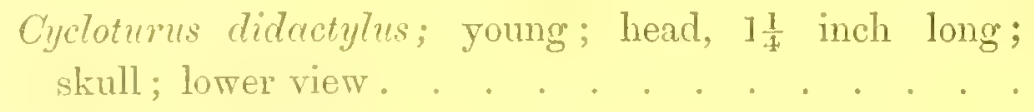 & $3 \frac{1}{3}$ \\
\hline 2 & The same; upper view . . . . . . . . . . . . . . , & $3 \frac{1}{3}$ \\
\hline 3 & The same; side view . . . . . . . . . . . . & $3 \frac{1}{3}$ \\
\hline $3 \AA$ & The same; lower jaw; inner view . . . . . . . . . & $3 \frac{1}{3}$ \\
\hline 4 & The same; end view of skull . . . . . . . . . & $3 \frac{1}{3}$ \\
\hline 5 & $\begin{array}{l}\text { The same species; larger specimen; } 4 \frac{1}{2} \text { inches long; } \\
\text { head, } 1 \frac{1}{2} \text { inch; ossicula auditus ; outer view . . . . }\end{array}$ & 10 \\
\hline 6 & The same; os hyoides; inner view . . . . . . . . & 10 \\
\hline 7 & The same; vertical section of skull; inner view . . . & $3 \frac{1}{3}$ \\
\hline 8 & The same; part of skull, showing turbinals . . . . . & $3 \frac{1}{3}$ \\
\hline 9 & $\begin{array}{c}\text { The sane species; lesser specimen; temporal region } \\
\text { oblique; lower view . . . . . . . . . . . . . }\end{array}$ & $6 \frac{2}{3}$ \\
\hline 10 & $\begin{array}{l}\text { The same; larger specimen; vomer and related parts; } \\
\text { lower view . . . . . . . . . . . . . . . }\end{array}$ & 6 \\
\hline
\end{tabular}


II ITK 11

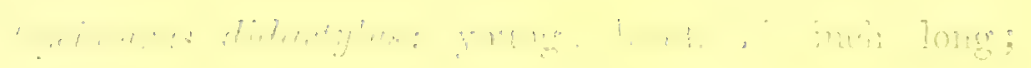

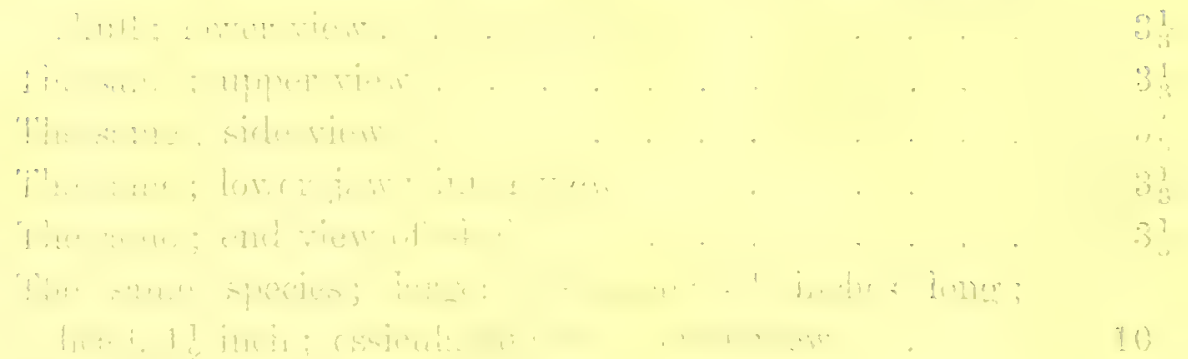

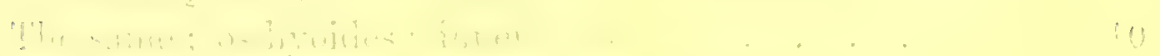

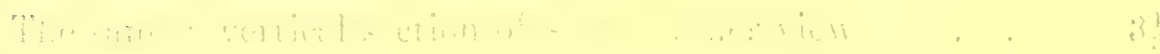

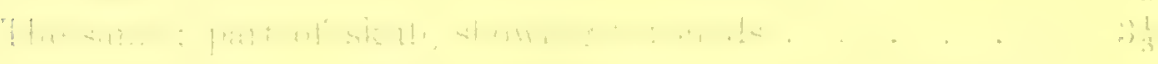

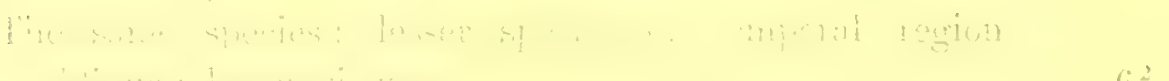

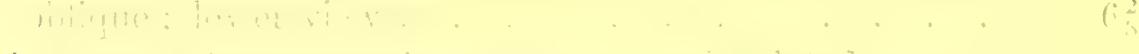

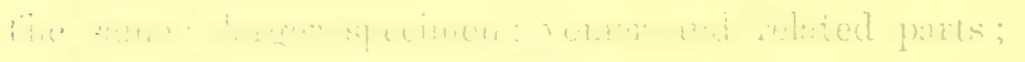




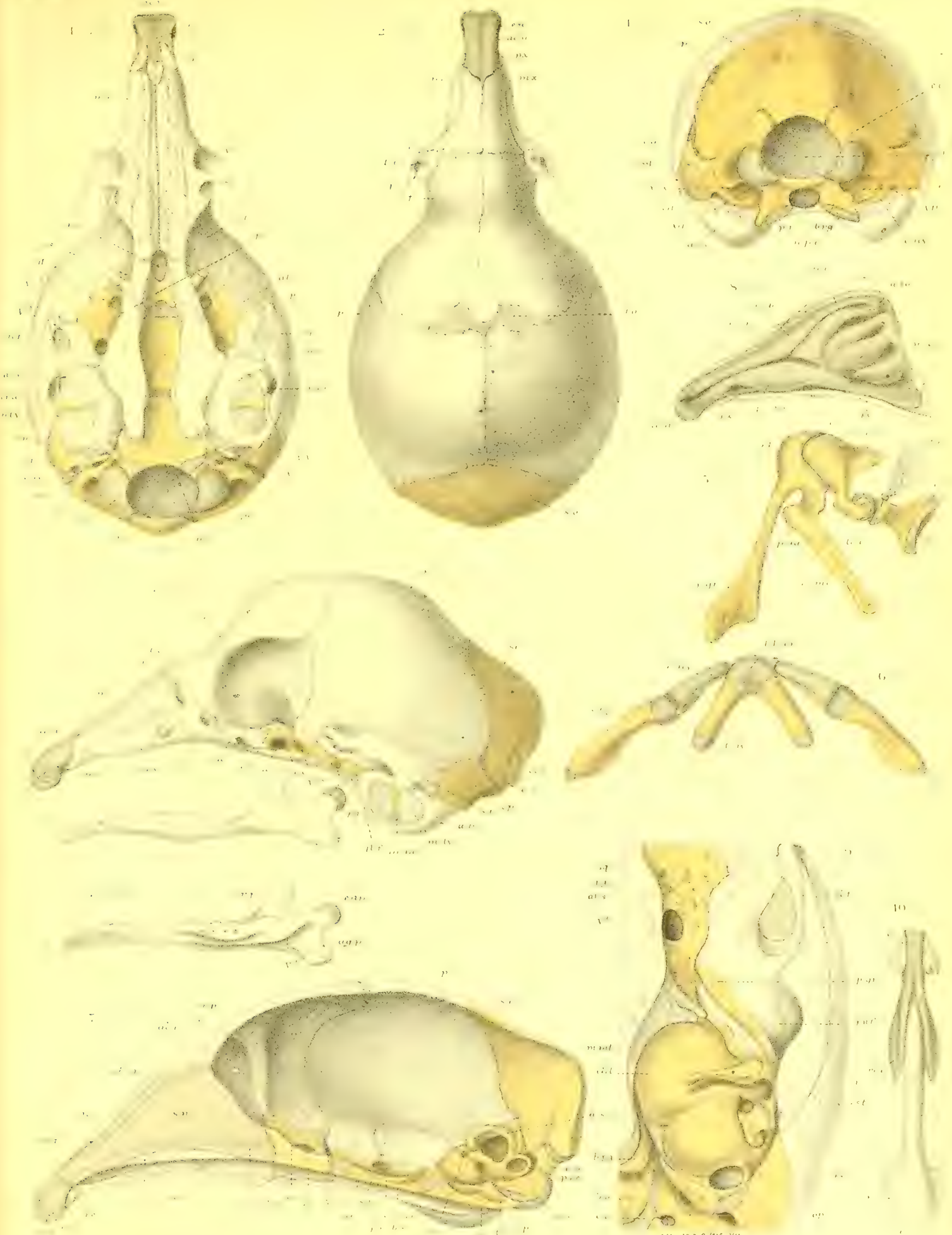






\section{PLATE 11.}

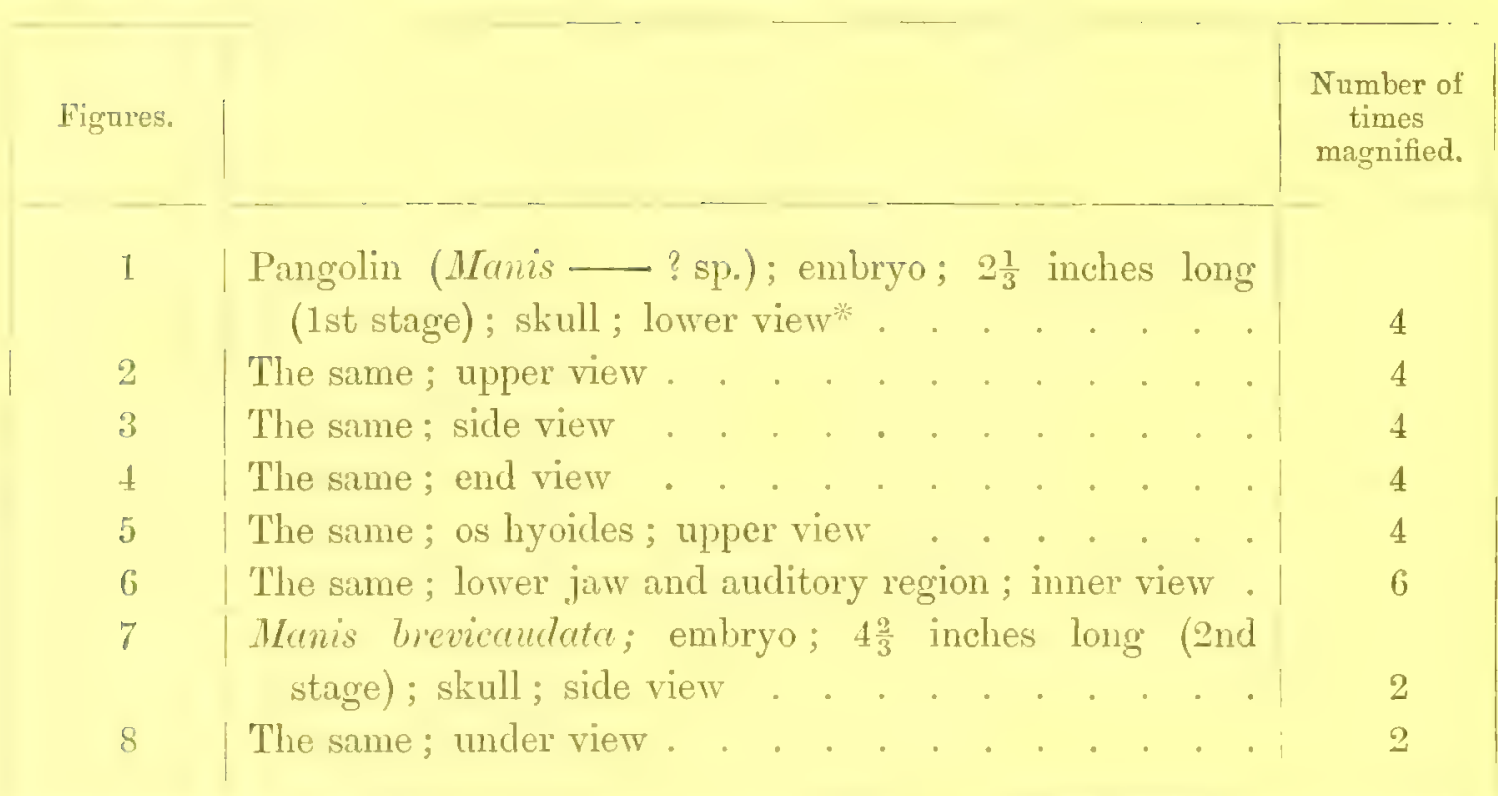

* All the parts behind b.o. and oc.c. should have been drawn in shade; they belong to the roof. 
Phil.Trans.1885 Platell. 


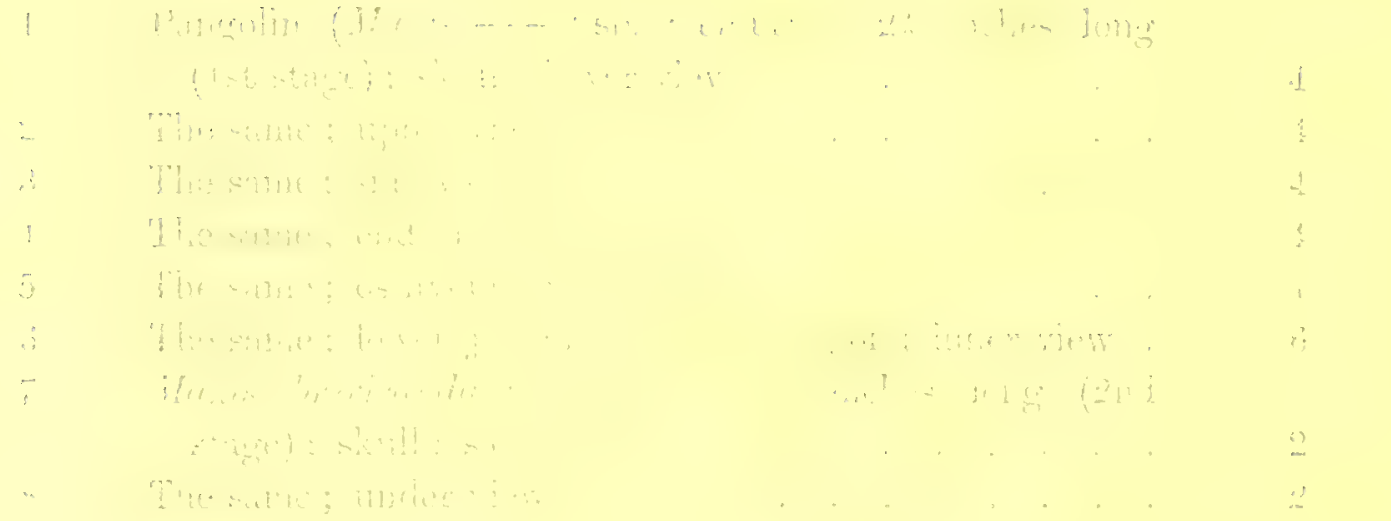



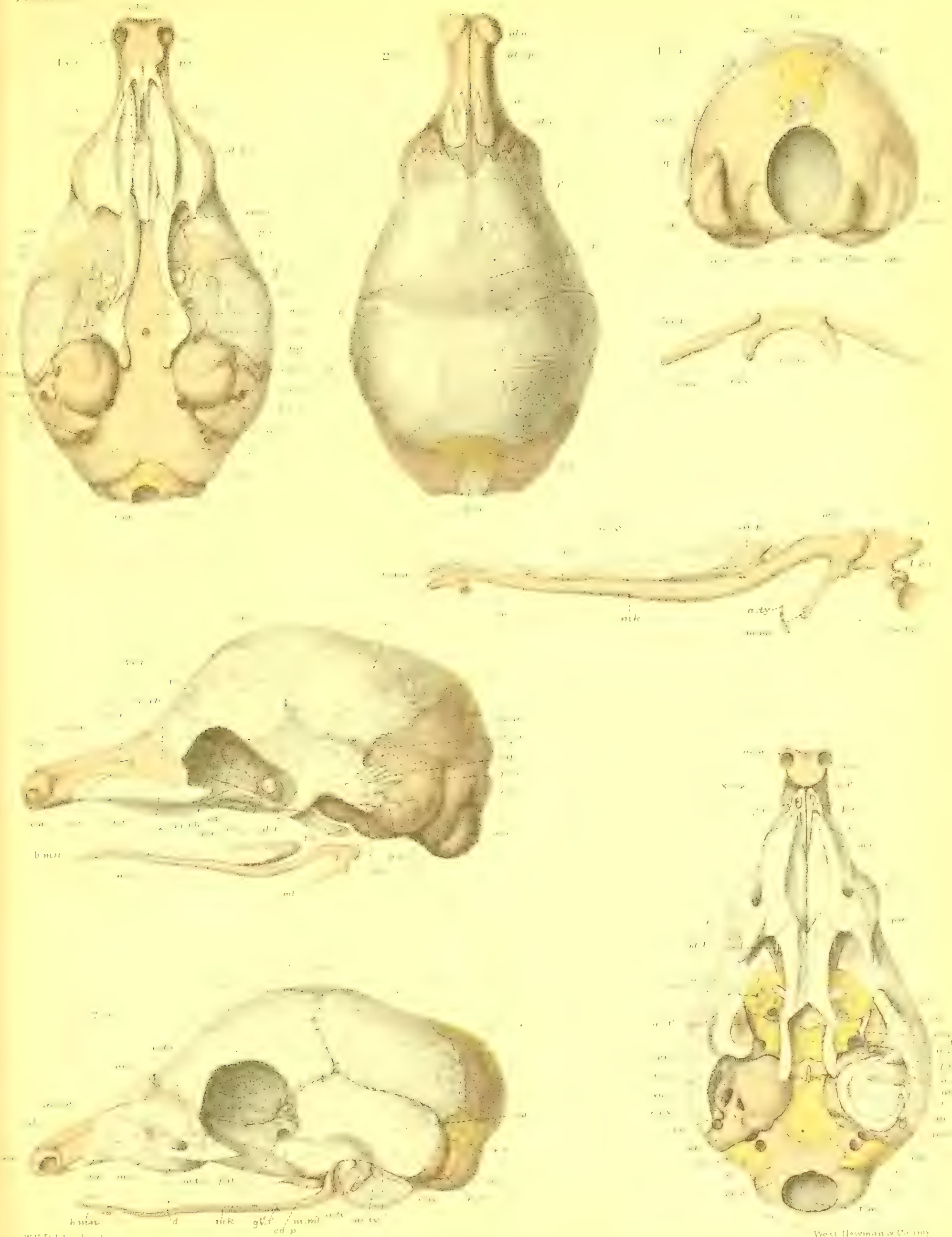

- 
IIR. W. K. PAREER ON THE SKULL IN THL MAMIIALIA.

PLATE 12.

\begin{tabular}{|c|c|c|}
\hline Figures. & & $\begin{array}{l}\text { Number of } \\
\text { times } \\
\text { magnified. }\end{array}$ \\
\hline 1 & $\begin{array}{l}\text { Mamis brevicunduta (as in figs. } 7 \text { and } 8 \text { of last Plate); } \\
\text { skull; upper view* . . . . . . . . . }\end{array}$ & 3 \\
\hline 2 & The same; end riew. & 3 \\
\hline 3 & The same; os hyoides; inner view . . . . . . . . & 3 \\
\hline 4 & The same; lower jaw and ossicula auditûs; inner view. & $4 \frac{1}{2}$ \\
\hline 5 & The sime; both lower jaws; fore part of under view . & $4 \frac{1}{2}$ \\
\hline 6 & $\begin{array}{l}\text { Manis Temminckii; young; 2nd day after birth; head, } \\
2 \frac{1}{4} \text { inches long (3rd stage); skull; lower view . . }\end{array}$ & 2 \\
\hline 7 & The same ; upper riew. . . . . . . . . . . & 2 \\
\hline 8 & The same; side riew . . . . . . . . . . . & 2 \\
\hline ? & The same; end riew . . . . . . . . . . . . & 2 \\
\hline 10 & Lower jaw; inner view. . . . . . . . . . . . & 2 \\
\hline 11 & The same part; with ossicula auditus ; inner view . . . & $2 \frac{2}{3}$ \\
\hline 12 & The same; stapes and part of incus . . . . . . . & 8 \\
\hline 13 & The same; os hyoides; inner view . . . . . . . . & $2 \frac{2}{3}$ \\
\hline
\end{tabular}

* In any want of correspondence between the number of times a figure is said to le magnified, on the Plate, aul in the descriptive page, the latter gires the true number. 
Fhit Trans. 1885. Plour 12

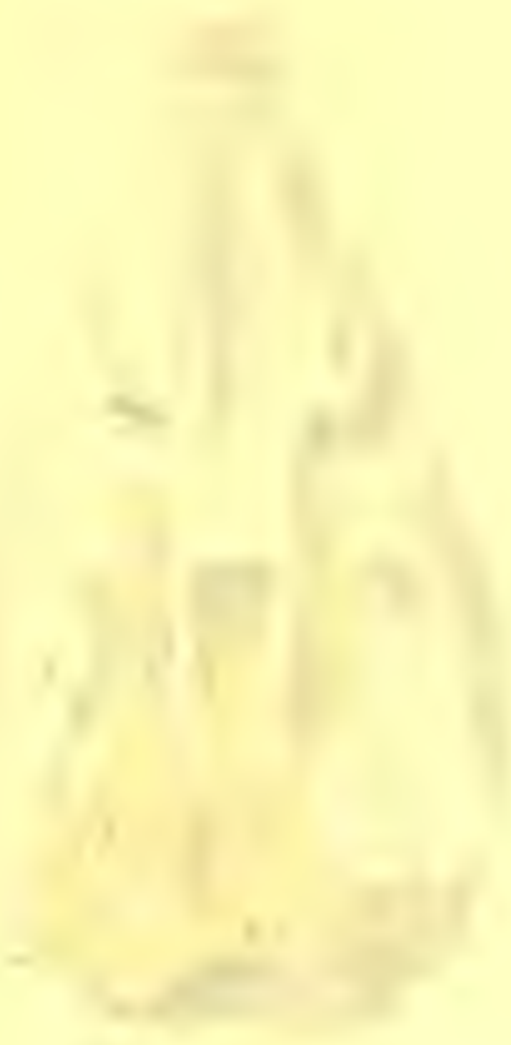




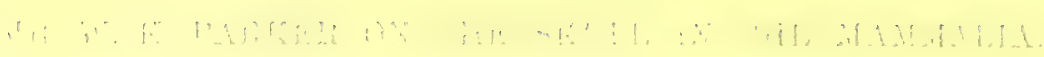

Pis:?

in.........

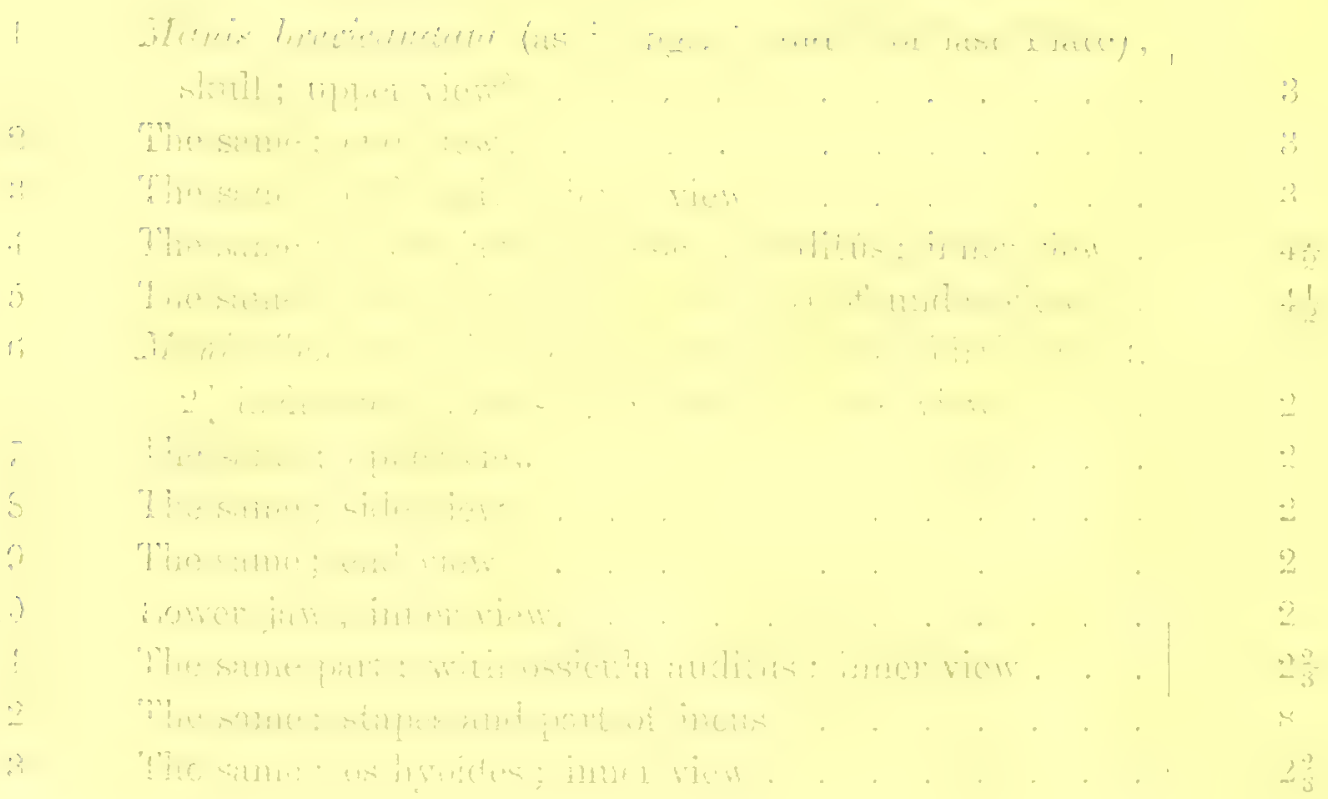

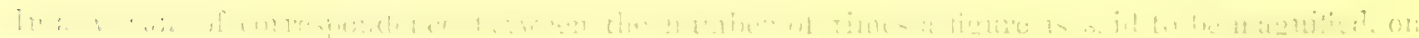

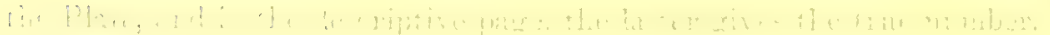




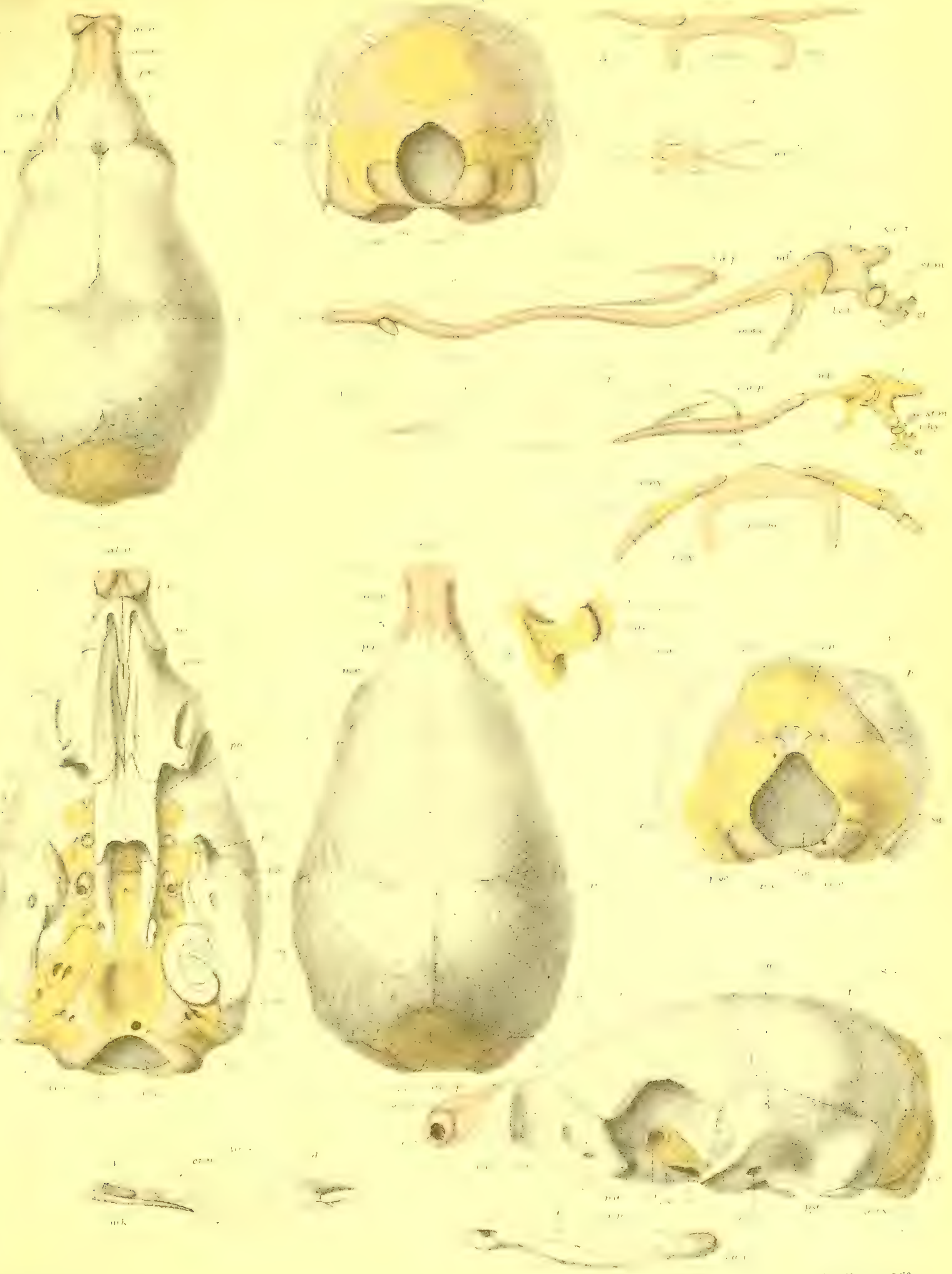



. 
MR. W. K. PARKER ON THE SKULL IN THE MAMMALIA.

PLA'T'E 13.

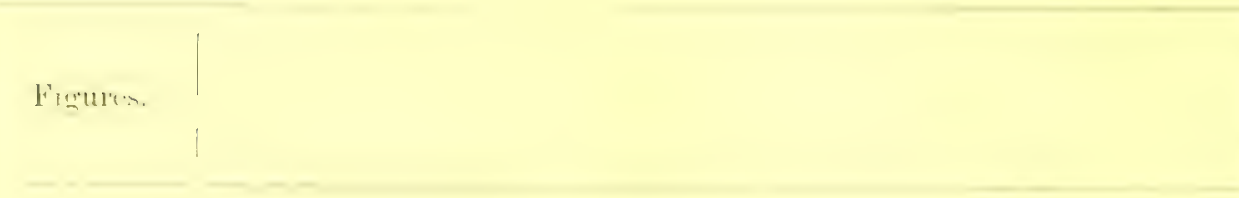

Number of

times magnified.

1 Manis Temminckii (3rd stage); left part of basis cranii ; lower view

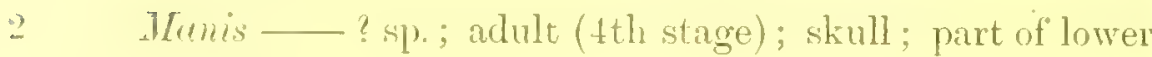
view . . . . . . . . . . . . . . . . . $1 \frac{1}{4}$

; | The same; cribriform plate; hinder view . . . . . . | $1 \frac{1}{4}$

4 The same; front view of nasal region . . . . . . . | $1 \frac{1}{2}$

5 Bicedypus tridectylus, Linn.; half-grown (th stage); part of skull; side view . . . . . . . . . . . $1 \frac{1}{2}$

(i) The same; lower view . . . . . . . . . . . . $1 \frac{1}{2}$

7 The same; hinder view . . . . . . . . . . . . $1 \frac{1}{2}$

ऽ The same; os tympanicum; onter view . . . . . . 2

9) The same; inner view . . . . . . . . . . . . 2

11) Bradypus (Arctopithecus) (2nd stage); skull; hind view I

1) The same; section of basisphenoidal region . . . . I I

l:- Manis brevicandatu (2nd stage); vertical section of skull; inner view 

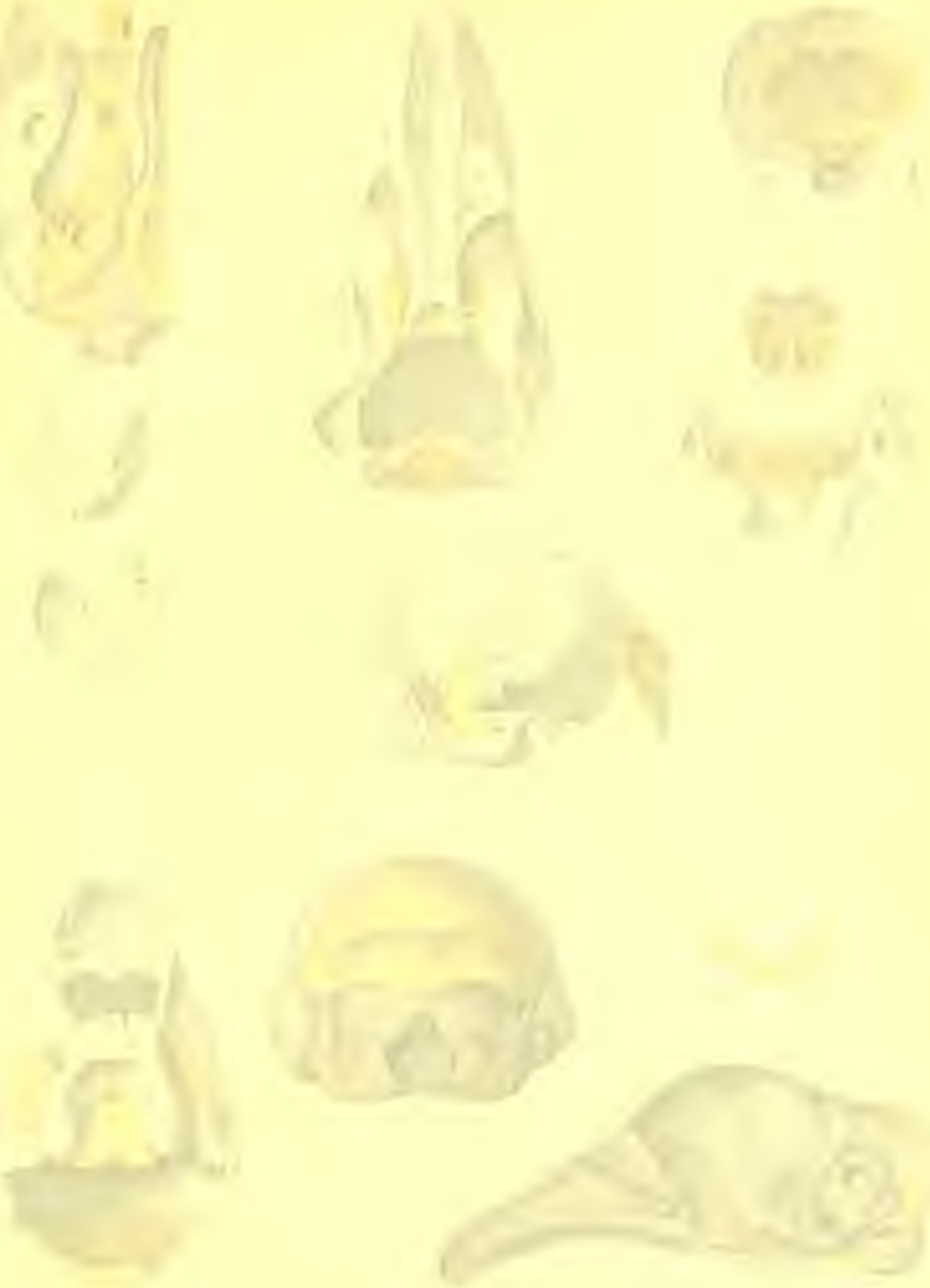


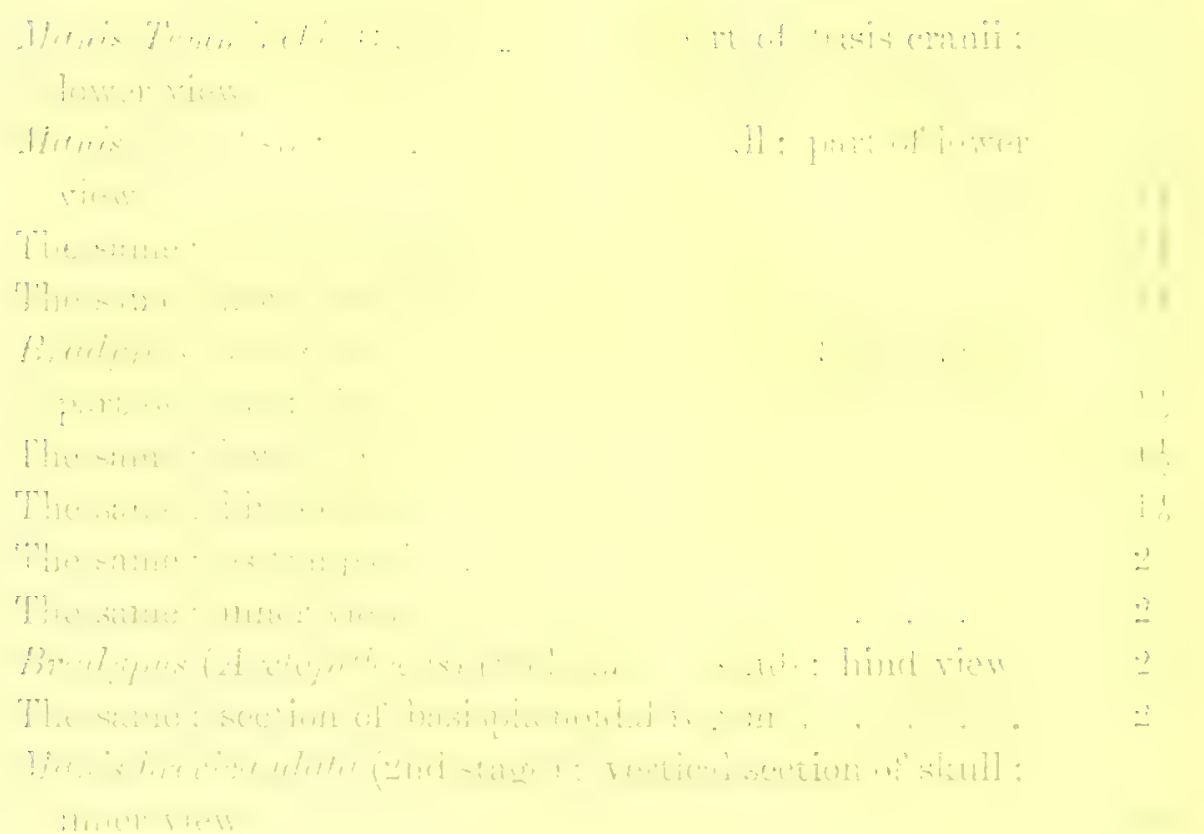



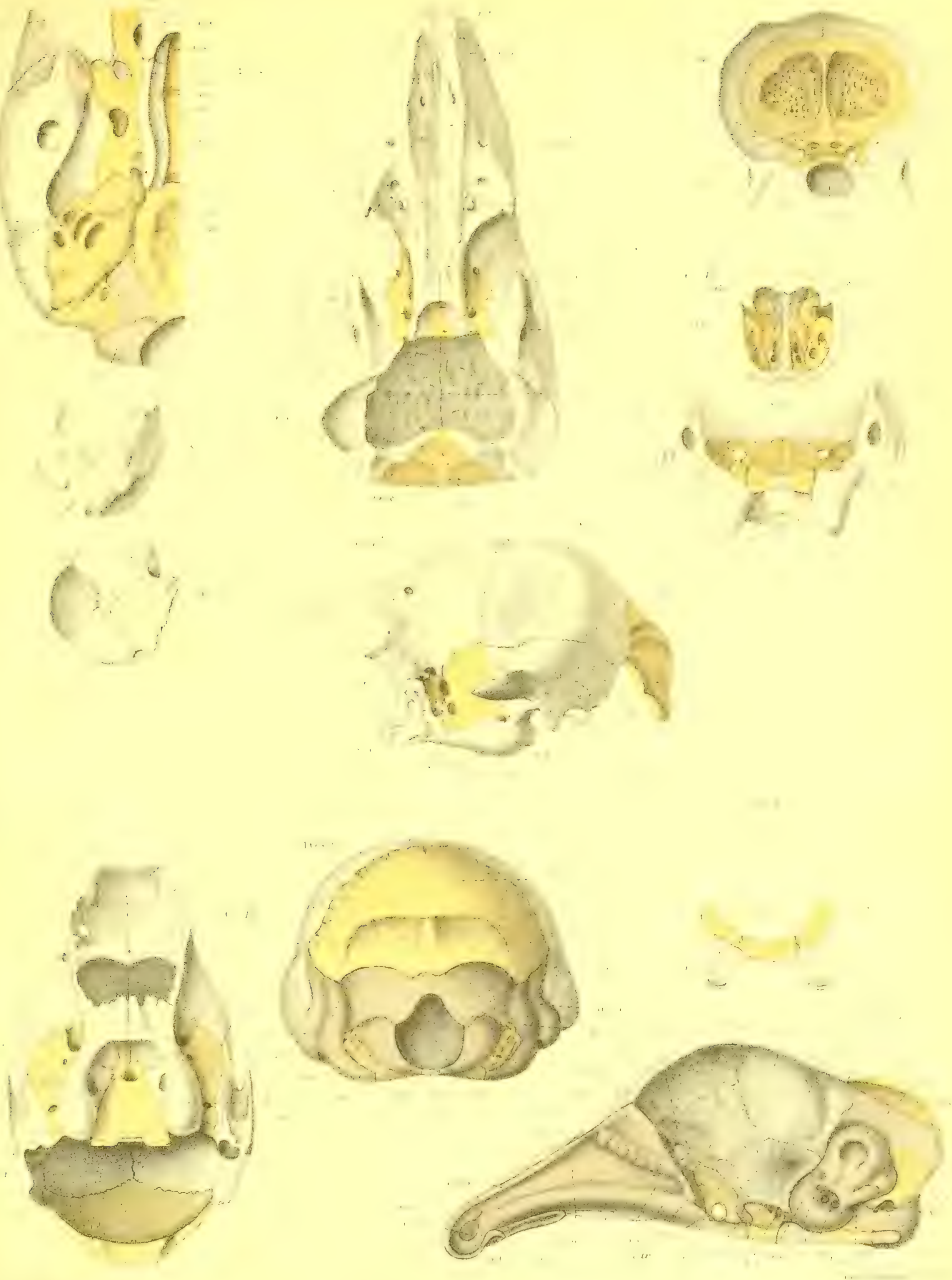


IIR. W. K. PARKER ON THE SKULL IN THE MAIMALTA.

PLATE 14.

Finures

Number of

times

magnified.

1 Aurl-Verk (Omycteropus capensis); nearly ripe embryo; skull; lower view* . . . . . . . . . 1 1 1 neirly

$2 \quad$ The same; upper view. . . do.

3 | The same; side view . . . . . . . . . . . do.

4 The same; hind view . . . . . . . . . . . . do.

5 The same; vomerine region; lower view . . . . . . . ?

* These figures should have been marked $\times 1 \frac{7}{3}$ and $\times 2 \frac{2}{3}$, like those of the next Plate. 
$3+1 ; ;$

number of

time.

natent int

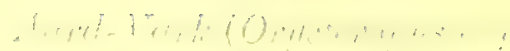

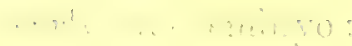

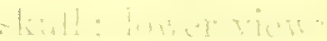

$\therefore$ iscirir

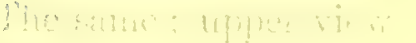

(1).

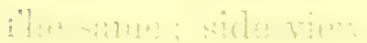

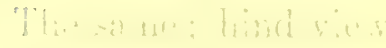

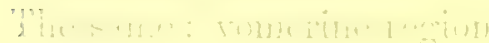



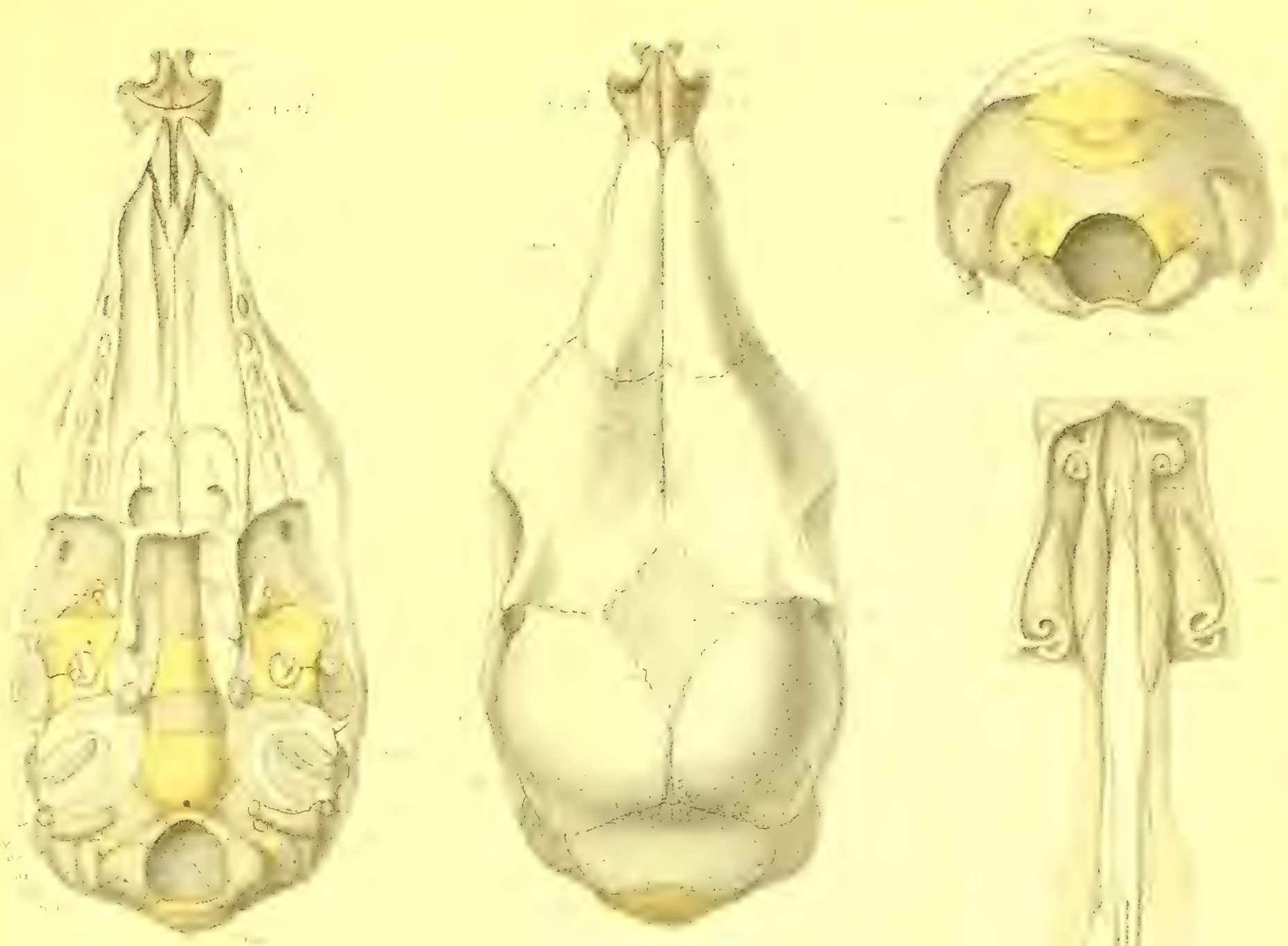


PLATE 15.

\section{Figures.}

Number of times magnified.

1 Orycteropus capensis (continued); endocranium; lower view . . . . . . . . . . . . . $1 \frac{1}{2}$ nearly 2 The same; upper view . . . . . . . . . . $\mid$ do.

3 The same; septum nasi and vomer; side view . . . . $\quad$ do.

4 | 'The same; ossicula auditus ; inner view . . . . . . | 4

5 Cholopus didactylus (?) (1st stage), vertical section of skull; inner view . . . . . . . . . . . . . . . . . . 4

\begin{tabular}{l|l|l}
5.1 & The same; separate; anterior paired vomer . . . . . & 20
\end{tabular}

6 The same; vomerine region of skull; lower view . . . | 4 


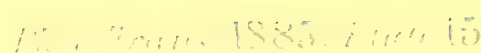
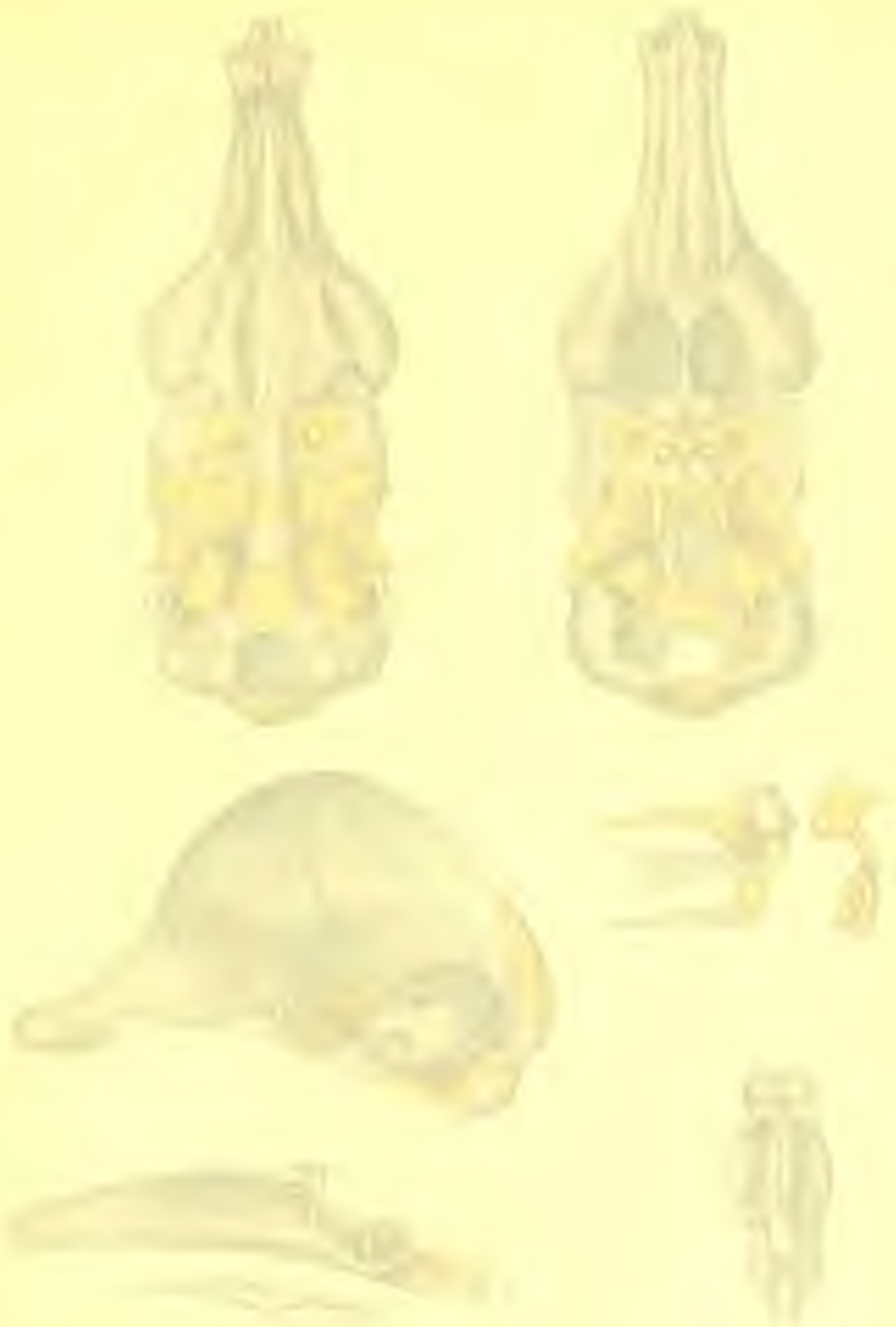
: $-\{1,1$;

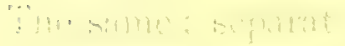




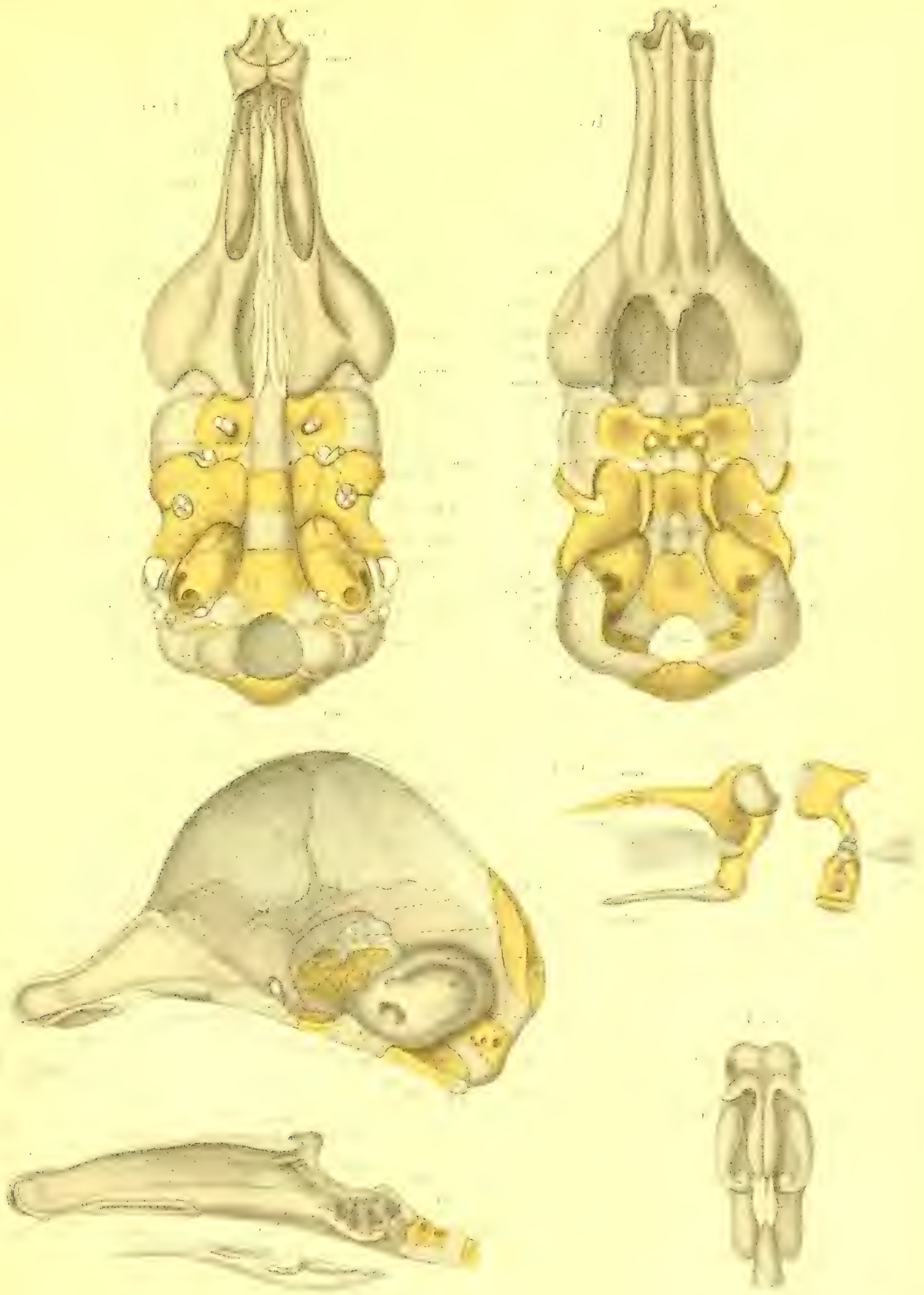



I'A A'TE 16.

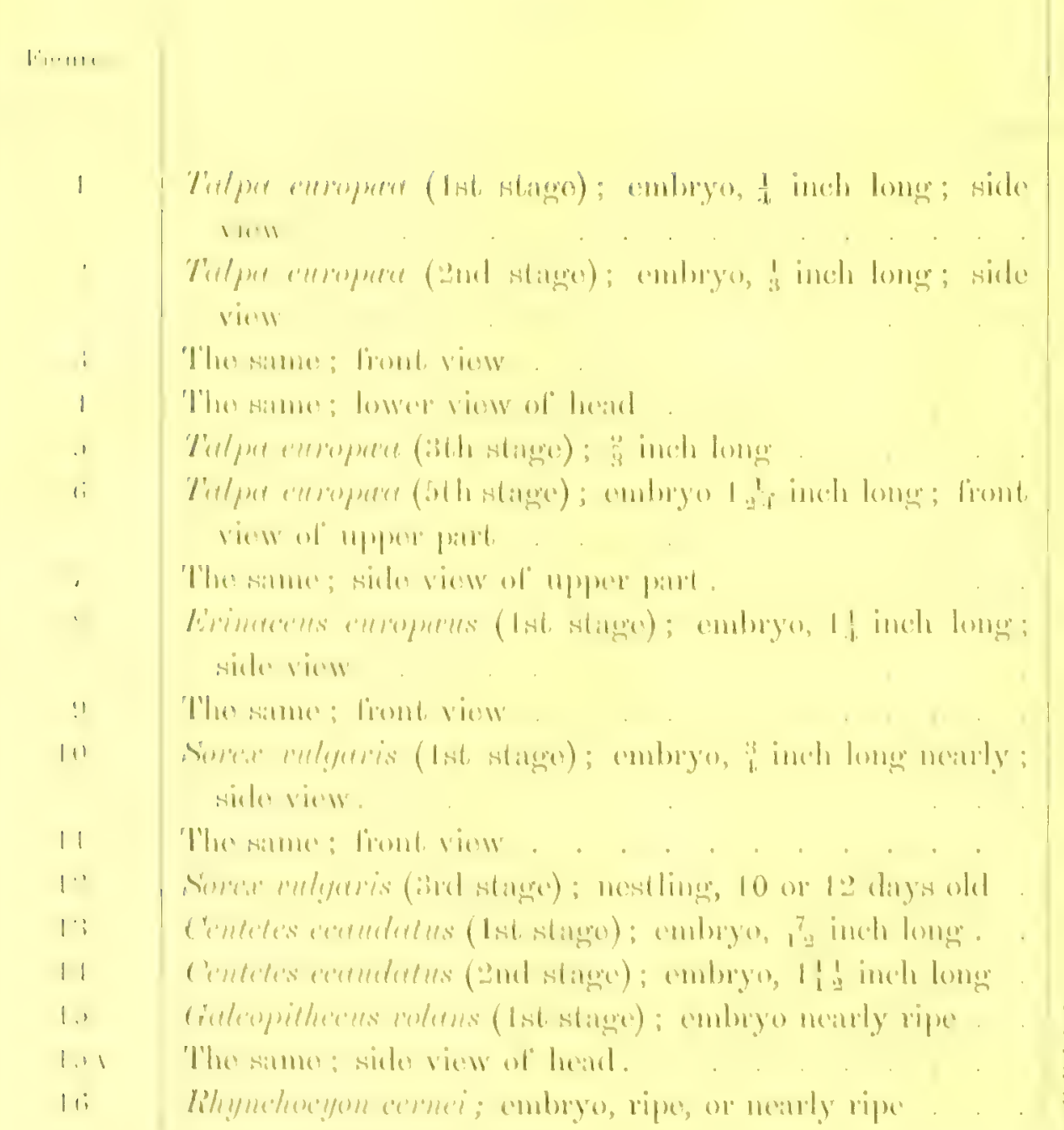

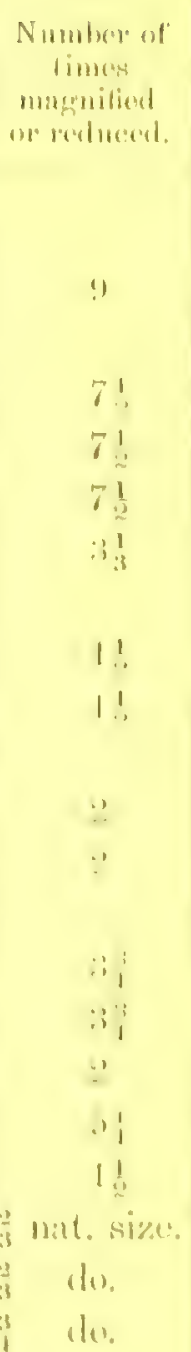




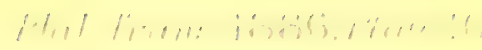
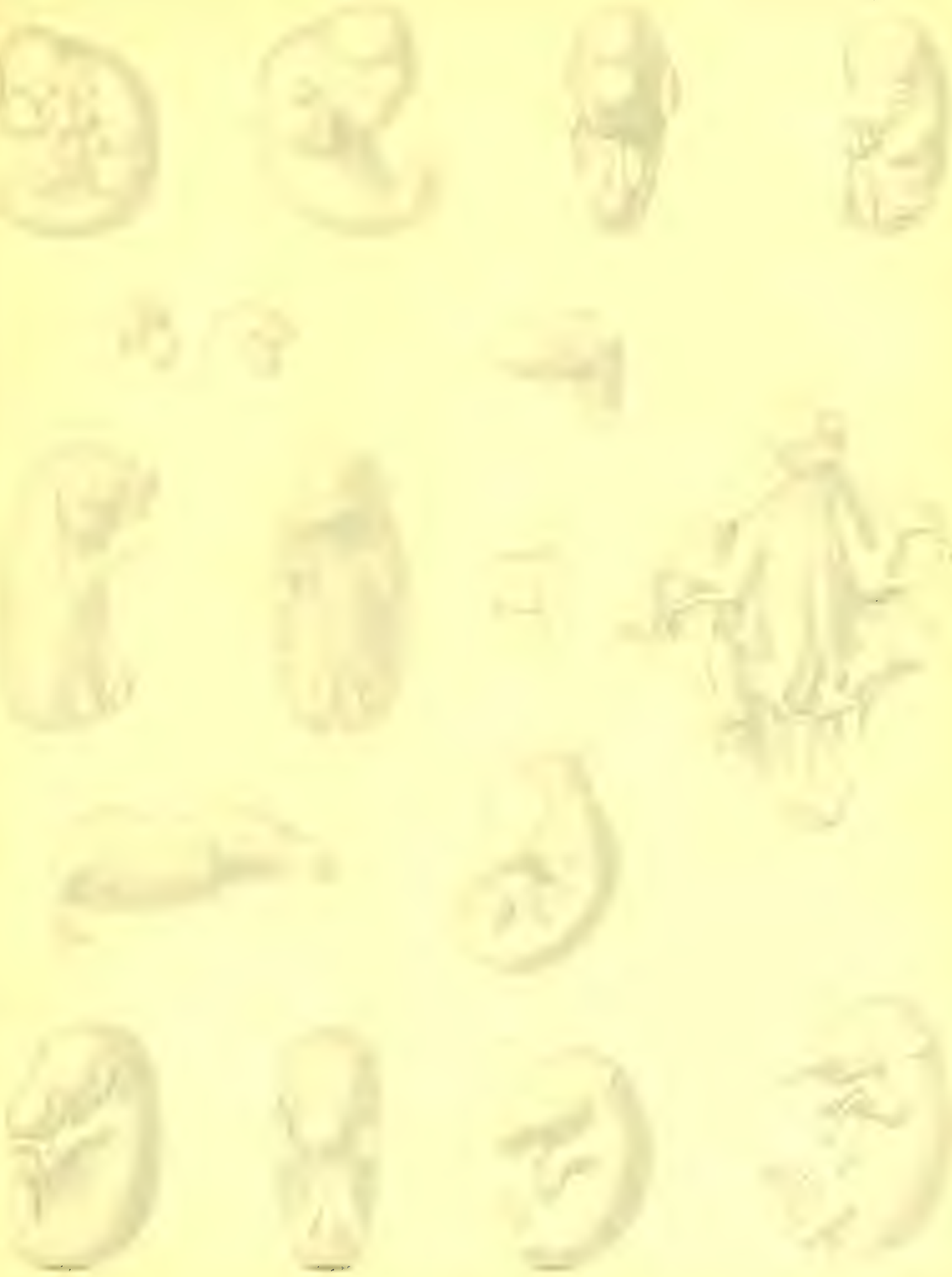


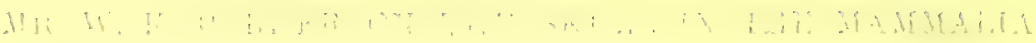

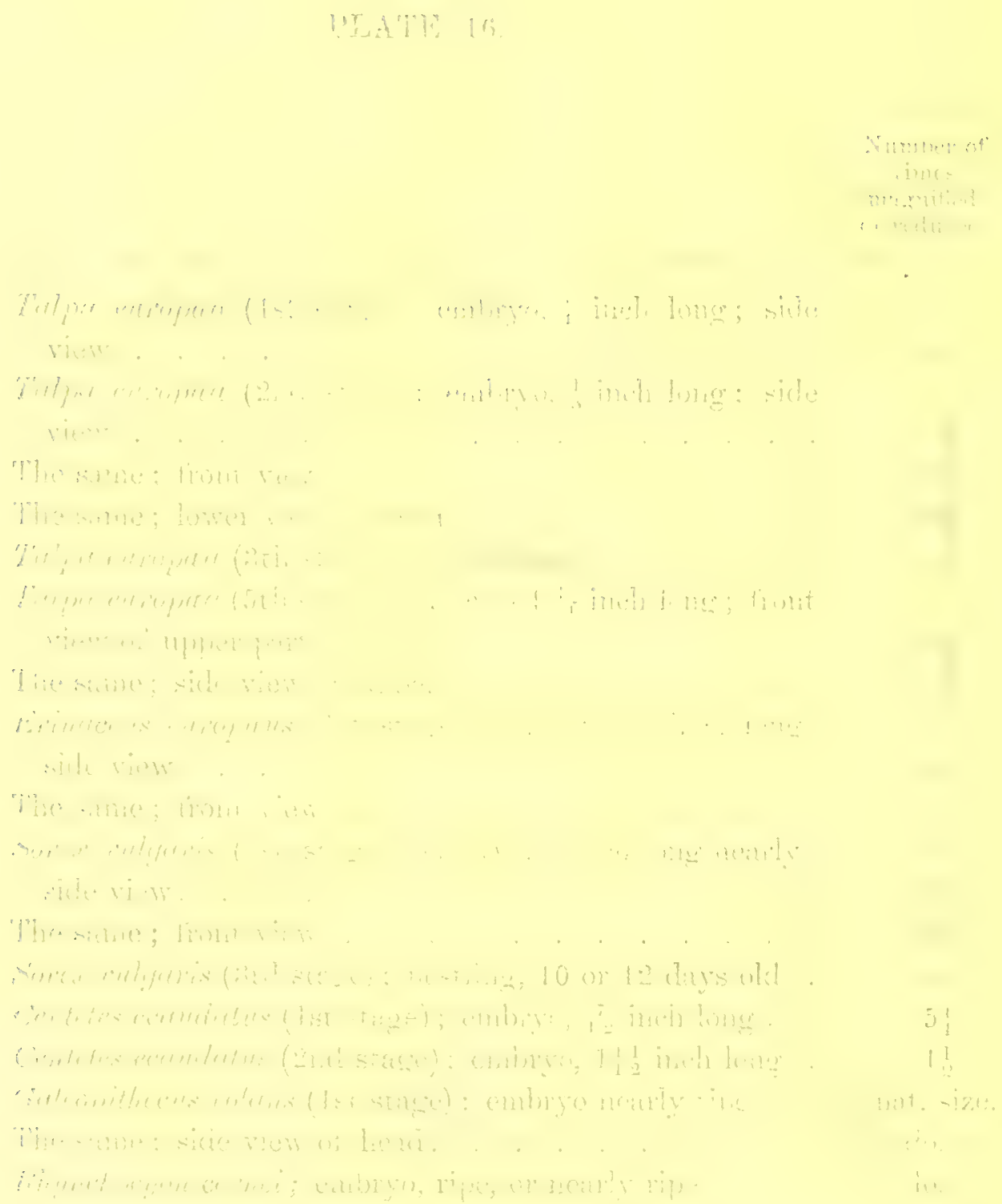




MR. IV. K, PARKER ON THE SKULL IN THE MAMMALIA.

PLATE 17 .

Figures.

Number of times magnificd.

I Einaceus europaus (1st stage); embryo, 1: inch long; endocranium; lower view . . . . . . . . . . 8

\begin{tabular}{l|l}
2 & The same; upper view . . . . . . . . . . . 8
\end{tabular}

:B Erincecus enropers (2nd stage); ripe young, $2 \frac{1}{4}$ inches long; dissected skull; lower view . . . . . . . . $66_{6}^{1}$ The sume; upper" view . . . . . . . . . . . . . . . . . . 6 The sime; side view . . . . . . . . . . . . . . . 6 The sime; end view . . . . . . . . . . . . $66_{15}^{1}$ The same; section . . . . . . . . . . . 60 The same; part of basal view, with hard palate removed $\quad 6{ }_{6}^{1}$ 

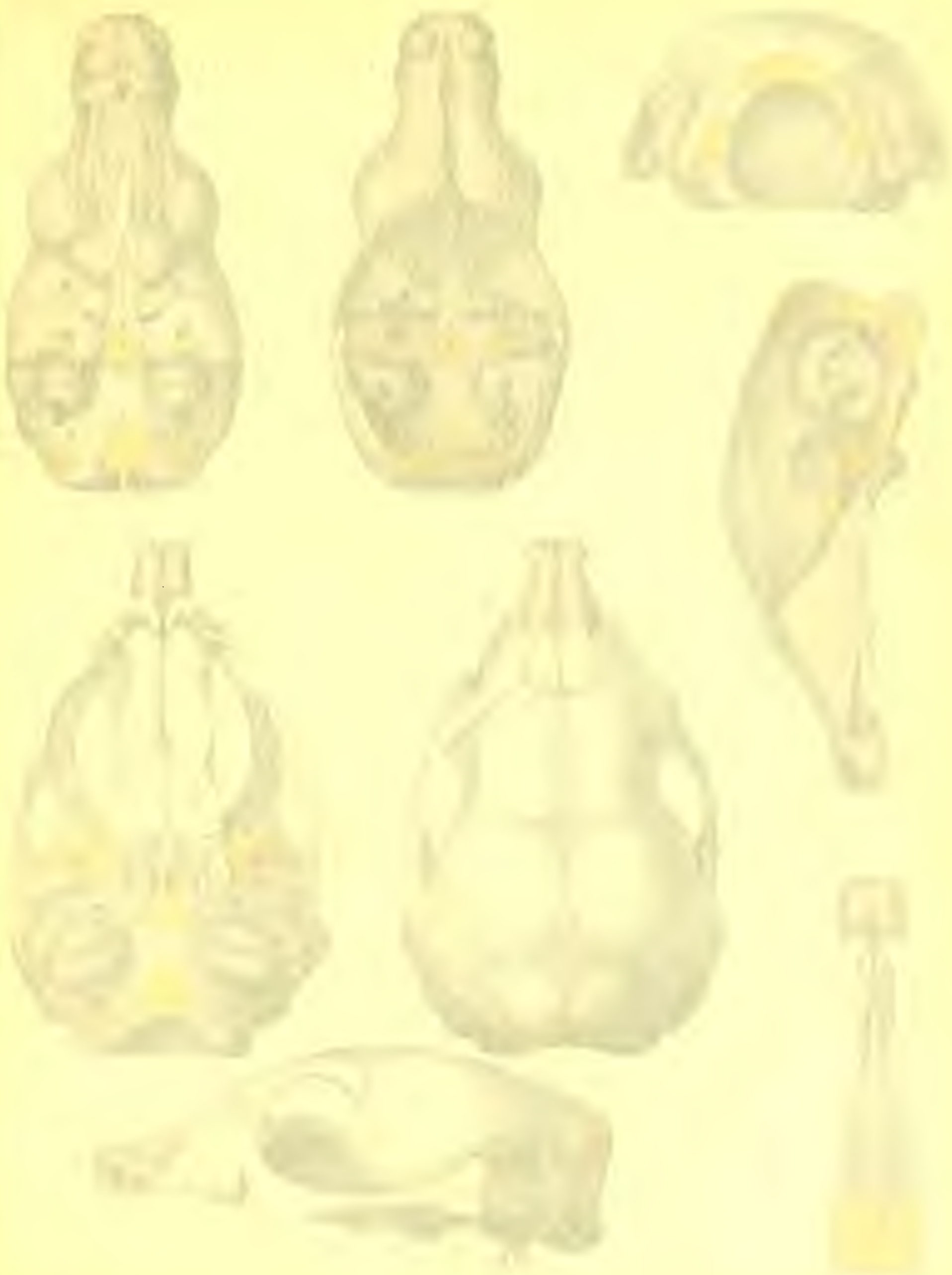


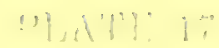

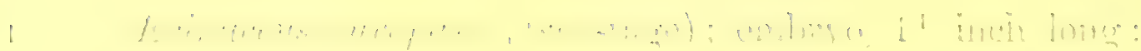

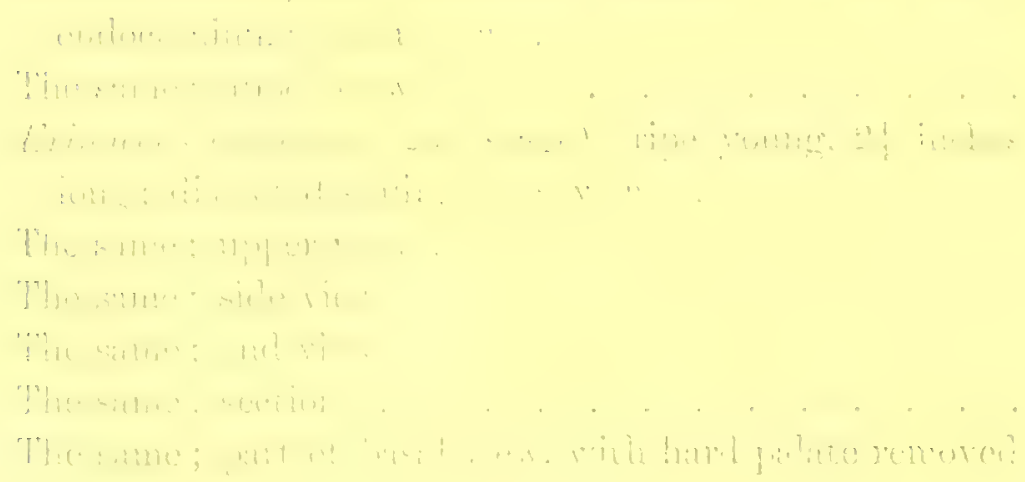


Phil 7rum 1885. Plate 17.
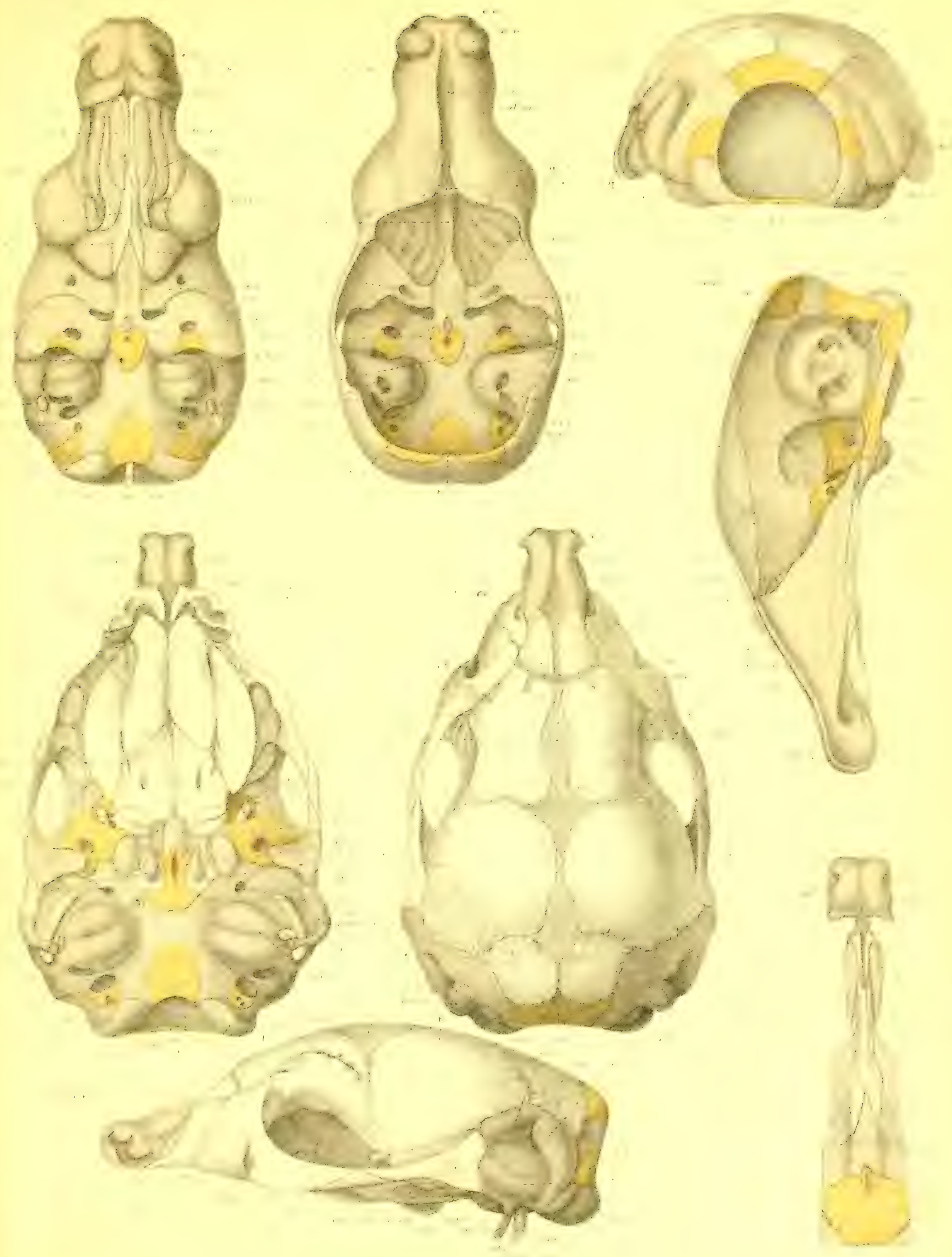

- 
MR. W. K. PARKER ON THE SKULL IN THE MAMMALTA.

PLA'TE 18.

\begin{tabular}{|c|c|c|c|c|c|c|c|}
\hline Figures. & & & & & & & $\begin{array}{c}\text { Number of } \\
\text { times } \\
\text { magnified. }\end{array}$ \\
\hline 1 & $\begin{array}{l}\text { Eininaceus curopaus (1st } \\
\text { 1st of a series of vertica }\end{array}$ & $\begin{array}{l}\text { stage) } \\
\text { ally-tran }\end{array}$ & $\begin{array}{l}\text {; embr" } \\
\text { unsverse }\end{array}$ & $\begin{array}{l}\text { ryo, } \\
\text { se sect }\end{array}$ & $\begin{array}{l}1 \frac{1}{4} \text { inch } \\
\text { etions. }\end{array}$ & long; & 11 \\
\hline 2 & The same; 2nd section. & . . . & . . . & . . & . . . & . . . & 11 \\
\hline 3 & The same; 3rd section. & . . . & . . . & . . & . . . & . . . & 11 \\
\hline 4 & The same; 4th section. & . . . & . . . & . . & . . . & . . . & 11 \\
\hline 5 & The same; 5th section. & . . . & . . . & . . & . . . &.$\quad$. & 11 \\
\hline 6 & The same; 6 th section. & . . . & . . . & . . & & . . . & 11 \\
\hline 7 & The same; 7 th section. & . . . & . . . & . . & . . . & . . . & 12 \\
\hline 8 & The same; 8th section. & & . . . & . . & . . . & . . . & 12 \\
\hline 9 & The same; 9th section. & . . . & . . . & & . . . & . . . & 12 \\
\hline 10 & The same; 10 th section & . . . & . . . & . . & . . . & . . . & 8 \\
\hline 11 & The same; 11th section & . . . & . . . & . . & . . . & . . . & 8 \\
\hline 12 & The same; 12th section & . . . & . . . & $\cdot$. & . . . & . . . & 8 \\
\hline 13 & The same; 13 th section & . . . & . . . & . . & . . . & . . . & 8 \\
\hline 11 & The same; 14th section & . . . & . . . & . . & . . . & . . . & 8 \\
\hline 15 & The same; 15 th section & . . . & . . . & $\cdot$ & . . . & . . . & 8 \\
\hline 16 & The same; 16th section & . . . & . . . & . . & . . . & . . . & 8 \\
\hline 17 & The same; 17 th section & . . . & . . . & $\cdot$. & . . . & . . . & 8 \\
\hline 18 & The same; 18 th section & . . . & . . . & . . & . . . & . . . & 8 \\
\hline 19 & The same; 19th section & . . . & . . . & . . & . . . & . . . & 8 \\
\hline 20 & 'The same; 20th section & . . . & . . . & . $\cdot$ & . . . & . . . & 8 \\
\hline 21 & The same; 21st section & . . . & . . . & $\cdot$. & . . . & . . . & 8 \\
\hline 22 & The same; 22nd section &.$\quad$. & . . . & . & . . & . . . & 8 \\
\hline
\end{tabular}


PhilTrons 1885. Plate 18.
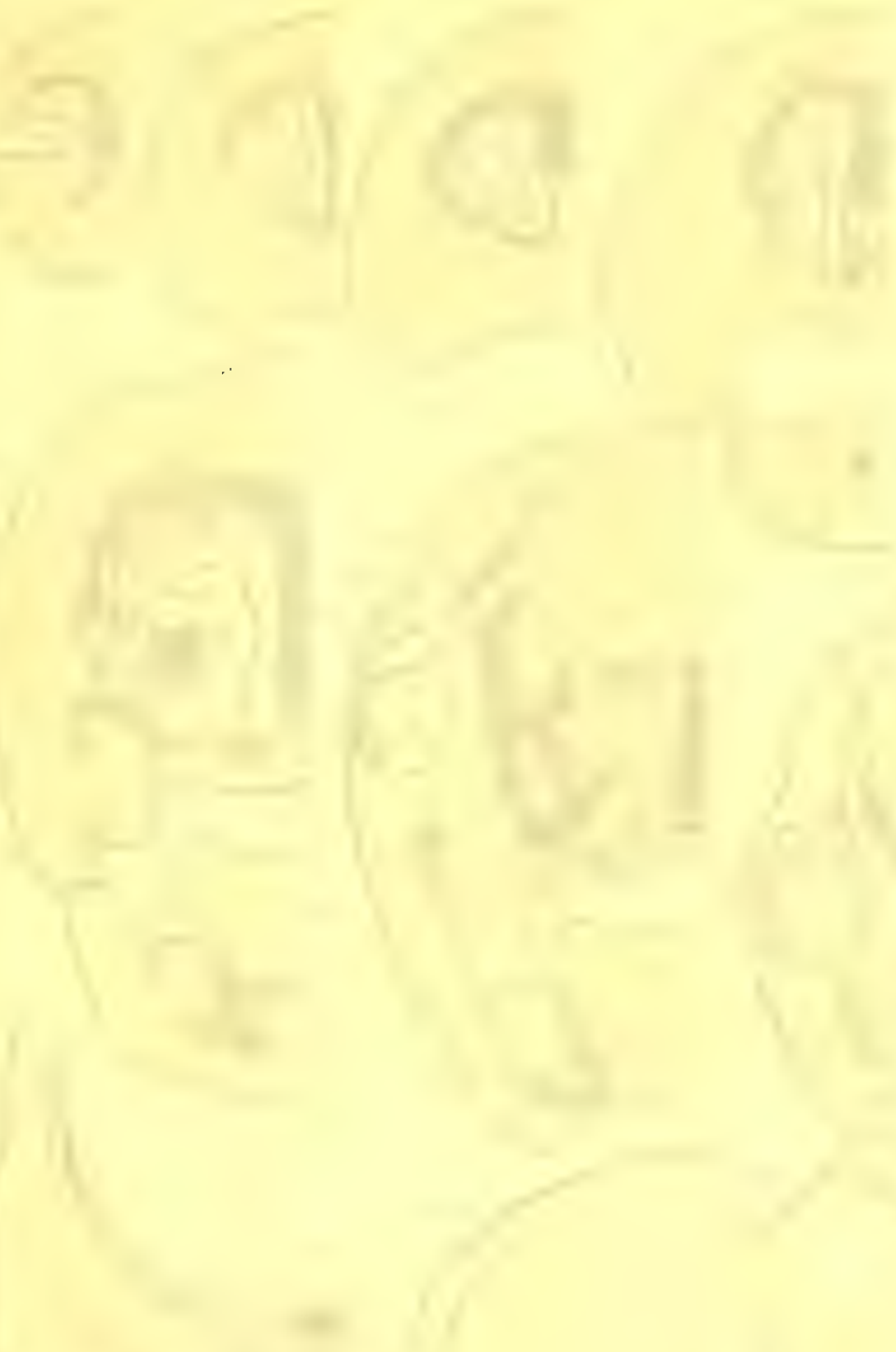


\section{IPI'He ts}

Finde of

armich is

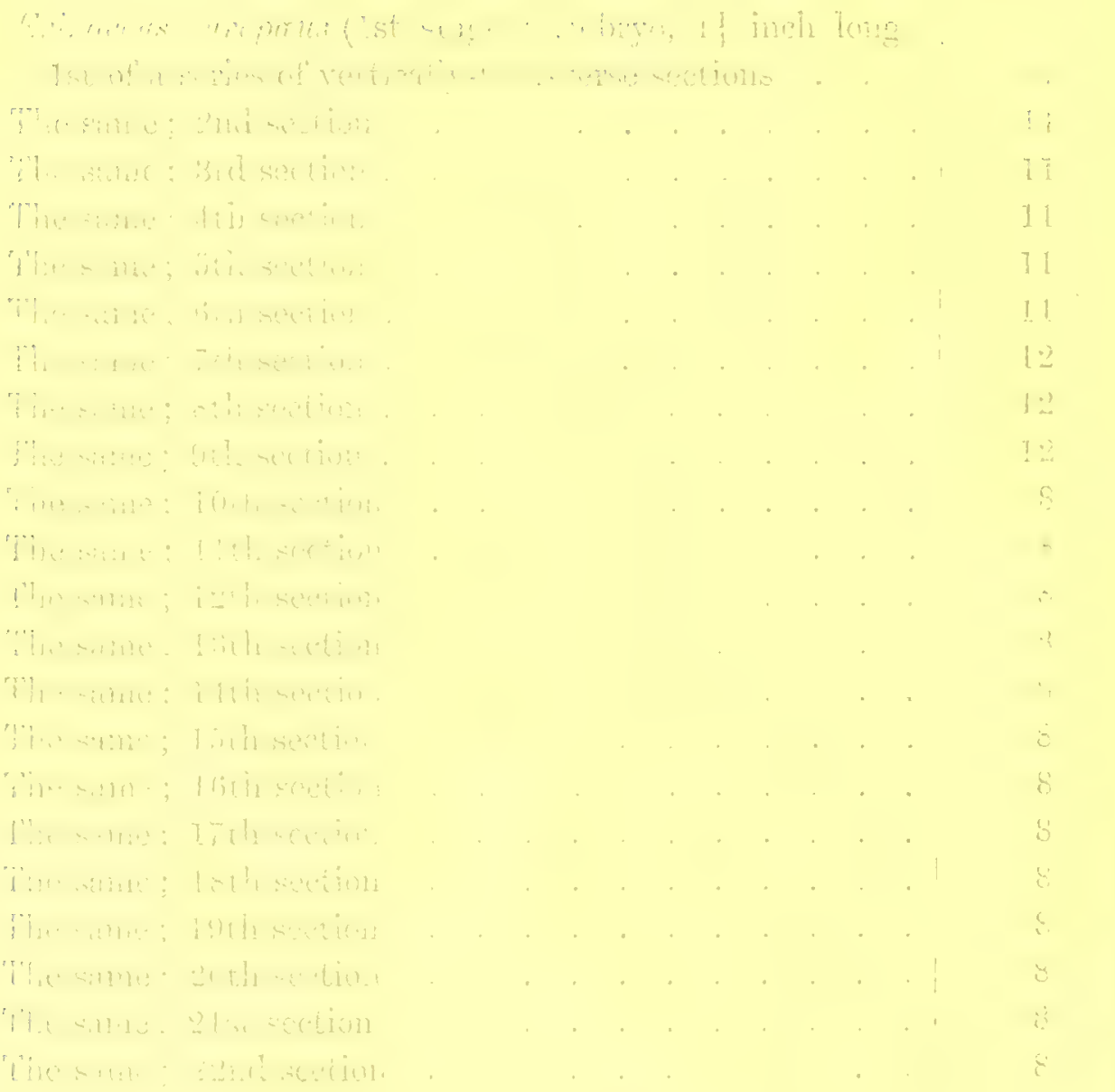



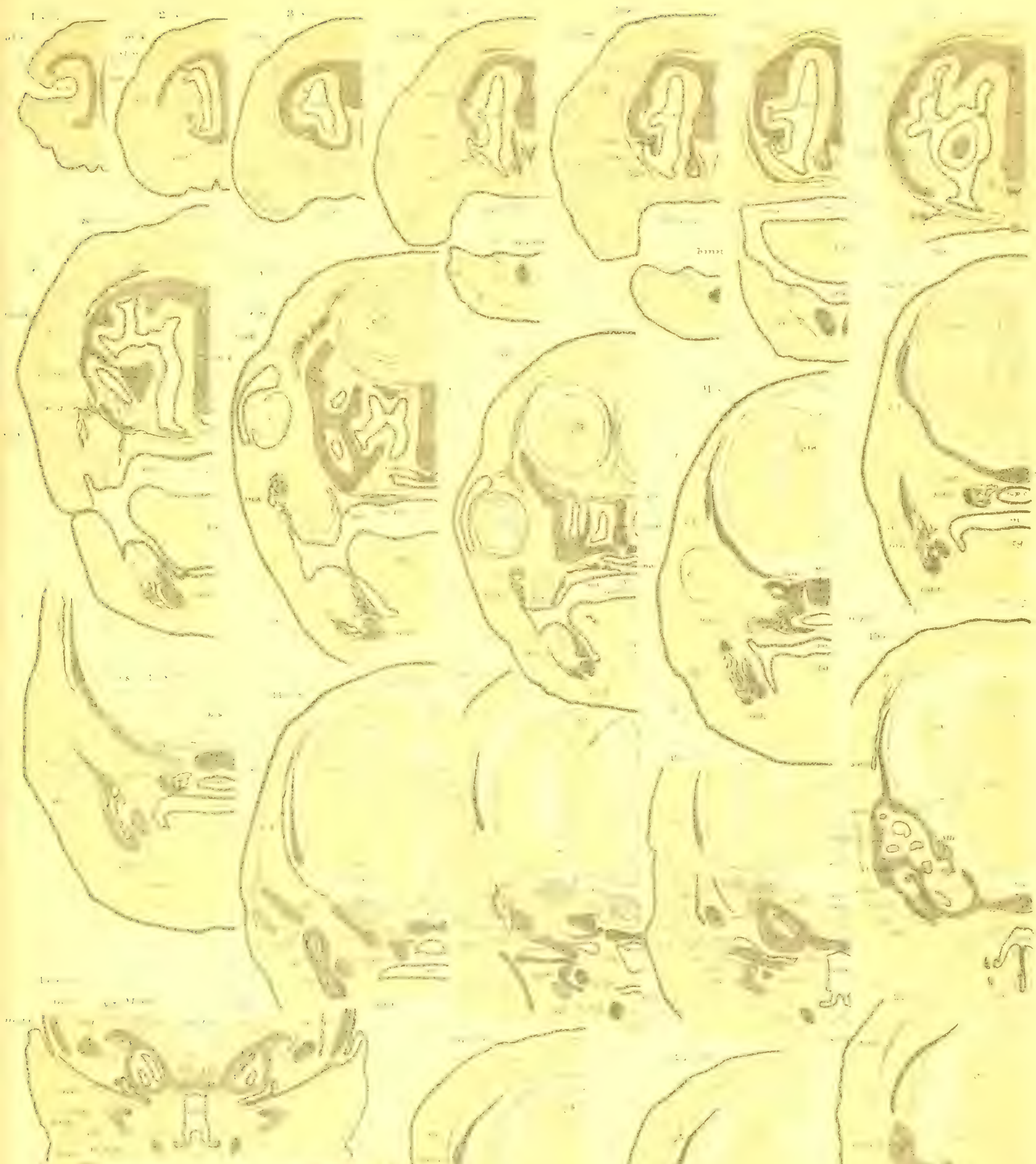

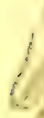






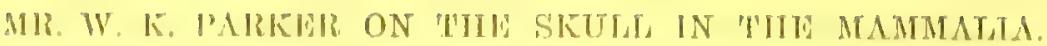

PIAT'T 19

\begin{tabular}{|c|c|c|}
\hline lindra: & & $\begin{array}{l}\text { Number of } \\
\text { limes } \\
\text { mamnifiod. }\end{array}$ \\
\hline 1 & 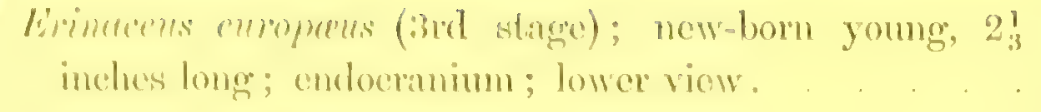 & $\vdots$ \\
\hline$\because$ & 'The sime; "1plex view . . . . . . . . . . . & .5 \\
\hline$: ;$ & 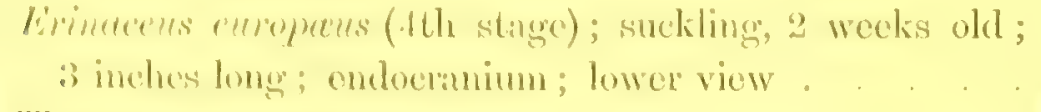 & .1 \\
\hline 1 & 'Tho stmo; пррес riow . . . . . . . . . . . & 1 \\
\hline .1 & 'Tho sime; part of endoctminm; upper viow . . . . & .1 \\
\hline ii & 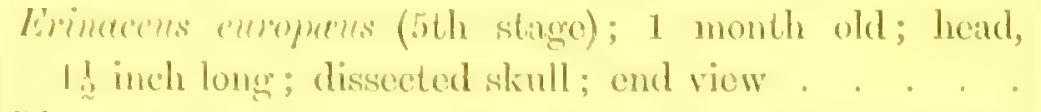 & $\because ;$ \\
\hline$\because$ & $\begin{array}{l}\text { The same; part of codocranim, with some splints } \\
\text { rotaned; lower view }\end{array}$ & $: 3$ \\
\hline$\therefore$ & The simo; section of skull . . . . . . . . . . . & $\therefore$ \\
\hline$!$ & Tho simo; part of skull; outer view of auditory region . & $\because$ \\
\hline
\end{tabular}



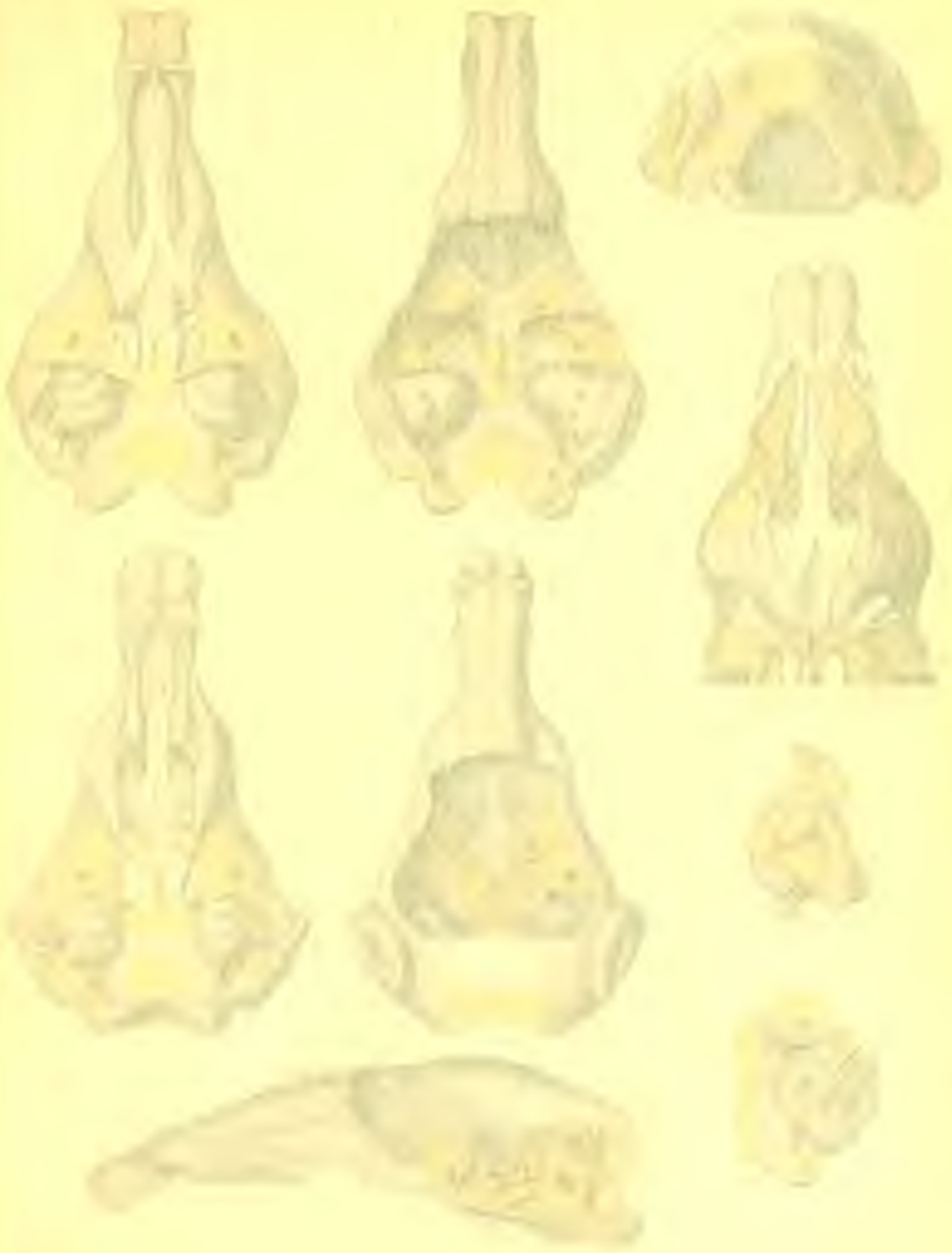


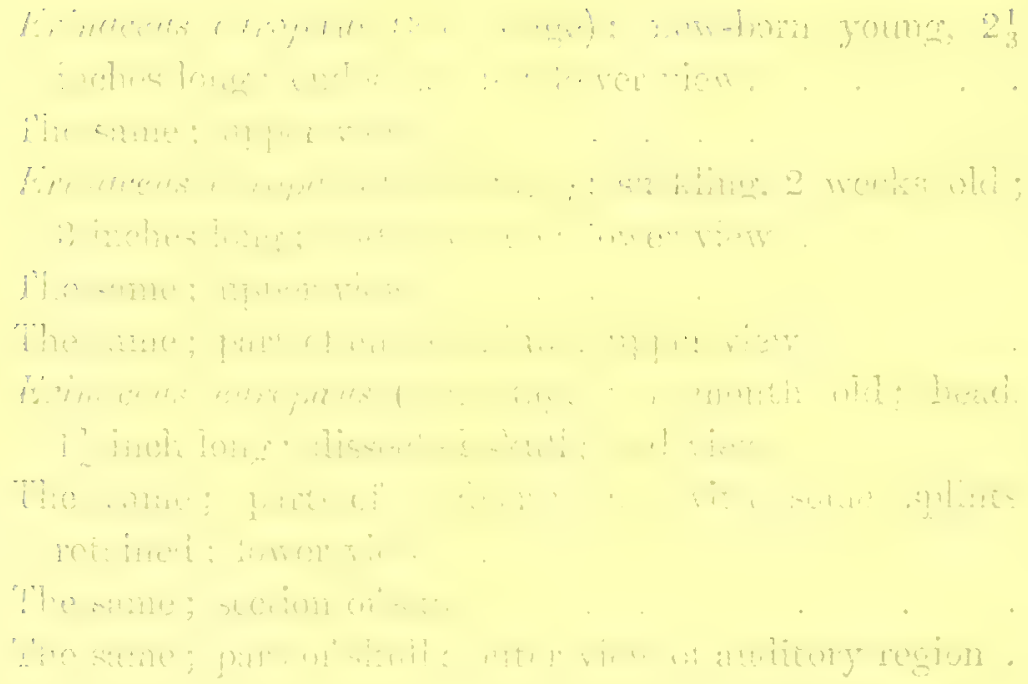




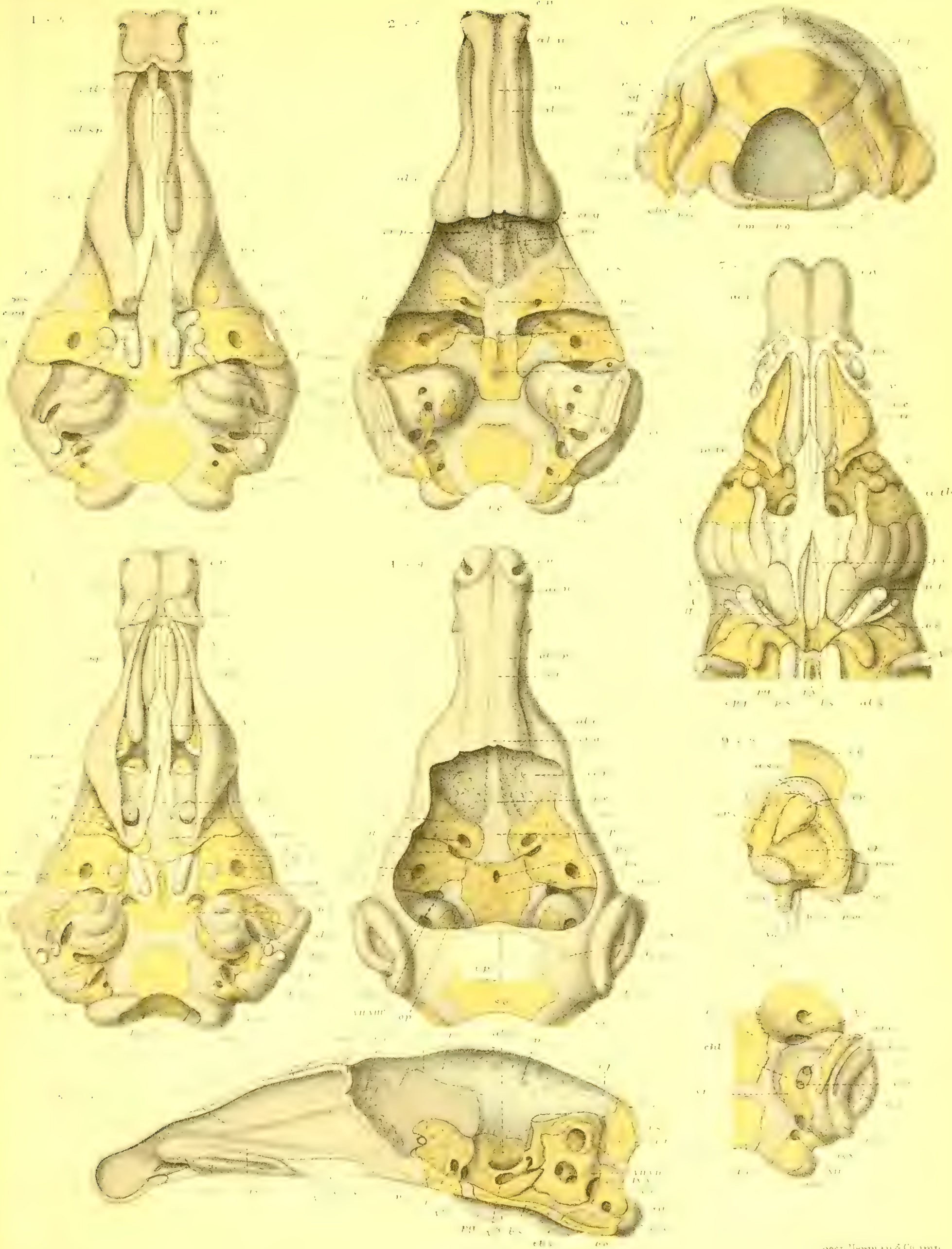



IIR. W. K. PARKER ON THE SKULL IN THE MAMMALIA.

PLATE 20.

\begin{tabular}{|c|c|c|}
\hline Figures. & & $\begin{array}{l}\text { Number of } \\
\text { times } \\
\text { magnified. }\end{array}$ \\
\hline 1 & $\begin{array}{l}\text { Erinaceus curopare (5th stage, continued); skull; lower } \\
\text { view . . . . . . . . . . . . . . }\end{array}$ & 3 \\
\hline 2 & The same; upper view . . . . . . . . . . . . & 3 \\
\hline 3 & The same; side view . . . . . . . . . . . . & 3 \\
\hline 4 & $\begin{array}{l}\text { Erinaceus europaeus (6th stage); young, } \frac{2}{3} \text { grown; section } \\
\text { of skull . . . . . . . . . . . . . . . . }\end{array}$ & $2 \frac{2}{3}$ \\
\hline 5 & The same (part); with septum removed . . . . . . & $2 \frac{2}{3}$ \\
\hline 6 & $\begin{array}{l}\text { Erinaceus europous (Sth stage); sub-adult; posterior } \\
\text { sphenoid; upper view . . . . . . . . . . . }\end{array}$ & $2 \frac{1}{2}$ \\
\hline 7 & 'The same; lower view . . . . . . . . . . . . & $2 \frac{1}{2}$ \\
\hline 8 & The same; end view, behind. . . . . . . . . . & $2 \frac{1}{2}$ \\
\hline 9 & The same; inferior (maxillary) turbinals; front view . . & $2 \frac{1}{2}$ \\
\hline 10 & The same; internal view . . . . . . . . . & $2 \frac{1}{2}$ \\
\hline
\end{tabular}



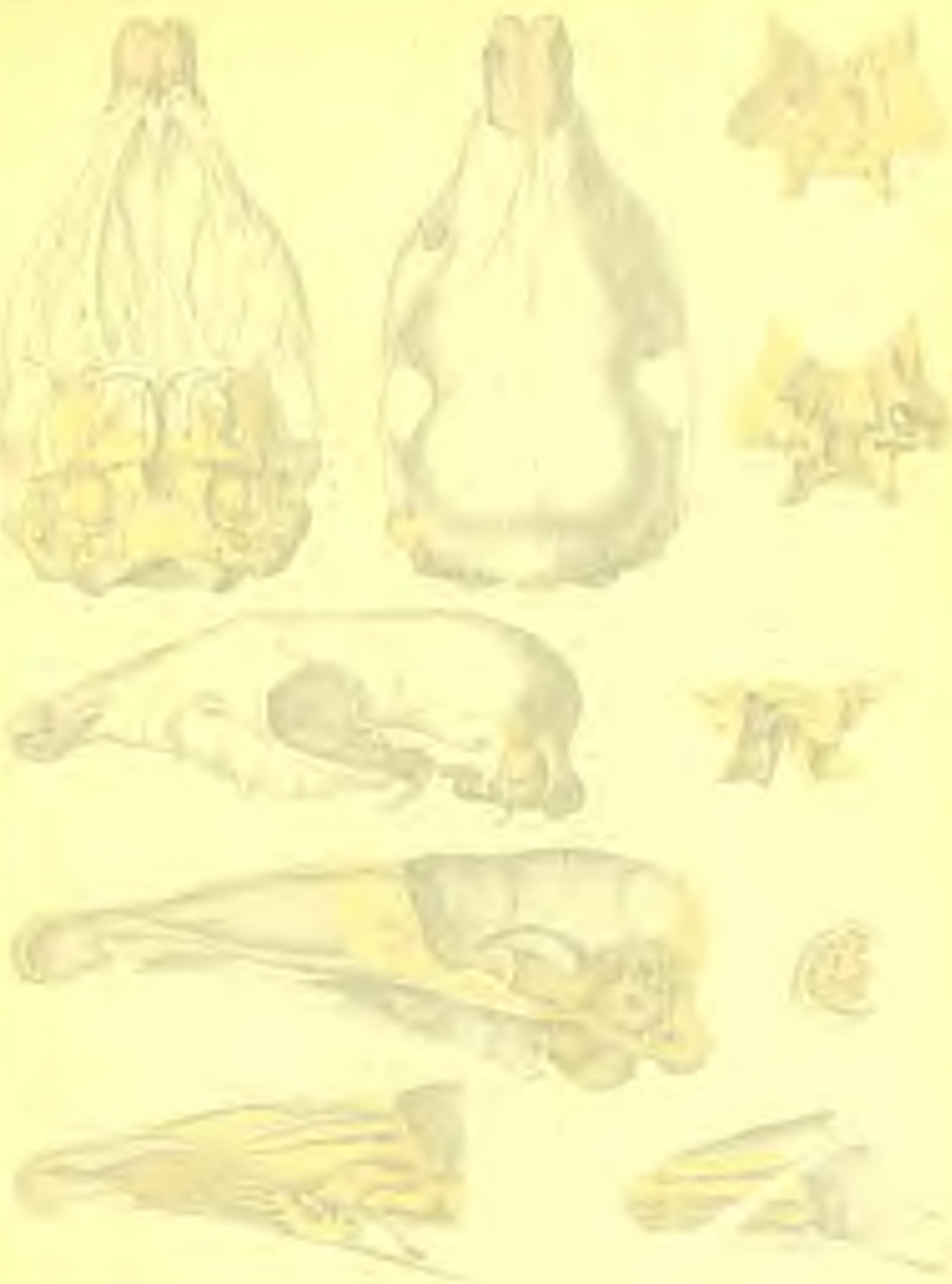


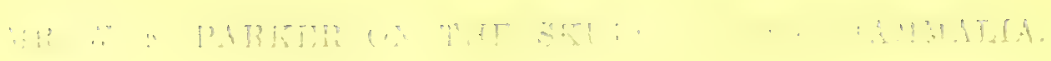

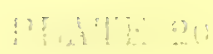

1.11, 1

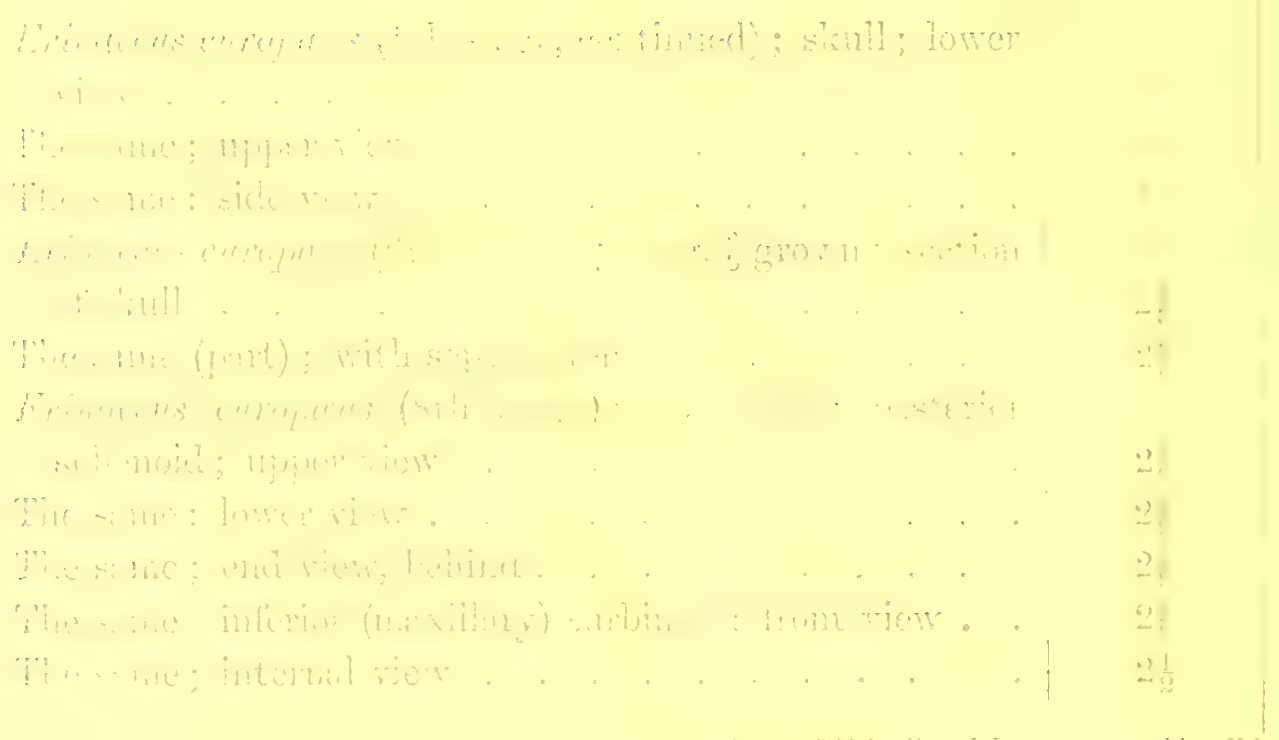




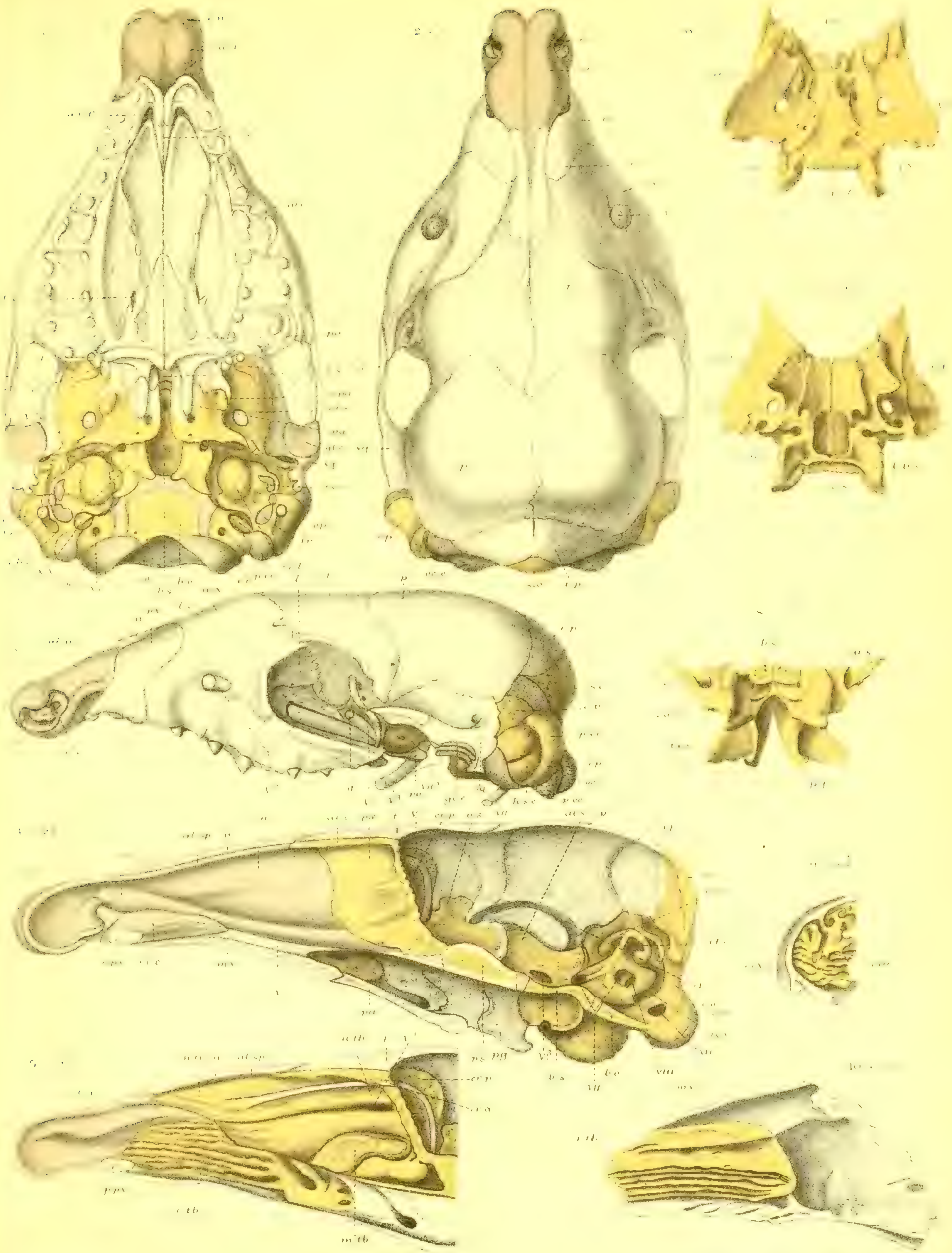




MR. W. K. PARKER ON THE SKULL IN THE MAMMALIA.

PLA'TE 21.

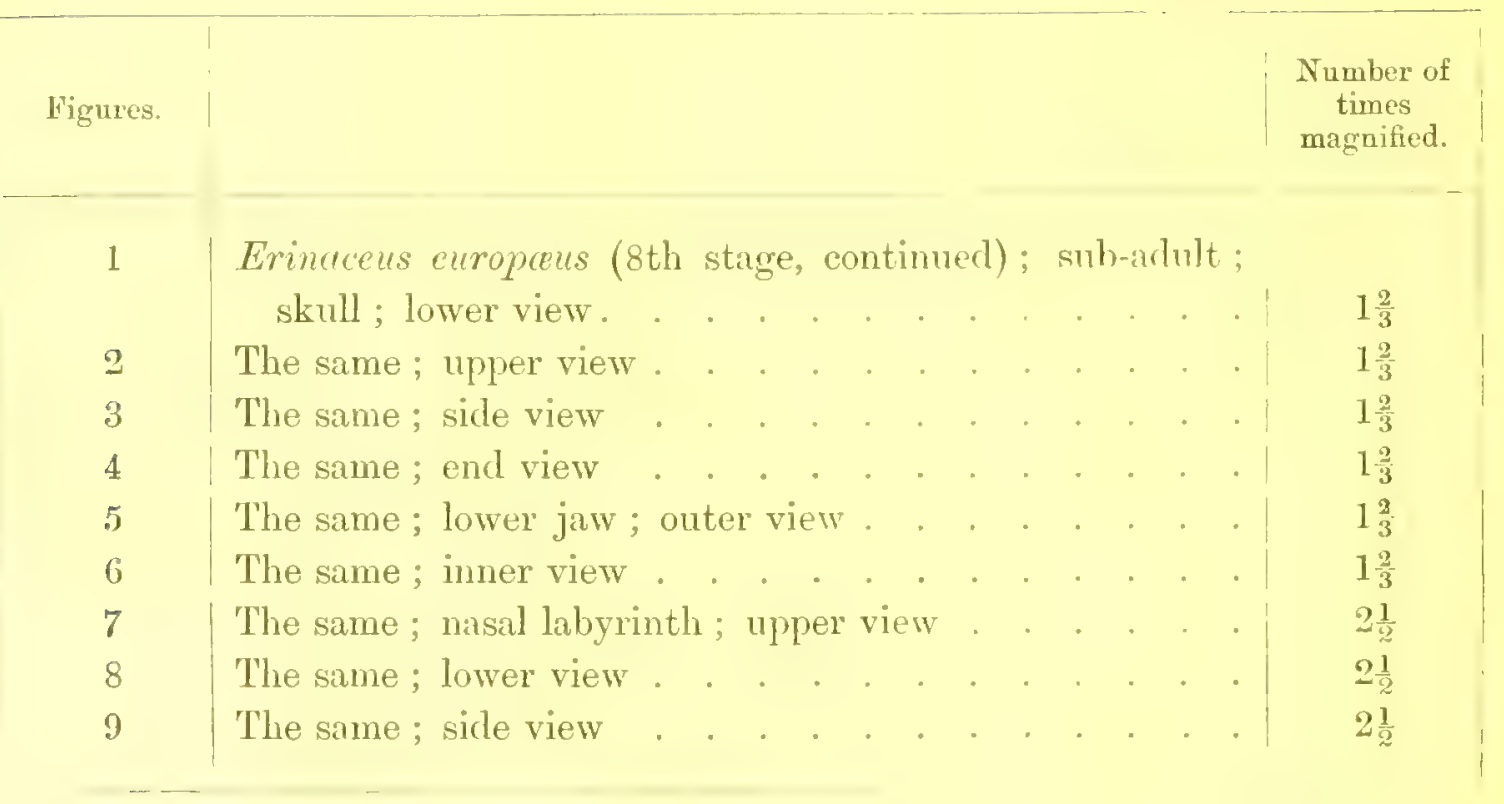



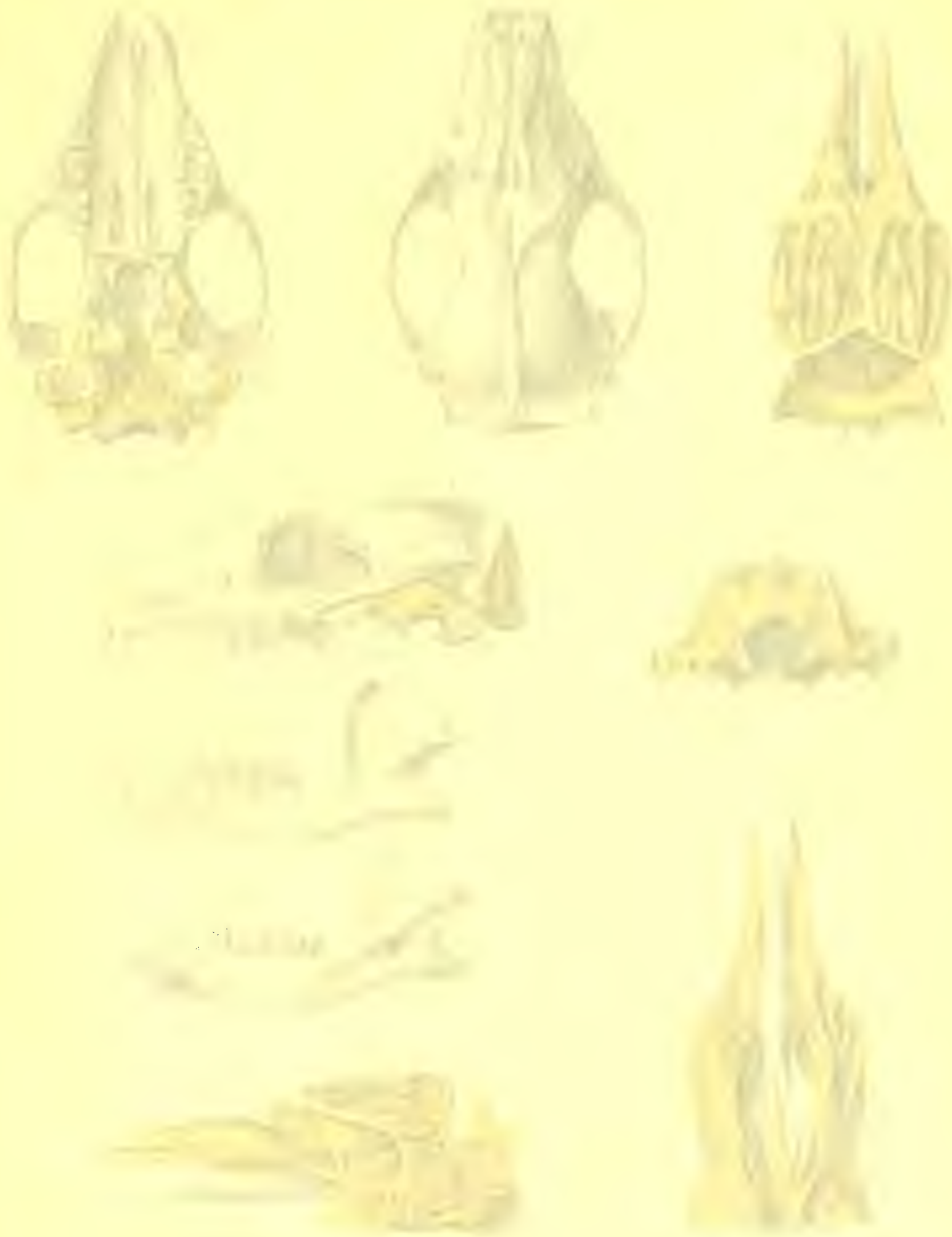

Ërrautus. 


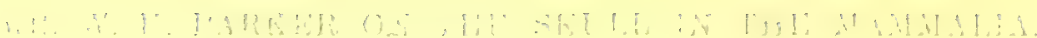

Simmixu of

tim :

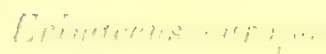

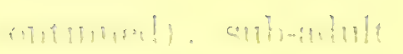

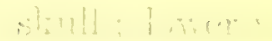

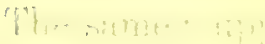

'Ille silly

"Thes

'The rits.

[1]. sx+111,

Filize solnes

?!! $2: 4,114$ 

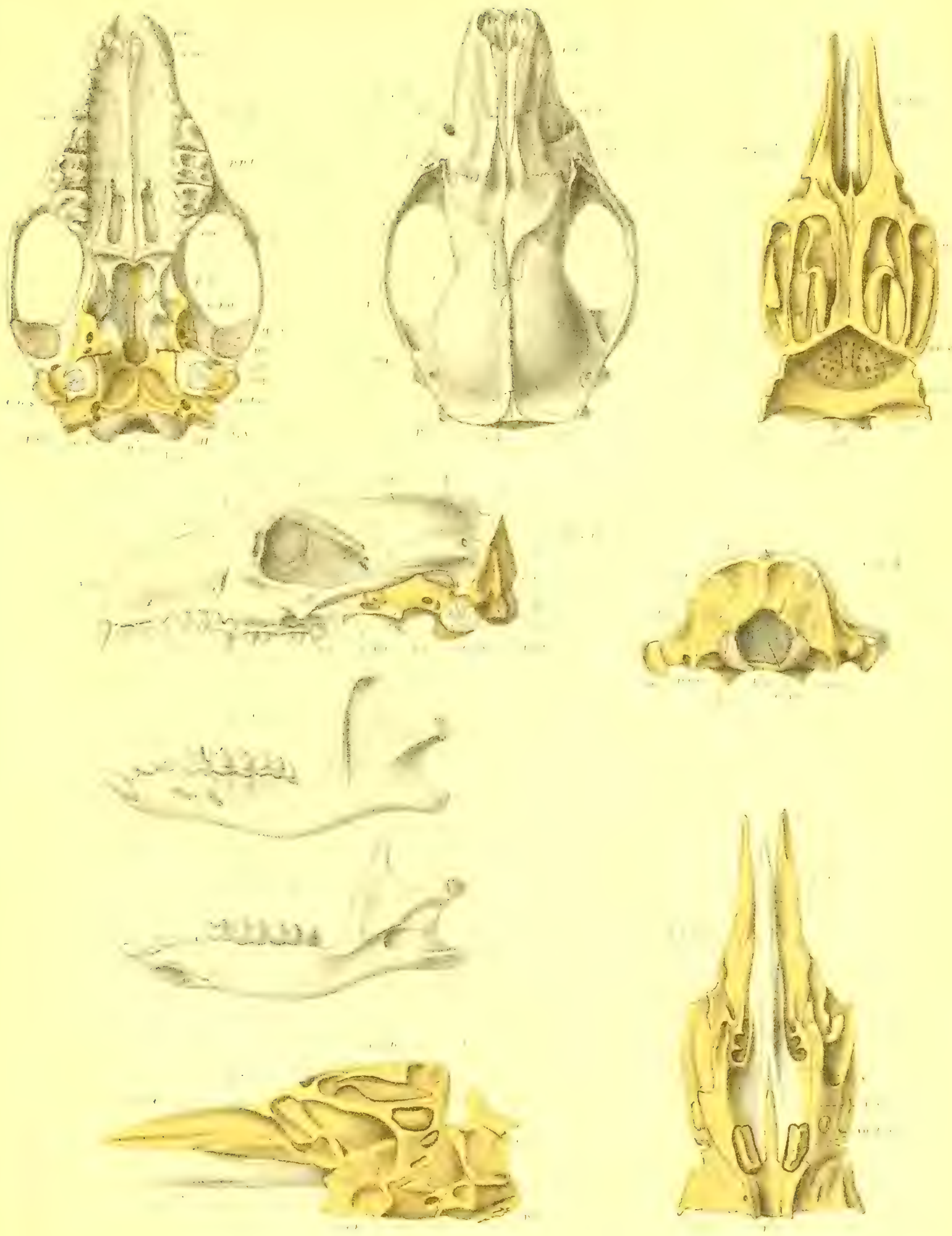


PLATE 22.

\begin{tabular}{|c|c|c|}
\hline Figrures. & & $\begin{array}{l}\text { Number of } \\
\text { times } \\
\text { magnified. }\end{array}$ \\
\hline 1 & $\begin{array}{l}\text { Erinceus europous (a series of stages of visceral arches); } \\
\text { deep and superficial mandible and ear-drum; inner } \\
\text { viev (1st stage); embryo; } 1 \frac{1}{4} \text { inch long . . . . . }\end{array}$ & 8 \\
\hline 2 & The same; fore part of deep mandible; upper view . . & 16 \\
\hline 3 & The same; hyoid arch; oblique view . . . . . . . & 8 \\
\hline 4 & $\begin{array}{l}\text { 2nd stage; embryo; } 2 \frac{1}{4} \text { inches long; deep and super- } \\
\text { ficial mandible; and ear-drum; inner view . . . . }\end{array}$ & 6 \\
\hline 5 & $\begin{array}{l}\text { 3rd stage; ripe young; } 2 \frac{1}{3} \text { inches long; the same parts; } \\
\text { imner view . . . . . . . . . . . . . }\end{array}$ & $5 \frac{1}{3}$ \\
\hline 6 & The same; hyoid arch; npper view. . . . . . . . & $5 \frac{1}{3}$ \\
\hline 7 & $\begin{array}{l}\text { thl stage; young, } 2 \text { weeks old; the same parts; inner } \\
\text { view . . . . . . . . . . . . . . }\end{array}$ & 4 \\
\hline 8 & 5th stage; head, $1 \frac{1}{2}$ inch long; same parts; inner view . & 3 \\
\hline 9 & The same; hyoid arch; upper view. . . . . . . . & 3 \\
\hline 10 & 7th stage; 3 grown ; ear-clrum ; outer view . . . . . & 8 \\
\hline 11 & The same; inner view . . . . . . . . . . . . & 8 \\
\hline 12 & Sth stage; adult; malleus; outer view . . . . . . & 8 \\
\hline 13 & The same ; amnulus tympanicus; outer view. . . . . & 8 \\
\hline 14 & The sime; hyoid arch; upper view . . . . . . . & $2 \frac{2}{3}$ \\
\hline
\end{tabular}



PLATE 23.

Figures.

Number of

times

magnified.

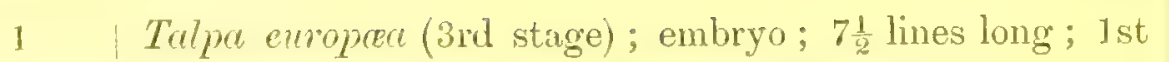
of a series of vertically-transverse sections . . . . | 13

$2 \quad$ The same; 2nd section . . . . . . . . . . 13

3 | The same; 3rd section . . . . . . . . . . 13

4 | The same; 4th section . . . . . . . . . 13

5 The same; 5th section . . . . . . . . . . 13

6 The same; 6th section . . . . . . . . . . 13

7 The same; 7 th section . . . . . . . . . . 13

8 The same; 8th section . . . . . . . . . 13

$9 \quad$ The same; 10th section . . . . . . . . . 13

10 The same; 11 th section . . . . . . . . . . 13

11 The same; 12 th section . . . . . . . . . . 13

12 | The same; 9 th section . . . . . . . . . . 13

13 The same; 13 th section . . . . . . . . . . 13

14 The same; 14 th section . . . . . . . . . 13

15 The same; 15 th section . . . . . . . . . | 13

16 Tulpa europece (4th stage); embryo; $\frac{3}{4}$ inch long; 1 st of a series of vertically-transverse sections . . . . 13

17 The same; 2nd section. . . . . . . . 13

18 The same; 3 rd section . . . . . . . . . . 13

19 'The same; 4th section . . . . . . . . . . . 13

20 The same; 5 th section . . . . . . . . . . . 13

21 The same; 6th section . . . . . . . . . | 13

22 The same; 7th section. . . . . . . . . . . 13

23 The same; sth section . . . . . . . . . . 13

24 The same; 9th section. . . . . . . . . . 13

25 The same; 10 th section . . . . . . . . . 13 


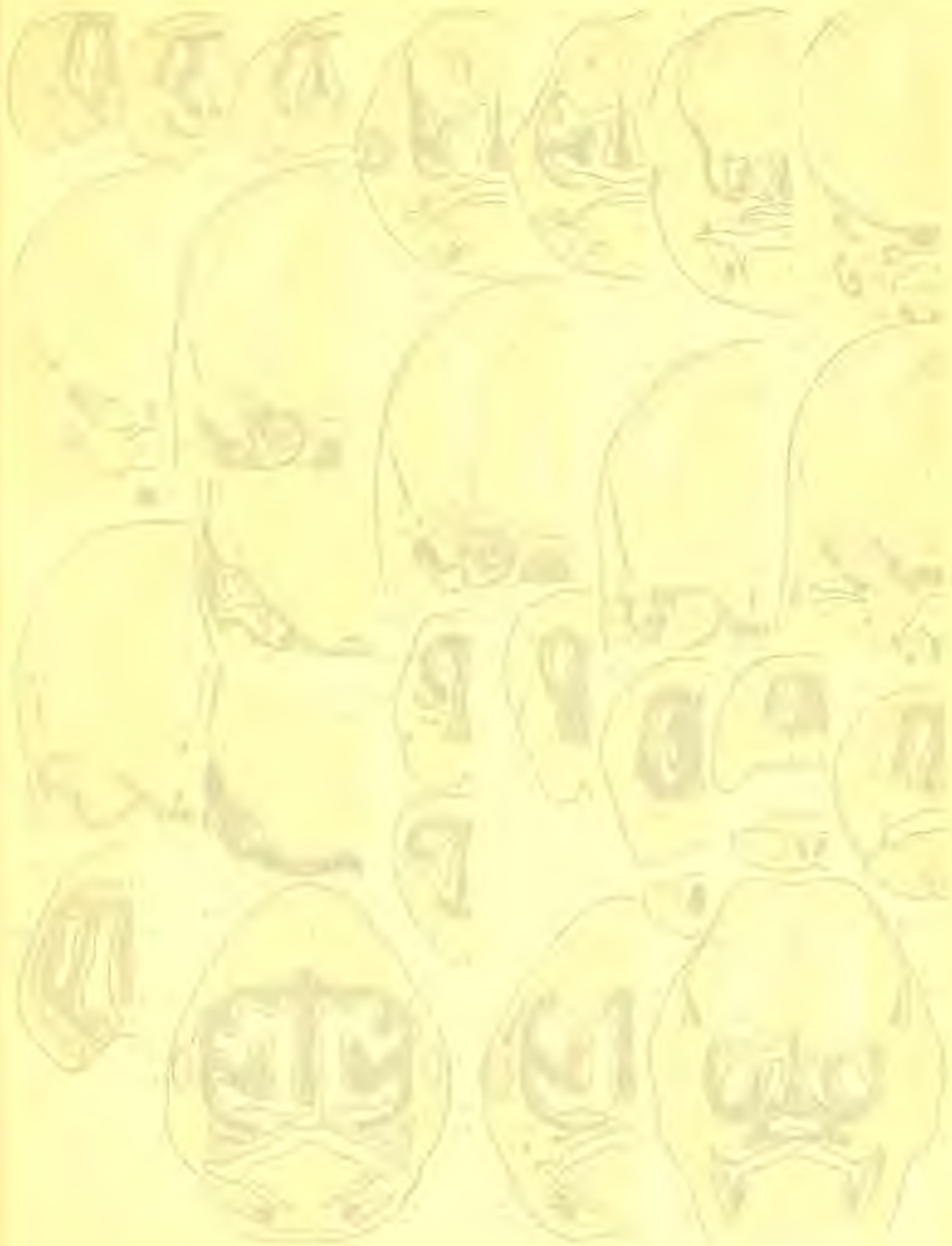




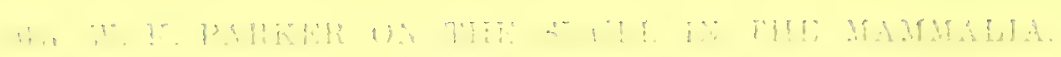

H.:

Simminer of

times

mignitied.

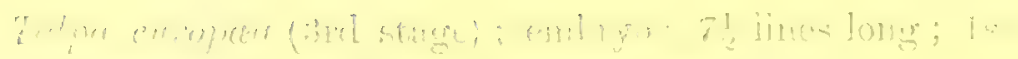

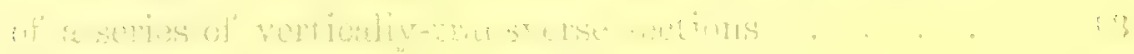

Thes sume; Hent section.

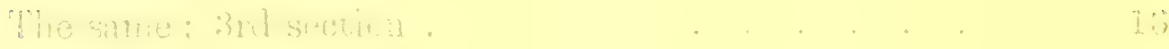

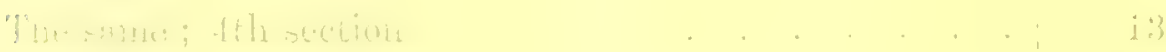

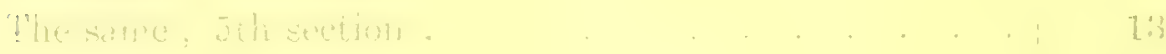

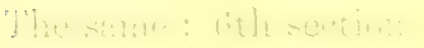

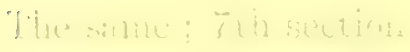

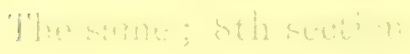

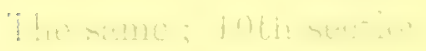

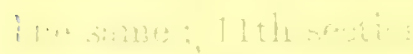

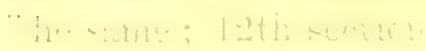

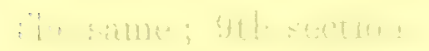

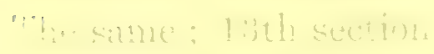

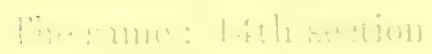

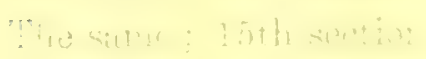

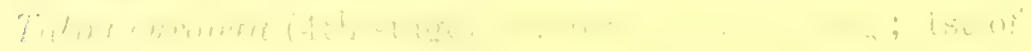

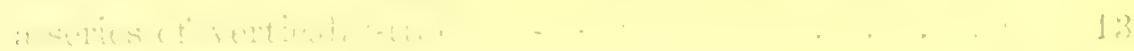

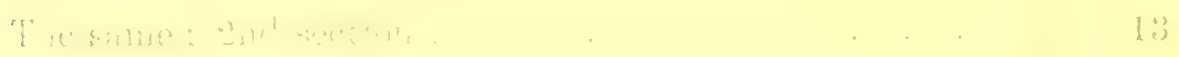

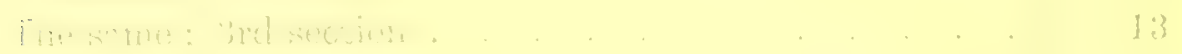

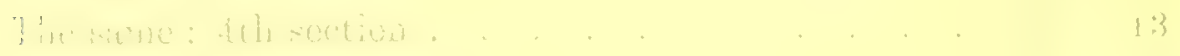

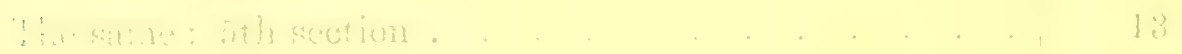

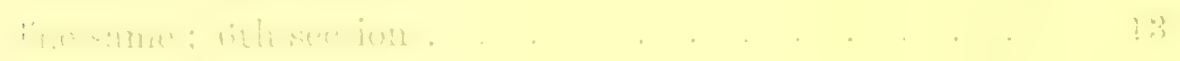

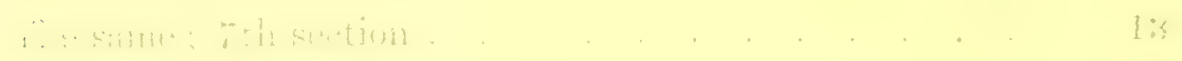

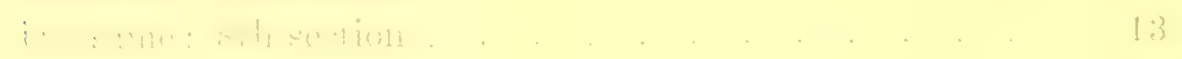

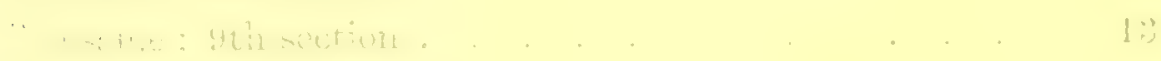

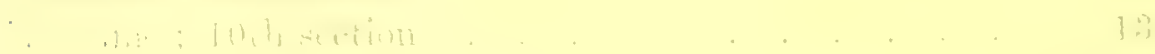




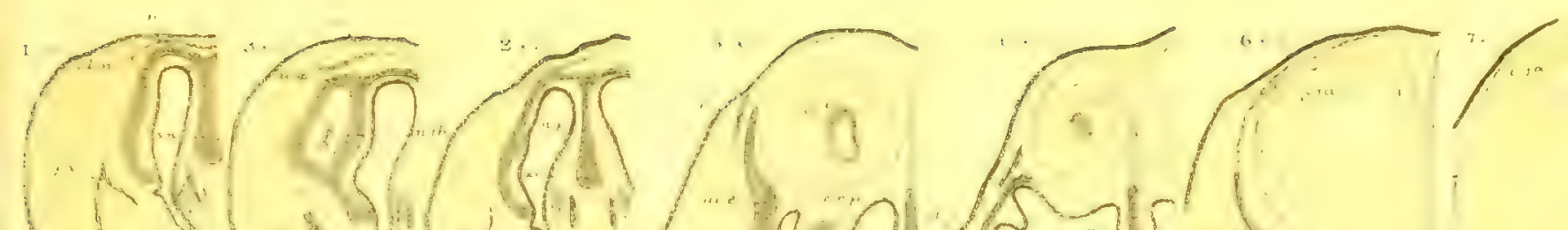

(1)
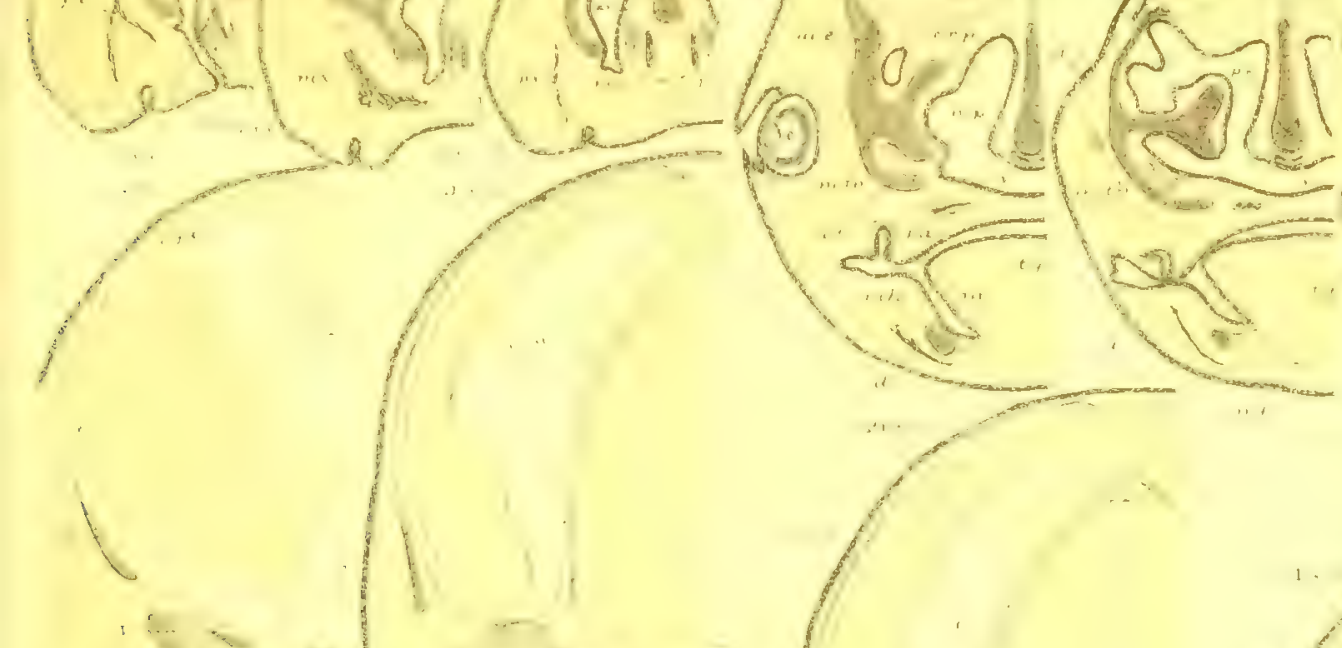


MR. W. K. PAREER ON THE SKULL IN THE MAMMALIA.

PLA'TE 24.

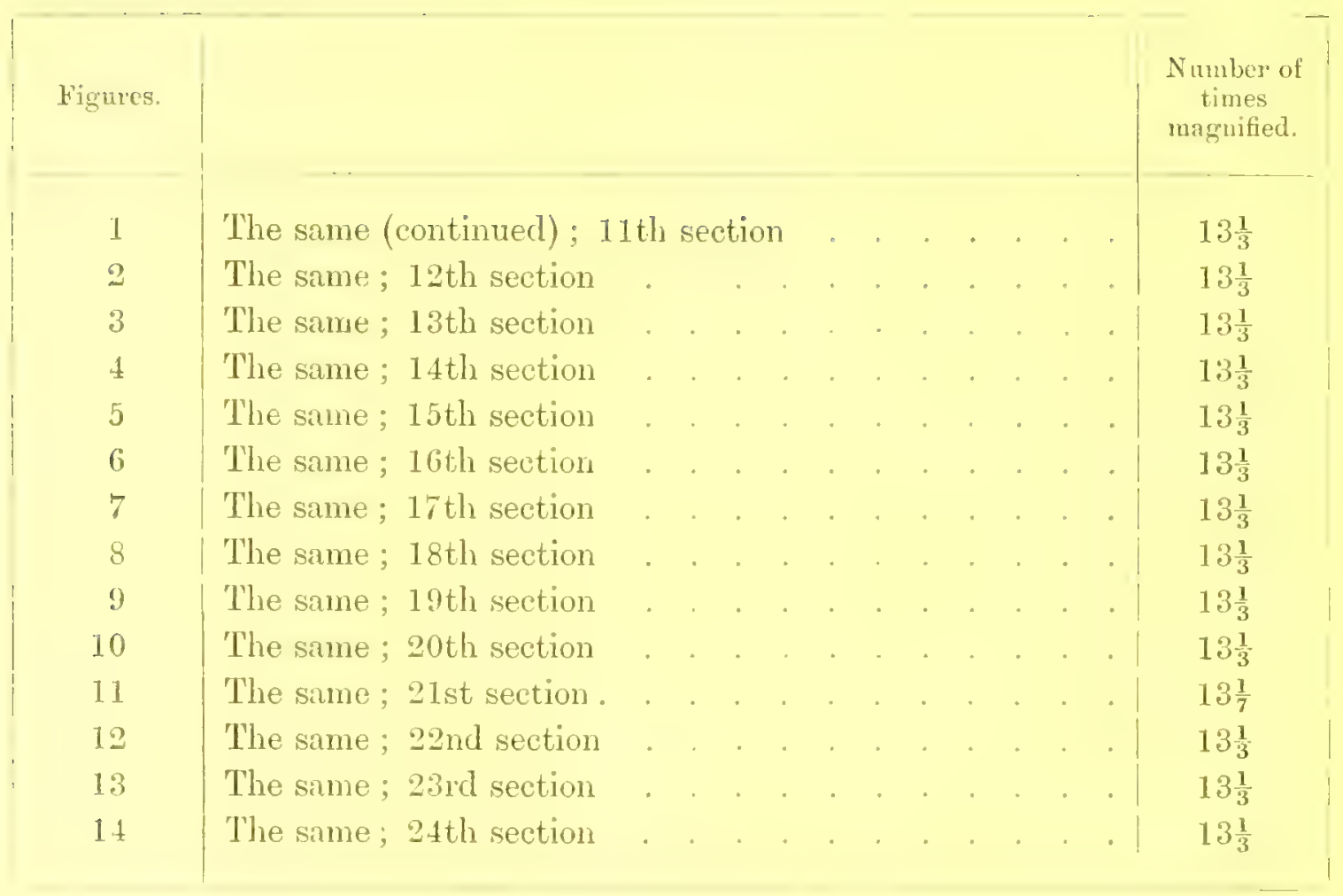



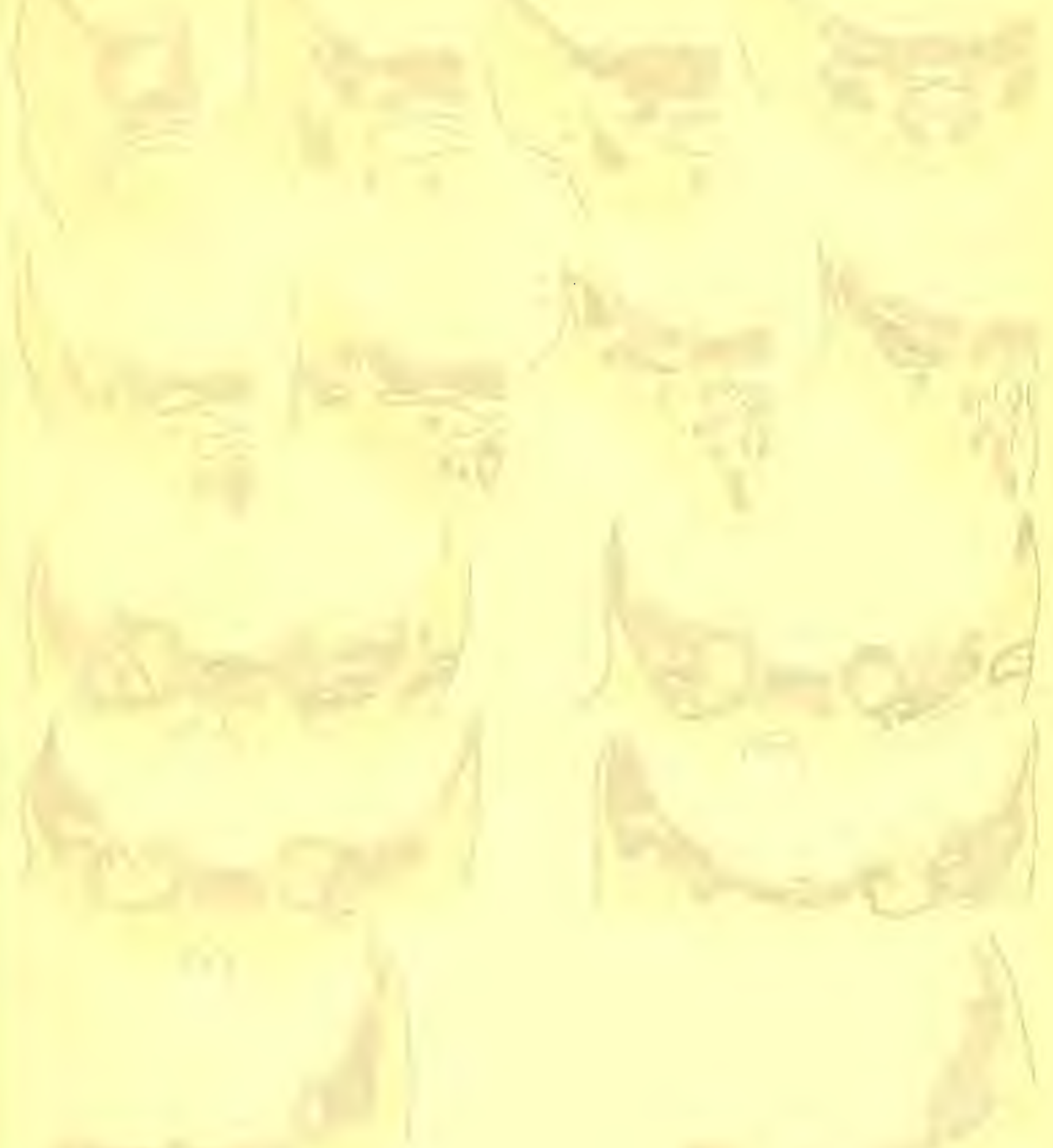


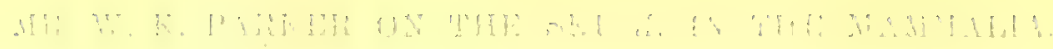

E'I.: "il'

$\therefore+1+1+\cdots$

tim:

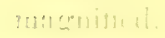

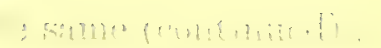

-illix: :

S. Sillit :

$-i+11:+:$

1: $-1111+$ :

2:1!11:

:4n

$\because 11113^{\circ}$ :

viline the : ate:

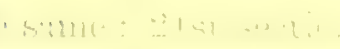

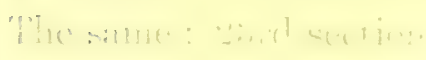

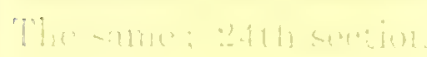



PLATE 25.

\begin{tabular}{|c|c|c|}
\hline Figures. & & $\begin{array}{l}\text { Number of } \\
\text { times } \\
\text { magnified. }\end{array}$ \\
\hline 1 & $\begin{array}{l}\text { Talpe enopere (sth stage); ripe young, } 1 \frac{2}{3} \text { inch long; } \\
\text { vertical section of head. . . . . . . . . . . }\end{array}$ & $6 \frac{2}{3}$ \\
\hline 2 & $\begin{array}{l}\text { Telpe eureprec (4th stage); embryo, } \frac{3}{4} \text { inch long; endo- } \\
\text { cranium, lower view . . . . . . . . . . . . }\end{array}$ & 10 \\
\hline 3 & The same; upper view . . . . . . . . . . . . & 10 \\
\hline 4 & $\begin{array}{l}\text { Trulpe europer (9th special, 12th general stage); young } \\
\text { mole, } \frac{3}{4} \text { grown; malleus; imner view . . . . . . }\end{array}$ & 10 \\
\hline 5 & The same; outer view . . . . . . . . . . . . . & 10 \\
\hline 6 & The same; incus; inner view . . . . . . . . . & 10 \\
\hline 7 & 'The same; incus; outer view . . . . . . . . . & 10 \\
\hline 8 & $\begin{array}{l}\text { Talpu curopera (10th special, 13th general stage); adult; } \\
\text { malleus and incus; inner riew . . . . . . . }\end{array}$ & 10 \\
\hline 9 & The same; outer view . . . . . . . . . . . . & 10 \\
\hline 10 & The sime; stapes; side view . . . . . . . . . . & 10 \\
\hline 11 & $\begin{array}{l}\text { Tulpe eurnece (12th stage); young mole, } \frac{3}{4} \text { grown; } \\
\text { annulus tympanicus; inner view. . . . . . . . }\end{array}$ & $6 \frac{2}{3}$ \\
\hline 12 & $\begin{array}{l}\text { Talpe enopace (3rd stage); embryo, } \frac{3}{4} \text { inch long; hori- } \\
\text { zontal section of snout. . . . . . . . . }\end{array}$ & $6 \frac{2}{3}$ \\
\hline 13 & $\begin{array}{c}\text { Talpa curopere (10th stage); young mole, } 3 \text { inches long; } \\
\text { annulus and meatus externus. . . . . . . }\end{array}$ & $6 \frac{2}{3}$ \\
\hline 14 & $\begin{array}{l}\text { Talpe europee (13th stage); adult; rertical section of } \\
\text { snout. }\end{array}$ & $3 \frac{2}{3}$ \\
\hline
\end{tabular}



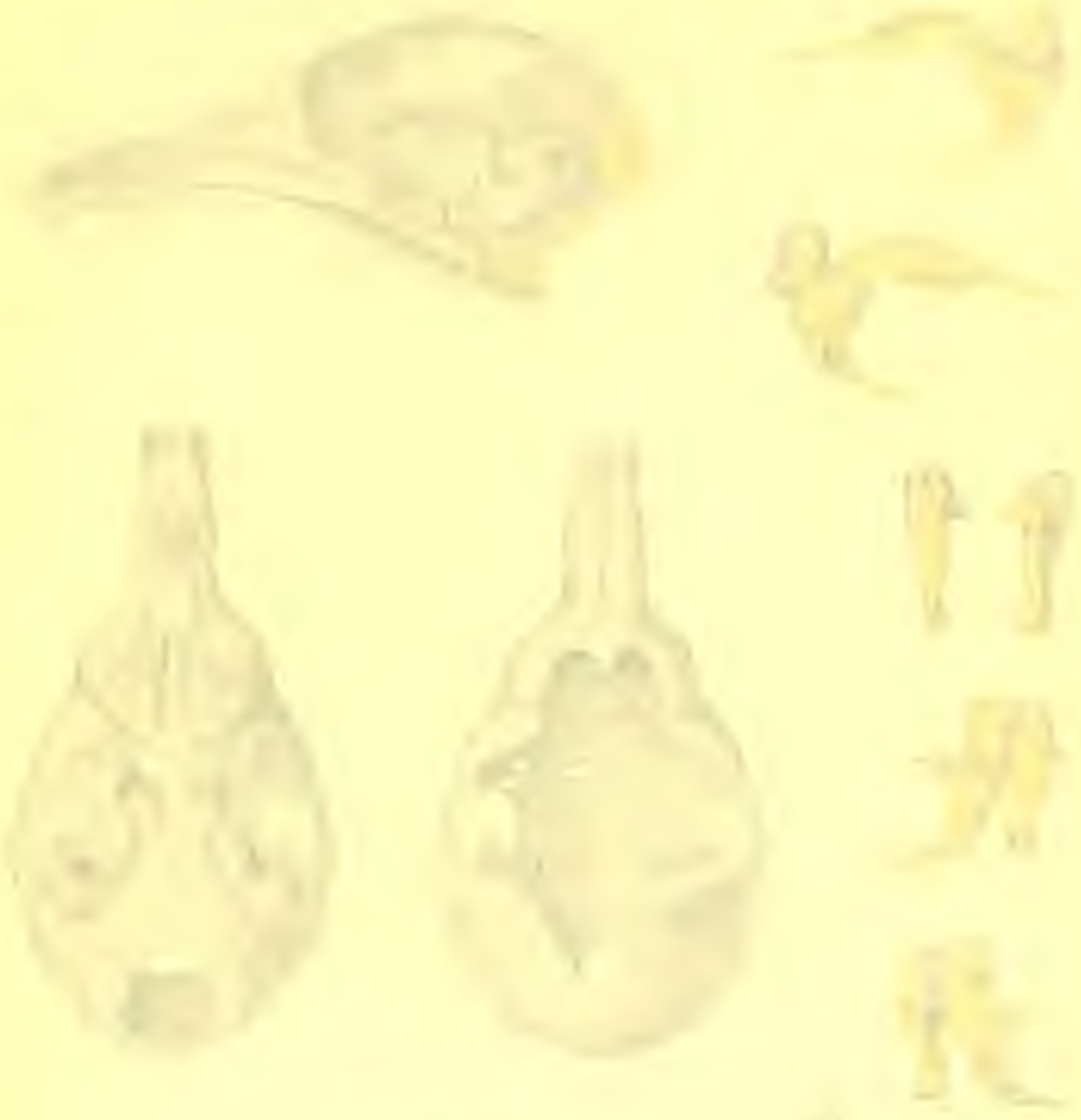
P'P'H

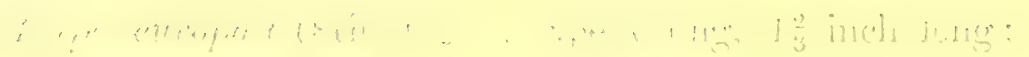

a

...., inut :

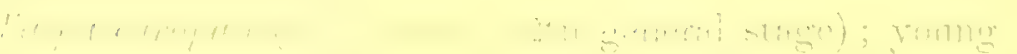

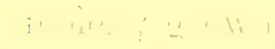

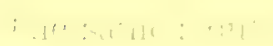

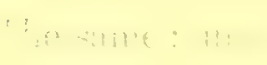

How:

$\because, \cdots, \ldots, \ldots$

(a) itil $: 3 \cdot$.

$\because \ldots \ldots+1, i+$

$\because+i,+7,+4 ;$

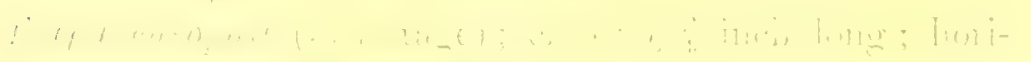

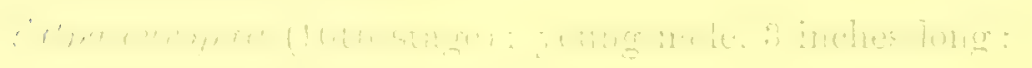



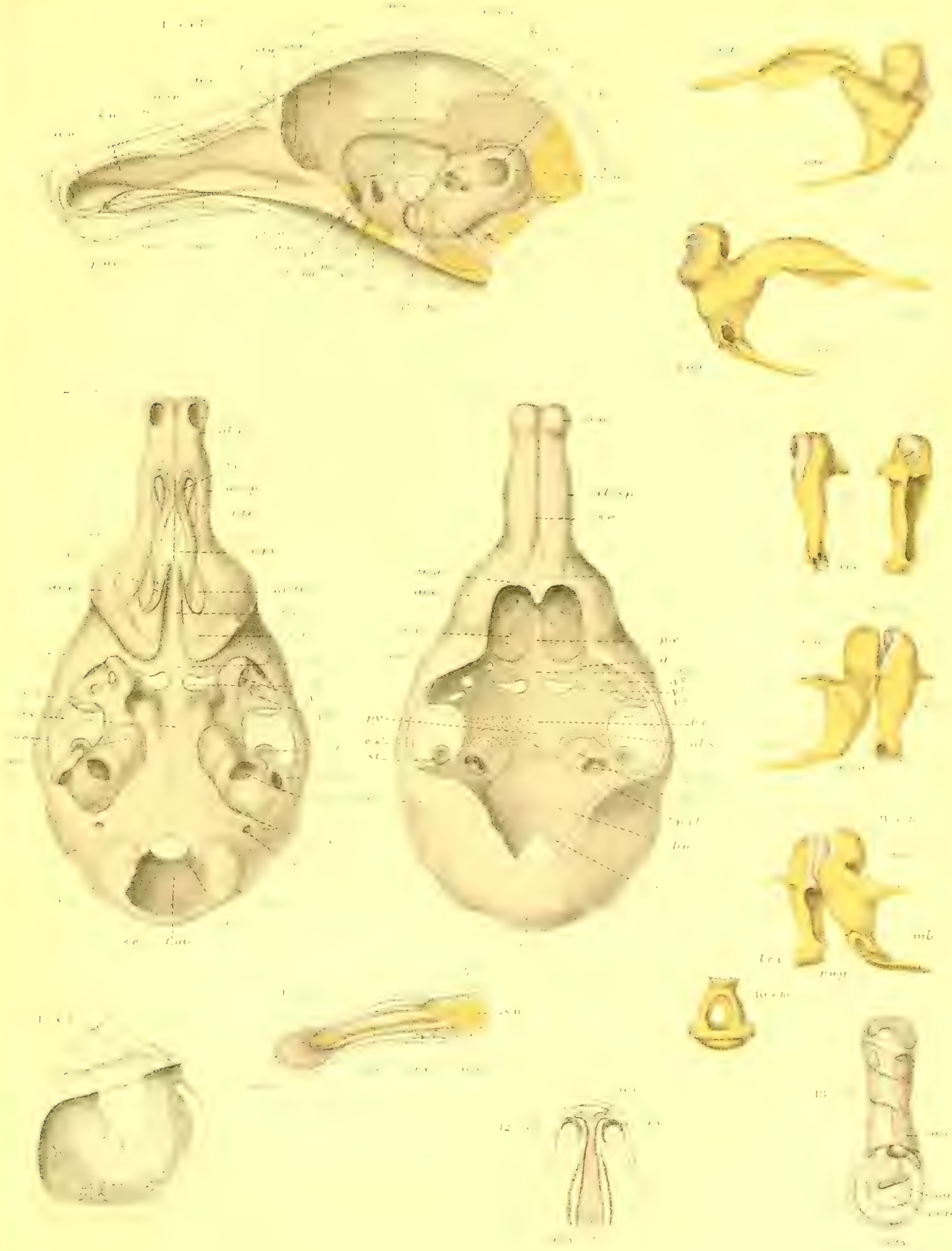


Mr. W. K. PARKER ON THE SKULL IN THE MAMMALIA.

PLA'TE 26.

Figures.

Number of times maguified.

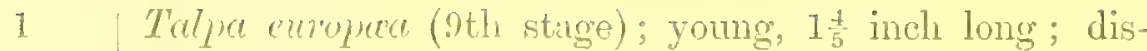
sected skull; upper view

2 The same; lowel view .

3 The same; side view

4 The same; endocranium; upper view .

63

$6 \div$

$6 \frac{20}{3}$

5 The same; lower view.

$6 \frac{2}{3}$

6 The same; inner view (part).

15

$6 \frac{2}{3}$ 

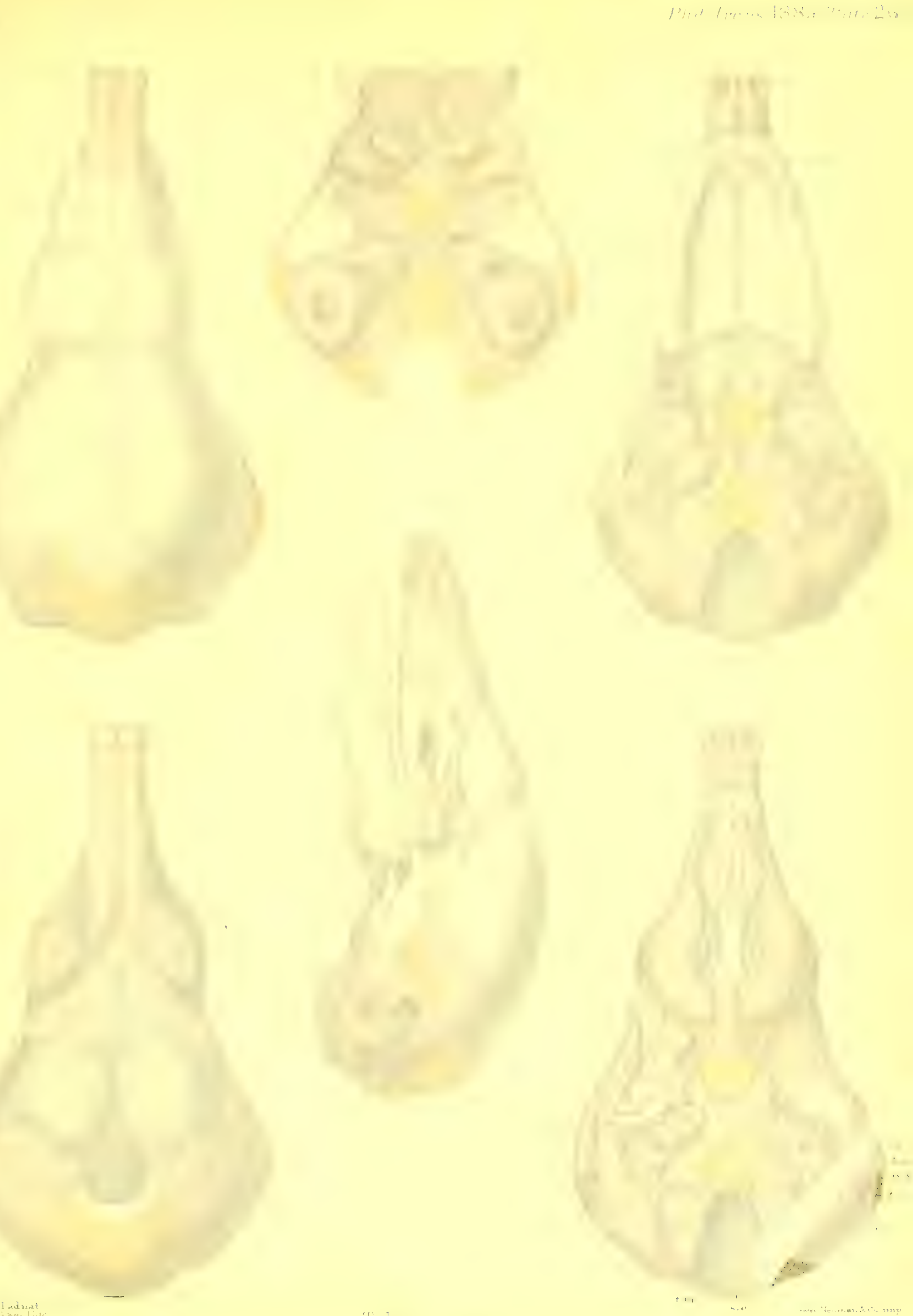

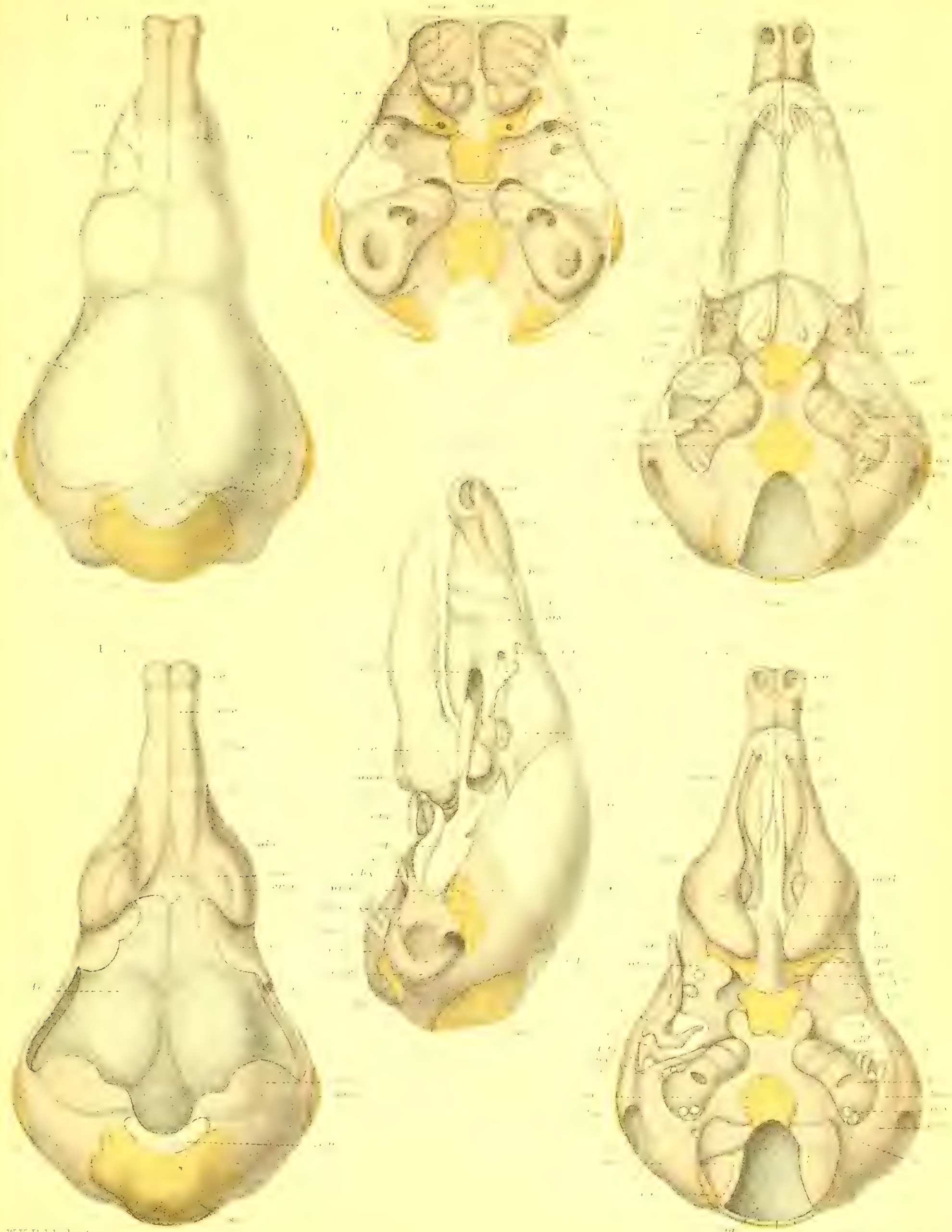


MR. W. K. PARKER ON THE SKULL IN THL MAMMALA.

PLATE 27.

Figures.
$\begin{gathered}1 \\ 2 \\ 3 \\ 3 \\ 4 \\ 5 \\ 6 \\ 7 \\ 8\end{gathered}$

Ialpe erropece (10th stage); young mole, 3 inches loug; endocranium; upper view

The same; lower view

The same; dissected skull with some bones removed;

Ninmber of

times

magnified. side view

Talpa erropere (11th stage); young mole, $\frac{2}{3}$ grown; skull, with jugal bone removed; side view

Same skull (perfect); lower view

'The same; upprer view .

'The same; end view

The same; inside of hind skull.

$3 \frac{3}{4}$

$3 \frac{3}{4}$

$3 \frac{3}{4}$

$3 \frac{1}{8}$

$3 \frac{1}{8}$

$3 \frac{1}{8}$

$3 \frac{1}{5}$

$3 \frac{3}{4}$ 

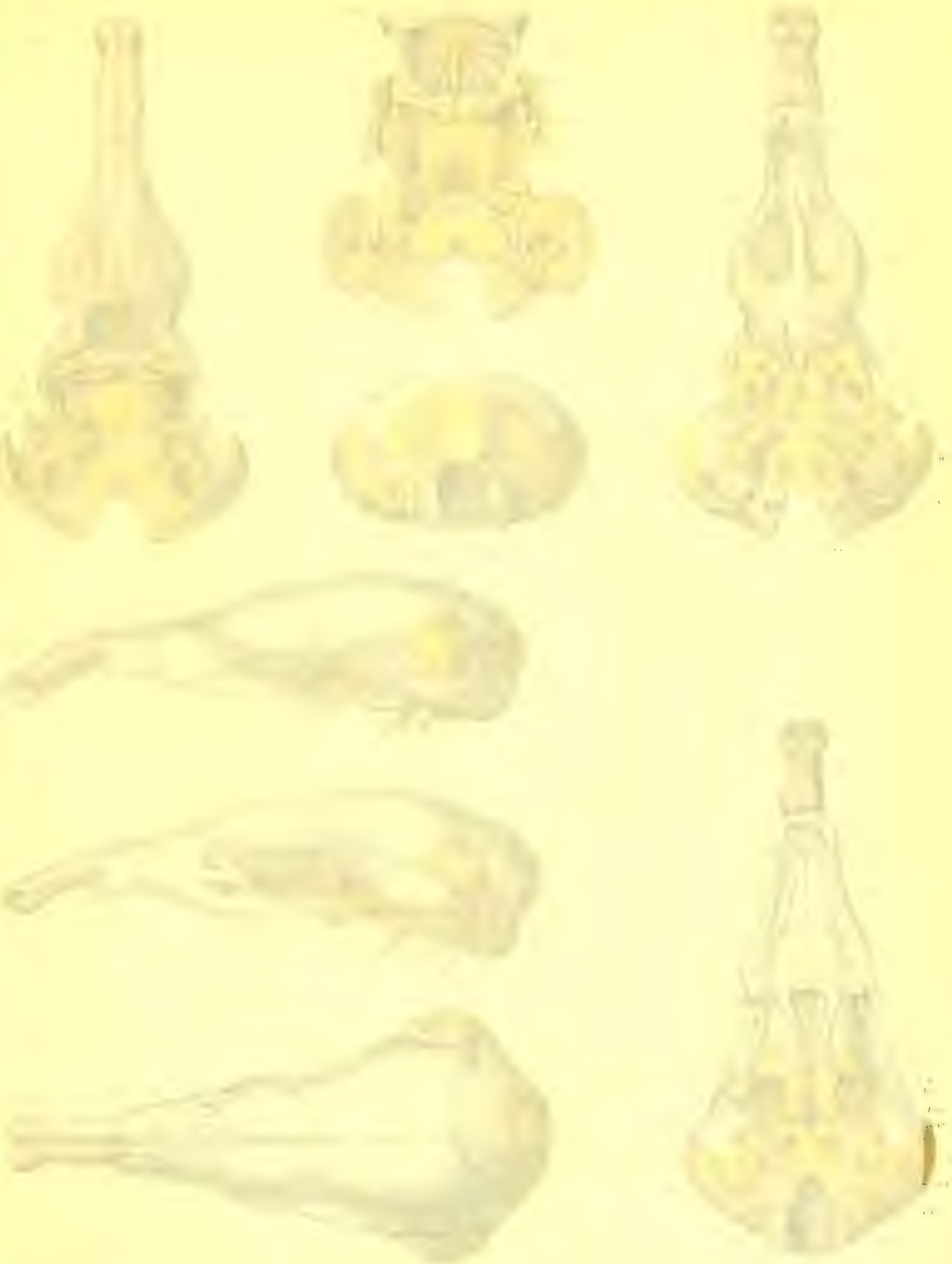

MR. W. K. PARKFR ON THE SRULI, IN THE MAMMALIA.

PLA'TE 28.

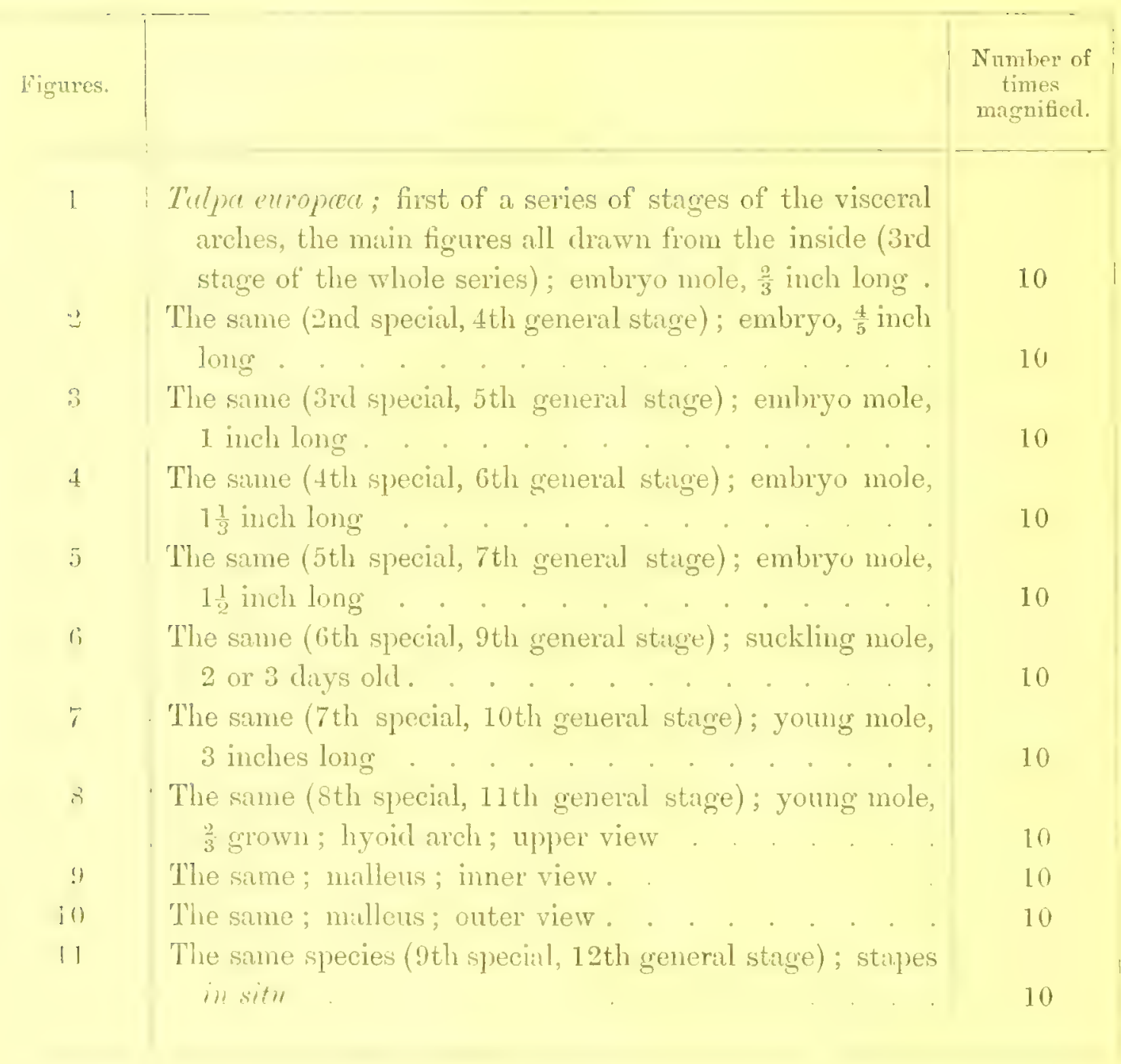



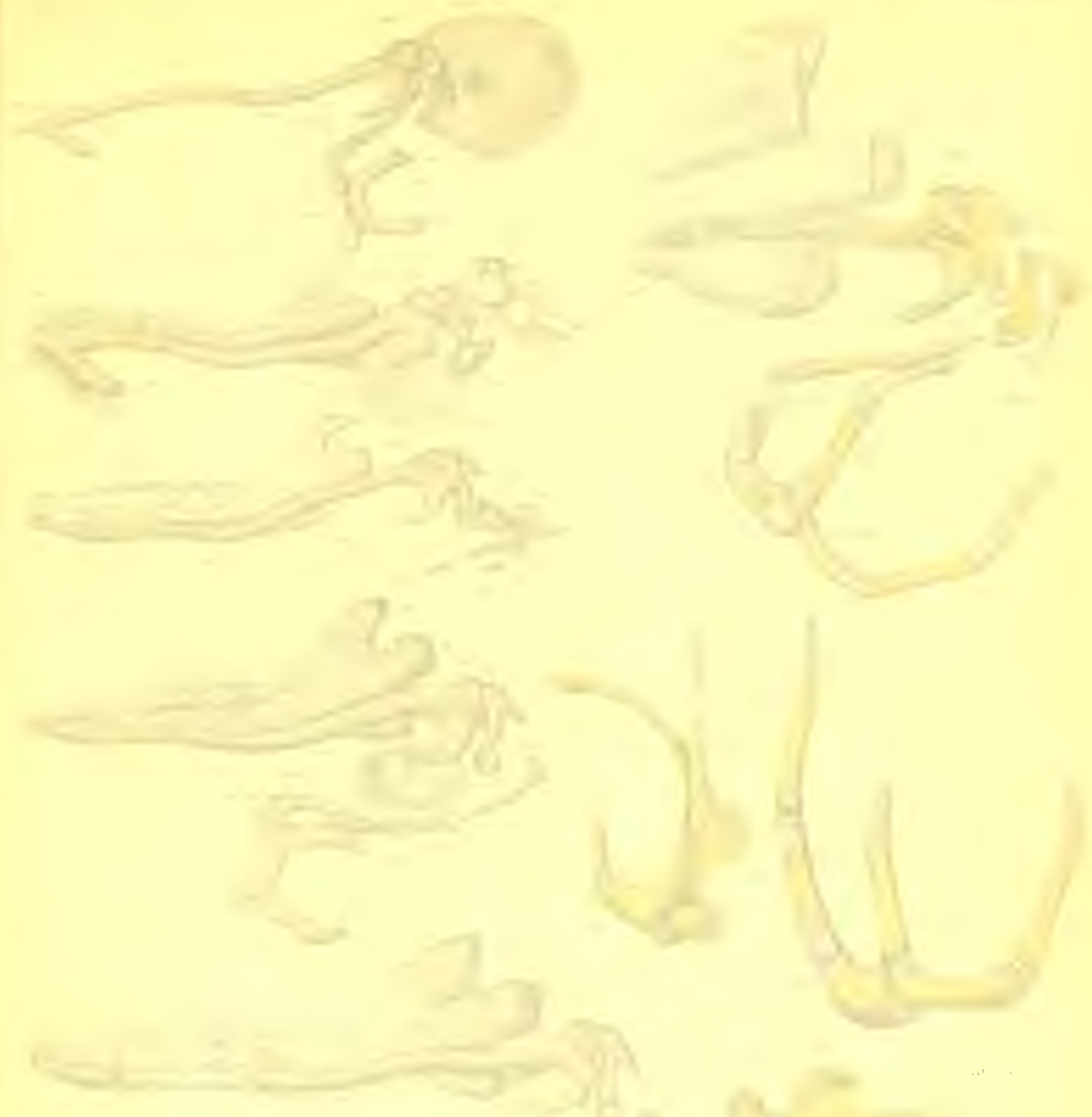

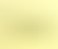
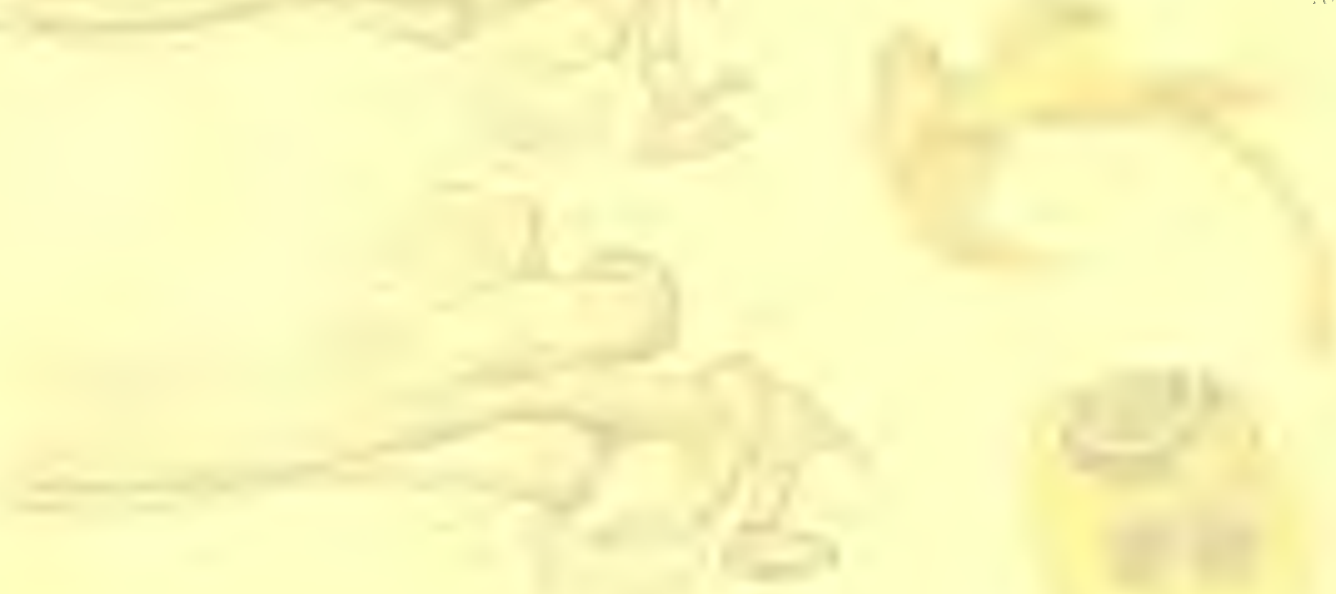

11

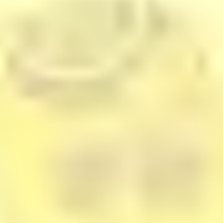




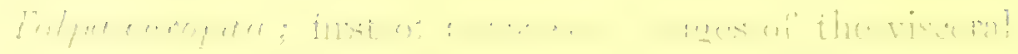

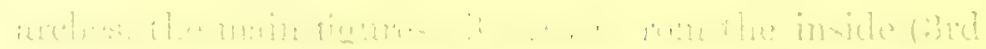

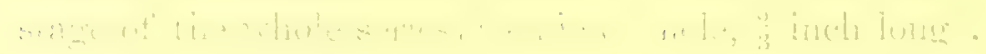



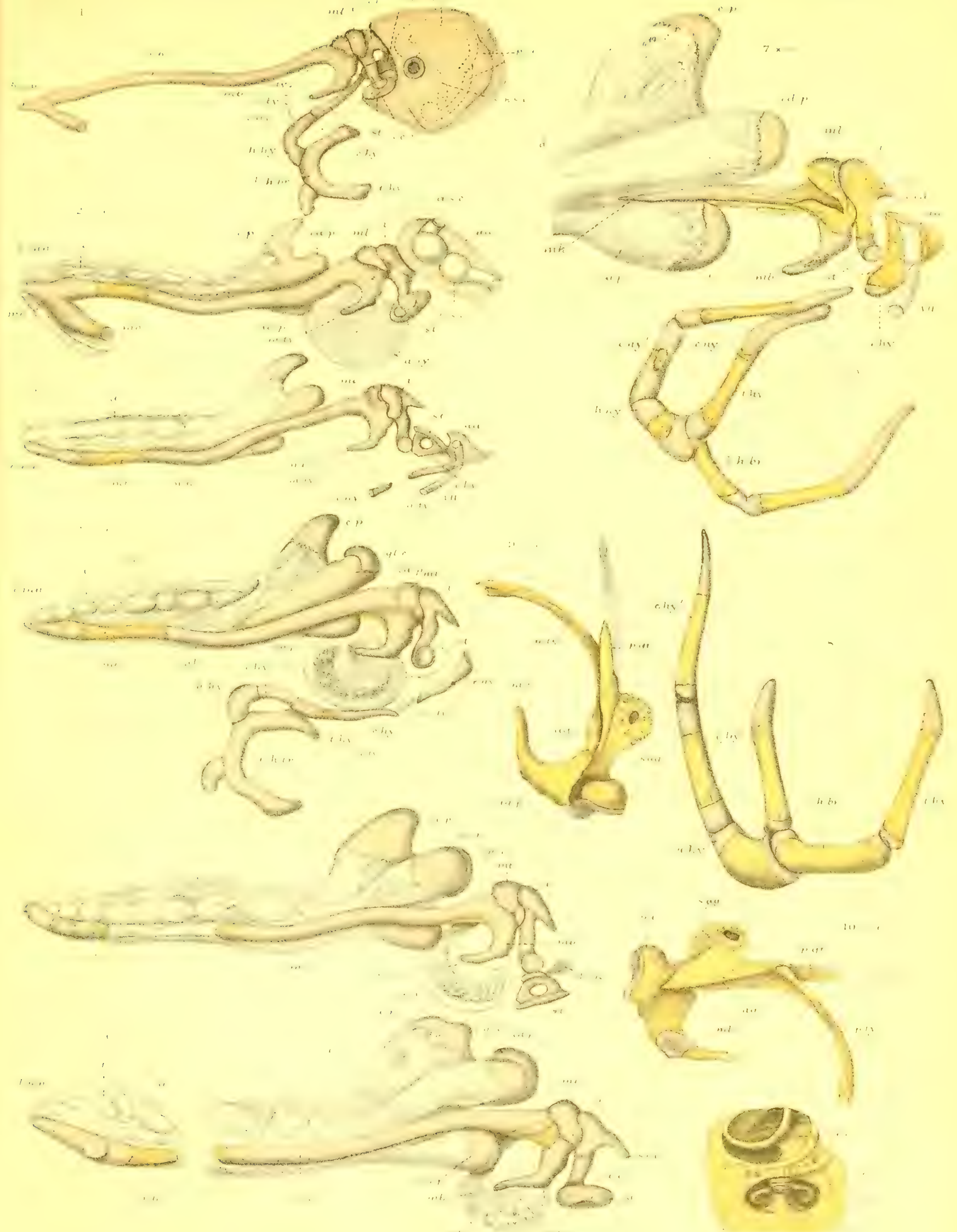


MR. W. K. PARKER ON THE SKULL IN THE MAMMALIA.

PLATE 29.

\begin{tabular}{|c|c|c|}
\hline Figures. & & $\begin{array}{c}\text { Number of } \\
\text { times } \\
\text { magnified. }\end{array}$ \\
\hline $\begin{array}{l}2 \\
3 \\
4 \\
5 \\
6 \\
7\end{array}$ & 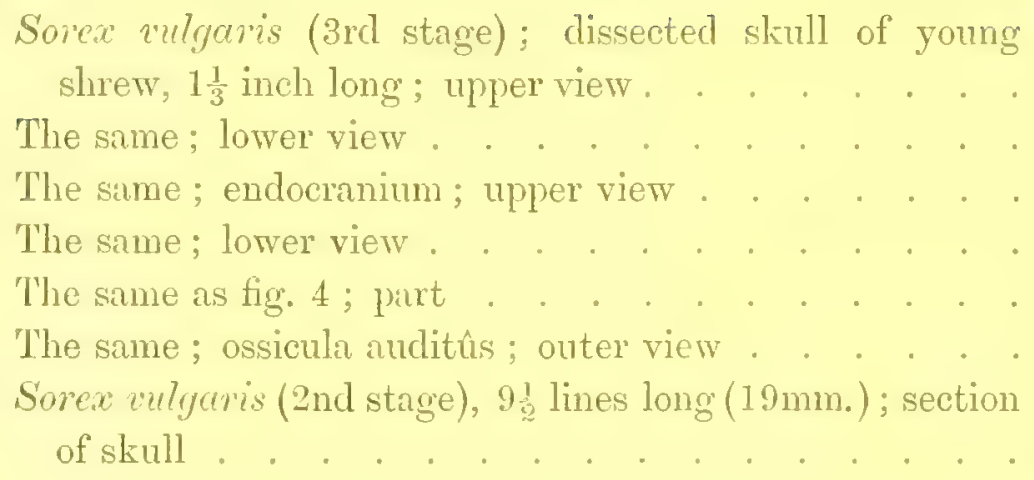 & $\begin{array}{r}8 \\
8 \\
8 \\
8 \\
22 \\
20 \\
12\end{array}$ \\
\hline
\end{tabular}


385. P7atc2?.
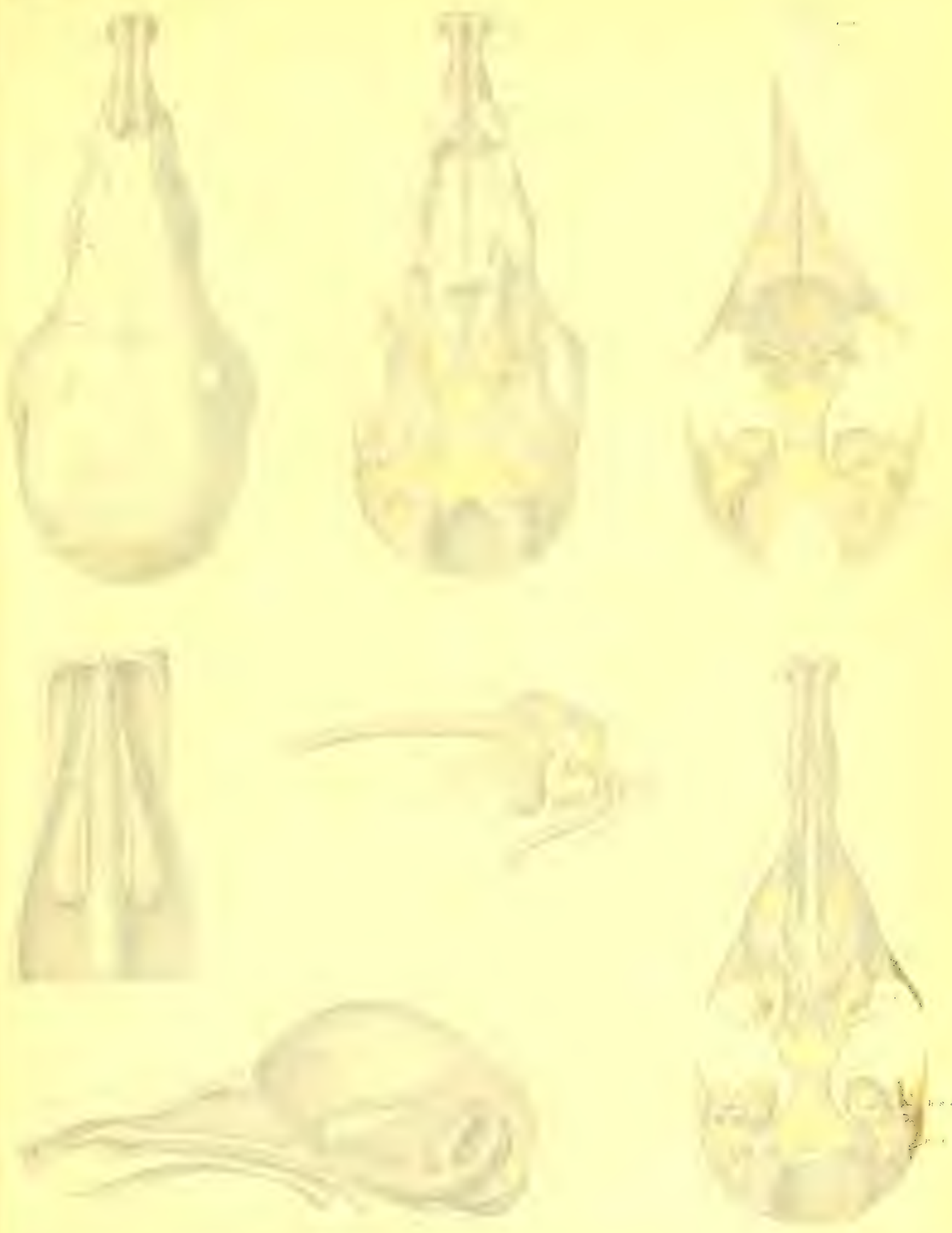


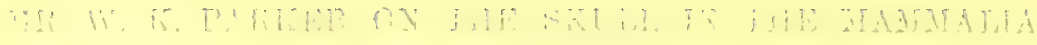

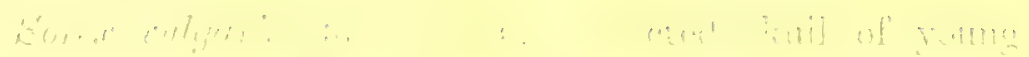


l'artien.
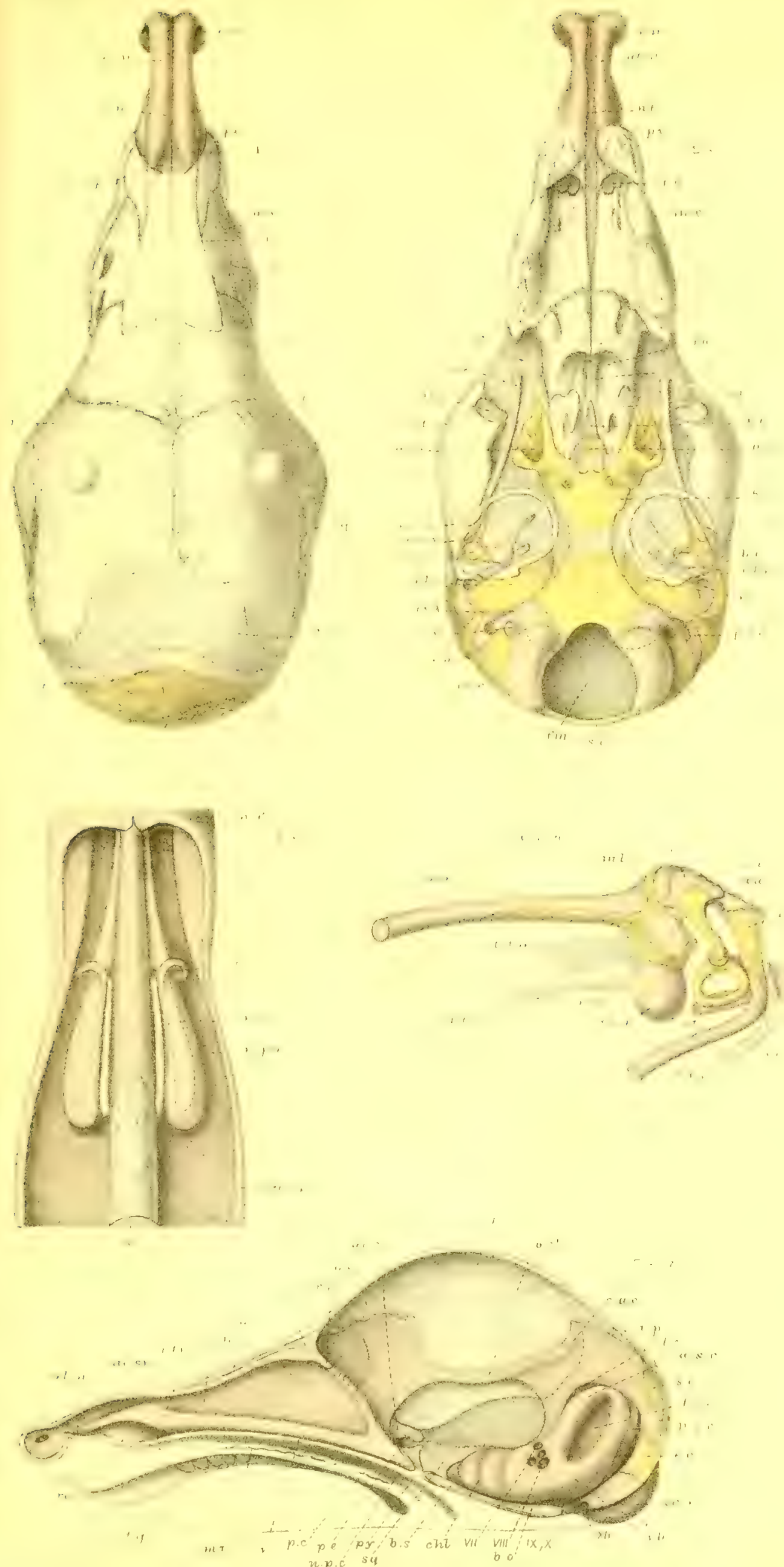

Phil.Trans 1885. Plate2?.
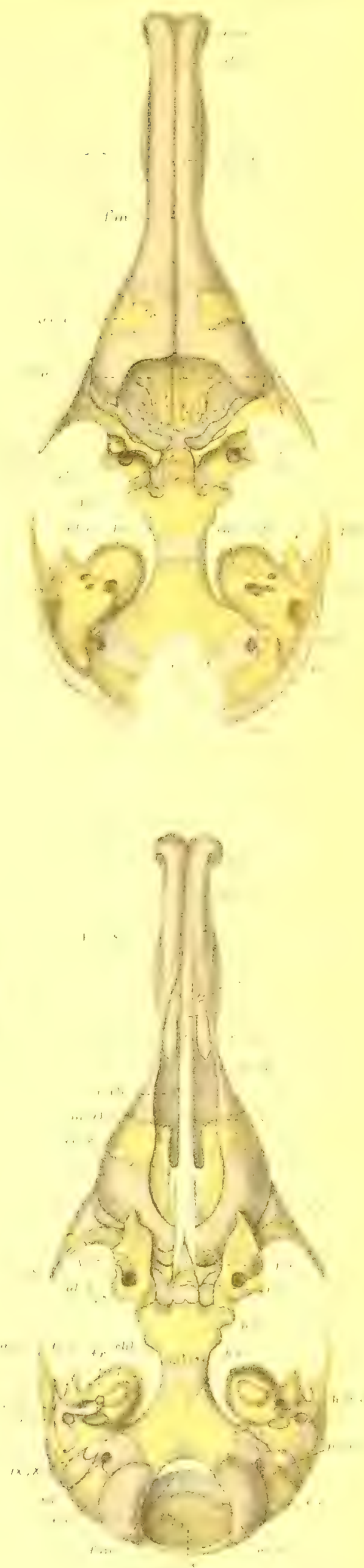


PLA'IE 30.

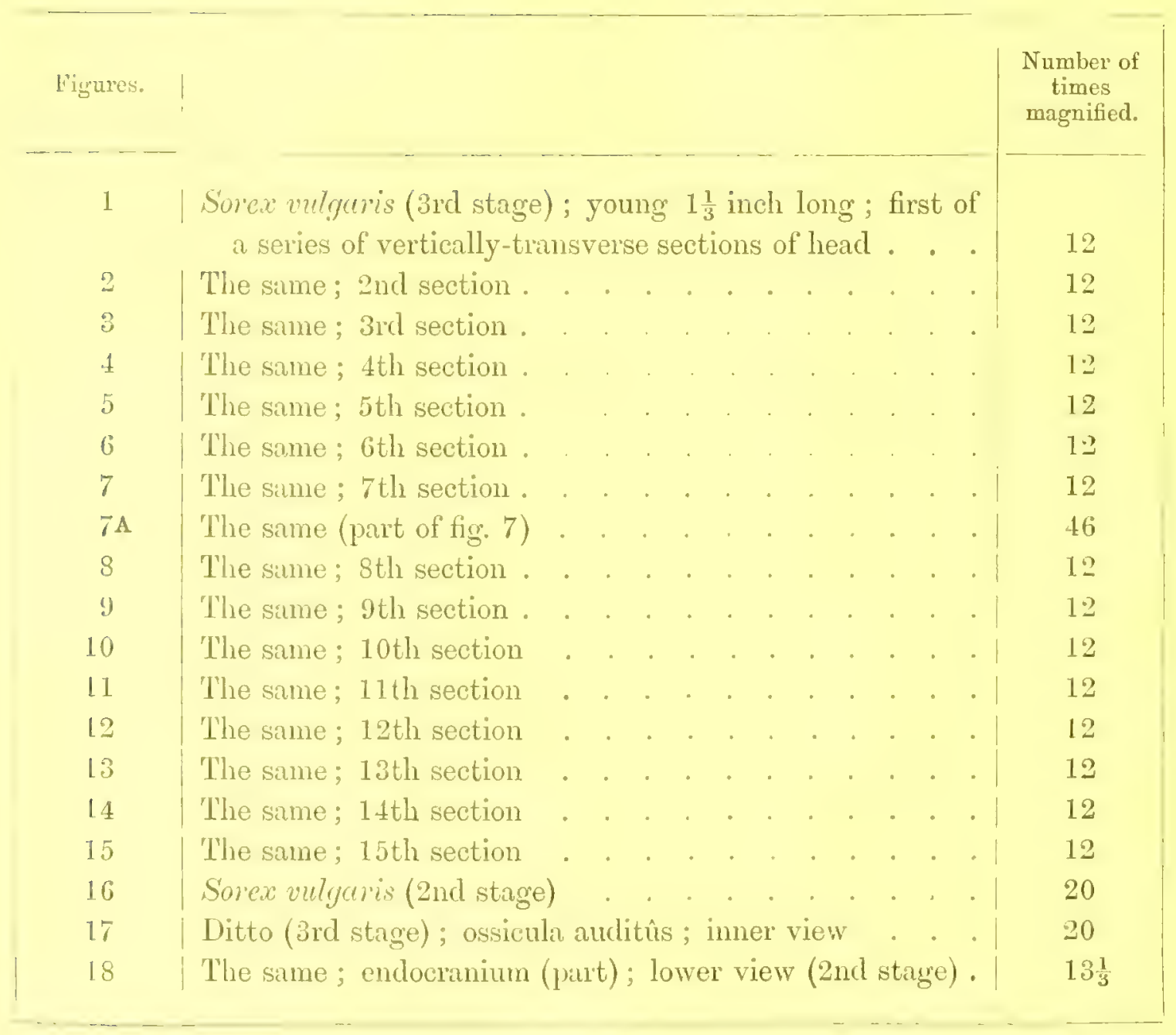




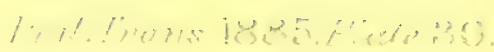
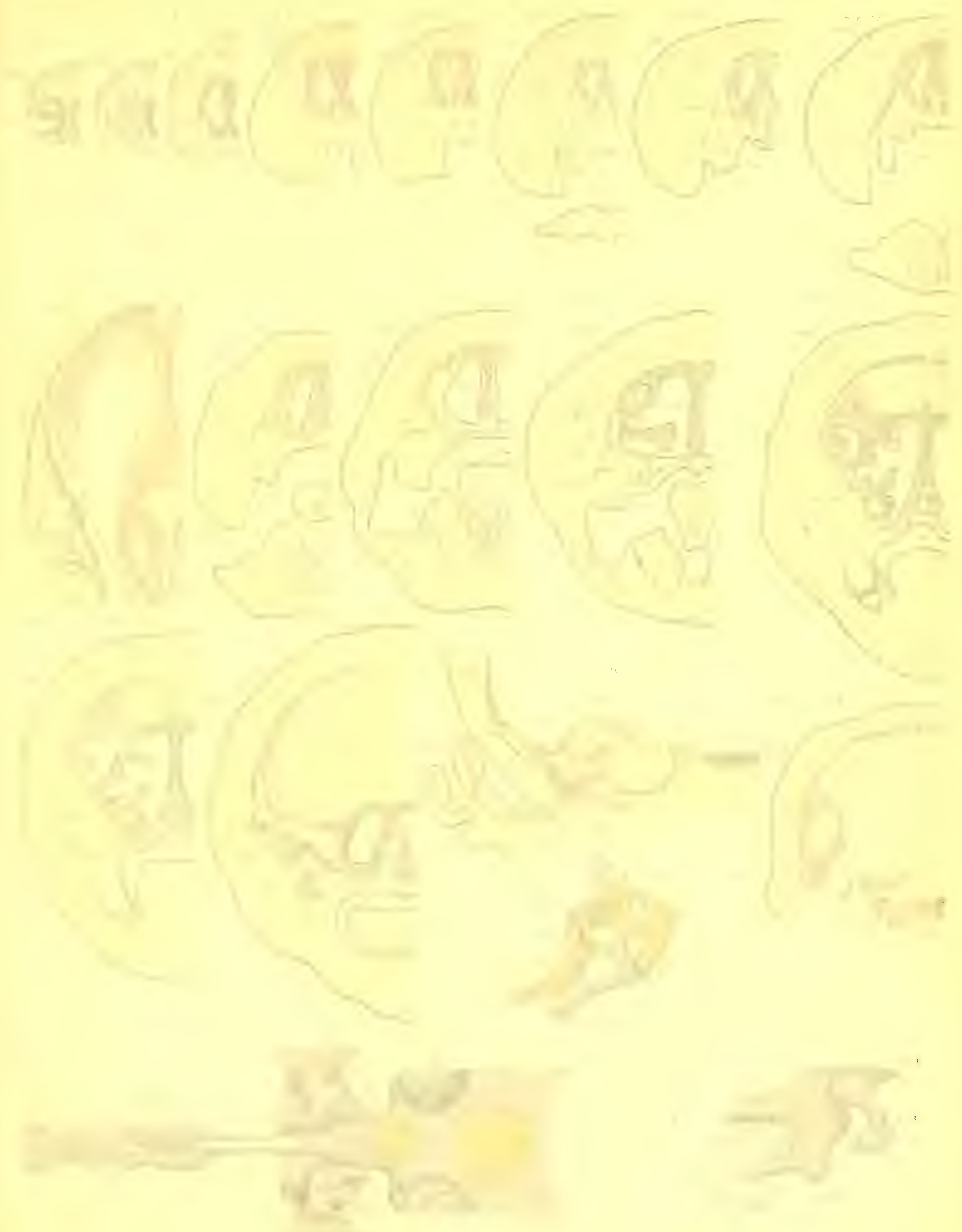


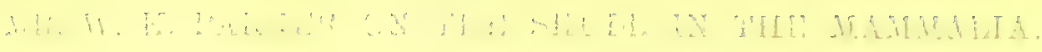

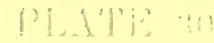

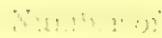

$i^{2}+4$

ragentitica?

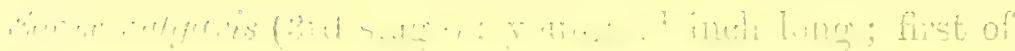

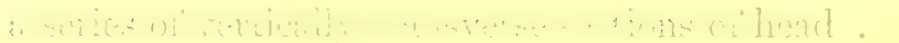

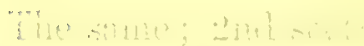

Yil

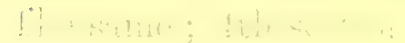

11:1 : ind

lia =itak : lith

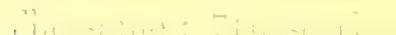

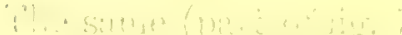

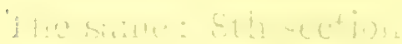

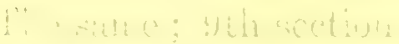

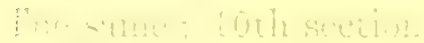

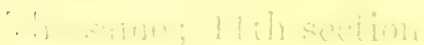

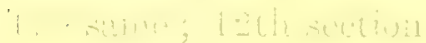

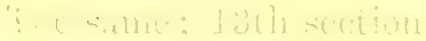

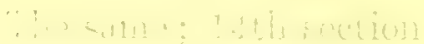

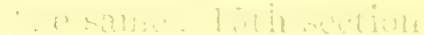

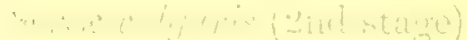

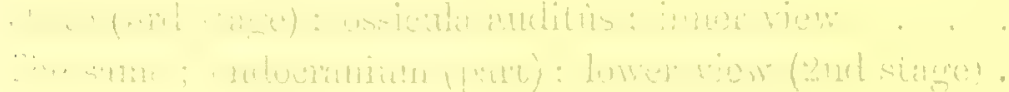


$\sin \operatorname{arn}(\pi)$
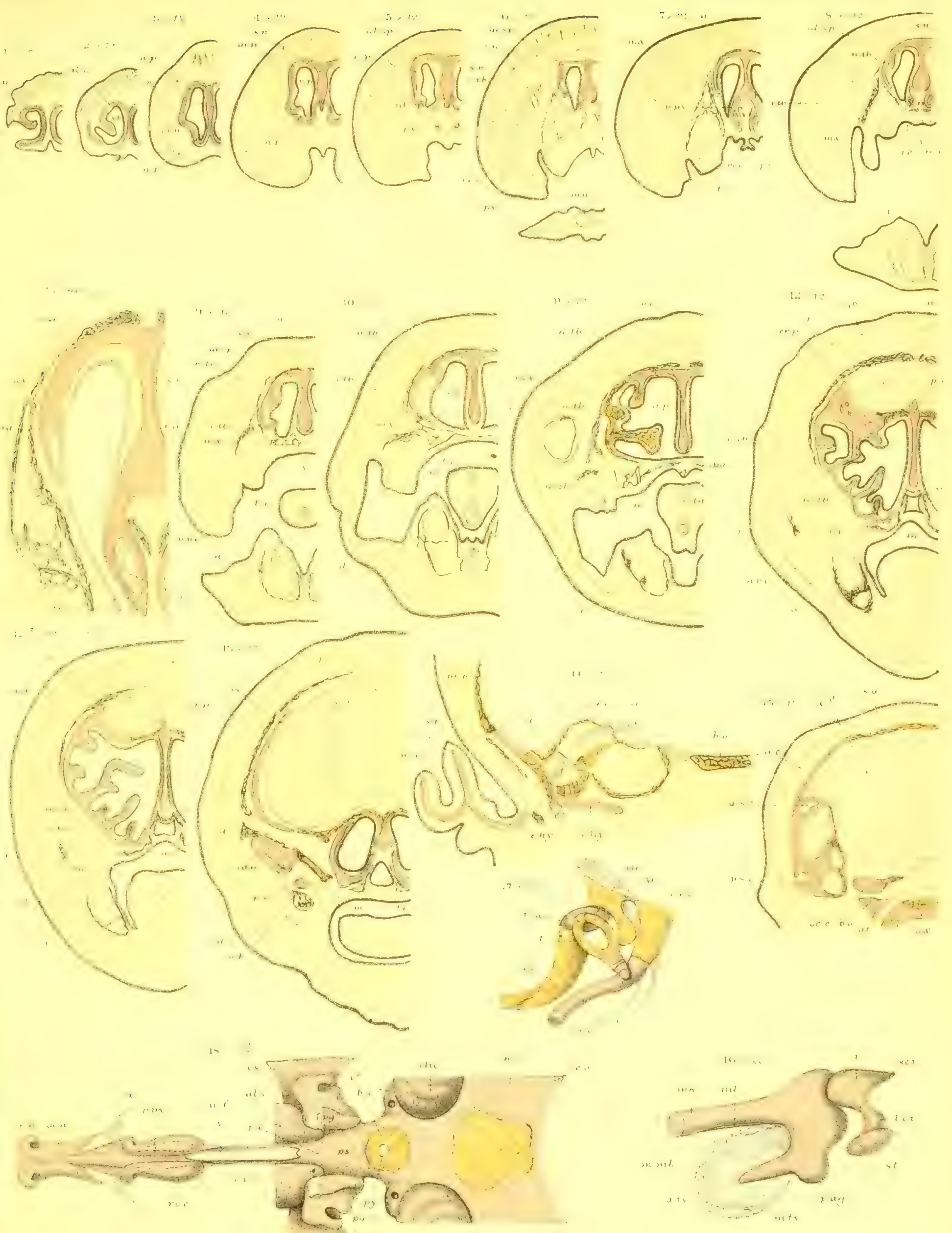


MR. W. K. PARKER ON THE SKULL IN THE MAMMALIA.

PLA'TE 31.

\begin{tabular}{|c|c|c|}
\hline Figrares. & & $\begin{array}{c}\text { Number of } \\
\text { times } \\
\text { magnified. }\end{array}$ \\
\hline 1 & Sorex vulgaris (4th stage); skull of adult; upper view . & 5 \\
\hline 2 & 'The same; lower view . . . . . . . . . . & 5 \\
\hline 3 & The same; side view . . . . . . . . . . . . & 5 \\
\hline $3 \mathrm{~A}$ & The same; end view of lower jaw . . . . . . . & 5 \\
\hline 4 & 'The same; petromastoid bone; inner view . . . . . & 12 \\
\hline 5 & The same; outer view . . . . . . . . . . . & 12 \\
\hline 6 & 'The same; malleus, incus, and tympanic ; outer view . & 18 \\
\hline 7 & The same; inner view . . . . . . . . . . . & 18 \\
\hline 8 & The same; stapes; side view . . . . . . . . . & 18 \\
\hline 9 & Sorex vulgaris (4th stage); adult; hyoid arch; inner view & 7 \\
\hline 10 & The same (3rd stage); skull; side view . . . . . . & 7 \\
\hline 11 & The same; section; side view . . . . . . . . & 7 \\
\hline 12 & The same; hyoid arch . . . . . . . . . . . . & 12 \\
\hline
\end{tabular}




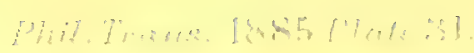
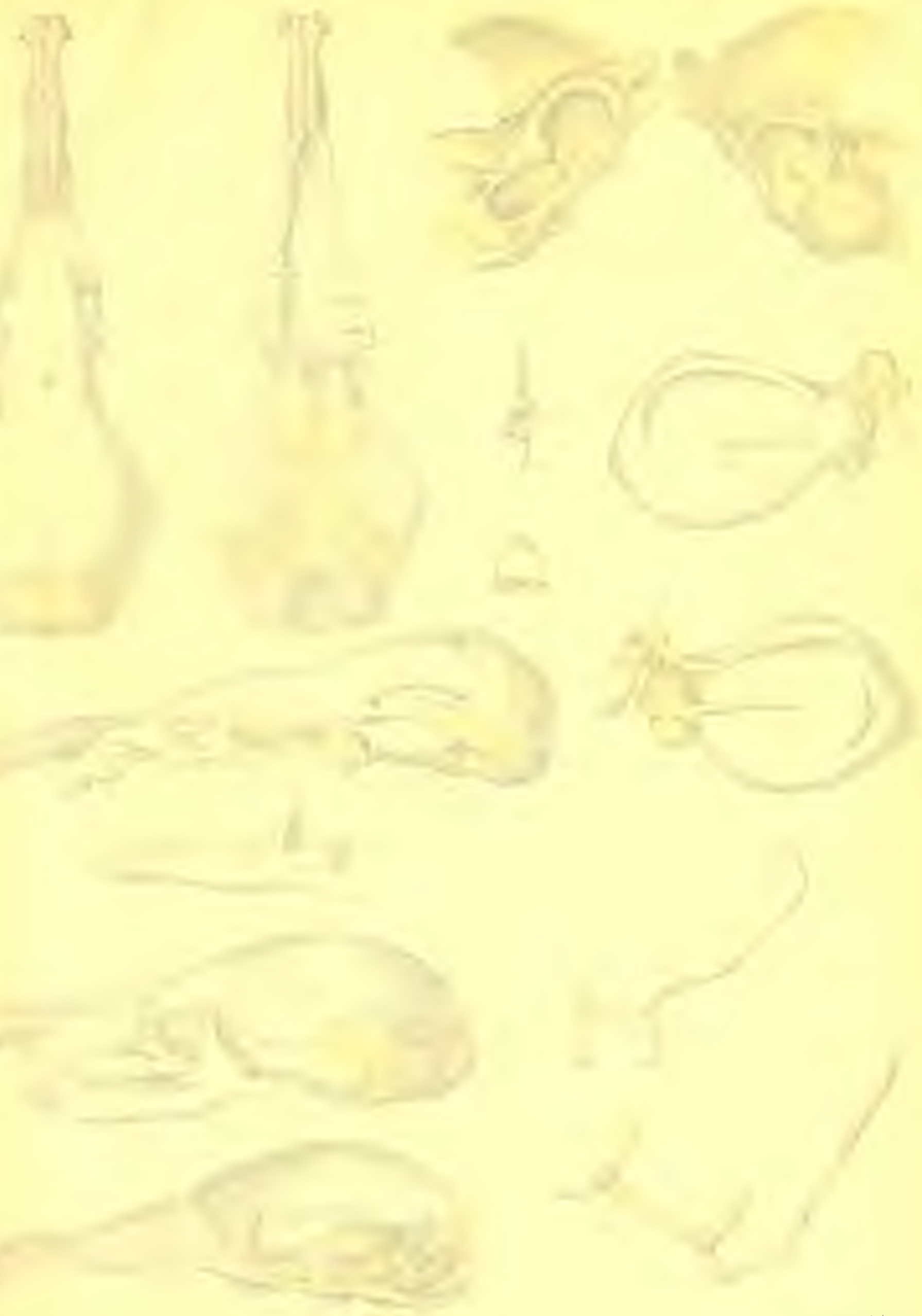
Parker:
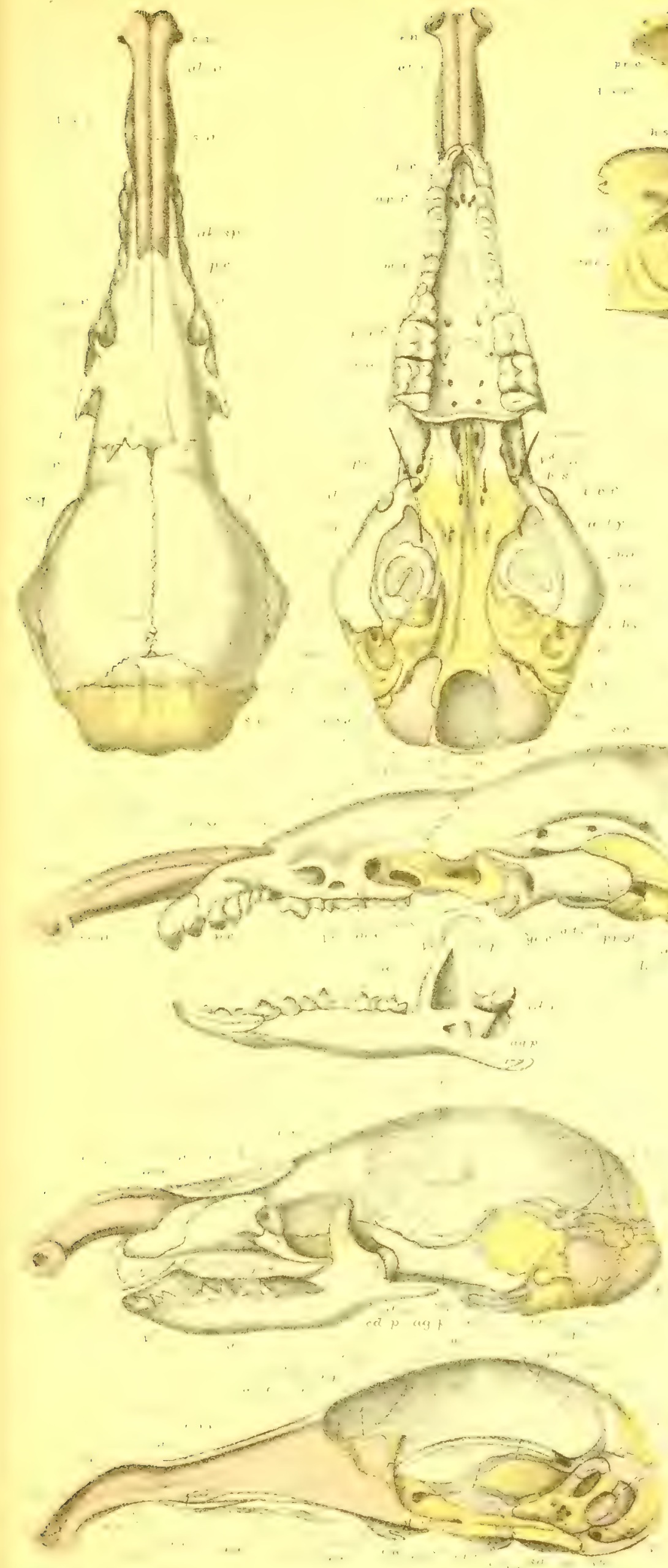

Phil. Trans. 1885. Plote:31.
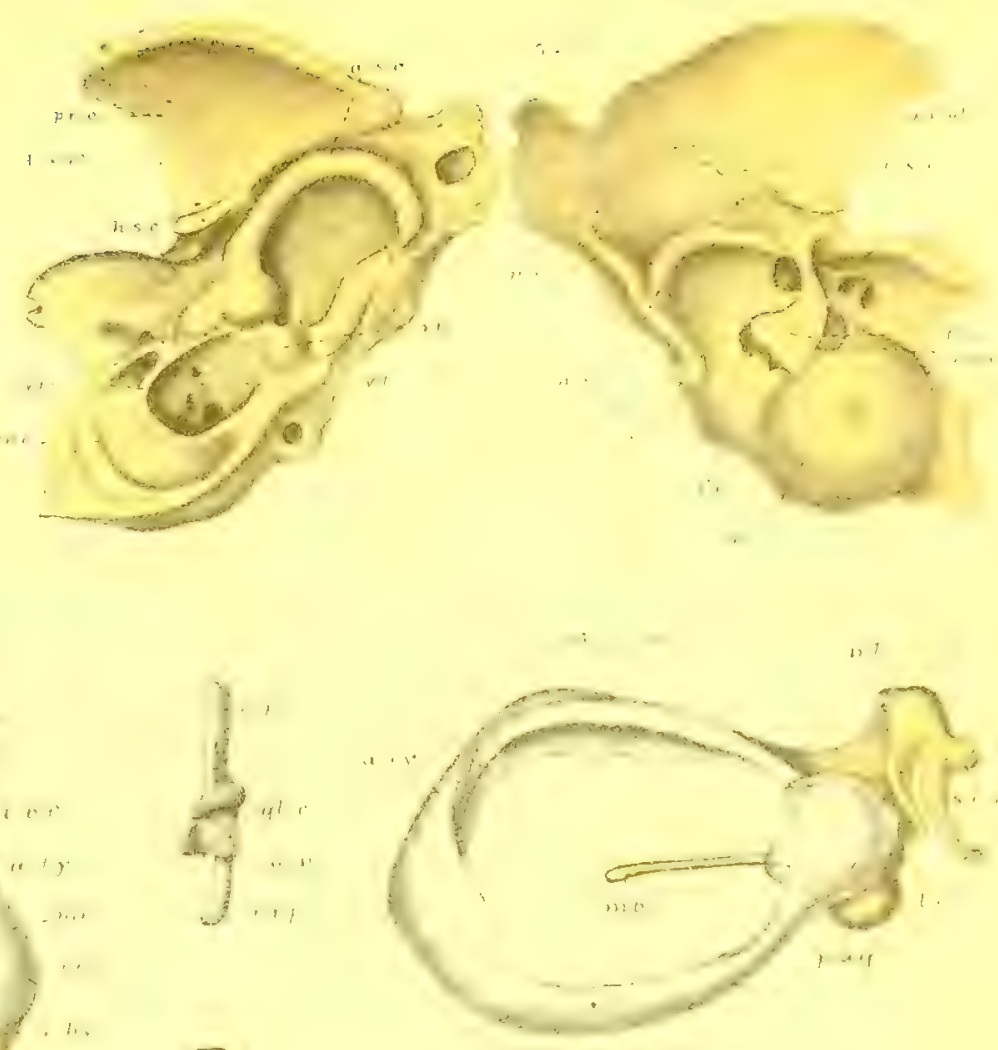<smiles>c1ccccc1</smiles>
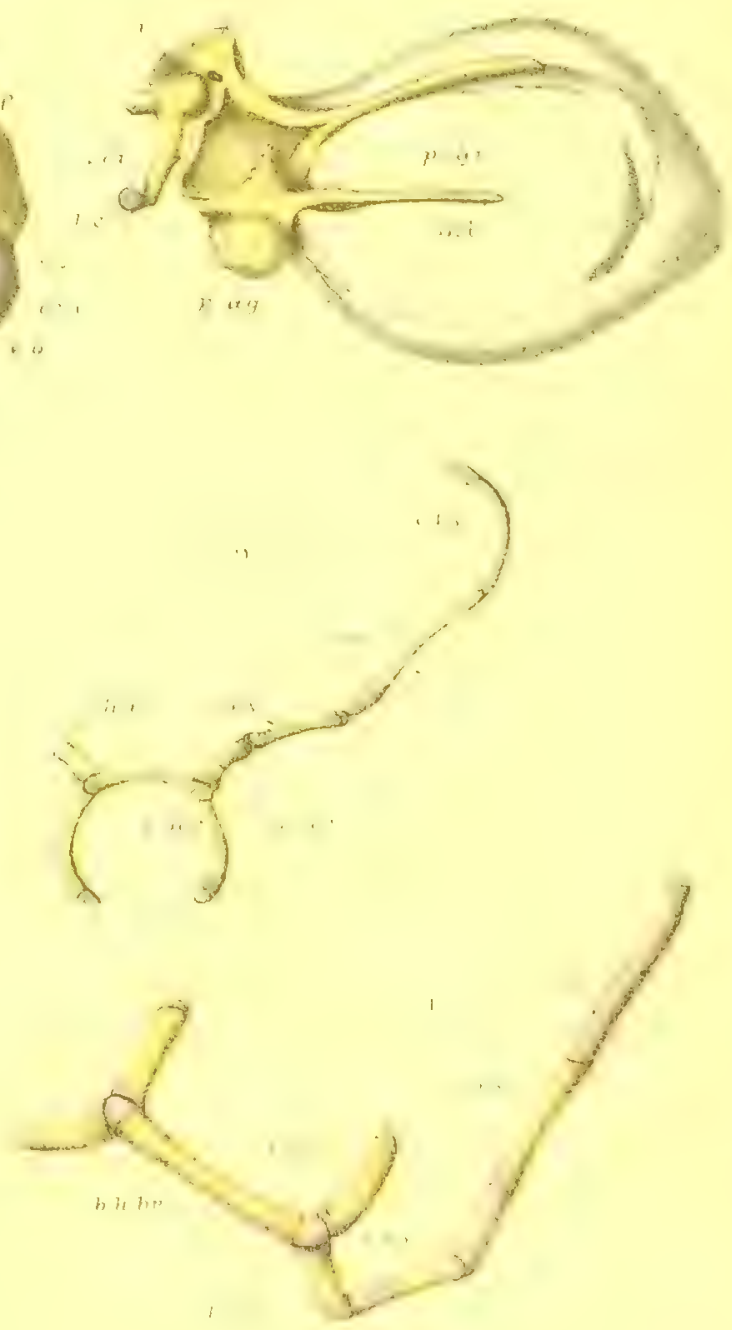

MR. W. K. PARKER ON THE SKULL IN THE MAMMALIA.

PLATE 32.

\begin{tabular}{|c|c|c|}
\hline Figures. & & $\begin{array}{l}\text { Number of } \\
\text { times } \\
\text { magnified. }\end{array}$ \\
\hline 1 & $\begin{array}{l}\text { Centetes ccaudatus (2nd stage); embryo; } 1 \frac{11}{12} \text { inch long; } \\
\text { skull; upper view . . . . . . . . . . . }\end{array}$ & $5 \frac{1}{3}$ \\
\hline 2 & The same; lower view . . . . . . . . . & $5 \frac{1}{3}$ \\
\hline 3 & 'The same; side view . . . . . . & $5 \frac{1}{3}$ \\
\hline 4 & The same; endocranium; lower view. & $5 !$ \\
\hline 5 & The same; upper view . . . . . . . . & $5 !$ \\
\hline (j) & The same; ethmo-septal region; side view . . & 8 \\
\hline 7 & The same; ossicula auditus; inner view . . . . & 20 \\
\hline 8 & The same; hyoid arch; imner view . . . . . . & $13 !$ \\
\hline
\end{tabular}



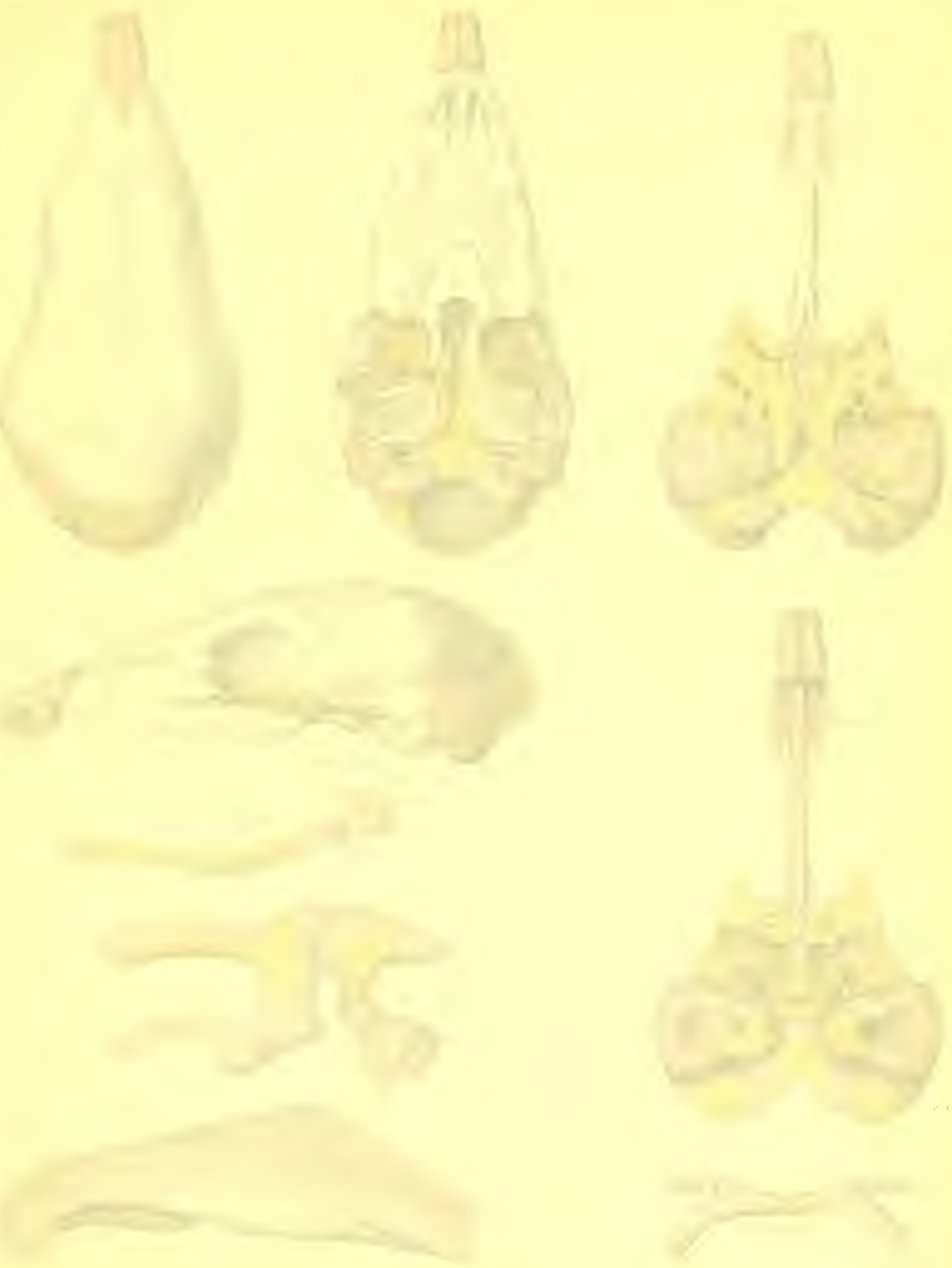
T. $17, \ldots$

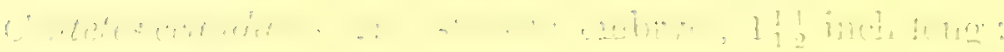

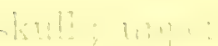

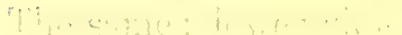




PLATE 33.

\begin{tabular}{|c|c|c|}
\hline Figures. & & $\begin{array}{l}\text { Number of } \\
\text { times } \\
\text { magnified. }\end{array}$ \\
\hline 1 & $\begin{array}{l}\text { Centetes caudatus (3rd stage); nestling Tenrec; } 3 \frac{1}{4} \text { inches } \\
\text { long; skull; lower rien }\end{array}$ & $3 ?$ \\
\hline 2 & The same; upper view. . . . . . . . . . . . . & 31 \\
\hline 3 & The same; side view . . . . . . . . . . & $: 3$ \\
\hline $3 \mathrm{~A}$ & The same; lower jaw; end view . . . . & $\because 1$ \\
\hline 4 & The same; skull; end view . . . . . . & $3 \frac{1}{3}$ \\
\hline 5 & The same; skull in section . . . . . . & $: 3$ \\
\hline 6 & The same; ossicula and tympanic; inner view . & $1: 3$ \\
\hline 7 & The same; bones (part); outer view . . . & $1: 3 \frac{1}{3}$ \\
\hline 8 & The same; part of romerine region; lower view & $3_{3}^{1}$ \\
\hline 9 & The same; hyoid arch; upper view . . . . & $: 3)_{3}^{1}$ \\
\hline 10 & The same; nasal labyrinth; side riew . . . . . . . & $\therefore \frac{1}{3}$ \\
\hline
\end{tabular}



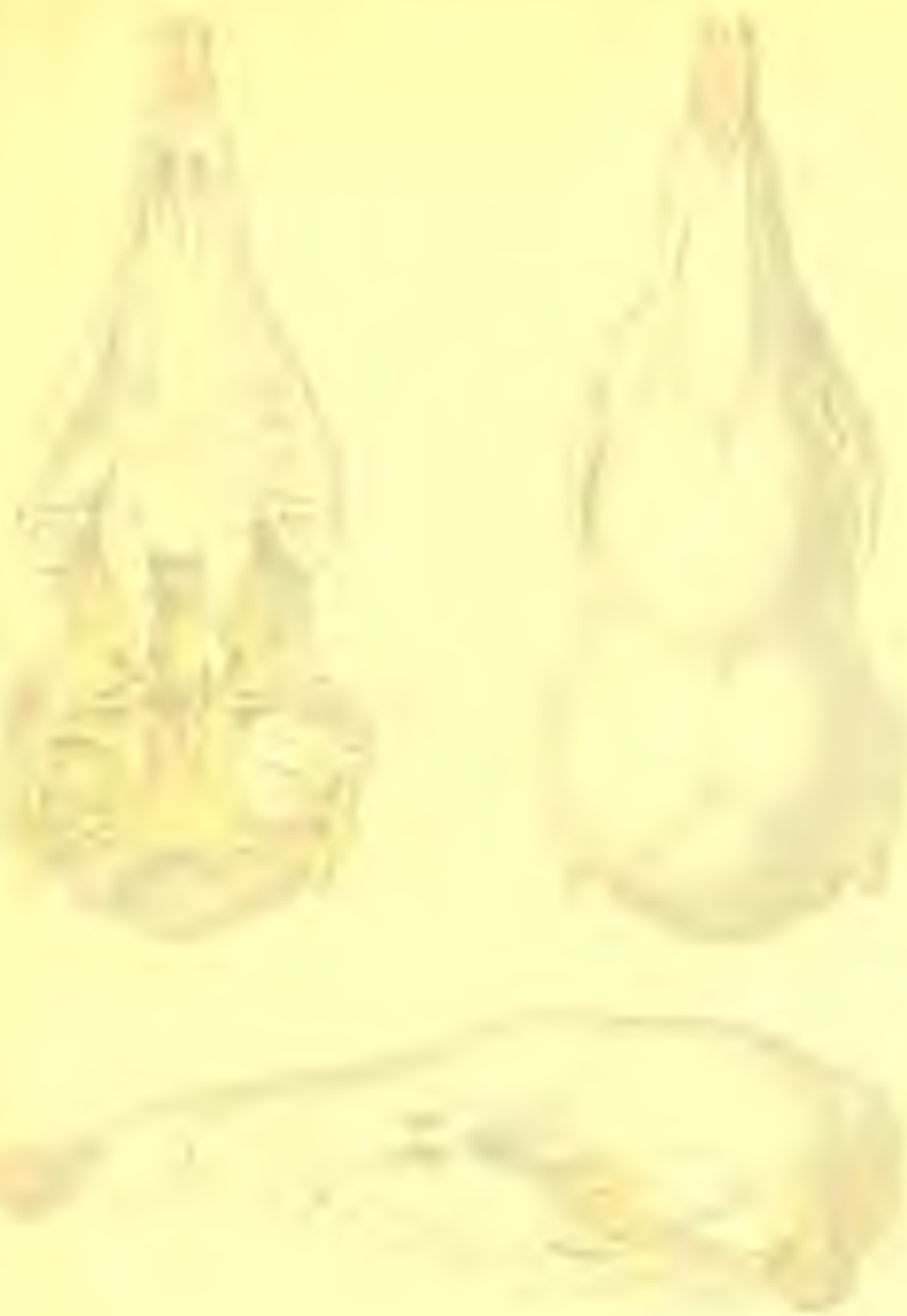


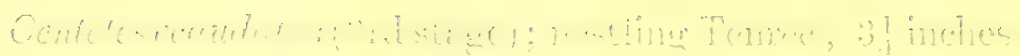

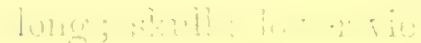

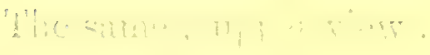

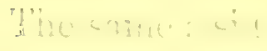

Whe

The ston:

Thosition

rille : ane ;

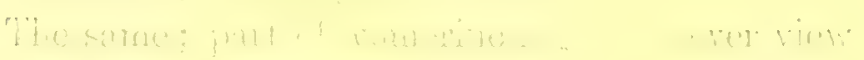

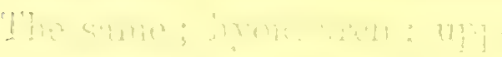

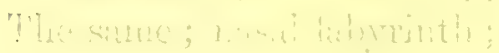




MR. W. K. PARKER ON TIIE SEULL IN THE MAMMALIA.

PLATE 34.

\begin{tabular}{|c|c|c|c|}
\hline Figures. & & & $\begin{array}{l}\text { Number of } \\
\text { times } \\
\text { magnified. }\end{array}$ \\
\hline 1 & $\begin{array}{l}\text { IIemicentetes Madagascarensis; sub-adult; s } \\
\text { vierw . . . . . . . . . . }\end{array}$ & skull; lower & $3 \frac{1}{3}$ \\
\hline 2 & The same; upper view . . . . . . . & . . . . . & $3 \frac{1}{3}$ \\
\hline 3 & The same; side view . . . . . . . . & . . . . . & $3 \frac{1}{3}$ \\
\hline 4 & The same; end view . . . . . . . . . & . . . . & $3 \frac{1}{3}$ \\
\hline 5 & The same; lower jaw; end view . . . . & . . . . . & $3 \frac{1}{3}$ \\
\hline 6 & $\begin{array}{l}\text { Hemicentetes nigrescens; sub-adult; hyoid } \\
\text { view . . . . . . . . . . . . }\end{array}$ & arch; inner & $3 \frac{1}{3}$ \\
\hline 7 & The same; ethmo-septal region . . . . . & . . . . . & $3 \frac{1}{3}$ \\
\hline 8 & The same; with vomers in situ . . . . . & . . . . . & $3 \frac{1}{3}$ \\
\hline 9 & The same; ossicula and tympanic; inner vier & $\mathrm{W} . . \quad$. & 15 \\
\hline
\end{tabular}


1. 


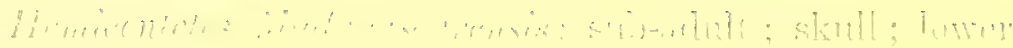

$$
\text { ifis }
$$$$
\text { Wh. Wh: }
$$ 
ti. line:

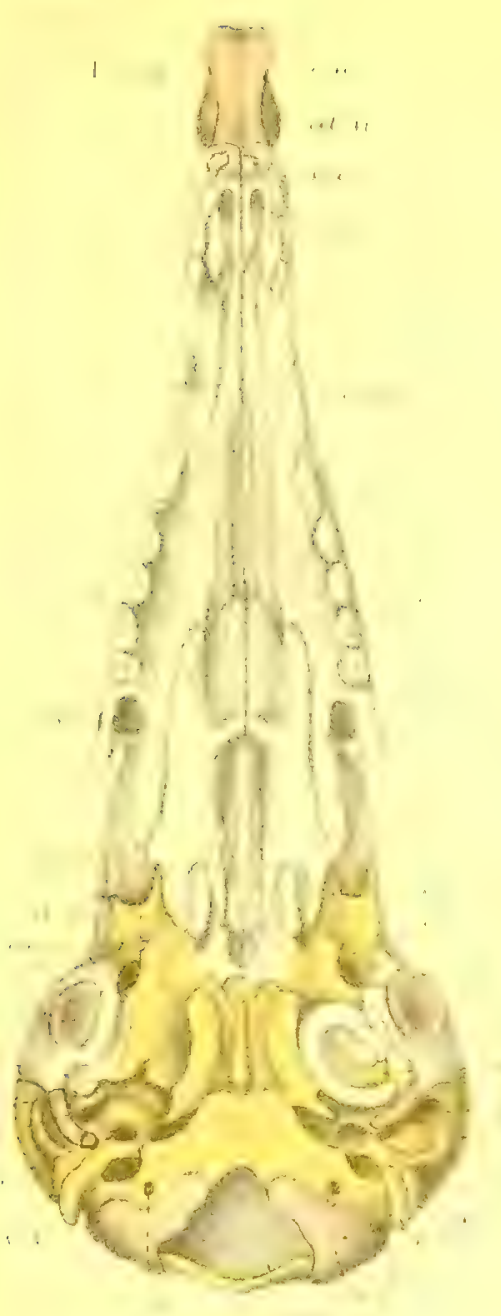

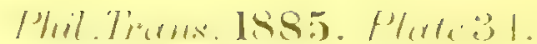
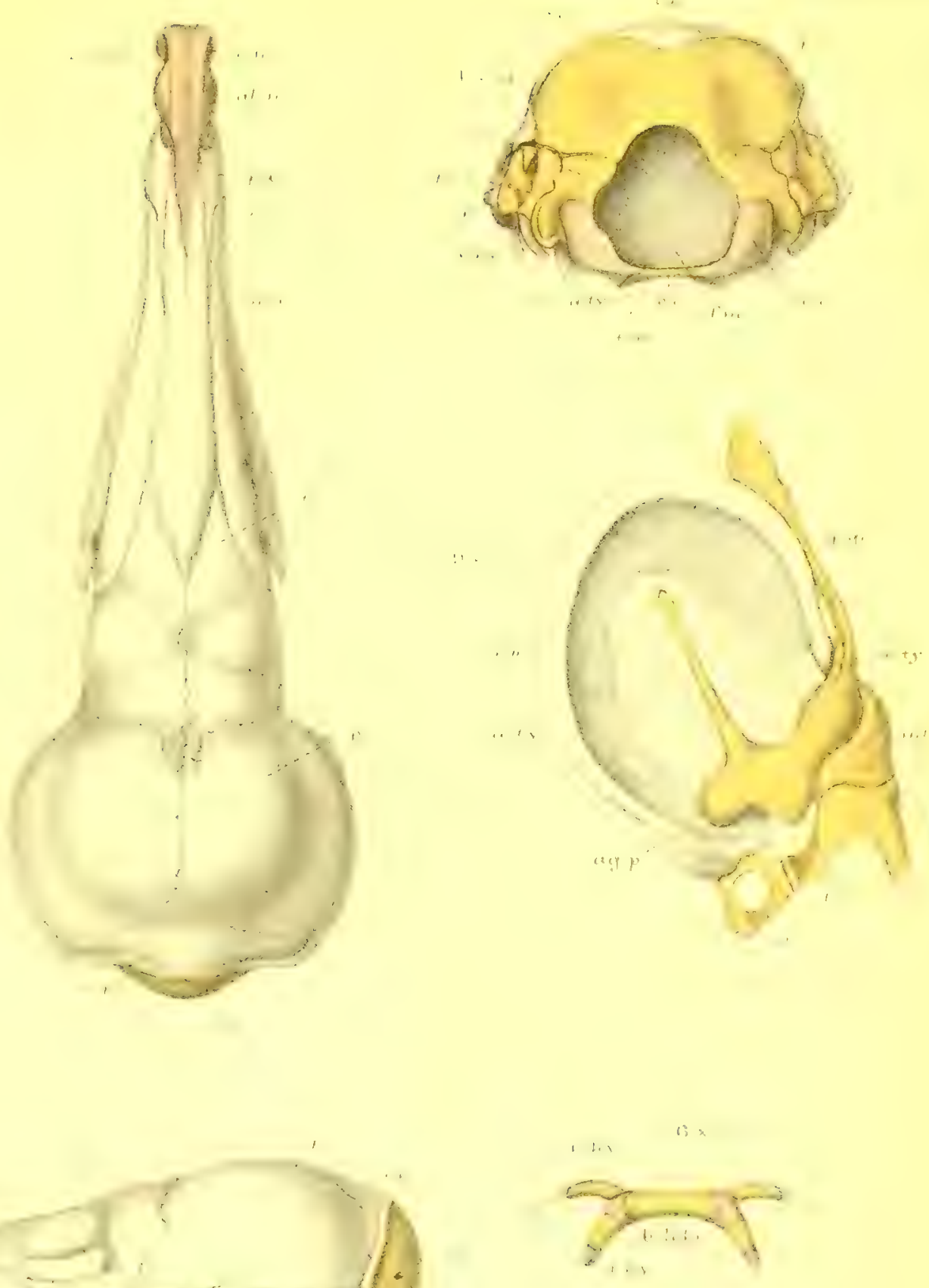
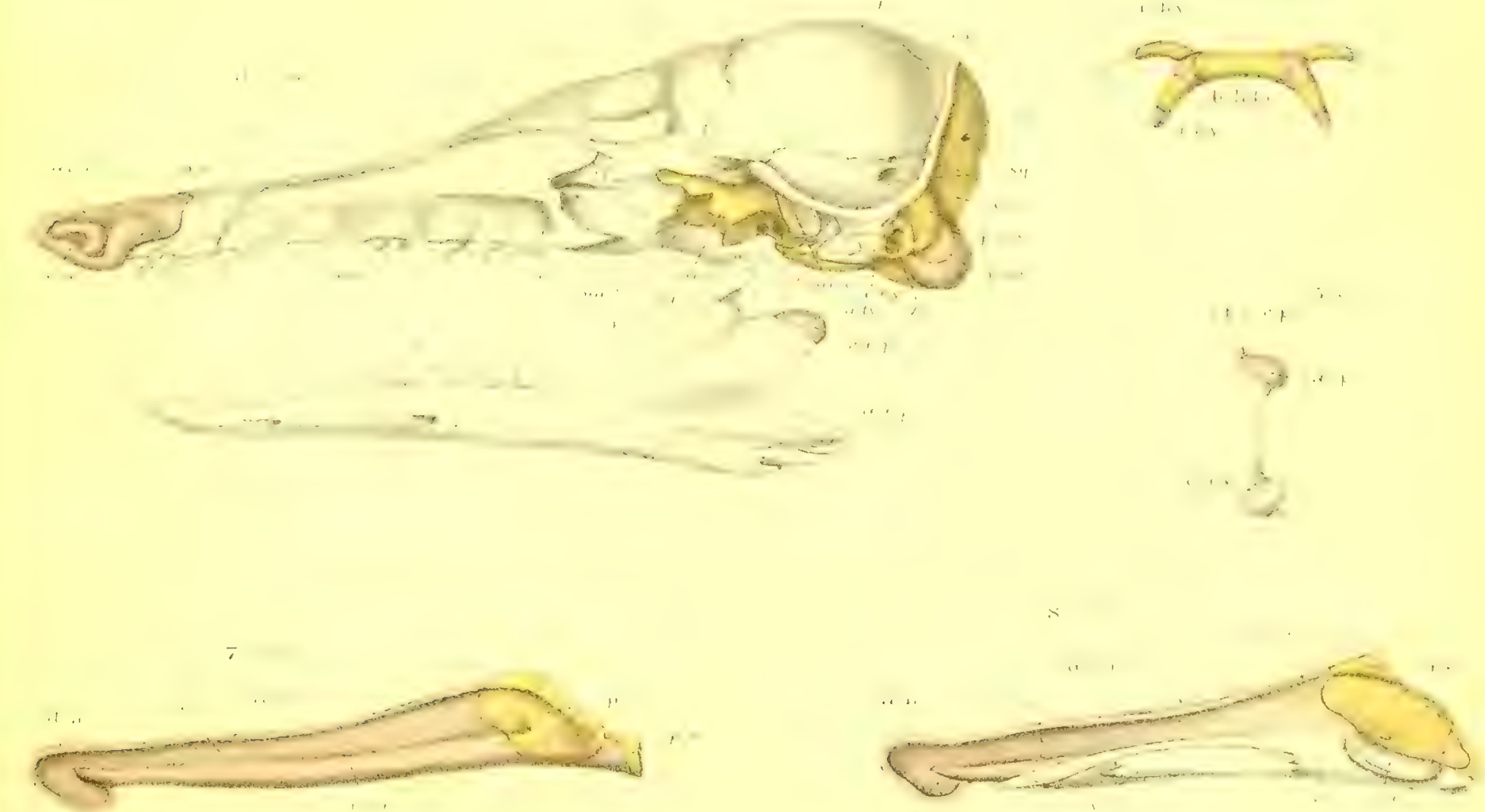

MIR. IV. K. PARTER ON THE SKULL IN THE MAMMALIA.

PLATE 35.

\begin{tabular}{|c|c|c|c|}
\hline Figures. & & & $\begin{array}{c}\text { Number of } \\
\text { times } \\
\text { magnified. }\end{array}$ \\
\hline 1 & Microgale longicaudata; adult; skull ; lower view & . & $5 \frac{1}{3}$ \\
\hline 2 & The same; upper view . . . . . . . . . . & . & $5 \frac{1}{3}$ \\
\hline 3 & The same; side view . . . . . . . . . . . & . & $5 \frac{1}{3}$ \\
\hline 4 & The same; end view of lower jaw . . . . . . & . & $5 \frac{1}{3}$ \\
\hline 5 & The sume; skull; end view . . . . . . . . & . & $5 \frac{1}{3}$ \\
\hline 6 & The same; hyoid arch; inner view . . . . & & $5 \frac{1}{3}$ \\
\hline 7 & The same; malleus and tympanic; inner view. & & $21 \frac{2}{3}$ \\
\hline 8 & The same; incus and stapes; inner view . . . . & . & $21 \frac{2}{3}$ \\
\hline 9 & The same; incus; outer view . . . . . . . . & . & $21 \frac{2}{3}$ \\
\hline 10 & The same; meatus-cartilage . . . . . . . . & . & $21 \frac{2}{3}$ \\
\hline 11 & Ericulus nigrescens; adult; lower view of skull (par & & $3 \frac{1}{3}$ \\
\hline
\end{tabular}



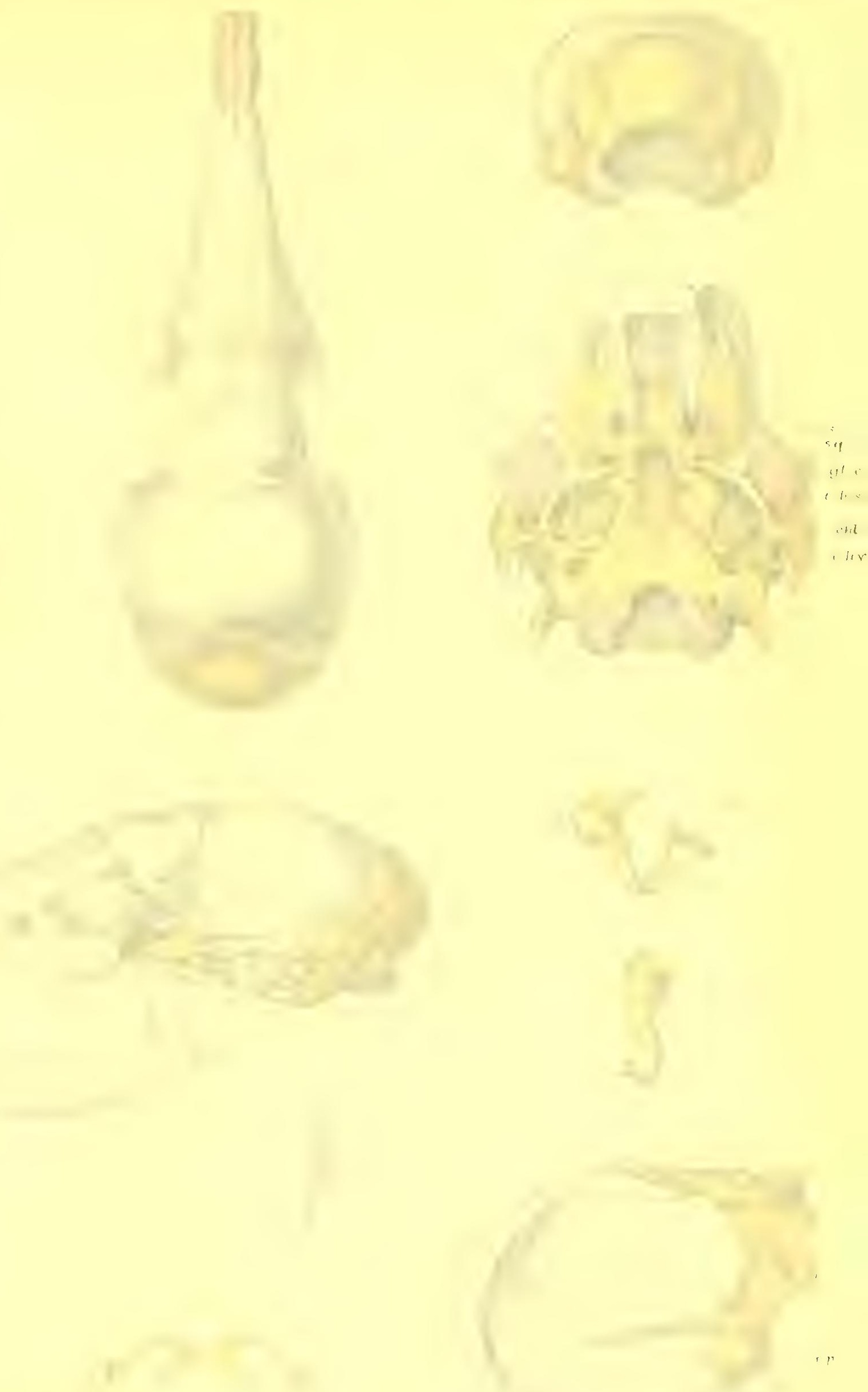
TT:Tl:

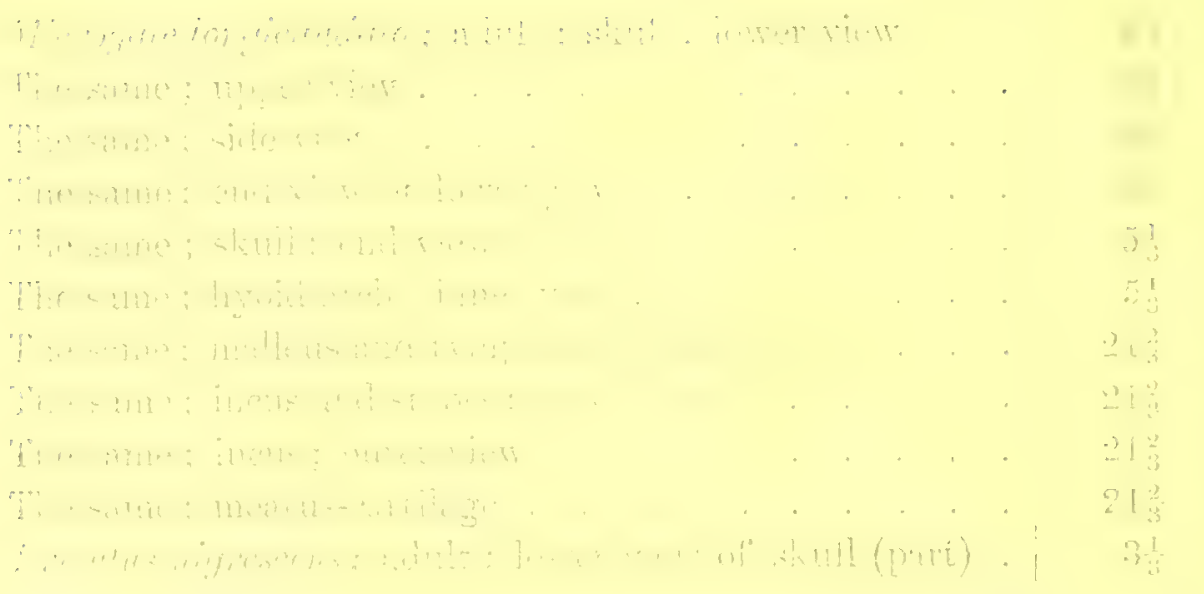



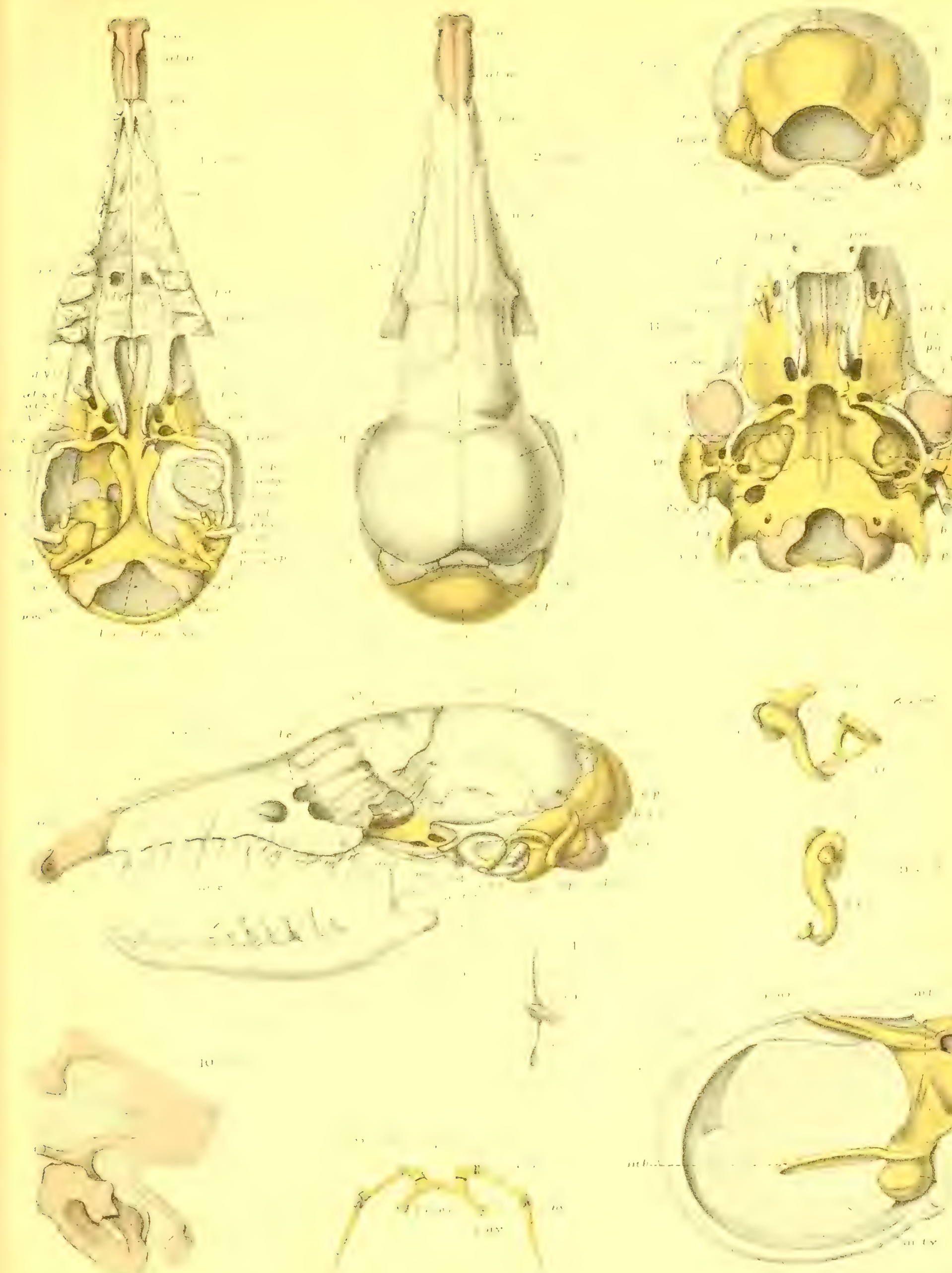

. 
MR. W. K. PARKER ON THE SKULT IN THE MAMMALIA.

PLATE 36.

Figures.

I Rhynchocyon cemei; embryo; 4 inches long; skull; upper view . . . . . . . . . . . . . . . . . . . . . . . 3

2 The same; lower view . . . . . . . . . . . . . 3

3 The same; side view . . . . . . . . . . . . 3

4 The same; endocranium; upper view . . . . . . . 3

5 The same; lower view . . . . . . . . . . . . 3

6 The same; ossicula auditus ; inner view . . . . . . 12

7 The same; ethmo-septal region . . . . . . . . $4 \frac{1}{2}$ 
Particer

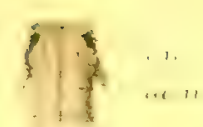

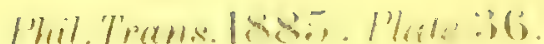

$$
\text { 21.. }
$$$$
\text { , } 1 \text {, तो }
$$ 


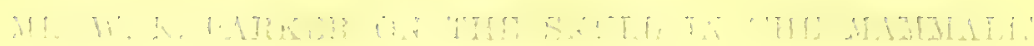

$\therefore 1.13: \vdots$

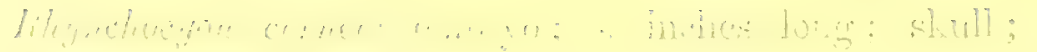

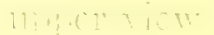

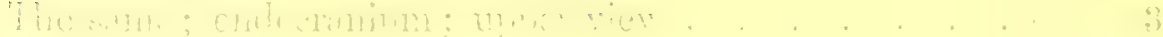

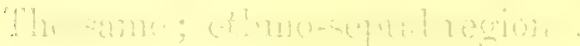


linticen.
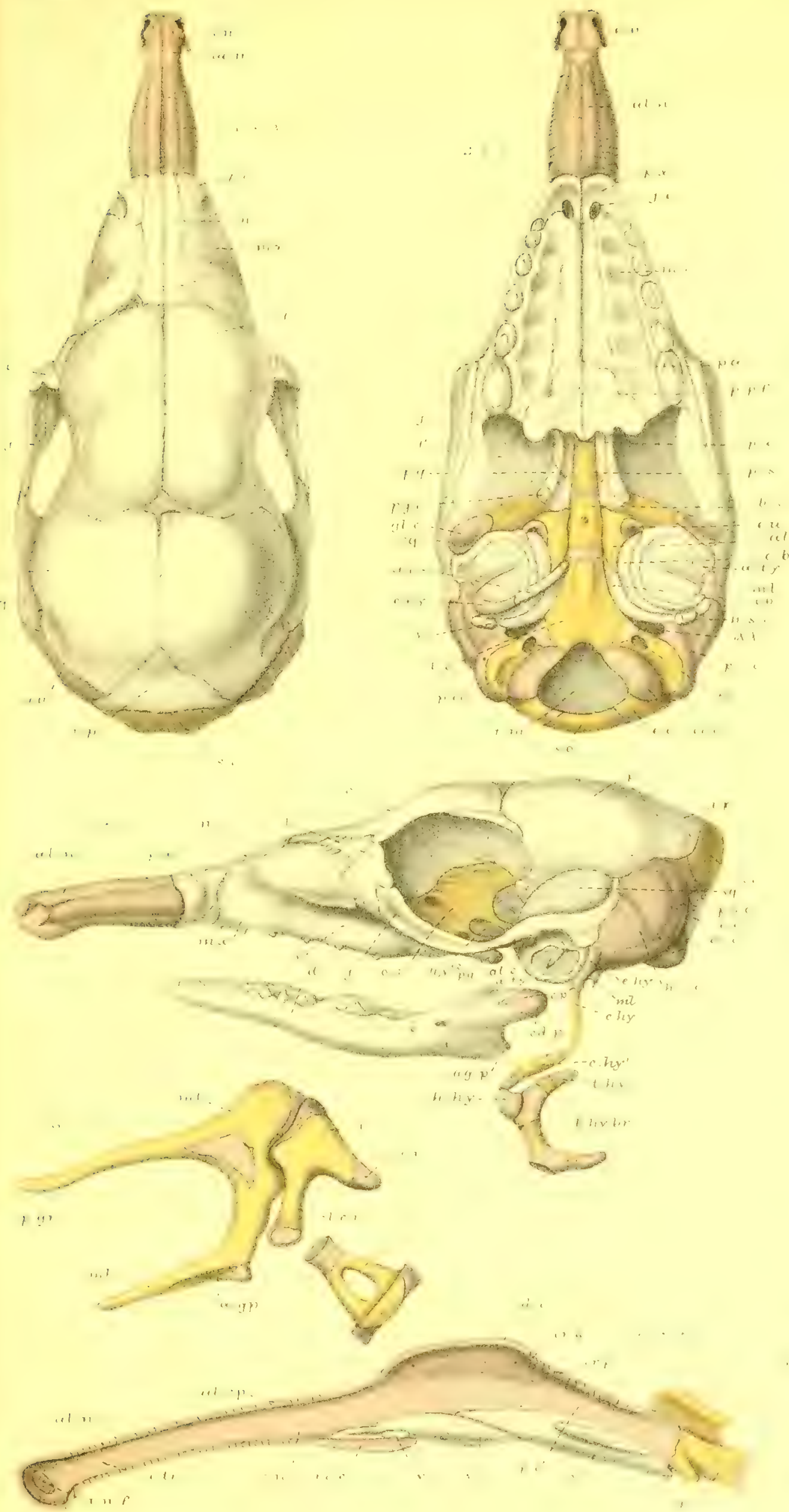

Phit. Trans.1885. Plate:36.
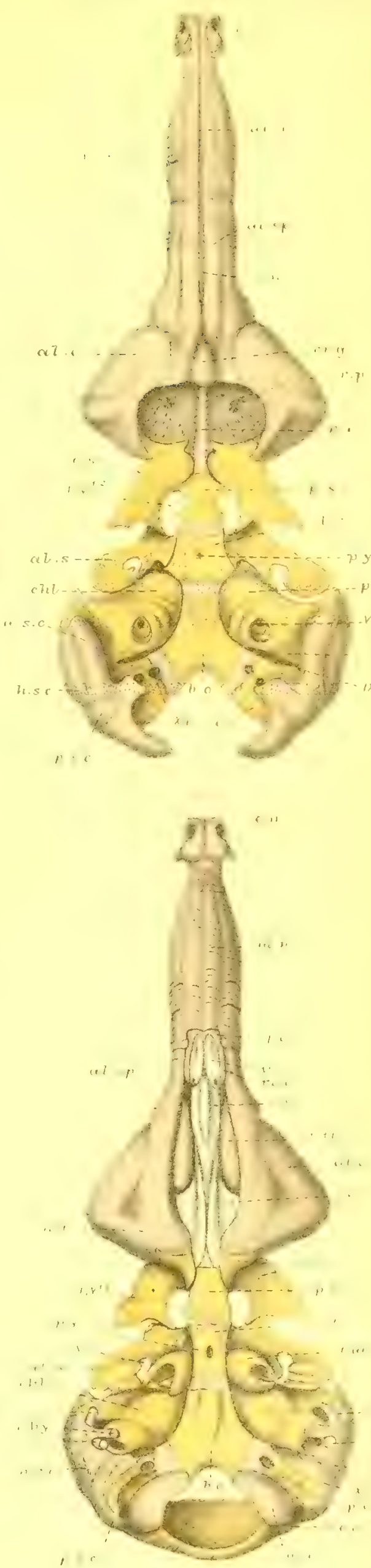


PLATE 37.

\begin{tabular}{|c|c|c|}
\hline Figures. & & $\begin{array}{l}\text { Number of } \\
\text { times } \\
\text { magnified. }\end{array}$ \\
\hline 1 & $\begin{array}{l}\text { Galeopithecus volans (1st stage); embryo; } 5 \frac{1}{4} \text { inches long; } \\
\text { skull; lower view. . . . . . . . . . . . }\end{array}$ & $2 \frac{2}{3}$ \\
\hline 2 & The same; upper view . . . . . . . . . . & $2 \frac{2}{3}$ \\
\hline 3 & The same ; end view. . . . . . . . . . . . .. & $2 \frac{2}{3}$ \\
\hline 4 & The same; ossicula auditûs; onter view . . . . . . & 6 \\
\hline 5 & The same; concha auris . . . . . . . . . . . . & 3 \\
\hline 6 & $\begin{array}{l}\text { Guleoprithecus phitippensis (2nd stage); young; s inches } \\
\text { long; skull; lower view. . . . . . . . . . . . }\end{array}$ & $1 \frac{4}{5}$ \\
\hline 7 & The same; end view. . . . . . . . . . . . & $1 \frac{4}{5}$ \\
\hline 8 & $\begin{array}{l}\text { The same species (3rd stage); larger young; part of } \\
\text { skull; lower view. . . . . . . . . . . . . }\end{array}$ & $2 \frac{1}{4}$ \\
\hline
\end{tabular}




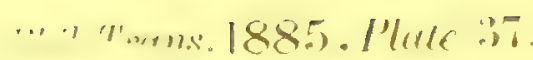
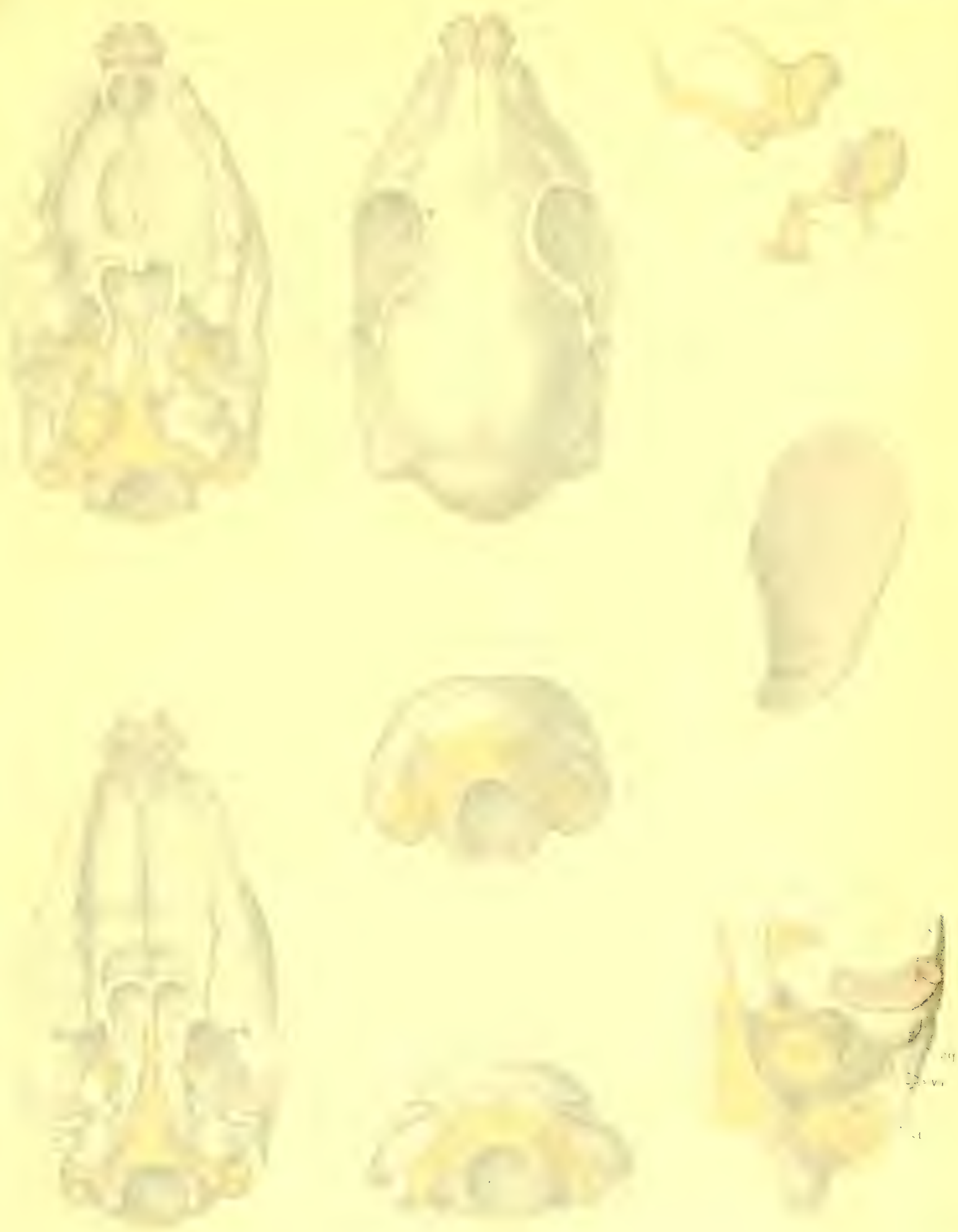
Wh

il $: \cdots \cdots$

Atiminger of

tives:s

magnified.

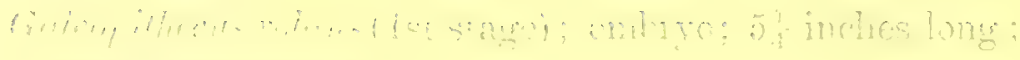

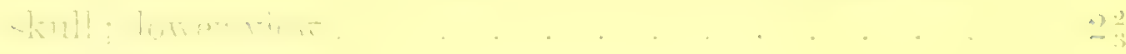

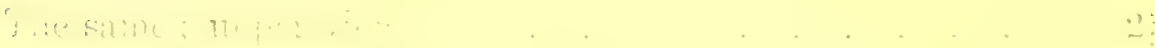

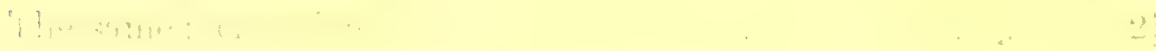

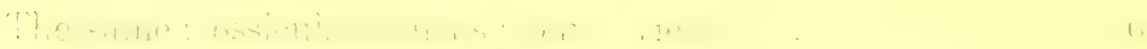

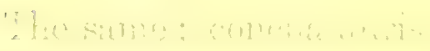

f 1 l

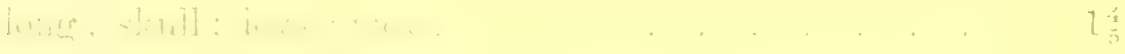

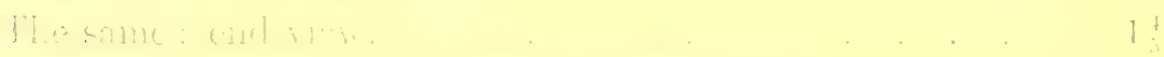

(1) 
l'erliven

Phil.Trans. 1885. Plate 37.
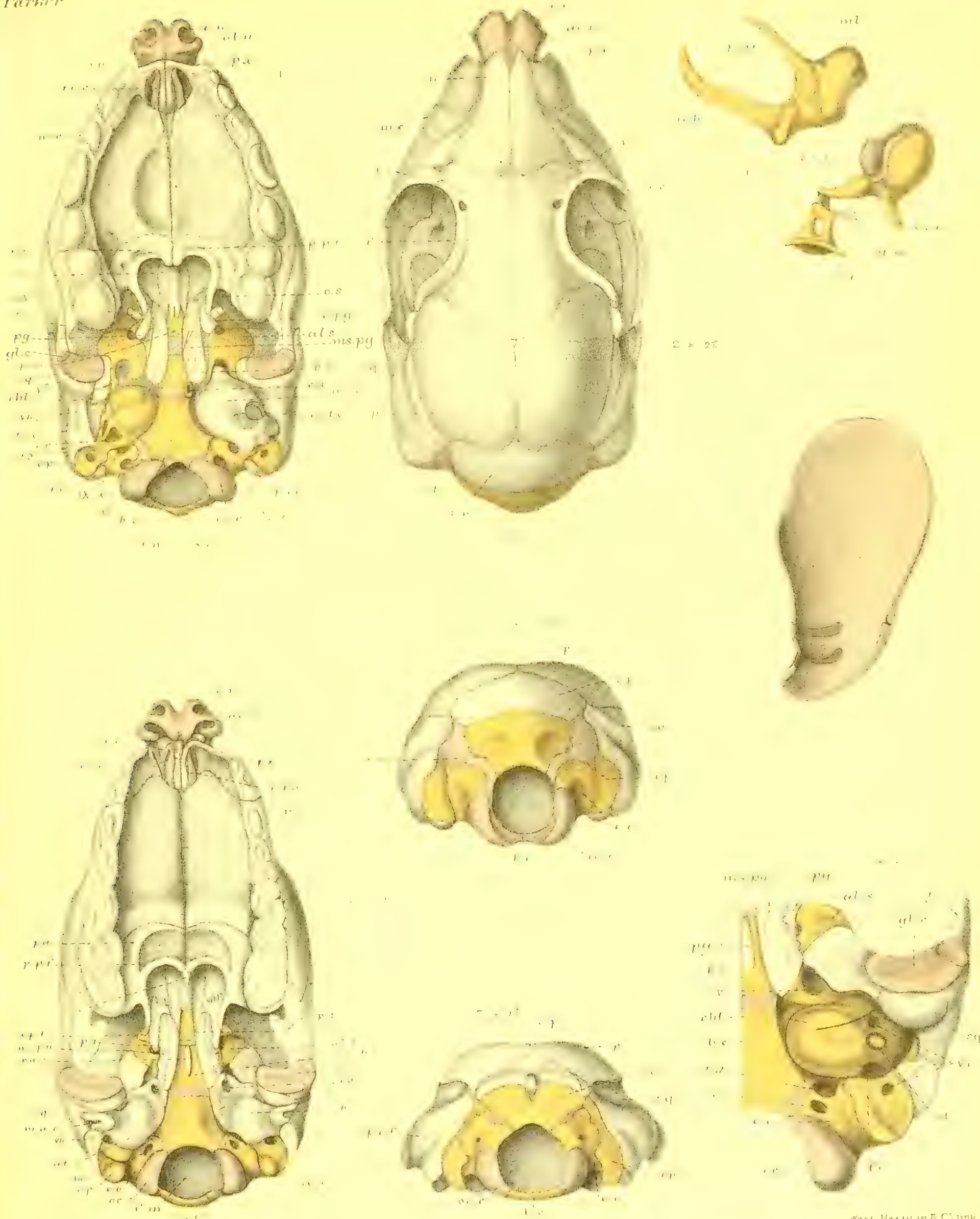


MR. W. K. PARKER ON THE SKULL IN THE MAMMALiA.

PLATE 38.

Figures.

Number of

times

magnified.

$1 \quad$ Galcopithecus volans (1st stage); embryo; $5 \frac{1}{4}$ inches long; skull; side view . . . . . . . . . . . $2 \frac{2}{3}$

$2 \quad$ The same; lower jaw ; imer view . . . . . . . . $22_{3}^{2}$

3 | The same; hyoid arch; upper view . . . . . . . . 4

$+\quad$ Galeopithecus phitippensis (2nd stage); young; 8 inches long; skull; side view . . . . . . . . . . . $1 \frac{1}{5}$

$5 \quad$ The same; lower juw; end view. . . . . . . . . 13

(i) The same; hyoid arch; upper view . . . . . . . . 3

$7 \quad$ Same species (3rd stage); section of stull . . . . $1 \frac{4}{5}$

$8 \quad$ The same; hyoid arch; upper view. . . . . . . . 3

? Same species (4th stage); adult; hyoid arch; side view . B

10 'The same; upper view . . . . . . . . . 3 

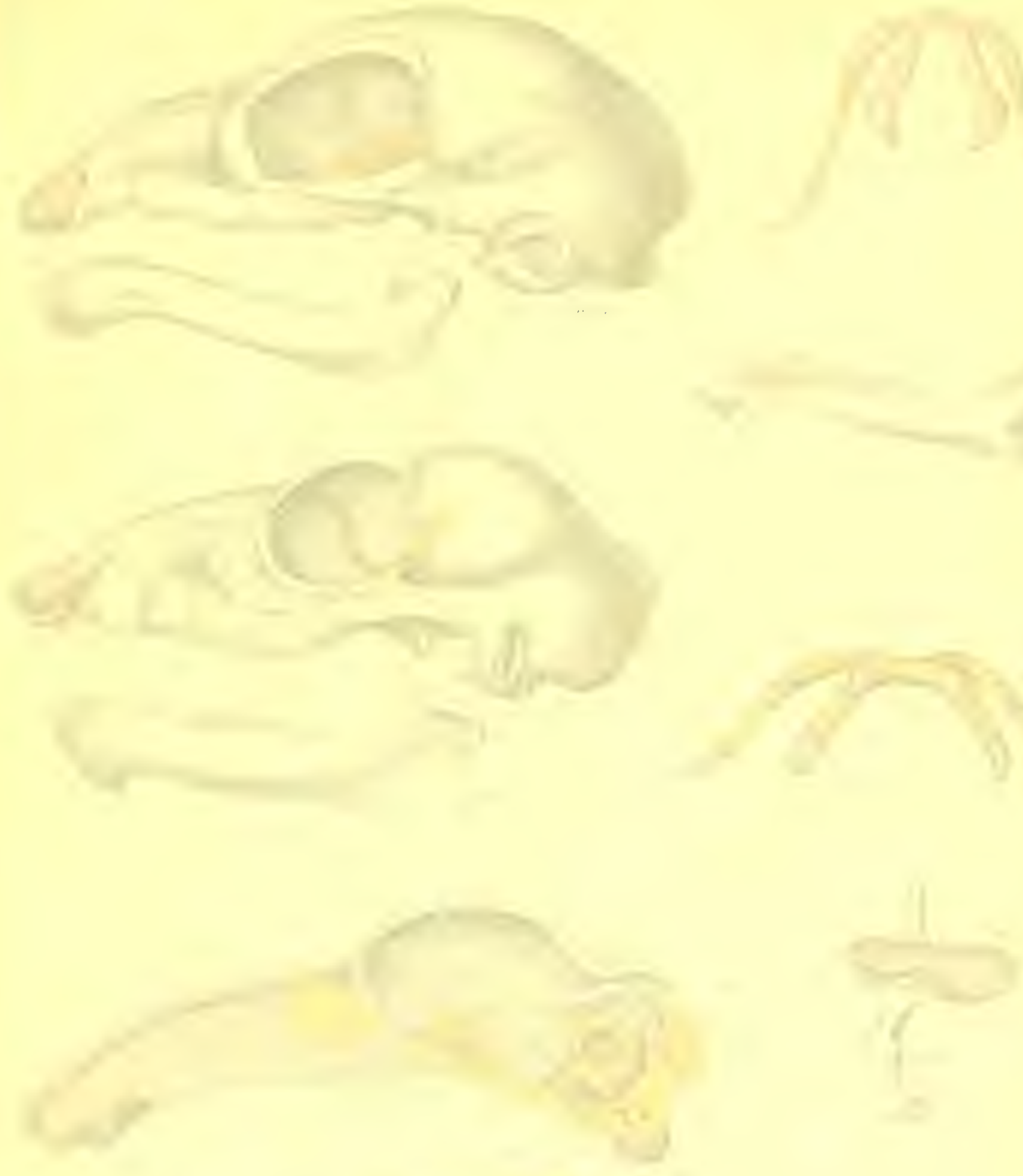
II

PY. Yij : :

in $121: 1\}$ in of

timess

matrmifict?

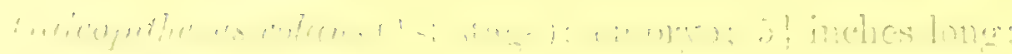

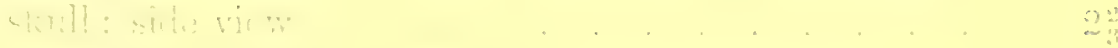

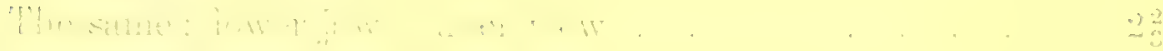

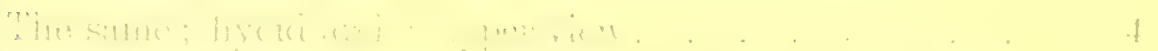

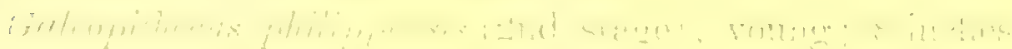

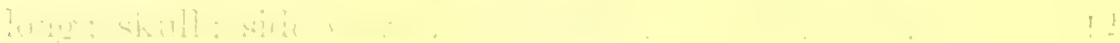

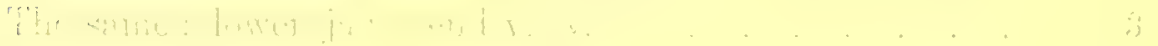

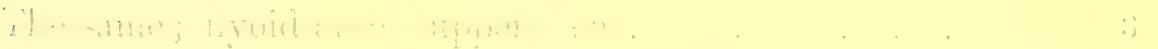

Sitate

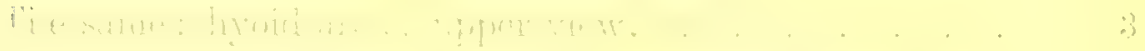

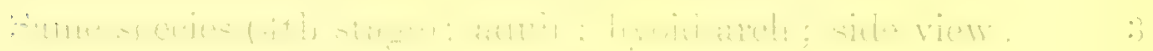



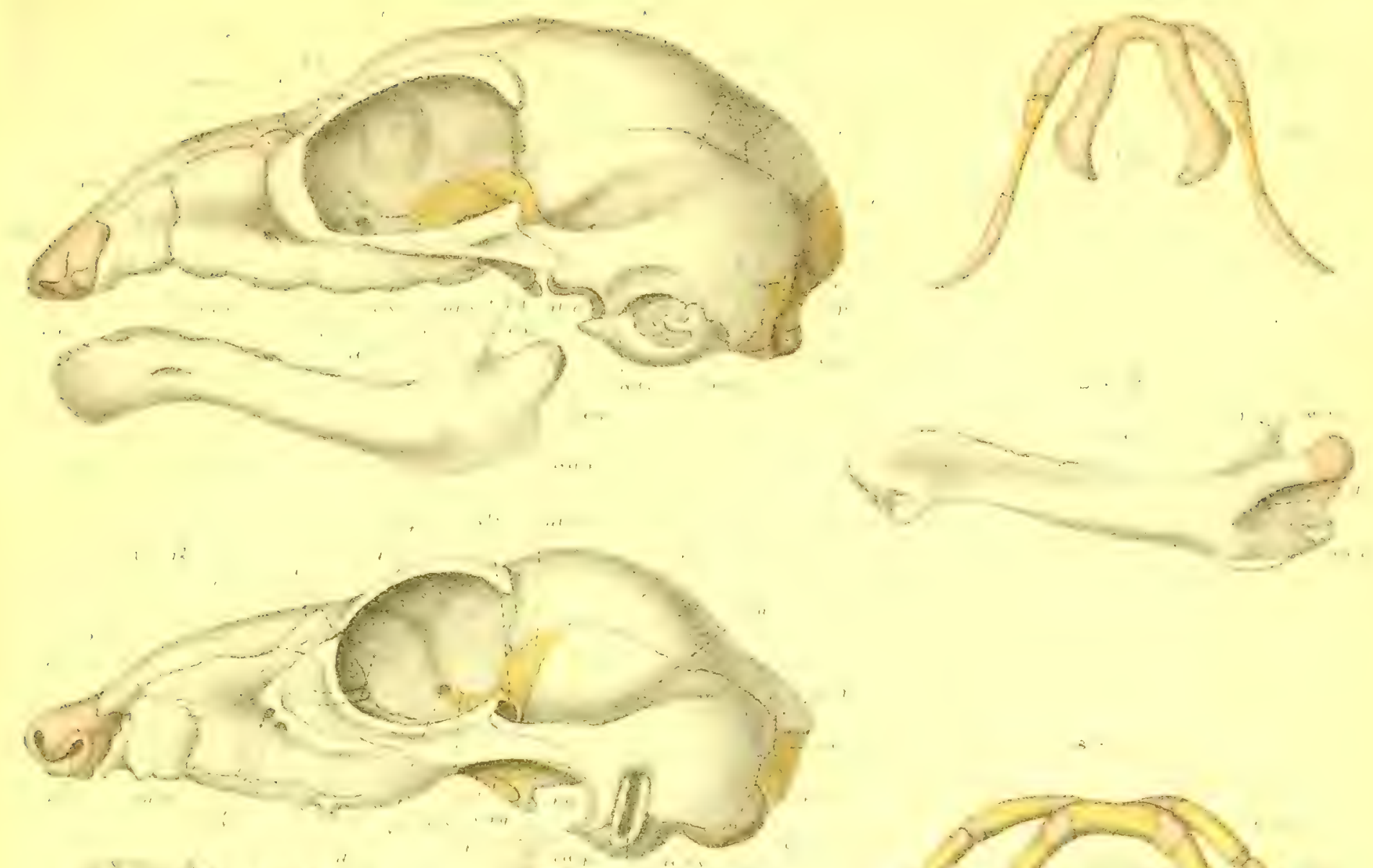

$\therefore-b, a x=\cdots+\cdots+\cdots, \ldots$
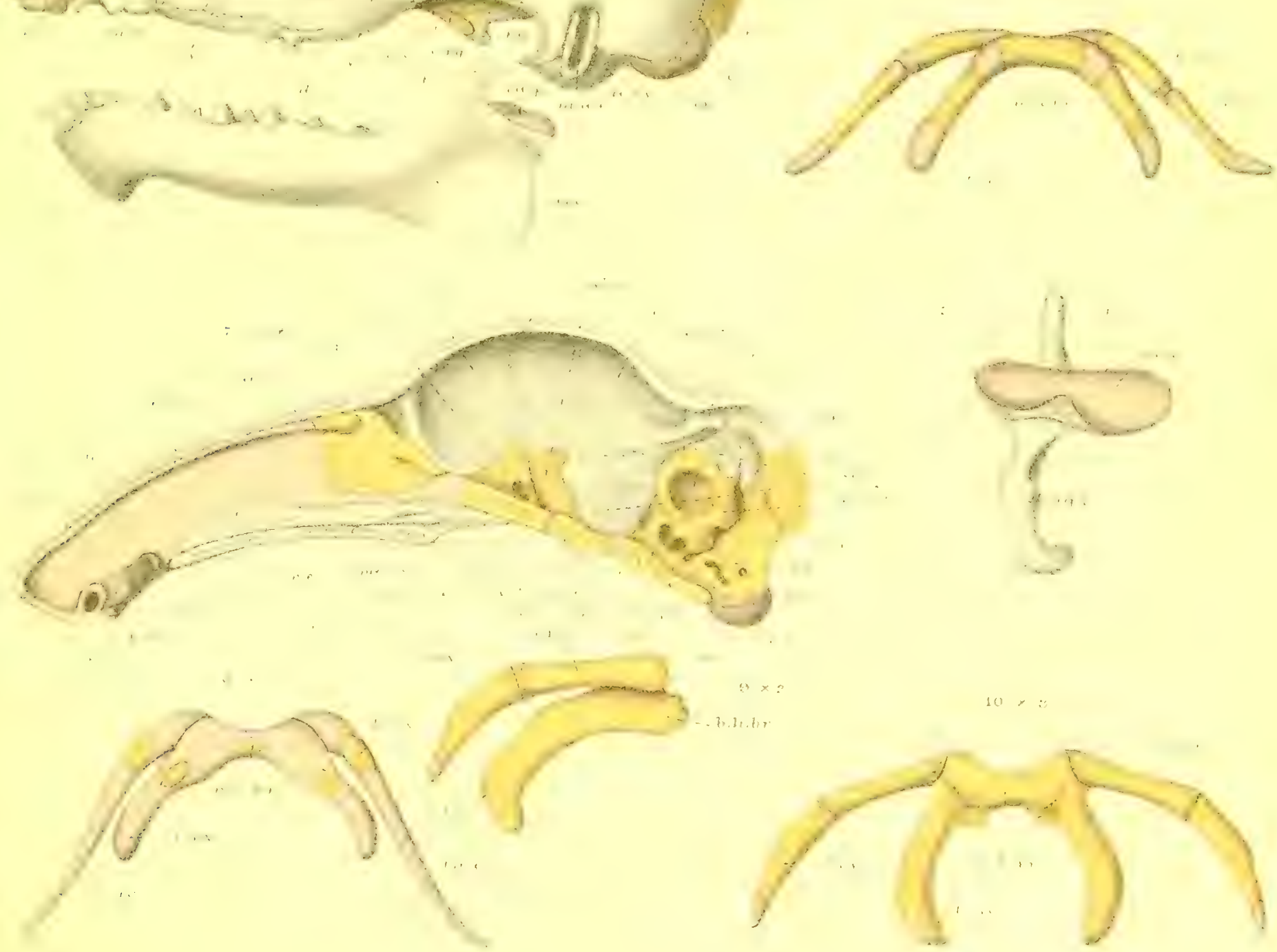
, 
MR. W. K. PARKER ON THE SKULL IN THE MAMALALIA

PLATE 39.

\begin{tabular}{|c|c|c|}
\hline Figures. & & $\begin{array}{c}\text { Number of } \\
\text { times } \\
\text { magnified. }\end{array}$ \\
\hline 1 & Galcopithecus roluns (1st stage); endocranium; lower view & $2 \frac{2}{3}$ \\
\hline 2 & The same; upper view . & $2 \frac{2}{3}$ \\
\hline 3 & $\begin{array}{l}\text { Galeopithecus phitippensis (4th stage); adult; section of } \\
\text { skull. . . . . . . . . . . . . . . . . }\end{array}$ & $1 \frac{1}{2}$ \\
\hline 4 & The same; end view. . & $1 \frac{1}{2}$ \\
\hline 5 & The same; front view. . & 2 \\
\hline 6 & The same; vertical section of temporal region . . . . & 3 \\
\hline 7 & The same; ossicula auditûs; outer view . . . . . . & 8 \\
\hline 8 & The same; lower view of skull, with part sawn away. . & 3 \\
\hline
\end{tabular}



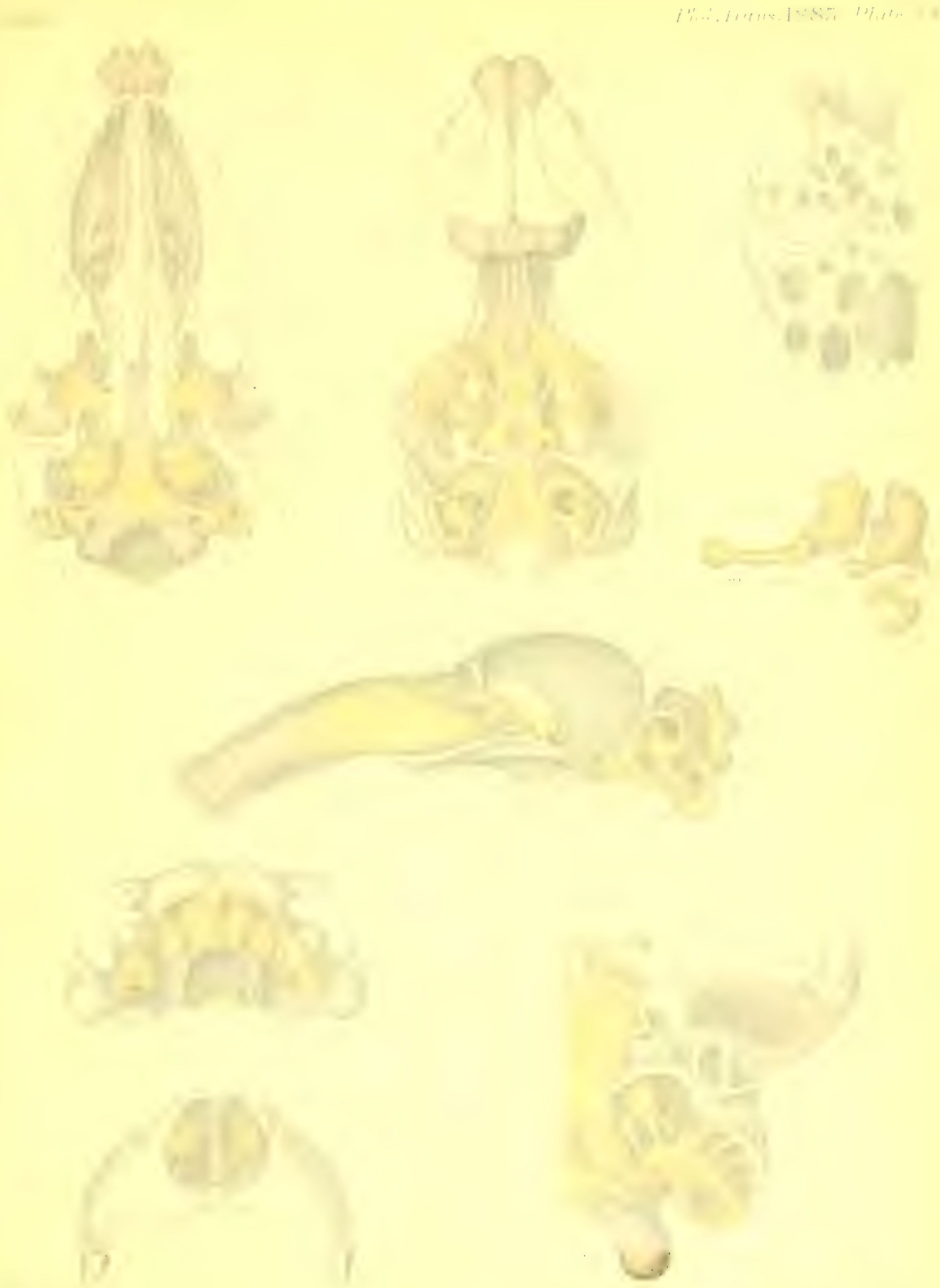


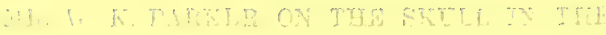

PYATE 30

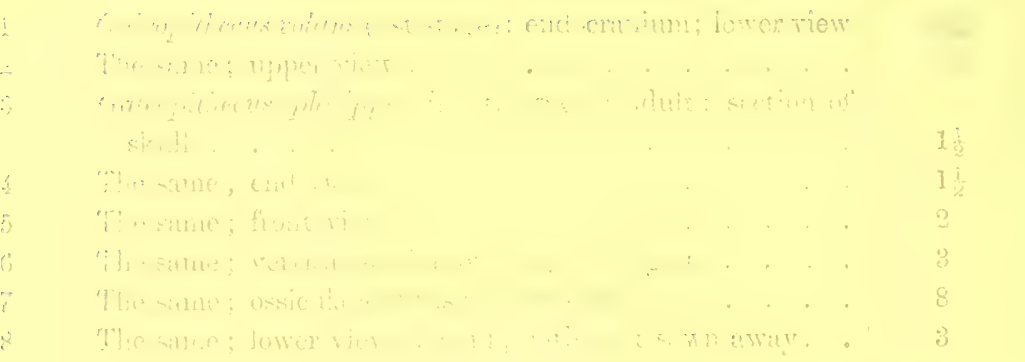



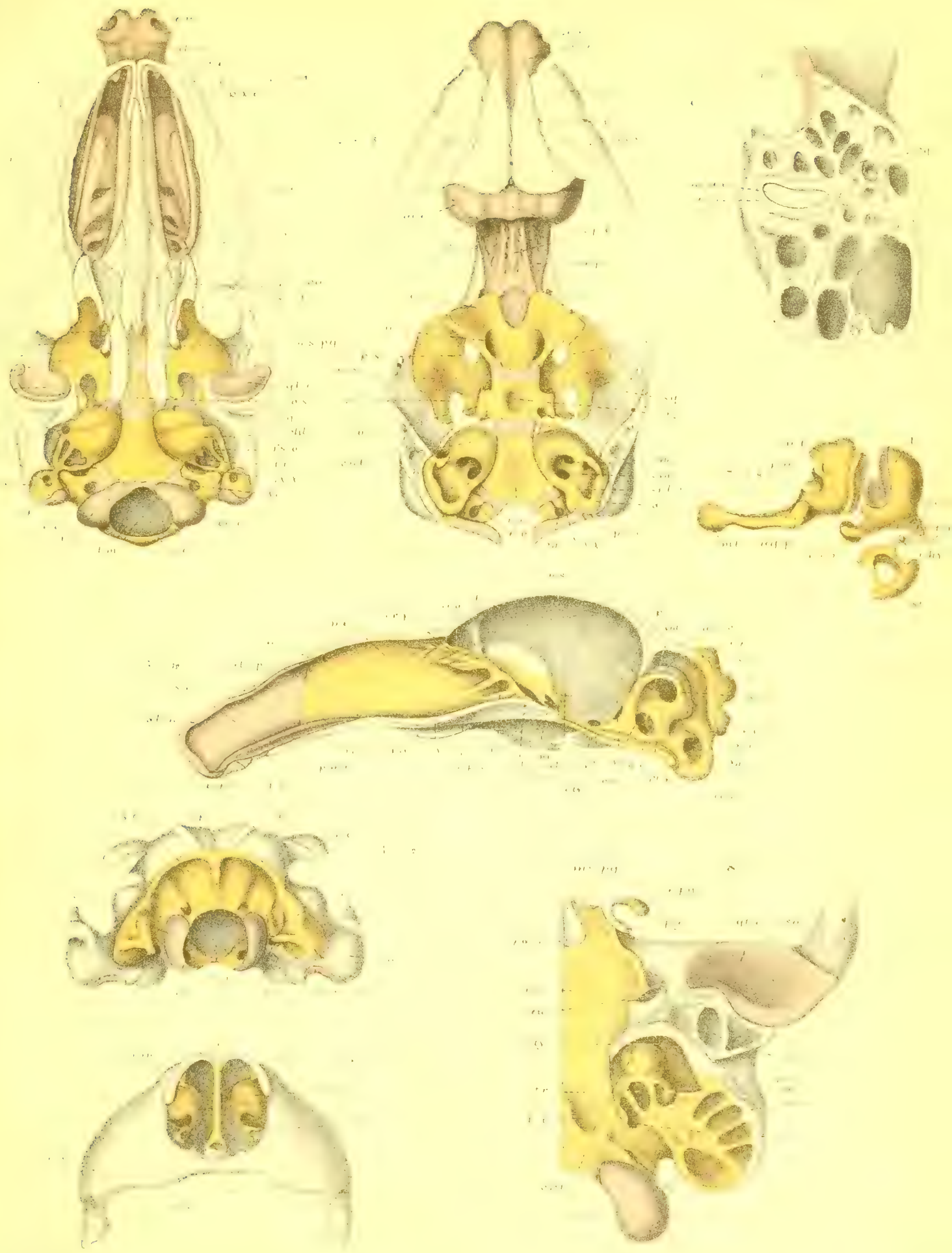










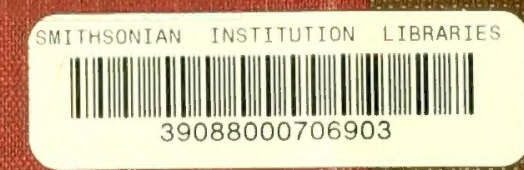

